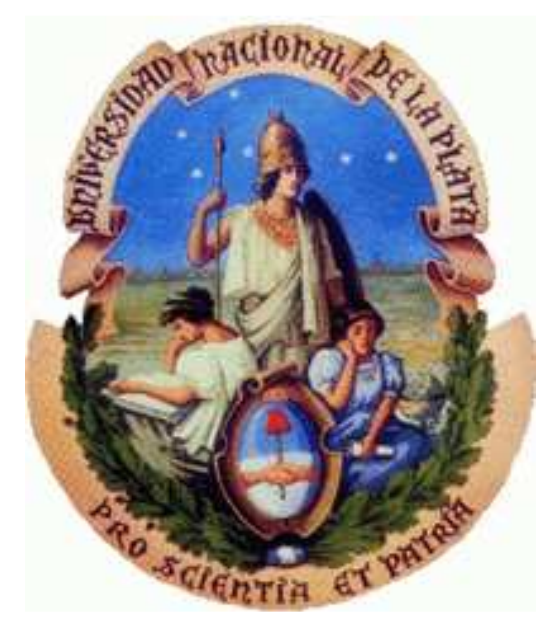

TESIS DOCTORAL

\title{
"ESTUDIO DE LA INFLUENCIA DE UN ENTORNO DE SIMULACIÓN EN LA ENSEÑANZA DE REDES DE COMPUTADORAS EN EL NIVEL UNIVERSITARIO"
}

$\begin{array}{ll}\text { Tesista: } & \text { Daniel Arias Figueroa } \\ \text { Director: } & \text { Francisco Javier Diaz (UNLP) } \\ \text { Codirector: } & \text { María Cecilia Gramajo (UNSa) }\end{array}$

Tesis presentada para obtener el grado de Doctor en Ciencias Informáticas

Facultad de Informática - Universidad Nacional de La Plata Mayo de 2017 
Por su apoyo y ánimo constante en este sendero lleno de altibajos.

A mis padres por el ejemplo 


\section{Agradecimientos}

Agradezco a la Universidad Nacional de La Plata por permitirme culminar esta nueva etapa de mi formación profesional, a la Universidad Nacional de Salta - Facultad de Ciencias Exactas - Departamento de Informática, por apoyar y creer en la proyección de sus docentes para la excelencia.

A mi Director Francisco Javier Díaz y a mi Codirectora María Cecilia Gramajo, por sus invaluables aportes como guías.

A los docentes Esp. Ernesto Sánchez, Ing. Álvaro Ignacio Gamarra, Lic. Jorge Alberto Silvera, Mgr. Gustavo D. Gil y Mgr. Loraine Gimson Saravia, que participaron activamente en la investigación, por su tiempo y desinterés para contribuir a mejorar la calidad de la enseñanza.

Al Dr. Orlando José Ávila Blas, por su invaluable ayuda con el análisis estadístico de los datos.

A la Lic. Andrea Sayago, por su invaluable aporte en la temática de educación.

A mis estudiantes por la motivación y aportes a lo largo de todo el proceso experimental.

A los profesores y compañeros del doctorado, por sus enseñanzas, aportes y apoyo en todo el proceso.

Al C.I.D.I.A. - Centro de Investigación y Desarrollo en Informática Aplicada, por toda la infraestructura aportada.

Al C.I.U.N.Sa. - Consejo de Investigación de la Universidad Nacional de Salta, por el equipamiento de red donado para la realización de los laboratorios con dispositivos Cisco. A todos, muchas gracias. 


\section{INDICE DE CONTENIDO}

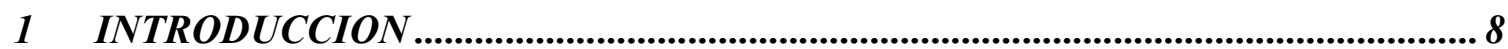

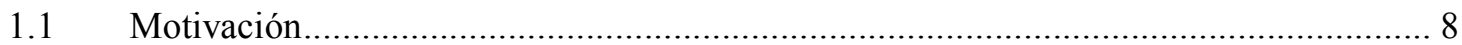

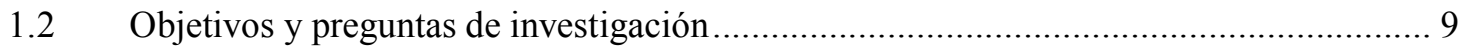

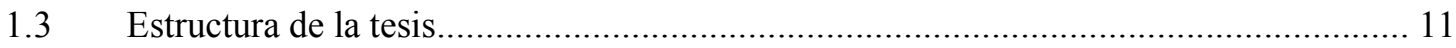

2 FUNDAMENTOS DEL TEMA: MARCO TEÓRICO............................................. 12

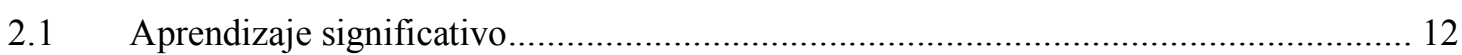

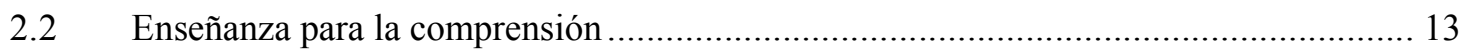

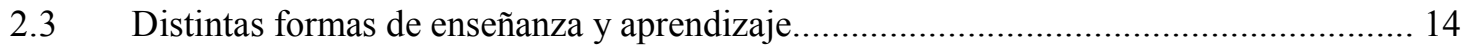

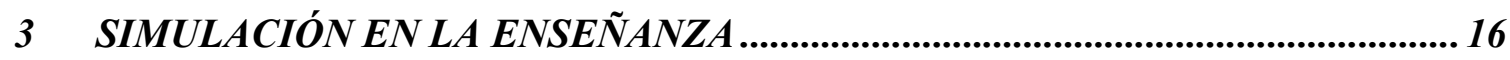

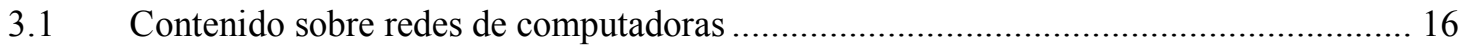

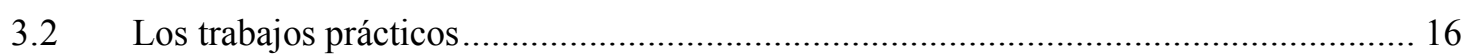

3.2.1 Los trabajos prácticos en el currículo de sistemas ............................................................... 19

3.2.2 Trabajos prácticos tradicionales y trabajos prácticos con simulación.........................................2 20

3.2.3 Trabajos prácticos con simulación para la realización de las experiencias.............................. 22

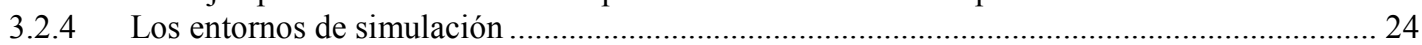

3.3 Análisis del Simulador Packet Tracer en la enseñanza de Redes TCP/IP ..................... 26

3.3.1 Características en la enseñanza de la capa de aplicación........................................................... 26

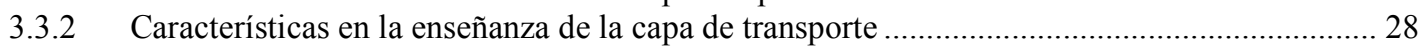

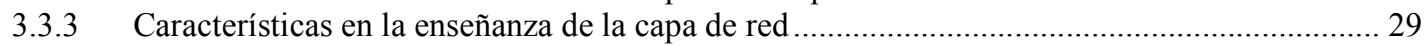

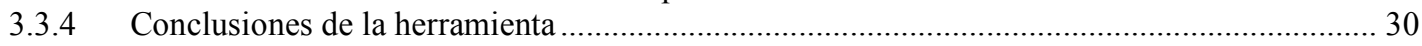

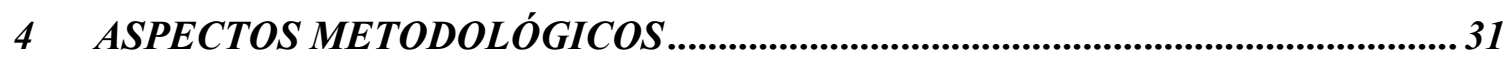

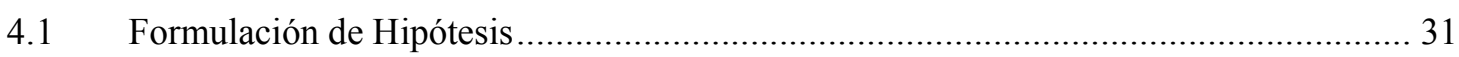

4.2 Estrategia metodológica, diseño de la investigación y recolección de datos.................... 31

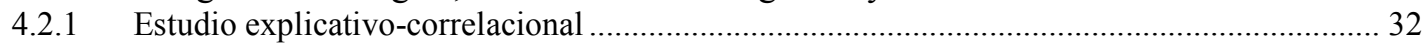

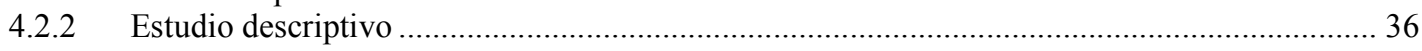

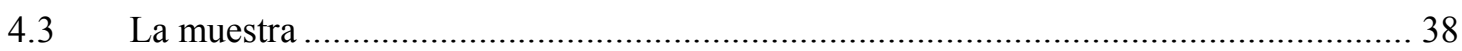

5 ANALISIS DE LAS EXPERIENCIAS REALIZADAS ...................................... 41

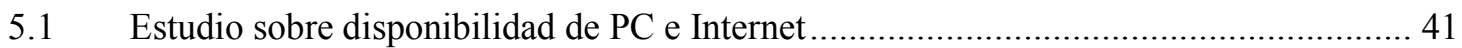

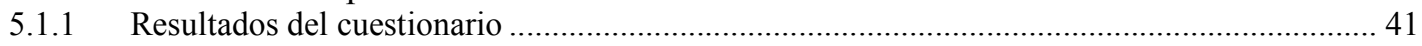

5.2 Experiencia No 1: Simulador Packet Tracer en Conectividad y Teleinformática ............ 44

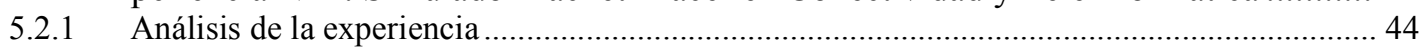

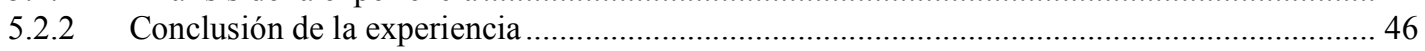

5.3 Experiencia N $N^{\circ}$ 2: Simulador Kiva-NS en Conectividad y Teleinformática................... 47

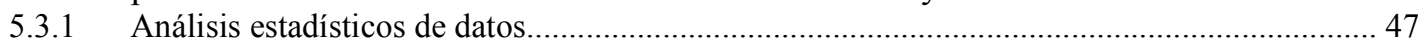

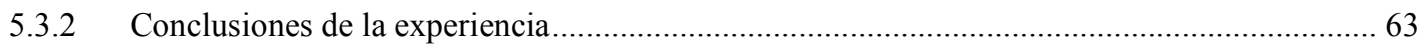

5.4 Experiencia No 3: Simulador Packet Tracer en Redes de Computadoras I ......................64 64

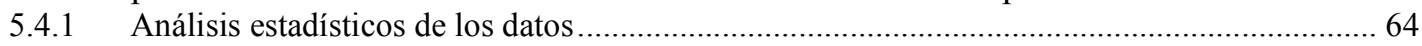

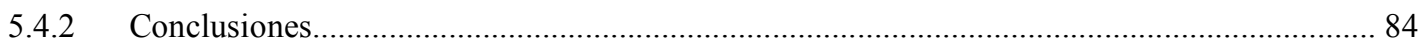

5.5 Experiencia $N^{\circ}$ 4: Simulador Packet Tracer y el Protocolo DNS en un Curso de

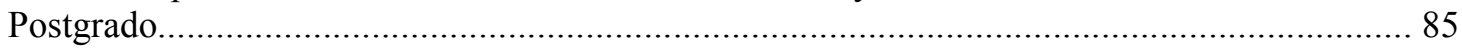




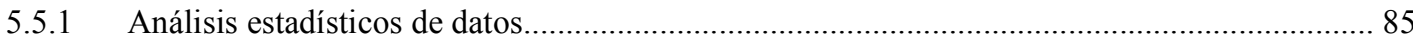

5.5.2 Conclusiones de la experiencia...................................................................................... 92

5.6 Experiencia No 5: Simulador Packet Tracer en Redes de Computadoras I .................. 93

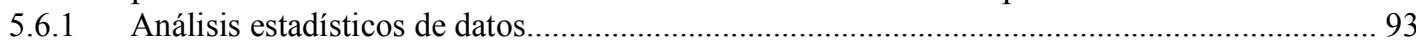

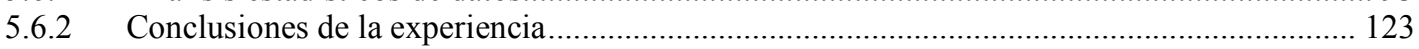

5.7 Experiencia N $N^{\circ}$ 6: Simulador MACSim en Redes de Computadoras II .......................124

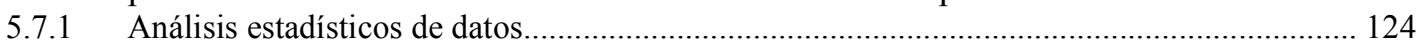

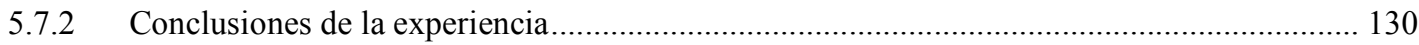

5.8 Experiencia N $N^{\text {0 }}$ 7: Simulador Packet Tracer y el Protocolo ARP en Redes de

Computadoras II ............................................................................................. 131

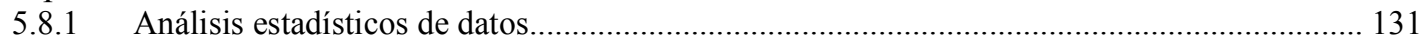

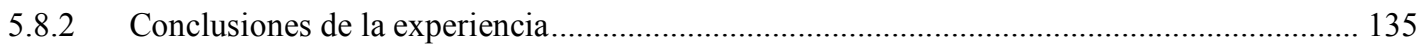

5.9 Experiencia $N^{\circ}$ 8: Simulador MACSim en Conectividad y Teleinformática ................136

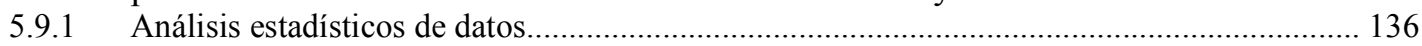

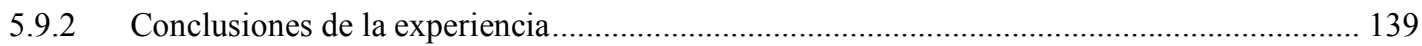

5.10 Experiencia $N^{\circ}$ 9: Simulador Packet Tracer y el Protocolo DNS en Redes de

Computadoras I ............................................................................................. 140

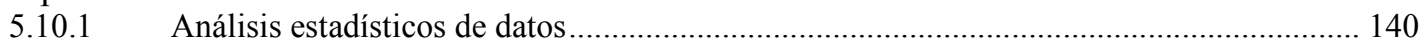

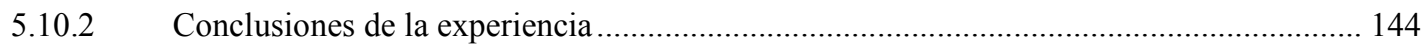

5.11 Experiencia No 10: Simulador GNS3 en un curso en el marco de las Jornadas de Ingeniería

5.11.1 Análisis estadísticos de datos

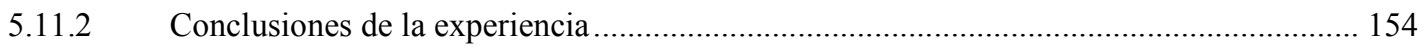

5.12 Experiencia $N^{0}$ 11: Simulador Packet Tracer y el Direccionamiento IP en Redes de Computadoras I

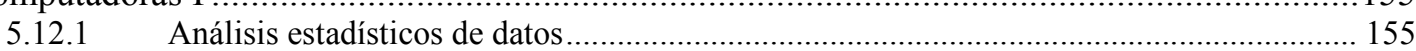

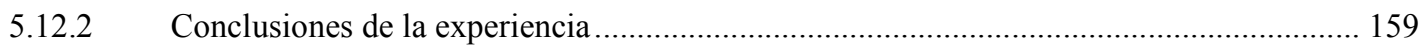

5.13 Experiencia N ${ }^{\circ}$ 12: Simulador Packet Tracer y el Ruteo IP en Redes de Computadoras I 160

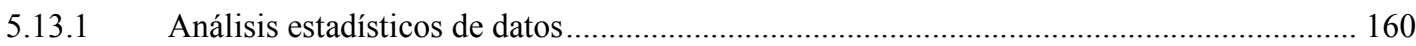

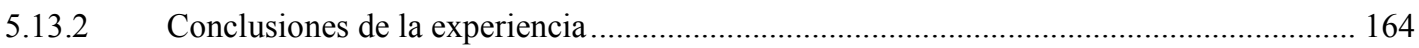

5.14 Experiencia $N^{0}$ 13: Simulador MACSim en Redes I en la UCASAL ..........................165

5.14.1 Análisis estadísticos de datos .................................................................................... 165

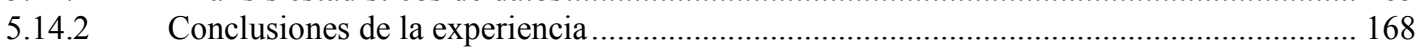

5.15 Experiencia N ${ }^{0}$ 14: Simulador GNS3 en un curso organizado por el CIDIA ...............169

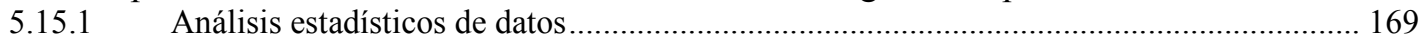

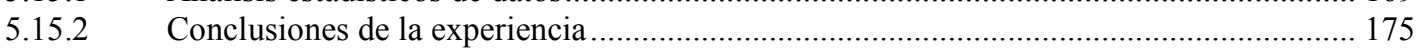

5.16 Experiencia No 15: Simulador MACSim en Redes de Computadoras II .....................177

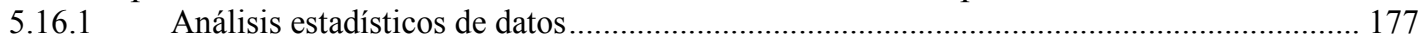

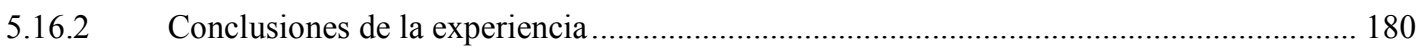

5.17 Experiencia $N^{\circ}$ 16: Simulador Packet Tracer y el Protocolo ARP en Redes de

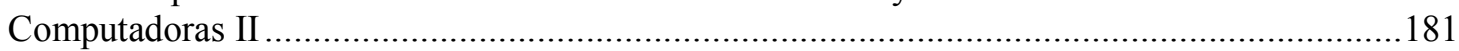

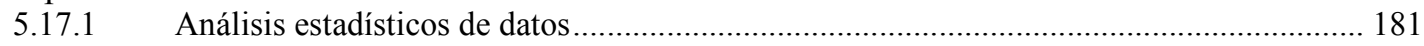

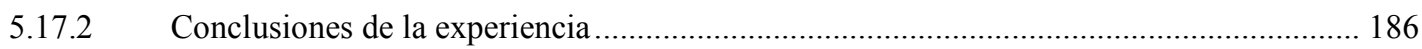

5.18 Experiencia N $N^{\circ}$ 17: Simulador Packet Tracer y el Direccionamiento IP en Redes de

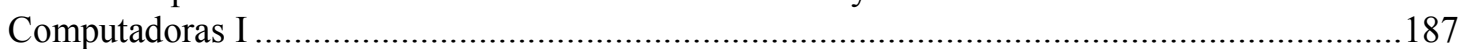

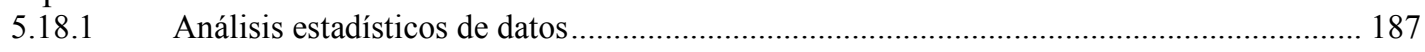


5.18.2 Conclusiones de la experiencia 190

5.19 Experiencia $N^{\circ}$ 18: Simulador Packet Tracer y el Ruteo IP en Redes de Computadoras I 191

5.19.1 Análisis estadísticos de datos. 191

5.19.2 Conclusiones de la experiencia

5.20 Experiencia No 19: Direccionamiento IP con Router Cisco 3600 en Redes de

Computadoras I

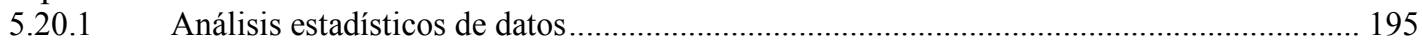

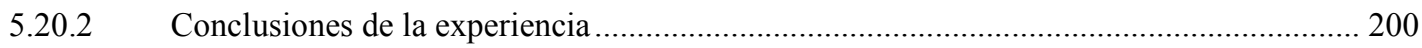

5.21 Experiencia N ${ }^{\circ}$ 20: Ruteo IP con Router Cisco 3600 en Redes de Computadoras I......202

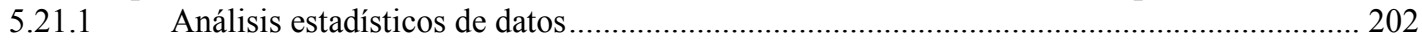

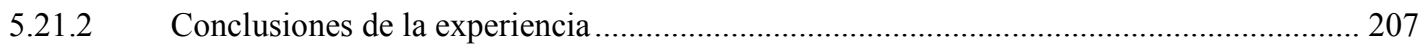

5.22 Experiencia N N 21: Simulador MACSim en Redes de Computadoras II .....................208

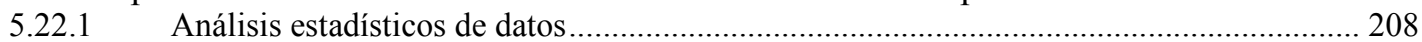

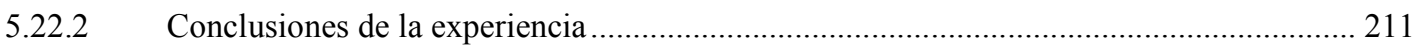

5.23 Experiencia $N^{\circ}$ 22: Curso para certificación Mikrotik organizado por el CIDIA..........212

5.23.1 Análisis estadísticos de datos ...................................................................................... 212

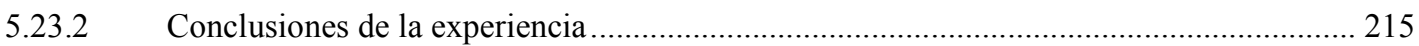

5.24 Experiencia No 23: GNS3 y Laboratorio real en Redes I - UCASAL .........................216

5.24.1 Análisis estadísticos de datos .......................................................................... 216

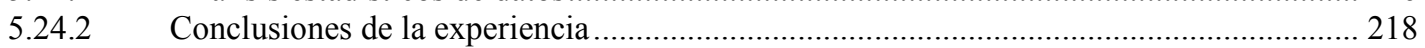

5.25 Encuesta a docentes de asignaturas de redes de computadoras ................................219

5.25.1 Análisis estadísticos de los datos ........................................................................... 220

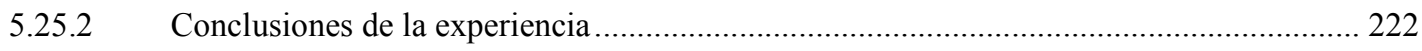

$6 \quad \mathrm{RESULTADOS}$ Y CONCLUSIONES ................................................................ 223

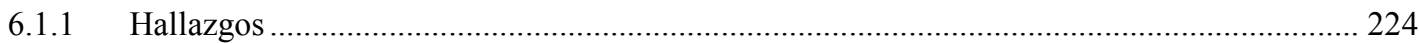

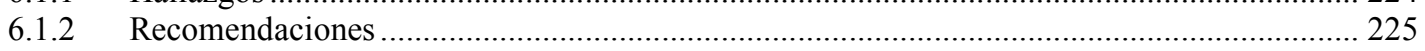

BIBLIOGRAFIA ............................................................................ 226

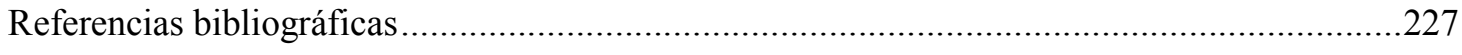

APENDICE I: CONTRIBUCIONES ..................................................................... 230

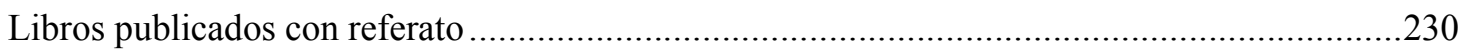

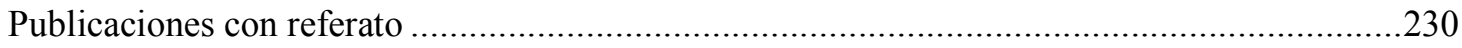

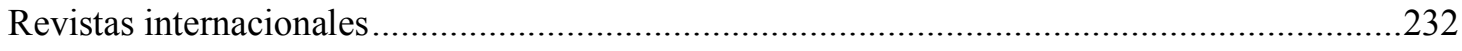

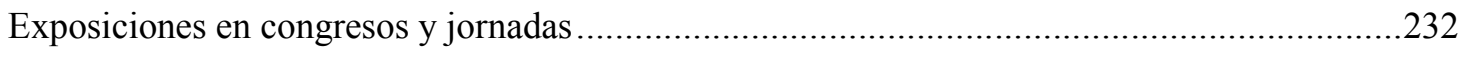

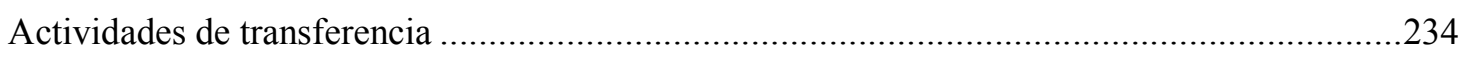

Tesis de postgrado dirigidas, relacionadas a esta investigación ..........................................2235

APENDICE II: ESTADÍSTICA DESCRIPTIVA......................................................... 236

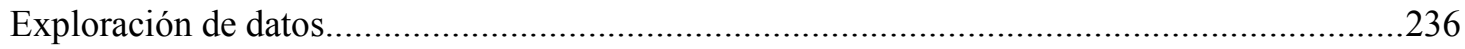

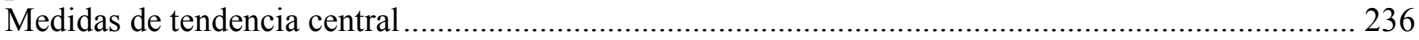

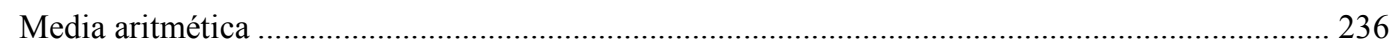

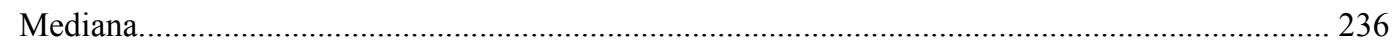

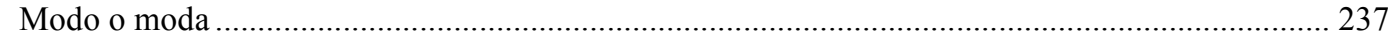

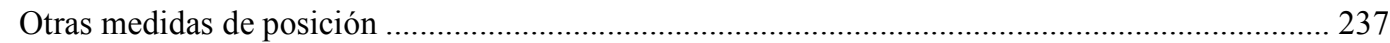

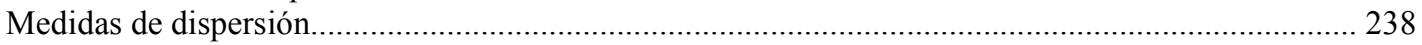


Rango

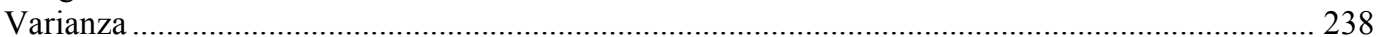

Desviación Típica y Cuasidesviación Típica …................................................................... 238

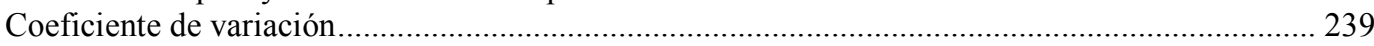

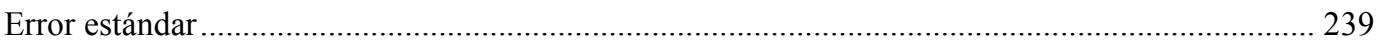

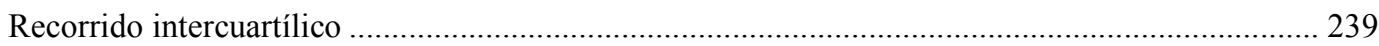

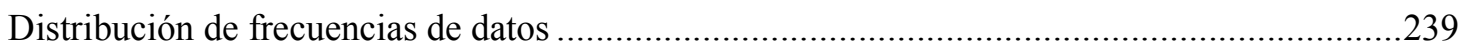

Distribuciones de frecuencia de datos para variables continuas ................................................... 240

La distribución de frecuencias Normal(o de Gauss) ................................................................ 240

La distribución de frecuencias de Student.................................................................................. 244

La distribución de frecuencias de Chi cuadrado $\left(\chi^{2}\right)$ con $v$ grados de libertad .............................. 246

La distribución de frecuencias de $F$ (de Fisher-Snedecor) ...................................................... 247

Métodos para determinar el tipo de distribución .........................................................250

Muestras categorizadas (Distribuciones para variables continuas o discretas) ............................... 250

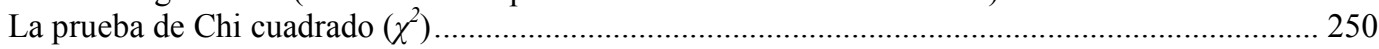

Muestras no categorizadas (Distribuciones continuas) ........................................................... 251

Prueba de Kolmogorov-Smirnov (prueba $K-S$ ) .................................................................. 251

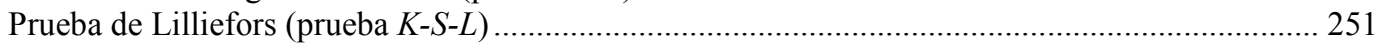

Prueba de contraste de normalidad de Shapiro-Wilk .......................................................... 251

Prueba de contraste de normalidad de Anderson-Darling ........................................................ 252

INDICE DE FIGURAS................................................................................................ 253

INDICE DE TABLAS ....................................................................................................... 256 


\section{INTRODUCCION}

Los altos costos de equipos específicos necesarios para montar un laboratorio de red, sumados a los escasos recursos con los que cuenta el Departamento de Informática de la Facultad de Ciencias Exactas de la Universidad Nacional de Salta (similares a los recursos con los que cuentan la mayoría de las universidades públicas en el interior del país), hacen considerar a las herramientas de simulación como una posible solución para que las prácticas sean mejor aprovechadas por los estudiantes, posibilitando además la utilización de estas herramientas fuera de los horarios de clases.

De acuerdo a lo dicho anteriormente, se podría resumir la problemática de la siguiente manera:

- El docente debe plantear los trabajos prácticos de laboratorio adecuándose a las características del equipamiento disponible, generalmente escaso (actualmente en el laboratorio del Departamento de Informática, existen 3 enrutadores marca Cisco, 5 enrutadores del tipo SOHO - Small Office Home Office y diversos conmutadores).

- La cantidad de estudiantes habitualmente es elevada (aproximadamente 15-20 estudiantes cada año).

- Los equipos de hardware (enrutadores, conmutadores, concentradores, cableado de red, conectores, etc.) son costosos, y su actualización y mantenimiento también significa costos elevados, por lo que usualmente se puede contar con a lo sumo uno o dos dispositivos por comisión o grupos de estudiantes. Lo que hace impracticable los laboratorios con equipo real.

- La curva de aprendizaje para la administración de los dispositivos es alta, lo mismo ocurre con la conectorización física para definir una determinada topología, ya que se disponen diferentes tipos de interfaces de red tal como Ethernet, FastEthernet y puertos Seriales. Esto impide realizar demasiados grupos que accedan al hardware de red.

Desde hace un tiempo, el uso de herramientas de software de simulación ha demostrado ser de gran utilidad en los procesos de enseñanza y aprendizaje en varios contextos. Concretamente en redes, son muchas las ventajas que se pueden enumerar, entre las que se destacan, la reducción significativa en costos de adquisición de dispositivos de red tales como enrutadores, conmutadores LAN, cableado, entre otros. Asimismo, se reducen los tiempos para la puesta en marcha de los laboratorios.

En ese sentido, se está constantemente en la búsqueda de estrategias para mejorar la calidad de los aprendizajes. Una de esas estrategias es el uso de tecnologías de la información y la comunicación (TIC) en los procesos de enseñanza.

\subsection{Motivación}

Una de las preocupaciones constantes de las universidades es estar a la vanguardia en los métodos de enseñanza y ofrecer oportunidades de prácticas innovadoras que apoyen la preparación de sus estudiantes para su futura vida laboral. El rápido y continuo desarrollo tecnológico que las organizaciones viven, particularmente en las áreas de tecnología, altera la manera de enseñar $y$, por supuesto, de aprender. 
En muchas universidades la computadora, las redes, los sistemas de videoconferencias, la Internet y las soluciones de software se usan a diario. Toda esta infraestructura tecnológica no solo contribuye a facilitar las tareas y actividades como la documentación y obtención de información, si no que sirven como punta de lanza para la investigación sobre los cambios que se experimentan, tanto en el uso de herramientas en la educación como en los posibles métodos de enseñanza que se requieren para incorporar estos recursos.

Uno de los objetivos clave en la enseñanza de las redes de computadoras en la carrera de Licenciatura en Análisis de Sistemas es transmitir conceptos básicos y fundamentos a los estudiantes. Sin embargo, desde hace un tiempo se viene investigando como facilitar la relación entre la realidad y las teorías y modelos, es decir, entre lo concreto y lo abstracto. Así, las computadoras personales (PC), con la variedad de software que se ha desarrollado, tienen en sí mismas un gran potencial para mejorar el proceso de enseñanza y aprendizaje, a fines que:

- El aprendizaje sea más interesante.

- El aprendizaje sea activo, no pasivo en las aulas.

- Los estudiantes estén más motivados.

- El aprendizaje sea al ritmo del estudiante en forma personalizada.

- La educación sea permanente.

El Departamento de Informática considera a la simulación como una herramienta de apoyo pedagógico, que facilita la investigación y el desarrollo de una mejor calidad y pertinencia de la educación y de formación de saberes contextualizados entre teoría y práctica en el estudiante.

\subsection{Objetivos y preguntas de investigación}

El objetivo general de esta tesis doctoral fue evaluar la influencia de la utilización de software de simulación en la enseñanza de contenidos de redes de computadoras en el ámbito de las asignaturas relacionadas con la temática en la carrera de Licenciatura en Análisis de Sistemas, cursos de extensión y postgrado organizados por el C.I.D.I.A. Centro de Investigación y Desarrollo en Informática Aplicada que depende de la Facultad de Ciencias Exactas de la Universidad Nacional de Salta - y en la carrera Ingeniería en Telecomunicaciones en la Universidad Católica de Salta. Para ello se llevó a cabo un estudio aplicado, longitudinal y experimental que, asumiendo la complejidad del fenómeno educativo, considera aspectos cuantitativos y cualitativos.

A partir de éste se plantearon los siguientes objetivos específicos:

- Establecer la relación entre la utilización de la simulación y la actitud de los estudiantes hacia el estudio de los protocolos IP;

- Determinar si existe diferencia significativa en el nivel de comprensión de los principios de los protocolos de red analizados, entre estudiantes que reciben instrucción mediada por herramientas de simulación y estudiantes que reciben instrucción tradicional. 
Las preguntas que se plantearon en este sentido son:

A. ¿Cómo influyen en la enseñanza y el aprendizaje los trabajos realizados con un software de simulación?, ¿Qué efectos causan los programas de simulación en lo que hace a la motivación del estudiante a aprender a resolver los problemas analizados en las clases teóricas?

B. ¿Cuánto pueden contribuir los trabajos sobre el simulador a que se reafirmen los conceptos teóricos y la comprensión de los fundamentos y funcionamiento en general de las redes?

C. ¿El trabajo con el simulador permite al estudiante sentir la seguridad de quien ha explorado un tema acabadamente, especialmente con la posibilidad de variar arbitrariamente los valores de los componentes y variables?

D. Dado que el estudiante puede diseñar e inventar topologías y experimentar con ellas ¿hasta qué punto favorece la creatividad?

E. ¿Hasta qué punto contribuyen a reemplazar un aprendizaje memorístico por aprendizaje significativo?

F. ¿En qué momento conviene aplicar estos métodos, antes y/o después de los trabajos prácticos tradicionales? ¿Qué condiciones deben darse para la aplicación de estos métodos?

G. ¿Es deseable estructurar otras actividades prácticas utilizando métodos de simulación?

De lo expresado se desprende que, si bien muchas universidades comenzaron a aplicar este recurso, porque intuitivamente se reconoce su importancia, no se han encontrado muchas investigaciones didácticas realizadas en relación al mismo, y mucho menos asociadas a teorías cognitivas. Por lo que se plantea una línea de investigación dentro del paradigma cuantitativo, en el cual se encuentran los diseños experimentales y los métodos estadísticos de contraste de hipótesis y de correlación entre variables, que serán aplicados en la tesis.

Este estudio aportará evidencia empírica sobre la incidencia del uso de herramientas de simulación en la enseñanza de conceptos de redes de computadoras en el nivel universitario. Existen importantes estudios sobre el tema orientados hacia otros niveles de educación y otras áreas de la ciencia (García y Gil, 2006; Esquembre, 2005; Kofman, Catalán y Concari, 2004; Giorgi, Cámara y Kofman, 2004; Debel y Álvarez, 2008). Asimismo, existen estudios enfocados a la física, química y matemáticas ámbitos de la física diferentes a la cinemática bidimensional (Becerra, 2005; Amaya, 2008). En el área específica de la redes de computadoras se puede mencionar a Cameron, B. (2003): Effectiveness of simulation in a hybrid online networking course. Quarterly Review of Distance Education, 4(1), 51. Teaching Computer Networks through Network Simulation Programs. Dr S. Y. Zhu. Faculty of Business, Computing and Law - School of Computing. 
Esta investigación beneficiará a los diferentes actores del proceso educativo: docentes, investigadores y autoridades educativas. Los resultados de esta investigación permitirán tomar importantes decisiones sobre la inclusión de herramientas TIC como medios para favorecer el aprendizaje de conceptos y fundamentos no solo de redes de computadoras.

\subsection{Estructura de la tesis}

En el segundo capítulo se aborda los fundamentos del tema y marco teórico. En el tercer capítulo se presenta una revisión de la simulación en la enseñanza con base en la literatura más relevante relacionada con la temática. En el cuarto capítulo se describen en detalle los aspectos metodológicos y las técnicas y herramientas con las que se efectuaron las mediciones de las experiencias. En el capítulo quinto, se detalla cada una de las experiencias realizadas y el análisis estadístico de los datos exponiendo diferentes gráficos descriptivos. Finalmente, en el sexto capítulo se exponen los resultados, conclusiones y líneas futuras de investigación. 


\section{FUNDAMENTOS DEL TEMA: MARCO TEÓRICO}

\subsection{Aprendizaje significativo}

A partir de la década de los años 60, Ausubel, psicólogo norteamericano estudia los aspectos centrales del aprendizaje en los contextos áulicos. En (Pozo, 1989) se menciona que la teoría del aprendizaje significativo consiste en una teoría psicológica cognitiva del aprendizaje que se construye a partir del análisis y prácticas de enseñanza.

La concepción del aprendizaje significativo continúa teniendo vigencia y valor pedagógico debido a que se constituye en un constructo explicativo de los procesos educativos que acontecen en las aulas. Esta teoría posee implicaciones psicológicas y pedagógicas ya que estudia los procesos que acontecen en las instituciones educativas, en el plano áulico y aborda el estudio de ciertos procesos que los sujetos ponen en juego en el momento del aprendizaje, en la naturaleza de ese aprendizaje; en las condiciones necesarias a considerar para que el aprendizaje se produzca. (Ausubel, 1976). El autor sostiene que el aprendizaje de los estudiantes depende de la estructura cognitiva previa que poseen y de las relaciones que establecen con la información nueva que reciben. En este sentido, el aprendizaje significativo se constituye en el proceso según el cual se vincula un nuevo conocimiento o información con la estructura cognitiva que se posee de forma no arbitraria y sustantiva. La presencia de ideas, conceptos o proposiciones inclusivas, claras y disponibles en la mente del aprendiz es lo que dota de significado a ese nuevo contenido en interacción con el mismo (Moreira, 2000 a). En este proceso los nuevos contenidos adquieren significado para el sujeto produciéndose una transformación de su estructura cognitiva.

De este modo, el aprendizaje significativo ocurre cuando los contenidos pueden ser relacionados de manera sustancial y no arbitraria con lo que el estudiante ya sabe. Ausubel, en el epígrafe de su obra señala: "Si tuviese que reducir toda la psicología educativa a un solo principio, enunciaría este: El factor más importante que influye en el aprendizaje es lo que el alumno ya sabe. Averígüese esto y enséñese consecuentemente" (Ausubel, 1983). Esto implica que el aprendizaje significativo se evidencia cuando la nueva información se vincula, "se conecta" con un concepto relevante preexistente en la estructura cognitiva, es decir que las nuevas ideas, conceptos, proposiciones pueden ser aprendidos de manera significativa en la medida en que otras ideas, conceptos, proposiciones se encuentren disponibles en la estructura cognitiva de los sujetos del aprendizaje.

Por otro lado, plantea que para que sea posible el aprendizaje significativo debe procurarse ciertas condiciones fundamentales:

- Actitud potencialmente significativa del estudiante. Predisposición para aprender de manera significativa. Ausubel plantea: "El alumno debe manifestar [...] una disposición para relacionar sustancial y no arbitrariamente el nuevo material en su estructura cognoscitiva, como que el material que aprende es potencialmente significativo para él, es decir, relacionable en su estructura de conocimiento sobre una base no arbitraria" (Ausubel, op. cit.:48)

- Material potencialmente significativo:

- Significatividad lógica: Esto implica que el material de estudio debe poder ser relacionable de manera sustancial y no arbitraria con las estructuras cognitivas del estudiante. Debe poseer un orden y secuenciación que permita su comprensión. 
- Significatividad psicológica: implica la existencia de ideas de anclaje adecuados en el sujeto que permitan la interacción con el material nuevo que se presenta.

La teoría del aprendizaje significativo postula que el aprendizaje "va más allá de un simple cambio de la conducta", sino que conduce a una modificación en el significado de la experiencia. Desde sus posicionamientos teóricos, plantea que para poder entender la labor educativa es necesario considerar tres elementos clave del proceso educativo:

- Los profesores y su modo de desplegar la enseñanza;

- La estructura de los conocimientos curriculares;

- El entramado social en el que se desarrolla el proceso educativo.

\subsection{Enseñanza para la comprensión}

Uno de los avances más significativos en la educación en los últimos años constituye la posibilidad de efectuar análisis reflexivos acerca de los procesos que ocurren en las aulas, considerando los postulados que intervienen para la mejora de la enseñanza. Pogré (en Aguerrondo, 2001) sostiene que el marco conceptual vinculado a la enseñanza para la comprensión fue utilizado en todos los niveles de los sistemas educativos de diversos países.

La definición de aprendizaje como "la apropiación instrumental de la realidad para transformarla" acuñada por Riviere, acerca conceptualmente a la concepción de comprensión como desempeño. En (Perkins, 1999) se sostiene que comprender es la "habilidad de pensar y actuar con flexibilidad a partir de lo que uno sabe". Desde este punto de vista, la comprensión de un tópico constituye la capacidad que poseen los sujetos de tener "desempeños flexibles". La comprensión se hace presente cuando los sujetos pueden reflexionar y actuar con flexibilidad a partir de lo que saben. La comprensión de esos tópicos se vincula con las posibilidades de relacionar, describir, comparar, operar, diferenciar, adecuar, relatar, diagramar, analizar, decidir, representar, secuenciar, organizar, etc. (Pogré, 2001)

Asimismo, Perkins (op. cit.) sostiene: "primero, para apreciar la comprensión de una persona en un momento determinado, pídanle que haga algo que ponga su comprensión en juego, explicando, resolviendo un problema, construyendo un argumento, armando un producto. Segundo, lo que los estudiantes responden no sólo demuestra su nivel de comprensión real sino que lo más probable es que los haga avanzar. Al trabajar por medio de su comprensión en respuesta a un desafio particular, llegan a comprender mejor.". Los procesos mentales que se activan hacen referencia al rol activo del sujeto del aprendizaje. Por contraste, cuando un estudiante se encuentra anclado en procesos relacionados exclusivamente con la memorización, el pensamiento y la acción rutinarios, implica que se encuentra atravesando una falta de comprensión.

Perkins (op. cit.) menciona la importancia de los "desempeños de comprensión" o "desempeños comprensivos" que aluden a actividades que van más allá de la memorización y la rutina.

De lo expuesto se evidencia que la postura didáctica adoptada es la de brindar una enseñanza orientada o preparada para que sea fácilmente internalizada por un estudiante activo, creando el entorno que conduzca a un aprendizaje significativo. No se trata de crear 
máquinas o métodos de "hacer conocimiento" en un estudiante pasivo. Si se realiza una comparación con la transferencia de información por parte de una emisora de radio o TV, que para ser captada por el receptor debe este último sintonizarse en la frecuencia del emisor, en este caso es el emisor (docente) quien debe tratar de reconocer las estructuras cognitivas del receptor, para crear un entorno y enseñar de una forma que pueda ser fácilmente captada por el receptor, transformando (cuando corresponde) la estructura cognitiva original.

El otro enfoque a tener en cuenta en este trabajo, es la teoría sicológica de Vygotski, apuntando particularmente a describir la naturaleza de los procesos de desarrollo en su vinculación con las prácticas educativas. En particular analizar la categoría de Zona de Desarrollo Próximo (ZDP) y las particularidades que ha guardado su uso en el terreno educativo.

En la figura 2-1 puede observarse el gráfico, del tipo “x, y” que resume, según Ausubel, los distintos tipos y formas de aprendizaje, valorando las mismas en función de lo que la teoría y la experiencia han mostrado. El eje vertical está relacionado con el tipo de aprendizaje que realiza el estudiante, mientras que el horizontal se relaciona con la estrategia de enseñanza que puede planificar el docente. Las conclusiones de distintas investigaciones afirman que el aprendizaje más conveniente es el aprendizaje significativo por descubrimiento autónomo, y se debería tender a él, en lo posible. Esto como un criterio a tener en cuenta, de hecho habrá contenidos que solo pueden memorizarse. En lo que respecta al docente, el desafío será pasar de la clase expositiva, a una clase donde se le haga "descubrir" conclusiones al estudiante, posibilitarle que aprenda a pensar y valerse por sí mismo para hacer sus propios descubrimientos.

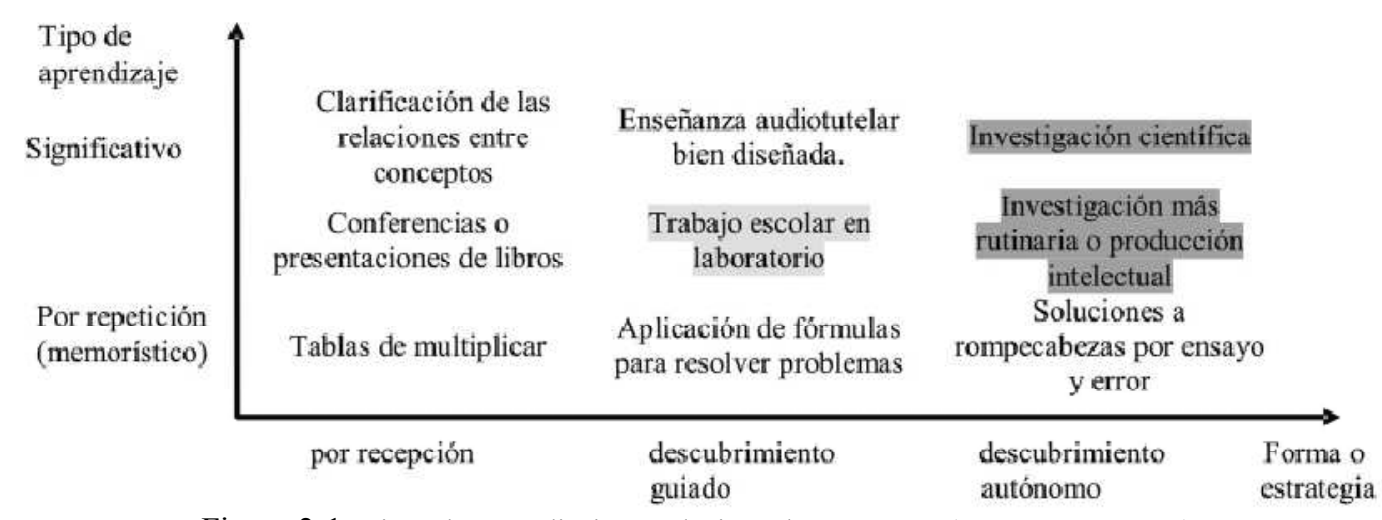

Figura 2-1: Tipos de aprendizaje en relación a la enseñanza (Pozo, J. 1997: 211)

En carreras como las ingenierías y licenciaturas, se implementan actividades prácticas ("trabajos prácticos"), los que se prestan a que el estudiante pueda realizar experiencias que lo lleven a un aprendizaje por descubrimiento guiado. Más adelante se dedica especial atención a los trabajos prácticos en las carreras de sistemas.

\subsection{Distintas formas de enseñanza y aprendizaje}

Existen tres formas de enseñanza y aprendizaje según (Cámara, Alzugaray, 2011), a través de: una clase en aula, una experiencia personal sin participación de un docente y una experiencia personal, asistido por un docente 
- A través de una clase en aula (o un libro, dentro de ciertos límites este hace el papel del docente, aunque sin que exista interacción). Se identifican los hechos de la realidad del mundo físico, la figura del docente, y el estudiante. Se observa que en este caso el estudiante está "distanciado" de los hechos.

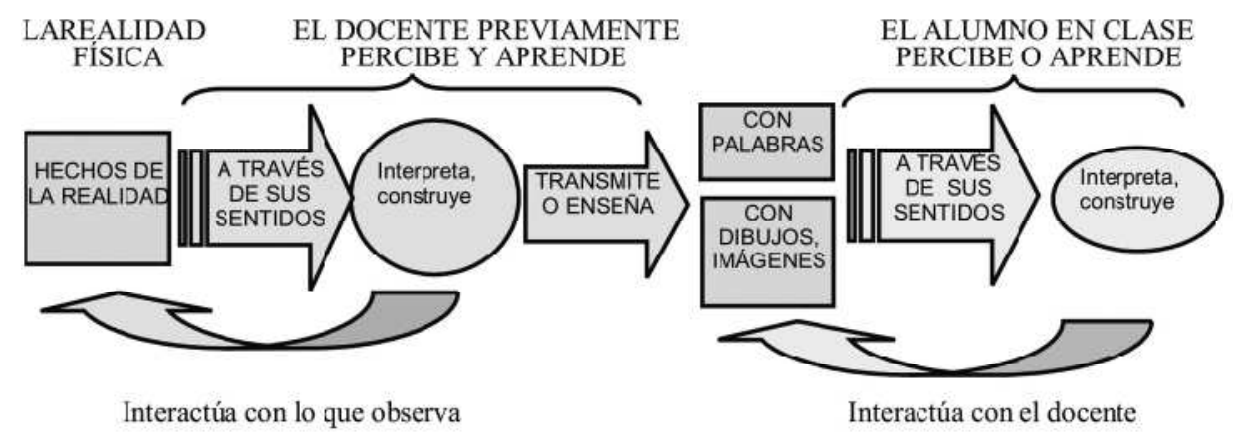

Figura 2-2: Clase en un aula, sin experiencias (Cámara, Alzugaray, 2011)

- A través de una experiencia personal, sin participación de un docente. En este caso el estudiante está directamente en contacto con la realidad. Puede aprender libremente, sin condicionamientos, y realizar un aprendizaje autónomo. La desventaja es que puede malinterpretar los hechos, al no contar con la participación de un docente.

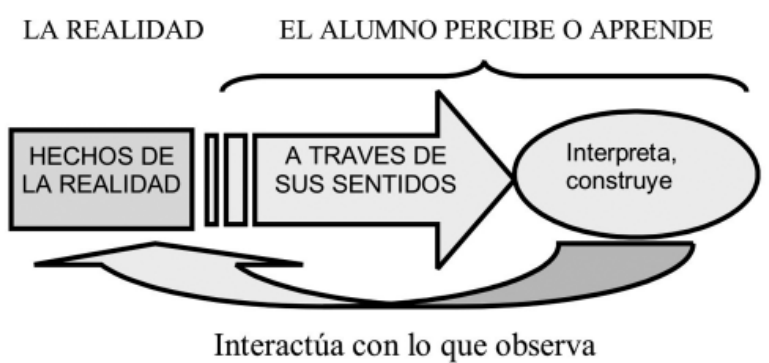

Figura 2-3: Experiencias sin participación de un docente (Cámara, Alzugaray, 2011)

- A través de una experiencia personal, asistido por un docente ("los trabajos prácticos"). Este es el caso de las actividades prácticas de laboratorio. Con las mismas ventajas que el anterior (ver gráfico), aunque la desventaja observada en cuanto a la posibilidad de malas interpretaciones de los hechos (inductivismo extremo) se subsana por la participación del docente.

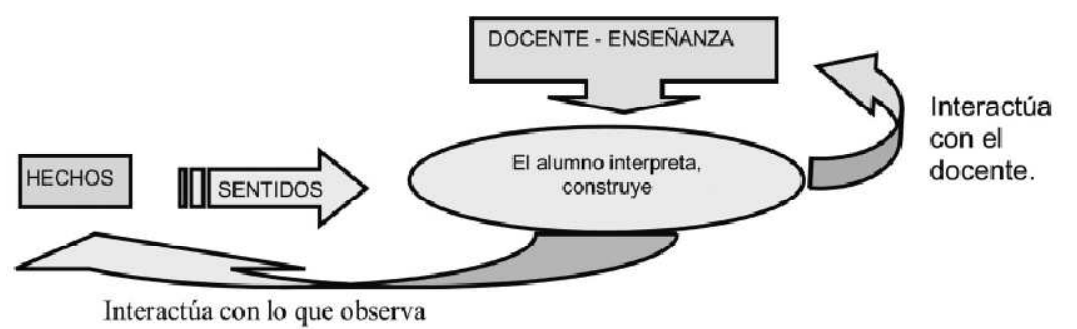

Figura 2-4: Experiencias con participación de un docente (Cámara, Alzugaray, 2011). 


\section{SIMULACIÓN EN LA ENSEÑANZA}

\subsection{Contenido sobre redes de computadoras}

Teniendo en cuenta el perfil del estudiante se podría clasificar la enseñanza de contenidos de redes de computadoras en dos grandes áreas: la primera y más antigua es la formación de personal técnico que se desempeñará como administrador de redes y la segunda, es la enseñanza de conceptos y fundamentos de redes de computadoras en la formación de licenciados o ingenieros en informática, sistemas o sus diversas variantes.

Claramente la formación de técnicos en redes o especialistas en telecomunicaciones, involucra la enseñanza de conceptos de redes aplicados sobre dispositivos específicos de fabricantes como Cisco, Mikrotik, Ubiquiti, etc., ya que el futuro desempeño profesional de este estudiante está directamente relacionado con la administración de dispositivos y con el funcionamiento de una red real implementada y operativa. En estos casos, la simulación es de gran ayuda en la formación, pero está claro que no reemplaza la práctica sobre los dispositivos específicos. La virtualización por sobre la simulación, pareciera ser más apropiada en estos casos, ya que sobre un entorno como GNS3, se pueden ejecutar imágenes de sistemas operativos de dispositivos Cisco o Mikrotik por ejemplo, y el estudiante puede simular la administración de estos dispositivos que soportan el conjunto total de comandos (simulan el funcionamiento real del dispositivo y no un subconjunto de comandos como en el caso de la simulación), como si de un dispositivo real se tratara. La bibliografía tradicional, como Computer Networks de Andrew Tanembaun y David Wetherall, Data and Computer Communications de Williams Stallings, Computer Networks: A Systems Approach de Larry Peterson y Bruce Davie, TCP/IP Illustrated de Richard Stevens, Computer Networks and Internets de Douglas Comer y Data Communications, Computer Networks, and Open Systems de Fred Halsall, acompañan este tipo de formación.

En la formación de licenciados o ingenieros en sistemas, el aprendizaje de temas relacionados con la redes se enfoca desde una óptica conceptual y de fundamentos. Estos profesionales no requieren realizar la administración de dispositivos de redes (con excepción de aquellos que se dediquen específicamente a ello) sino, comprender con mucho detalle el funcionamiento de una red de computadoras para poder implementar eficientemente los sistemas de software que analicen y diseñen. En estos casos, las herramientas de simulación, que se independizan en cierta medida de los fabricantes de redes, son muy útiles para su formación, además de brindar ayuda contextual para que el estudiante pueda resolver con mayor facilidad los problemas que se le plantean. La bibliografía para este tipo de formación es reciente y el libro de referencia es el Computer Networking: A Top-Down Approach de James F. Kurose y Keith W. Ross.

\subsection{Los trabajos prácticos}

La necesidad de buscar la superación de un aprendizaje puramente memorístico con la realización de abundantes trabajos prácticos, y la solución a la falta de motivación por el aprendizaje de las ciencias, cuenta con una larga tradición (Lazarowitz y Tamir, 1994; Lunett a, 1998). De hecho, constituye una intuición básica de la generalidad de los profesores de ciencias y de los propios estudiantes que contemplan el paso a una enseñanza 
eminentemente experimental como una especie de "revolución pendiente" (Gil-Pérez et al., 1988), necesaria para lograr la familiarización con la naturaleza de la actividad científica. Una "revolución" permanentemente dificultada se afirma por factores externos (falta de instalaciones y material adecuado, excesivo número de estudiantes, carácter enciclopédico de las currículas...). La influencia de esta tendencia ha sido particularmente notable en el mundo anglosajón, donde en los años sesenta y setenta se elaboraron y pusieron en práctica numerosos proyectos de aprendizaje "por descubrimiento autónomo", centrados, casi exclusivamente, en el trabajo experimental y en "los procesos de la ciencia", como por ejemplo Physical Science Study Committee (PSSC), Chemical Education Material Study (CHEM Study), Biological Sciences Curriculum Study (BSCS) en los Estados Unidos, y los cursos Nuffield de física, química y biología en Inglaterra. De estos proyectos derivaron incluso prototipos de equipamiento y variantes de trabajos experimentales que se extendieron por muchos países.

Pero, ¿hasta qué punto las prácticas que se realizan, en mayor o menor número, contribuyen a dicha familiarización?. Es importante contestar a esta cuestión mediante un cuidadoso análisis de las prácticas habituales. Es cierto que, como ya señalaba Bunge (1976), los diseños experimentales son deudores del cuerpo de conocimientos, pero su realización concreta exige resolver problemas prácticos en un proceso complejo con muchas de las características del trabajo tecnológico. Es precisamente éste el sentido que debe darse a lo que manifiesta Hacking (1982) cuando -parafraseando la conocida frase de que la observación está cargada de teoría (Hanson, 1958)- afirma que "la observación y la experimentación científica están cargadas de una competente práctica previa”.

Esta dependencia de la ciencia respecto de la tecnología (y viceversa) se ha hecho cada vez más notable por lo que hoy corresponde hablar de una estrecha interrelación cienciatecnología (Maiztegui et al., 2002). Pero todo el papel de la tecnología en el desarrollo científico es algo que las prácticas de laboratorio habituales dejan de lado, al presentar diseños experimentales como simples recetas ya preparadas, y excluir así cualquier reflexión acerca de las relaciones ciencia-tecnología.

Concretamente, se puede referir a este papel de los diseños, al desarrollar un ejemplo de práctica de laboratorio. En definitiva, el trabajo experimental no sólo tiene una deficiente presencia en la enseñanza de las ciencias, sino que la orientación de las escasas prácticas que suelen realizarse contribuye a una visión distorsionada y empobrecida de la actividad científica. Es preciso, pues, proceder a una profunda reorientación.

Si se quiere avanzar en la transformación de las prácticas de laboratorio, es necesario analizar cuidadosamente las propuestas concretas, llevarlas al aula y contrastar su validez (Gil-Pérez, 1993; Salinas, 1998; Gil-Pérez y Valdés, 1996). Una práctica de laboratorio que pretenda aproximarse a una práctica significativa para el estudiante debe dejar de ser un trabajo exclusivamente "experimental" e integrar muchos otros aspectos de la actividad científica igualmente esenciales. De forma muy resumida se presenta a continuación un conjunto de aspectos a tener en cuenta para la mejora de la enseñanza de este tema:

1. Presentar situaciones problemáticas abiertas de un nivel de dificultad adecuada, con el objetivo de que los estudiantes puedan tomar decisiones para precisarlas y entrenarse, así, en la transformación de situaciones problemáticas abiertas en problemas precisos.

2. Favorecer la reflexión de los estudiantes sobre la relevancia y el posible interés de las situaciones propuestas que dé sentido a su estudio, considerando las posibles 
implicaciones Ciencia - Tecnología - Sociedad - Ambiente (CTSA), etc.; y evitar un estudio descontextualizado, socialmente neutro.

3. Potenciar los análisis cualitativos, significativos, que ayuden a comprender y a acotar las situaciones planteadas (a la luz de los conocimientos disponibles, del interés del problema, etc.) y a formular preguntas operativas sobre lo que se busca. Se trata de salir al paso de una manera ciega de operar, sin negar, muy al contrario, el papel esencial de las matemáticas como instrumento de investigación, que interviene en todo el proceso, desde el enunciado mismo de problemas precisos (con la necesaria formulación de preguntas operativas) hasta el análisis de los resultados.

4. Plantear la emisión de hipótesis como actividad central de la investigación científica, susceptible de orientar el tratamiento de las situaciones y de hacer explícitas, funcionalmente, las preconcepciones de los estudiantes. Insistir en la necesidad de fundamentar dichas hipótesis y prestar atención, en ese sentido, a la actualización de los conocimientos que constituyan prerrequisitos para el estudio emprendido. Reclamar cuidado al hacer operativas las hipótesis, es decir, la derivación de consecuencias contrastables, prestando la debida atención al control de variables, a cómo es la dependencia esperada entre las variables, etc.

5. Conceder toda su importancia a la elaboración de diseños y a la planificación de la actividad experimental por los propios estudiantes dando a la dimensión tecnológica el papel que le corresponde en este proceso. Potenciar, allí donde sea posible, la incorporación de la tecnología actual a los diseños experimentales (computadoras, electrónica, automatización...), con objeto de favorecer una visión más correcta de la actividad científico-técnica contemporánea.

6. Plantear el análisis detenido de los resultados (su interpretación física, fiabilidad, etc.) tomando en cuenta el cuerpo de conocimientos disponible, las hipótesis manejadas y los resultados de "otros investigadores" (los de otros equipos de estudiantes y los aceptados por la comunidad científica, recogidos en los libros de texto).

7. Favorecer, a la luz de los resultados, la "autorregulación" del trabajo de los estudiantes, es decir, las necesarias revisiones de los diseños, de las hipótesis o, incluso, del planteamiento del problema. Prestar una particular atención, en su caso, a los conflictos cognitivos entre los resultados y las concepciones iniciales, facilitando así, de una forma funcional, los cambios conceptuales.

8. Plantear la consideración de posibles perspectivas (replanteamiento del estudio a otro nivel de complejidad, problemas derivados, etc.) y contemplar, en particular, las implicaciones CTSA del estudio realizado (posibles aplicaciones, repercusiones negativas, etc.)

9. Promover un esfuerzo de integración que considere la contribución del estudio realizado a la construcción de un cuerpo coherente de conocimientos, así como las posibles implicaciones en otros campos del conocimiento.

10. Conceder una especial importancia a la elaboración de memorias científicas que reflejen el trabajo realizado y puedan servir de base para resaltar el papel de la comunicación y el debate en la actividad científica.

11. Potenciar la dimensión colectiva del trabajo científico organizando equipos de trabajo y facilitando la interacción entre cada equipo y la comunidad científica, representada en la clase por el resto de los equipos, el cuerpo de conocimientos ya construido (recogido en los textos), el profesor como experto, etc. 
12. Problematizar los resultados ya que una sola persona o un solo equipo, no pueden bastar para verificar o falsar una hipótesis y que el cuerpo de conocimientos constituye la cristalización del trabajo realizado por la comunidad científica y la expresión del consenso alcanzado en un determinado momento.

\subsubsection{Los trabajos prácticos en el currículo de sistemas}

Los trabajos prácticos en el currículum de carreras de sistemas constituyen un campo de desarrollo e investigación cuyas implicancias en la enseñanza y aprendizaje de conceptos relacionados a las asignaturas básicas, son muy relevantes. Forman parte de una de las estrategias didácticas utilizadas con gran frecuencia por los docentes para favorecer la integración de contenidos tanto disciplinares como multidisciplinares, y de este modo resultan ser una herramienta valiosa en la enseñanza.

Por ello, los diseños y el desarrollo de las actividades constituyen un significativo campo de estudio generando cuestiones de diversa índole, componentes y materiales susceptibles de ser sometidos a análisis, evaluación e investigación permanente. Las prácticas de laboratorio, además de desarrollar destrezas relacionadas con habilidades procedimentales y actitudinales, pueden ayudar al estudiante a comprender, reelaborar y/o afianzar conceptos fundamentales, así como también a encauzar el conflicto cognitivo y posibilitar cambios conceptuales.

Dichas prácticas pueden desarrollarse entonces, en el presente, a través de dos tipos de laboratorio:

- El laboratorio real: donde el estudiante a través de un contacto directo con los distintos materiales y equipos, manipula los dispositivos requeridos para el experimento. En este caso las distintas prácticas se realizan en el mismo ámbito físico, y a menudo con los mismos grupos de estudiantes a través del dictado de una asignatura.

- El laboratorio con simulación: utilizando aplicaciones de software, se realizan simulaciones interactivas programadas y ejecutadas en una PC. Puede ser utilizado en distintos ámbitos físicos y con distintos grupos de estudiantes, con el agregado que el educando lo puede repetir en cualquier lugar en que disponga de esos mínimos medios necesarios (incluso en su domicilio).

Dada la relevancia que revisten las actividades que se diseñan para la enseñanza, se considera importante que la inclusión de materiales curriculares -en particular el softwaredeba ir acompañado de un proceso reflexivo de los profesores, que fundamente la elección, teniendo en cuenta un planteamiento metodológico y diseñado en función de los objetivos de la enseñanza. No se trata tanto de qué software seleccionar, o qué material elaborar sólo por el atractivo o interés que conlleve en sí mismo, sino más bien, de cómo diseñar estrategias de enseñanza en el marco de determinados enfoques disciplinares y didácticos, evaluando para ello qué materiales y tecnologías pueden integrarse y ser coherentes con dicho planteamiento (Alzugaray, et.al., 2006).

En el momento de pensar en la selección de materiales didácticos para la enseñanza, un desafío pedagógico importante es abrir el espectro de mediadores culturales y el pensar en aquellos instrumentos y usos más favorables. Entre los distintos tipos de materiales que pueden utilizarse, el software es una herramienta que puede brindar amplias y variadas 
posibilidades de aprendizajes, por la potencialidad didáctica que lleva en sí mismo, cuando cumple determinadas especificaciones.

Para iniciar una reflexión sobre los usos didácticos del software en la enseñanza, puede partirse de las tres vertientes propuestas por Santos Guerra (1996) para realizar la evaluación de los materiales didácticos:

- las políticas de elaboración y difusión,

- la potencialidad didáctica en función de su naturaleza y

- la utilización de los mismos.

En el caso particular de las asignaturas de sistemas, las competencias que las mismas quieren lograr y las actitudes que los Trabajos Prácticos deben generar en el estudiante son:

- complemento a la enseñanza impartida en las clases teóricas,

- el conocimiento y funcionalidad de dispositivos de red,

- armado y operación de distintas topologías de red,

- análisis de escenarios propuestos, direccionamiento de red, enrutamiento,

- análisis de errores,

- captura y análisis de tráfico relacionado con los diferentes protocolos de las capas de aplicación, transporte y red,

- simulación de los diferentes algoritmos relacionados con las capas del modelo TCPIP,

- elaboración de conclusiones,

- presentación de la información,

- trabajo en grupo, escuchando y respetando las opiniones de los demás,

En el caso específico de las asignaturas en la carrera Licenciatura en Análisis de Sistemas, que forman parte del grupo ARSO - Arquitectura, Redes y Sistemas Operativos, de acuerdo a los lineamientos de la Red UNCI - Red de Universidades Nacionales con Carreras en Informática, las prácticas tradicionales para la mayoría de los temas, se realizan con enunciados de problemas en el aula, algunas asignaturas comienzan a utilizar software de simulación, pero en general, en la mayoría de los casos, se realiza una o dos prácticas integradoras y globalizadoras para el final del cursado de las mismas (con equipo real), debido a las limitaciones de laboratorios y equipos comentadas.

\subsubsection{Trabajos prácticos tradicionales y trabajos prácticos con simulación}

Se resume a continuación la relación que existe entre trabajos prácticos tradicionales y los trabajos prácticos con software de simulación (o con métodos de simulación).

- Por las cuestiones mencionadas de organización, gestión, seguridad, disponibilidad de docentes, horarios, cuidado de los equipos, etc.; en la práctica, los trabajos prácticos de laboratorio los realiza el estudiante durante momentos acotados, únicos e irrepetibles en el cursado de la asignatura. Por otra parte, los trabajos con simulación los puede realizar en todo momento que disponga de una computadora personal. Todo ello sin riesgo de accidentes y sin necesidad de equipamiento adicional.

- En los trabajos de laboratorio reales, el estudiante participa parcialmente (por momentos sólo como espectador), dado que se realizan en grupo, mientras que en 
un laboratorio con simulación el estudiante puede realizarlo todo, y lo que es muy importante no se ve forzado a seguir una rutina prefijada, sino que puede variar a voluntad, imaginar e improvisar experiencias, dando rienda suelta a su imaginación y creatividad. Sin embargo, se considera que siempre es necesaria una guía conductora para la práctica propuesta, ya que de lo contrario se podría perder el objetivo de la práctica específica.

- Como desventaja, los trabajos de simulación se perciben a través de un solo sentido, dos dimensiones (en "2D", pantalla plana). Tampoco se desarrollan algunas de las aptitudes que tienen que ver con la manipulación de los materiales y dispositivos, como por ejemplo la conectorización del cableado para el armado de una topología específica, a pesar que existen simuladores donde esta conectorización se realiza seleccionando el cable y el puerto específico en el dispositivo de manera muy cercana a la realidad.

- En el caso del laboratorio con simulación, la implementación de un método puede tener ventajas o problemas dependiendo de la carrera y la asignatura, pero en lo que hace a los resultados, hay factores que son intrínsecos al software en sí, sea porque lo hacen más o menos preciso, funcional o didáctico, como también más o menos "amigable" (usando una terminología que la práctica ha impuesto para reflejar cuan atractivo, práctico y fácil de aprender y usar es un programa).

En la Tabla 3-1 se resume el resultado de comparar los trabajos prácticos con equipo real con los trabajos prácticos con simulación. En color gris oscuro se destacan las desventajas de cada uno de ellos frente al otro, y viceversa, en color gris claro los aspectos positivos.

Por lo antedicho, los Trabajos Prácticos con equipo real - TPR, en el gráfico se ubican en la zona destacada en gris oscuro, mientras que los Trabajos Prácticos con simulación - TPS se corresponden con la zona gris claro, correspondiente a un tipo de aprendizaje mejor, aunque con las desventajas que se muestran en dicha tabla. 


\begin{tabular}{|c|c|}
\hline $\begin{array}{c}\text { Trabajos Prácticos con equipo real - } \\
\text { TPR }\end{array}$ & $\begin{array}{c}\text { Trabajos Prácticos con simulación - } \\
\text { TPS }\end{array}$ \\
\hline Dispositivos (routers, switchs, hubs, pcs) & -- \\
\hline Cables (UTP, fibra, coaxil) & -- \\
\hline Conectores & -- \\
\hline $\begin{array}{l}\text { Costo del equipo específico de red solo } \\
\text { para las asignaturas }\end{array}$ & $\begin{array}{c}\text { Costo del Laboratorio de PCs } \\
\text { Compartido con otras asignaturas }\end{array}$ \\
\hline Plantel docente & Durante la práctica en aula \\
\hline $\begin{array}{l}\text { Grupos pequeños de estudiantes donde no } \\
\text { hacen "todo" }\end{array}$ & Tarea individual o grupal \\
\hline Horario acotado & Libertad de horario \\
\hline Limitación de equipos disponibles & $\begin{array}{l}\text { Amplio abanico de dispositivos soportados } \\
\text { por los simuladores }\end{array}$ \\
\hline $\begin{array}{l}\text { Plan de actividad acotado, aprendizaje por } \\
\text { descubrimiento guiado }\end{array}$ & $\begin{array}{c}\text { Plan guiado o no, aprendizaje por } \\
\text { descubrimiento autónomo, creatividad }\end{array}$ \\
\hline $\begin{array}{l}\text { Manipulación de material (dispositivos y } \\
\text { cables) }\end{array}$ & -- \\
\hline Experiencia real & Visualización de la experiencia en "2D" \\
\hline
\end{tabular}

Tabla 3-1: Comparación entre trabajos prácticos con equipo real y trabajos prácticos con simulación.

\subsubsection{Trabajos prácticos con simulación para la realización de las experiencias}

Muchas veces, el estudio de una materia se hace particularmente difícil por la ausencia de ejercicios y estudio de casos resueltos que permitan comprender los conceptos y fundamentos teóricos. La comprensión de estos fundamentos permite enfrentarse con mayor confianza a la resolución de problemas complejos.

Los prácticos realizados en la cátedra Redes de Computadoras I se desarrollaron con la intención de ayudar a los estudiantes en el aprendizaje de los conceptos básicos de las redes de computadoras. En este sentido, se consideró que la mejor manera de apoyar al estudiante en el aprendizaje de las redes de computadoras, fue la de realizar una serie de guías prácticas donde se planteen ejercicios relacionados con la configuración de protocolos y su posterior análisis. Estos ejercicios fueron acompañados de la solución para que el estudiante pudiera trabajar de forma personal su resolución y poder contrastar con la solución propuesta.

Este conjunto de guías prácticas se estructuró en diferentes capítulos siguiendo el esquema del título "Redes de Computadoras - Un enfoque descendente" de James F. Kurose y Keith 
W. Ross, por lo que sirvió de apoyo o complemento para la comprensión de los conceptos introducidos en dicha obra. Esta orientación no limitó su uso, ya que los ejercicios propuestos se refieren a configuración y conceptos elementales sobre las redes de computadoras.

Así, el primer apartado del material de Cátedra se dedicó a la introducción de redes, presentando ejercicios que familiaricen al estudiante con la herramienta de simulación Packet Tracer, con los elementos esenciales que conforman una red y con la configuración básica de redes tipo SOHO (Small Office, Home Office). El segundo apartado trató sobre la capa de aplicación y sus diferentes protocolos. En una primera instancia se propusieron ejercicios de configuración de los servidores y clientes, para luego realizar el análisis de los protocolos involucrados. En el tercer apartado se analizaron los protocolos de capa de transporte TCP y UDP, utilizados por las aplicaciones vistas en el capítulo anterior. Finalmente en el apartado cuatro se analizaron los distintos protocolos que conforman la capa de red, proponiendo ejercicios de configuración cuando el protocolo lo permitiera y realizando un análisis detallado de los mismos.

Los ejercicios prácticos propuestos comienzan acercando el simulador al estudiante a través de configuraciones sencillas de redes hogareñas formadas por dos o tres computadoras conectadas a un router y analizando una red empresarial más compleja, con muchas conexiones y equipamiento de red. Allí, el estudiante utilizó los comandos ping y traceroute para verificar conectividad y comenzar a entender la complejidad de una red.

En el estudio de los protocolos de la capa de aplicación, primero se propusieron prácticos para que el estudiante tenga un primer contacto realizando configuraciones y verificando la funcionalidad en el modo tiempo real del simulador, lo que se llamó "Punto de vista del usuario". Dependiendo del protocolo estudiado, se propusieron desde prácticas sencillas a prácticas más complejas sin abandonar la premisa de servir de complemento del libro citado. Luego si, una vez que el estudiante conoce las aplicaciones que implementan los protocolos de la capa de aplicación, se propusieron prácticas de análisis de los protocolos utilizando el modo simulación de la herramienta y tratando de sacar el máximo provecho de las implementaciones en PT, lo que se llamó "Análisis del protocolo".

Seguidamente, a partir de los protocolos de aplicación estudiados se analizaron los protocolos de la capa de transporte (TCP y UDP) que dan servicio a la capa de aplicación, en el modo simulación de la herramienta PT.

Finalmente se han propuesto ejercicios resueltos para el estudio de los protocolos de la capa de red con ejercicios de configuración y análisis con captura para todos los protocolos.

Este material no pretendió ser un curso para la formación de técnicos en redes, sino, un material que permitiera llevar al plano de lo concreto, lo abstracto del estudio de las redes en el ámbito de carreras de grado en sistemas o computación, como nuestra Licenciatura en Análisis de Sistemas. Tampoco se pretendió realizar un estudio profundo de cada protocolo, sino, servir de acompañamiento al libro citado, tratando cada tema en el nivel de abstracción que lo trata el mismo.

Cabe aclarar que, siendo una herramienta pensada para la formación de técnicos en redes en el programa de la Academia Cisco, la funcionalidad de las aplicaciones y protocolos de capa de aplicación que se soportan son susceptibles de mejoras. Este material permitió la realización de la mayor parte de las experiencias realizadas en esta tesis doctoral utilizando el simulador Packet Tracer.

Además, se desarrollaron guías de trabajos prácticos para los simuladores Kiva-NS, MACSim y GNS3 siguiendo la misma filosofía, pero con la finalidad de realizar 
experiencias mucho más acotadas. En el caso del simulador Kiva-NS se realizaron guías de trabajos prácticos para los temas Direccionamiento IP, Protocolo ICMP, Fragmentación IP, Enrutamiento estático IP y Protocolo ARP. En el caso del Simulador MACSim se realizó una guía de trabajos prácticos para el tema del algoritmo de contención del medio CSMA/CD.

\subsubsection{Los entornos de simulación}

La diversidad de aplicaciones de las herramientas de simulación ha permitido el desarrollo de numerosos entornos de simulación adaptados al área de conocimiento en la que se pretenden utilizar. Es difícil, por esta cuestión, realizar una clasificación de características comunes a todos los entornos y, por lo tanto, las que se incluyen en este trabajo son susceptibles de ser ampliadas en función del criterio del usuario.

Las características comunes y más importantes son:

- Entorno gráfico

- Ayuda contextual que permita la resolución de problemas (sobre funcionamiento y protocolos).

- Posibilidad de conexión con el exterior.

- Incorporación de módulos de planificación del aprendizaje

- Seguimiento de eventos.

- Posibilidad de generar autoevaluaciones para el estudiante.

- Posibilidad de conexión con otros programas.

- Soporte para lenguaje de programación

- Posibilidad de ampliación de biblioteca de objetos.

- Posibilidad de generar objetos de aprendizajes que puedan ser accesibles desde una plataforma de aprendizaje.

Los entornos gráficos son aquellos que aprovechando las posibilidades de los modernos sistemas operativos y lenguajes de programación facilitan al usuario la posibilidad de trabajar con imágenes gráficas de alta resolución y representación gráfica. La incorporación de sistemas gráficos facilitó el avance en este campo de tal manera que las herramientas de simulación pueden gozar de ventajas hasta ahora inalcanzables en máquinas de propósito general. La incorporación de los menús iconográficos y la ayuda de contexto son un valor añadido muy importante a los entornos de simulación.

La posibilidad de conexión con el exterior de una herramienta de simulación es un paso muy importante con la finalidad de acercar los modelos simulados a la realidad física.

Existen por otra parte, simuladores que adquieren los datos de bases de datos o sistemas de almacenamiento de información. En cualquier caso, la posibilidad de recoger datos del exterior es una manera de acercarnos a escenarios de simulación reales y ésta es una importante cualidad de un buen simulador. El seguimiento de los eventos permite visualizar paso a paso los eventos que ocurren entre dos estados determinados, por ejemplo, permite visualizar cómo un paquete recorre una ruta desde el origen hasta el destino mostrando los cambios que ocurren en el encabezado del mismo en cada fase.

La incorporación de módulos de planificación del aprendizaje en una herramienta de simulación permite una mayor dimensión pedagógica de la herramienta ya que en este caso se está facilitando la conducción del aprendizaje. Estos módulos pueden ser entre otros: 
planificadores de ejemplos, sistemas de averías guiadas, y tutores inteligentes. En este sentido las técnicas de simulación han evolucionado mucho, sobre todo si tomamos en consideración aquellas primeras herramientas tipo EAO (Enseñanza Asistida por Computadora) que poseían una estructura absolutamente rígida. Las técnicas de Inteligencia Artificial aplicadas a la enseñanza promueven el desarrollo de entornos muy poderosos que integran auténticos lenguajes de autor dentro de entornos de simulación coordinados por un Sistema Experto Planificador.

La posibilidad de conexión con otros programas: la incorporación de estándares de gestión de funciones y librerías escritas en diversos lenguajes. Estas técnicas las debe aprovechar al máximo un entorno de simulación en lo que se refiere a manejo de imágenes gráficas.

Muy pocas herramientas de simulación permiten la posibilidad de generar un objeto de aprendizaje que pueda interactuar dentro de una plataforma de educación.

Los campos de aplicación de las herramientas de simulación son muy diversos pero entre los más importantes se consideran los siguientes:

- Estudio del desempeño de redes de comunicaciones

- Diseño y rediseño de redes (diferentes topologías y escenarios)

- Validación de topologías.

- Análisis de protocolos.

- Análisis de algoritmos que implementan los protocolos.

- Entorno de estudio y entrenamiento.

- Laboratorio virtual.

- Interacción con el medio externo.

A la hora de estudiar el comportamiento de un sistema o modelo son numerosos los campos en los que se puede pensar, sin embargo, la mayor parte de los entornos de simulación para redes de computadoras están orientados a las tecnologías: proveedores específicos de redes cuyo objetivo principal es capacitación y certificación de una marca.

En general las aplicaciones de simulación pueden llegar a ser realmente complejas y permitir todo tipo de trabajos de entrenamiento. Al plantear una actividad de simulación con una herramienta es preciso realizar una serie de pasos que permitan llevar a cabo la actividad con buenos resultados. A modo de sugerencia y en base a la experiencia con estudiantes se enumeran los siguientes.

- Elección de un modelo básico, fácil y sencillo.

- Estudio de los distintos operadores técnicos básicos.

- Análisis de los parámetros de Entrada/salida.

- Estudio Funcional del modelo.

- Modelización del sistema teniendo en cuenta los flujos de datos y su presentación

- Implementación del modelo con una herramienta.

- Simulación en distintos escenarios.

- Valoración de resultados.

Es preciso que se sistematice por parte del profesor la utilización de herramientas de simulación en el aula, y que, antes de ponerla al servicio de los estudiantes, éstos hayan recibido la instrucción necesaria tanto en el terreno que se quiera aplicar como en el conocimiento de la propia herramienta. Las tareas de simulación deben empezar utilizando modelos fáciles de comprender e incluso de los que se conozcan sus resultados y 
comportamientos, de este modo se empezará por realizar simulaciones de pequeños sistemas o modelos que sean rápidos de diseñar. Conviene asimismo conocer los distintos operadores que se van a manejar: sus parámetros de configuración, sus variables de entrada y salida y la función que van a realizar.

Cuando se realiza el estudio de un modelo conviene tener claro el flujo y la naturaleza de los datos, dado que ello permitirá saber interpretar los resultados. El uso de herramientas de simulación no garantiza el éxito en el aprendizaje si no se parte de un conocimiento de la materia que se está abordando.

La elección de los escenarios de simulación, una vez construido el modelo, es muy importante y de ella va a depender su comprensión. Un escenario debe estar siempre dimensionado de acuerdo con la realidad y siempre dentro de uno marco posibilista.

\subsection{Análisis del Simulador Packet Tracer en la enseñanza de Redes TCP/IP}

Packet Tracer es una herramienta de simulación interactiva que permite aprender las operaciones de distintos dispositivos de red en las diferentes capas del modelo TCP-IP. Permite que el usuario construya sus propias redes y observe el comportamiento de los paquetes de datos en su recorrido por routers, switches y demás dispositivos de red. La interfaz ofrece un "Espacio de Trabajo Lógico" que tiene asociado dos modos de operación el modo en "Tiempo Real y el modo de "Simulación":

- Modo tiempo real: en este modo se realiza el diseño de la topología de la red, agregando dispositivos y configurando los mismos, incluso verificando la funcionalidad.

- Modo simulación: en este modo de operación se visualiza de manera gráfica cómo se comportan los paquetes que viajan en la red creada.

Este apartado describe las características, resaltando las limitaciones encontradas en la herramienta en su ver 5.3.3 en la enseñanza de redes TCP/IP. Las mismas surgen del uso de la herramienta en las distintas experiencias realizadas en las asignaturas Conectividad y Teleinformática y Redes de Computadoras I del plan de estudios de la Licenciatura en Análisis de Sistemas Plan 1997 y Plan 2010 respectivamente, y en cursos de postgrado y extensión, en el marco del Proyecto de Investigación en el CIUNSa Tipo A No 2230/0 denominado "Estudio de la influencia del uso de simulación en la enseñanza de redes de computadoras en el nivel universitario".

A continuación se describe de manera detallada, tales características, siguiendo el enfoque descendente, a partir del modelo de capas TCP/IP.

\subsubsection{Características en la enseñanza de la capa de aplicación}

Protocolo HTTP, comentarios y limitaciones de Packet Tracer (PT):

Es una implementación funcional en tiempo real pero incompleta de la capa de aplicación. En esta versión 5.3.3 soporta únicamente conexiones HTTP no persistentes. Sería deseable para una futura versión, que la herramienta soporte conexiones HTTP persistentes sin entubamiento y con entubamiento, además de la implementación de los métodos POST y HEAD. 
En el análisis de los paquetes HTTP intercambiados en una sesión entre un cliente y un servidor en "modo simulación", tanto el cliente como el servidor especifican la versión HTTP/1.1. En este modo de trabajo, la PDU HTTP muestra, en formato de texto, el comando ejecutado como parte de la cabecera HTTP. También se puede observar perfectamente el detalle de la conexión y desconexión TCP en cada momento, aunque esto, en este momento es un tanto irrelevante, si se utiliza el enfoque descendente que proponen Kurose y Ross en su libro.

El Servidor HTTP de PT incluye por defecto las páginas index.html, helloworld.html e image.html. Además, es posible crear nuevas páginas y borrar páginas HTML existentes. Los tags HTML que se soportan son: $a$, address, $b$, big, blockquote, body, br, center, cite, code, dd, dfn, div, dl, dt, em, font, h1, h2, h3, h4, h5, h6, head, hr, html, i, img, kbd, meta, li, nobr, ol, p, pre, qt, s, samp, small, span, strong, sub, sup, table, tbody, td, tfoot, th, thead, title, $t r, t t, u, u l$, var.

Packet Tracer soporta además diferentes tipos de imágenes (JPEG, JPG, GIF, PNG). Es importante que las imágenes referenciadas en las páginas html, estén disponibles en la misma carpeta en donde se encuentra el archivo con extensión .pkt, ya que de lo contrario mostrará el error de archivo no encontrado.

\section{Protocolo FTP, comentarios y limitaciones de Packet Tracer:}

La implementación del protocolo FTP en PT 5.3.3 es muy completa ya que soporta los siguientes comandos: $c d$, delete, pwd, get, put, dir, passive, rename y quit.

El modo por defecto en el cliente es el modo pasivo, esto implica que la conexión de dato TCP no se realiza en el puerto 20 sino a un número de puerto aleatorio generado por el servidor, lo que permite realizar transferencias de archivos detrás de un firewall.

Para utilizar el puerto 20 se debe ejecutar el comando ftp>passive.

En una sesión FTP en modo simulación es posible observar (como parte de los mensajes intercambiados) los distintos comandos FTP soportados de una manera simplificada. La conexión y desconexión TCP se pueden ver perfectamente en detalle durante la sesión.

En la configuración del Servidor FTP es posible agregar y remover cuentas FTP de acceso (usuario y clave), modificar permisos (de escritura, de lectura, de borrado, de renombrado y de listado) y borrar archivos directamente en el servidor (se disponen de archivos de imágenes IOS por defecto, para realizar pruebas).

\section{Protocolo SMTP y POP3, comentarios y limitaciones de Packet Tracer (PT):}

La implementación del protocolo SMTP y POP3 en PT 5.3.3 es funcional en tiempo real. En modo simulación es extremadamente básica, es posible analizar los segmentos a nivel TCP, y mensajes a nivel SMTP y POP3 entre los clientes y servidores. Sin embargo, la implementación se realiza con una sola solicitud y una sola respuesta tanto para SMTP como para POP3, es decir, no presenta el intercambio real de mensajes del protocolo. Tampoco presenta el detalle de los campos en la PDU, en su defecto muestra "Información SMTP" o "Información POP3". Sería deseable para una futura versión completar estos protocolos.

La configuración del agente (POP3) solo soporta la opción de borrar los mails desde el servidor.

En la configuración del Servidor SMTP es posible agregar y remover cuentas SMTP de acceso (usuario y clave) e ingresar el nombre del dominio que atiende un determinado servidor. 


\section{Protocolo DNS, comentarios y limitaciones de Packet Tracer (PT):}

La implementación es bastante completa y funcional. En modo simulación se puede analizar una resolución recursiva y ver en detalle los campos del mensaje. Si bien el comando nslookup admite la configuración de la consulta en modo iterativo, no se logró que esto funcione. También admite la opción debug para realizar un análisis más detallado. A nivel de configuración en el servidor, es muy completo y admite configuraciones complejas como la realizada en la práctica involucrando un servidor DNS Raíz, un servidor DNS Autoritativo y un servidor DNS Local.

\section{Protocolo TFTP, comentarios y limitaciones de Packet Tracer (PT):}

La implementación es perfectamente funcional en tiempo real, pero incompleta en modo simulación, ya que las PDUs TFTP muestran el mensaje "Datos TFTP", sin poder ver el detalle de los campos de solicitudes y respuestas del protocolo. En la solapa "Modelo OSI" sí se describen los tipos de mensajes, SOLICITUD, ACK, DATOS.

El cliente TFTP solo puede ser invocado desde un router o switch con el comando copy run tftp, la PC no dispone de un cliente como en el caso del Protocolo FTP.

A nivel de configuración, el servidor admite la posibilidad de habilitar y deshabilitar el servicio y eliminar archivos directamente desde la interfaz, simplemente seleccionando y oprimiendo el botón Eliminar.

\section{Protocolo Telnet, comentarios y limitaciones de Packet Tracer (PT):}

La implementación es perfectamente funcional en tiempo real, pero rudimentaria en modo simulación, ya que las PDUs Telnet muestran el mensaje "Datos Telnet" sin poder ver el detalle de los campos de solicitudes y respuestas del protocolo. Sin embargo, es posible observar el intercambio de mensajes para la autenticación del usuario perfectamente (usuario y clave), con algunos comentarios enriquecedores en la solapa "Modelo OSI".

El cliente Telnet puede ser invocado desde una línea de comando de la PC o desde un router.

En los routers no viene configurado por defecto, es necesario realizar la configuración de un usuario y clave.

\subsubsection{Características en la enseñanza de la capa de transporte}

\section{Protocolo UDP, comentarios y limitaciones de Packet Tracer (PT):}

La implementación es completa y funcional ya que es posible ver los campos del segmento UDP, puerto origen, puerto destino, longitud en hexadecimal y la suma de comprobación que no se calcula. En la "Solapa Modelo OSI" del simulador, no se aportan comentarios enriquecedores como en el caso del protocolo TCP.

\section{Protocolo TCP, comentarios y limitaciones de Packet Tracer:}

La implementación del protocolo TCP es completa y funcional. Es posible observar los campos del segmento TCP, puerto origen, puerto destino, número de secuencia, número de ack, banderas habilitadas, etc.

El encabezado TCP hace referencia a un campo de offset donde debería estar la longitud del encabezado. 
El anuncio de la ventana y la suma de comprobación no se encuentran implementadas, apareciendo en el campo "ventana" y "checksum: 0x0" respectivamente.

La opción de negociación del MSS en el saludo de tres vías, aparece perfectamente implementada en la "Solapa Modelo OSI" pero no en la estructura del segmento.

A fin de facilitar al estudiante el seguimiento del número de secuencia y ack en el progreso de la conexión TCP, el simulador PT comienza cada nueva conexión con el valor 0 para estos dos campos.

El saludo de tres vías para la conexión se implementa perfectamente. No así para el cierre de la conexión, que lo simplifica en dos segmentos (FIN, FIN+ACK).

No se puede observar retransmisión, quizás porque no está implementada. Sin embargo, la PC simulada dispone de algunos parámetros de configuración global, donde pareciera se prevé para futuras versiones.

\subsubsection{Características en la enseñanza de la capa de red}

\section{Protocolo IP, Direccionamiento IP, Subredes, CIDR, VLSM comentarios y limitaciones de Packet Tracer:}

La implementación es totalmente completa y funcional. De hecho, es uno de los aspectos sobresalientes de esta herramienta. Con el simulador es posible diseñar topologías de redes muy simples o muy complejas, y verificar su funcionalidad. La herramienta dispone de advertencias cuando se comente un error en la asignación de direcciones IP.

Fragmentación IP, comentarios y limitaciones de Packet Tracer:

La implementación es completa y funcional. En modo simulación, se puede hacer el seguimiento en los fragmentos de los campos identificación, longitud y desplazamiento perfectamente. También se dispone de información adicional en la solapa Modelo OSI del simulador. Implementa fragmentación en origen y en tránsito.

La implementación del comando ping en PT no dispone de la posibilidad de especificar como parámetro la longitud del datagrama. Para lograr esto, se utiliza la opción PDU Complex de la caja de herramientas del simulador.

\section{Protocolo DHCP, comentarios y limitaciones de Packet Tracer:}

La implementación de este protocolo es completa y funcional. En la configuración de DHCP Relay, el router que actúa como relay, en la Solapa OSI del modo simulación, se advierte al usuario con un mensaje que al no tener un pool configurado, debe descartar el paquete, pero finalmente no lo realiza y funciona correctamente.

\section{Protocolo ICMP, comentarios y limitaciones de Packet Tracer:}

El protocolo se implementa con los comandos ping y tracert que funcionan perfectamente. No soporta la opción ICMP Redirect, es decir, la posibilidad de instalar una ruta en un host dinámicamente, cuando un router descubre una mejor ruta (evitar un salto adicional por ejemplo).

\section{Protocolo NAT, comentarios y limitaciones de Packet Tracer:}

La implementación es completa y funcional. Es posible observar la Tabla NAT en el router en todo momento, con la herramienta inspeccionar. 
Enrutamiento Estático, por defecto y rutas alternativas

La implementación es completa y funcional. Se puede realizar la configuración completamente desde la solapa "Config" de configuración general (independiente del proveedor) y también con comandos IOS.

Enrutamiento Dinámico con RIP, comentarios y limitaciones de Packet Tracer:

La implementación es completa y funcional. Se puede realizar la configuración completamente desde la solapa "Config" de configuración general y también con comandos IOS.

Se puede observar como el protocolo RIP mantiene una entrada con costo infinito (una red que se encuentra a 16 saltos, es inalcanzable para RIP) cuando se deshabilita una interfaz que conecta una determinada subred o se elimina de la configuración RIP, de manera que deja de anunciarse. Al cabo de un tiempo también la elimina de la tabla.

Cuando una ruta es inalcanzable y la instala en la tabla con costo infinito (16), el router sigue entregando paquetes para ese destino. Se puede ver claramente que instala una ruta con costo infinito a los 180 seg. Cuando no recibe novedades y luego de otros $180 \mathrm{seg}$ aproximadamente, la desinstala de la tabla.

Enrutamiento Dinámico con OSPF, comentarios y limitaciones de Packet Tracer:

La implementación es completa y funcional. Solo se puede realizar la configuración con comandos IOS, no está disponible desde la solapa "Config" de configuración general.

\section{Enrutamiento Dinámico con BGP, comentarios y limitaciones de Packet Tracer:} En la versión 5.3.3 de PT solo se soporta BGP Externo.

\subsubsection{Conclusiones de la herramienta}

Después de haber analizado el simulador Packet Tracer en el desarrollo de las actividades prácticas propuestas y entendiendo que no todos los aspectos relacionados al estudio de las redes de computadoras pueden ser "modelados" y que los procesos de interacción de los protocolos del modelo de capas TCP/IP revisten un alto grado de complejidad, se concluye que una única herramienta no podría acercar en un ciento por ciento la "visualización" del comportamiento y funcionalidad de los mismos, sino que tales herramientas deben ser usadas en conjunto con otras, tales como analizadores de tráfico y herramientas de virtualización y emulación. Es importante destacar que la herramienta de simulación Packet Tracer puede presentar muchas otras limitaciones no documentadas en este trabajo ya que las mismas surgieron de la implementación de los prácticos desarrollados como complemento al libro mencionado de James F. Kurose y Keith W. Ross. Además, siendo una herramienta pensada para la formación de técnicos en redes en el programa de la Academia CISCO, la funcionalidad de las aplicaciones y protocolos de capa de aplicación que se soportan, son susceptibles de mejoras. 


\section{ASPECTOS METODOLÓGICOS}

\subsection{Formulación de Hipótesis}

El desafío fue de qué manera poder llegar a evaluar los resultados que permitan dar respuestas a las preguntas de investigación. De lo expuesto en el marco teórico, el resultado de la búsqueda realizada y la formación y experiencia adquiridas, surgieron las siguientes hipótesis causales de investigación, en relación a las correlaciones aprendizaje-métodos de simulación:

- Hipótesis I: A igualdad de recursos utilizados y experiencias, el estudiante aprende mejor, más significativamente, cuando complementa esas experiencias con métodos de simulación.

- Hipótesis II: El uso de software de simulación como complemento a los prácticos tradicionales o de laboratorio, mejora el aprendizaje de conceptos y la comprensión.

- Hipótesis complementaria: La realización de trabajos prácticos por simulación va a redundar en un aprendizaje significativo y creativo en los estudiantes. Esta hipótesis intenta responder a las preguntas C, D, y E del apartado: “objetivos y preguntas de investigación".

Las hipótesis I y II intentan responder a las preguntas A, B, F y G del apartado: “objetivos y preguntas de investigación".

\subsection{Estrategia metodológica, diseño de la investigación y recolección de datos}

La investigación se dividió en tres etapas: la primera etapa consistió en la aplicación de un cuestionario (inicialmente exploratorio), que se prolongó en todas las demás etapas. Por lo analizado en el marco teórico, cuando no se registran muchos antecedentes en relación a un tema, lo indicado es comenzar con un estudio de este tipo que permita preparar el terreno para la investigación posterior. Esta circunstancia definió el carácter y la profundidad con que se diseñó la investigación. A los efectos de precisar el lenguaje utilizado para caracterizar los estudios, se aclara que la terminología utilizada responde a la clasificación de Dankhe (1989), adoptada por Sampieri, (1998), quien los divide en: exploratorios, explicativos, descriptivos o correlacionales. En la segunda etapa se realizó un estudio explicativo-correlacional (evaluaciones de conceptos), y paralelamente un estudio descriptivo (encuesta para medir actitudes), que se prolongó en la tercera etapa.

Las actividades en las tres etapas se mencionan a continuación: 


\begin{tabular}{|c|c|c|}
\hline Primera Etapa & Segunda Etapa & Tercera Etapa \\
\hline Cuestionario & Cuestionario & Cuestionario \\
\hline Encuesta para medir actitudes & Encuesta para medir actitudes & Encuesta para medir actitudes \\
\cline { 2 - 3 } & & Evaluación de conceptos \\
\hline & & Encuesta a docentes \\
\hline
\end{tabular}

Tabla 4-1: Actividades en las distintas etapas de investigación

Para la segunda y tercera etapa, la investigación se diseñó de la siguiente forma:

Se planificó realizar, por un lado, un estudio explicativo y correlacional a través de experimentos y por otro lado un estudio descriptivo a través de encuestas. En una primera instancia el estudio fue descriptivo, luego ambos estudios se realizaron en forma paralela, aunque temporalmente el estudio descriptivo fue realizado, cada año, al finalizar las experiencias con los trabajos prácticos propuestos.

\subsubsection{Estudio explicativo-correlacional}

Consistió en la realización de experiencias en las que se investigó la relación entre aprendizaje y los métodos de simulación y las actividades prácticas tradicionales. Se planificaron los experimentos, entendiendo por experimento tanto lo que Babbie (1979) define en forma general como "tomar una acción y después observar las consecuencias", como la acepción más científica que lo define: "un estudio de investigación en el que se manipulan deliberadamente una o más variables independientes (supuestas causas) para analizar las consecuencias que la manipulación tiene sobre una o más variables dependientes (supuestos efectos), dentro de una situación de control para el investigador" (Sampieri, 1998).

Las variables independientes, en este caso fueron:

- Trabajos prácticos tradicionales - TPT: en el aula.

- Actividades prácticas con simulación - TPS: con software de simulación.

Y como variables dependientes de ellas, a evaluar, se consideraron varios conceptos o protocolos como son:

- Protocolo ARP,

- Protocolo DNS,

- Direccionamiento IP,

- Ruteo IP: Estático y Protocolo RIP,

- Algoritmo CSMA/CD.

Estos y otros conceptos, el estudiante los profundiza con las actividades, y son los mismos, tanto en los TPT, como en los TPS.

Cabe aclarar también que el estudio y análisis de un protocolo o algoritmo de red no implica un solo concepto que puede se memorizado, sino por el contrario un conjunto de reglas que necesariamente se tienen que dar para el funcionamiento del mismo.

En primer lugar, como parte de la experiencia, se impartieron los conceptos teóricos con la ayuda de presentaciones. 
En la primera actividad práctica se utilizaron los conceptos relacionados al protocolo en estudio.

En la actividad práctica con software de simulación se trabajó con los mismos conceptos del trabajo práctico tradicional, solo que el estudiante necesitó familiarizarse antes en el uso del software específico para el tema en cuestión.

Dado que la cantidad de estudiantes en cada cohorte en las asignaturas en cuestión es pequeña, se dividió en dos grupos, un grupo experimental que realizó la práctica con software de simulación, y un grupo de control que realizó la práctica tradicional en el aula. La cantidad de estudiantes en cada grupo fue así función de la cantidad de estudiantes que constituyeron cada cohorte.

La totalidad de estudiantes de una cohorte (grupo experimental y grupo de control) recibió la misma clase teórica programada para el tema simultáneamente, de acuerdo al cronograma de la asignatura. Posteriormente, la totalidad de los estudiantes realizaron la clase práctica tradicional estructurada con un Trabajo Práctico Tradicional - TPT. Al finalizar esta clase, los estudiantes se dividieron en grupo de control y grupo experimental. El grupo experimental realizó un Trabajo Práctico con Simulación - TPS. Posteriormente se realizó la misma evaluación de conceptos a los dos grupos simultáneamente. Cabe aclarar que esta evaluación no formó parte de los requisitos para la regularización de la asignatura involucrada, es decir que los estudiantes lo vivenciaron como un coloquio (evaluación de repaso) y no como una evaluación parcial. Finalmente, se facilitaron los medios, de manera que el grupo de control realice también el TPS, a los fines de que la experiencia de investigación interfiera lo menos posible en el desempeño académico para la regularización de la asignatura.

Clase Teórica para ambos grupos: Grupo Experimental y Grupo de Control

\section{Clase Práctica para ambos grupos: TPT Grupo Experimental y Grupo de Control}

\section{Grupo Experimental: TPS}

Evaluación de conceptos: Grupo Experimental y Grupo de Control

Grupo de Control: TPS

Figura 4-1: Distribución de las actividades, prácticas tradicionales y prácticas con simulación.

Este diseño cumple con todos los requisitos que debe reunir un experimento, a saber:

- La manipulación intencional de una o más variables independientes. 
En este caso los TPT y TPS, considerados como la causa de los efectos a observar. Por el hecho de que a un grupo se le aplica una variable (el TPT) y al otro la otra (el TPS), sin que se dé la ausencia total de ambas, lo que se evaluó fue la diferencia entre los efectos que produce la aplicación de ellas separadamente, a uno y a otro grupo.

- La medición del efecto que la variable independiente tiene en la variable dependiente.

La evaluación a la que se someten ambos grupos es la misma, incluyen los conceptos vistos en la clase teórica. Intencionalmente no se quiso restringir las evaluaciones solo a las variables dependientes para evitar que el estudiante centre su atención solo en ellas. La mayoría de las evaluaciones realizadas fueron del tipo elección-múltiple que incluyeron una pregunta de tipo abierta, que permitió analizar con mayor profundidad el conocimiento del concepto adquirido. En el caso de la evaluación del concepto del algoritmo CSMA/CD, que se replicó en seis oportunidades, las preguntas fueron todas del tipo abiertas.

- El control o validez interna de la situación experimental.

- Los grupos se constituyeron en forma aleatoria, se repartieron por igual, por tanto, puede decirse que como grupos son equivalentes.

- Se analizaron los planes de estudios de las distintas carreras involucradas y se puede aseverar que los conceptos evaluados no son vistos con anterioridad en ninguna asignatura previa a las asignaturas bajo estudio, por lo que no se hizo necesario realizar un pretest de conceptos.

- Los grupos bajo estudio pueden considerarse homogéneos o en igualdad de condiciones al inicio de cada experiencia. No se incluyeron los estudiantes recursantes en ninguno de los grupos ni tratamientos.

- Las circunstancias en que se tomaron las evaluaciones fueron tales que se evitó el "ruido" (perturbaciones) debido a interacciones entre los estudiantes (las evaluaciones fueron individuales).

- Se trató siempre de que los estudiantes sientan lo menos posible que participaban de un experimento. Las encuestas fueron anónimas.

- Se realizaron pruebas que permitieron contrastar la hipótesis nula de que ambos grupos puedan mantener algún tipo de relación, es decir, no fueren independientes los tratamientos de los métodos con y sin simulación.

Se considera por tanto que se han evitado todos los efectos que pueden quitarle validez interna a la experiencia.

En relación a la recolección de información a través de las evaluaciones, y por la forma en que fueron planeadas, se las considera confiables ya que el hecho de tener que aplicar el concepto a evaluar conlleva a responder siempre lo mismo en función de la estructura conceptual que tenga el estudiante en ese momento. Por la misma razón también son válidas, ya que no hay posibilidad de estar evaluando algo distinto a lo que se quiere evaluar. Las preguntas en todas las evaluaciones cubrieron completamente el contenido (los conceptos en cuestión a evaluar, protocolos y algoritmos). Por ser conceptos no tan definidos, resulta más complicado determinar en cada caso lo acertado, o no, de las respuestas (validez de criterio). 
El momento de aplicación de las pruebas fue adecuado así como también la duración de las mismas. Se realizaron al comienzo de la clase ya que implicaba más concentración y actividad por parte del estudiante.

En las evaluaciones de las primeras experiencias que se realizaron se detectó algunos problemas que llevaron a mejorar la redacción y adecuar mejor los espacios en las posteriores.

Las respuestas de las evaluaciones realizadas se puntuaron con una escala de 0 a 100 puntos. Las evaluaciones con repuestas correctas superiores a 50 puntos, se consideraron como una evaluación aprobada. En el caso de las evaluaciones de elección-múltiple que incluyeron una pregunta del tipo abierta, permitió conocer con mayor profundidad la claridad del concepto por parte del estudiante, y de esa manera poder detectar repuestas más elaboradas que otras.

Cabe aclarar que la evaluación de un protocolo o algoritmo implica el conocimiento de varios conceptos, no solo de uno.

La fiabilidad y validez de estos instrumentos fueron validadas a través de pruebas piloto donde se calcularon coeficientes de confiabilidad.

Cada cohorte del taller con simulación se desarrolló en tres etapas. La primera de ellas, la fase pre-instruccional donde se llevó a cabo la selección de la muestra y designación de los grupos y contextualización. La segunda etapa fue la fase instruccional donde se desarrollaron las secuencias didácticas respectivas similares para los dos grupos y además para el grupo experimental con el método con simulación. Por último, se realizó la fase post-instruccional en la cual se aplicaron las pospruebas y se realizó el análisis de datos. Para el análisis de los datos se aplicó estadística descriptiva y pruebas paramétricas mediante el uso del Paquete Estadístico para las Ciencias Sociales (Statistical Package for the Social Sciences o SPSS ${ }^{\circledR}$ de IBM).

Para la prueba de conceptos, el objetivo principal fue contrastar estadísticamente si ambos grupos de estudio presentaron una diferencia significativa en cuanto a alguna medida de tendencia central o de variabilidad, a los fines de poder tomar una decisión confiable sobre el beneficio o no de la aplicación de la nueva técnica de enseñanza. Es decir, se pretendía determinar si el uso de la herramienta de simulación como complemento a las prácticas tradicionales, favorece el aprendizaje. Dado que los grupos de trabajo fueron relativamente pequeños, esto es, con un tamaño muestral chico $(\mathrm{N}<=10)$, para realizar las pruebas de contraste antes mencionadas en los casos que correspondiere, se utilizaron aquellas asociadas a la distribución normal o de Gauss. En los casos en que ello no fue posible, se recurrió a las técnicas contempladas en la estadística no paramétrica (ya que prescinden de la distribución de los datos).

La idea básica en el análisis estadístico de los datos fue utilizar teoría y el software mencionado para poder completar los resultados estadísticos descriptivos ya realizados, completándolos con estadísticas que permitan decidir por ejemplo: si existe diferencia significativa entre ambas metodologías de enseñanza. Este tipo de acciones se pudo realizar mediante test de hipótesis con respecto a medida de tendencia central, como ser media, mediana, etc.; medidas de variabilidad que permiten analizar la homogeneidad entre las respuestas de los estudiantes que participaron de las diferentes pruebas.

Para cada experiencia se realizaron los test con pruebas específicas como KolmogorovSmirnov, coeficientes de correlación no paramétricos y gráficos específicos que permitieron ver características no siempre mostradas por los gráficos descriptivos. También se realizó la prueba de los rangos con signo de Wilcoxon que permitió contrastar la 
hipótesis nula de que ambos grupos puedan mantener algún tipo de relación, es decir, no fueren independientes los tratamientos de los métodos con y sin simulación. Otras pruebas estadísticas apropiadas para complementar los resultados obtenidos fueron: calcular estadísticos descriptivos: medidas de tendencia central (mediana) y desviación estándar como medida de variabilidad.

\subsubsection{Estudio descriptivo}

El estudio descriptivo se realizó en la primera parte de la investigación y se prolongó en la segunda y tercera etapa. Se utilizó como instrumento de investigación un cuestionario con escalas de actitudes, a los fines de encontrar respuestas a las preguntas planteadas. Si bien estos escalamientos (tipo Likert), pueden ser indicadores de actitudes, pero no de la conducta en sí, se considera que estas actitudes son como la semilla que puede "germinar" dando lugar a hechos concretos.

Para el test actitudinal se optó por una escala de valoración de Likert de 5 puntos para cada una de las variables o preguntas, donde 5 hace referencia al valor máximo y 1 al valor mínimo, tal como se puede ver en la siguiente tabla. Esto permite medir actitudes y conocer el grado de conformidad del encuestado con las afirmaciones propuestas.

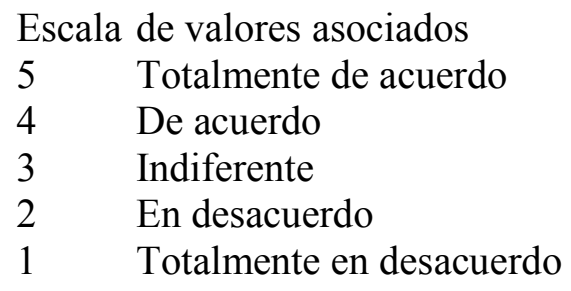

Otra Escala de Valores asociados

$5 \quad$ En gran medida

$4 \quad$ En buena medida

3 Lo suficiente

2 Poco

1 Prácticamente nada

Al respecto de la escala de Likert, existen diversas opiniones sobre el número de niveles a utilizar en la misma (Edmondson, 2005). Normalmente, el formato más popular consiste en una escala de Likert de 5 puntos. Un estudio empírico reciente demostró que la información obtenida en escalas con 5, 7 y 10 niveles posibles de respuestas muestran las mismas características respecto a la media, varianza, asimetría y curtosis después de aplicar transformaciones simples. La escala de Likert, al ser una escala que mide actitudes, es importante que pueda aceptar que las personas tienen actitudes favorables, desfavorables o neutras, lo cual es perfectamente normal en términos de información. Debido a ello, es importante considerar siempre que una escala de actitud puede y debe estar abierta a la posibilidad de aceptar opciones de respuesta neutrales.

Para garantizar la fiabilidad del instrumento se utilizó el coeficiente Alfa de Cronbach. La medida de la fiabilidad mediante el Alfa de Cronbach asume que los ítems (medidos en escala tipo Likert) miden un mismo constructo y que están altamente correlacionados (Welch \& Comer, 1988). Cuanto más cerca se encuentre el valor del alfa a 1, mayor es la 
consistencia interna de los ítems analizados. La fiabilidad de la escala debe obtenerse siempre con los datos de cada muestra para garantizar la medida fiable del constructo en la muestra concreta de investigación. Como criterio general, George y Mallery (2003, p. 231) sugiere un valor de 7 como aceptable.

Los tests actitudinales indagaron sobre los siguientes puntos:

- Actitud de los estudiantes para realizar simulaciones con otra temática de la misma asignatura,

- Actitud de los estudiantes para realizar simulaciones en otras asignaturas del plan de estudio,

- Limitaciones de los simuladores,

- Forma en que influyen los cambios de determinados parámetros,

- Facilidad para experimentar con otras topologías,

- Aspectos específicos del simulador (facilidad de uso, ayuda contextual, facilidad de instalación, etc.),

- Claridad de las simulaciones,

- Apoyo brindado por la herramienta a la educación no presencial,

- Facilidad para realizar el seguimiento de los eventos,

- Implementación de los protocolos en el simulador,

- Tiempo asignado a los prácticos propuestos.

Tal como propone el método, las primeras versiones de las encuestas tuvieron más ítems (proposiciones) que las que se deseaba realizar en la encuesta definitiva. Así, en una primera instancia se validaron y permitieron arribar a las encuestas definitivas.

Para responder a cada pregunta de investigación, se plantearon conjuntos de proposiciones, que en sí tratan de indagar el pensamiento del estudiante en torno de lo que plantea la pregunta de investigación, pero al estar redactadas de distintas formas, permiten incrementar la precisión con que se evalúa.

Las variables se clasificaron en 3 categorías, a saber: Variables de Entrada, Variables de Proceso y Variables de Salida.

Variables de Entrada (VE): también llamadas variables categóricas, son aquellas que dependen de su propia naturaleza, y no son alterables. Normalmente, sirven para identificar de forma unívoca las características de la población encuestada. Las variables de entrada incluyen:

- Datos personales

- Datos de disponibilidad de PCs

- Disponibilidad de conexión a Internet

Variables de Proceso (VP): son las que recogen la parte esencial del trabajo de investigación; pretenden recabar la opinión de la población encuestada sobre los aspectos más relevantes del estudio. En este caso, las variables de proceso contienen:

- Datos académicos generales.

- Datos sobre enseñanza presencial con apoyo virtual.

- Datos sobre enseñanza totalmente virtual. 
- Datos de utilización de Simulación.

- Datos sobre aprendizaje autónomo.

Variables de Salida (VS): también llamadas variables de producto, son las que condensan el resultado final del trabajo de investigación. En ellas, se pretende constatar las tesis defendidas inicialmente, o por el contrario, reconducir la investigación posterior hacia los requisitos y necesidades detectadas en dichas variables. Las variables de salida se agrupan como sigue:

- Datos sobre satisfacción de la enseñanza con simulación.

- Datos sobre prácticos propuestos.

- Datos sobre protocolos estudiados.

- Datos sobre herramientas de simulación (interface, facilidad de uso, ayuda contextual, etc.).

- Otros datos no contemplados inicialmente.

A la vista de los valores obtenidos se puede afirmar que la media aritmética supera, en todos los casos, al menos el valor medio de la escala (3.00), lo que confirma la validez del contenido de todos los ítems incluidos en los cuestionarios. Para el análisis de la fiabilidad de los dos cuestionarios de requisitos se calculó el coeficiente Alfa de Cronbach de los elementos tipificados en los cuestionarios (Cronbach, 1951). Para cada experiencia realizada se eliminaron las variables con varianza nula para el cálculo. Como podrá observarse en el análisis de las experiencias realizadas, el coeficiente Alfa de Cronbach calculado supera en casi todos los casos, el valor de 0,7, lo que permite afirmar que el grado de fiabilidad de los cuestionarios es muy bueno (George \& Mallery, 1994).

\subsection{La muestra}

La muestra para el estudio descriptivo actitudinal se presenta en la Tabla 4-4, detallando para cada experiencia realizada la asignatura, la temática, el período y cantidad de estudiantes involucrados. 


\begin{tabular}{|c|c|c|c|}
\hline Experiencia en Asignatura & Temática & Período & $\begin{array}{r}\text { Cantidad } \\
\text { de } \\
\text { Estudiantes }\end{array}$ \\
\hline $\begin{array}{l}\text { Conectividad y } \\
\text { Teleinformática } \\
\text { UNSa }\end{array}$ & Redes IP & 2012 & 5 \\
\hline $\begin{array}{l}\text { Conectividad y } \\
\text { Teleinformática - UNSa }\end{array}$ & $\begin{array}{l}\text { Redes IP, ARP, } \\
\text { Fragmentación }\end{array}$ & 2012 & 13 \\
\hline $\begin{array}{l}\text { Redes de Computadoras I - } \\
\text { UNSa }\end{array}$ & $\begin{array}{l}\text { Protocolos Capa } \\
\text { de Aplicación }\end{array}$ & 2013 & 5 \\
\hline Curso DNS - UNSa & Protocolo DNS & 2013 & 10 \\
\hline $\begin{array}{l}\text { Redes de Computadoras I - } \\
\text { UNSa }\end{array}$ & Fundamentos & 2014 & 15 \\
\hline $\begin{array}{l}\text { Redes de Computadoras I - } \\
\text { UNSa }\end{array}$ & $\begin{array}{l}\text { Protocolos Capa } \\
\text { de Aplicación }\end{array}$ & 2014 & 12 \\
\hline $\begin{array}{l}\text { Redes de Computadoras I - } \\
\text { UNSa }\end{array}$ & $\begin{array}{l}\text { Protocolos Capa } \\
\text { de Transporte }\end{array}$ & 2014 & 9 \\
\hline $\begin{array}{l}\text { Redes de Computadoras I - } \\
\text { UNSa }\end{array}$ & $\begin{array}{l}\text { Protocolos Capa } \\
\text { de Red }\end{array}$ & 2014 & 9 \\
\hline Curso Jornadas de Ingeniería & Ruteo con GNS3 & 2015 & 6 \\
\hline Curso de Extensión & $\begin{array}{l}\text { Virtualización } \\
\text { con GNS3 }\end{array}$ & 2015 & 6 \\
\hline $\begin{array}{l}\text { Redes de Computadoras I - } \\
\text { UNSa }\end{array}$ & $\begin{array}{l}\text { Capas de } \\
\text { Aplicación, } \\
\text { Trasporte y Red }\end{array}$ & 2015 & 8 \\
\hline $\begin{array}{l}\text { Redes de Computadoras I - } \\
\text { UNSa }\end{array}$ & $\begin{array}{l}\text { Direccionamiento } \\
\text { IP - Lab. real }\end{array}$ & 2016 & 10 \\
\hline $\begin{array}{l}\text { Redes de Computadoras I - } \\
\text { UNSa }\end{array}$ & $\begin{array}{l}\text { Ruteo IP - Lab. } \\
\text { real }\end{array}$ & 2016 & 9 \\
\hline Curso Mikrotik & $\begin{array}{l}\text { Ruteo IP - Lab. } \\
\text { real }\end{array}$ & 2016 & 10 \\
\hline Encuesta UCASAL & Redes IP & 2016 & 10 \\
\hline Encuesta docentes de redes & Redes IP & 2016 & 13 \\
\hline Total e encuestados & & & 140 \\
\hline
\end{tabular}

Tabla 4-2: Muestra del estudio descriptivo actitudinal

Se trabajó con tamaños muestrales pequeños. Se diseñaron diferentes experiencias en diferentes asignaturas y diferente temática, muchas de las cuales se replicaron en años siguientes. La población de estudio estuvo conformada por la totalidad de los estudiantes cursantes en cada cohorte en cada una de las asignaturas bajo estudio.

En todos los casos se intentó que el grupo experimental y el grupo de control tuvieran la misma cantidad de estudiantes, lo que no siempre fue posible.

En la Tabla 4-5, se presenta la muestra para el estudio explicativo-correlacional de evaluación de conceptos, detallando la asignatura, la temática, el período y la cantidad de estudiantes que conformaron el grupo experimental y el grupo de control en cada caso. 


\begin{tabular}{|c|c|c|c|c|c|}
\hline Experiencia en Asignatura & Temática & Período & $\begin{array}{r}\text { Grupo } \\
\text { Experimental }\end{array}$ & $\begin{array}{r}\text { Grupo de } \\
\text { Control }\end{array}$ & $\begin{array}{r}\text { Cantidad } \\
\text { de } \\
\text { Estudiantes }\end{array}$ \\
\hline $\begin{array}{l}\text { Conectividad y } \\
\text { Teleinformática } \\
\text { UNSa }\end{array}$ & Redes IP & 2013 & 13 & 43 & 56 \\
\hline $\begin{array}{l}\text { Redes de Computadoras II - } \\
\text { UNSa }\end{array}$ & $\begin{array}{l}\text { Redes LAN } \\
\text { CSMA/CD }\end{array}$ & 2014 & 4 & 5 & 9 \\
\hline $\begin{array}{l}\text { Conectividad y } \\
\text { Teleinformática - UNSa }\end{array}$ & $\begin{array}{l}\text { Redes LAN } \\
\text { CSMA/CD }\end{array}$ & 2014 & 4 & 5 & 9 \\
\hline $\begin{array}{l}\text { Redes de Computadoras II - } \\
\text { UNSa }\end{array}$ & Protocolo ARP & 2014 & 5 & 5 & 10 \\
\hline Redes I - UCASAL & $\begin{array}{l}\text { Redes LAN } \\
\text { CSMA/CD }\end{array}$ & 2015 & 3 & 3 & 6 \\
\hline $\begin{array}{l}\text { Redes de Computadoras II - } \\
\text { UNSa }\end{array}$ & $\begin{array}{l}\text { Redes LAN } \\
\text { CSMA/CD }\end{array}$ & 2015 & 5 & 7 & 12 \\
\hline $\begin{array}{l}\text { Redes de Computadoras I - } \\
\text { UNSa }\end{array}$ & Protocolo DNS & 2015 & 5 & 16 & 21 \\
\hline $\begin{array}{l}\text { Redes de Computadoras I - } \\
\text { UNSa }\end{array}$ & $\begin{array}{l}\text { Direccionamiento } \\
\text { IP }\end{array}$ & 2015 & 4 & 12 & 16 \\
\hline $\begin{array}{l}\text { Redes de Computadoras I - } \\
\text { UNSa }\end{array}$ & Ruteo IP & 2015 & 5 & 11 & 16 \\
\hline $\begin{array}{l}\text { Redes de Computadoras I - } \\
\text { UNSa }\end{array}$ & $\begin{array}{l}\text { Direccionamiento } \\
\text { IP }\end{array}$ & 2016 & 6 & 6 & 12 \\
\hline $\begin{array}{l}\text { Redes de Computadoras I - } \\
\text { UNSa }\end{array}$ & Ruteo IP & 2016 & 5 & 8 & 13 \\
\hline $\begin{array}{l}\text { Redes de Computadoras II - } \\
\text { UNSa }\end{array}$ & $\begin{array}{l}\text { Redes LAN } \\
\text { CSMA/CD }\end{array}$ & 2016 & 5 & 5 & 10 \\
\hline Total de estudiantes & & & 64 & 126 & 190 \\
\hline
\end{tabular}

Tabla 4-3: Muestra del estudio explicativo-correlacional

La muestra total para los dos tipos de experimentos asciende a un total de 330 estudiantes que participaron de la investigación.

Cabe destacar que los grupos bajo estudio pueden considerarse homogéneos o en igualdad de condiciones al inicio de cada experiencia, ya que se analizaron los planes de estudio correspondientes y el contenido de los programas de las respectivas asignaturas correlativas previas, y los mismos no contienen los conceptos evaluados en esta experiencia. Además no se incluyeron los estudiantes recursantes en ninguno de los grupos ni tratamientos, como se mencionó anteriormente. 


\section{ANALISIS DE LAS EXPERIENCIAS REALIZADAS}

Los instrumentos empleados para el análisis de las experiencias realizadas fueron revisados por expertos quienes emitieron un concepto favorable. Se comprobó la fiabilidad y la validez de cada instrumento.

\subsection{Estudio sobre disponibilidad de PC e Internet}

En la primera etapa de la investigación se realizó un cuestionario a los estudiantes que cursaban la asignatura Redes de Computadoras I de la carrera Licenciatura en Análisis de Sistemas en la Universidad Nacional de Salta en el año 2013, asignatura donde se realizaron la mayor parte de las experiencias con software de simulación. Este cuestionario se repitió en los años siguientes, con las cohortes de cada año, hasta el año 2016 inclusive.

El objetivo de este cuestionario fue:

- Investigar la disponibilidad del estudiante de computadora personal (PC). Se observó la evolución a lo largo del período considerado (2013 al 2016). Este hecho fue un factor muy importante a considerar, dado que determinó la factibilidad de que el estudiante accediera o no a la posibilidad de realizar las prácticas en su domicilio, dando un fuerte aval a la utilización de las técnicas de simulación.

- Determinar la experiencia previa con software de simulación: si utilizó, cuál utilizó y el grado de su utilización. La pregunta del cuestionario para evaluar esta experiencia previa (“cuanto”), fue: “¿cuántas experiencias simuló?”, con tres opciones de respuesta: $<5,5$ a $10,>10$, lo que permitió "categorizar" la experiencia anterior al cursado de la asignatura. Se consideró que un estudiante que realizó menos de 5 experiencias apenas conoció el software, quien realizó de 5 a 10 tuvo una formación media y el que realizó más de 10 puede decirse que tuvo un dominio del mismo como para usarlo y seguir aprendiendo en forma autónoma.

- Determinar la cantidad de horas dedicadas a trabajar. Se solicitó información respecto a si trabaja, además de estudiar, y cuántas horas por semana. En esta pregunta, tendiente a investigar la disponibilidad de tiempo para el estudio, al evaluar el cuestionario se categorizaron las respuestas en: "no", "menos de 20 horas semanales", y "más de 20 horas semanales".

\subsubsection{Resultados del cuestionario}

El cuestionario permitió determinar, durante los años que se realizó, que el promedio de los estudiantes que posee PC fue cercano al 90\%. Asimismo, se pudo notar una evolución a lo largo del tiempo que coincide con un fenómeno social, el uso cada vez más creciente de la PC, considerando también el nivel socioeconómico del estudiante que asiste a la universidad pública. Ello se puede observar en la Figura 5-1. 


\section{Disponibilidad de PC en domicilio}

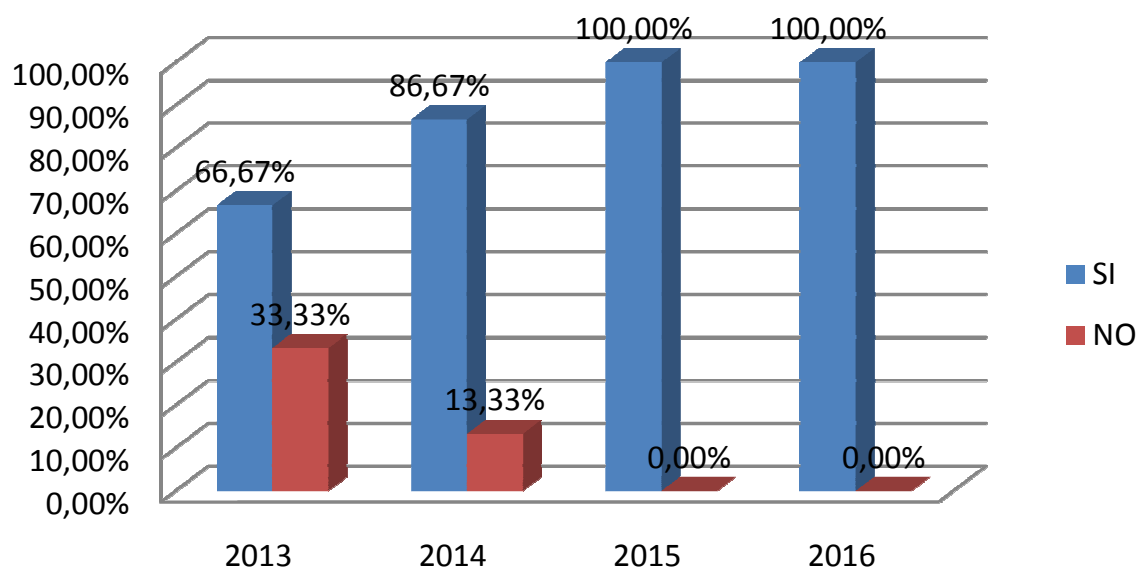

Figura 5-1: Disponibilidad de PC en domicilio

Esta conclusión es un factor muy importante, dado que determina que existe cada vez más (totalmente en las cohortes 2015 y 2016) la disponibilidad, por parte del estudiante, del "laboratorio virtual" en su domicilio y también la disponibilidad de conexión a Internet en el domicilio (ver Figura 5-2). Como se expresó anteriormente, esto es un factor relevante a favor de la utilización de los métodos de simulación.

\section{Conexión a Internet en domicilio}

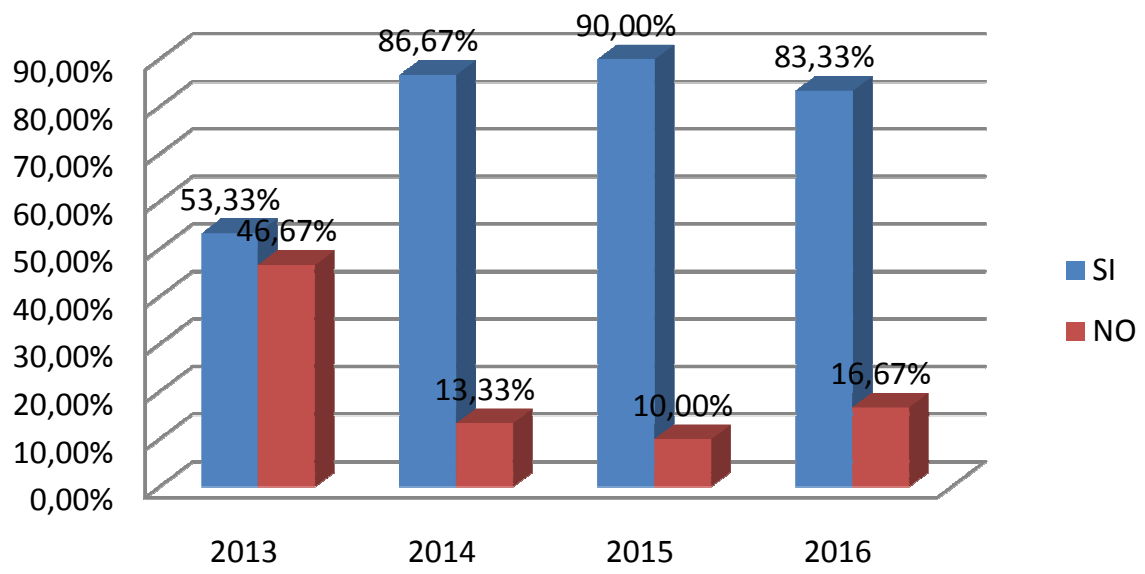

Figura 5-2: Disponibilidad de conexión a Internet en domicilio

Respecto a si usó software de simulación en asignaturas de la carrera previas a Redes de Computadoras, la respuesta fue en promedio menor al 25\%, lo que demuestra la escasa utilización de herramientas de simulación en las asignaturas previas. Los que sí las utilizaron, lo hicieron en la asignatura Arquitectura y Organización de la Computadora en particular los simuladores Digital Works, Virtual Box y VMWare. En la gran mayoría de los casos, la respuesta fue que se los utilizó muy poco (menos de 5 experiencias). Ver Figura 5-3. Por los valores recolectados se considera que la gran mayoría apenas conoce este tipo de herramientas. 
Uso previo de SW de simulación

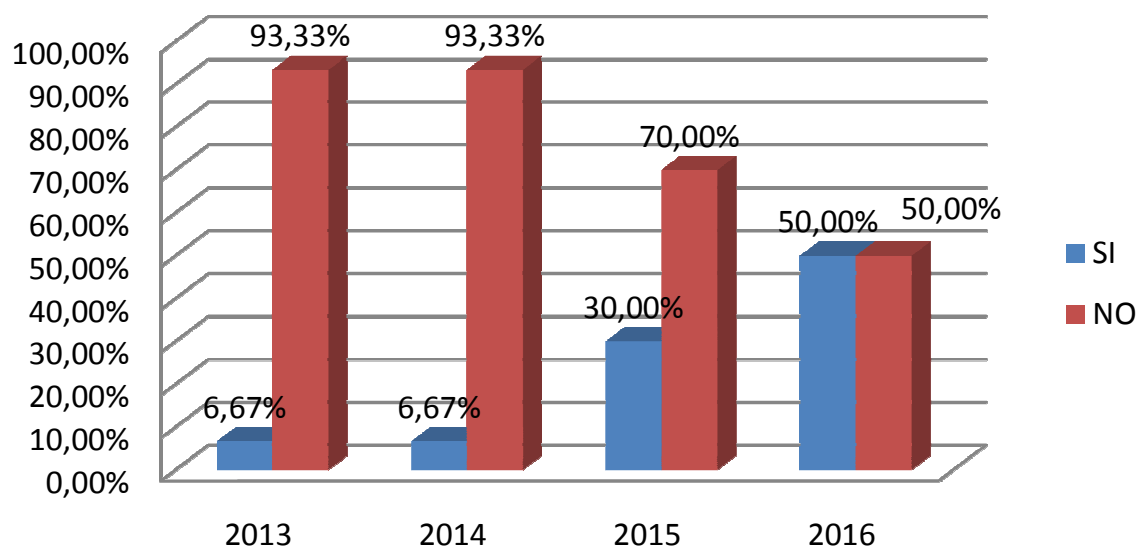

Figura 5-3: Uso previo de SW de simulación

Respecto a si los estudiantes trabajan, el cuestionario reveló que, en ese período, un $80 \%$ en promedio no trabajaba, y de los estudiantes que trabajan, casi en su totalidad lo hacían menos de 20 horas semanales. Esto puede observarse en la Figura 5-4.

\section{Estudiantes que trabajan}

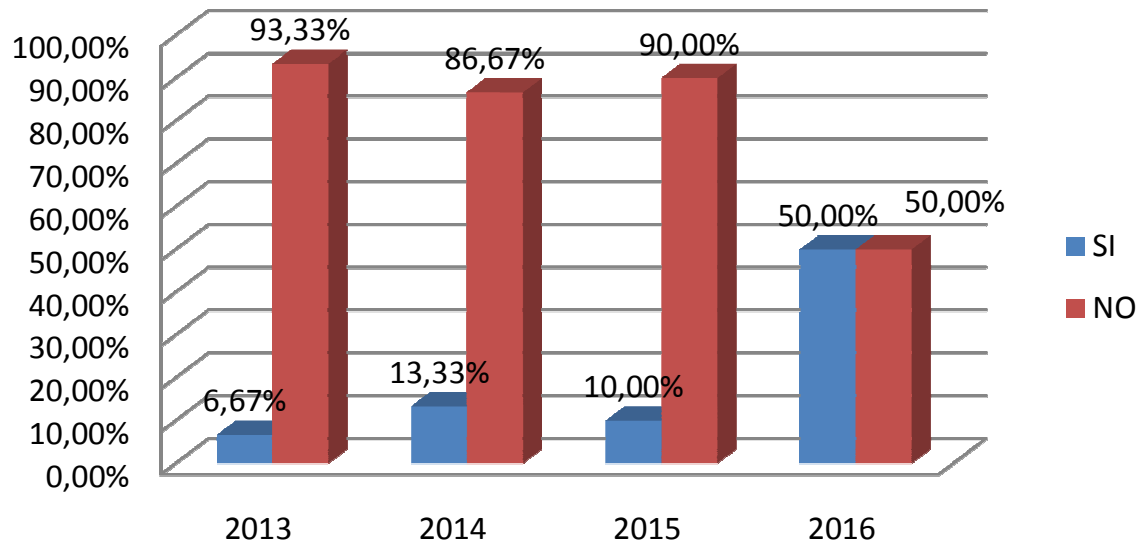

Figura 5-4: Estudiantes que trabajan 


\subsection{Experiencia $\mathrm{N}^{0}$ 1: Simulador Packet Tracer en Conectividad y Teleinformática}

Esta experiencia, con la herramienta Packet Tracer en su ver.5.3.3, se realizó en el primer semestre del año 2012 con estudiantes que cursaron la asignatura Conectividad y Teleinformática de la carrera Licenciatura en Análisis de Sistemas de la Facultad de Ciencias Exactas de la Universidad Nacional de Salta, durante el segundo semestre del año 2011. La misma se aprobó en la Facultad como un curso de extensión con RESD-EXA: 233/2012. EXP-EXA: 8121/2012 “Taller de Redes con Packet Tracer”. Los estudiantes que participaron del mismo, lo hicieron de forma voluntaria.

El temario se dividió en seis apartados: Generalidades, Direccionamiento IP, Protocolos de Control, Fragmentación IP, Ruteo Estático y Ruteo Dinámico con RIP.

Para cada tema propuesto se desarrolló una guía de trabajos prácticos específica para ser resuelta en el laboratorio con simulación. Cabe destacar que el temario del taller con simulación, está relacionado con la última parte del programa de la asignatura Conectividad y Teleinformática.

En la primera parte del taller Generalidades, se mostró la interfaz del simulador y su funcionalidad, cómo realizar la configuración básica de dos PCs conectadas directamente, luego dos PCs conectadas por medio de un concentrador, posteriormente dos PCs conectadas con un conmutador, la configuración básica IP y prueba de conectividad. También se analizó la configuración de servicios de capa de aplicación como DHCP, DNS y FTP. En la segunda parte, Direccionamiento IP, se analizaron los conceptos de enrutamiento básico, subredes IP y la configuración de un router conectando tres segmentos de red LANs. Posteriormente se examinaron los protocolos de control en internet ICMP, las utilidades ping y traceroute. Se analizó el protocolo de resolución de direcciones ARP para el caso de la resolución local y cuando el destino se encuentra fuera de la red local. También se analizó el proceso de fragmentación IP. Para el tema de Ruteo Estático, se propuso la configuración de una topología conformada por tres segmentos de red LANs vinculadas por dos routers. Se indagó sobre el proceso de ruteo desde el origen al destino. Finalmente, para el tema de Ruteo Dinámico con el protocolo RIP, se propuso realizar la configuración para la misma topología propuesta en el ruteo estático.

\subsubsection{Análisis de la experiencia}

Una vez finalizadas las clases teóricas-prácticas con la asistencia de dos profesores, se les solicitó a los estudiantes que relataran libremente la experiencia realizada con la herramienta de simulación. A partir de las narrativas entregadas, se confeccionó un cuestionario que sintetiza lo expresado.

La evaluación de la experiencia se consideró como muy positiva, no solo desde el punto de vista del aprendizaje, sino también desde el punto de vista de la enseñanza.

Las preguntas que surgieron de los relatos de las experiencias se pueden dividir en dos apartados: por un lado, la herramienta en sí misma, y por otro, la utilización de la herramienta en la resolución de la práctica propuesta en el taller.

La muestra: esta experiencia la realizaron 5 estudiantes voluntarios.

\section{Preguntas que surgieron de las narrativas}




\section{Sobre la herramienta de simulación Packet Tracer}

- ¿Permite el simulador ver cómo funcionan las redes realmente, equipos, conexiones, protocolos, configuraciones?

- ¿Considera PT una herramienta adecuada para el estudio de fundamentos de redes, es decir, poner en concreto lo abstracto de los protocolos tal como lo estudiamos en la asignatura Conectividad y Teleinformática?

- ¿Es intuitivo el uso de PT o considera necesario más tiempo para la adaptación a la herramienta?

- ¿Es sencillo probar una y otra vez las simulaciones para poder analizar lo que ocurre en una determinada topología y configuración?

- ¿Nos da confianza el simulador de poder realizar pruebas sin temor a los fallos?

- La visualización de la funcionalidad, es decir, cómo presenta el simulador su entorno, ¿considera que es amigable, entendible, facilita la interpretación de los protocolos y configuraciones?

- ¿Considera que se acerca a la realidad la funcionalidad que percibimos de los distintos dispositivos como usuarios?

- ¿Nos damos una idea, con las topologías simples analizadas, del costo necesario si quisiéramos replicar las mismas en un laboratorio real?

- La ayuda contextual que dispone para el usuario, ¿la considera suficiente?

- ¿La ayuda de contexto del simulador, facilita la depuración cuando se producen fallos, producto de errores de configuración?

- ¿La traducción de la interfaz al español del simulador, facilita su operación?

- Sobre la Guía de ejercicios propuestos.

El nivel de complejidad de la guía utilizada en los laboratorios ¿es adecuada?

- La redacción de la guía utilizada ¿es comprensible?

- El tiempo asignado a cada laboratorio ¿se considera adecuado?

- ¿Considera necesario tener cierta práctica en la configuración real de redes previa, para el uso del simulador?

\section{Sobre generalidades del uso de la herramienta}

- ¿Considera que el uso del simulador permitió afianzar los conceptos y fundamentos de redes vistos durante el cursado de la asignatura?

- ¿Podría describir la utilidad de los modos de funcionamiento del PT "tiempo real” y "simulación"?

- ¿Considera que muchos escenarios de configuración es posible visualizarlos más fácilmente en el simulador que en papel?

- ¿Considera que el simulador nos acerca el contacto con los distintos dispositivos de red?

- ¿Recomendaría el uso del simulador durante el cursado de la asignatura?

- ¿Podría quedar como laboratorios adicionales sólo para los interesados en profundizar los conocimientos sobre redes?

- Tal cual se vio en los laboratorios ¿lo considera como un complemento o como reemplazo de los prácticos tradicionales?

- ¿Es necesario tener muy claros los conceptos para visualizarlos en el simulador? 


\subsubsection{Conclusión de la experiencia}

Los estudiantes percibieron al simulador de red como una valiosa herramienta de aprendizaje que ayuda a involucrarse con las tareas y les ayuda a hacer un uso más eficiente del tiempo dedicado a la práctica. La simulación proporcionó un gran beneficio para todas las partes implicadas, es decir, a los estudiantes que obtuvieron más experiencia sobre el temario de la asignatura, a los profesores que pudieron centrarse mejor en los objetivos reales de las sesiones de laboratorio, y a las instituciones que apreciaron los menores costos involucrados en equipamiento específico de red.

Los conceptos de redes de computadoras pueden ser difíciles de entender y enseñar ya que con frecuencia se relacionan con procesos complejos y dinámicos que generalmente no son fácilmente visibles o intuitivos y, por tanto, la conceptualización es un verdadero problema. Los docentes suelen incorporar herramientas de simulación y virtualización para apoyar el proceso de enseñanza-aprendizaje, pero a menudo de una manera superficial y sin evaluar su eficacia.

Esta experiencia sirvió también para la validación y reestructuración de los prácticos propuestos para el desarrollo con el simulador Packet Tracer en la asignatura Conectividad y Teleinformática.

Las preguntas que surgieron del análisis de los relatos, sirvieron de base para el diseño de las encuestas en las siguientes experiencias. 


\subsection{Experiencia $\mathrm{N}^{0}$ 2: Simulador Kiva-NS en Conectividad y Teleinformática}

Esta experiencia se realizó con un grupo de estudiantes voluntarios que se encontraban cursando la asignatura Conectividad y Teleinformática del Plan de Licenciatura en Análisis de Sistemas del año 1997, durante el segundo semestre del año 2012. El taller se realizó paralelamente al cursado de la asignatura, lo que permitió analizar el desempeño de los estudiantes que participaron del mismo, en la evaluación del segundo parcial que abarca la temática Capa de Red y Capa de Transporte.

Considerando que la plataforma Kiva-NS es una herramienta sencilla e intuitiva, el taller se llevó a cabo en tres clases teóricas-prácticas de tres horas cada una. El taller se denominó "Simulador KivaNS en la enseñanza de Redes IP" y fue aprobado en la Facultad de Ciencias Exactas como curso de extensión bajo resolución RESD-EXA: 801/2012. EXPEXA: 8676/2012.

La teoría impartida como parte del cursado de la asignatura facilitó la realización del taller, permitiendo al plantel docente concentrarse en la presentación de la herramienta y en su utilización. Al finalizar el taller se realizó una encuesta actitudinal dividida en dos partes: en la primera parte se evaluó a Kiva-NS como herramienta de software, y en la segunda parte se evaluó Kiva-NS en el desarrollo de laboratorios y prácticas. El objetivo de esta encuesta fue analizar el impacto del uso de la herramienta por los estudiantes y de esa manera determinar que tan efectiva podría ser incluirla como apoyo durante el cursado de la asignatura.

Paralelamente se realizó una prueba de conceptos, cuyo objetivo principal fue contrastar estadísticamente si ambos grupos de estudio presentaron una diferencia significativa en cuanto a alguna medida de tendencia central o de variabilidad, a los fines de poder tomar una decisión confiable sobre el beneficio o no de la aplicación de la nueva técnica de enseñanza, es decir, si el uso de la herramienta de simulación como complemento a las prácticas tradicionales, favorece el aprendizaje.

El estudio fue del tipo cuantitativo, con diseño cuasi-experimental con grupo de control, lo que permitió contrastar el desempeño del grupo experimental (estudiantes que utilizaron métodos de simulación) y el grupo de control.

Se podría decir además, que esta fue la única experiencia donde los estudiantes no estuvieron en igualdad de condiciones para la regularización de la asignatura.

\subsubsection{Análisis estadísticos de datos}

\section{Primera parte de la encuesta: Kiva-NS como herramienta}

Para este análisis, la media aritmética supera, en todos los casos, al menos el valor medio de la escala (3.00), lo que confirma la validez del contenido de todos los ítems incluidos.

Como puede observarse en la Tabla 5-1, el coeficiente Alfa de Cronbach calculado es de 0,826 que supera el valor de 0,7 (George y Mallery, 2003), lo que permite afirmar el grado de fiabilidad del cuestionario. Por lo tanto, se aprecia en este caso una alta polarización de respuestas confiables por parte de los estudiantes. 
Estudio de la influencia de un entorno de simulación en la enseñanza de redes de computadoras en el nivel universitario

\begin{tabular}{|r|r|r|}
\hline \multicolumn{1}{|c|}{$\begin{array}{c}\text { Alfa de } \\
\text { Cronbach }\end{array}$} & $\begin{array}{c}\text { Alfa de } \\
\text { Cronbach } \\
\text { basada en los } \\
\text { elementos } \\
\text { tipificados }\end{array}$ & \\
\hline 0,853 & 0,826 & \\
\hline
\end{tabular}

Tabla 5-1 E2-P1: Estadísticos de fiabilidad

\begin{tabular}{|l|r|r|r|}
\hline & \multicolumn{1}{|c|}{ Media } & $\begin{array}{c}\text { Desviación } \\
\text { típica }\end{array}$ & $\mathrm{N}$ \\
\hline VAR00001 & 4,5385 & 0,77625 & 13 \\
VAR00002 & 4,7692 & 0,43853 & 13 \\
VAR00003 & 4,3077 & 0,63043 & 13 \\
VAR00004 & 4,3077 & 0,63043 & 13 \\
VAR00005 & 4,3077 & 1,18213 & 13 \\
VAR00006 & 4,0000 & 0,81650 & 13 \\
VAR00007 & 4,3846 & 0,65044 & 13 \\
VAR00008 & 4,6154 & 0,76795 & 13 \\
VAR00009 & 4,1538 & 1,06819 & 13 \\
VAR00010 & 3,7692 & 1,30089 & 13 \\
VAR00011 & 4,2308 & 0,92681 & 13 \\
\hline
\end{tabular}

Tabla 5-2 E2-P1: Estadísticos de los elementos

\begin{tabular}{|l|r|r|r|r|r|r|r|}
\hline & Media & Mínimo & Máximo & Rango & $\begin{array}{c}\text { Máximo/ } \\
\text { mínimo }\end{array}$ & Varianza & $\begin{array}{c}\mathrm{N} \text { de } \\
\text { elementos }\end{array}$ \\
\hline $\begin{array}{l}\text { Medias de los } \\
\text { elementos }\end{array}$ & 4,308 & 3,769 & 4,769 & 1,000 & 1,265 & 0,078 & 11 \\
\hline
\end{tabular}

Tabla 5-3 E2-P1: Estadísticos de resumen de los elementos

\begin{tabular}{|c|r|r|r|}
\hline Media & Varianza & $\begin{array}{c}\text { Desviación } \\
\text { típica }\end{array}$ & N de elementos \\
\hline 47,3846 & 37,256 & 6,10380 & 11 \\
\hline
\end{tabular}

Tabla 5-4 E2-P1: Estadísticos de la escala 


\section{Segunda parte de la encuesta: Kiva-NS en el desarrollo de prácticas}

Para este análisis, la media aritmética supera en la mayoría de los casos al menos el valor medio de la escala (3.00), lo que confirma la validez del contenido de todos los ítems incluidos.

Como puede observarse en la Tabla 5-5, el coeficiente Alfa de Cronbach calculado es de 0,859 que supera el valor de 0,7 (George y Mallery, 2003), lo que permite afirmar el grado de fiabilidad del cuestionario. Por lo tanto, se aprecia en este caso una alta polarización de respuestas confiables por parte de los estudiantes.

\begin{tabular}{|r|r|r|}
\hline \multicolumn{1}{|c|}{$\begin{array}{c}\text { Alfa de } \\
\text { Cronbach }\end{array}$} & $\begin{array}{c}\text { Alfa de } \\
\text { Cronbach } \\
\text { basada en los } \\
\text { elementos } \\
\text { tipificados }\end{array}$ & \\
\hline 0,716 & 0,859 & \\
\hline
\end{tabular}

Tabla 5-5 E2-P2: Estadísticos de fiabilidad

\begin{tabular}{|l|r|r|r|}
\hline & \multicolumn{1}{|c|}{ Media } & \multicolumn{1}{c|}{$\begin{array}{c}\text { Desviación } \\
\text { típica }\end{array}$} & $\mathrm{N}$ \\
\hline VAR00001 & 4,3077 & 0,63043 & 13 \\
VAR00002 & 4,4615 & 0,77625 & 13 \\
VAR00003 & 4,7692 & 0,43853 & 13 \\
VAR00004 & 4,6923 & 0,63043 & 13 \\
VAR00005 & 4,4615 & 0,66023 & 13 \\
VAR00006 & 4,6923 & 0,48038 & 13 \\
VAR00007 & 3,1538 & 1,51911 & 13 \\
VAR00008 & 2,6154 & 1,38675 & 13 \\
VAR00009 & 3,7692 & 1,83275 & 13 \\
VAR00010 & 4,7692 & 0,43853 & 13 \\
VAR00011 & 3,8462 & 0,68874 & 13 \\
\hline
\end{tabular}

Tabla 5-6 E2-P2: Estadísticos de los elementos

\begin{tabular}{|l|r|r|r|r|r|r|r|}
\hline & Media & Mínimo & Máximo & Rango & $\begin{array}{c}\text { Máximo/míni } \\
\text { mo }\end{array}$ & $\begin{array}{c}\text { Varianz } \\
\text { a }\end{array}$ & $\begin{array}{c}\mathrm{N} \text { de } \\
\text { elementos }\end{array}$ \\
\hline $\begin{array}{l}\text { Medias de los } \\
\text { elementos }\end{array}$ & 4,140 & 2,615 & 4,769 & 2,154 & 1,824 & 0,516 & 11 \\
\hline
\end{tabular}

Tabla 5-7 E2-P2: Estadísticos de resumen de los elementos 


\begin{tabular}{|c|r|r|r|}
\hline Media & Varianza & $\begin{array}{c}\text { Desviación } \\
\text { típica }\end{array}$ & N de elementos \\
\hline 45,5385 & 30,103 & 5,48658 & 11 \\
\hline
\end{tabular}

Tabla 5-8 E2-P2: Estadísticos de la escala

Desempeño de los estudiantes en la evaluación del segundo parcial de la asignatura Conectividad y Teleinformática.

Con el objeto de justificar estadísticamente el desempeño de los estudiantes, si X es el número de estudiantes que aprobaron el examen con el método de simulación, Y el número de estudiantes que aprobaron con el método tradicional con una escala de evaluación del tipo (aprobado, no aprobado).

X: 0,1 Y: 0,1 se da un caso de dicotomía.

Como criterio para calificar al método de simulación como válido (fiable), en la muestra de estudiantes que rindieron con esta metodología, se debe observar al menos un $90 \%$ de aprobados. A los fines de medir las chances de ocurrencia de tener éxito con el criterio antes mencionado, corresponde calcular las probabilidades asociadas usando la distribución binomial.

$$
\begin{aligned}
& P(X \geq 9,9)=1=1^{9,9} \\
& P(Y \geq 20,7)=(0,87)^{20,7}(0,13)^{3,7}=2,6 \times 10^{5}
\end{aligned}
$$

Siendo $\mathrm{P}=67$ / $77=0,87$ La probabilidad de aprobar el examen con el método tradicional.

Claramente la probabilidad para el primer método es muy superior a la correspondiente al segundo método, con lo cual se corrobora probabilísticamente que el método de simulación es altamente recomendable. 


\section{Análisis de Kiva-NS como herramienta de software}

A continuación se presentan los gráficos con las respuestas de los estudiantes, para cada una de las preguntas del cuestionario realizado.

\section{La instalación y puesta en funcionamiento de la herramienta es sencilla}

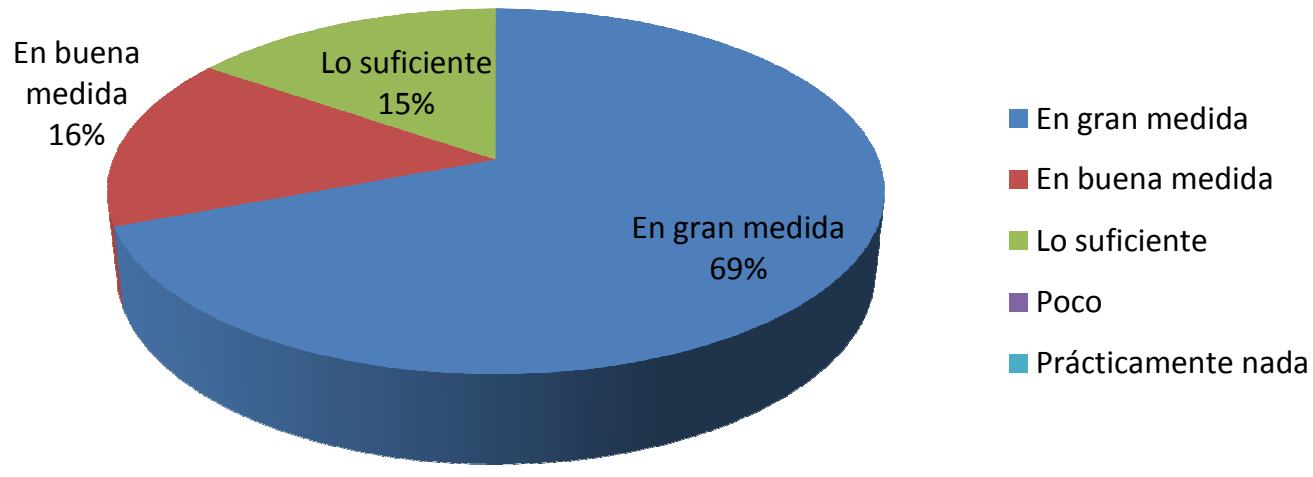

KivaNS como herramienta de software

Figura 5-5 E2: La instalación es sencilla

\section{La interfaz gráfica que ofrece la aplicación es amigable e intuitiva}

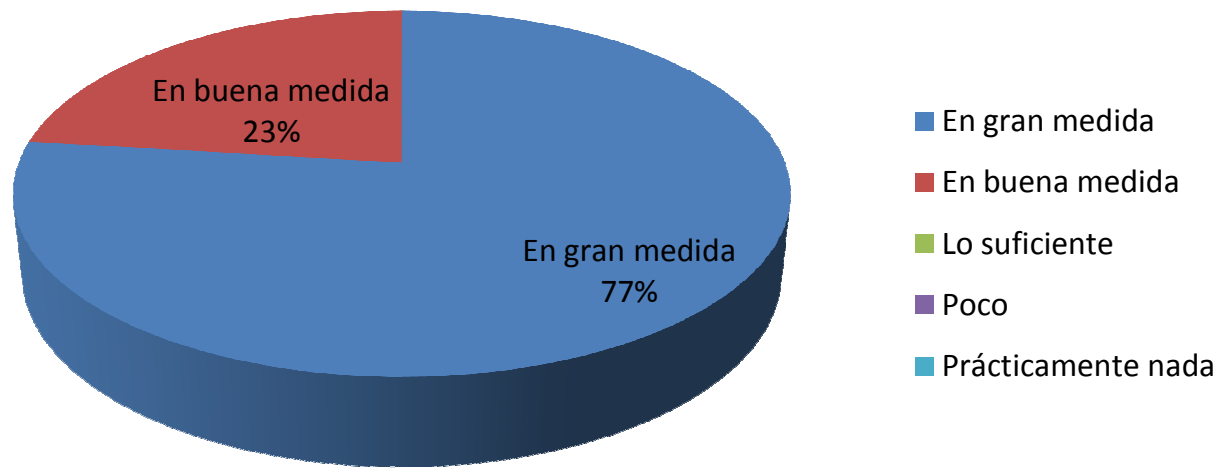

KivaNS como herramienta de software

Figura 5-6 E2: La interfaz gráfica es intuitiva 


\section{La aplicación posee los componentes necesarios para realizar un laboratorio de redes IP}

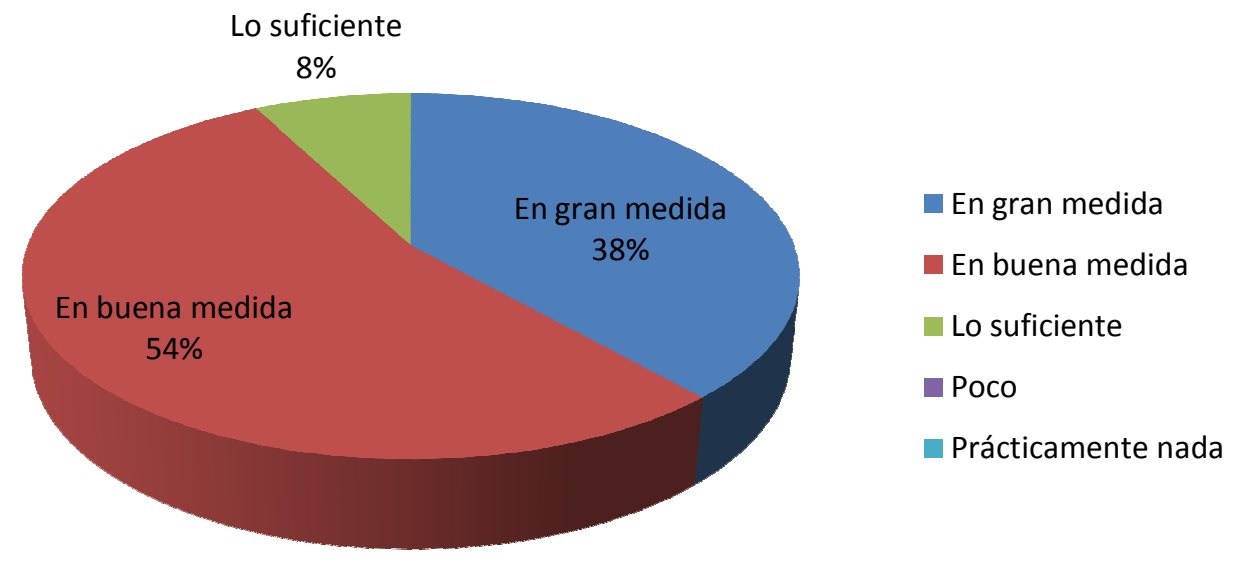

KivaNS como herramienta de software

Figura 5-7 E2: Posee los componentes necesarios para un laboratorio IP

\section{Se cuenta con ayuda que permita resolver dudas sobre el uso de la herramienta}

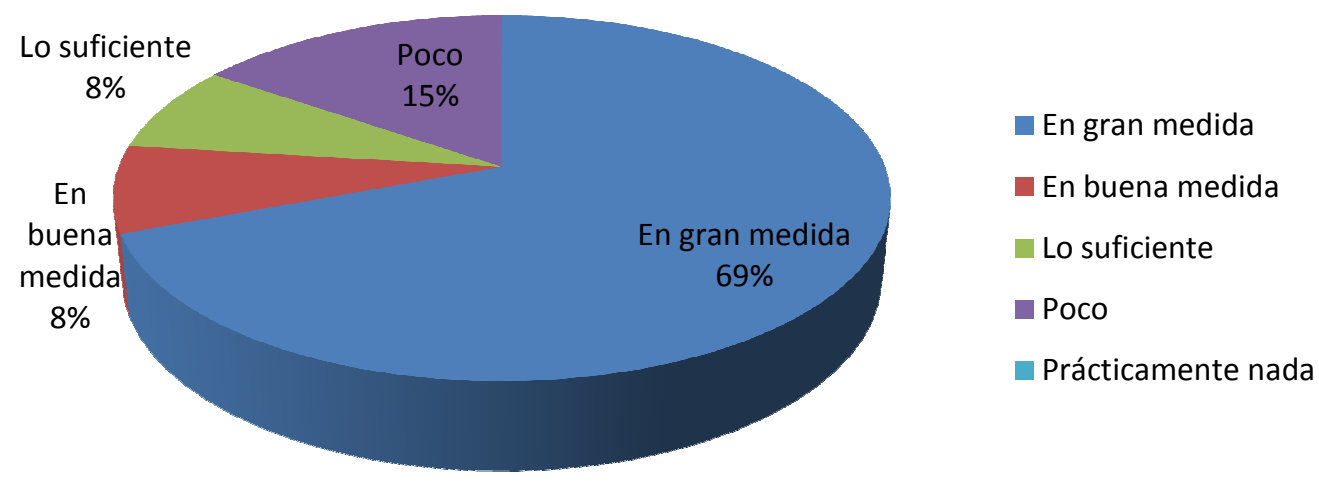

KivaNS como herramienta de software

Figura 5-8 E2: Cuenta con ayuda sobre el uso 


\section{La herramienta permite realizar simulaciones claras y reales sobre el entorno físico que se va a montar}

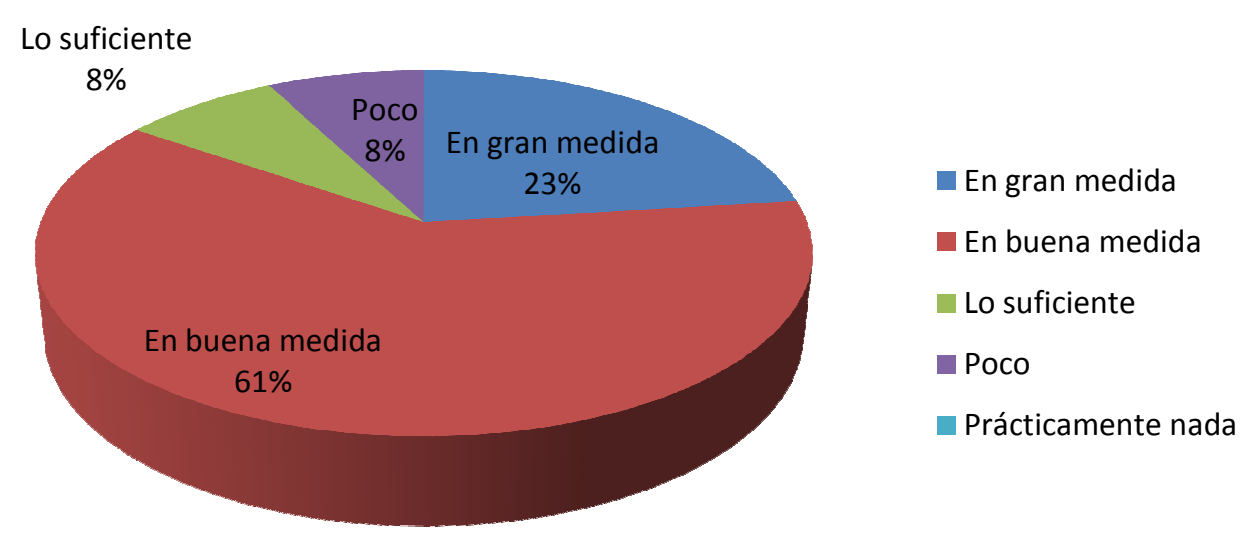

KivaNS como herramienta de software

Figura 5-9 E2: Permite realizar simulaciones claras

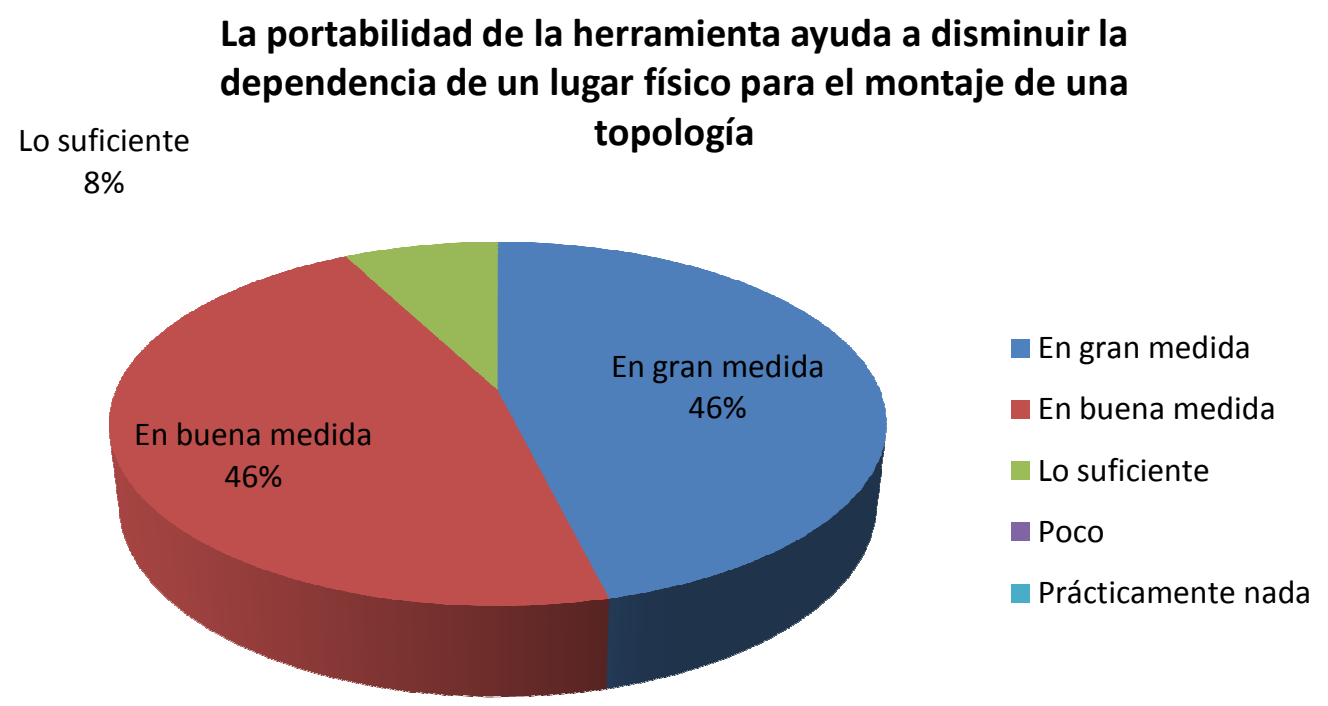

KivaNS como herramienta de software

Figura 5-10 E2: La portabilidad de la herramienta independiza 


\section{Con esta herramienta, la configuración de los dispositivos se desentiende de una marca particular, concentrándose en el concepto teórico}

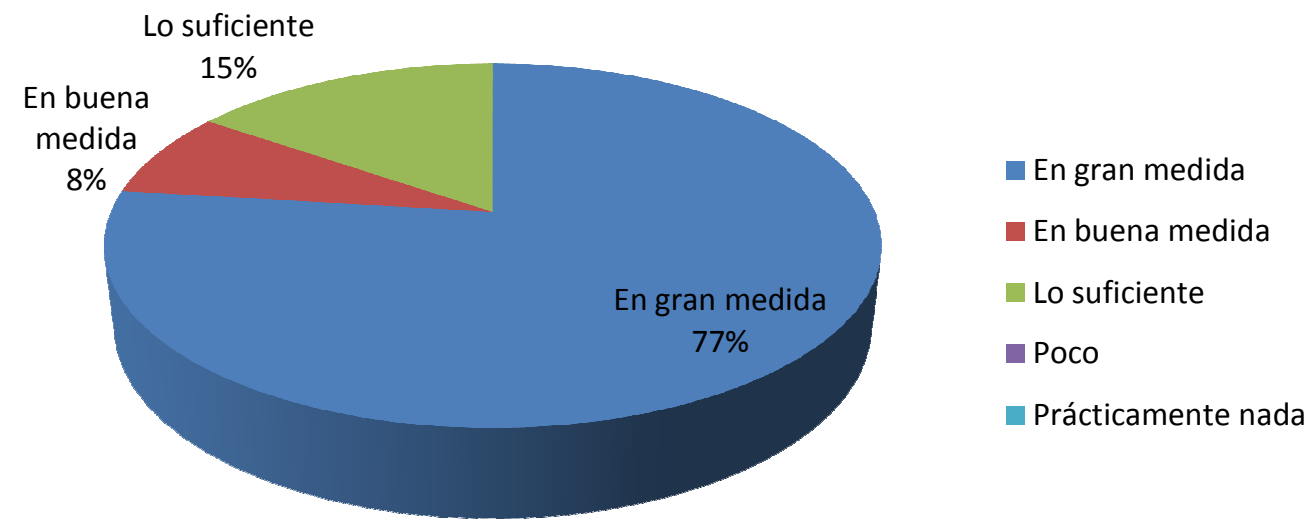

KivaNS como herramienta de software

Figura 5-11 E2: La configuración de los dispositivos se desentiende del fabricante

\section{Permite realizar cambios en la topología fácilmente para adecuarla a las necesidades}

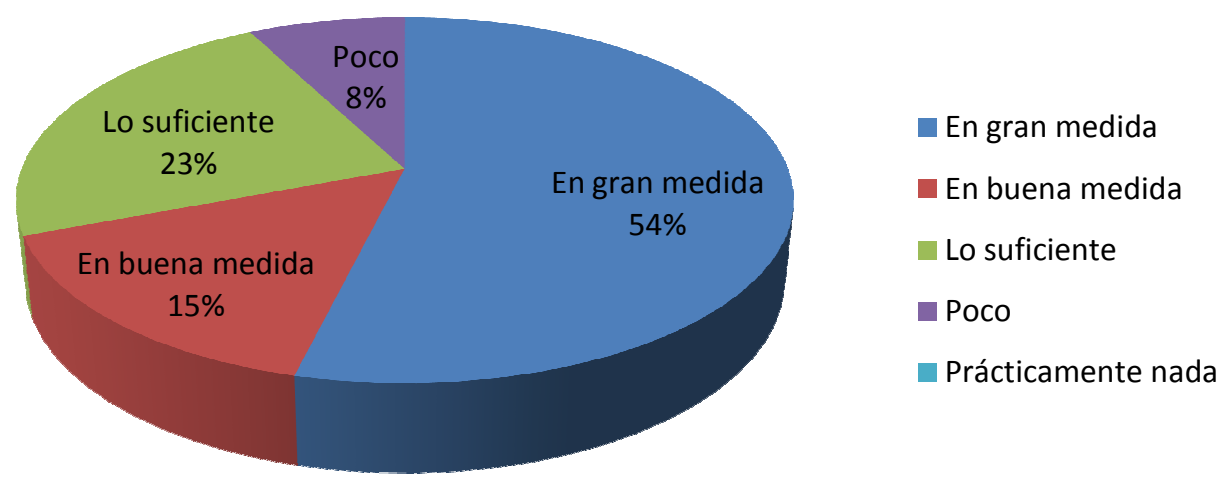

KivaNS como herramienta de software

Figura 5-12 E2: Permite realizar cambios en la topología 


\section{Permite simular cambios en dispositivos de manera efectiva en una determinada topología}

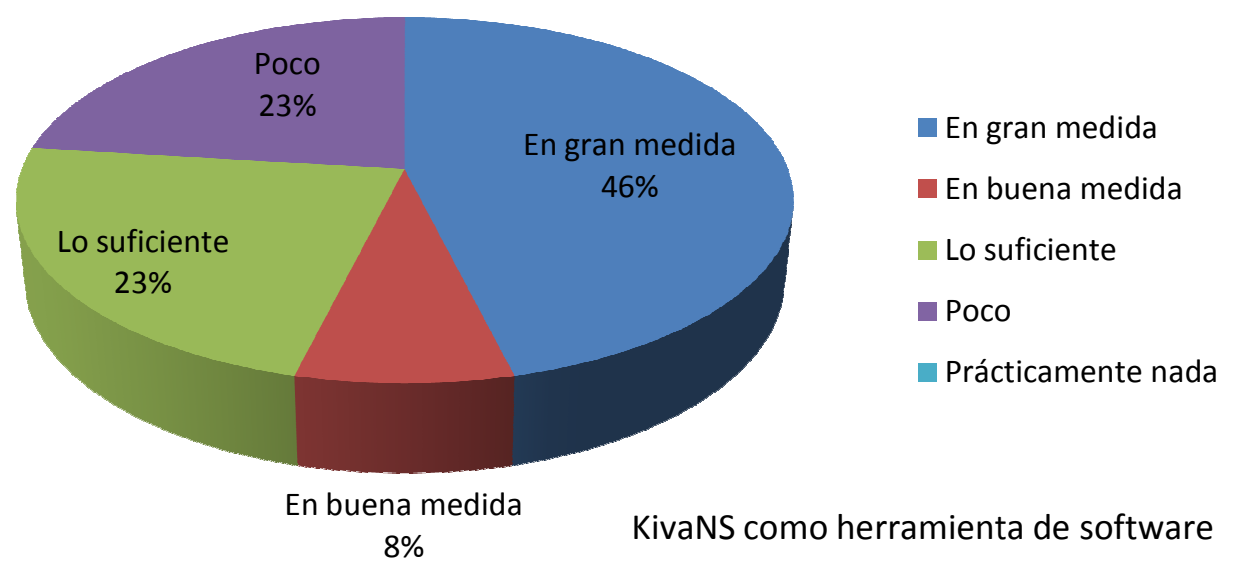

Figura 5-13 E2: Permite simular cambio s en dispositivos

\section{La herramienta facilita el seguimiento de los eventos ocurridos en cada uno de los dispositivos dentro de la topología}

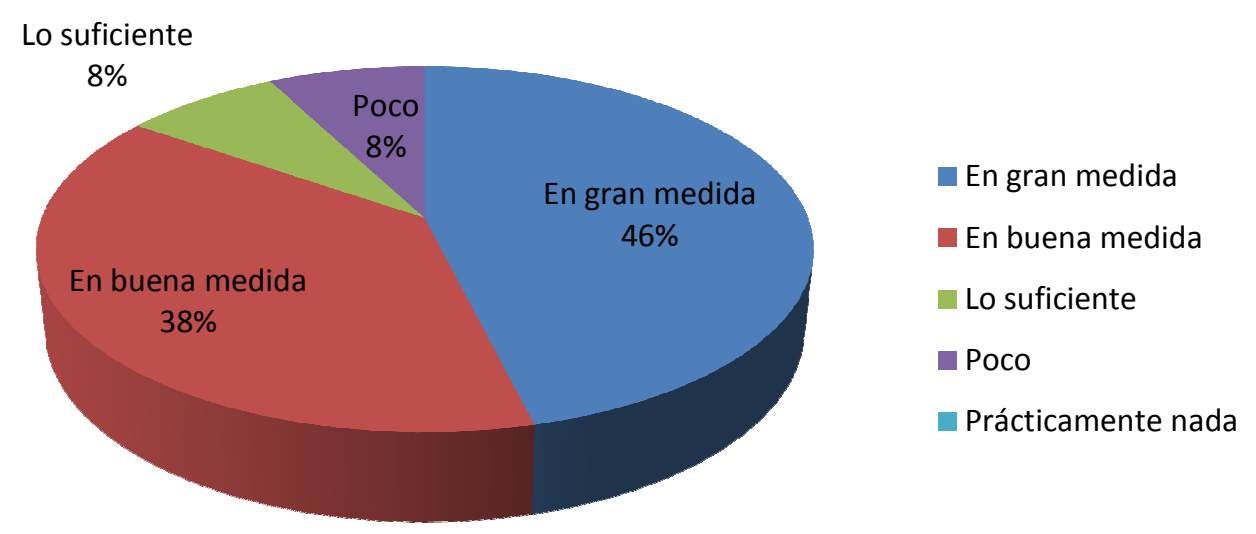

KivaNS como herramienta de software

Figura 5-14 E2: Facilita el seguimiento de los eventos 
Análisis de KivaNS en el desarrollo de laboratorios y prácticas

\section{Con el uso de KivaNS se optimiza el tiempo invertido en la realización de los laboratorios}

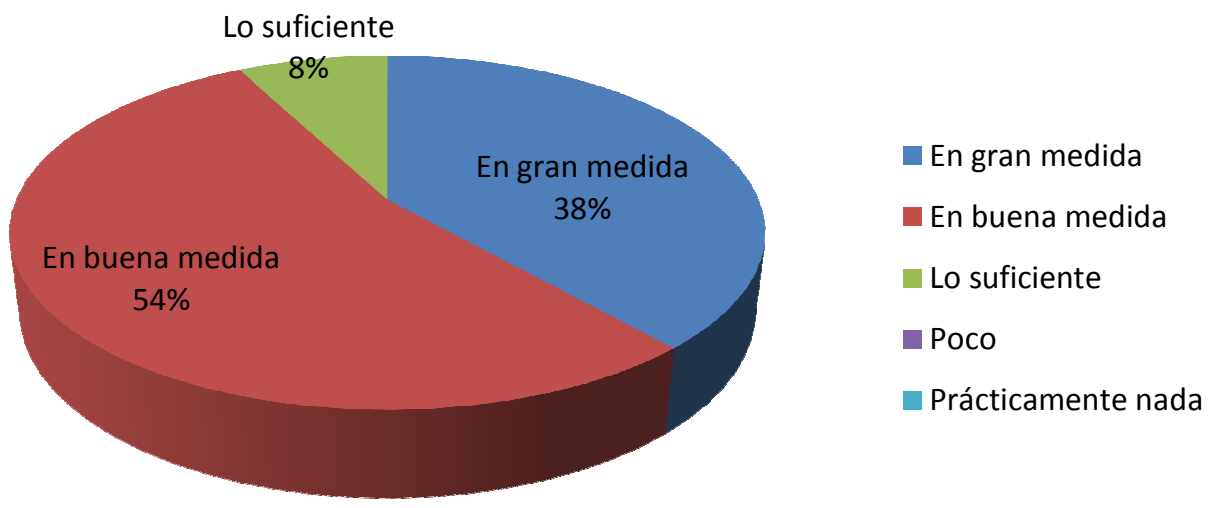

KivaNS en el desarrollo de laboratorios y prácticas

Figura 5-15 E2: KivaNS optimiza el tiempo para laboratorios

El uso de una herramienta de simulación como KivaNS minimiza el riesgo de daño de los dispositivos empleados en los laboratorios

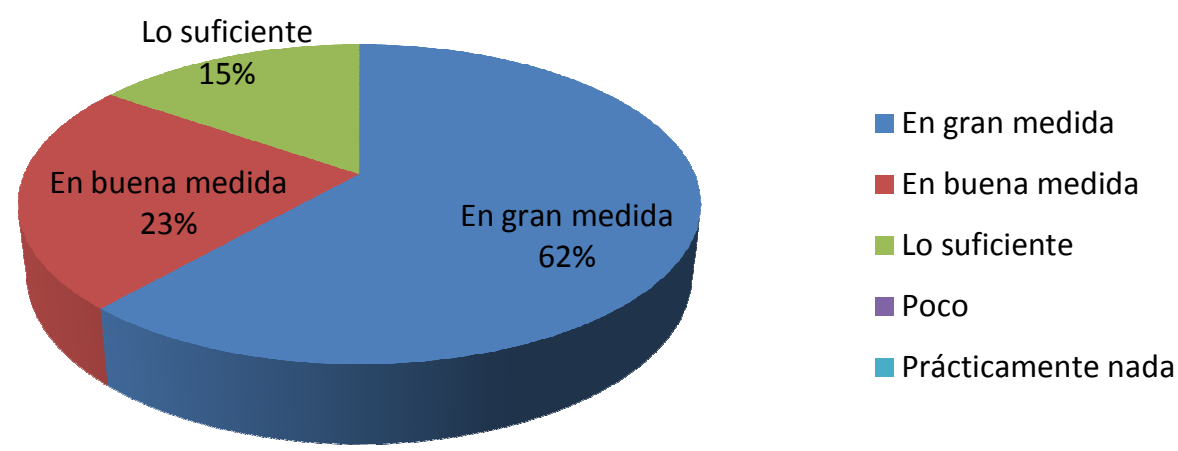

KivaNS en el desarrollo de laboratorios y prácticas

Figura 5-16 E2: KivaNS minimiza el riesgo de daños en dispositivos 


\section{Facilita el entendimiento y el estudio de las topologías de red y sus dispositivos}

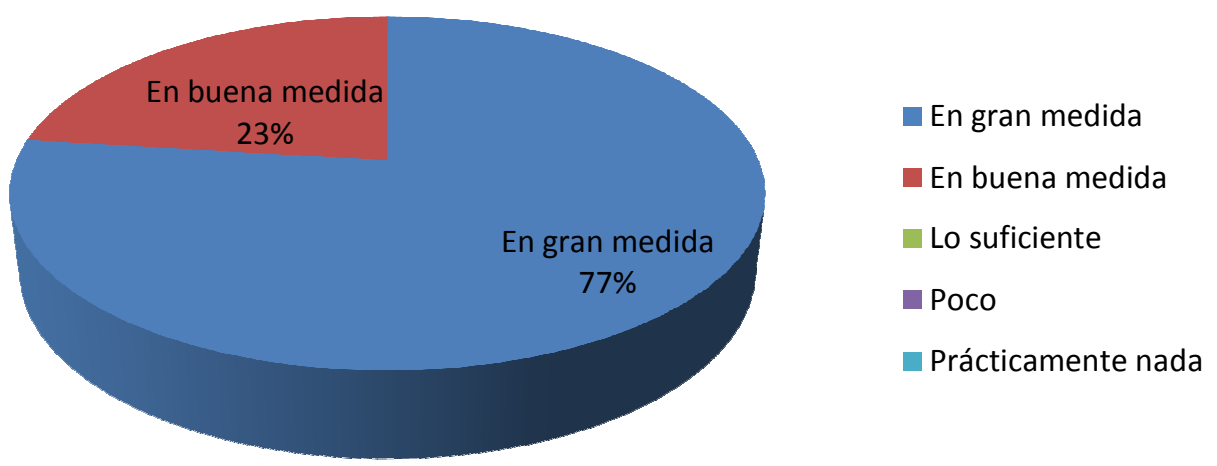

KivaNS en el desarrollo de laboratorios y prácticas

Figura 5-17 E2: Facilita el entendimiento de topologías de red

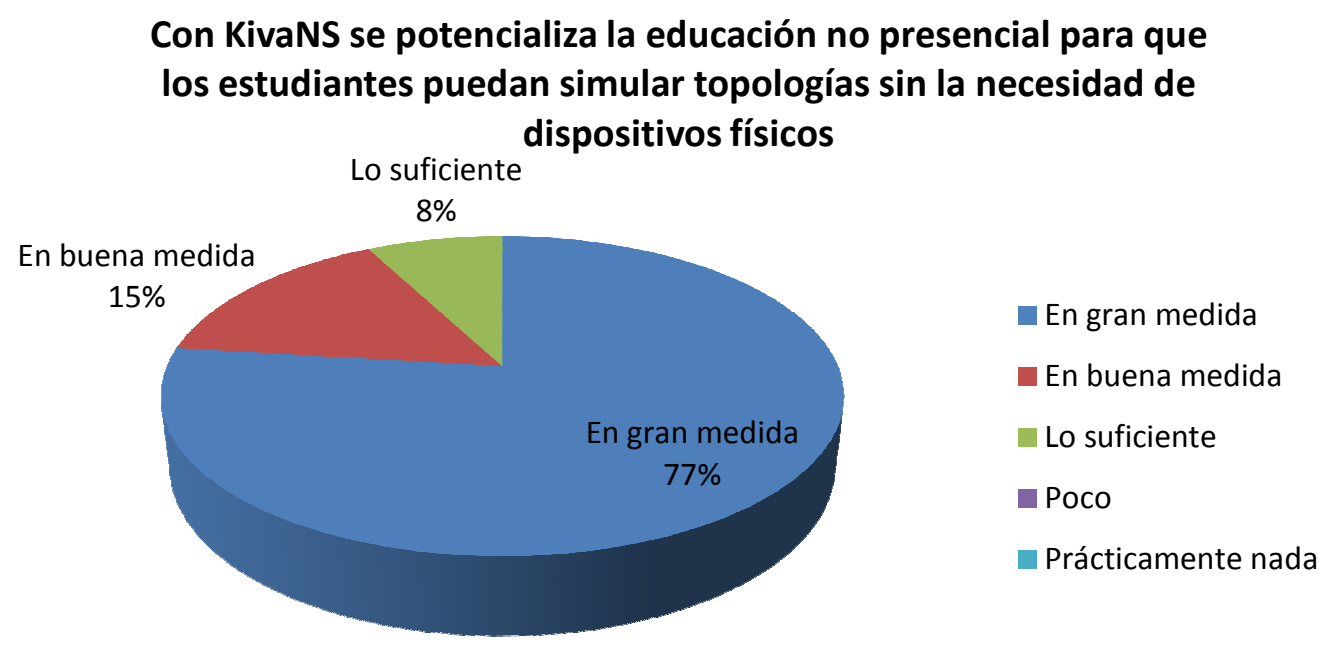

KivaNS en el desarrollo de laboratorios y prácticas

Figura 5-18 E2: KivaNS potencializa la educación no presencial 


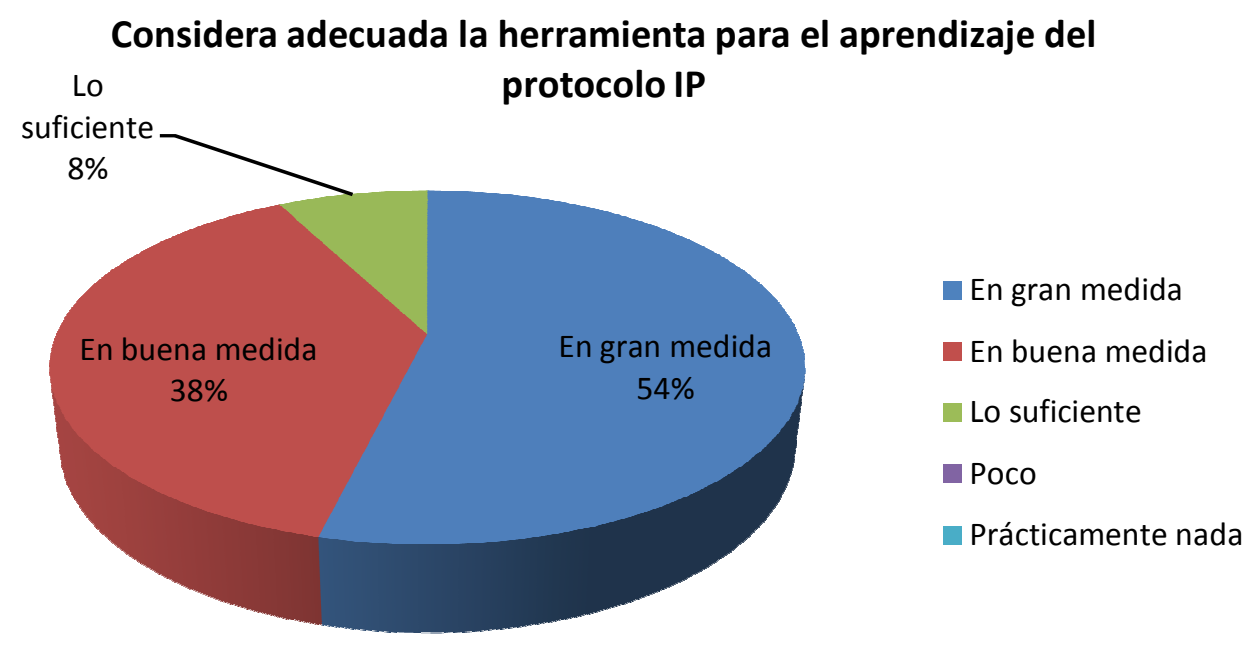

KivaNS en el desarrollo de laboratorios y prácticas

Figura 5-19 E2: Herramienta adecuada para el aprendizaje del protocolo IP

\section{Considera adecuada la herramienta para el aprendizaje del protocolo ARP}

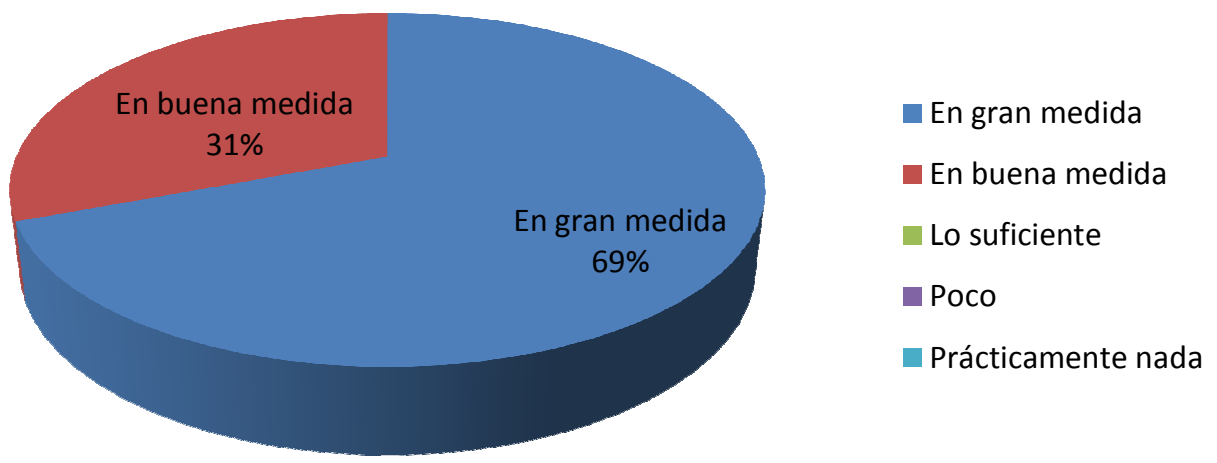

KivaNS en el desarrollo de laboratorios y prácticas

Figura 5-20 E2: Herramienta adecuada para el aprendizaje del protocolo ARP 


\section{Considera adecuada la herramienta para el aprendizaje del protocolo ICMP}

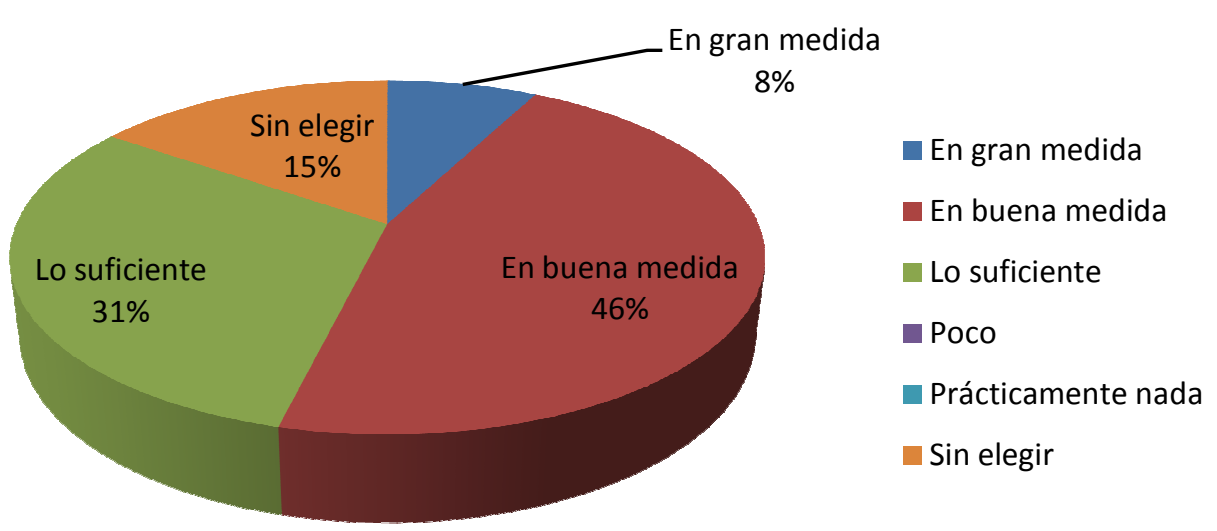

KivaNS en el desarrollo de laboratorios y prácticas

Figura 5-21 E2: Herramienta adecuada para el aprendizaje del protocolo ICMP

\section{Considera adecuada la herramienta para el aprendizaje de Fragmentación IP}

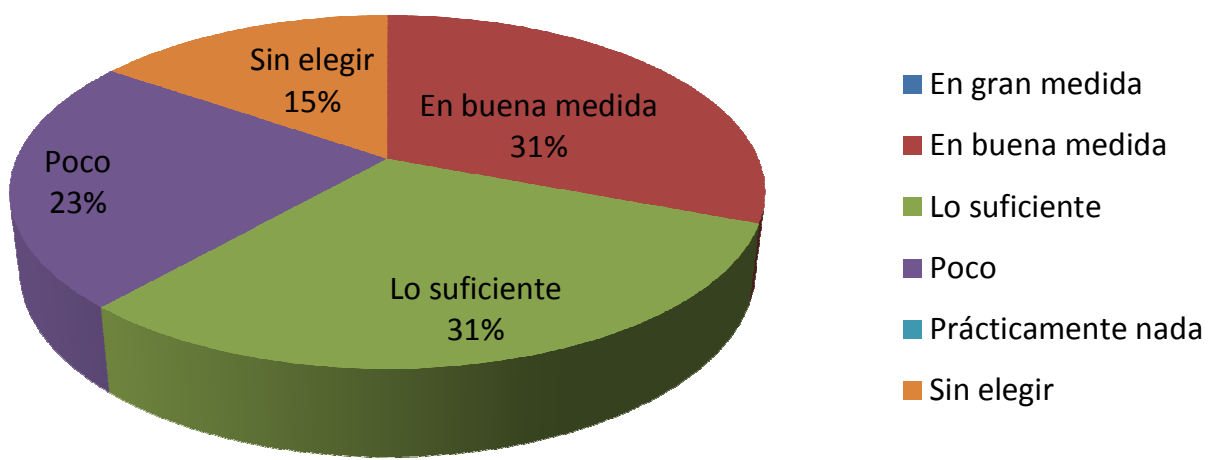

KivaNS en el desarrollo de laboratorios y prácticas

Figura 5-22 E2: Herramienta adecuada para el aprendizaje de fragmentación IP 


\section{Considera adecuada la herramienta para el aprendizaje de Ruteo Estático IP}

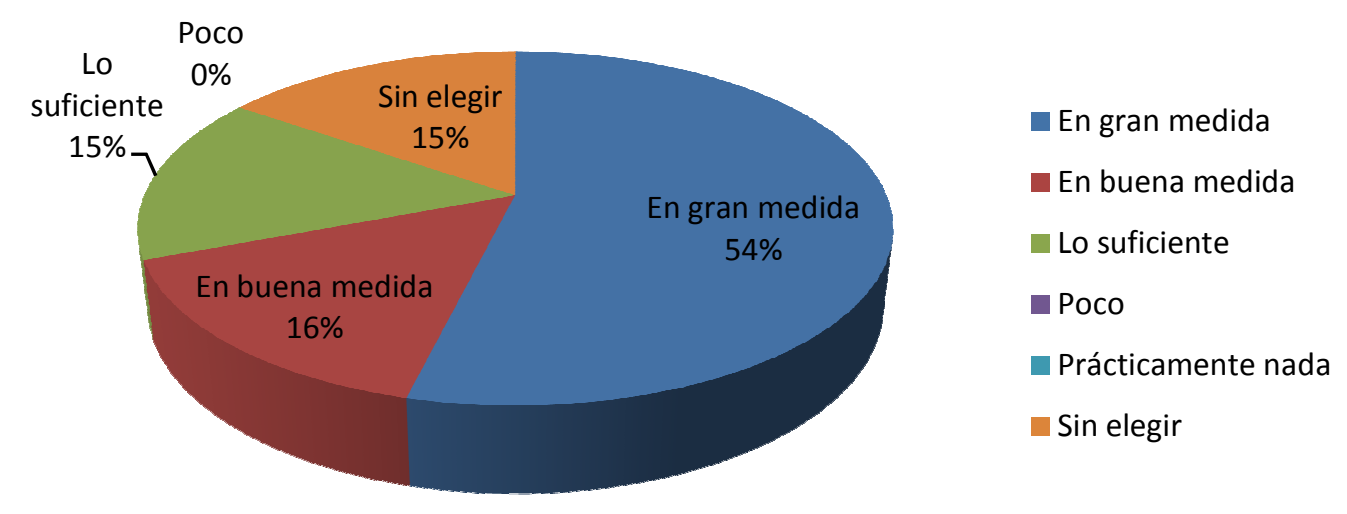

KivaNS en el desarrollo de laboratorios y prácticas

Figura 5-23 E2: Herramienta adecuada para el aprendizaje de ruteo estático IP

\section{Considera adecuados los prácticos propuestos en el taller}

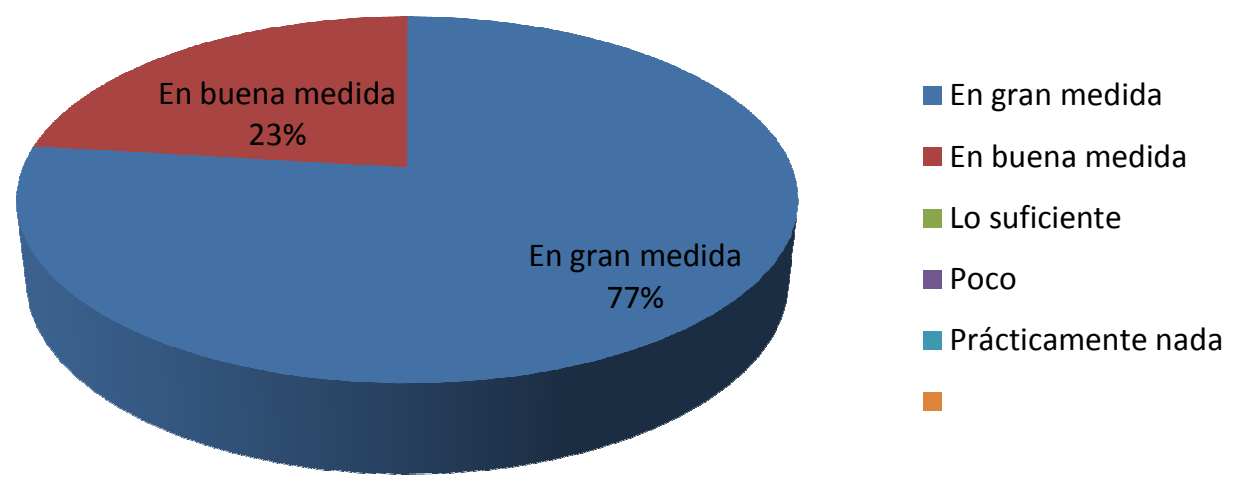

KivaNS en el desarrollo de laboratorios y prácticas

Figura 5-24 E2: Los Prácticos propuestos son adecuados 


\section{Considera adecuado el tiempo asignado para la resolución de los prácticos propuestos en el taller}

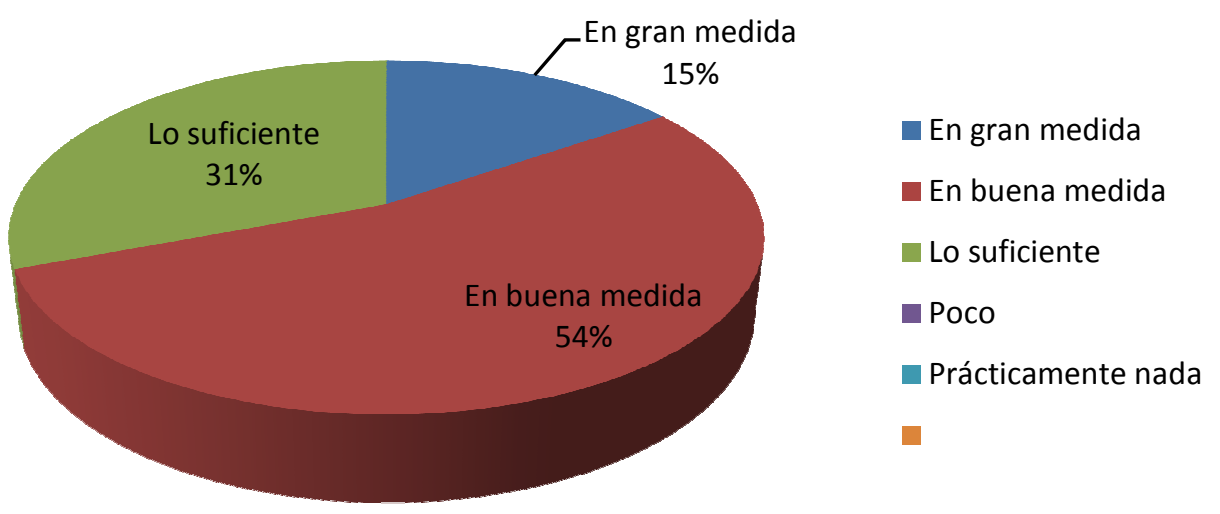

KivaNS en el desarrollo de laboratorios y prácticas

Figura 5-25 E2: Tiempo asignado a la resolución del práctico adecuado 


\section{Análisis del desempeño de los estudiantes}

A continuación se presenta gráficamente el desempeño de los estudiantes en la evaluación del segundo examen parcial de la asignatura Conectividad y Teleinformática.

\section{Ej. 5b del Segundo Parcial de Conectividad y Teleinformática \\ Año 2012}

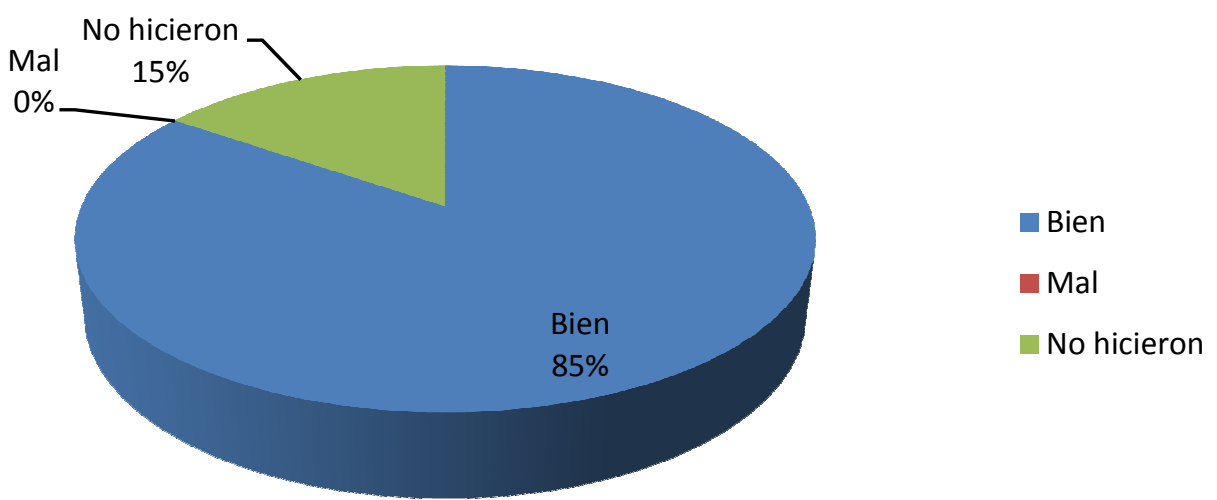

Alumnos que realizaron el Taller de Kiva antes del segundo parcial

Figura 5-26 E2: Evaluación de conceptos (con simulación)

\section{Ej. 5b del Segundo Parcial de Conectividad y Teleinformática}

Año 2012

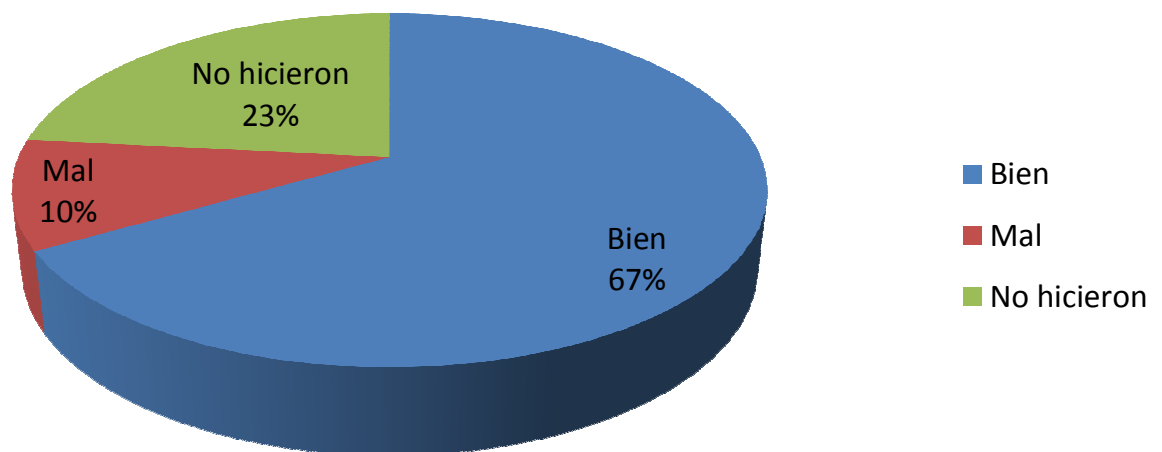

Alumnos que no realizaron el Taller de Kiva antes del segundo parcial

Figura 5-27 E2: Evaluación de conceptos (sin simulación) 


\section{Ej. 5b del Segundo Parcial de Conectividad y Teleinformática}

Año 2012

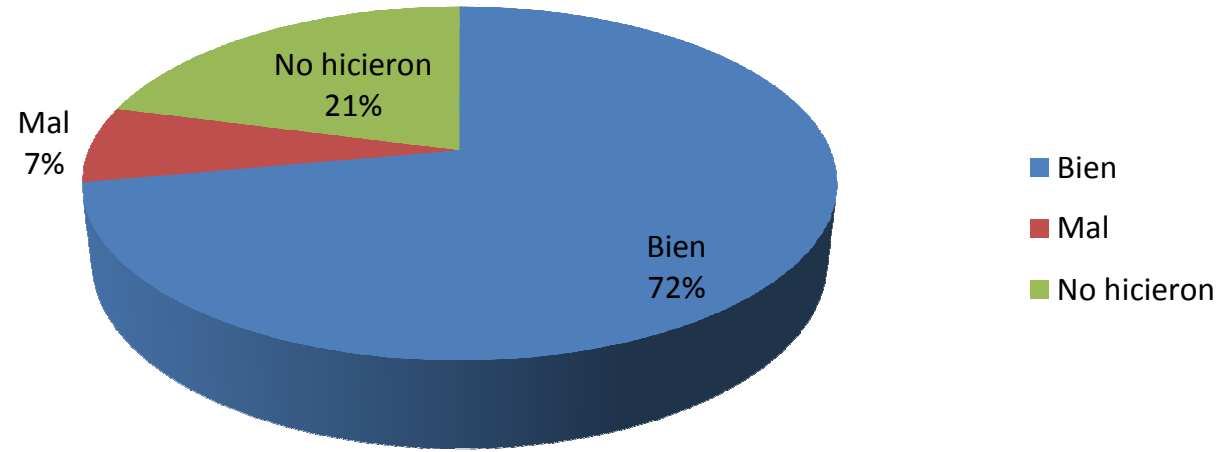

Total de Alumnos de Conectividad y Teleinformática

Figura 5-28 E2: Evaluación de conceptos (total de estudiantes)

\subsubsection{Conclusiones de la experiencia}

De acuerdo a los resultados de las encuestas realizadas para determinar el impacto de la utilización de KivaNS en la asignatura Conectividad y Teleinformática, se concluyó que en términos generales el acercamiento inicial fue considerado por los estudiantes como positivo. En la utilización de KivaNS como simulador de topologías de red, se evidenció que la herramienta fue en gran medida aceptada y apoyó el proceso de enseñanza de redes IP, concretamente el protocolo IP, ARP, subredes y ruteo estático. En menor medida, el protocolo ICMP y la fragmentación IP. Cabe aclarar que la implementación en el simulador Kiva de la fragmentación IP es muy rudimentaria y elemental ya que no intervienen las variables más importantes involucradas en el proceso como son el offset de fragmentación, ni los diferentes flags necesarios para su funcionalidad.

Acerca de KivaNS como herramienta de software, se evidenció que en gran medida se consideró a la interfaz como intuitiva, la simulación fue clara y real, facilitó el seguimiento de los eventos ocurridos en la simulación, la instalación y puesta en funcionamiento fueron sencillas, se contó con ayuda al usuario, la configuración de los dispositivos de red se independizó del fabricante, permitió realizar cambios en una topología fácilmente y cambios en dispositivos de manera efectiva.

Además, se pudo observar que, si bien los prácticos fueron considerados adecuados en gran medida por los estudiantes, no fue así con el tiempo asignado para su resolución.

Respecto de la evaluación de conceptos, las pruebas paramétricas permitieron concluir que, existió diferencia estadísticamente significativa a favor de los estudiantes que emplearon una estrategia basada en simulación.

Del análisis realizado a los resultados de la evaluación del segundo parcial de la asignatura, Figuras 5-26 y 5-27, se pudo observar que el $85 \%$ de los estudiantes que realizaron el taller aprobaron el examen, mientras que de los alumnos que no lo realizaron, aprobó el $67 \%$. 


\subsection{Experiencia $\mathrm{N}^{0}$ 3: Simulador Packet Tracer en Redes de Computadoras I}

Esta experiencia se realizó con un grupo de estudiantes que se encontraban cursando la asignatura Redes de Computadoras I del nuevo Plan de Licenciatura en Análisis de Sistemas - Plan LAS 2010 durante el primer semestre del año 2013. El taller se realizó paralelamente al cursado de la asignatura, lo que permitió evaluar la utilización del simulador Packet Tracer como herramienta de software y su funcionalidad con los diferentes protocolos de Capa de Aplicación correspondiente al Capítulo 2 del programa de la asignatura, además de evaluar la herramienta para acompañar el tema introductorio de redes y fundamentos del Capítulo 1 del programa de la asignatura.

La asignatura Redes de Computadoras I comienza con una introducción a las redes para luego adentrarse en las Capa de Aplicación, Capa de Transporte y Capa de Red del modelo TCP/IP.

El primer objetivo planteado para el desarrollo de la práctica con simulación, fue muy ambicioso, ya que se desarrollaron guías de trabajos prácticos guiadas y resueltas, para los temas introductorios de fundamentos y para cada uno de los protocolos tratados en la Capa de Aplicación, de manera de acompañar casi la mitad del cursado de la asignatura, con el uso del simulador.

La experiencia se llevó a cabo durante dos meses, cada clase teórica fue acompañada con su correspondiente clase práctica tradicional y además con la clase práctica sobre el simulador. Las clases teóricas y prácticas impartidas en el cursado de la asignatura facilitaron la realización del taller permitiendo al equipo docente, concentrarse en la presentación de la herramienta y su utilización.

Al finalizar cada tema se realizó una encuesta, en primera instancia se evaluó al simulador Packet Tracer como herramienta de software, luego se evaluó al simulador Packet Trace y los Fundamentos de Redes, y finalmente Packet Tracer y la Capa de Aplicación.

El objetivo de estas encuestas fue analizar el impacto del uso de la herramienta por los estudiantes, asociado a los diferentes temas y protocolos tratados.

\subsubsection{Análisis estadísticos de los datos}

\section{Primera parte de la encuesta: Packet Tracer como Herramienta}

Para este análisis la media aritmética supera, en todos los casos, al menos el valor medio de la escala (3.00), lo que confirma la validez del contenido de todos los ítems incluidos.

Como puede observarse en la Tabla 5-9, el coeficiente Alfa de Cronbach calculado es de 0,826 que supera el valor de 0,7 (George y Mallery, 2003), lo que permite afirmar el grado de fiabilidad del cuestionario. Por lo tanto, se aprecia una alta polarización de respuestas confiables por parte de los estudiantes. 
Estudio de la influencia de un entorno de simulación en la enseñanza de redes de computadoras en el nivel universitario

\begin{tabular}{|r|r|r|}
\hline \multicolumn{1}{|c|}{$\begin{array}{c}\text { Alfa de } \\
\text { Cronbach }\end{array}$} & $\begin{array}{c}\text { Alfa de } \\
\text { Cronbach } \\
\text { basada en los } \\
\text { elementos } \\
\text { tipificados }\end{array}$ & \\
\hline 0,842 & 0,826 & \\
\hline
\end{tabular}

Tabla 5-9 E3-P1: Estadísticos de fiabilidad

\begin{tabular}{|l|r|r|r|}
\hline & Media & $\begin{array}{c}\text { Desviación } \\
\text { típica }\end{array}$ & $\mathrm{N}$ \\
\hline VAR00001 & 4,8000 & 0,44721 & 5 \\
VAR00002 & 3,8000 & 1,09545 & 5 \\
VAR00003 & 3,8000 & 0,83666 & 5 \\
VAR00004 & 4,2000 & 0,44721 & 5 \\
VAR00005 & 4,2000 & 0,44721 & 5 \\
VAR00006 & 4,2000 & 0,83666 & 5 \\
VAR00007 & 3,6000 & 2,07364 & 5 \\
VAR00008 & 3,8000 & 0,83666 & 5 \\
VAR00009 & 4,2000 & 1,09545 & 5 \\
VAR00010 & 4,0000 & 0,70711 & 5 \\
VAR00011 & 4,8000 & 0,44721 & 5 \\
VAR00012 & 4,2000 & 0,83666 & 5 \\
\hline
\end{tabular}

Tabla 5-10 E3-P1: Estadísticos de los elementos

\begin{tabular}{|l|r|r|r|r|r|r|r|}
\hline & Media & Mínimo & Máximo & Rango & $\begin{array}{c}\text { Máximo/míni } \\
\text { mo }\end{array}$ & $\begin{array}{c}\text { Varianz } \\
\text { a }\end{array}$ & $\begin{array}{c}\text { N de } \\
\text { elementos }\end{array}$ \\
\hline $\begin{array}{l}\text { Medias de los } \\
\text { elementos }\end{array}$ & 4,133 & 3,600 & 4,800 & 1,200 & 1,333 & 0,141 & 12 \\
\hline
\end{tabular}

Tabla 5-11 E3-P1: Estadísticos de resumen de los elementos

\begin{tabular}{|r|r|r|r|}
\hline Media & Varianza & $\begin{array}{c}\text { Desviación } \\
\text { típica }\end{array}$ & N de elementos \\
\hline 49,6000 & 47,300 & 6,87750 & 12 \\
\hline
\end{tabular}

Tabla 5-12 E3-P1: Estadísticos de la escala 


\section{Segunda parte de la encuesta: Packet Tracer y los Fundamentos de Redes}

Para este análisis la media aritmética supera, en todos los casos, al menos el valor medio de la escala (3.00), lo que confirma la validez del contenido de todos los ítems incluidos.

Como puede observarse en la Tabla 5-13, el coeficiente Alfa de Cronbach calculado es de 0,727 que supera el valor de 0,7 (George y Mallery, 2003), lo que permite afirmar el grado de fiabilidad del cuestionario. Por lo tanto, se aprecia una polarización de respuestas confiables por parte de los estudiantes.

\begin{tabular}{|r|c|c|}
\hline \multicolumn{1}{|c|}{$\begin{array}{c}\text { Alfa de } \\
\text { Cronbach }\end{array}$} & $\begin{array}{c}\text { Alfa de } \\
\text { Cronbach } \\
\text { basada en los } \\
\text { elementos } \\
\text { tipificados }\end{array}$ & \\
\hline 0,772 & 0,727 & \\
\hline
\end{tabular}

Tabla 5-13 E3-P2: Estadísticos de fiabilidad

\begin{tabular}{|l|r|r|r|}
\hline & Media & \multicolumn{1}{|c|}{$\begin{array}{c}\text { Desviación } \\
\text { típica }\end{array}$} & $\mathrm{N}$ \\
\hline VAR00001 & 4,6000 & 0,54772 & 5 \\
VAR00002 & 4,2000 & 0,83666 & 5 \\
VAR00003 & 4,2000 & 0,83666 & 5 \\
VAR00004 & 4,2000 & 0,83666 & 5 \\
\hline
\end{tabular}

Tabla 5-14 E3-P2: Estadísticos de los elementos

\begin{tabular}{|l|r|r|r|r|r|r|r|}
\hline & Media & Mínimo & Máximo & Rango & $\begin{array}{c}\text { Máximo/ } \\
\text { mínimo }\end{array}$ & Varianza & $\begin{array}{c}\mathrm{N} \text { de } \\
\text { elementos }\end{array}$ \\
\hline $\begin{array}{l}\text { Medias de los } \\
\text { elementos }\end{array}$ & 4,300 & 4,200 & 4,600 & 0,400 & 1,095 & 0,040 & 4 \\
\hline
\end{tabular}

Tabla 5-15 E3-P2: Estadísticos resumen de los elementos

\begin{tabular}{|r|r|r|r|}
\hline Media & Varianza & $\begin{array}{c}\text { Desviación } \\
\text { típica }\end{array}$ & N de elementos \\
\hline 17,2000 & 5,700 & 2,38747 & 4 \\
\hline
\end{tabular}

Tabla 5-16 E3-P2: Estadísticos de la escala 


\section{Tercera parte de la encuesta: Packet Tracer y la Capa de Aplicación}

Para este análisis la media aritmética supera, en todos los casos, al menos el valor medio de la escala (3.00), lo que confirma la validez del contenido de todos los ítems incluidos.

Como puede observarse en la Tabla 5-17, el coeficiente Alfa de Cronbach calculado es de 0,881 que supera el valor de 0,7 (George y Mallery, 2003), lo que permite afirmar el grado de fiabilidad del cuestionario. Por lo tanto, se aprecia una alta polarización de respuestas confiables por parte de los estudiantes.

\begin{tabular}{|r|r|r|}
\hline \multicolumn{1}{|c|}{$\begin{array}{c}\text { Alfa de } \\
\text { Cronbach }\end{array}$} & $\begin{array}{c}\text { Alfa de } \\
\text { Cronbach } \\
\text { basada en los } \\
\text { elementos } \\
\text { tipificados }\end{array}$ & \\
\hline 0,836 & 0,881 & \\
\hline
\end{tabular}

Tabla 5-17 E3-P3: Estadísticos de fiabilidad

\begin{tabular}{|l|r|r|r|}
\hline & Media & \multicolumn{1}{c|}{$\begin{array}{c}\text { Desviación } \\
\text { típica }\end{array}$} & $\mathrm{N}$ \\
\hline VAR00001 & 4,0000 & 0,70711 & 5 \\
VAR00002 & 4,4000 & 0,54772 & 5 \\
VAR00003 & 4,0000 & 1,00000 & 5 \\
VAR00004 & 4,6000 & 0,54772 & 5 \\
VAR00005 & 4,0000 & 1,00000 & 5 \\
VAR00006 & 3,8000 & 1,64317 & 5 \\
VAR00007 & 4,4000 & 0,89443 & 5 \\
VAR00008 & 4,8000 & 0,44721 & 5 \\
VAR00009 & 4,2000 & 0,83666 & 5 \\
VAR00010 & 3,0000 & 1,87083 & 5 \\
VAR00011 & 3,2000 & 1,92354 & 5 \\
VAR00012 & 3,4000 & 2,07364 & 5 \\
VAR00013 & 3,4000 & 2,07364 & 5 \\
\hline
\end{tabular}

Tabla 5-18 E3-P3: Estadísticos de los elementos 
Estudio de la influencia de un entorno de simulación en la enseñanza de redes de computadoras en el nivel universitario

\begin{tabular}{|l|r|r|r|r|r|r|r|}
\hline & Media & Mínimo & Máximo & Rango & $\begin{array}{c}\text { Máximo/ } \\
\text { mínimo }\end{array}$ & Varianza & $\begin{array}{c}\mathrm{N} \text { de } \\
\text { elementos }\end{array}$ \\
\hline $\begin{array}{l}\text { Medias de los } \\
\text { elementos }\end{array}$ & 3,938 & 3,000 & 4,800 & 1,800 & 1,600 & 0,309 & 13 \\
\hline
\end{tabular}

Tabla 5-19 E3-P3: Estadísticos de resumen de los elementos

\begin{tabular}{|c|r|c|r|}
\hline Media & Varianza & $\begin{array}{c}\text { Desviación } \\
\text { típica }\end{array}$ & N de elementos \\
\hline 51,2000 & 102,200 & 10,10940 & 13 \\
\hline
\end{tabular}

Tabla 5-20 E3-P3: Estadísticos de la escala

\section{Gráficos descriptivos}

A continuación se presentan gráficamente las respuestas de los estudiantes, para cada una de las preguntas del cuestionario realizado en sus tres apartados.

\section{El simulador Packet Tracer como herramienta de software}

\section{La instalación y puesta en funcionamiento de la herramienta es sencilla}

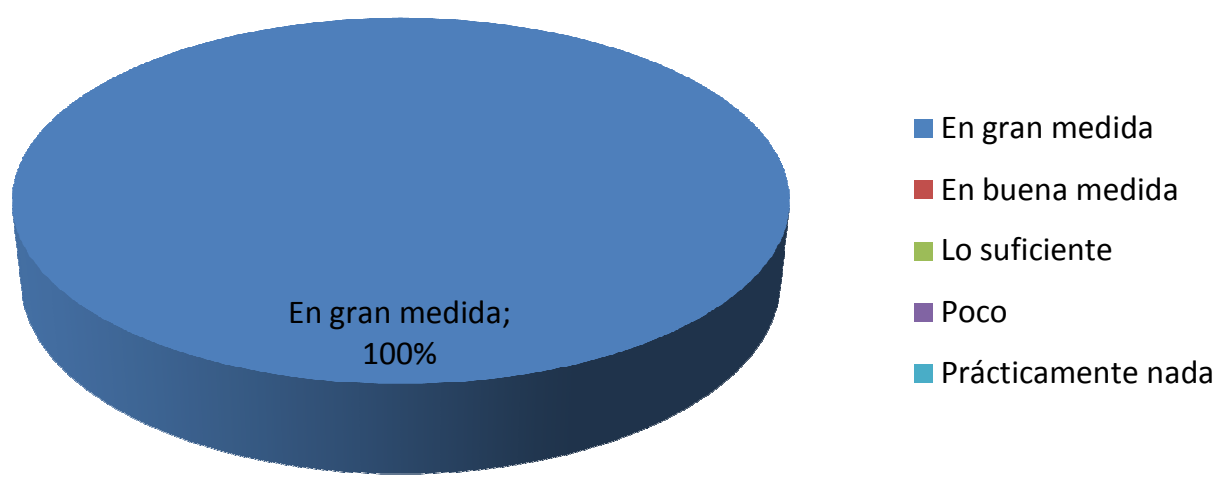

Packet Tracer como herramienta de software

Figura 5-29 E3: La instalación de la herramienta es sencilla 


\section{La configuración de la interfaz en idioma español es sencilla}

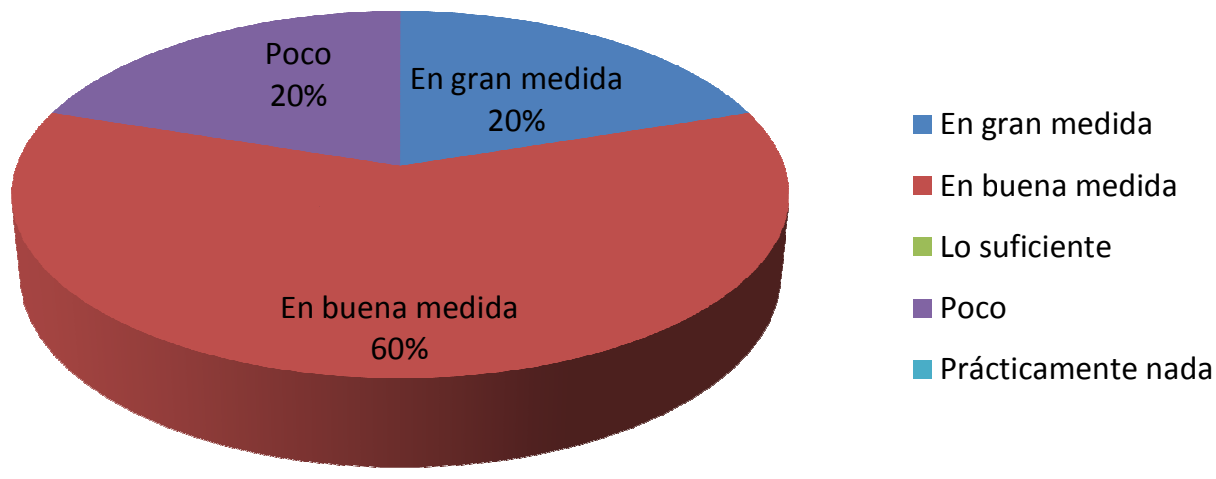

Packet Tracer como herramienta de software

Figura 5-30 E3: La configuración de la interfaz en español es sencilla

\section{La interfaz gráfica que ofrece la aplicación es amigable e intuitiva}

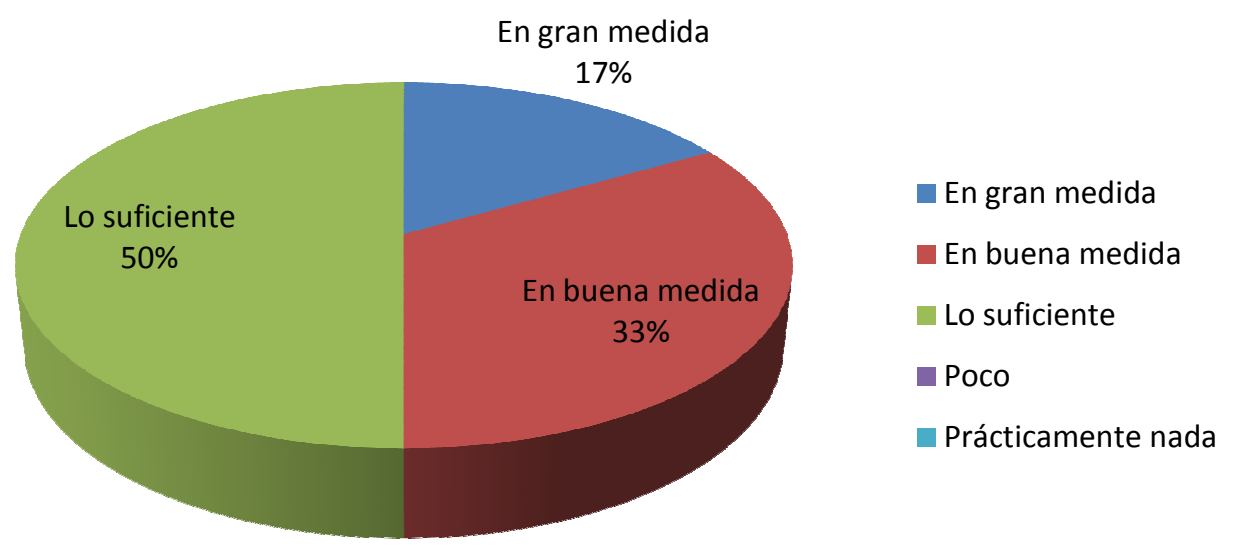

Packet Tracer como herramienta de software

Figura 5-31 E3: La interfaz es intuitiva 


\section{La aplicación posee los componentes necesarios para realizar un laboratorio de redes IP}

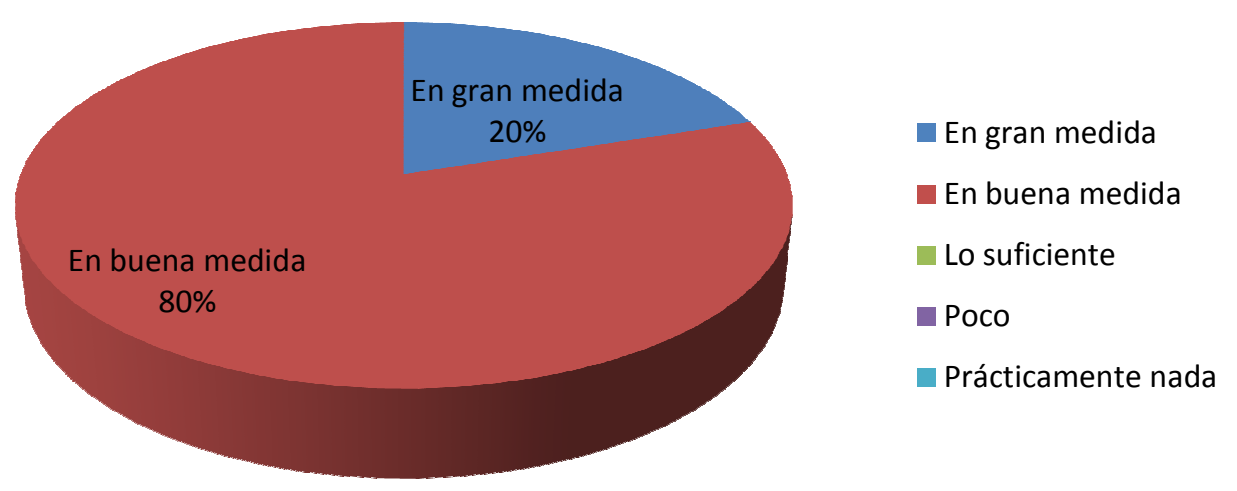

Packet Tracer como herramienta de software

Figura 5-32 E3: Posee componentes necesarios para un laboratorio IP

\section{La herramienta ofrece disponibilidad que garantice la realización de los laboratorios sin interrupciones}

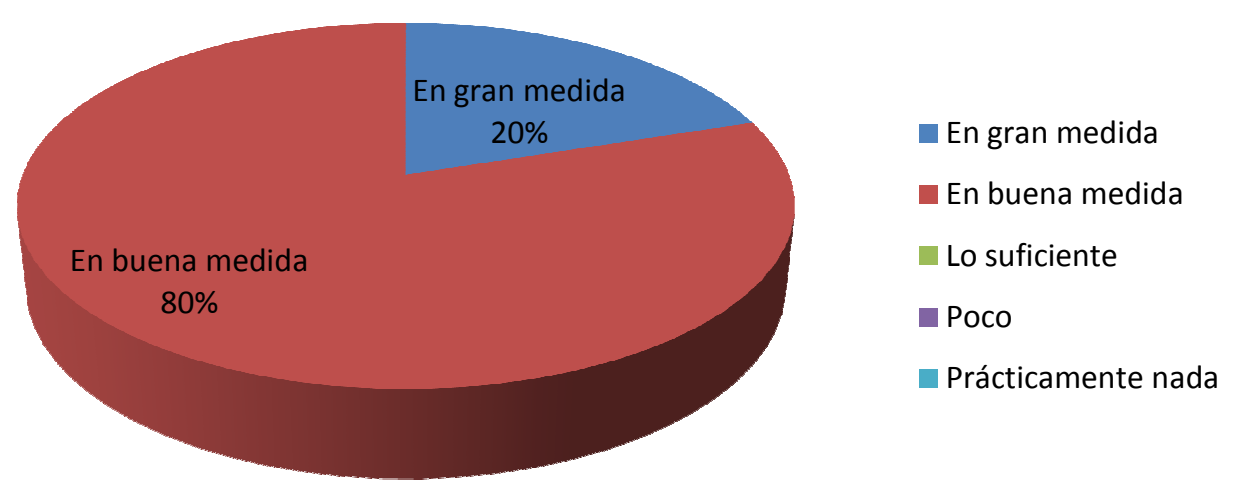

Packet Tracer como herramienta de software

Figura 5-33 E3: Disponibilidad para la realización de laboratorios 


\section{Se cuenta con ayuda que permita resolver dudas sobre el uso de la herramienta}

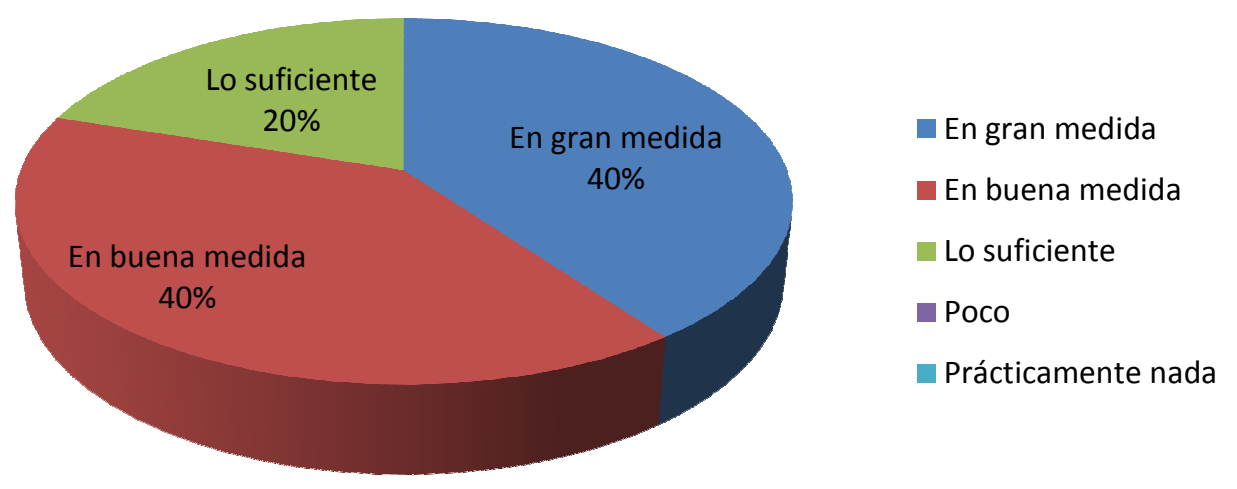

Packet Tracer como herramienta de software

Figura 5-34 E3: La herramienta ofrece ayuda sobre su uso

\section{La herramienta permite realizar simulaciones claras y reales}

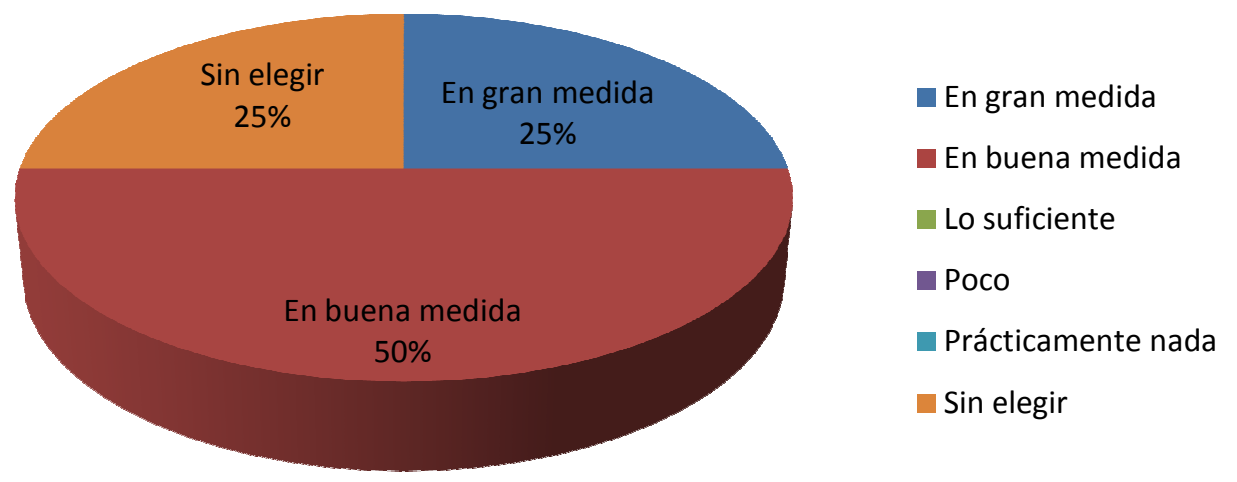

Packet Tracer como herramienta de software

Figura 5-35 E3: Permite simulaciones claras 


\section{Con esta herramienta, la configuración de los dispositivos se desentiende de una marca particular, concentrándose en el concepto teórico}

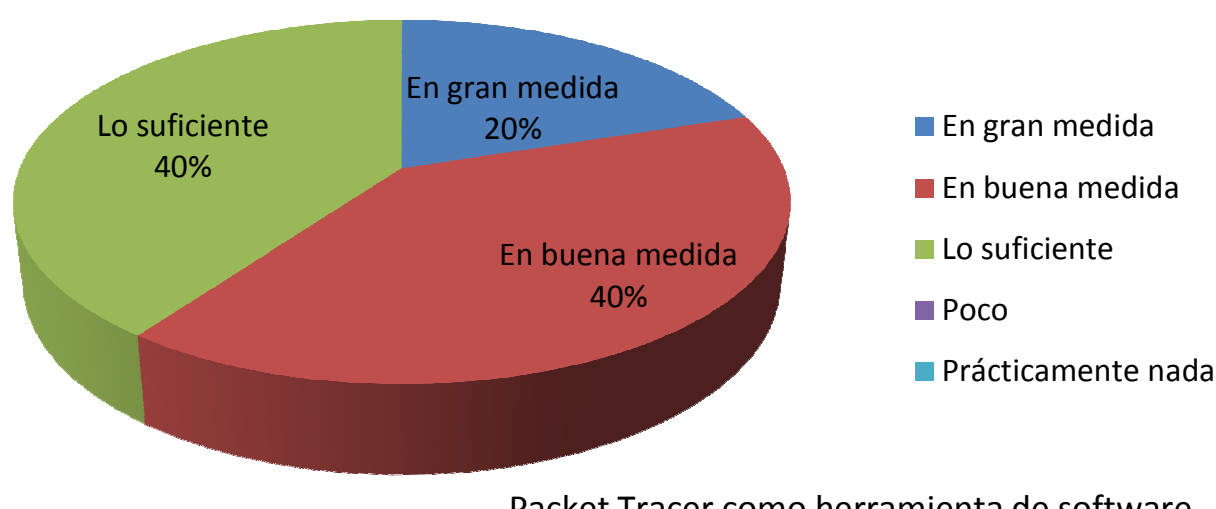

Figura 5-36 E3: La configuración de dispositivos es independiente del fabricante

\section{Permite realizar cambios en la topología fácilmente para adecuarla a las necesidades}

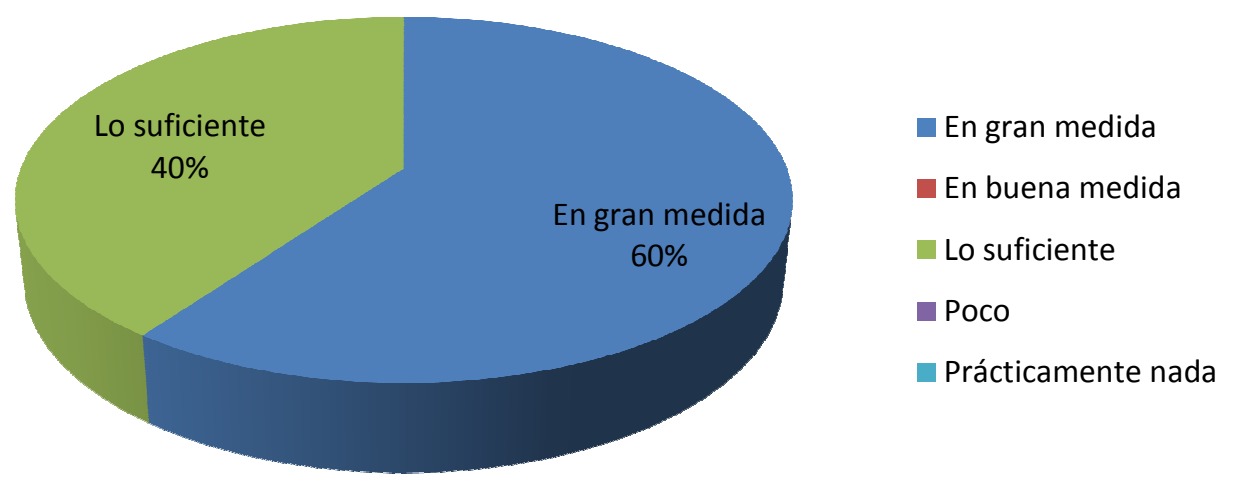

Packet Tracer como herramienta de software

Figura 5-37 E3: Permite realizar cambios en la topología 


\section{Permite simular cambios en dispositivos de manera efectiva en una determinada topología}

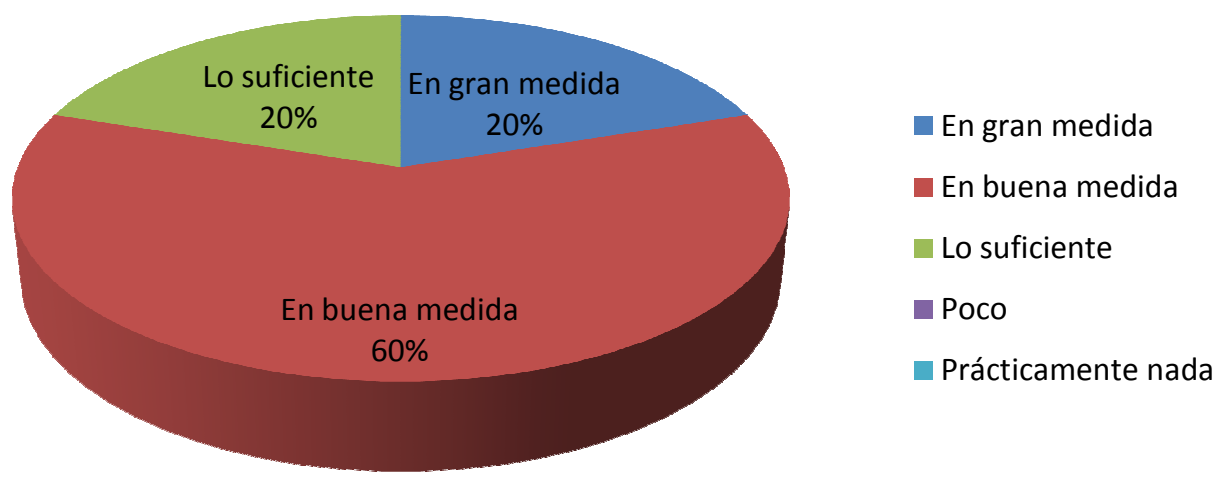

Packet Tracer como herramienta de software

Figura 5-38 E3: Permite simular cambios en dispositivos

\section{La herramienta facilita el seguimiento de los eventos ocurridos en cada uno de los dispositivos dentro de la red}

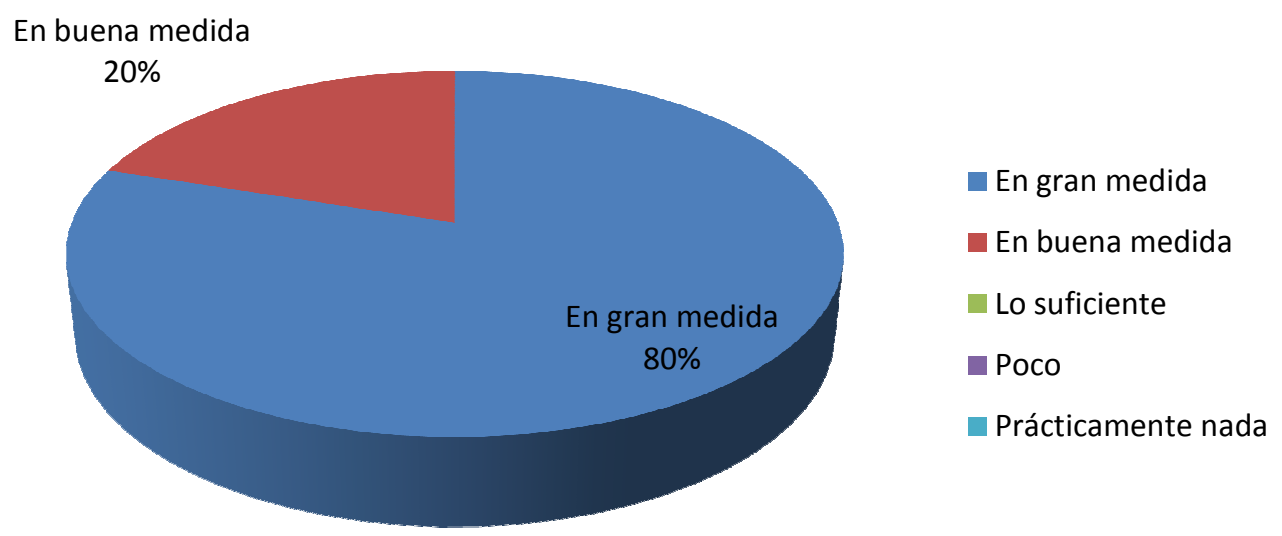

Packet Tracer como herramienta de software

Figura 5-39 E3: Facilita el seguimiento de los eventos 


\section{Con PT se potencializa la educación no presencial}

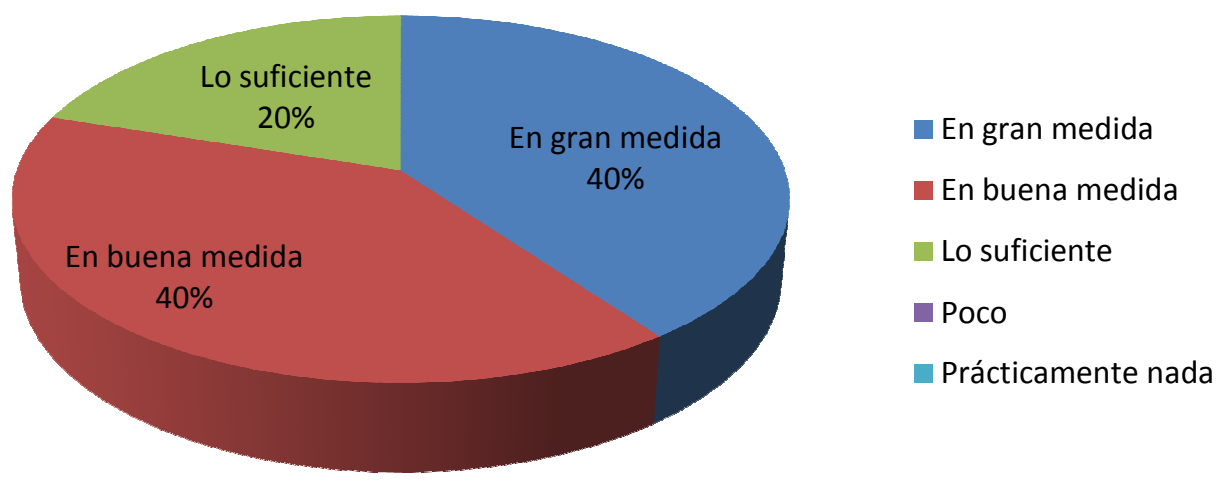

Packet Tracer como herramienta de software

Figura 5-40 E3: Con Packet Tracer se potencializa la educación no presencial

A continuación se enumeran textualmente algunas opiniones sobre la experiencia de los estudiantes.

\section{Comentarios adicionales de los estudiantes}

- Me gusto la herramienta para ver cómo funcionan los distintos dispositivos y como es la parte de simulación es muy sencillo de manejar PT como para llevarlo a una situación real, pero me hubiese gustado ver con más detalle para qué sirven los distintos componentes de la herramienta y cómo funcionan.

- Se cuenta con ayuda que permita resolver dudas sobre el uso de la herramienta.

- Sobre este punto quiero destacar algo de PT que está muy bueno, si en el PT nos vamos a la opción ayuda y de ahí a tutoriales se encuentra cosas muy buenas para aprender a usar la herramienta. Explicaciones fáciles y muy entendibles que hasta incluyen videos explicativos, la verdad muy bueno.

- Algo que me paso en una netbook con Ubuntu 13.04. Cuando pongo el modo simulación se me cubre más de la mitad de la pantalla con las opciones propias de la simulación, dificultando visualizar la simulación. Y no me permite desplegar la ventana hacia los lados para ver justamente la simulación. Esto no me ocurrió con W7. 


\section{EI simulador Packet Tracer y los Fundamentos de Redes}

El simulador PT es adecuado para el estudio y análisis de los diferentes conceptos y fundamentos en una introducción a las redes

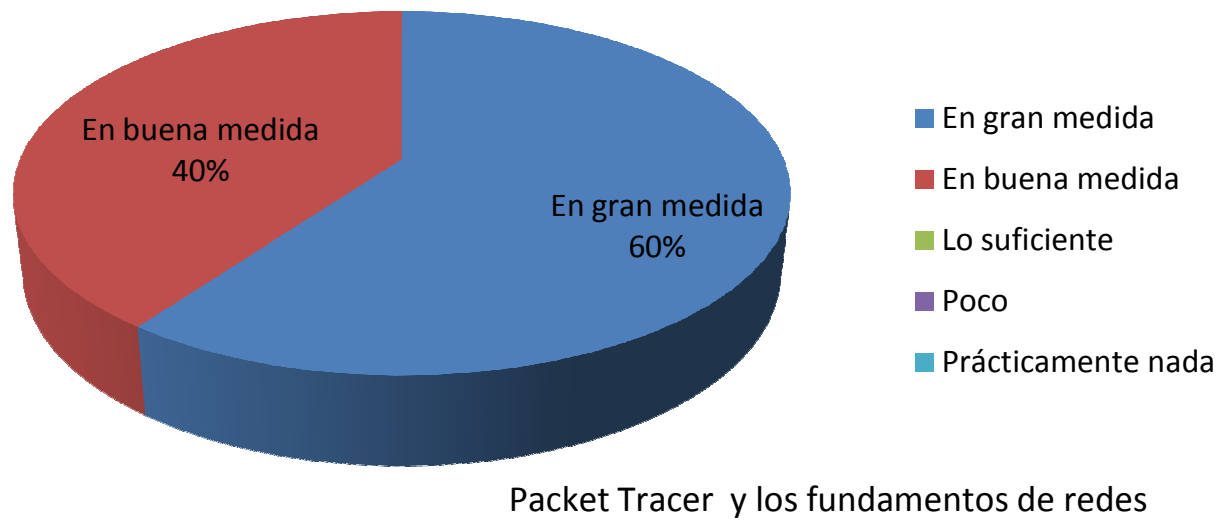

Figura 5-41 E3: PT es adecuado para el estudio de fundamentos de redes

\section{Considera adecuado el Práctico № 1 para comprender una mínima red hogareña}

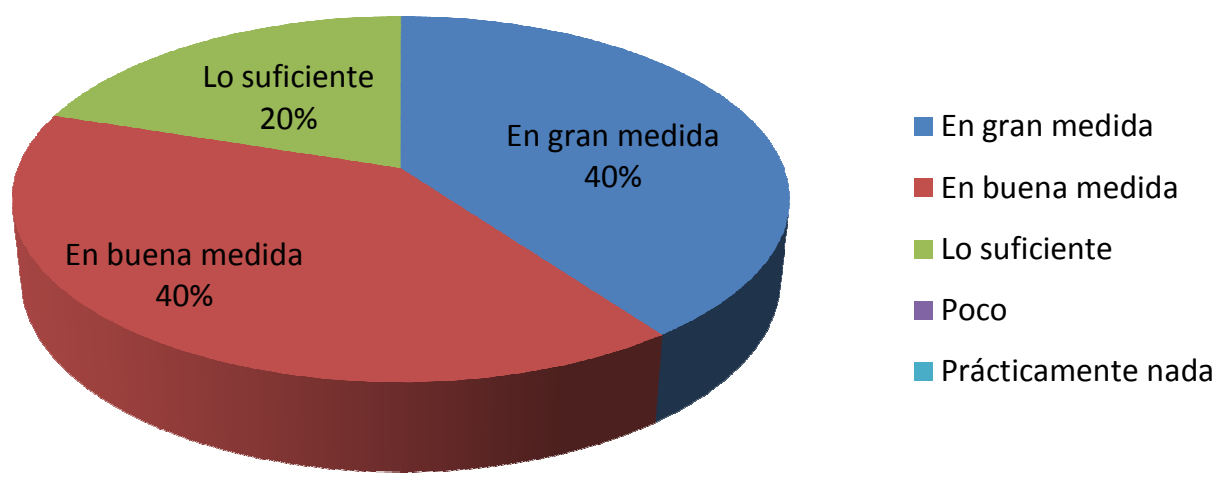

Packet Tracer y los fundamentos de redes

Figura 5-42 E3: E1 Práctico 1 es adecuado 


\section{Considera adecuado el Práctico № 2 para comprender los distintos componentes de una red empresarial compleja}

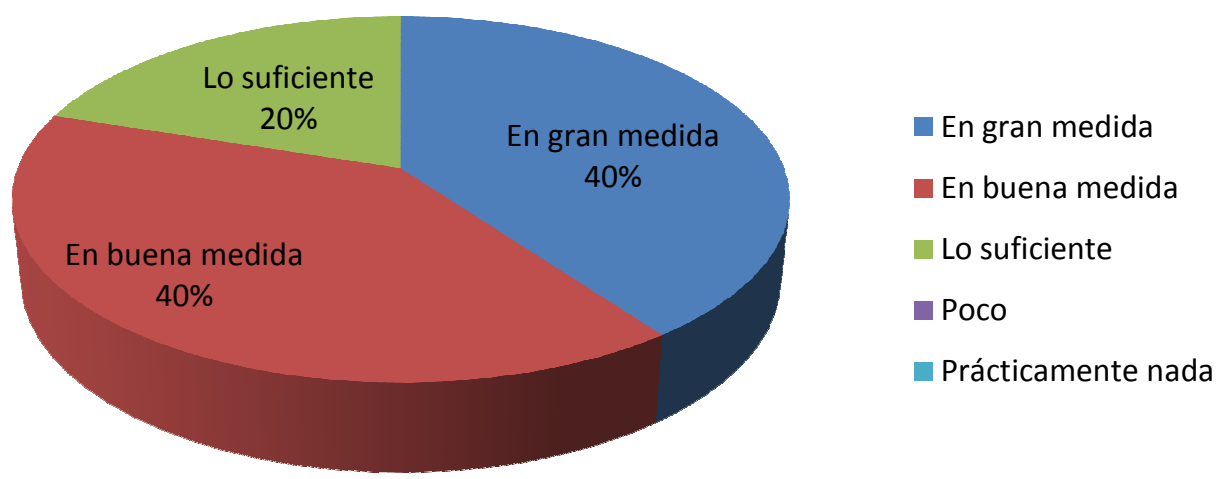

Packet Tracer y los fundamentos de redes

Figura 5-43 E3: E1 Práctico 2 es adecuado

\section{Considera adecuado el Práctico № 3 para comprender una red hogareña que comparte Internet}

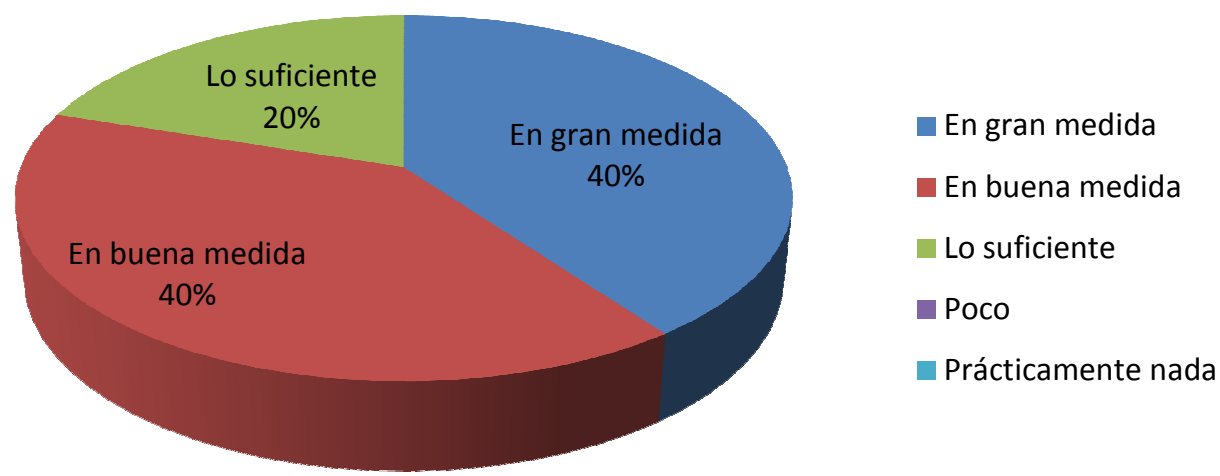

Packet Tracer y los fundamentos de redes

Figura 5-44 E3: E1 Práctico 3 es adecuado

A continuación se enumeran textualmente algunas opiniones sobre la experiencia de los estudiantes. 


\section{Comentarios adicionales de los estudiantes}

- La guía para hacer los prácticos me resultó muy sencilla y no tuve muchas complicaciones para hacerlos, aclaro que si hice una mala conexión con algún cable o puerto me sirvió para darme cuenta que tipo de conexiones se deben y no se deben hacer.

- $\quad$ Algo que no vi (no use), y no sé si lo tiene o no es: algo que me permita visualizar la fragmentación IP.

- Me refiero a dada una topología con determinados MTU y un cierto datagrama IP ver como se fragmenta el datagrama original, los fragmentos que se generan incluyendo su desplazamiento e ID.

- Los primeros trabajos prácticos fueron (salvo por el 2), para mi punto de vista, muy sencillos y sin cosas nuevas que aprender ya que prácticamente todos conocemos esas conexiones (están presentes en la mayoría de los hogares). De todos modos, los considero como una buena introducción para la herramienta PT.

\section{Packet Tracer y la Capa de Aplicación}

\section{El simulador PT es adecuado para el estudio y análisis de los diferentes protocolos de Capa de Aplicación en general}

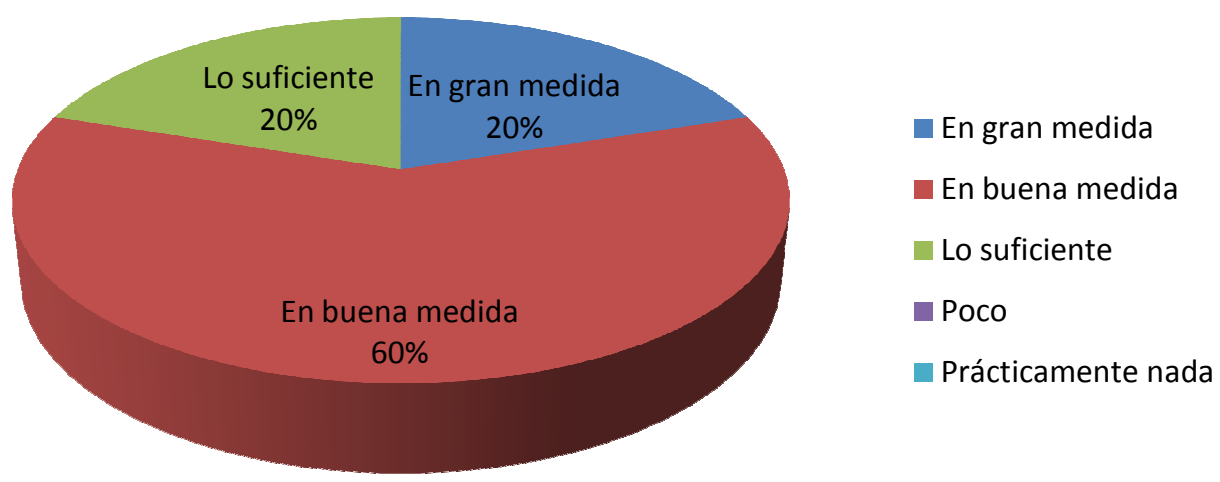

Packet Tracer y la capa de aplicación

Figura 5-45 E3: PT es adecuado para el estudio de protocolos de aplicación 


\section{Considera adecuado el simulador PT para el estudio y análisis del Protocolo HTTP}

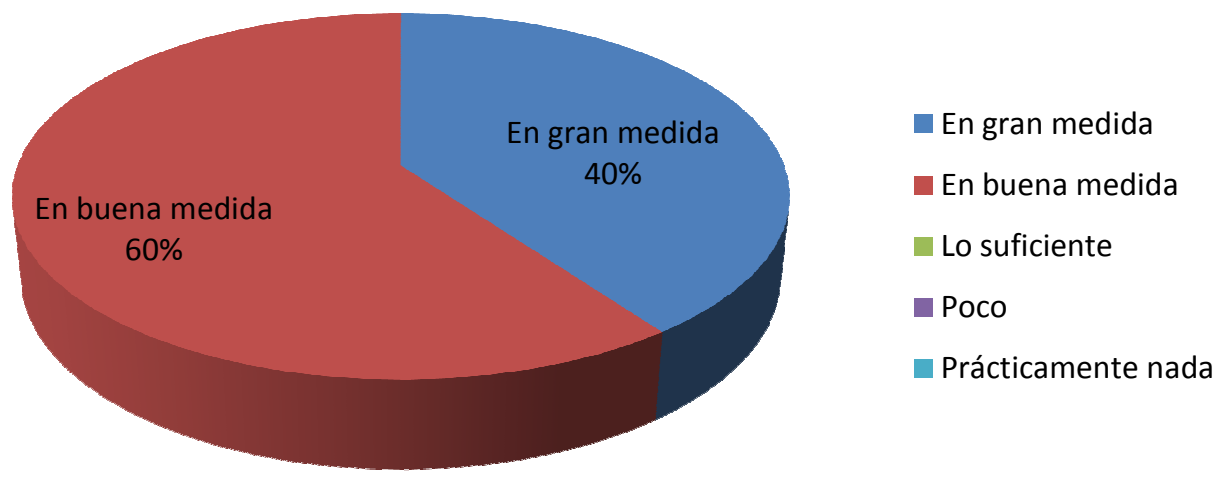

Packet Tracer y la capa de aplicación

Figura 5-46 E3: PT es adecuado para el estudio del protocolo HTTP

\section{Considera adecuado el Práctico sobre el Protocolo HTTP}

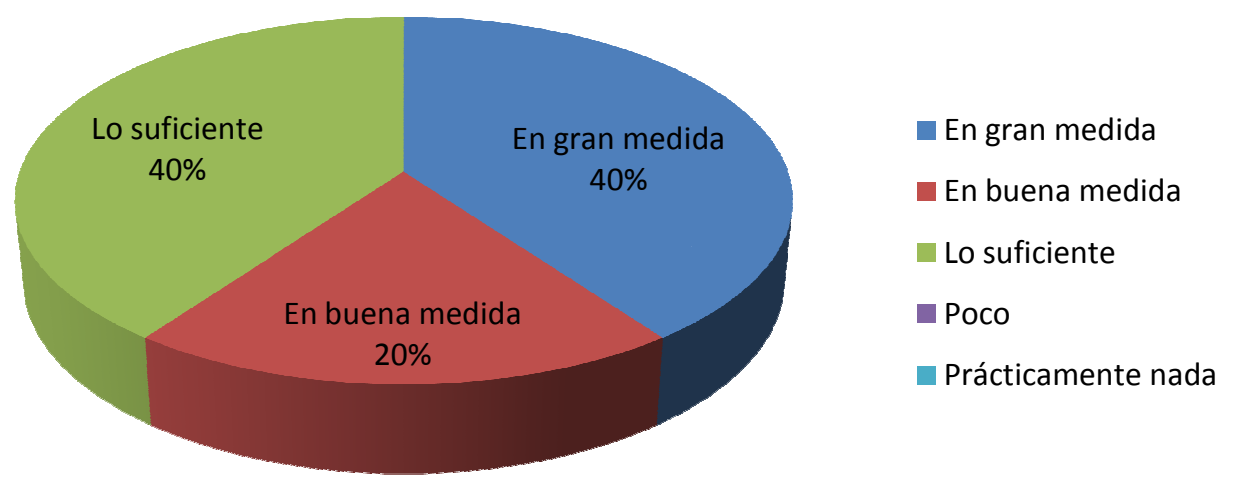

Packet Tracer y la capa de aplicación

Figura 5-47 E3: El Práctico sobre HTTP es adecuado 


\section{Considera adecuado el simulador PT para el estudio y análisis del Protocolo FTP}

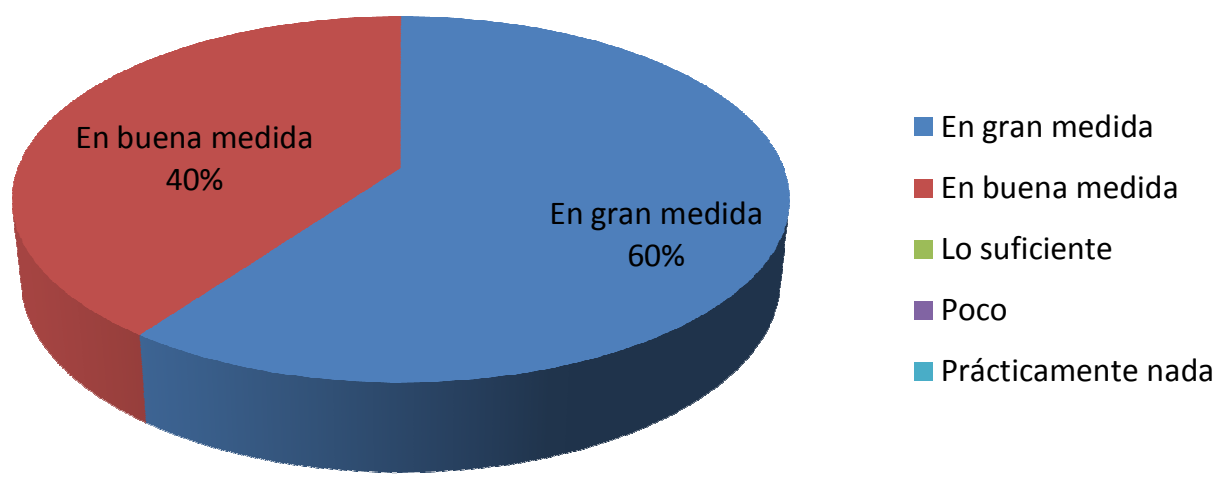

Packet Tracer y la capa de aplicación

Figura 5-48 E3: PT es adecuado para el estudio del protocolo FTP

\section{Considera adecuado el Práctico sobre el Protocolo FTP}

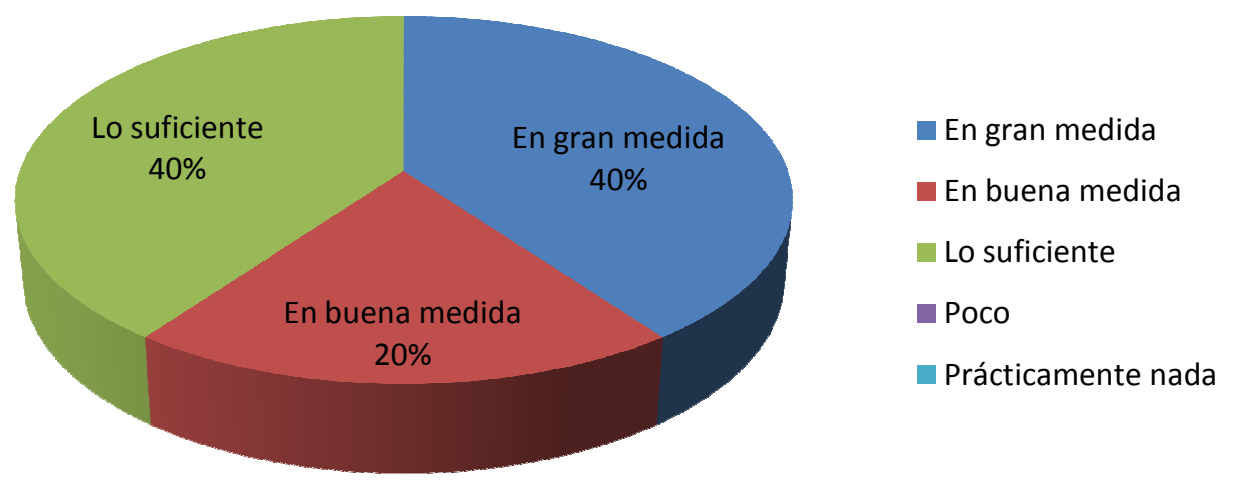

Packet Tracer y la capa de aplicación

Figura 5-49 E3: El Práctico sobre FTP es adecuado 


\section{Considera adecuado el simulador PT para el estudio y análisis de los Protocolos SMTP y POP3}

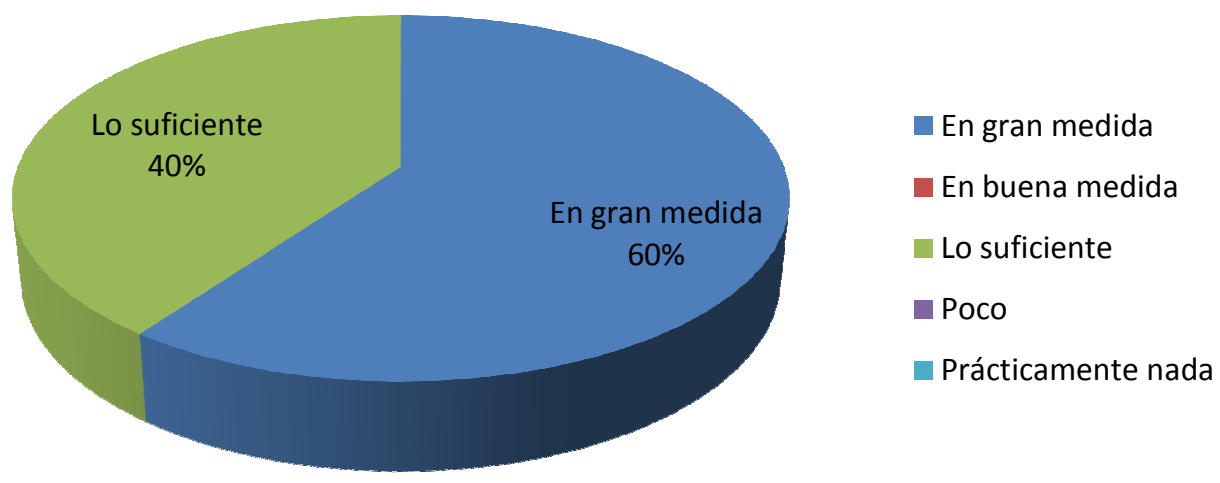

Packet Tracer y la capa de aplicación

Figura 5-50 E3: PT es adecuado para el estudio del protocolo SMTP y POP3

\section{Considera adecuado el Práctico sobre los Protocolos SMTP y POP3}

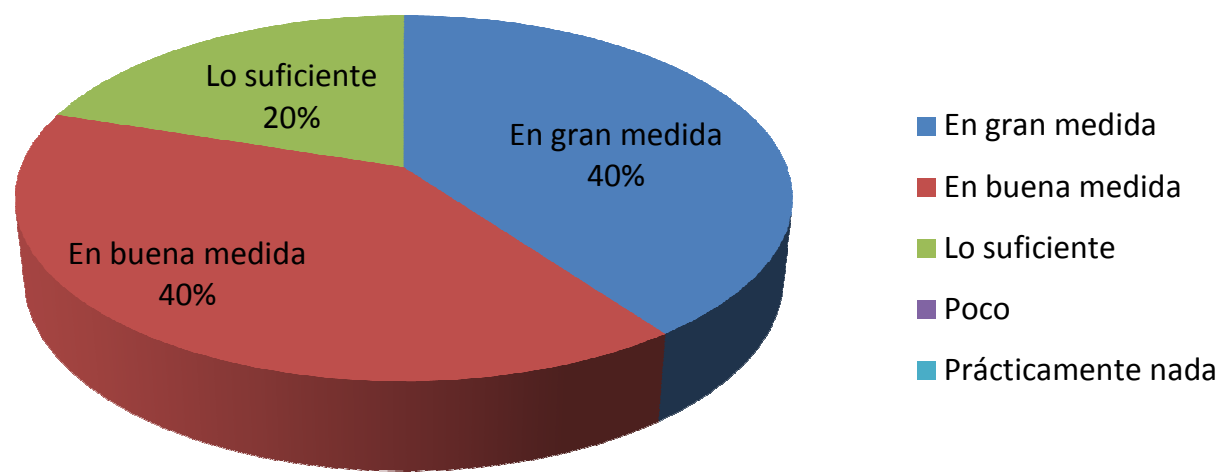

Packet Tracer y la capa de aplicación

Figura 5-51 E3: Considera adecuado el Práctico sobre SMTP y POP3 


\section{Considera adecuado el simulador PT para el estudio y análisis del Protocolo DNS}

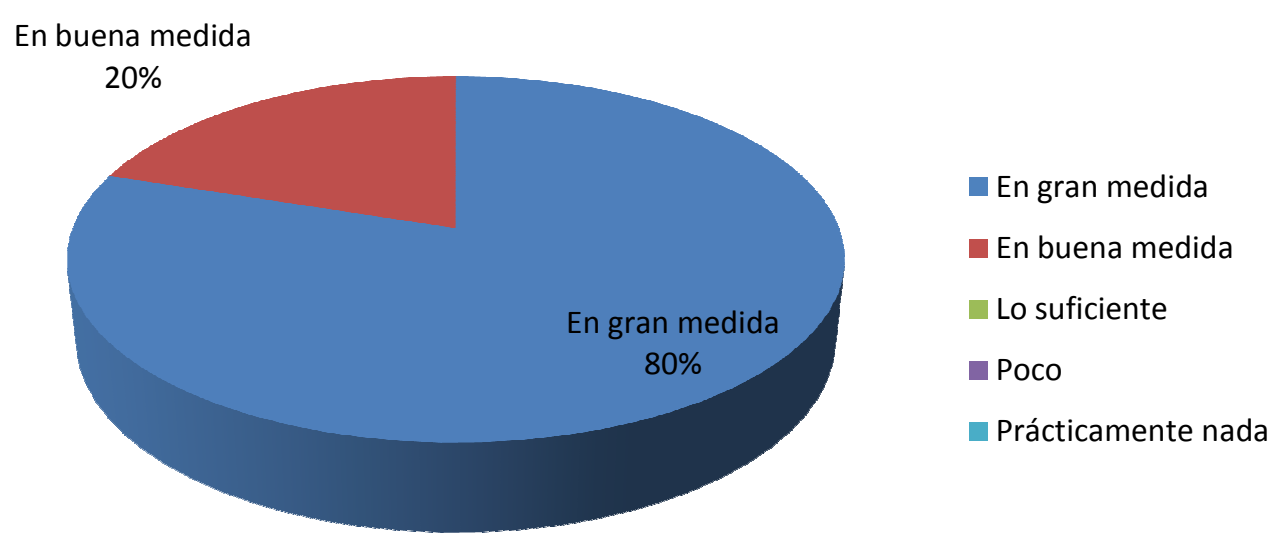

Packet Tracer y la capa de aplicación

Figura 5-52 E3: PT es adecuado para el estudio del protocolo DNS

\section{Considera adecuado el Práctico sobre el Protocolo DNS}

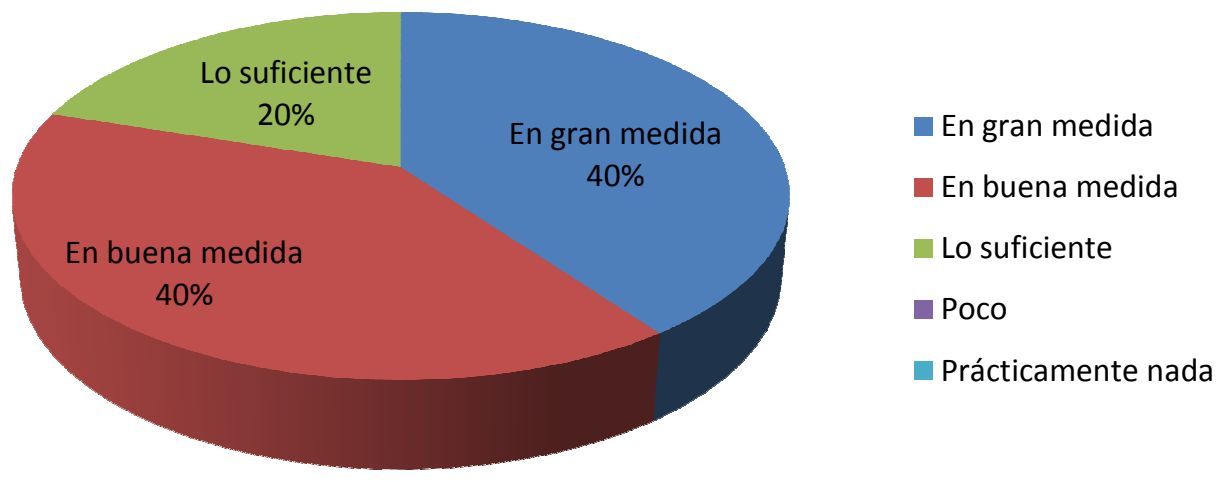

Packet Tracer y la capa de aplicación

Figura 5-53 E3: El Práctico sobre DNS es adecuado 


\section{Considera adecuado el simulador PT para el estudio y análisis del Protocolo TFTP}

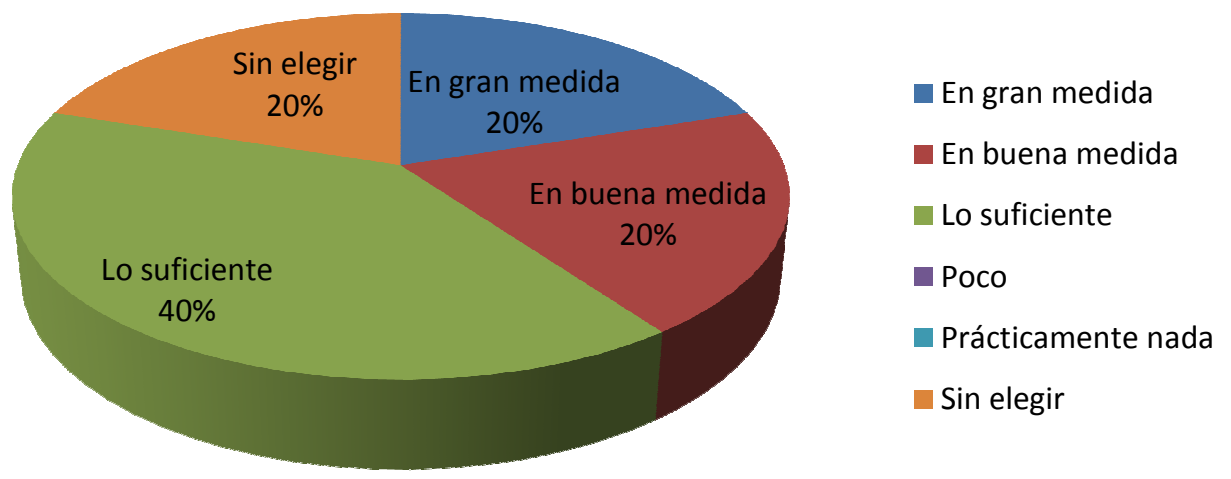

Packet Tracer y la capa de aplicación

Figura 5-54 E3: PT es adecuado para el estudio del protocolo TFTP

\section{Considera adecuado el Práctico sobre el Protocolo TFTP}

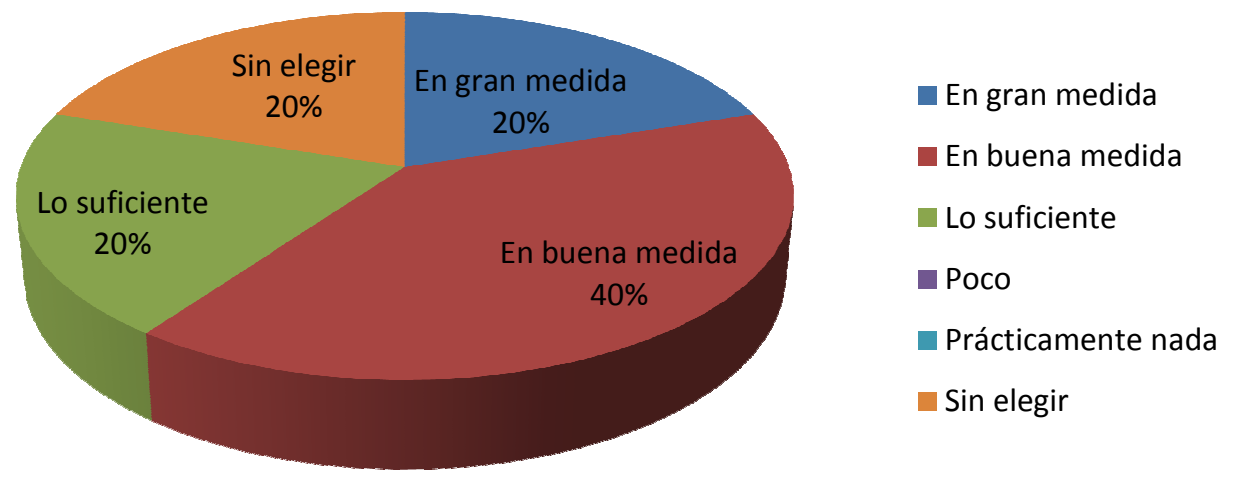

Packet Tracer y la capa de aplicación

Figura 5-55 E3: El Práctico sobre TFTP es adecuado 


\section{Considera adecuado el simulador PT para el estudio y análisis del Protocolo Telnet}

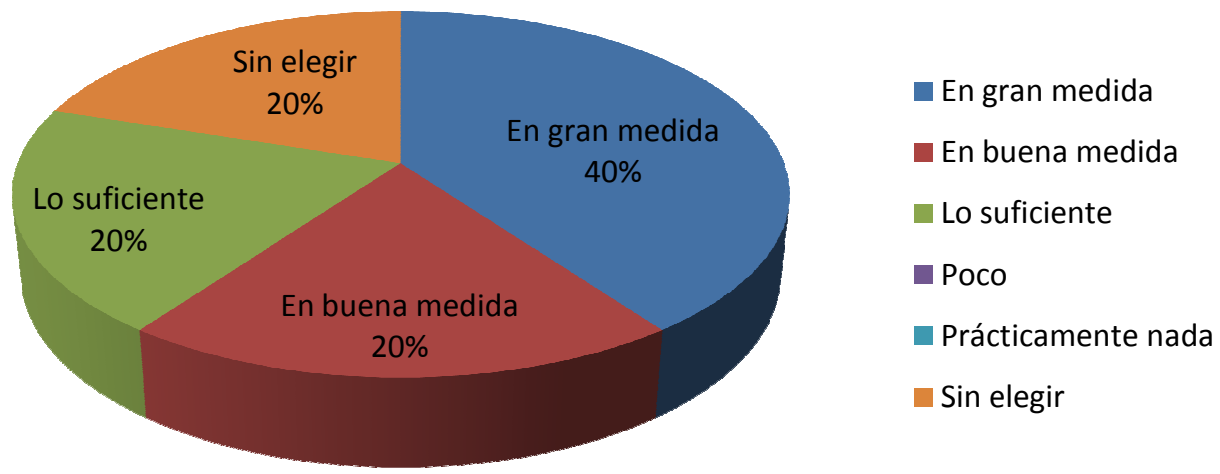

Packet Tracer y la capa de aplicación

Figura 5-56 E3: PT es adecuado para el estudio de Telnet

\section{Considera adecuado el Práctico sobre el Protocolo Telnet}

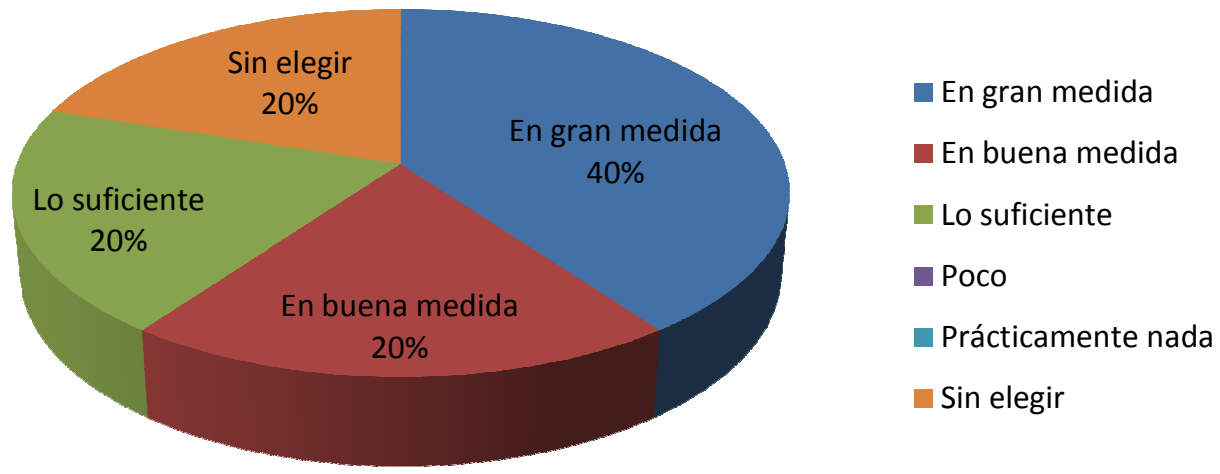

Packet Tracer y la capa de aplicación

Figura 5-57 E3: E1 Práctico sobre Telnet es adecuado

A continuación se enumeran textualmente algunas opiniones sobre la experiencia de los estudiantes.

\section{Comentarios adicionales de los estudiantes}

- A pesar de las limitaciones que tiene el PT, se ve claramente cómo funcionan los diferentes protocolos pero no pude ver la diferencia que hay en las distintas capas, la parte de simulación también es fácil de realizar pero es muy recursivo por ejemplo si yo sigo capturando y reenviando 
algo en ningún momento me dice que se terminó el envío y la recepción de dicho paquete o que sucede si hay algún error o fallo de envío.

- Creo que la parte de HTTP y FTP podría ser vista tranquilamente en una práctica real, en lugar de hacerlo con PT. Sin embargo, la parte de SMTP, POP3 y DNS me pareció bastante útil la herramienta.

- Las últimas 4 preguntas no las respondo ya que no realicé los TPs de esos temas por falta de tiempo.

- Considero que es una gran herramienta para reforzar conocimiento y ver en acción lo que se estudia en teoría. Es un buen software para usar en clase en cuanto se termina de ver un protocolo, haciendo un último estudio a fondo. Sin embargo considero que los prácticos deben ser más específicos y puntuales. Realizar prácticos sobre los protocolos en donde se desee el máximo conocimiento del estudiante.

\subsubsection{Conclusiones}

De acuerdo a los resultados de las encuestas realizadas a los estudiantes para determinar el impacto de la utilización de Packet Tracer en la asignatura Redes de Computadoras I de la carrera Licenciatura en Análisis de Sistemas, se concluyó que en términos generales el acercamiento inicial fue considerado por los estudiantes como positivo en aspectos tales como:

- Disposición para aprender y utilizar una herramienta de simulación.

- Trabajo colaborativo en la resolución de los trabajos prácticos

Ahora bien, mediante la utilización de Packet Tracer como simulador de topologías de red, se evidenció que esta herramienta fue en gran medida aceptada y apoyó el proceso de enseñanza de redes IP, en particular para los conceptos y fundamentos de redes con topologías sencillas para el estudiante y concretamente los protocolos de capa de aplicación HTTP, FTP, SMTP y POP3. TFTP y Telnet.

Acerca de Packet Tracer como herramienta de software se evidenció que en gran medida se consideró que tiene una interfaz intuitiva, que la simulación fue clara y real, facilitó el seguimiento de los eventos ocurridos en la simulación, la instalación y puesta en funcionamiento fueron sencillas, contó con ayuda al usuario, la configuración se independizó del fabricante, permitió realizar cambios en una topología fácilmente y cambios en dispositivos de manera efectiva.

Además, se pudo observar que los prácticos propuestos para los temas fundamentos y capa de aplicación para el uso del simulador, en general fueron considerados adecuados por los estudiantes. 


\subsection{Experiencia $\mathrm{N}^{0}$ 4: Simulador Packet Tracer y el Protocolo DNS en un Curso de Postgrado}

Esta experiencia se instrumentó con el grupo de estudiantes que realizó el Curso de Postgrado "Extensiones de Seguridad para el Sistema de Nombres de Dominio (DNS SEC)", organizado por el C.I.D.I.A., durante el segundo semestre del año 2013. El taller tuvo lugar paralelamente a la realización del curso, y el objetivo fue evaluar la utilización del simulador Packet Tracer como herramienta de software y la funcionalidad puntualmente del Protocolo DNS.

Para ello, se propuso una práctica a los estudiantes a fin de que pudieran realizar una configuración compleja y jerárquica de servidores DNS (de múltiples niveles), similar a la que encontramos en la Internet. Configurando un servidor DNS Local, un servidor DNS de Autoridad y un servidor DNS Raíz.

El taller se llevó a cabo en tres clases teóricas-prácticas de tres horas cada una. El curso fue aprobado en la Facultad de Ciencias Exactas como curso de postgrado bajo resolución RESD-EXA: 460/2013. EXP-EXA: 8092/2013. La parte teórica impartida facilitó la realización del taller permitiendo al equipo docente concentrarse en la presentación de la herramienta y su utilización.

Al finalizar el taller se realizó una encuesta dividida en dos partes, en la primera parte se evaluó a Packet Tracer como herramienta de software y en la segunda parte se evaluó a Packet Tracer y el protocolo DNS.

El objetivo de esta encuesta fue analizar el impacto del uso de la herramienta por los estudiantes.

\subsubsection{Análisis estadísticos de datos}

Para este análisis la media aritmética supera, en todos los casos, al menos el valor medio de la escala (3.00), lo que confirma la validez del contenido de todos los ítems incluidos.

Como puede observarse en la Tabla 5-21, el coeficiente Alfa de Cronbach calculado es de 0,893 que supera el valor de 0,7 (George y Mallery, 2003), lo que permite afirmar el grado de fiabilidad del cuestionario. Por lo tanto, se aprecia una alta polarización de respuestas confiables por parte de los estudiantes.

\begin{tabular}{|r|r|r|}
\hline \multicolumn{1}{|c|}{$\begin{array}{c}\text { Alfa de } \\
\text { Cronbach }\end{array}$} & $\begin{array}{c}\text { Alfa de } \\
\text { Cronbach } \\
\text { basada en los } \\
\text { elementos } \\
\text { tipificados }\end{array}$ & \\
\hline 0,883 & 0,893 & \\
\hline
\end{tabular}

Tabla 5-21 E4: Estadísticos de fiabilidad 
Estudio de la influencia de un entorno de simulación en la enseñanza de redes de computadoras en el nivel universitario

\begin{tabular}{|l|r|r|r|}
\hline & \multicolumn{1}{|c|}{ Media } & \multicolumn{1}{|c|}{$\begin{array}{c}\text { Desviación } \\
\text { típica }\end{array}$} \\
\hline item1 & 4,00 & 0,943 & 10 \\
item2 & 3,90 & 0,876 & 10 \\
item3 & 4,00 & 0,816 & 10 \\
item4 & 3,90 & 0,568 & 10 \\
item5 & 3,90 & 0,738 & 10 \\
item6 & 3,40 & 0,699 & 10 \\
item7 & 3,70 & 0,949 & 10 \\
item8 & 3,50 & 1,179 & 10 \\
item9 & 3,80 & 0,919 & 10 \\
item10 & 3,90 & 0,568 & 10 \\
item11 & 3,70 & 0,483 & 10 \\
item12 & 3,80 & 0,789 & 10 \\
item13 & 3,90 & 0,738 & 10 \\
item14 & 4,10 & 0,738 & 10 \\
item15 & 3,80 & 0,422 & 10 \\
item16 & 3,80 & 0,632 & 10 \\
item17 & 3,60 & 0,843 & 10 \\
item18 & 3,80 & 0,632 & 10 \\
item19 & 3,80 & 0,789 & 10 \\
\hline
\end{tabular}

Tabla 5-22 E4: Estadísticos de los elementos

\begin{tabular}{|c|c|c|c|c|c|c|c|}
\hline & Media & Mínimo & Máximo & Rango & $\begin{array}{c}\text { Máximo/mín } \\
\text { imo }\end{array}$ & $\begin{array}{c}\text { Varianz } \\
\text { a } \\
\end{array}$ & $\begin{array}{c}\mathrm{N} \text { de } \\
\text { elementos }\end{array}$ \\
\hline Medias de los elementos & 3,805 & 3,400 & 4,100 & 0,700 & 1,206 & 0,029 & 19 \\
\hline $\begin{array}{l}\text { Varianzas de los } \\
\text { elementos }\end{array}$ & 0,599 & 0,178 & 1,389 & 1,211 & 7,813 & 0,082 & 19 \\
\hline $\begin{array}{l}\text { Covarianzas inter- } \\
\text { elementos }\end{array}$ & 0,171 & $-0,333$ & 0,667 & 1,000 & $-2,000$ & 0,046 & 19 \\
\hline $\begin{array}{l}\text { Correlaciones inter- } \\
\text { elementos }\end{array}$ & 0,305 & $-0,671$ & 0,916 & 1,587 & $-1,366$ & 0,132 & 19 \\
\hline
\end{tabular}

Tabla 5-23 E4: Estadísticos resumen de los elementos 
Estudio de la influencia de un entorno de simulación en la enseñanza de redes de computadoras en el nivel universitario

\begin{tabular}{|r|r|r|r|}
\hline Media & Varianza & $\begin{array}{c}\text { Desviación } \\
\text { típica }\end{array}$ & N de elementos \\
\hline 72,30 & 69,789 & 8,354 & 19 \\
\hline
\end{tabular}

Tabla 5-24 E4: Estadísticos de la escala

\section{Gráficos descriptivos}

A continuación se presentan gráficamente las respuestas de los estudiantes, para cada una de las preguntas del cuestionario realizado.

Se utilizó la siguiente escala de Likert donde 5 es el valor máximo.

5 -> En gran medida, 4 -> En buena medida, 3 -> Lo suficiente, 2-> Poco, 1-> Prácticamente nada

Al finalizar cada segmento de la encuesta, se enumeran textualmente algunas opiniones sobre la experiencia de los estudiantes.

\section{El simulador Packet Tracer como herramienta de software}

La instalación y puesta en funcionamiento de la herramienta es sencilla.

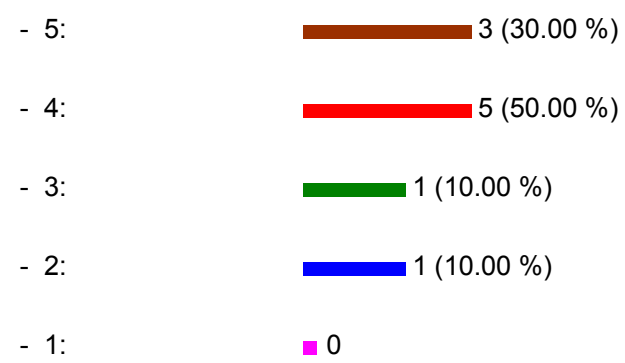

La configuración de la interfaz en idioma español es sencilla.

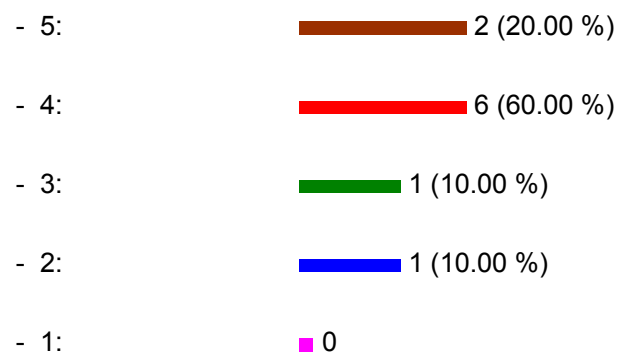

La interfaz gráfica que ofrece la aplicación es amigable e intuitiva.

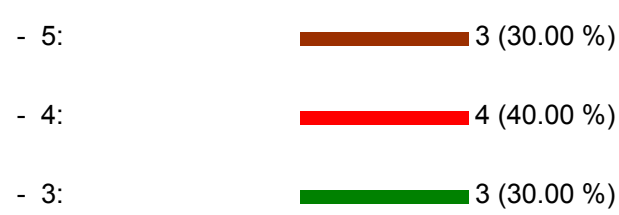




$\begin{array}{ll}-2: & =0 \\ -1: & \quad 0\end{array}$

La aplicación posee los componentes necesarios para realizar un laboratorio de redes IP.

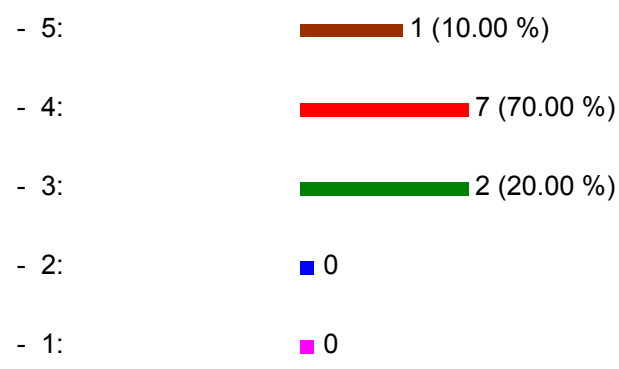

La herramienta ofrece disponibilidad que garantice la realización de los laboratorios sin interrupciones.

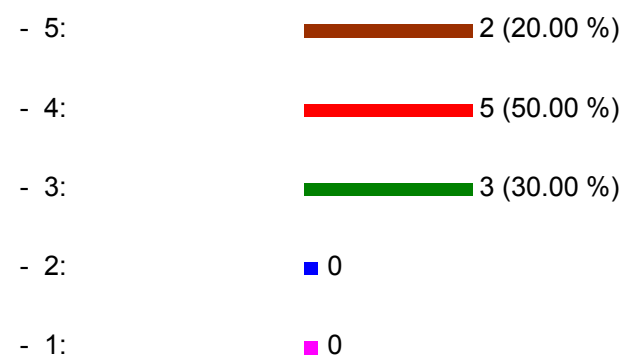

Se cuenta con ayuda que permita resolver dudas sobre el uso de la herramienta.

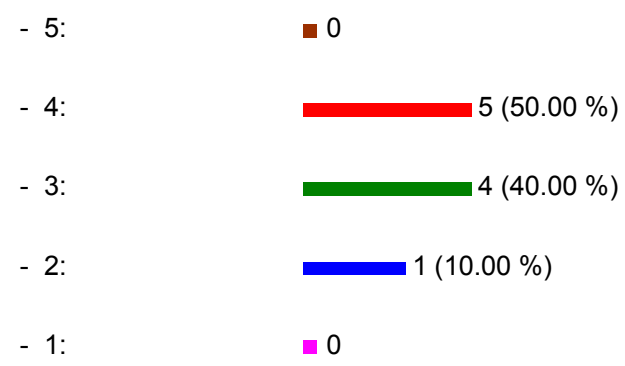

La herramienta permite realizar simulaciones claras y reales.

\begin{tabular}{|c|c|}
\hline - $5:$ & $2(20.00 \%)$ \\
\hline - 4: & $4(40.00 \%)$ \\
\hline - 3: & $3(30.00 \%)$ \\
\hline - 2: & $1(10.00 \%)$ \\
\hline - 1: & $\square 0$ \\
\hline
\end{tabular}


Con esta herramienta, la configuración de los dispositivos se desentiende de una marca particular, concentrándose en el concepto teórico.

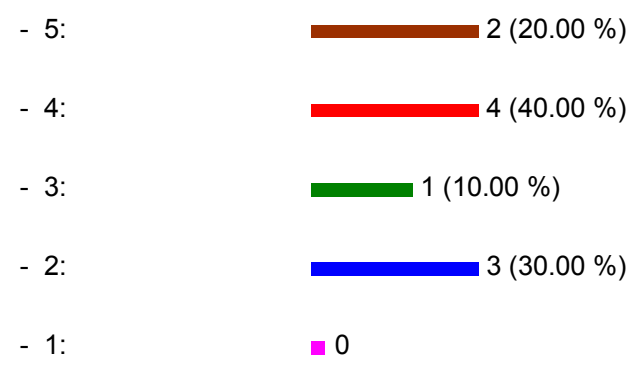

Permite realizar cambios en la topología fácilmente para adecuarla a las necesidades.

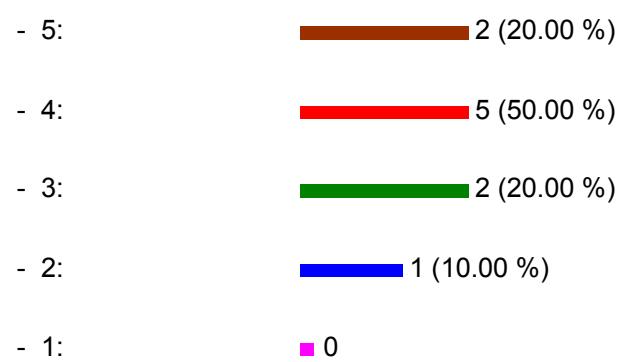

Permite simular cambios en dispositivos de manera efectiva en una determinada topología.

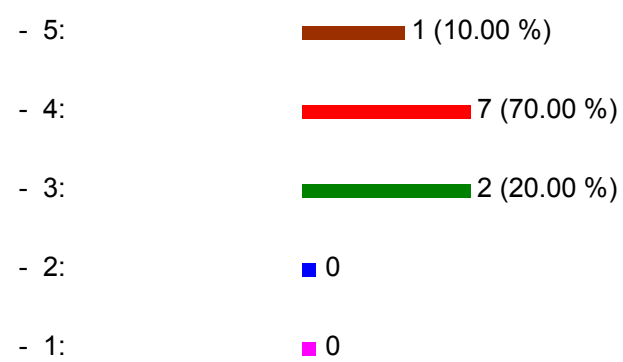

La herramienta facilita el seguimiento de los eventos ocurridos en cada uno de los dispositivos dentro de la red.

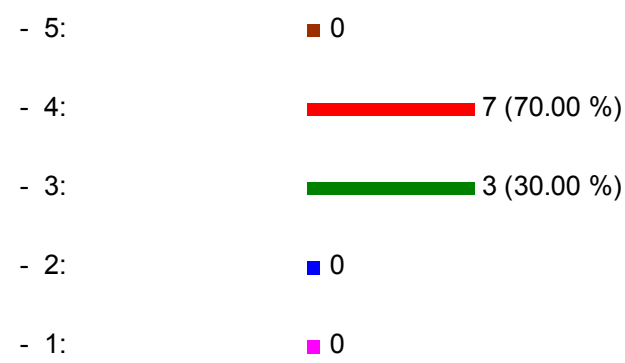

Con PT se potencializa la educación no presencial. 


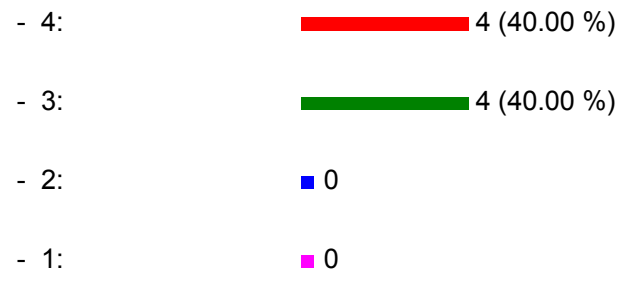

Observaciones y comentarios adicionales de los estudiantes sobre la herramienta PT

- En general me parece una herramienta muy interesante desde el punto teórico, aunque tengo entendido que también se asemeja a lo práctico.

En mi caso particular no pude hacer el trabajo final por cuestiones de tiempo, pero me hubiera gustado hacerlo.

- Muy buena herramienta, y muy útil permite poner en práctica los conceptos teóricos con simulaciones muy reales

- $\quad$ El uso de packet tracer debería complementarse con talleres donde el estudiante tenga contacto con algunos de los dispositivos que se simulan con la herramienta, de este modo se pueden internalizar mejor los conceptos. Es imposible que alguien conozca la administración de red de datos desde un simulador, sobre todo cuando hay ambientes que tienen que ver con la infraestructura (dispositivos intermedios) que son muy importantes.

- Una buena herramienta para aprender cómo funcionan los dispositivos. Tiene una interfaz muy amigable.

- $\quad$ Muy buena la herramienta. Útil para cuando no se dispone de equipos para las prácticas.

- $\quad$ Es fácil e intuitiva

- Es una buena herramienta para poder simular topologías antes de implementarlas.

- $\quad$ Tiene un gran valor didáctico que debería ser mas explotado

- $\quad$ Muy buena

\section{Packet Tracer y el Protocolo DNS}

Considera adecuado el simulador PT para el estudio y análisis del Protocolo DNS.

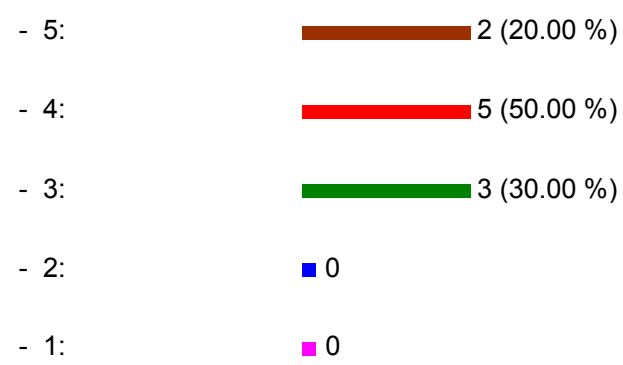

Considera adecuado el enunciado del Práctico sobre el Protocolo DNS simple usuario.
-5 :
$3(30.00 \%)$
$-4:$
-3 :
$2(20.00 \%)$
-2 :
- 0 


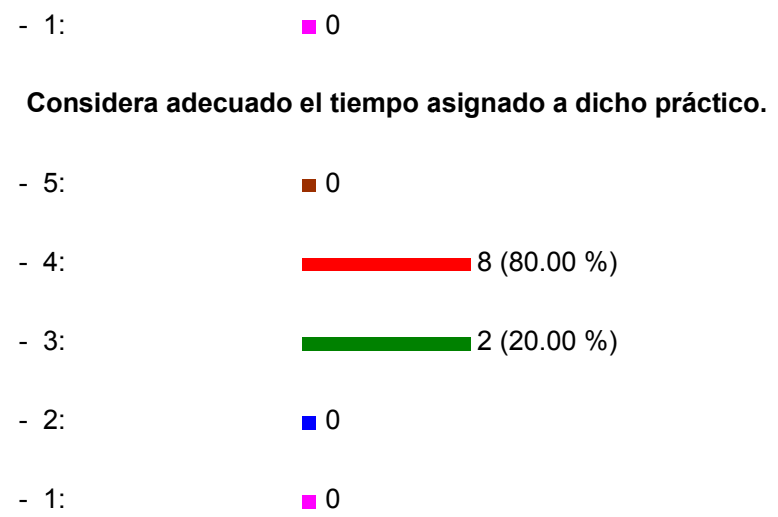

Considera adecuado el enunciado del Práctico sobre el Protocolo DNS multinivel usuario.

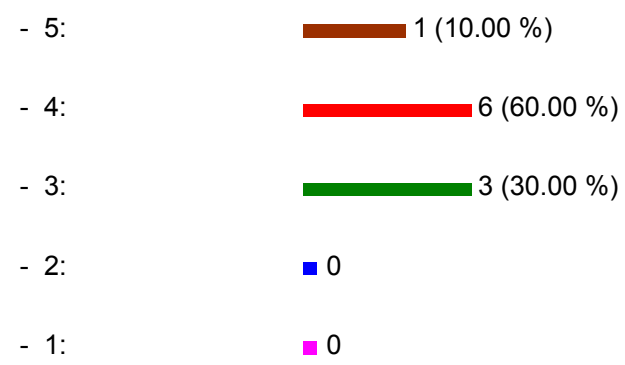

Considera adecuado el tiempo asignado a dicho práctico.

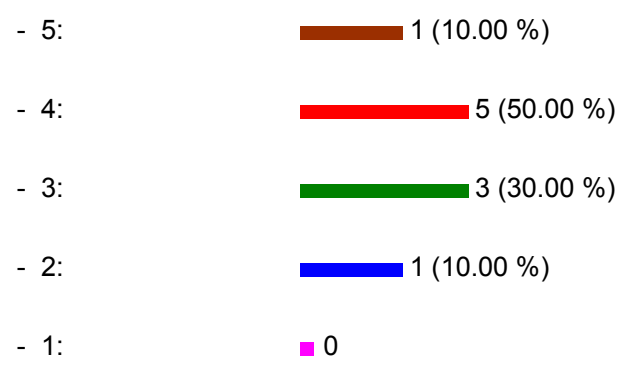

Considera adecuado el enunciado del Práctico sobre el Protocolo DNS multinivel protocolo.

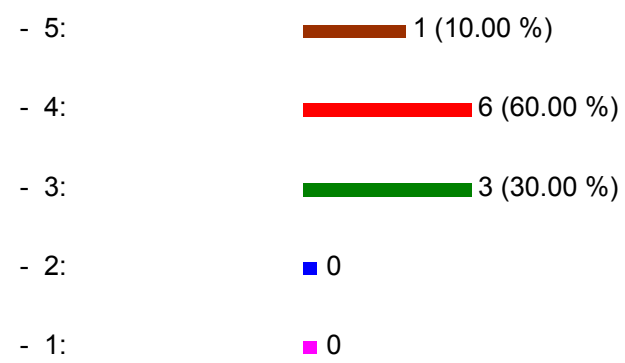

Considera adecuado el tiempo asignado a dicho práctico.

- 5: $2(20.00 \%)$ 


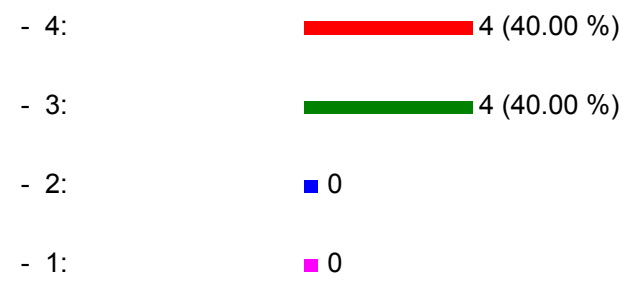

Observaciones y comentarios adicionales de los estudiantes respecto de la Capa de Aplicación Protocolo DNS

- Ninguna

- $\quad$ PT es ideal para trabajar con DNS al permitir la construcción de toda la arquitectura.

- $\quad$-Simular una topología y ver el funcionamiento despeja muchas dudas.

- $\quad$ No se contaba con las herramientas necesarias en el laboratorio de informática para poder realizar las pruebas necesarias.

- $\quad$ Muy útil, particularmente me ayudo a terminar de entender DNS

- $\quad$ Muy bueno el curso. Pero estuvo muy sobre el límite de fin de año e interrumpido por vacaciones

- Estaría bueno tener unas horas mas para dedicarlas con mas tranquilidad este tema...

- Ofrece a las aplicaciones (de usuario o no) la posibilidad de acceder a los servicios de las demás capas y define los protocolos que utilizan las aplicaciones para intercambiar datos, como correo electrónico (POP y SMTP), gestores de bases de datos y protocolos de transferencia de archivos (FTP).

- Creo que es importante realizar una configuración real, ya que no siempre funcionan en el primer intento. Esto ayudaría a probar varias configuraciones no sólo en el IOS sino en otro tipos de SO (por ej. los basados en UNIX).

Figura 5-58 E4: Análisis del Protocolo DNS

\subsubsection{Conclusiones de la experiencia}

De acuerdo a los resultados de las encuestas realizadas a los estudiantes para determinar el impacto de la utilización de la herramienta Packet Tracer en el Curso de Postgrado "Extensiones de Seguridad para el Sistema de Nombres de Dominio (DNS SEC)", se concluyó que en términos generales el acercamiento inicial fue considerado por los estudiantes como positivo.

Acerca de Packet Tracer como herramienta de software, se evidenció que en gran medida se consideró a la interfaz intuitiva, la simulación fue clara, facilitó el seguimiento de los eventos ocurridos en la simulación, la instalación y puesta en funcionamiento fueron sencillas; sin embargo, los estudiantes consideraron también que la herramienta no cuenta con ayuda al usuario suficiente y, que la configuración de los dispositivos de red no se independiza del fabricante.

Ahora bien, mediante la utilización de Packet Tracer para estudiar y analizar el Protocolo DNS, se evidenció que esta herramienta fue en gran medida aceptada y apoyó el proceso de enseñanza del protocolo DNS, tanto para los enunciados propuestos como práctica con el simulador como para la herramienta en sí misma, no así el tiempo asignado para la resolución de los prácticos propuestos.

Cabe aclarar que la configuración jerárquica propuesta en la práctica para el protocolo DNS, es compleja y requiere de un conocimiento profundo del protocolo. 


\subsection{Experiencia $N^{0}$ 5: Simulador Packet Tracer en Redes de Computadoras I}

Esta experiencia se instrumentó con un grupo de estudiantes que se encontraban cursando la asignatura Redes de Computadoras I del nuevo Plan de Licenciatura en Análisis de Sistemas 2010, durante el primer semestre del año 2014. El taller se realizó paralelamente al cursado de la asignatura lo que permitió evaluar la utilización del simulador Packet Tracer como herramienta de software, como apoyo al estudio de Fundamentos de redes y los diferentes protocolos de Capa de Aplicación, Capa de Transporte y Capa de Red.

La asignatura Redes de Computadoras I, comienza con una introducción a las redes para luego adentrarse en las Capas de Aplicación, Capa de Transporte y Capa de Red del Modelo TCP/IP. En esta segunda cohorte del taller, se revisaron las guías de trabajos prácticos para el simulador, para los temas introductorios de Fundamentos y para cada protocolo tratado en la Capa de Aplicación, asimismo se desarrollaron nuevas guías para las Capa de Transporte y Capa de Red, de manera de acompañar la totalidad del cursado de la asignatura, con práctica con el simulador.

El taller se llevó a cabo durante los cuatro meses de cursado de la asignatura, cada clase teórica fue acompañada con su correspondiente clase práctica sobre papel y además con la clase práctica sobre el simulador. Las clases teóricas y prácticas impartidas en el cursado de la asignatura, facilitaron la realización del taller, permitiendo al equipo docente, concentrarse en la herramienta y su utilización.

Al finalizar el taller, se realizó una encuesta dividida en cinco partes, en primera instancia se evaluó a Packet Tracer como herramienta de software, luego se evaluó a Packet Trace y los Fundamentos de Redes, Packet Tracer y la Capa de Aplicación, Packet Tracer y la Capa de Transporte y finalmente Packet Tracer y la Capa de Red.

El objetivo de esta encuesta fue analizar el impacto del uso de la herramienta por los estudiantes, asociado a los diferentes temas y protocolos de cada capa del modelo TCP/IP tratados.

\subsubsection{Análisis estadísticos de datos}

Primera parte de la encuesta: Packet Tracer como Herramienta y Fundamentos

Para este análisis la media aritmética supera, en todos los casos, al menos el valor medio de la escala (3.00), lo que confirma la validez del contenido de todos los ítems incluidos.

Como puede observarse en la Tabla 5-25, el coeficiente Alfa de Cronbach calculado es de 0,732 que supera el valor de 0,7 (George y Mallery, 2003), lo que permite afirmar el grado de fiabilidad del cuestionario. Por lo tanto, se aprecia una alta polarización de respuestas confiables por parte de los estudiantes. 


\begin{tabular}{|r|r|r|}
\hline \multicolumn{1}{|c|}{$\begin{array}{c}\text { Alfa de } \\
\text { Cronbach }\end{array}$} & $\begin{array}{c}\text { Alfa de } \\
\text { Cronbach } \\
\text { basada en los } \\
\text { elementos } \\
\text { tipificados }\end{array}$ & \\
\hline 0,734 & 0,732 & \\
\hline
\end{tabular}

Tabla 5-25 E5-P1: Estadísticos de fiabilidad

\begin{tabular}{|l|r|r|r|}
\hline & Media & \multicolumn{1}{|c|}{$\begin{array}{c}\text { Desviación } \\
\text { típica }\end{array}$} \\
\hline VAR00001 & 4,80 & 0,561 & 15 \\
VAR00002 & 4,40 & 0,737 & 15 \\
VAR00003 & 4,20 & 0,775 & 15 \\
VAR00004 & 4,47 & 0,640 & 15 \\
VAR00005 & 4,13 & 0,743 & 15 \\
VAR00006 & 3,47 & 0,743 & 15 \\
VAR00007 & 4,33 & 0,488 & 15 \\
VAR00008 & 3,73 & 0,799 & 15 \\
VAR00009 & 4,00 & 0,756 & 15 \\
VAR00010 & 4,00 & 0,535 & 15 \\
VAR00011 & 4,27 & 0,594 & 15 \\
VAR00012 & 4,27 & 0,884 & 15 \\
VAR00013 & 4,60 & 0,632 & 15 \\
VAR00014 & 4,47 & 0,743 & 15 \\
VAR00015 & 4,20 & 0,775 & 15 \\
VAR00016 & 4,47 & 0,743 & 15 \\
\hline
\end{tabular}

Tabla 5-26 E5-P1: Estadísticos de los elementos 


\begin{tabular}{|c|c|c|c|c|c|c|c|}
\hline & Media & Mínimo & Máximo & Rango & $\begin{array}{c}\text { Máximo/mín } \\
\text { imo }\end{array}$ & $\begin{array}{c}\text { Varianz } \\
\mathrm{a} \\
\end{array}$ & $\begin{array}{c}\mathrm{N} \text { de } \\
\text { elementos }\end{array}$ \\
\hline Medias de los elementos & 4,238 & 3,467 & 4,800 & 1,333 & 1,385 & 0,108 & 16 \\
\hline $\begin{array}{c}\text { Varianzas de los } \\
\text { elementos }\end{array}$ & 0,496 & 0,238 & 0,781 & 0,543 & 3,280 & 0,022 & 16 \\
\hline $\begin{array}{l}\text { Covarianzas inter- } \\
\text { elementos }\end{array}$ & 0,073 & $-0,329$ & 0,429 & 0,757 & $-1,304$ & 0,025 & 16 \\
\hline $\begin{array}{l}\text { Correlaciones inter- } \\
\text { elementos }\end{array}$ & 0,146 & $-0,548$ & 0,828 & 1,375 & $-1,512$ & 0,090 & 16 \\
\hline
\end{tabular}

Tabla 5-27 E5-P1: Estadísticos resumen de los elementos

\begin{tabular}{|r|r|r|r|}
\hline Media & Varianza & \multicolumn{1}{|c|}{$\begin{array}{c}\text { Desviación } \\
\text { típica }\end{array}$} & N de elementos \\
\hline 67,80 & 25,457 & 5,046 & 16 \\
\hline
\end{tabular}

Tabla 5-28 E5-P1: Estadísticos de la escala

\section{Segunda parte de la encuesta: Packet Tracer y la Capa de Aplicación}

Para este análisis la media aritmética supera, en todos los casos, al menos el valor medio de la escala (3.00), lo que confirma la validez del contenido de todos los ítems incluidos.

Como puede observarse en la Tabla 5-9, el coeficiente Alfa de Cronbach calculado es de 0,784 que supera el valor de 0,7 (George y Mallery, 2003), lo que permite afirmar el grado de fiabilidad del cuestionario. Por lo tanto, se aprecia una alta polarización de respuestas confiables por parte de los estudiantes.

\begin{tabular}{|r|r|r|}
\hline \multicolumn{1}{|c|}{$\begin{array}{c}\text { Alfa de } \\
\text { Cronbach }\end{array}$} & $\begin{array}{c}\text { Alfa de } \\
\text { Cronbach } \\
\text { basada en los } \\
\text { elementos } \\
\text { tipificados }\end{array}$ & \\
\hline 0,792 & 0,784 & \\
\hline
\end{tabular}

Tabla 5-29 E5-P2: Estadísticos de fiabilidad 
Estudio de la influencia de un entorno de simulación en la enseñanza de redes de computadoras en el nivel universitario

\begin{tabular}{|l|r|r|r|}
\hline & Media & \multicolumn{1}{|c|}{$\begin{array}{c}\text { Desviación } \\
\text { típica }\end{array}$} \\
\hline VAR00001 & 4,17 & 0,937 & 12 \\
VAR00002 & 4,25 & 0,622 & 12 \\
VAR00003 & 4,42 & 0,669 & 12 \\
VAR00004 & 4,08 & 0,669 & 12 \\
VAR00005 & 4,17 & 0,577 & 12 \\
VAR00006 & 4,33 & 0,778 & 12 \\
VAR00007 & 4,33 & 0,651 & 12 \\
VAR00008 & 4,08 & 0,669 & 12 \\
VAR00009 & 3,58 & 0,515 & 12 \\
VAR00010 & 3,83 & 0,389 & 12 \\
VAR00011 & 3,58 & 0,996 & 12 \\
VAR00012 & 4,42 & 0,793 & 12 \\
VAR00013 & 4,33 & 0,888 & 12 \\
VAR00014 & 4,08 & 0,900 & 12 \\
VAR00015 & 4,17 & 1,030 & 12 \\
VAR00016 & 3,67 & 0,651 & 12 \\
VAR00017 & 3,83 & 0,718 & 12 \\
VAR00018 & 3,75 & 0,754 & 12 \\
\hline
\end{tabular}

Tabla 5-30 E5-P2: Estadísticos de los elementos

\begin{tabular}{|l|r|r|r|r|r|r|r|}
\hline & Media & Mínimo & Máximo & Rango & $\begin{array}{r}\text { Máximo/mín } \\
\text { imo }\end{array}$ & $\begin{array}{c}\text { Varianz } \\
\text { a }\end{array}$ & $\begin{array}{c}\text { N de } \\
\text { elementos }\end{array}$ \\
\hline $\begin{array}{l}\text { Medias de los elementos } \\
\text { Varianzas de los }\end{array}$ & $\begin{array}{r}4,060 \\
0,565\end{array}$ & $\begin{array}{r}3,583 \\
0,152\end{array}$ & $\begin{array}{r}4,417 \\
1,061\end{array}$ & $\begin{array}{r}0,833 \\
0,909\end{array}$ & $\begin{array}{r}1,233 \\
7,000\end{array}$ & 0,080 & 18 \\
elementos & 0,099 & $-0,326$ & 0,848 & 1,174 & $-2,605$ & 0,037 & 18 \\
$\begin{array}{l}\text { Covarianzas inter- } \\
\text { elementos }\end{array}$ & 0,168 & $-0,571$ & 0,928 & 1,500 & $-1,624$ & 0,100 & 18 \\
$\begin{array}{l}\text { Correlaciones inter- } \\
\text { elementos }\end{array}$ & & & & & & \\
\hline
\end{tabular}

Tabla 5-31 E5-P2: Estadísticos de resumen de los elementos

Estadísticos de la escala

\begin{tabular}{|r|r|r|r|}
\hline Media & Varianza & $\begin{array}{c}\text { Desviación } \\
\text { típica }\end{array}$ & N de elementos \\
\hline 73,08 & 40,447 & 6,360 & 18 \\
\hline
\end{tabular}

Tabla 5-32 E5-P2: Estadísticos de la escala 
Tercera parte de la encuesta: Packet Tracer y la Capa de Transporte

Para este análisis la media aritmética supera, en todos los casos, al menos el valor medio de la escala (3.00), lo que confirma la validez del contenido de todos los ítems incluidos.

Como puede observarse en la Tabla 5-33, el coeficiente Alfa de Cronbach calculado es de 0,835 que supera el valor de 0,7 (George y Mallery, 2003), lo que permite afirmar el grado de fiabilidad del cuestionario. Por lo tanto, se aprecia una alta polarización de respuestas confiables por parte de los estudiantes.

\begin{tabular}{|r|r|r|}
\hline \multicolumn{1}{|c|}{$\begin{array}{c}\text { Alfa de } \\
\text { Cronbach }\end{array}$} & $\begin{array}{c}\text { Alfa de } \\
\text { Cronbach } \\
\text { basada en los } \\
\text { elementos } \\
\text { tipificados }\end{array}$ & \\
\hline 0,815 & 0,835 & \\
\hline
\end{tabular}

Tabla 5-33 E5-P3: Estadísticos de fiabilidad

\begin{tabular}{|l|r|r|r|}
\hline & Media & $\begin{array}{c}\text { Desviación } \\
\text { típica }\end{array}$ & $N$ \\
\hline VAR00001 & 4,7778 & 0,66667 & 9 \\
VAR00002 & 4,4444 & 0,72648 & 9 \\
VAR00003 & 4,3333 & 0,70711 & 9 \\
VAR00004 & 4,3333 & 0,70711 & 9 \\
VAR00005 & 4,2222 & 0,83333 & 9 \\
VAR00006 & 3,3333 & 0,86603 & 9 \\
VAR00007 & 4,3333 & 0,50000 & 9 \\
VAR00008 & 3,8889 & 0,92796 & 9 \\
VAR00009 & 4,1111 & 0,78174 & 9 \\
VAR00010 & 4,0000 & 0,50000 & 9 \\
VAR00011 & 4,4444 & 0,52705 & 9 \\
VAR00012 & 4,3333 & 0,86603 & 9 \\
VAR00013 & 4,4444 & 0,52705 & 9 \\
VAR00014 & 4,0000 & 0,86603 & 9 \\
VAR00015 & 4,1111 & 0,60093 & 9 \\
VAR00016 & 4,7778 & 0,44096 & 9 \\
VAR00017 & 4,6667 & 0,50000 & 9 \\
VAR00018 & 4,4444 & 0,52705 & 9 \\
VAR00019 & 4,6667 & 0,70711 & 9 \\
VAR00020 & 4,6667 & 0,70711 & 9 \\
\hline
\end{tabular}

Tabla 5-34 E5-P3: Estadísticos de los elementos 


\begin{tabular}{|c|c|c|c|c|c|c|c|}
\hline & Media & Mínimo & Máximo & Rango & $\begin{array}{c}\text { Máximo/míni } \\
\text { mo }\end{array}$ & $\begin{array}{c}\text { Varianz } \\
\mathrm{a} \\
\end{array}$ & $\begin{array}{c}\mathrm{N} \text { de } \\
\text { elementos }\end{array}$ \\
\hline $\begin{array}{l}\text { Medias de los } \\
\text { elementos }\end{array}$ & 4,317 & 3,333 & 4,778 & 1,444 & 1,433 & 0,121 & 20 \\
\hline $\begin{array}{l}\text { Varianzas de los } \\
\text { elementos }\end{array}$ & 0,476 & 0,194 & 0,861 & 0,667 & 4,429 & 0,043 & 20 \\
\hline $\begin{array}{l}\text { Covarianzas inter- } \\
\text { elementos }\end{array}$ & 0,086 & $-0,375$ & 0,556 & 0,931 & $-1,481$ & 0,026 & 20 \\
\hline $\begin{array}{l}\text { Correlaciones inter- } \\
\text { elementos }\end{array}$ & 0,202 & $-0,707$ & 0,919 & 1,626 & $-1,300$ & 0,108 & 20 \\
\hline
\end{tabular}

Tabla 5-35 E5-P3: Estadísticos de resumen de los elementos

\begin{tabular}{|c|r|r|r|}
\hline Media & Varianza & $\begin{array}{c}\text { Desviación } \\
\text { típica }\end{array}$ & N de elementos \\
\hline 86,3333 & 42,250 & 6,50000 & 20 \\
\hline
\end{tabular}

Tabla 5-36 E5-P3: Estadísticos de la escala

\section{Cuarta parte de la encuesta: Packet Tracer y la Capa de Red}

Para este análisis la media aritmética supera, en todos los casos, al menos el valor medio de la escala (3.00), lo que confirma la validez del contenido de todos los ítems incluidos.

Como puede observarse en la Tabla 5-37, el coeficiente Alfa de Cronbach calculado es de 0,962 que supera ampliamente el valor de 0,7 (George y Mallery, 2003), lo que permite afirmar el grado de fiabilidad del cuestionario. Por lo tanto, se aprecia una alta polarización de respuestas confiables por parte de los estudiantes.

\begin{tabular}{|r|c|c|}
\hline \multicolumn{1}{|c|}{$\begin{array}{c}\text { Alfa de } \\
\text { Cronbach }\end{array}$} & $\begin{array}{c}\text { Alfa de } \\
\text { Cronbach } \\
\text { basada en los } \\
\text { elementos } \\
\text { tipificados }\end{array}$ & \\
\hline 0,961 & 0,962 & \\
\hline
\end{tabular}

Tabla 5-37 E5-P4: Estadísticos de fiabilidad 


\begin{tabular}{|c|c|c|c|}
\hline & Media & $\begin{array}{c}\text { Desviación } \\
\text { típica }\end{array}$ & $\mathrm{N}$ \\
\hline VAR00001 & 4,50 & 0,548 & 6 \\
\hline VAR00002 & 4,67 & 0,516 & 6 \\
\hline VAR00003 & 4,67 & 0,816 & 6 \\
\hline VAR00004 & 4,83 & 0,408 & 6 \\
\hline VAR00005 & 4,83 & 0,408 & 6 \\
\hline VAR00006 & 4,00 & 0,632 & 6 \\
\hline VAR00007 & 4,00 & 0,632 & 6 \\
\hline VAR00008 & 3,83 & 0,753 & 6 \\
\hline VAR00009 & 4,67 & 0,516 & 6 \\
\hline VAR00010 & 4,50 & 0,548 & 6 \\
\hline VAR00011 & 4,50 & 0,548 & 6 \\
\hline VAR00012 & 4,33 & 0,816 & 6 \\
\hline VAR00013 & 4,50 & 0,837 & 6 \\
\hline VAR00014 & 4,67 & 0,516 & 6 \\
\hline VAR00015 & 4,50 & 0,837 & 6 \\
\hline VAR00016 & 4,17 & 0,753 & 6 \\
\hline VAR00017 & 4,00 & 0,894 & 6 \\
\hline VAR00018 & 4,17 & 0,753 & 6 \\
\hline VAR00019 & 4,50 & 0,837 & 6 \\
\hline VAR00020 & 4,50 & 0,837 & 6 \\
\hline VAR00021 & 4,50 & 0,548 & 6 \\
\hline VAR00022 & 4,33 & 0,516 & 6 \\
\hline VAR00023 & 4,33 & 0,516 & 6 \\
\hline VAR00024 & 4,17 & 0,753 & 6 \\
\hline
\end{tabular}

Tabla 5-38 E5-P4: Estadísticos de los elementos

\begin{tabular}{|l|r|r|r|r|r|r|r|}
\hline & Media & Mínimo & Máximo & Rango & $\begin{array}{c}\text { Máximo/mín } \\
\text { imo }\end{array}$ & $\begin{array}{c}\text { Varianz } \\
\text { a }\end{array}$ & $\begin{array}{c}\text { N de } \\
\text { elementos }\end{array}$ \\
\hline Medias de los elementos & 4,403 & 3,833 & 4,833 & 1,000 & 1,261 & 0,075 & 24 \\
Varianzas & 0,453 & 0,167 & 0,800 & 0,633 & 4,800 & 0,041 & 24 \\
Covarianzas & 0,231 & $-0,133$ & 0,700 & 0,833 & $-5,250$ & 0,029 & 24 \\
Correlaciones inter- & 0,516 & $-0,343$ & 1,000 & 1,343 & $-2,915$ & 0,092 & 24 \\
elementos & & & & & & & \\
\hline
\end{tabular}

Tabla 5-39 E5-P4: Estadísticos de resumen de los elementos 
Estudio de la influencia de un entorno de simulación en la enseñanza de redes de computadoras en el nivel universitario

\begin{tabular}{|c|c|c|c|}
\hline Media & Varianza & $\begin{array}{c}\text { Desviación } \\
\text { típica }\end{array}$ & N de elementos \\
\hline 105,67 & 138,267 & 11,759 & 24 \\
\hline
\end{tabular}

\section{Estudio descriptivo}

Tabla 5-40 E5-P4: Estadísticos de la escala

Para este análisis la media aritmética supera, en todos los casos, al menos el valor medio de la escala (3.00), lo que confirma la validez del contenido de todos los ítems incluidos.

Como puede observarse en la Tabla 5-41, el coeficiente Alfa de Cronbach calculado es de 0,925 que supera ampliamente el valor de 0,7 (George y Mallery, 2003), lo que permite afirmar el grado de fiabilidad del cuestionario.

\begin{tabular}{|r|r|r|}
\hline $\begin{array}{c}\text { Alfa de } \\
\text { Cronbach }\end{array}$ & $\begin{array}{c}\text { Alfa de } \\
\text { Cronbach } \\
\text { basada en los } \\
\text { elementos }\end{array}$ & N de elementos \\
\hline 0,916 & 0,925 & 18 \\
\hline
\end{tabular}

Tabla 5-41 E5-P5: Estadísticos de fiabilidad

\begin{tabular}{|l|r|r|r|}
\hline & Media & $\begin{array}{c}\text { Desviación } \\
\text { típica }\end{array}$ & $\mathrm{N}$ \\
\hline VAR00001 & 3,71 & 0,951 & 7 \\
VAR00002 & 3,57 & 0,787 & 7 \\
VAR00003 & 3,71 & 0,756 & 7 \\
VAR00004 & 4,14 & 0,690 & 7 \\
VAR00005 & 4,14 & 0,690 & 7 \\
VAR00006 & 3,86 & 0,900 & 7 \\
VAR00007 & 4,14 & 0,690 & 7 \\
VAR00008 & 4,14 & 0,690 & 7 \\
VAR00009 & 4,43 & 0,535 & 7 \\
VAR00010 & 4,00 & 1,000 & 7 \\
VAR00011 & 3,86 & 0,690 & 7 \\
VAR00012 & 3,00 & 1,414 & 7 \\
VAR00013 & 3,71 & 1,113 & 7 \\
VAR00014 & 4,00 & 0,816 & 7 \\
VAR00015 & 3,71 & 0,951 & 7 \\
VAR00016 & 4,43 & 0,787 & 7 \\
VAR00017 & 4,00 & 0,577 & 7 \\
VAR00018 & 4,14 & 0,690 & 7 \\
\hline
\end{tabular}

Tabla 5-42 E5-P5: Estadísticos de los elementos 


\begin{tabular}{|c|c|c|c|c|c|c|c|}
\hline & Media & Mínimo & Máximo & Rango & $\begin{array}{c}\text { Máximo/mín } \\
\text { imo }\end{array}$ & $\begin{array}{c}\text { Varianz } \\
\text { a } \\
\end{array}$ & $\begin{array}{c}\mathrm{N} \text { de } \\
\text { elementos }\end{array}$ \\
\hline Medias de los elementos & 3,929 & 3,000 & 4,429 & 1,429 & 1,476 & 0,113 & 18 \\
\hline $\begin{array}{l}\text { Varianzas de los } \\
\text { elementos }\end{array}$ & 0,712 & 0,286 & 2,000 & 1,714 & 7,000 & 0,165 & 18 \\
\hline $\begin{array}{l}\text { Covarianzas inter- } \\
\text { elementos }\end{array}$ & 0,268 & $-0,333$ & 0,833 & 1,167 & $-2,500$ & 0,046 & 18 \\
\hline $\begin{array}{l}\text { Correlaciones inter- } \\
\text { elementos }\end{array}$ & 0,407 & $-0,441$ & 0,923 & 1,364 & $-2,092$ & 0,088 & 18 \\
\hline
\end{tabular}

Tabla 5-43 E5-P5: Estadísticos de resumen de los elementos

\begin{tabular}{|r|r|r|r|}
\hline \multicolumn{1}{|c|}{ Media } & Varianza & \multicolumn{1}{|c|}{$\begin{array}{c}\text { Desviación } \\
\text { típica }\end{array}$} & N de elementos \\
\hline 70,71 & 94,905 & 9,742 & 18 \\
\hline
\end{tabular}

Tabla 5-44 E5-P5: Estadísticos de la escala

\section{Gráficos descriptivos}

A continuación se presentan gráficamente las respuestas de los estudiantes, para cada una de las preguntas del cuestionario realizado.

Se utilizó la siguiente escala donde 5 es el valor máximo.

5 -> En gran medida, $4->$ En buena medida, $3 \rightarrow$ Lo suficiente, 2-> Poco, 1-> Prácticamente nada

Al finalizar cada segmento de la encuesta, se enumeran textualmente algunas opiniones sobre la experiencia de los estudiantes.

\section{Packet Tracer como herramienta de simulación}

La instalación y puesta en funcionamiento de la herramienta es sencilla.

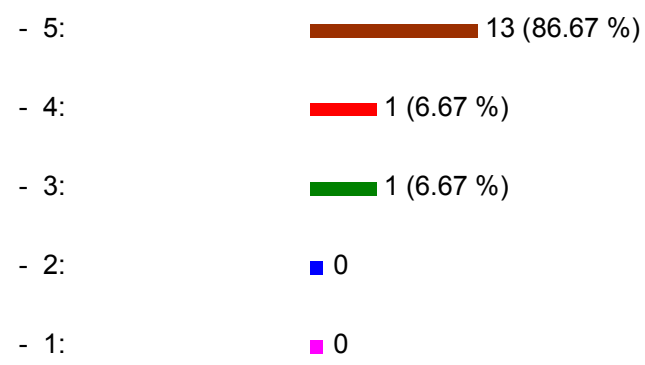

La configuración de la interfaz en idioma español es sencilla.

- 5: $\quad 8(53.33 \%)$ 


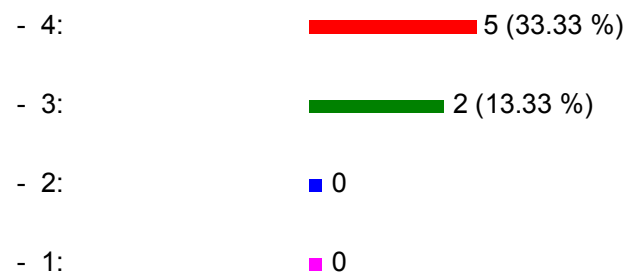

La interfaz gráfica que ofrece la aplicación es amigable e intuitiva.

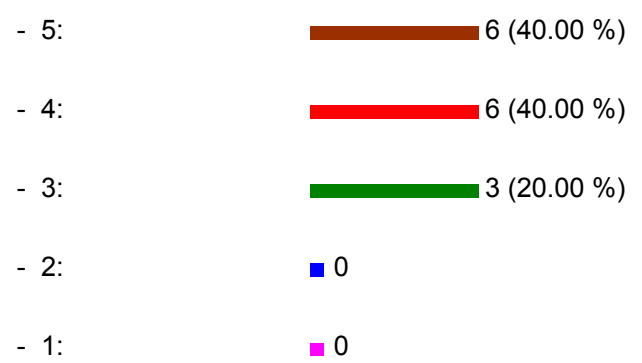

La aplicación posee los componentes necesarios para realizar un laboratorio de redes IP.

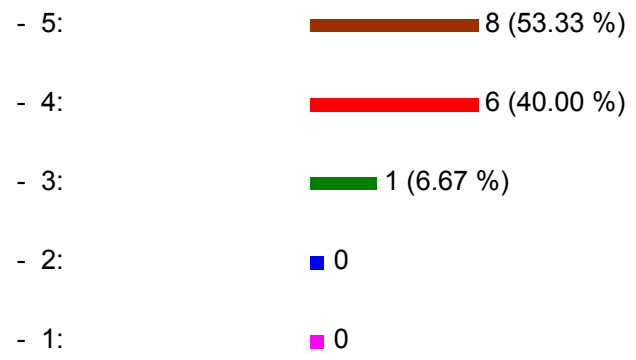

La herramienta ofrece disponibilidad que garantice la realización de los laboratorios sin interrupciones.

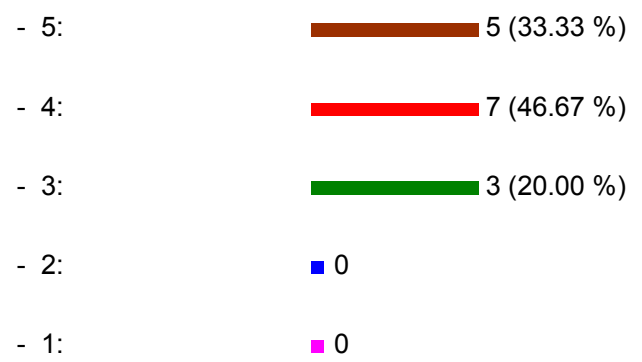

PT cuenta con ayuda que permita resolver dudas sobre el uso de la herramienta.
- 5: $\quad-0$
- 4: $9(60.00 \%)$
- 3: $4(26.67 \%)$ 


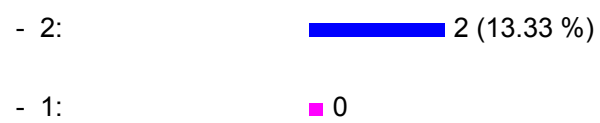

La herramienta permite realizar simulaciones claras y reales.

\begin{tabular}{|c|c|}
\hline$-5:$ & $5(33.33 \%)$ \\
\hline - 4: & $10(66.67 \%)$ \\
\hline - 3: & $\square 0$ \\
\hline$-2:$ & $\square 0$ \\
\hline & $\because 0$ \\
\hline
\end{tabular}

Con esta herramienta, la configuración de los dispositivos se desentiende de una marca particular, concentrándose en el concepto teórico.

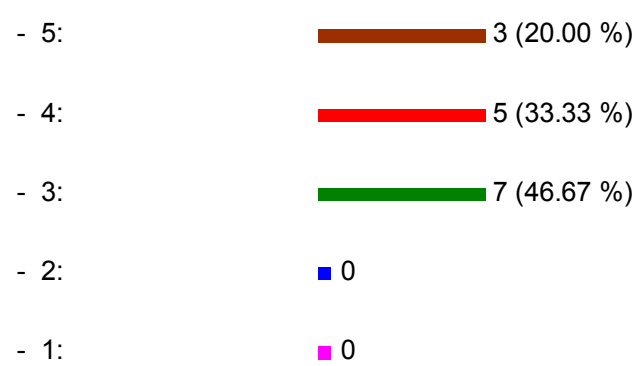

Permite realizar cambios en la topología fácilmente para adecuarla a las necesidades.

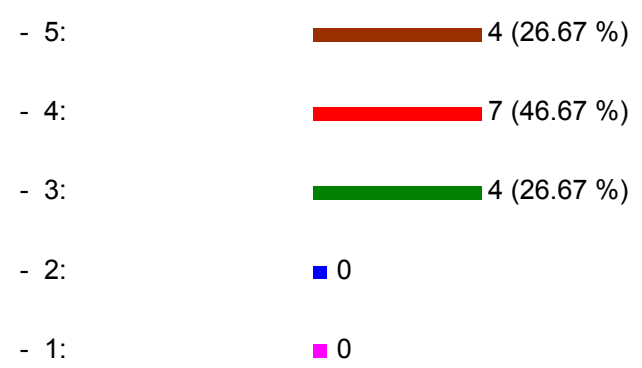

Permite simular cambios en dispositivos de manera efectiva en una determinada topología.

$\begin{array}{ll}-5: & \\ -4: & \\ -3: & \\ -3(13.33 \%) & \\ -2: & \square 0 \\ -1: & \square 0\end{array}$


La herramienta facilita el seguimiento de los eventos ocurridos en cada uno de los dispositivos dentro de la red.

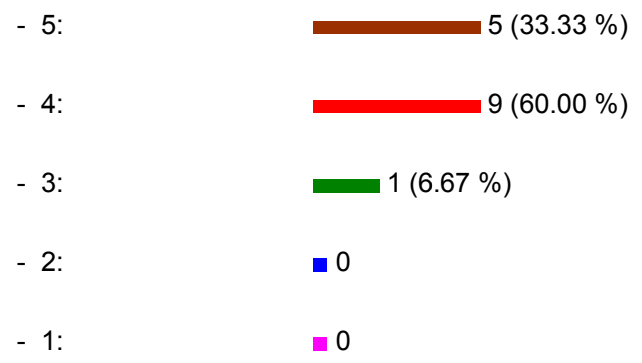

Con PT se potencializa la educación no presencial.

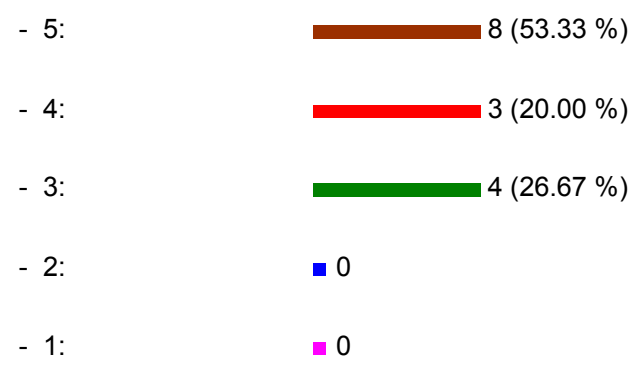

Observaciones y comentarios adicionales de los estudiantes sobre la herramienta PT

- $\quad$ Es muy buena y completa pero creería que se podría aprovecharla un poco más. Tiene un par de errores y en particular me fue muy útil para entender y practicar en la configuración de redes. Novedoso e interesante trabajo. Permite suplir las falencias de materiales de la Universidad. Sin embargo, aunque la simulación es muy real, siempre es preferible lo concreto.

Fácil de utilizar, muy intuitiva y nos ayuda a simular una red indicando la cantidad de diferentes tipos de dispositivos que queramos.

Con el PT además de poder visualizar e ilustrar todos los sucesos, permite plantearse nuevas alternativas y tratar de predecir qué sucedería.

Es una muy buena herramienta para la simulación de redes, pero que, quizás tiene aspectos muy técnicos en su configuración y como estudiante que cursa la primera materia relacionada con redes, a veces el simulador no resulta tan intuitivo.

Es muy buena y sencilla.

Una interfaz muy amigable, sencilla y concisa. Me es muy útil para terminar de comprender los conceptos teóricos de la materia.

La herramienta permite traspasar todo lo teórico a lo real o por lo menos simular grandes redes. $Y$ ver el funcionamiento de dichas redes, muy buena herramienta.

PT es una buena herramienta que nos permite aprender y conocer más de redes.

Encontramos un bug en la configuración dhcp de un router.

En mi caso no dispongo de PC en realidad la batería de mi notebook se rompió y realizo los trabajos en casa pero no es lo mismo ya que algunos conocimientos que adquiero en clase se me olvidan. Pero la herramienta en si es muy buena.

Considero que es una herramienta muy buena que permite realizar simulaciones muy reales.

hay muchos usos y dispositivos que quizás no lo utilizamos o no sabemos para que se utilizan si bien no lo usamos en la cátedra eso confunde

Me pareció una herramienta interesante que permite conocer a los estudiantes cómo funcionan las redes de computadoras. Sin embargo, me parecería importante dar a conocer a los estudiantes los diferentes dispositivos, en la medida que fuera posible que se emulan en este software y las diferencias que existen entre ellos. Esto sin dudas sería un gran complemento a la comprensión de las redes. 


\section{Packet Tracer y Los Fundamentos de Redes}

El simulador PT es adecuado para el estudio y análisis de los diferentes conceptos y fundamentos en una introducción a las redes como el Capítulo 1 del Libro.

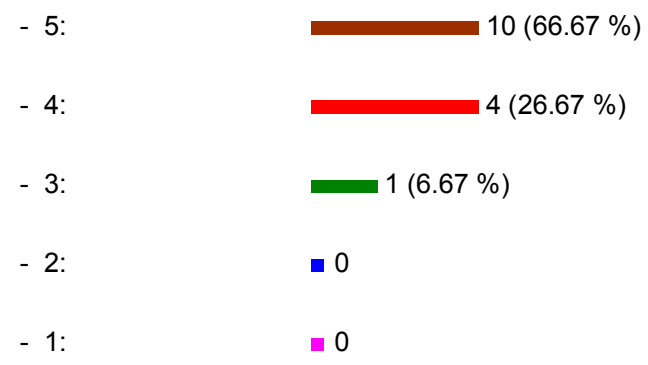

Considera adecuado el Práctico PT № 1 para comprender una mínima red hogareña.

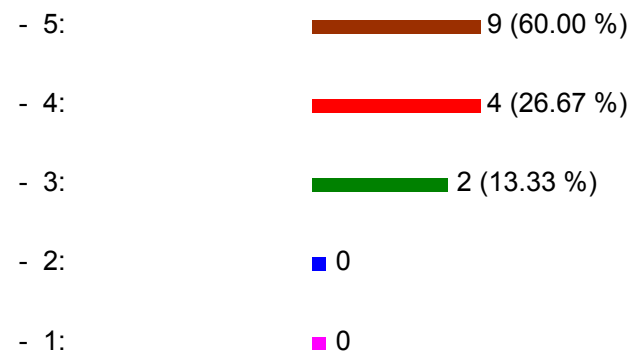

Considera adecuado el Práctico PT $\mathrm{N}^{\circ} 2$ para comprender los distintos componentes de una red empresarial compleja.

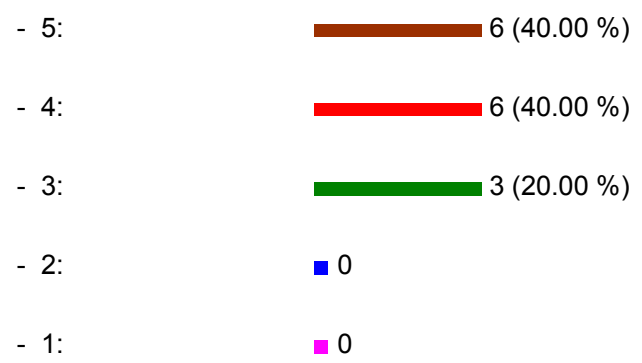

Considera adecuado el Práctico PT No 3 para comprender una red hogareña que comparte Internet.

$\begin{array}{ll}-5: & 9(60.00 \%) \\ -4: & 4(26.67 \%) \\ -3: & 2(13.33 \%) \\ -2: & 0 \\ -1: & -0\end{array}$




\section{Observaciones y comentarios adicionales de los estudiantes sobre Fundamentos}

- $\quad$ Los fundamentos básicos fueron correctamente implementados con PT

- Con los TPs desarrollados aprendí y pude entender mejor los conceptos básicos, y los fundamentos de redes.

- $\quad$ Particularmente tengo problemas con el tema de las configuraciones de los diferentes dispositivos.

- Como herramienta de simulación, permite afianzar en gran medida el aprendizaje y simulación de redes

- $\quad$ El libro elegido por la cátedra, es muy práctico, claro y específico. Muy bueno.

- Ninguno

- Ninguno

- $\quad$ El programa presenta algunas dificultades a la hora de configurar las IP y las gateways, sin embargo es el paquete más completo que existe de emulación, así que creo que es solo cuestión de tiempo a que se solucionen ciertas cosas y se eliminen los bugs.

- ninguna

- ninguno

- $\quad$ Al principio pueden parecer muchos nombres de conceptos y términos desconocidos, pero que alguna vez escuche, y al transcurrir las clases uno se va familiarizando mucho mas con esos términos y conceptos de redes y los termina asimilando

- $\quad$ Está bien diseñado y es muy útil porque se puede observar cm funciona cada uno y poderlo hacer no resulta complicado

Figura 5-59 E5: Análisis de Packet Tracer y los Fundamentos de Redes

\section{Packet Tracer y la Capa de Aplicación}

El simulador PT es adecuado para el estudio y análisis de los diferentes protocolos de Capa de Aplicación en general.

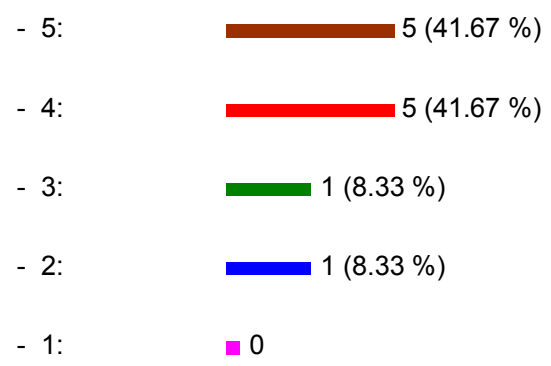

Considera adecuado el Simulador PT para el estudio y análisis del Protocolo HTTP.

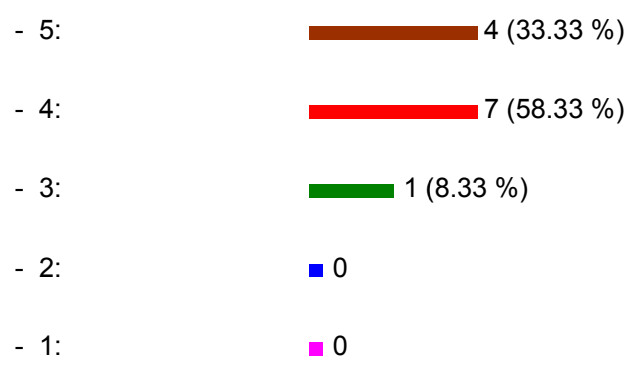

Considera adecuado el Práctico PT sobre la Vista del usuario del Protocolo HTTP. 


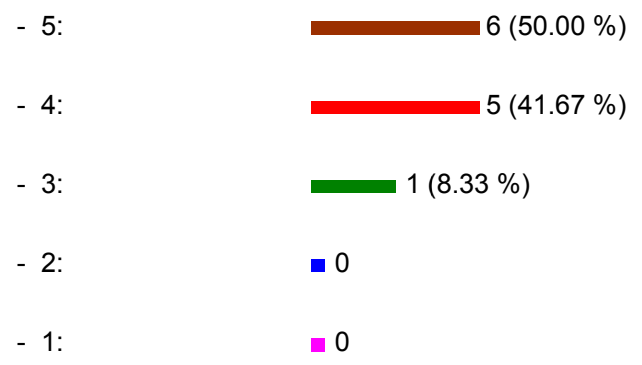

Considera adecuado el Práctico PT sobre el Análisis del Protocolo HTTP.

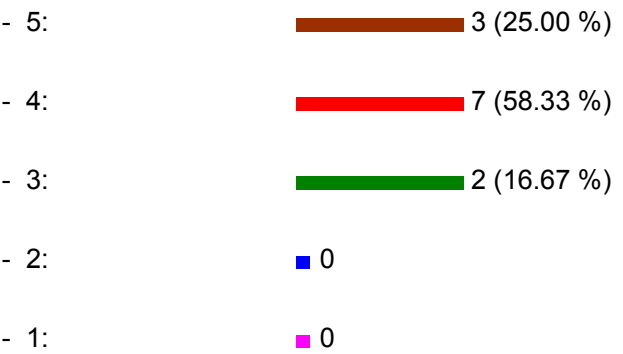

Considera adecuado el Simulador PT para el estudio y análisis del Protocolo FTP.

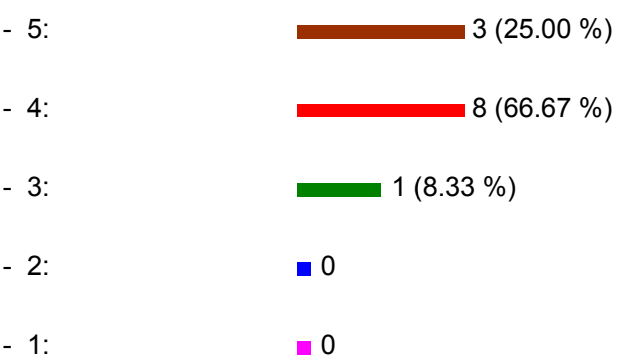

Considera adecuado el Práctico PT sobre la Vista del usuario simple del Protocolo FTP.

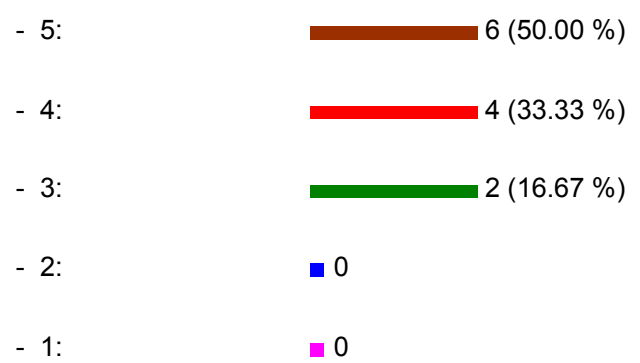

Considera adecuado el Práctico PT sobre la Vista del usuario avanzado del Protocolo FTP.
$-5:$
$5(41.67 \%)$
$-4:$ $6(50.00 \%)$
- 3: $1(8.33 \%)$ 


$\begin{array}{ll}-2: & \square 0 \\ -1: & \end{array}$

Considera adecuado el Práctico PT sobre el Análisis del Protocolo FTP.

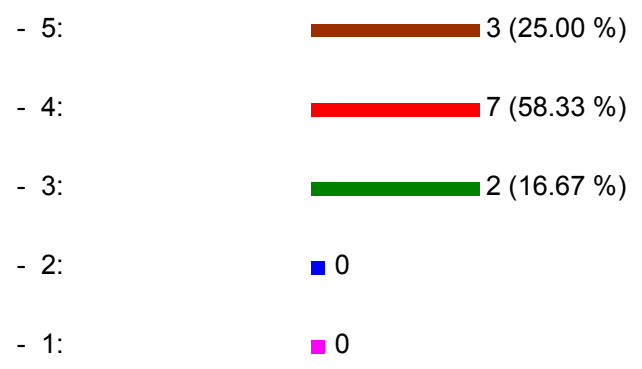

Considera adecuado el Simulador PT para el estudio y análisis del Protocolo SMTP.

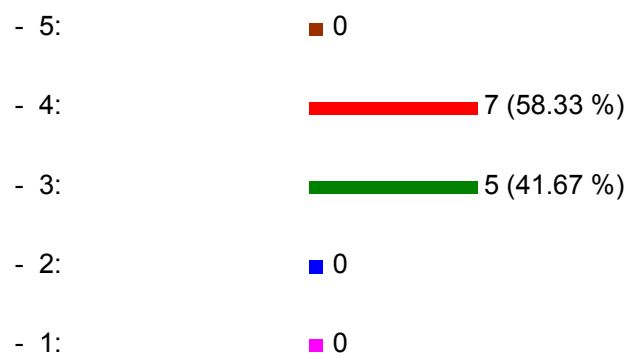

Considera adecuado el Práctico PT sobre la Vista del usuario del Protocolo SMTP.

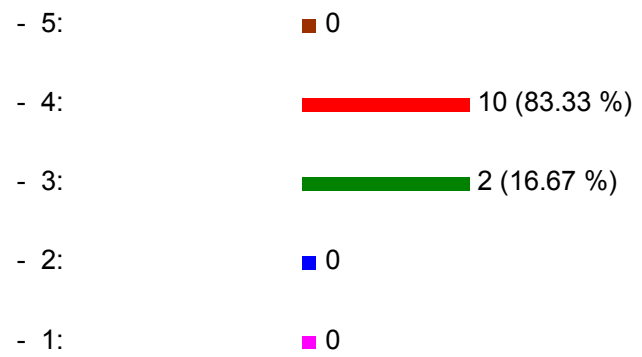

Considera adecuado el Práctico PT sobre el Análisis del Protocolo SMTP.

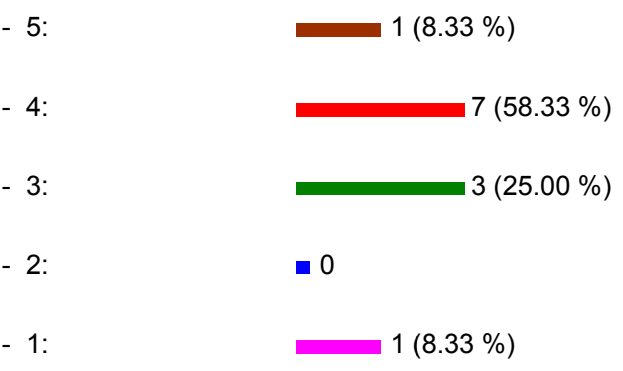

Considera adecuado el Simulador PT para el estudio y análisis del Protocolo DNS. 


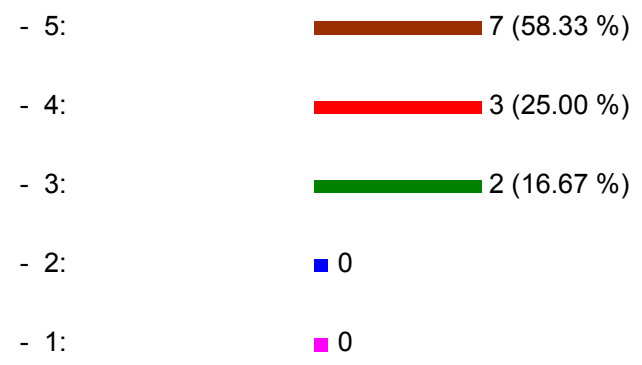

Considera adecuado el Práctico PT sobre la Vista del usuario simple del Protocolo DNS.

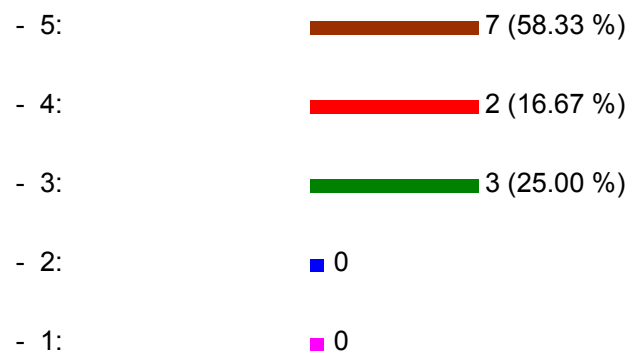

Considera adecuado el Práctico PT sobre la Vista del usuario multinivel del Protocolo DNS.

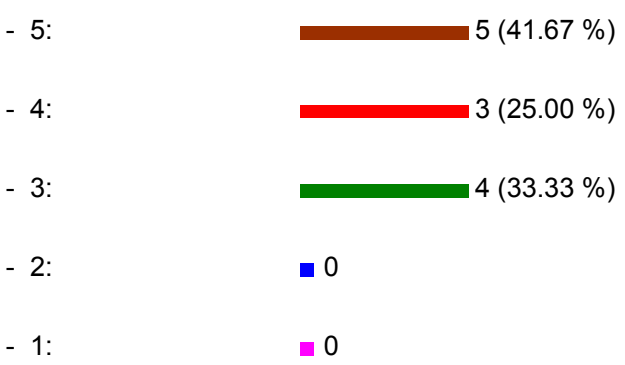

Considera adecuado el Práctico PT sobre el Análisis del Protocolo DNS.

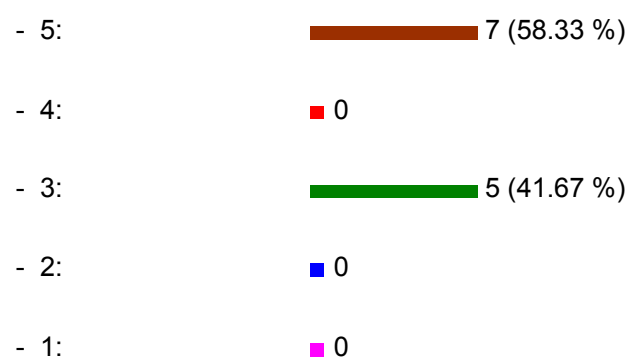

Considera adecuado el Simulador PT para el estudio y análisis del Protocolo TFTP.
-5 :
$1(8.33 \%)$
$-4:$ $6(50.00 \%)$
- 3:

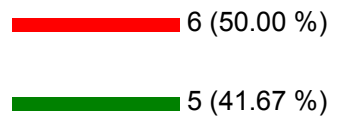




$\begin{array}{ll}-2: & \square 0 \\ -1: & \quad 0\end{array}$

Considera adecuado el Práctico PT sobre la Vista del usuario del Protocolo TFTP.

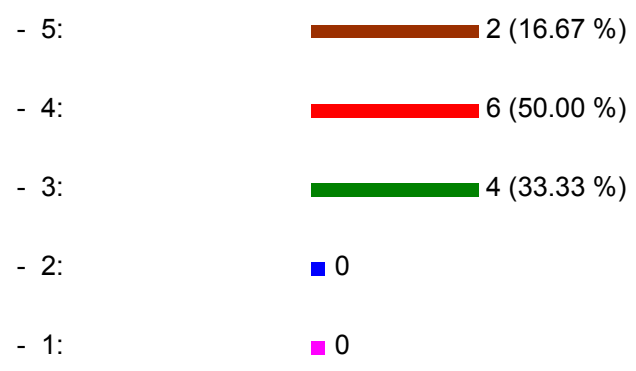

Considera adecuado el Práctico PT sobre el Análisis del Protocolo TFTP.

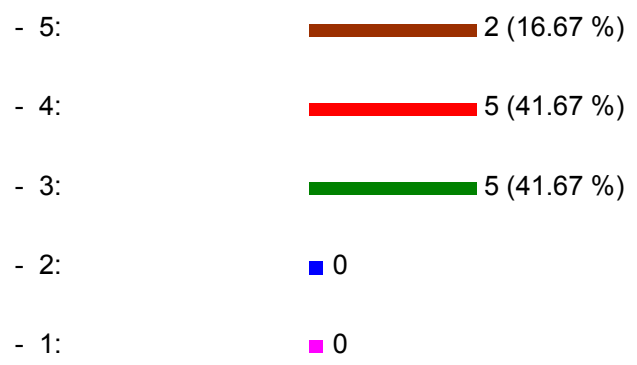

\section{Observaciones y comentarios adicionales de los estudiantes respecto de la Capa de Aplicación}

- Considero que los tps sobre la capa de aplicación estuvieron bien para ver y analizar los distintos protocolos, y entenderlos mejor y reforzar lo explicado en el libro, el mismo permitió conocer más el protocolo SMTP que al analizarlo con PT.

$-\quad-$

- La herramienta implementa una comunicación no persistente entre cliente-servidor para http, lo cual no refleja adecuadamente la realidad. Sin embargo a fines educativos y de comprender el protocolo, lo hallo bastante completo e intuitivo, no solo en http sino también en los otros protocolos. Considero además que la introducción de la herramienta wireshark por parte de la cátedra complemento mucho algunos aspectos que con el simulador no se notan.

- Por ahí esta bueno comentar antes de comenzar el práctico de cada protocolo un comentario introductorio y relación con el libro y no solo resolver las consignas.

En cuanto a lo trabajo me gusto mucho trabajar con DNS está bien implementado a lo que dice el libro

- $\quad$ sin comentarios

- $\quad$ PT se priva de un análisis más profundo sobre TCP y UDP.

- Con respecto al protocolo smtp, packet tracert todavía no tiene desarrollado de forma adecuada el protocolo para su análisis. Con respecto a DNS en mi opinión me gustaría un práctica mas larga y un poco más compleja para afirmar los conceptos teóricos, ya que a mi me resulto dificultoso comprender este tema, pero aclaro que el práctico de DNS es bastante completo.

- Considero que packet tracer funciona muy bien para analizar los diferentes protocolos.

\section{Packet Tracer y la Capa de Transporte}

El simulador PT es adecuado para el estudio y análisis de los diferentes protocolos de Capa de 


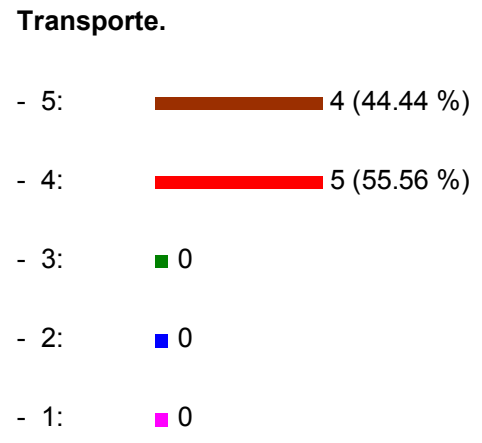

Considera adecuado el simulador PT para el estudio y análisis del Protocolo UDP.

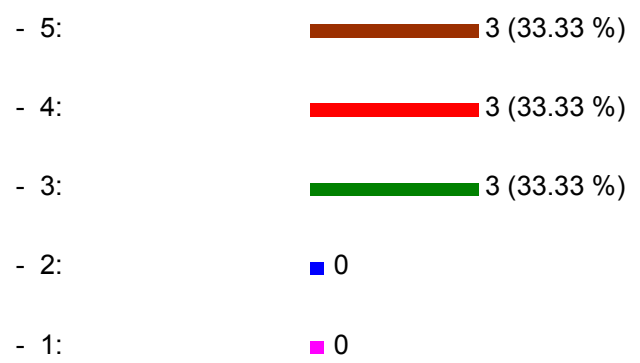

Considera adecuado el Práctico sobre el Protocolo UDP.

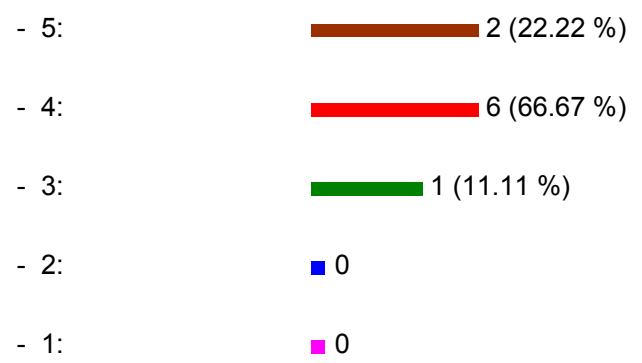

Considera adecuado el simulador PT para el estudio y análisis del Protocolo TCP.

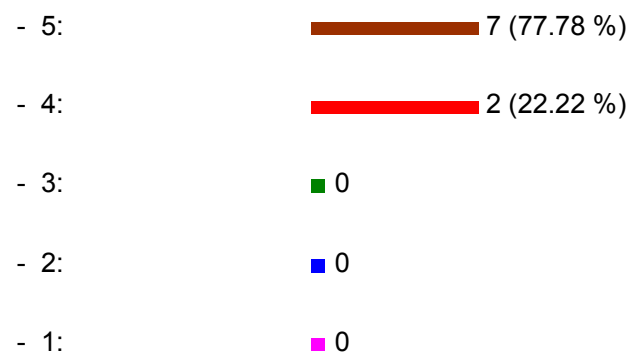

Considera adecuado el Práctico sobre el Protocolo TCP.

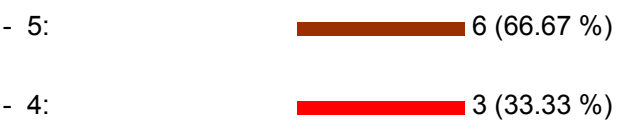




$\begin{array}{ll}-3: & \\ -2: & \\ -1: & \\ -0\end{array}$

Considera adecuado el ejemplo de captura analizado en clase práctica para la interpretación del Protocolo UDP

\begin{tabular}{|c|c|}
\hline$-5:$ & $4(44.44 \%)$ \\
\hline$-4:$ & $5(55.56 \%)$ \\
\hline - 3: & $\square 0$ \\
\hline$-2:$ & $\square 0$ \\
\hline - 1: & $\simeq 0$ \\
\hline
\end{tabular}

Considera adecuado el ejemplo de captura analizado en clase práctica para la interpretación del Protocolo TCP

$\begin{array}{ll}-5: & \\ -4: & 1(11.11 \%) \\ -3: & 1(11.11 \%) \\ -2: & \\ -1: & =0 \\ -12 \%) & \end{array}$

Considera adecuado complementar el simulador PT con análisis de captura de trafico para la Capa de Transporte

$\begin{array}{ll}-5: & \\ -4: & 1(11.11 \%) \\ -3: & 1(11.11 \%) \\ -2: & =0 \\ -1: & -0\end{array}$

\section{Observaciones y comentarios adicionales de los estudiantes respecto la Capa de Transporte} Ninguna

- El simulador funciona muy bien para el análisis de los protocolos. Sobre todo para TCP se puede ver como TCP fuerza un cierre de la conexión cuando se cierra el navegador.

- Los protocolos están implementados de forma muy real en el simulador. En esta capa tuvo mayor importancia para el aprendizaje la captura de tráfico con respecto a la capa de aplicación.

- $\quad$ ninguno

- $\quad$ Con PT se pudo analizar y ver bien la cabecera de TCP, fue muy bueno para comprender mejor y entender cómo trabaja este protocolo 
- Considero que la implementación en pt para el protocolo UDP es bastante completo. En cuanto a Tcp se encuentra bastante completa. Salvo en algunos detalles como en los que considero que no está del todo implementado como el cierre de la conexión en Tcp.

- $\quad$ no se puede analizar bien el protocolo udp con el PT en cambio si TCP, a mi criterio udp se lo puede ver mejor con el Wireshark

- TCP está muy bien implementado, solo que siempre se va a tener una conexión fiable por lo que no se pueden simular errores del protocolo como timeouts o ack duplicados. Algo que tampoco se puede observar es en cuanto a control de flujo y de congestión.

- $\quad$ Muy completo el simulador en esta unidad. Aunque hay algunos detalles que no se reflejan tal cual la realidad, sirve muchísimo para comprender como es realmente el funcionamiento de esta capa.

\section{Packet Tracer y la Capa de Red}

El simulador PT es adecuado para el estudio y análisis de los diferentes protocolos de Capa de Red.

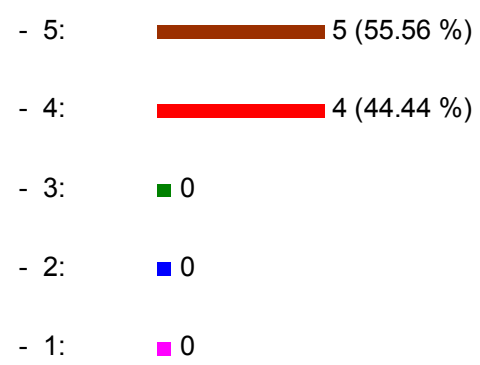

Considera adecuado el simulador PT para el estudio y análisis del Protocolo IP.

$\begin{array}{ll}-5: & \\ -4: & \\ -3: & \\ -3(77.78 \%) & 0 \\ -2: & \square 0 \\ -1: & \square 0\end{array}$

Considera adecuado el simulador PT para el estudio y análisis del Direccionamiento IP.

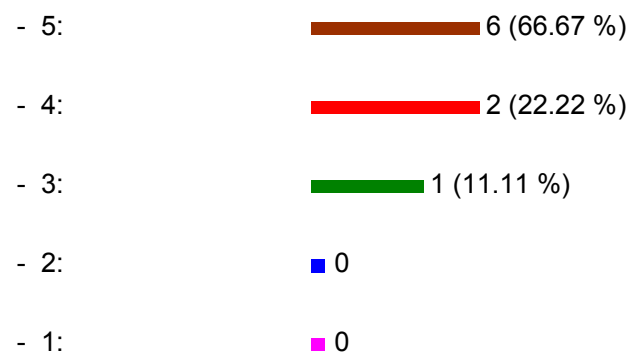

Considera adecuado los Prácticos sobre Direccionamiento Básico IP.

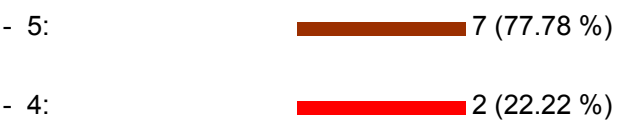




\begin{tabular}{|c|c|}
\hline - 3: & $=0$ \\
\hline - 2: & - 0 \\
\hline - 1: & $\square 0$ \\
\hline
\end{tabular}

Considera adecuado los Prácticos sobre Direccionamiento de Subred IP.

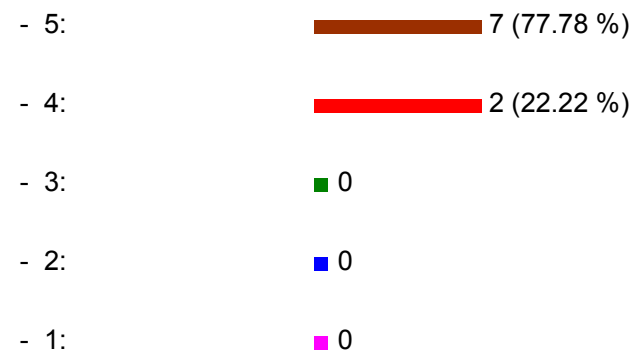

Considera adecuado los Prácticos sobre Direccionamiento VLSM IP (opcional).

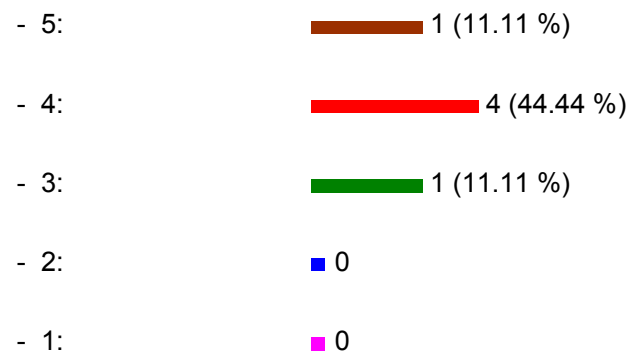

Considera adecuado el simulador PT para el estudio y análisis de la Fragmentación IP.

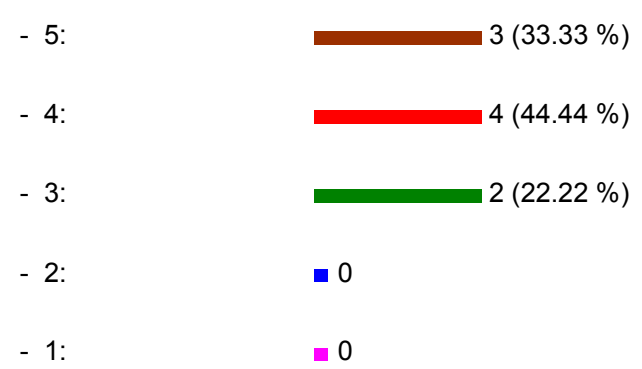

Considera adecuado el Práctico sobre Fragmentación IP.

\begin{tabular}{|c|c|}
\hline - 5: & $3(33.33 \%)$ \\
\hline$-4:$ & $3(33.33 \%)$ \\
\hline - 3: & $3(33.33 \%)$ \\
\hline$-2:$ & - 0 \\
\hline$-1:$ & $\because 0$ \\
\hline
\end{tabular}


Considera adecuado el simulador PT para el estudio y análisis del Protocolo ICMP.

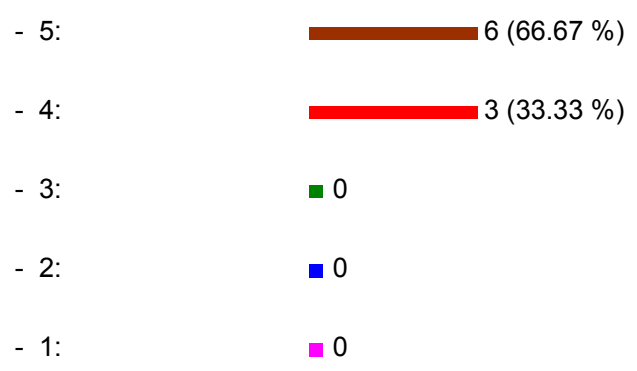

Considera adecuado el Práctico Vista del usuario sobre el Protocolo ICMP.

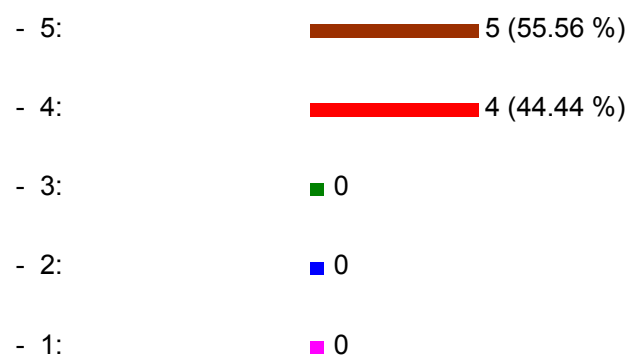

Considera adecuado el Práctico de Análisis del Protocolo ICMP.

\begin{tabular}{|c|c|}
\hline$-5:$ & $4(44.44 \%)$ \\
\hline$-4:$ & $5(55.56 \%)$ \\
\hline - 3: & $\square 0$ \\
\hline$-2:$ & - 0 \\
\hline - 1: & 0 \\
\hline
\end{tabular}

Considera adecuado el simulador PT para el estudio y análisis del Protocolo DHCP.

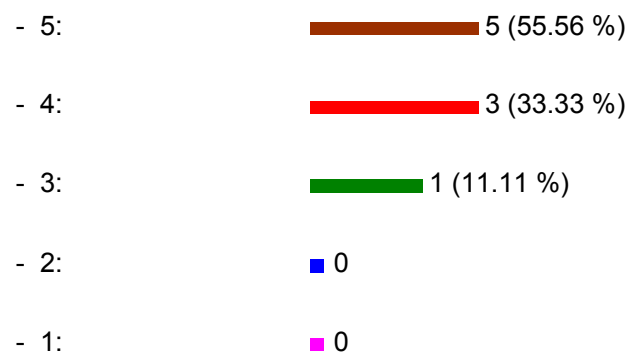

Considera adecuado el Práctico sobre el Protocolo DHCP linksys.

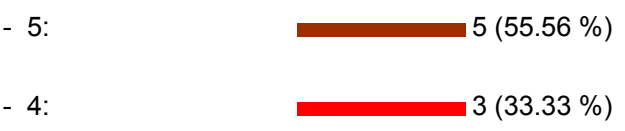




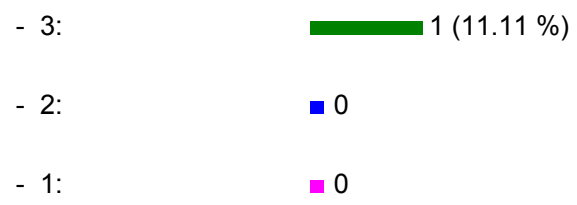

Considera adecuado el Práctico sobre el Protocolo DHCP relay.

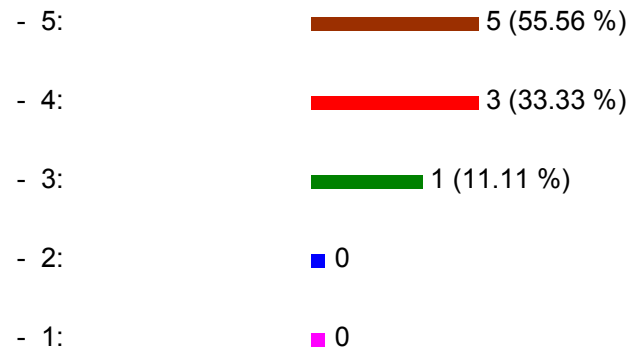

Considera adecuado el Práctico sobre el Análisis del Protocolo DHCP.

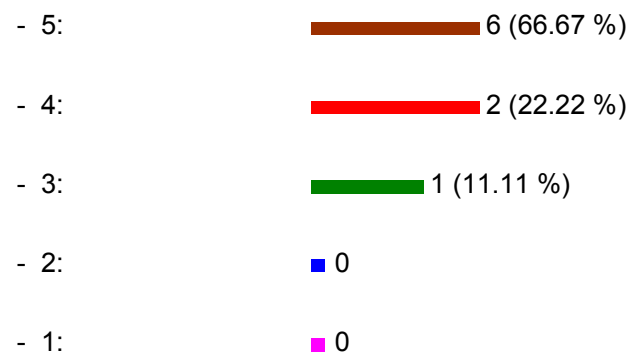

Considera adecuado el simulador PT para el estudio y análisis del Servicio NAT.

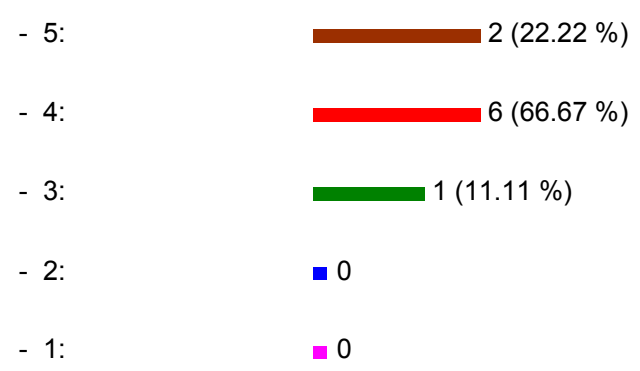

Considera adecuado el Práctico sobre el Servicio NAT linksys.

\begin{tabular}{|c|c|}
\hline$-5:$ & $2(22.22 \%)$ \\
\hline - 4: & $4(44.44 \%)$ \\
\hline - 3: & $3(33.33 \%)$ \\
\hline - 2: & 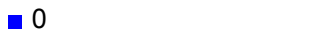 \\
\hline - 1: & $=0$ \\
\hline
\end{tabular}


Considera adecuado el Práctico sobre el Servicio NAT dinámico complejo.

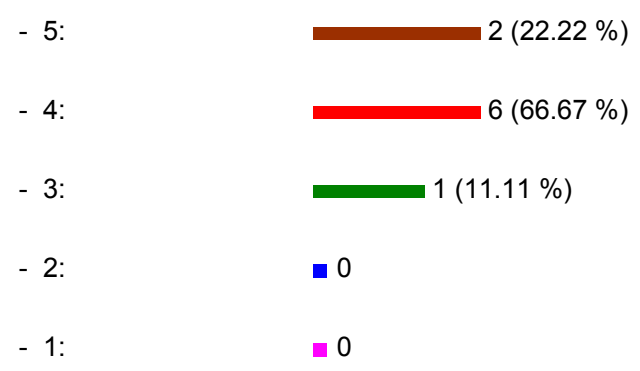

Considera adecuado el simulador PT para el estudio y análisis del Ruteo Estático.

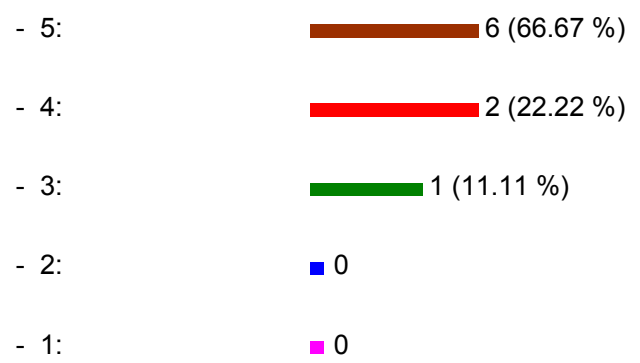

Considera adecuado el Práctico sobre Ruteo Estático.

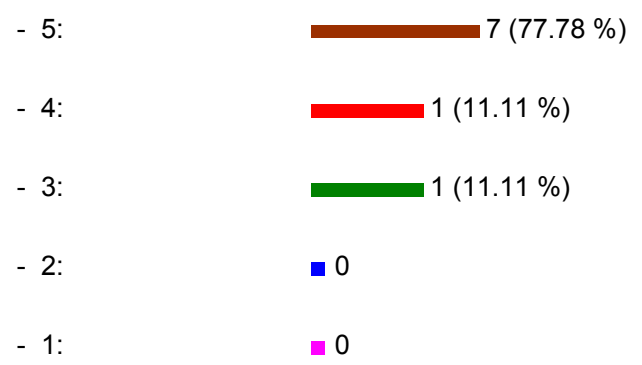

Considera adecuado el Práctico sobre Ruteo por Defecto.

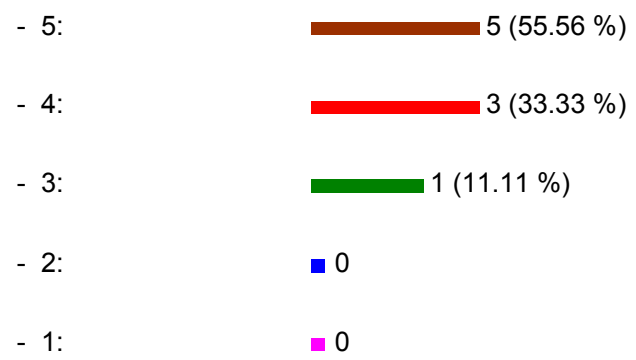

Considera adecuado el Práctico sobre Ruteo por Caminos Alternativos.

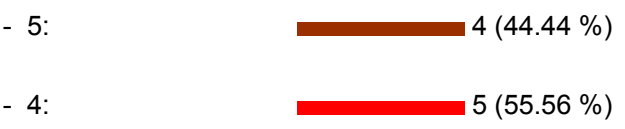




$\begin{array}{ll}-3: & =0 \\ -2: & =0 \\ -1: & =0\end{array}$

Considera adecuado el simulador PT para el estudio y análisis del Protocolo de Ruteo RIP.

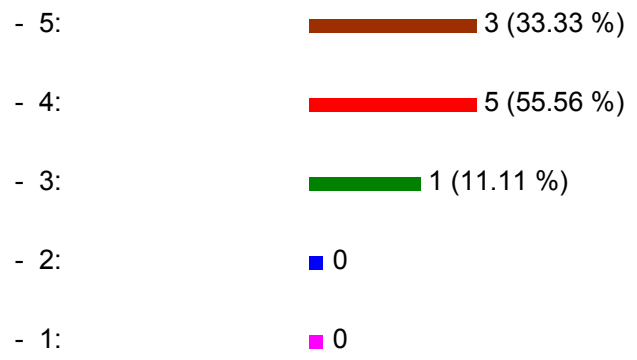

Considera adecuado el Práctico sobre del Protocolo de Ruteo RIP.

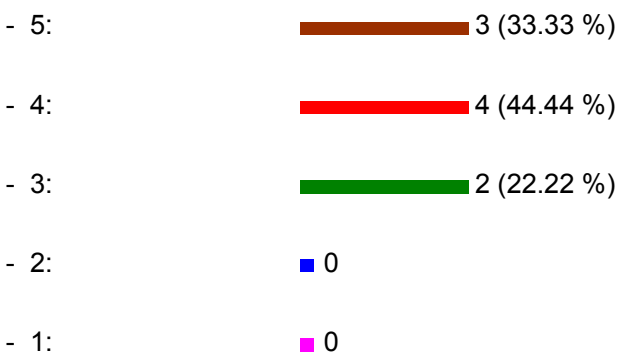

Observaciones y comentarios adicionales de los estudiantes respecto de la Capa de Red

- ninguna

- $\quad$ Lo considero muy adecuado para el estudio de esta capa

- $\quad$ sin comentarios

- $\quad$ sin comentario

- Ninguna

- $\quad$ En general, con PT se puede analizar y entender el funcionamiento de los protocolos de la Capa de Red En el caso del protocolo DHCP se puede apreciar muy bien cómo trabaja, es tal cual como el libro lo describe.

- $\quad$ Implementación bastante completa en PT.

Figura 5-60 E5: Análisis de Packet Tracer y las Capas de Aplicación, Transporte y Red

\section{Estudio actitudinal respecto de la asignatura}

Siento la inquietud de hacer simulaciones con temática de la asignatura Redes I.

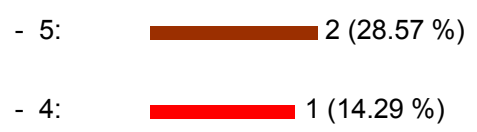




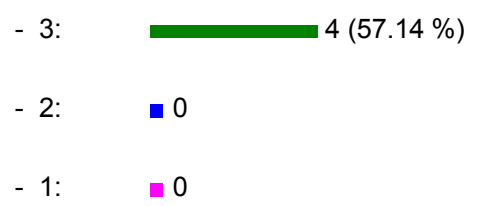

Siento la inquietud de hacer simulaciones con temática vistos en otras asignaturas.

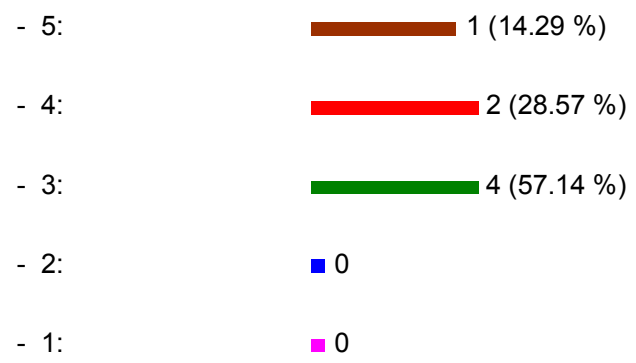

Puedo construir mis propias topologías de redes, sin las limitaciones de las redes reales.

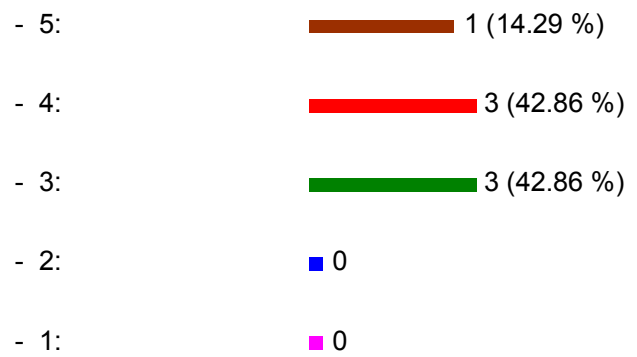

Si simulo tráfico en diferentes topologías podré comprender fácilmente como influyen los cambios en unos parámetros sobre otros.

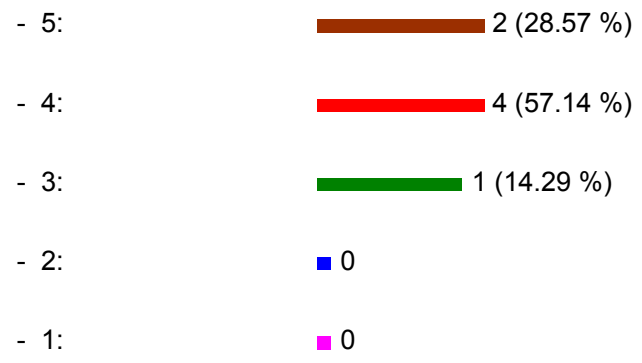

Puedo visualizar que pasa cuando cambia un parámetro o componente de la red.

$\begin{array}{ll}-5: & 2(28.57 \%) \\ -4: & 4(57.14 \%) \\ -3: & 1(14.29 \%) \\ -2: & 0 \\ -1: & =0\end{array}$


Estudio de la influencia de un entorno de simulación en la enseñanza de redes de computadoras en el nivel universitario

Puedo visualizar que variables se ven afectadas cuando cambia un parámetro o componente.

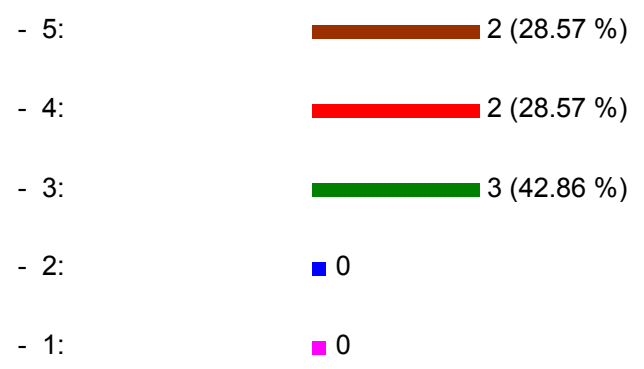

Simulando, puedo verificar las resoluciones analíticas de algunos problemas complejos ya resueltos.

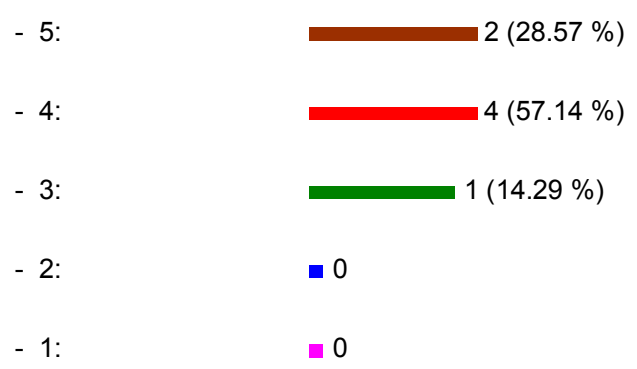

Puedo llevar al plano de lo concreto los fundamentos teóricos al resolver algunos problemas.

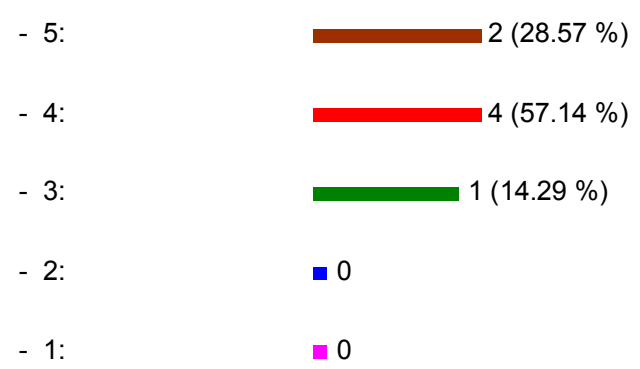

Puedo analizar los diferentes protocolos estudiados en teoría.

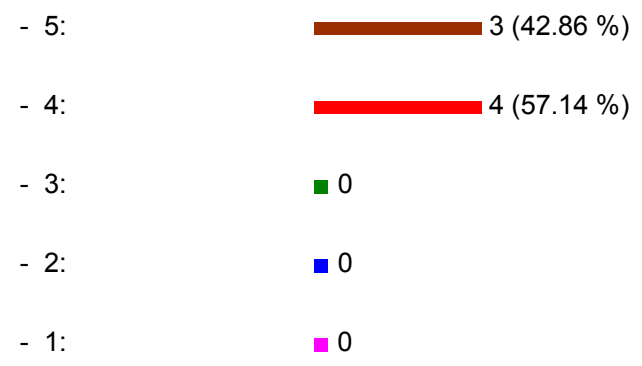

Me siento con ganas de crear y diseñar topologías de redes para experimentar con ellos.
- 5:
$3(42.86 \%)$
$-4:$
$1(14.29 \%)$ 


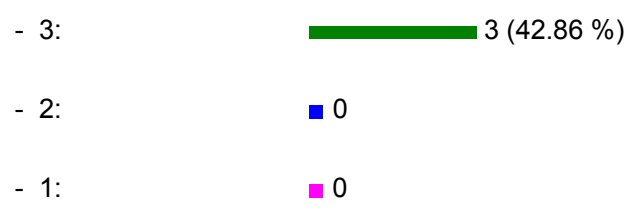

Puedo diseñar topologías y experimentar con ellas sin limitarme a los que realizamos en los TP.

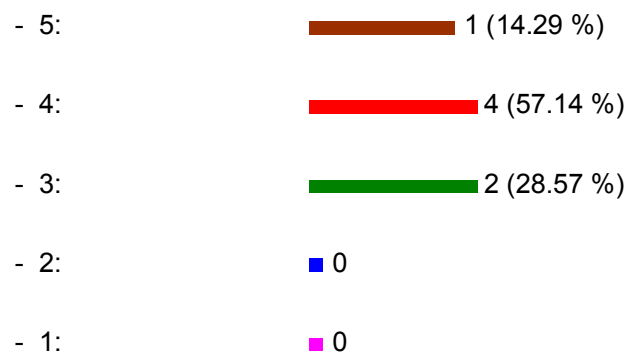

Dispongo de un laboratorio con equipos de redes virtuales, sin costo y sin peligros para realizar mis propias experiencias.

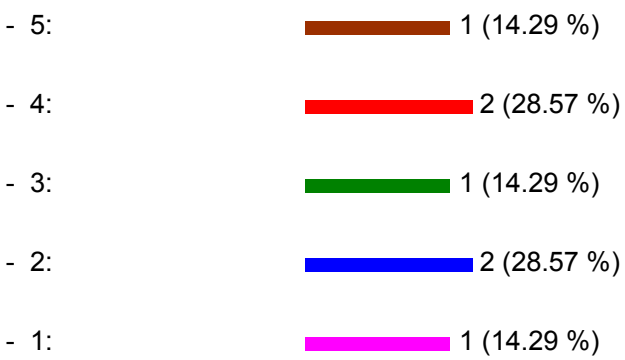

Puedo inventar nuevas topologías, probarlas y optimizarlas.

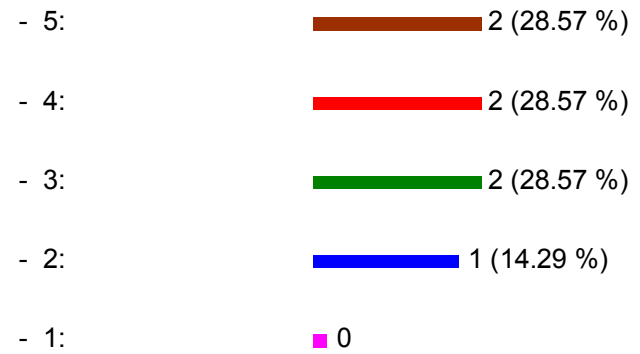

Al comprender el significado de los fundamentos teóricos, puedo deducir fácilmente, sin memorizar, los efectos de los cambios en determinados parámetros de la red.
-5 :
$2(28.57 \%)$
-4 :
$3(42.86 \%)$
- 3:
$2(28.57 \%)$
- 2:
- 0 


$$
-1: \quad-0
$$

Puedo predecir fácilmente los cambios que tendrán lugar en el comportamiento de la red, si cambian algunos parámetros.

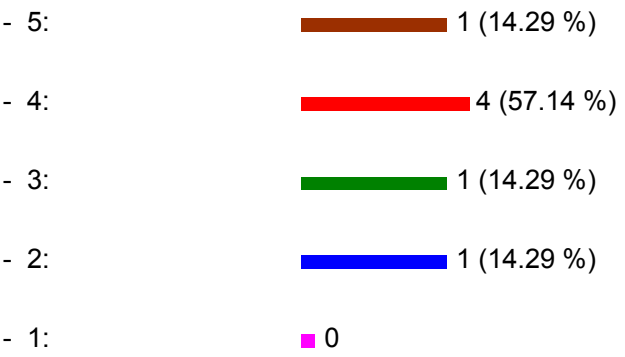

El practicar métodos de simulación, marca un antes y un después en lo que hace a mis posibilidades de analizar el funcionamiento y operación de las redes.

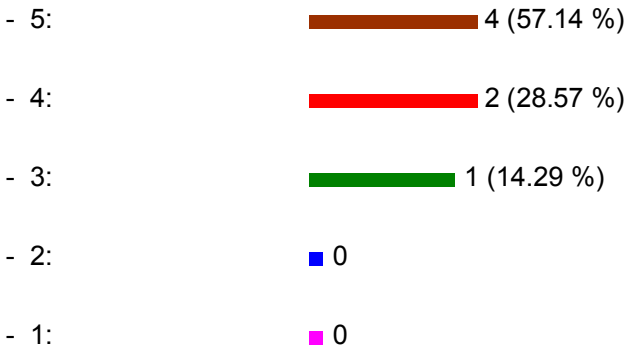

Me gustaría que simulemos redes y protocolos en todos los TP de Redes de Computadoras II.

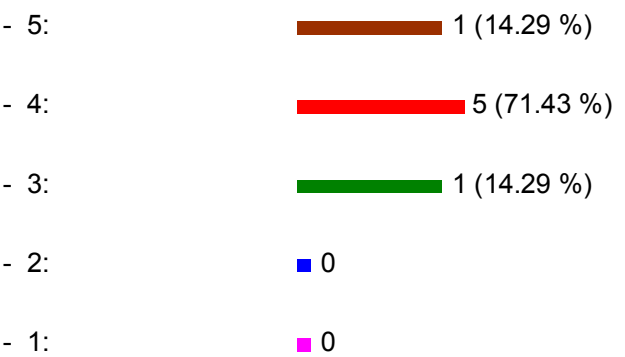

Me gustaría que simulemos casos de estudio en muchos TP de distintas asignaturas.

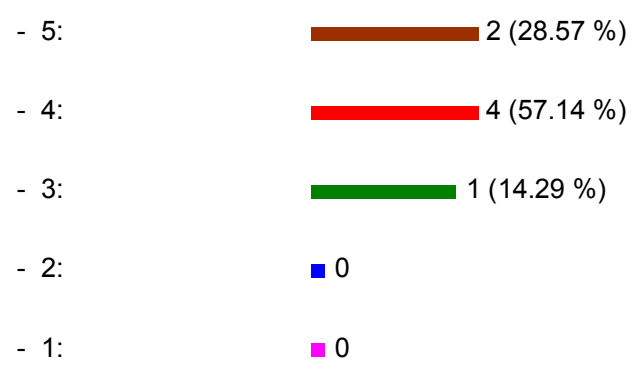

Figura 5-61 E5: Estudio actitudinal 


\subsubsection{Conclusiones de la experiencia}

De acuerdo a los resultados de las encuestas realizadas a los estudiantes para determinar el impacto de la utilización de la herramienta en la asignatura Redes de Computadoras I, se concluyó que en términos generales el acercamiento inicial fue considerado por los estudiantes como positivo.

Ahora bien, mediante la utilización de Packet Tracer como simulador de topologías de red, se evidenció que esta herramienta fue en gran medida aceptada y apoyó el proceso de enseñanza de redes IP, en particular los conceptos y fundamentos de redes con topologías sencillas, concretamente los protocolos de la capa de aplicación, los protocolos de capa de transporte y protocolos de la capa de red.

Acerca de Packet Tracer como herramienta de software se concluyó que en gran medida se consideró intuitiva a la interfaz, la simulación fue clara y real, facilitó el seguimiento de los eventos ocurridos en la simulación, la instalación y puesta en funcionamiento fueron sencillas, contó con ayuda al usuario, la configuración se independizó del fabricante, permitió realizar cambios en una topología fácilmente y cambios en dispositivos de manera efectiva.

Además, se pudo observar que los prácticos propuestos para todos los temas, en gran medida fueron considerados adecuados por los estudiantes.

Respecto del estudio actitudinal sobre la asignatura y temática estudiada, en general los estudiantes consideraron la facilidad de cambiar la topología propuesta, de llevar al plano de lo concreto los fundamentos estudiados, la facilidad de cambiar parámetros y observar el comportamiento, poder verificar resoluciones de problemas complejos. Sin embargo, cuando se indagó sobre la pregunta "Dispongo de un laboratorio con equipos de redes virtuales, sin costo y sin peligros para realizar mis propias experiencias", no parecieron estar convencidos. Lo mismo ocurrió con la pregunta "Puedo inventar nuevas topologías, probarlas y optimizarlas", lo que dio pie a proponer diferentes variantes de los ejercicios enunciados, a fin de despertar la creatividad en los estudiantes. 


\subsection{Experiencia $\mathbf{N}^{0}$ 6: Simulador MACSim en Redes de Computadoras II}

Esta experiencia se instrumentó con un grupo de estudiantes que se encontraban cursando la asignatura Redes de Computadoras II del Plan de Licenciatura en Análisis de Sistemas 2010, durante el segundo semestre del año 2014. El taller se realizó paralelamente al cursado de la asignatura.

Considerando que el simulador MACSim es una herramienta sencilla e intuitiva basada en SO DOS, el taller se llevó a cabo en 1 clase teórico-práctica de 4 horas. Se realizó el enfoque en la enseñanza de redes LAN y puntualmente de concepto del algoritmo de contención del medio CSMA/CD. En primer lugar, se realizó una exposición para todos los estudiantes con transparencias ilustrativas del algoritmo y su funcionamiento general, para luego ahondar en los detalles de tiempo de propagación de la señal en el medio y como esto influye en el normal desempeño del algoritmo. Luego se explicaron los conceptos de colisiones tardías y colisiones no detectadas con la ayuda de animaciones. Posteriormente se realizó la práctica tradicional en papel, también para todos los estudiantes, donde tenían que resolver preguntas sobre el CSMA/CD. Para el taller con el simulador se seleccionaron aleatoriamente la mitad de los estudiantes y se procedió a la resolución de una guía práctica con problemas sobre el simulador.

Finalmente, y con dos días de posterioridad, se evaluó el concepto de CSMA/CD con un cuestionario de 8 preguntas del tipo abiertas, a todos los estudiantes del curso.

\subsubsection{Análisis estadísticos de datos}

Grupos pequeños con grupo experimental Gx (con simulación). Grupo de control Gc o testigo es el que se capacita tradicionalmente.

Objetivo principal: contrastar estadísticamente si ambos grupos de estudio presentan una diferencia significativa en cuanto a alguna medida de tendencia central o de variabilidad, a los fines de poder tomar una decisión confiable sobre el beneficio o no de la aplicación de la nueva técnica de enseñanza, es decir, si el uso de la herramienta de simulación como complemento a las prácticas tradicionales, favorece el aprendizaje.

Lo ideal para este trabajo sería comprobar estadísticamente que el método de enseñanza con simulación presenta ventajas significativas con respecto al método de enseñanza tradicional.

Dado que los grupos de trabajo son relativamente pequeños, esto es, tienen un tamaño muestral pequeño $(\mathrm{N}<=10)$, para realizar las pruebas de contraste antes mencionadas en los casos que correspondiere, se utilizarán aquellas asociadas a la distribución normal o de Gauss.

En los casos en que ello no fuera posible, se recurrirá a las técnicas contempladas en la estadística no paramétrica (prescinden de la distribución de los datos).

Para el análisis de datos se utilizó el software de IBM ampliamente difundido SPSS en su versión 21.0.

La idea básica en el análisis estadístico de los datos es utilizar teoría y el software mencionado, para poder completar los resultados estadísticos descriptivos ya realizados, completándolos con estadísticas que nos permitan decidir, por ejemplo: si existe diferencia significativa entre ambas metodologías de trabajo. 
Este tipo de acciones se pueden realizar mediante test de hipótesis con respecto a medida de tendencia central, como ser media, mediana, etc.; medidas de variabilidad que permiten analizar la homogeneidad entre las respuestas de los estudiantes que participaron de las diferentes pruebas.

Se realizan los test con pruebas específicas, por ejemplo: Kolmogorov-Smirnov, coeficientes de correlación no paramétricos y gráficos específicos que permiten ver características no siempre mostradas por los gráficos descriptivos.

\section{Histogramas (Normal)}

Dibujo del Histograma (para la variable nota) y análisis de la aproximación de la curva empírica asociada al mismo a una distribución normal.

Si se comprueba estadísticamente la normalidad de los datos, se procederá a realizar un análisis bajo conceptos de estadística paramétrica; de lo contrario tendremos que utilizar pruebas incluidas en estadística no paramétrica.

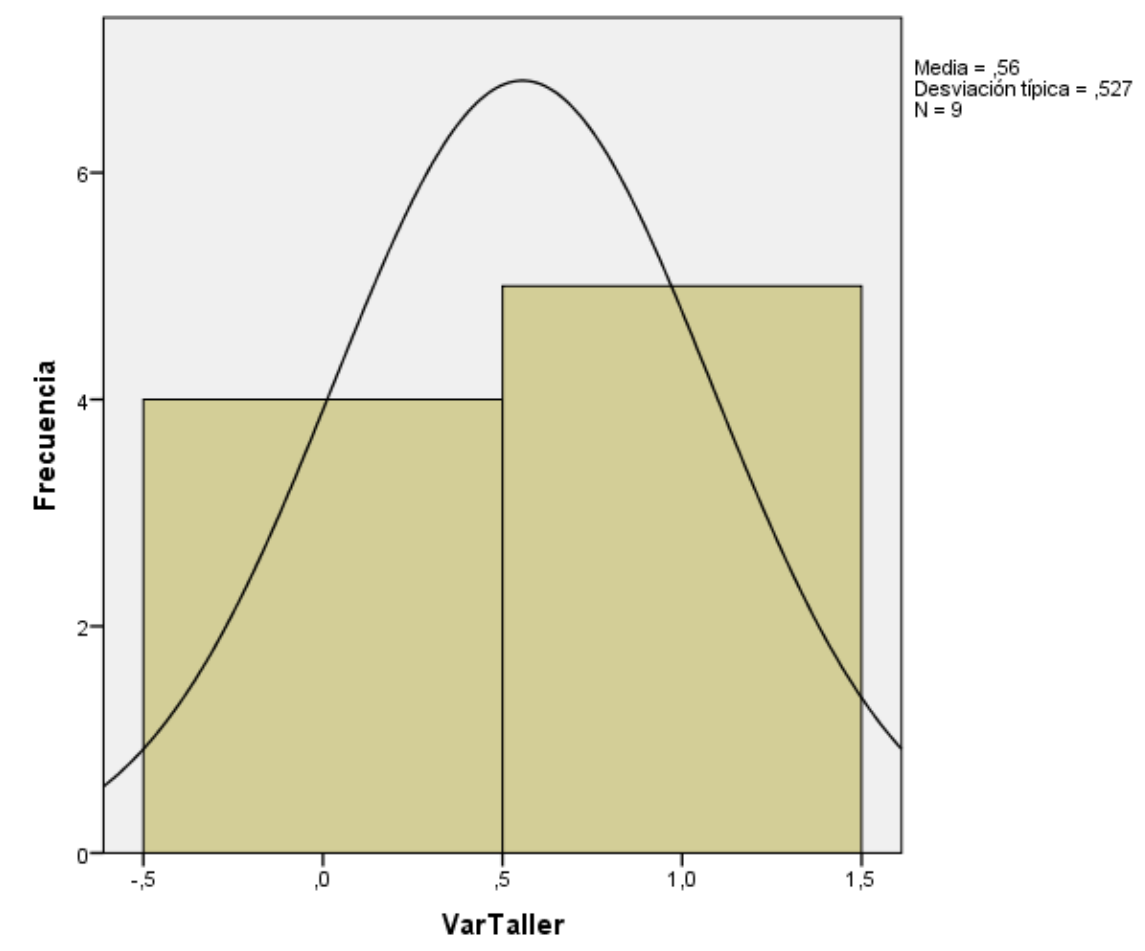

Figura 5-62 E6: Histograma para la variable Taller 


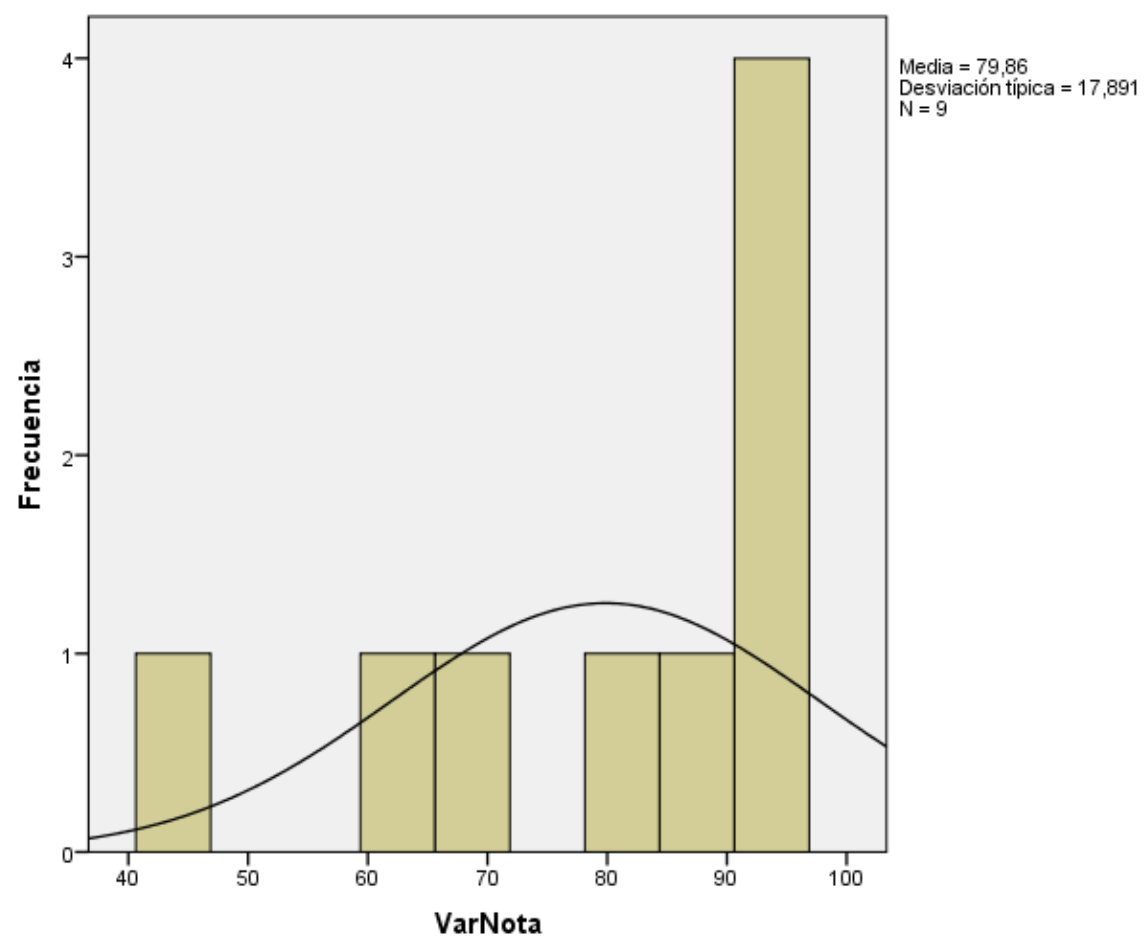

Figura 5-63 E6: Histograma para la variable Nota

Estos histogramas NO permiten tener una primera impresión del comportamiento probabilístico de los datos.

\section{Test de Kolmogorov-Smirnov - No paramétrica}

\section{Resumen de prueba de hipótesis}

\begin{tabular}{|c|c|c|c|c|}
\hline & Hipótesis nula & Test & Sig. & Decisión \\
\hline 1 & $\begin{array}{l}\text { Las categorias definidas por } \\
\text { VarTaller = Con simulación y Sin } \\
\text { simulación se producen con las } \\
\text { probabilidades de } 0,5 \text { y } 0,5 \text {. }\end{array}$ & $\begin{array}{l}\text { IPrueba binomial } \\
\text { de una muestra }\end{array}$ & $1,000^{-1}$ & $\begin{array}{l}\text { Retener la } \\
\text { hipótesis } \\
\text { nula. }\end{array}$ \\
\hline 2 & $\begin{array}{l}\text { La distribución de VarNota es } \\
\text { normal con la media } 79.861 \text { y la } \\
\text { desuiación típica } 17.89 \text {. }\end{array}$ & $\begin{array}{l}\text { Prueba } \\
\text { Kolmogorov- } \\
\text { amirnou de una } \\
\text { muestra }\end{array}$ & .749 & $\begin{array}{l}\text { Retener la } \\
\text { hipótesis } \\
\text { nula. }\end{array}$ \\
\hline
\end{tabular}

Se muestran las significancias asintóticas. El nivel de significancia es ,0E

${ }^{1}$ Se muestra la significancia exacta para esta prueba.

Tabla 5-45 E6: Test de Kolmogorov-Smirnov

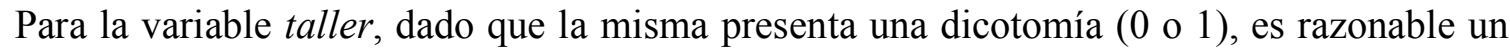
contraste de los datos con la distribución binomial, proponiendo como hipótesis nula, que ambos valores tienen la misma probabilidad de ocurrir, es igualmente probable obtener una respuesta favorable al método nuevo propuesto tanto en estudiantes que fueron sometidos al nuevo método de simulación, como en aquellos en lo que no. Con un nivel de significancia 
del $1 \%$ se acepta la hipótesis nula. (el software SPSS trabaja con un nivel de significancia del 5\%).

Para la variable nota, dado que en el histograma se observa una mayor variabilidad de datos (no hay una dicotomía como en la variable taller) parece ser más apropiado el ajuste de la distribución empírica por medio de una distribución normal como la sugerida por la curva superpuesta al histograma. Aunque a simple vista la distribución de los datos parece tener una asimetría negativa o una cola pronunciada a izquierda. Con un nivel de significancia del $0,7 \%$, se acepta la hipótesis nula de que los datos provienen de una población con distribución normal.

\section{Prueba no paramétrica}

\begin{tabular}{|c|c|c|c|c|}
\hline \multicolumn{5}{|c|}{ Rangos } \\
\hline & & $\mathrm{N}$ & $\begin{array}{c}\text { Rango } \\
\text { promedio }\end{array}$ & $\begin{array}{c}\text { Suma de } \\
\text { rangos }\end{array}$ \\
\hline \multirow{4}{*}{$G c-G x$} & Rangos negativos & $4^{a}$ & 2,50 & 10,00 \\
\hline & Rangos positivos & $0^{\mathrm{b}}$ & 0,00 & 0,00 \\
\hline & Empates & $0^{c}$ & & \\
\hline & Total & 4 & & \\
\hline
\end{tabular}
a. $\mathrm{Gc}<\mathrm{Gx}$
b. $G c>G x$
c. $G c=G x$

Tabla 5-46 E6: Prueba de los rangos con signo de Wilcoxon

Al realizar esta prueba estadística, se desea contrastar la hipótesis nula de que ambos grupos puedan mantener algún tipo de relación. Es decir, no serian independientes los tratamientos de los métodos con y sin simulación. Lo que se desea en realidad es demostrar con un nivel de confiabilidad alto $(95 \%)$ que ambos métodos conducen a resultados independientes. Por otro lado, con el cálculo de estadísticos descriptivos, se desea corroborar que el promedio de notas obtenidas por los estudiantes que estudian con simulación, es mayor que el correspondiente al de los estudiantes que estudian sin simulación. Para realizar el estudio estadístico de diferencia de medianas (que en este caso es equivalente al de diferencias de medias ya que estamos trabajando con distribuciones normales, en las que ambas coinciden), se usa la prueba de rangos de Wilcoxon, cuya tabla de resultados se muestra a continuación.

Estadísticos de contraste $^{\mathrm{a}}$

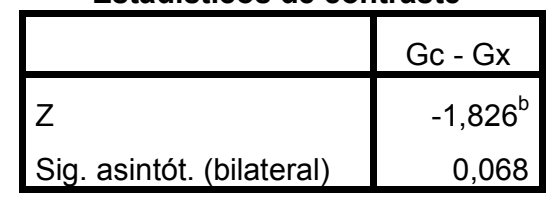

a. Prueba de los rangos con signo

de Wilcoxon

b. Basado en los rangos positivos.

Tabla 5-47 E6: Estadísticos de contraste 
En ella se observa que la significancia asintótica bilateral es aproximadamente 0,07, el cual resulta ser menor que el nivel de significancia $(0,05)$. Esto nos habilita a rechazar la hipótesis nula planteada.

Con el objetivo de complementar el resultado obtenido, se calcularon los estadísticos descriptivos: medidas de tendencia central (mediana) y desviación estándar como medida de variabilidad.

\section{Estadísticos descriptivos}

\begin{tabular}{|l|r|r|r|r|r|r|r|r|}
\hline & $N$ & Rango & Mínimo & Máximo & Media & \multicolumn{1}{|c|}{$\begin{array}{c}\text { Desv. } \\
\text { típ. }\end{array}$} & \multicolumn{2}{|c|}{ Curtosis } \\
\cline { 2 - 8 } & Estadístico & Estadístico & Estadístico & Estadístico & Estadístico & Estadístico & Estadístico & Error típico \\
\hline Gx & 4 & 6 & 88 & 94 & $\mathbf{9 2 , 1 9}$ & $\mathbf{3 , 1 2 5}$ & 4,000 & 2,619 \\
Gc & 5 & 50 & 44 & 94 & $\mathbf{7 0 , 0 0}$ & $\mathbf{1 8 , 9 5 7}$ & $-0,139$ & 2,000 \\
N válido (según & 4 & & & & & & & \\
lista) & & & & & & & & \\
\hline
\end{tabular}

Tabla 5-48 E6: Estadísticos descriptivos

El valor de la media para el grupo de estudiantes que realizaron simulación es 92,19, mayor que el correspondiente a los estudiantes que no realizaron simulación 70,0.

Se destaca además que el desvío estándar en el primer grupo, es aproximadamente del orden de la sexta parte del segundo grupo, lo cual significa que los estudiantes que realizaron simulación presentan una manifiesta homogeneidad o poca variabilidad. Esto puede considerarse como un indicador que resalta la bondad de la enseñanza con simulación.

\section{Gráfico descriptivo del concepto evaluado}

\section{Evaluación del concepto CSMA/CD}

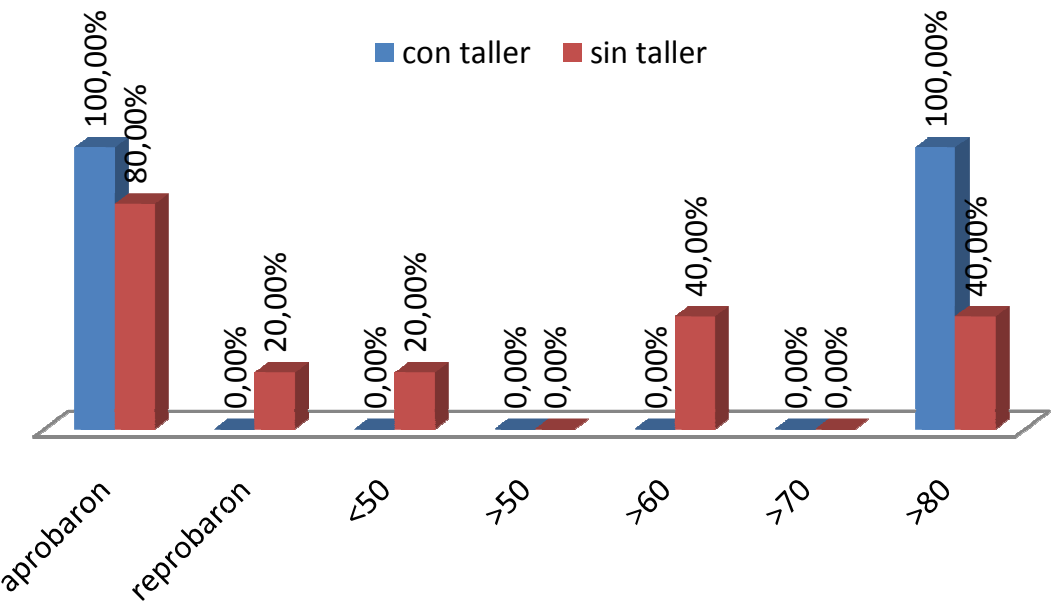

Figura 5-64 E6: Evaluación del concepto CSMA/CD 


\section{Estudio descriptivo actitudinal}

Paralelamente al estudio de conceptos para analizar el nivel de comprensión, se realizó un estudio de actitudinal de los estudiantes hacia la temática de redes de computadoras y otras temáticas del plan de estudios de la carrera Licenciatura en Análisis de Sistemas.

Para este análisis la media aritmética supera, en todos los casos, al menos el valor medio de la escala (3.00), lo que confirma la validez del contenido de todos los ítems incluidos.

Como puede observarse en la Tabla 5-49, el coeficiente Alfa de Cronbach calculado es de 0,829 que supera el valor de 0,7 (George y Mallery, 2003), lo que permite afirmar el grado de fiabilidad del cuestionario. Por lo tanto, se aprecia una alta polarización de respuestas confiables por parte de los estudiantes.

\begin{tabular}{|r|r|r|}
\hline \multicolumn{1}{|c|}{$\begin{array}{c}\text { Alfa de } \\
\text { Cronbach }\end{array}$} & $\begin{array}{c}\text { Alfa de } \\
\text { Cronbach } \\
\text { basada en los } \\
\text { elementos } \\
\text { tipificados }\end{array}$ & \\
\hline 0,747 & 0,828 & \\
\hline
\end{tabular}

Tabla 5-49 E6: Estadísticos de fiabilidad

\begin{tabular}{|l|r|r|r|}
\hline & Media & $\begin{array}{c}\text { Desviación } \\
\text { típica }\end{array}$ & $\mathrm{N}$ \\
\hline VAR00001 & 4,0000 & 0,81650 & 4 \\
VAR00002 & 3,0000 & 1,41421 & 4 \\
VAR00003 & 3,7500 & 0,95743 & 4 \\
VAR00005 & 4,0000 & 0,81650 & 4 \\
VAR00006 & 4,7500 & 0,50000 & 4 \\
VAR00007 & 4,0000 & 0,81650 & 4 \\
VAR00008 & 4,5000 & 0,57735 & 4 \\
VAR00009 & 4,2500 & 0,95743 & 4 \\
VAR00010 & 4,5000 & 0,57735 & 4 \\
VAR00011 & 3,2500 & 0,50000 & 4 \\
VAR00012 & 3,5000 & 1,29099 & 4 \\
VAR00013 & 3,0000 & 1,15470 & 4 \\
VAR00014 & 4,2500 & 0,50000 & 4 \\
VAR00015 & 4,5000 & 0,57735 & 4 \\
VAR00016 & 4,5000 & 0,57735 & 4 \\
VAR00017 & 4,0000 & 1,15470 & 4 \\
VAR00018 & 3,7500 & 0,95743 & 4 \\
\hline
\end{tabular}

Tabla 5-50 E6: Estadísticos de los elementos 


\begin{tabular}{|c|c|c|c|c|c|c|c|}
\hline & Media & Mínimo & Máximo & Rango & $\begin{array}{l}\text { Máximo/ } \\
\text { mínimo }\end{array}$ & Varianza & $\begin{array}{c}\mathrm{N} \text { de } \\
\text { elementos }\end{array}$ \\
\hline Medias de los elementos & 3,971 & 3,000 & 4,750 & 1,750 & 1,583 & 0,288 & 17 \\
\hline $\begin{array}{l}\text { Varianzas de los } \\
\text { elementos }\end{array}$ & 0,775 & 0,250 & 2,000 & 1,750 & 8,000 & 0,289 & 17 \\
\hline $\begin{array}{l}\text { Covarianzas inter- } \\
\text { elementos }\end{array}$ & 0,115 & $-1,167$ & 1,333 & 2,500 & $-1,143$ & 0,164 & 17 \\
\hline $\begin{array}{l}\text { Correlaciones inter- } \\
\text { elementos }\end{array}$ & 0,220 & $-0,944$ & 1,000 & 1,944 & $-1,059$ & 0,292 & 17 \\
\hline
\end{tabular}

Tabla 5-51 E6: Estadísticos de resumen de los elementos

\begin{tabular}{|c|r|r|r|}
\hline Media & Varianza & $\begin{array}{c}\text { Desviación } \\
\text { típica }\end{array}$ & N de elementos \\
\hline 67,5000 & 44,333 & 6,65833 & 17 \\
\hline
\end{tabular}

Tabla 5-52 E6: Estadísticos de la escala

\subsubsection{Conclusiones de la experiencia}

De acuerdo a los resultados obtenidos, se pudo determinar el impacto de la utilización del simulador MACSim en la enseñanza del algoritmo CSMA/CD en la asignatura Redes de Computadoras II de la carrera de Licenciatura en Análisis de Sistemas.

En la Figura 5-65 E5 se puede observar que el 20\% de los estudiantes que no realizaron el taller obtuvieron notas menores a 50 puntos (desaprobaron la evaluación). Además se pudo advertir del análisis realizado, que los estudiantes que sí realizaron el taller, aprobaron con mejores notas, lo que se traduce en respuestas mucho más acabadas y precisas del concepto evaluado.

De manera que los resultados evidenciaron que los estudiantes que desarrollaron la estrategia de aprendizaje con simulación tuvieron un mejor desempeño en la dimensión cognitiva. Los estudiantes que utilizaron simulación mostraron un nivel de comprensión más alto que aquellos que siguieron el método tradicional. Así, se encontró que el uso de software de simulación influyó positivamente en el mejoramiento del nivel de comprensión de los conceptos sobre el algoritmo de contención del medio estudiado.

Para esta experiencia realizada se concluyó que existió diferencia estadísticamente significativa a favor de los estudiantes que emplearon una estrategia basada en simulación para el concepto del algoritmo CSMA/CD evaluado. 


\subsection{Experiencia No 7: Simulador Packet Tracer y el Protocolo ARP en Redes de Computadoras II}

Esta experiencia se realizó con un grupo de estudiantes que se encontraba cursando la asignatura Redes de Computadoras II del nuevo Plan de Licenciatura en Análisis de Sistemas Año 2010 durante el segundo semestre del año 2014. El taller se realizó paralelamente al cursado de la asignatura, lo que permitió evaluar el desempeño tanto de los estudiantes que participaron del mismo, como de los que no participaron.

Considerando que el simulador Packet Tracer es intuitivo y estos estudiantes ya tuvieron su primer contacto con el mismo simulador en la asignatura Redes de Computadoras I durante el primer semestre del 2014, el taller se llevó a cabo en 1 clase teórico-práctica de 4 horas. El enfoque se centró en la enseñanza del Protocolo ARP, resolución local en la misma LAN y resolución remota cuando el destino está fuera de la LAN y se debe atravesar un router. En primer lugar, se realizó una exposición para todos los estudiantes con transparencias ilustrativas de la resolución local de ARP, luego se presentó una animación donde se podía observar las distintas etapas de la resolución remota (mapeo de direcciones IP y MAC en cada instancia). Posteriormente se realizó la práctica tradicional en papel, también para todos los estudiantes, donde tenían que resolver preguntas sobre el protocolo. Para el taller con el simulador se seleccionaron aleatoriamente la mitad de los estudiantes y se procedió a la resolución de una guía práctica con problemas sobre el simulador.

Finalmente, con varios días de posterioridad y luego de una clase de consulta, se evaluó el concepto del Protocolo ARP, con un cuestionario de 6 preguntas a todos los estudiantes del curso.

El objetivo de esta evaluación fue analizar el impacto del uso de la herramienta por los estudiantes que realizaron el taller de simulación.

\subsubsection{Análisis estadísticos de datos}

\section{Histogramas (Normal)}


Estudio de la influencia de un entorno de simulación en la enseñanza de redes de computadoras en el nivel universitario

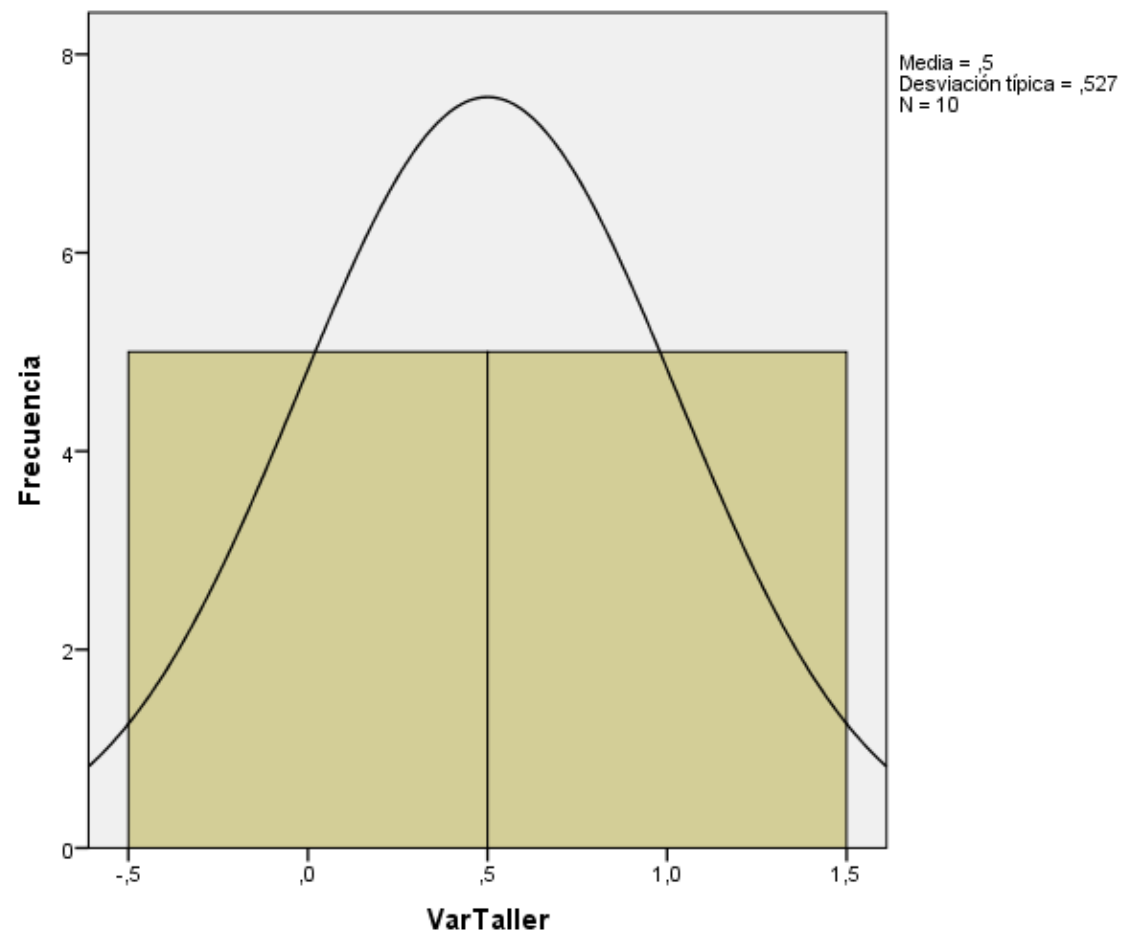

Figura 5-65 E7: Histograma de la variable Taller

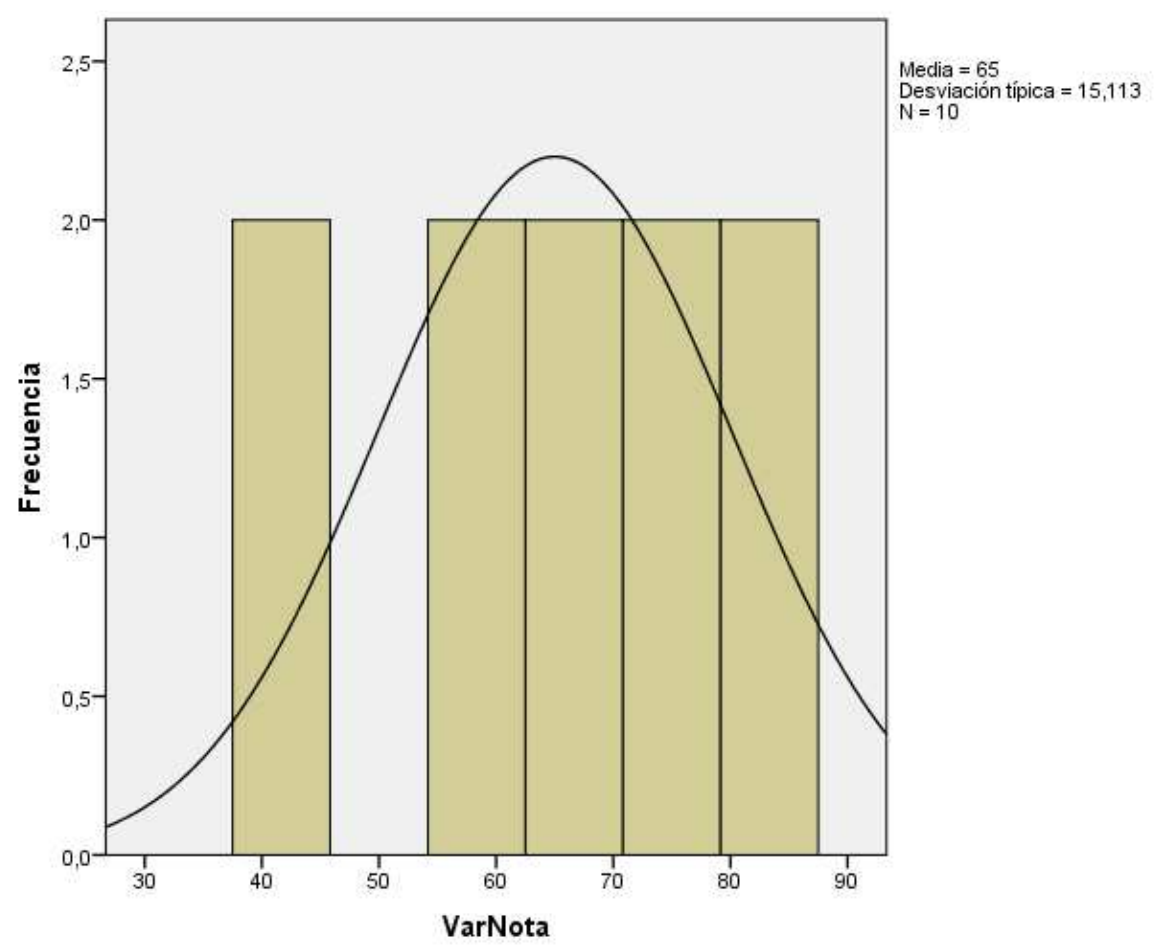

Figura 5-66 E7: Histograma de la variable Nota 
Estos histogramas no permiten tener una primera impresión del comportamiento probabilístico de los datos.

\section{Test de Kolmogorov-Smirnov - No paramétrica}

\begin{tabular}{|c|c|c|c|}
\hline \multicolumn{4}{|c|}{ Resumen de prueba de hipótesis } \\
\hline & Hipótesis nula & Sig. & Decisión \\
\hline 1 & $\begin{array}{l}\text { Las categorias definidas por } \\
\text { VarTaller = Con simulación y Sirfrueba binomial } \\
\text { simulación se producen con las de una muestra } \\
\text { probabilidades de } 0,5 \text { y } 0,5 \text {. }\end{array}$ & $1,000^{-1}$ & $\begin{array}{l}\text { Retener la } \\
\text { hipótesis } \\
\text { nula. }\end{array}$ \\
\hline 2 & $\begin{array}{l}\text { La distribución de VarNota es } \\
\text { normal con la media } 65,000 \text { y la labagorov- } \\
\text { desuiación típica } 15,11 .\end{array}$ & .983 & $\begin{array}{l}\text { Retener la } \\
\text { hipótesis } \\
\text { nula. }\end{array}$ \\
\hline
\end{tabular}

Tabla 5-53 E7: Test de Kolmogorov-Smirnov

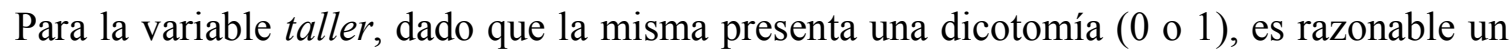
contraste de los datos con la distribución binomial, proponiendo como hipótesis nula, que ambos valores tienen la misma probabilidad de ocurrir, es igualmente probable obtener una respuesta favorable al método nuevo propuesto tanto en estudiantes que fueron sometidos al nuevo método de simulación, como en aquellos en lo que no. Con un nivel de significancia del 1\% se acepta la hipótesis nula. (el software SPSS trabaja con un nivel de significancia del 5\%). Para la variable nota, dado que en el histograma se observa una mayor variabilidad de datos (no hay una dicotomía como en la variable taller) parece ser más apropiado el ajuste de la distribución empírica por medio de una distribución normal como la sugerida por la curva superpuesta al histograma. Aunque a simple vista la distribución de los datos parece tener una asimetría negativa o una cola pronunciada a izquierda. Con un nivel de significancia del $0,98 \%$, se acepta la hipótesis nula de que los datos provienen de una población con distribución normal.

\section{Prueba de los rangos con signo de Wilcoxon - Prueba no paramétrica}

\begin{tabular}{|rl|r|r|r|}
\hline & $\mathrm{N}$ & Rango promedio & Suma de rangos \\
\hline \multirow{3}{*}{ Rangos negativos } & $4^{\mathrm{a}}$ & 3,50 & 14,00 \\
Gc - Gx & Rangos positivos & $1^{\mathrm{b}}$ & 1,00 & 1,00 \\
& Empates & $0^{\mathrm{c}}$ & & \\
& Total & 5 & & \\
\hline
\end{tabular}
a. $\mathrm{Gc}<\mathrm{Gx}$
b. $G c>G x$
c. $G c=G x$
Tabla 5-54 E7: Prueba de los rangos con signo de Wilcoxon 
Estadísticos de contraste ${ }^{a}$

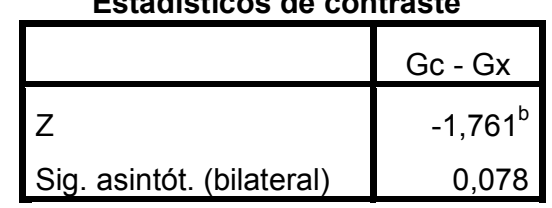
a. Prueba de los rangos con signo
de Wilcoxon
b. Basado en los rangos positivos.

Tabla 5-55 E7: Estadísticos de contraste

En ella se observa que la significancia asintótica bilateral es aproximadamente 0,07 , el cual resulta ser menor que el nivel de significancia $(0,05)$. Esto permite rechazar la hipótesis nula planteada.

\section{Estadísticos descriptivos}

\begin{tabular}{|l|r|r|r|r|r|r|r|}
\hline & \multicolumn{1}{|c|}{$\mathrm{N}$} & \multicolumn{1}{c|}{ Mínimo } & Máximo & \multicolumn{1}{c|}{ Media } & Desv. típ. & \multicolumn{2}{|c|}{ Curtosis } \\
\cline { 2 - 8 } & Estadístico & Estadístico & Estadístico & Estadístico & Estadístico & Estadístico & Error típico \\
\hline $\mathrm{Gx}$ & 5 & 67 & 83 & $\mathbf{7 5 , 0 0}$ & $\mathbf{8 , 3 3 3}$ & $-3,000$ & 2,000 \\
$\mathrm{Gc}$ & 5 & 42 & 75 & $\mathbf{5 5 , 0 0}$ & $\mathbf{1 3 , 9 4 4}$ & $-0,612$ & 2,000 \\
N válido (según & 5 & & & & & & \\
lista) & & & & & & & \\
\hline
\end{tabular}

Tabla 5-56 E7: Estadísticos descriptivos

El valor de la media para el grupo de estudiantes que realizó simulación es 75,00, mayor que el correspondiente a los estudiantes que no realizaron simulación 55,0.

Se destaca además que el desvío estándar en el primer grupo, es aproximadamente del orden de la mitad del segundo grupo, lo cual significa que los estudiantes que realizaron simulación presentan una manifiesta homogeneidad o menor variabilidad.

Esto puede considerarse como un indicador que resalta el beneficio de la enseñanza con simulación. 


\section{Gráfico descriptivo del concepto evaluado}

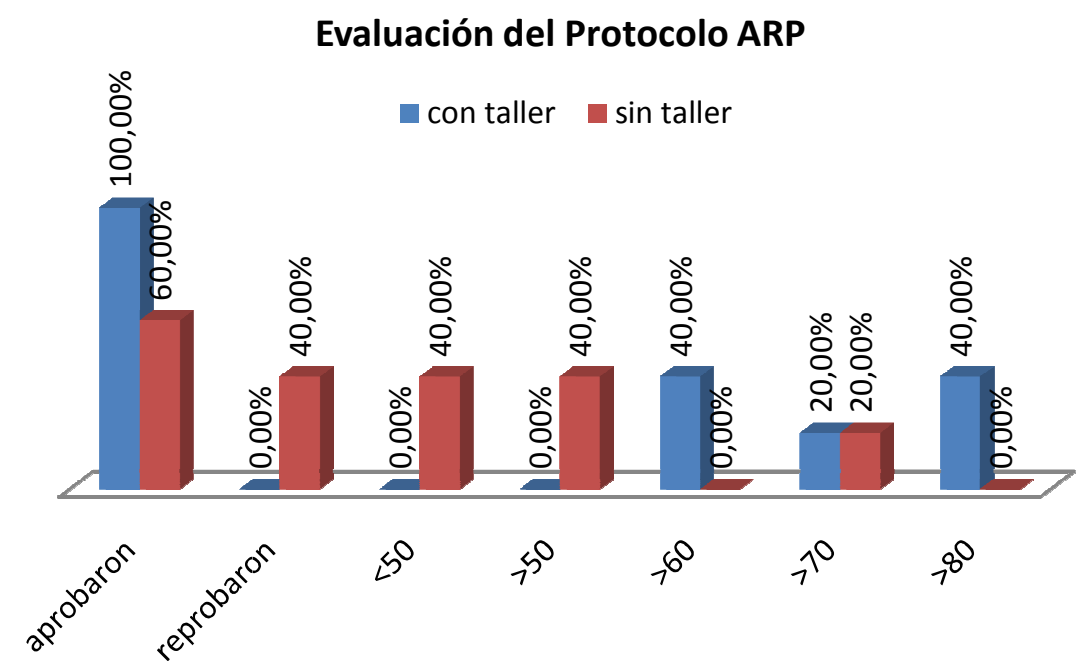

Figura 5-67 E7: Evaluación del Protocolo ARP

\subsubsection{Conclusiones de la experiencia}

De acuerdo a los resultados obtenidos se pudo determinar el impacto de la utilización del simulador Packet Tracer en la enseñanza del Protocolo ARP en la asignatura Redes de Computadoras II.

Del análisis realizado, se puede observar en la Figura 5-68 E7 que el 40\% de los estudiantes que no realizó el taller obtuvo notas menores a 50 puntos (desaprobaron la evaluación). Además se pudo advertir, que los estudiantes que sí realizaron el taller, aprobaron con mejores notas, lo que se traduce en respuestas mucho más acabadas y precisas del concepto evaluado.

Para esta experiencia realizada, se concluyó que existió diferencia estadísticamente significativa a favor de los estudiantes que emplearon una estrategia basada en simulación para el concepto del protocolo ARP evaluado. 


\subsection{Experiencia $\mathrm{N}^{0}$ 8: Simulador MACSim en Conectividad y Teleinformática}

Esta experiencia se realizó con un grupo de estudiantes que se encontraba cursando la asignatura Conectividad y Teleinformática del viejo Plan de Licenciatura en Análisis de Sistemas 1997 en extinción durante el segundo semestre del año 2014. El taller se realizó paralelamente al cursado de la asignatura.

Esta experiencia fue una réplica de lo realizado en la Experiencia $\mathrm{N}^{0}$ 6, utilizando el mismo diseño metodológico dado que se emplea la misma metodología de trabajo en un grupo de estudiantes que por pertenecer al plan de estudios en extinción, presentan similitud frente a los otros casos en los que se aplicó el mismo protocolo de trabajo.

\subsubsection{Análisis estadísticos de datos}

\section{Histogramas (Normal)}

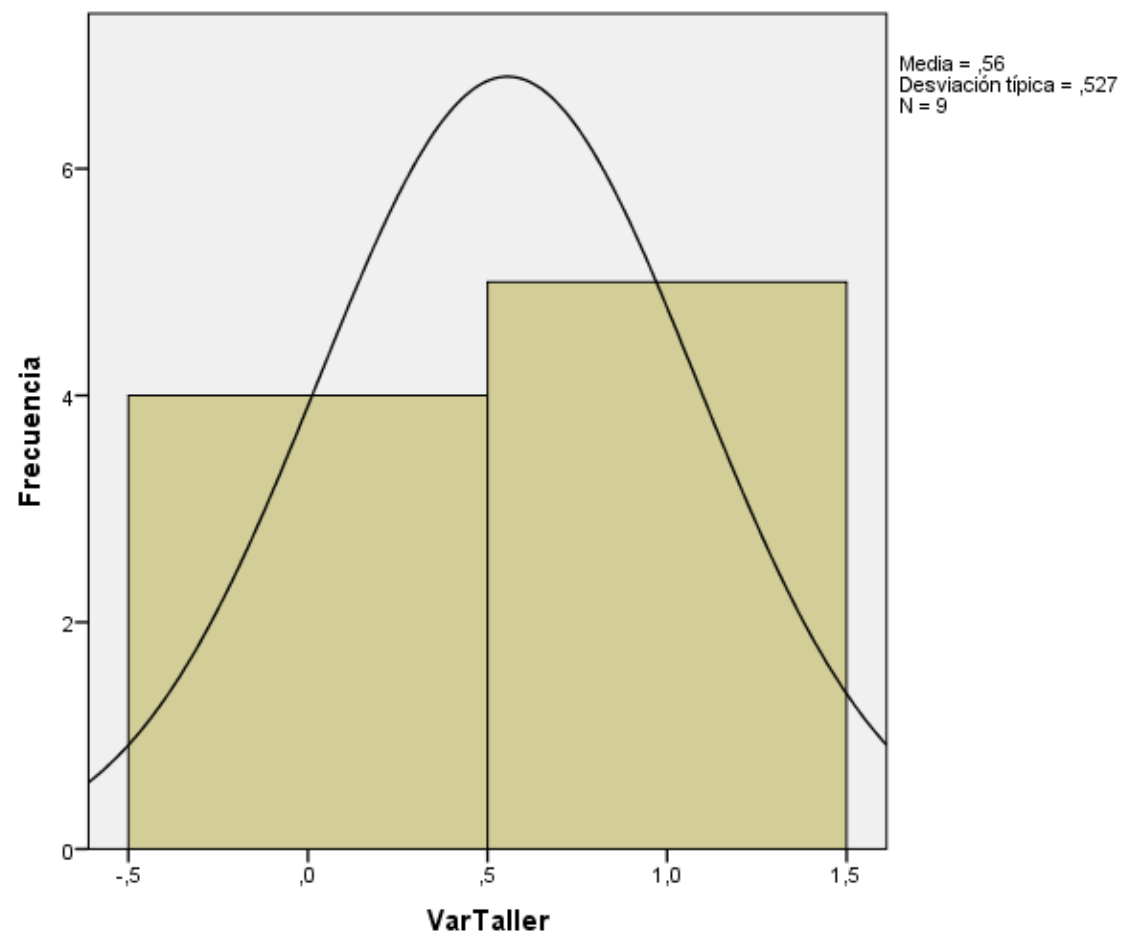

Figura 5-68 E8: Histograma de la variable Taller 


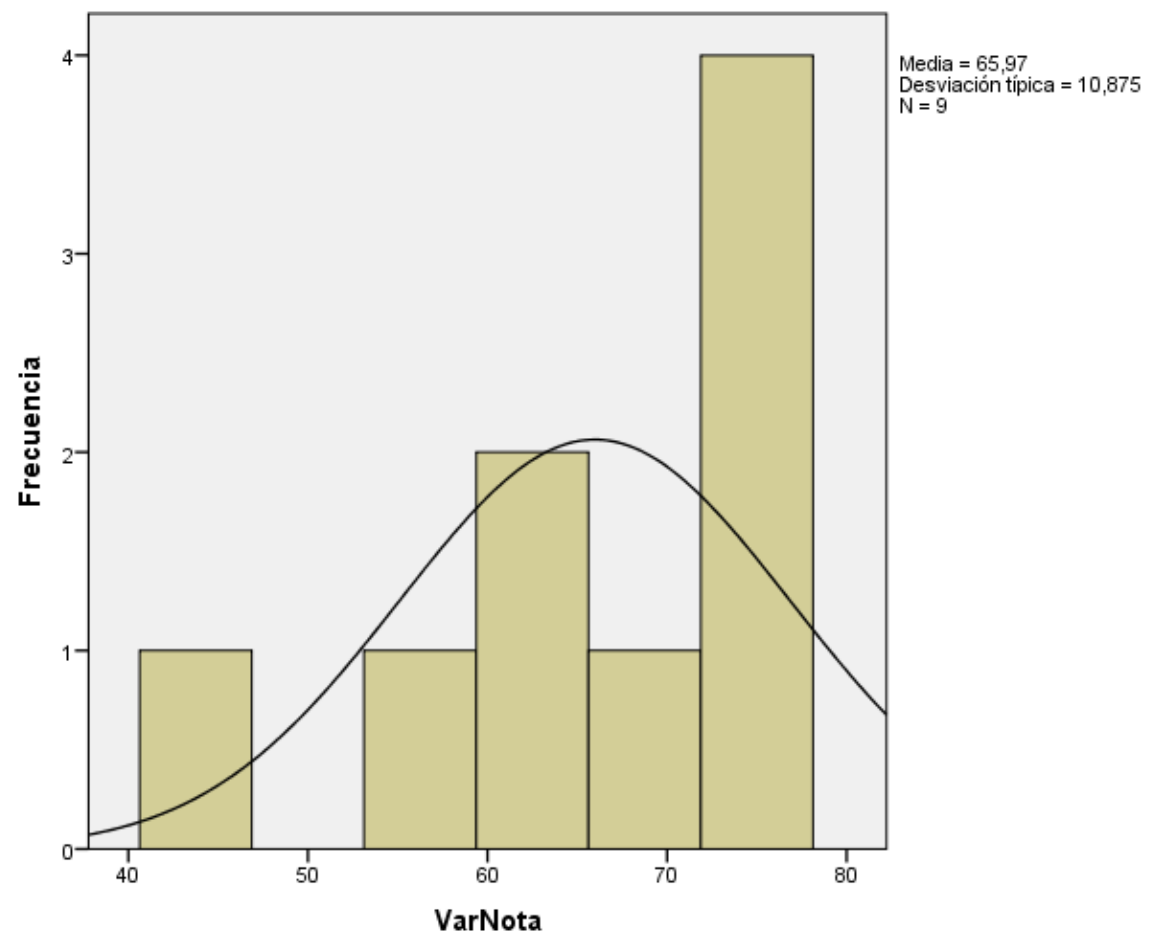

Figura 5-69 E8: Histograma de la variable Nota

\section{Test de Kolmogorov-Smirnov - No paramétrica}

\section{Resumen de prueba de hipótesis}

\begin{tabular}{|c|c|c|c|c|}
\hline & Hipótesis nula & Test & Sig. & Decisión \\
\hline 1 & $\begin{array}{l}\text { Las categorias definidas por } \\
\text { VarTaller = Con simulación y Sirf } \\
\text { simulación se producen con las d } \\
\text { probabilidades de } 0,5 \text { y } 0.5 \text {. }\end{array}$ & $\begin{array}{l}\text { IPrueba binomial } \\
\text { de una muestra }\end{array}$ & $1,000^{-1}$ & $\begin{array}{l}\text { Retener la } \\
\text { hipótesis } \\
\text { nula. }\end{array}$ \\
\hline 2 & $\begin{array}{l}\text { La distribución de VarNota es } \\
\text { normal con la media } 65,972 \text { y la } \\
\text { desuiación típica } 10,88 \text {. }\end{array}$ & $\begin{array}{l}\text { Prueba } \\
\text { Kolmogorov- } \\
\text { amirnou de una } \\
\text { muestra }\end{array}$ & .672 & $\begin{array}{l}\text { Retenerla } \\
\text { hipótesis } \\
\text { nula. }\end{array}$ \\
\hline
\end{tabular}

Se muestran las significancias asintóticas. El nivel de significancia es , 0 E

${ }^{1}$ Se muestra la significancia exacta para esta prueba.

Tabla 5-57 E8: Test de Kolmogorov-Smirnov

Para la variable taller, con un nivel de significancia del 1\% se acepta la hipótesis nula. Para la variable nota, con un nivel de significancia del $0,67 \%$, se acepta la hipótesis nula de que los datos provienen de una población con distribución normal. 


\section{Prueba de los rangos con signo de Wilcoxon - Prueba no paramétrica}

\begin{tabular}{|c|c|c|c|c|}
\hline \multicolumn{5}{|c|}{ Rangos } \\
\hline & & $\mathrm{N}$ & $\begin{array}{c}\text { Rango } \\
\text { promedio }\end{array}$ & $\begin{array}{c}\text { Suma de } \\
\text { rangos }\end{array}$ \\
\hline \multirow{4}{*}{$G c-G x$} & Rangos negativos & $2^{a}$ & 1,75 & 3,50 \\
\hline & Rangos positivos & $1^{b}$ & 2,50 & 2,50 \\
\hline & Empates & $1^{\mathrm{c}}$ & & \\
\hline & Total & 4 & & \\
\hline
\end{tabular}
a. $\mathrm{Gc}<\mathrm{Gx}$
b. $G c>G x$
c. $\mathrm{Gc}=\mathrm{Gx}$

Tabla 5-58 E8: Prueba de los rangos con signo de Wilcoxon

Al realizar esta prueba estadística se desea contrastar la hipótesis nula de que ambos grupos puedan mantener algún tipo de relación. Es decir, no serían independientes los tratamientos de los métodos con y sin simulación.

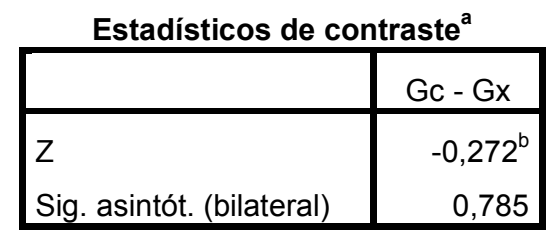
a. Prueba de los rangos con signo
de Wilcoxon
b. Basado en los rangos positivos.

Tabla 5-59 E8: Estadísticos de contraste

En ella se observa que el valor de la significancia asintótica bilateral es aproximadamente 0,785 , el cual resulta ser menor que el nivel de significancia $(0,05)$. Esto habilita a rechazar la hipótesis nula planteada.

\section{Estadísticos descriptivos}

\begin{tabular}{|l|r|r|r|r|r|r|r|}
\hline & \multicolumn{1}{|c|}{$\mathrm{N}$} & \multicolumn{1}{c|}{ Mínimo } & Máximo & Media & \multicolumn{1}{c|}{ Desv. típ. } & \multicolumn{2}{|c|}{ Curtosis } \\
\cline { 2 - 8 } & Estadístico & Estadístico & Estadístico & Estadístico & Estadístico & Estadístico & Error típico \\
\hline Gx & 4 & 56 & 75 & $\mathbf{6 5 , 6 3}$ & $\mathbf{8 , 0 6 9}$ & $-1,200$ & 2,619 \\
Gc & 5 & 44 & 75 & $\mathbf{6 6 , 2 5}$ & $\mathbf{1 3 , 6 9 3}$ & 1,745 & 2,000 \\
N válido (según & 4 & & & & & & \\
lista) & & & & & & & \\
\hline
\end{tabular}

Tabla 5-60 E8: Estadísticos descriptivos 
El valor de la media en este caso es muy parecido para ambos grupos. Lo que no permitiría resaltar bondades de ningún grupo de estudios. Sin embargo, el desvío estándar en el primer grupo, es aproximadamente del orden de la mitad del segundo grupo, lo cual significa que los estudiantes que realizaron simulación, presentan cierta homogeneidad al tener una variabilidad mucho menor.

Esto se puede considerar como un indicador que resalta el beneficio de la enseñanza con métodos de simulación.

\section{Gráfico descriptivo del concepto evaluado}

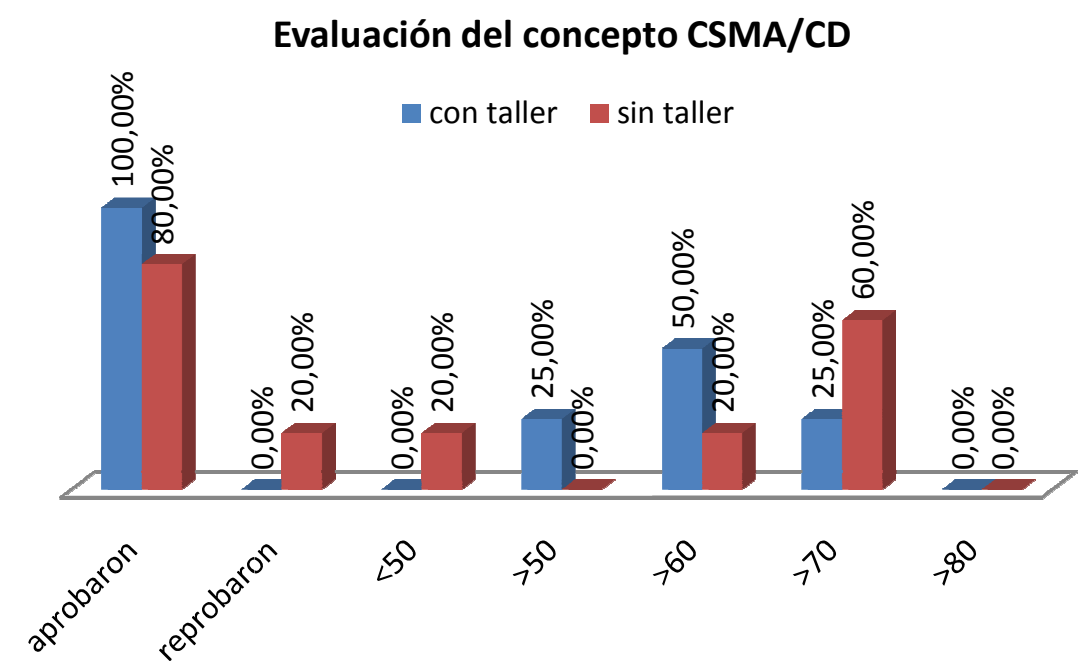

Figura 5-70 E8: Evaluación del concepto CSMA/CD

\subsubsection{Conclusiones de la experiencia}

De acuerdo a los resultados obtenidos se pudo determinar el impacto de la utilización del simulador MACSim en la enseñanza del algoritmo CSMA/CD en la asignatura Conectividad y Teleinformática.

Se puede observar en la Figura 5-71 E8 que el 20\% de los estudiantes que no realizó el taller obtuvo notas menores a 50 puntos (desaprobaron la evaluación), aunque también se puede observar que el porcentaje de notas mayores a 70 puntos es superior en los estudiantes que no realizaron el taller.

De manera que, para esta experiencia realizada, se concluyó que existió diferencia estadísticamente significativa a favor de los estudiantes que emplearon una estrategia basada en simulación para el concepto del algoritmo CSMA/CD evaluado. 


\subsection{Experiencia $N^{0}$ 9: Simulador Packet Tracer y el Protocolo DNS en Redes de Computadoras I}

Esta experiencia se realizó con un grupo de estudiantes que se encontraba cursando la asignatura Redes de Computadoras I del nuevo Plan de Licenciatura en Análisis de Sistemas Año 2010 durante el primer semestre del año 2015. El taller se realizó paralelamente al cursado de la asignatura.

La evaluación de conceptos tuvo dos intentos (por ser un protocolo más complejo) para el estudiante tomando como válida la nota más alta. En el caso de los estudiantes que realizaron el taller, realizaron una sola vez la evaluación. Los que no hicieron el taller, realizaron dos veces la evaluación en general con la misma nota en los dos intentos. Unos pocos estudiantes mejoraron su puntuación en el segundo intento de la evaluación.

\subsubsection{Análisis estadísticos de datos}

\section{Histogramas (Normal)}

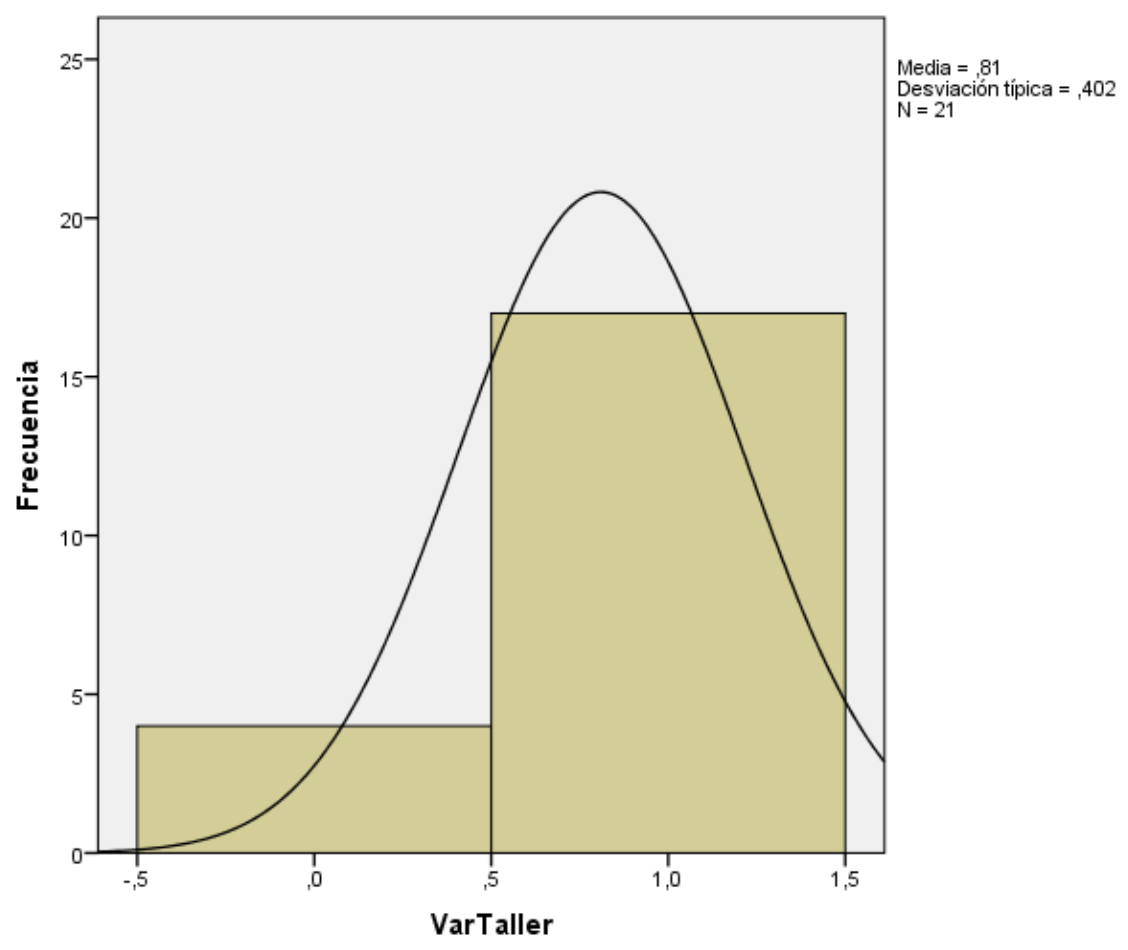

Figura 5-71 E9: Histograma de la variable Taller 


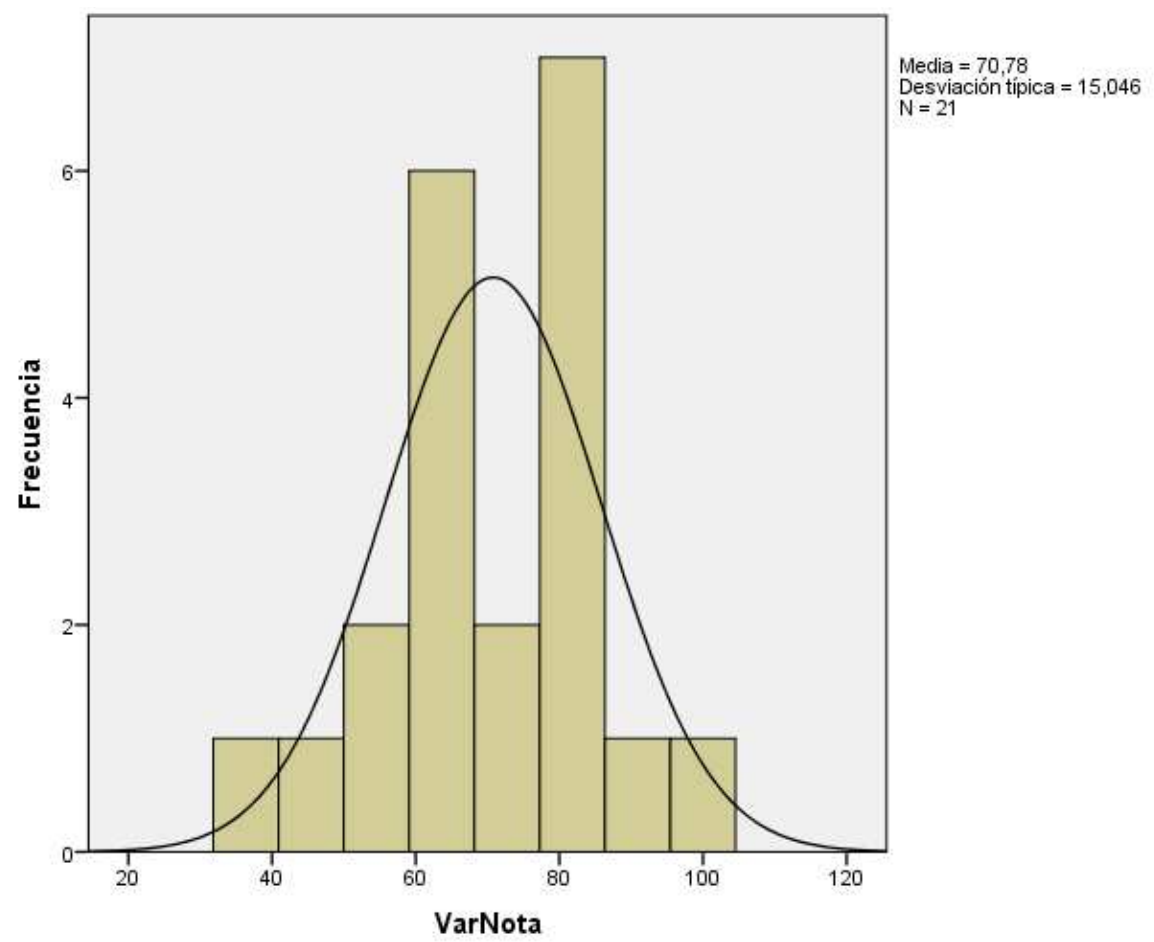

Figura 5-72 E9: Histograma de la variable Nota

Estos histogramas NO permiten tener una primera impresión del comportamiento probabilístico de los datos.

\section{Test de Kolmogorov-Smirnov - No paramétrica}

Resumen de prueba de hipótesis

\begin{tabular}{|c|c|c|c|c|}
\hline & Hipótesis nula & Test & Sig. & Decisión \\
\hline 1 & $\begin{array}{l}\text { Las categorias definidas por } \\
\text { VarTaller = Con simulación y Sin } \\
\text { simulación se producen con las } \\
\text { probabilidades de } 0,5 \text { y } 0,5 \text {. }\end{array}$ & $\begin{array}{l}\text { IPrueba binomial } \\
\text { de una muestra }\end{array}$ & $.007^{1}$ & $\begin{array}{l}\text { Rechazar la } \\
\text { hipótesis } \\
\text { nula. }\end{array}$ \\
\hline 2 & $\begin{array}{l}\text { La distribución de VarNota es } \\
\text { normal con la media } 70.779 \text { y la } \\
\text { desuiación típica } 15,05 \text {. }\end{array}$ & $\begin{array}{l}\text { Prueba } \\
\text { Kolmogorov- } \\
\text { Smimov de una } \\
\text { muestra }\end{array}$ & .389 & $\begin{array}{l}\text { Retener la } \\
\text { hipótesis } \\
\text { nula. }\end{array}$ \\
\hline
\end{tabular}

Se muestran las significancias asintóticas. El nivel de significancia es ,05

1 Se muestra la significancia exacta para esta prueba.

Tabla 5-61 E9: Test de Kolmogorov-Smirnov 
Para la variable taller, con un nivel de significancia del $0,7 \%$ NO se acepta la hipótesis nula (el software SPSS trabaja con un nivel de significancia del 5\%). No se cuenta con elementos estadísticos suficientes para concluir que se deba rechazar la hipótesis nula, es decir, no es posible aceptarla. Esto amerita a buscar otras alternativas de contraste de hipótesis. Existe asimetría en la variable taller, lo cual, junto con la decisión de no aceptar la hipótesis nula, lleva a tener que analizar el comportamiento de las medianas de cada grupo. Esto se hace calculando las respectivas medianas con estadística descriptiva, lo que da como resultado que el grupo experimental tiene un valor mediano muy superior al correspondiente al grupo de control. Como complemento, es aconsejable comparar estas medidas desde el punto de vista de variabilidad. Esto se hace trabajando con la desviación mediana.

Para la variable nota, con un nivel de significancia del 3,89\%, se acepta la hipótesis nula de que los datos provienen de una población con distribución normal.

Prueba de los rangos con signo de Wilcoxon - Prueba no paramétrica

\begin{tabular}{|c|c|c|c|c|}
\hline \multicolumn{5}{|c|}{ Rangos } \\
\hline & & $\mathrm{N}$ & $\begin{array}{c}\text { Rango } \\
\text { promedio }\end{array}$ & $\begin{array}{c}\text { Suma de } \\
\text { rangos }\end{array}$ \\
\hline \multirow{4}{*}{$G c-G x$} & Rangos negativos & $3^{a}$ & 2,00 & 6,00 \\
\hline & Rangos positivos & $0^{b}$ & 0,00 & 0,00 \\
\hline & Empates & $1^{c}$ & & \\
\hline & Total & 4 & & \\
\hline
\end{tabular}

a. $\mathrm{Gc}<\mathrm{Gx}$

b. $\mathrm{Gc}>\mathrm{Gx}$

c. $\mathrm{Gc}=\mathrm{Gx}$

Tabla 5-62 E9: Prueba de los rangos con signo de Wilcoxon

Estadísticos de contraste ${ }^{a}$

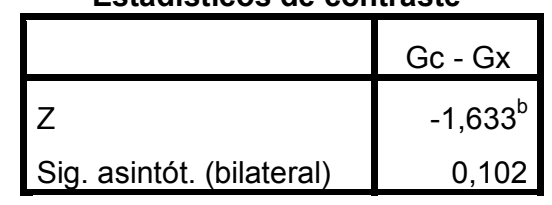

a. Prueba de los rangos con signo

de Wilcoxon

b. Basado en los rangos positivos.

Tabla 5-63 E9: Estadísticos de contraste

En ella se observa que la significancia asintótica bilateral es aproximadamente 0,1 , el cual resulta NO ser menor que el nivel de significancia $(0,05)$, sin embargo el percentil $Z$ en 
módulo 1.633 que es menor que el z crítico de la normal al 5\% que es de 1.96. Esto habilita a rechazar la hipótesis nula planteada.

\section{Estadísticos descriptivos}

\begin{tabular}{|l|r|r|r|r|r|r|r|r|r|}
\hline & N & Rango & Mínimo & Máximo & Media & $\begin{array}{r}\text { Desv. } \\
\text { típ. }\end{array}$ & Varianza & \multicolumn{2}{|c|}{ Curtosis } \\
\cline { 2 - 7 } & Estadístico & Estadístico & Estadístico & Estadístico & Estadístico & Estadístico & Estadístico & Estadístico & $\begin{array}{r}\text { Error } \\
\text { típico }\end{array}$ \\
\hline Gx & 4 & 14 & 82 & 95 & $\mathbf{8 7 , 5 0}$ & $\mathbf{6 , 8 1 8}$ & $\mathbf{4 6 , 4 8 8}$ & $-3,901$ & 2,619 \\
Gc & 17 & 45 & 36 & 82 & $\mathbf{6 6 , 8 4}$ & $\mathbf{1 3 , 7 0 9}$ & $\mathbf{1 8 7 , 9 2 5}$ & $-0,090$ & 1,063 \\
N válido & 4 & & & & & & & & \\
(según lista) & & & & & & & & & \\
\hline
\end{tabular}

Tabla 5-64 E9: Estadísticos descriptivos

El valor de la media para el grupo de estudiantes que realizó simulación es 87,50, mayor que el correspondiente a los estudiantes que no realizaron simulación 66,64.

Se destaca además que el desvío estándar en el primer grupo, es aproximadamente del orden de la mitad del segundo grupo, lo cual significa que los estudiantes que realizaron simulación presentan una manifiesta homogeneidad o menor variabilidad.

Esto puede considerarse como un indicador que resalta la bondad de la enseñanza con simulación.

\section{Gráfico descriptivo del concepto evaluado}

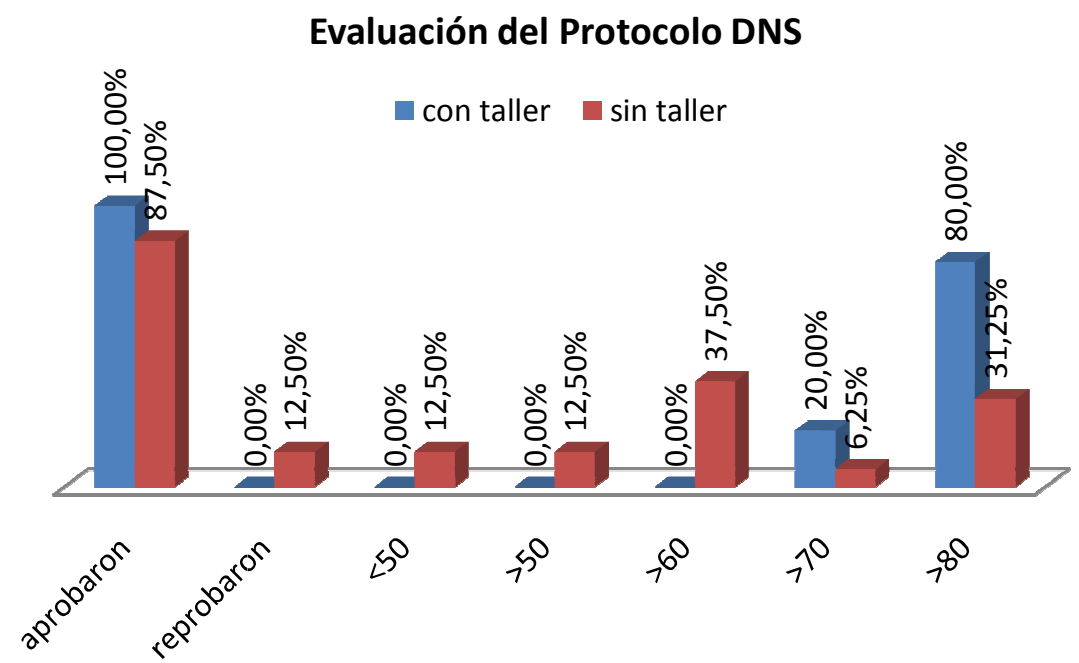

Figura 5-73 E9: Evaluación del Protocolo DNS 


\subsubsection{Conclusiones de la experiencia}

De acuerdo a los resultados obtenidos se pudo determinar el impacto de la utilización del simulador Packet Tracer en la enseñanza del protocolo DNS en la asignatura Redes de Computadoras I de la carrera de Licenciatura en Análisis de Sistemas.

Del análisis realizado se puede observar en la Figura 5-74 E9, que en el grupo que realizó simulación aprobó el 100\% de los estudiantes, mientras que en el grupo de control (los que no realizaron el taller con simulación) aprobó el $87 \%$ de los estudiantes. Se puede observar también que, el grupo que realizó el taller con simulación, obtuvo notas más altas y, en el caso de la pregunta abierta, permitió evidenciar que se lograron respuestas mucho más acabadas y precisas del concepto evaluado.

De manera que, para esta experiencia realizada, se concluyó que existió diferencia estadísticamente significativa a favor de los estudiantes que emplearon una estrategia basada en simulación para el concepto del protocolo DNS evaluado. 


\subsection{Experiencia $\mathrm{N}^{0}$ 10: Simulador GNS3 en un curso en el marco de las Jornadas de Ingeniería}

Esta experiencia se realizó con el grupo de estudiantes que se inscribió al curso de extensión denominado "Herramientas de simulación y virtualización de dispositivos de red para el diseño de redes multiplataforma simples y complejas", en el marco de las X Jornadas de Ciencia y Tecnología de Facultades de Ingeniería del NOA realizadas los días 21 y 22 de mayo de 2015 en la Ciudad de Salta.

El objetivo del curso fue presentar el entorno de virtualización GNS3 y su suite de herramientas. Se referenciaron los routers Cisco, Mikrotik y PC-Routers basados en Linux y la incorporación de imágenes IOS a GNS3.

Luego se realizó una práctica de configuración de estas 3 plataformas en el ruteo estático y dinámico con el protocolo RIP.

El taller se llevó a cabo en dos encuentros de 4 horas cada uno. Se presentaron los conceptos teóricos en cada clase y a continuación se realizó la práctica con el simulador. Fue requisito del curso haber cursado alguna asignatura introductoria de redes por lo que permitió al equipo docente concentrarse en la presentación de la herramienta y su utilización.

Al finalizar el curso, se realizó una encuesta, en la cual se evaluó a GNS3 como herramienta de software

El objetivo de esta encuesta fue analizar el impacto del uso de la herramienta por los estudiantes, asociado a los diferentes temas y protocolos tratados.

\subsubsection{Análisis estadísticos de datos}

Para este análisis la media aritmética supera, en todos los casos, al menos el valor medio de la escala (3.00), lo que confirma la validez del contenido de todos los ítems incluidos.

Como puede observarse en la Tabla 5-65, el coeficiente Alfa de Cronbach calculado es de 0,945 que supera el valor de 0,7 , lo que permite afirmar el grado de fiabilidad del cuestionario. Por lo tanto, se aprecia una alta polarización de respuestas confiables por parte de los estudiantes.

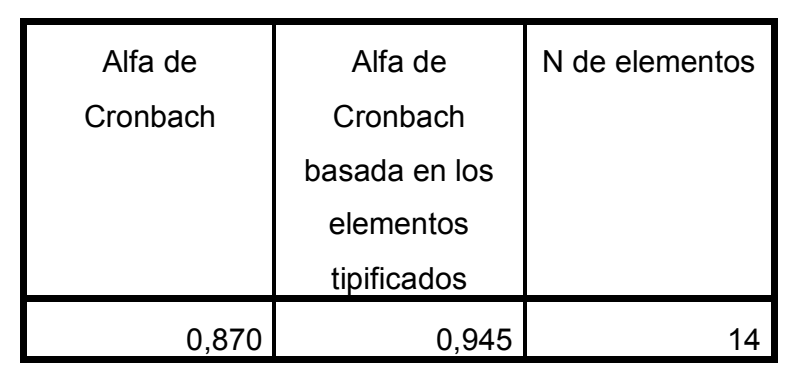

Tabla 5-65 E10: Estadísticos de fiabilidad 
Estudio de la influencia de un entorno de simulación en la enseñanza de redes de computadoras en el nivel universitario

\begin{tabular}{|l|r|r|r|}
\hline & \multicolumn{1}{|c|}{ Media } & \multicolumn{1}{|c|}{$\begin{array}{c}\text { Desviación } \\
\text { típica }\end{array}$} \\
\hline item1 & 4,33 & 1,633 & 6 \\
item2 & 3,50 & 1,761 & 6 \\
item3 & 3,83 & 1,941 & 6 \\
item4 & 4,50 & 0,837 & 6 \\
item5 & 3,67 & 1,966 & 6 \\
item6 & 3,67 & 1,862 & 6 \\
item7 & 4,83 & 0,408 & 6 \\
item8 & 3,67 & 1,966 & 6 \\
item9 & 4,17 & 0,753 & 6 \\
item10 & 4,67 & 0,516 & 6 \\
item11 & 4,50 & 0,837 & 6 \\
item12 & 4,33 & 0,816 & 6 \\
item13 & 4,50 & 0,837 & 6 \\
item14 & 4,83 & 0,408 & 6 \\
\hline
\end{tabular}

Tabla 5-66 E10: Estadísticos de los elementos

\begin{tabular}{|l|r|r|r|r|r|r|r|}
\hline & Media & Mínimo & Máximo & Rango & $\begin{array}{c}\text { Máximo/ } \\
\text { mínimo }\end{array}$ & Varianza & $\begin{array}{c}\mathrm{N} \text { de } \\
\text { elementos }\end{array}$ \\
\hline $\begin{array}{l}\text { Medias de los } \\
\text { elementos }\end{array}$ & 4,214 & 3,500 & 4,833 & 1,333 & 1,381 & 0,216 & 14 \\
\hline
\end{tabular}

Tabla 5-67 E10: Estadísticos de resumen de los elementos

\begin{tabular}{|r|r|r|r|}
\hline Media & Varianza & $\begin{array}{c}\text { Desviación } \\
\text { típica }\end{array}$ & N de elementos \\
\hline 59,00 & 128,400 & 11,331 & 14 \\
\hline
\end{tabular}

Tabla 5-68 E10: Estadísticos de la escala 


\section{Gráficos descriptivos}

A continuación se presentan gráficamente las respuestas de los estudiantes, para cada una de las preguntas del cuestionario realizado.

\section{GNS3 como herramienta de software}

\section{La instalación y puesta en funcionamiento de la herramienta es sencilla}

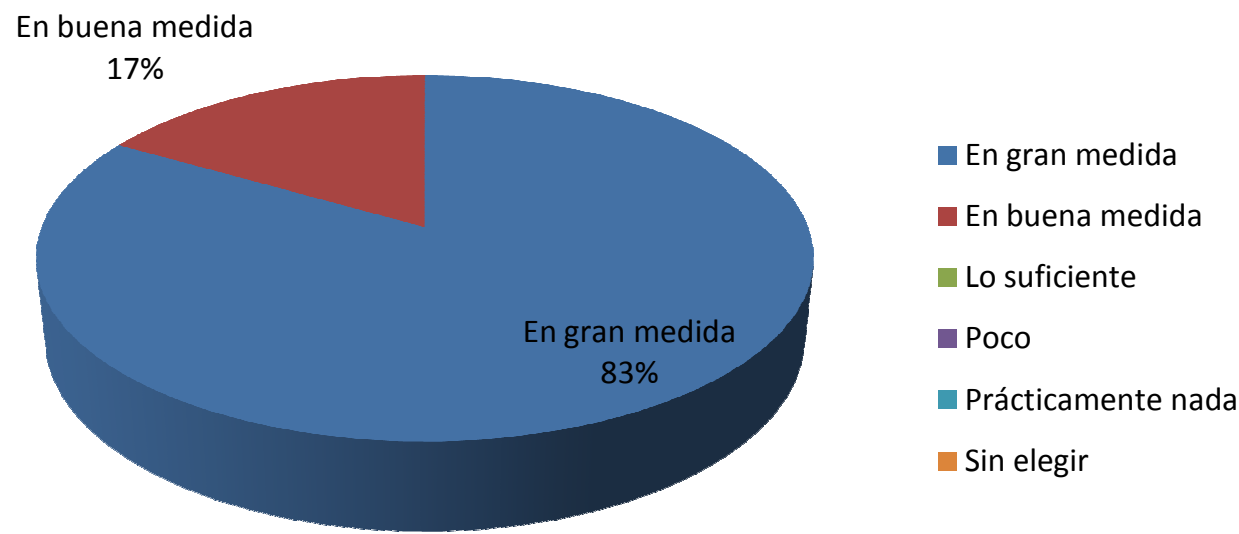

GNS3 como herramienta de software

Figura 5-74 E10: La instalación es sencilla

\section{La configuración de la interfaz en idioma español es sencilla}

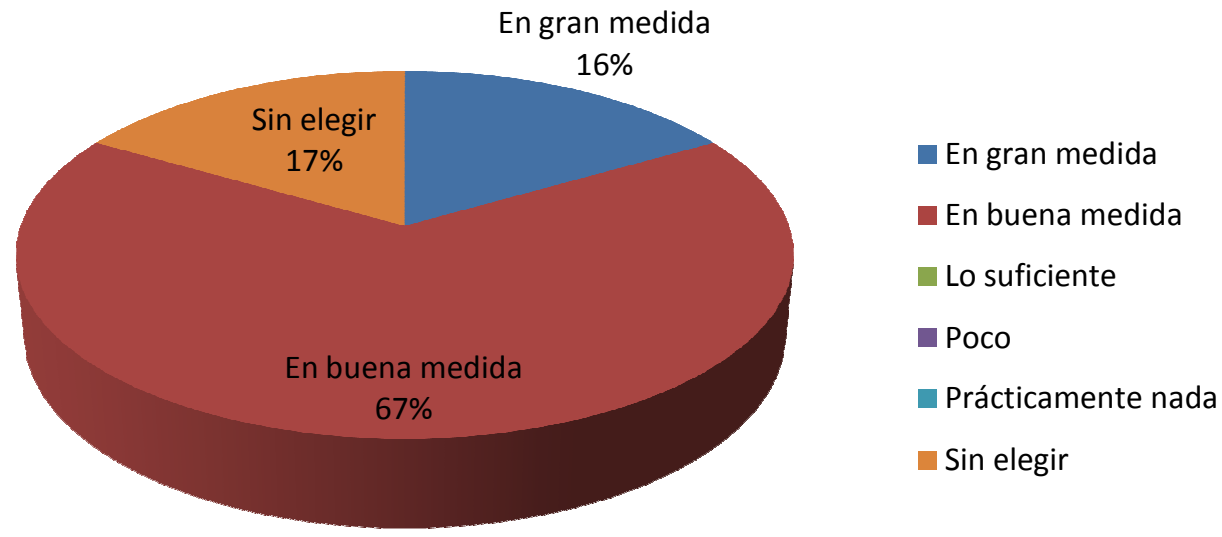

GNS3 como herramienta de software

Figura 5-75 E10: La configuración de la interfaz es sencilla 


\section{La interfaz gráfica que ofrece la aplicación es amigable e intuitiva}

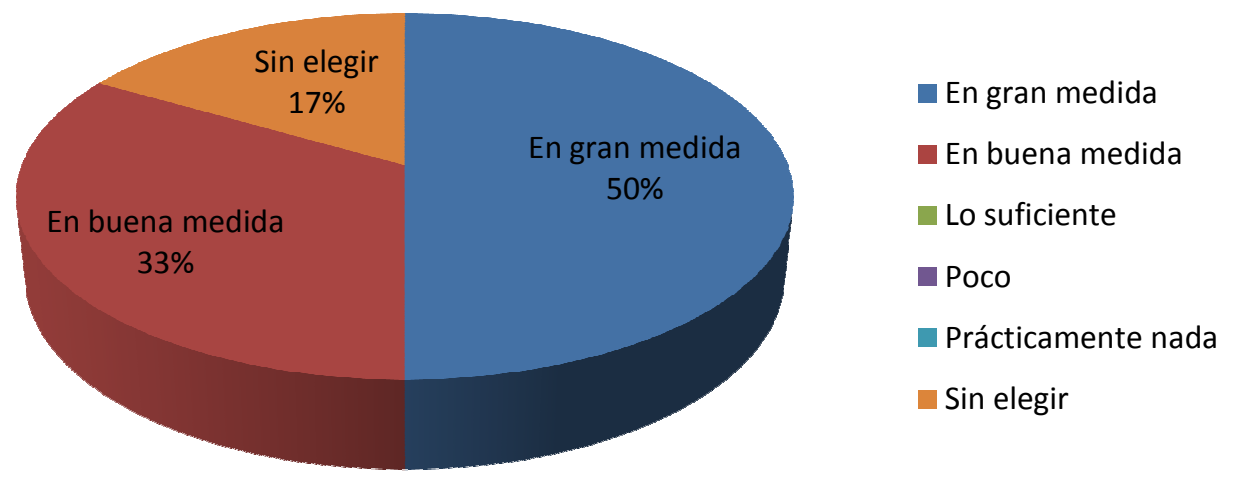

GNS3 como herramienta de software

Figura 5-76 E10: La interfaz gráfica es amigable

\section{La aplicación posee los componentes necesarios para realizar un laboratorio de redes IP}

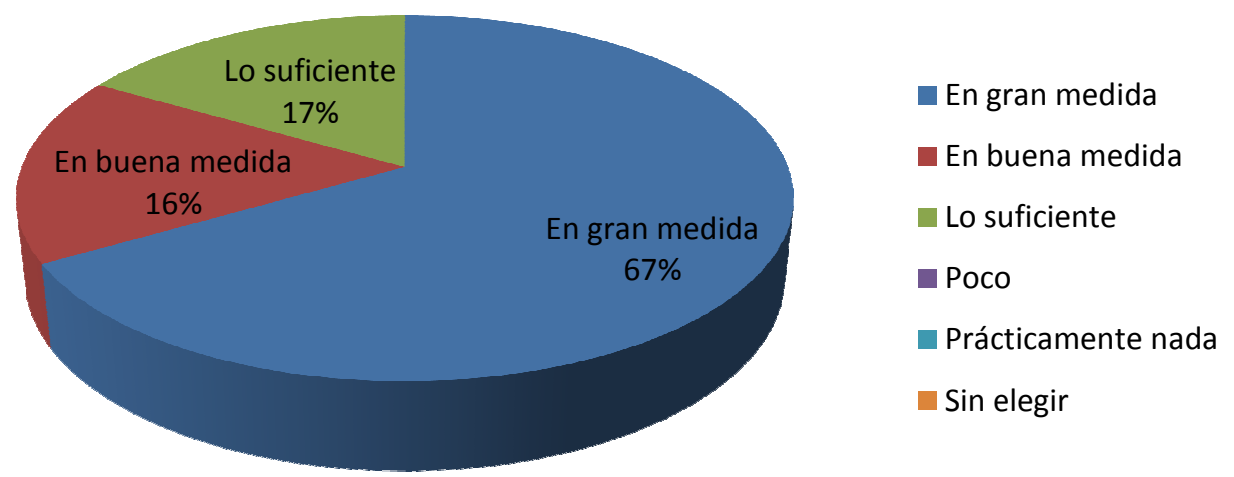

GNS3 como herramienta de software

Figura 5-77 E10: Posee los componentes necesarios para un laboratorio IP 


\section{La herramienta ofrece disponibilidad que garantice la realización de los laboratorios sin interrupciones}

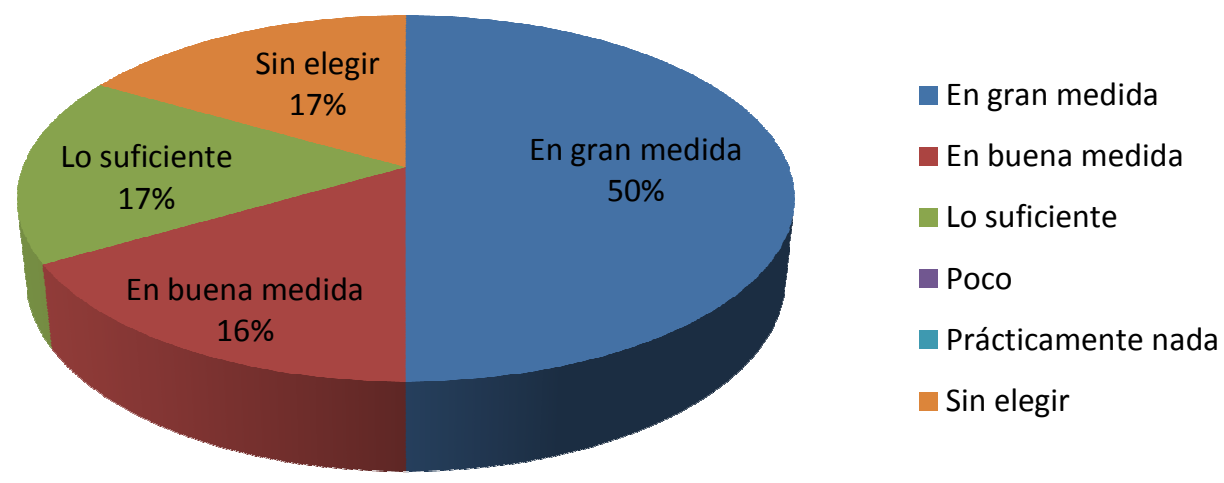

GNS3 como herramienta de software

Figura 5-78 E10: Ofrece disponibilidad que garantice la realización del laboratorio

\section{Se cuenta con ayuda que permita resolver dudas sobre el uso de la herramienta}

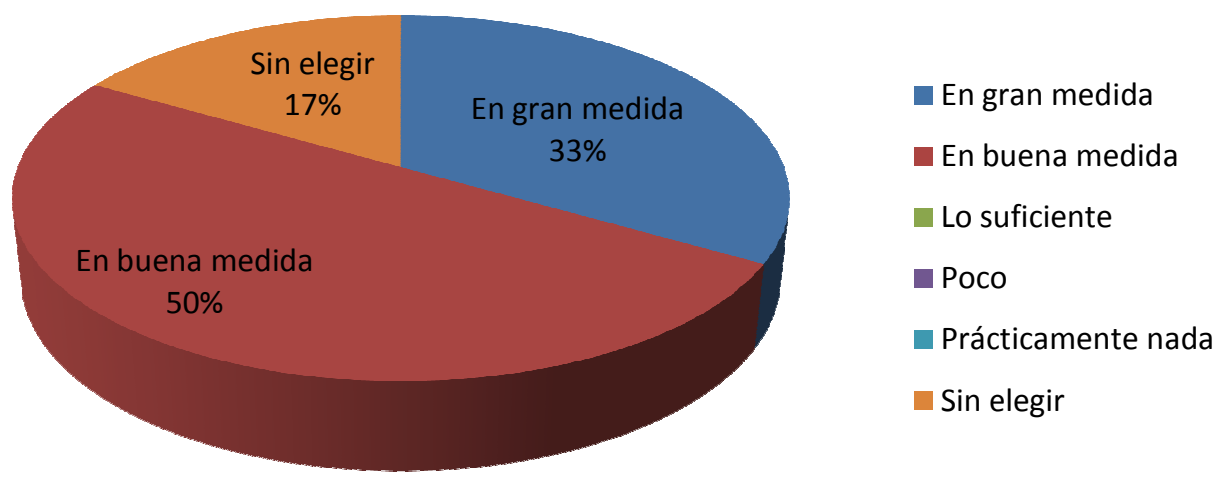

GNS3 como herramienta de software

Figura 5-79 E10: La herramienta cuenta con ayuda sobre el uso 


\section{La herramienta permite realizar simulaciones claras y reales}

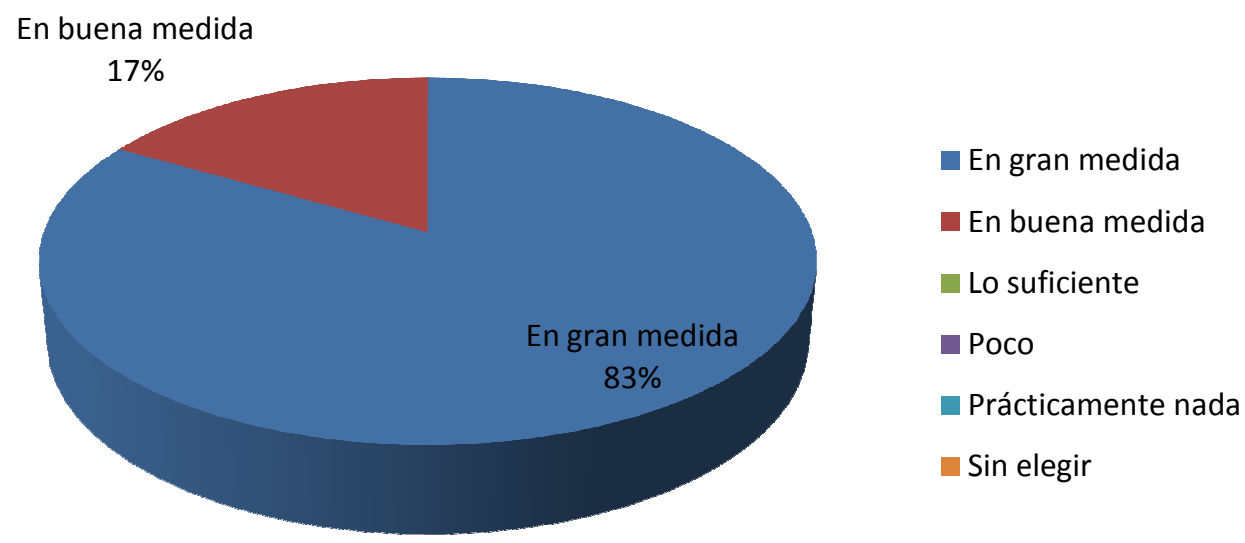

GNS3 como herramienta de software

Figura 5-80 E10: La herramienta permite simulaciones claras

\section{Con esta herramienta, la configuración de los dispositivos se desentiende de una marca particular, concentrándose en el concepto teórico}

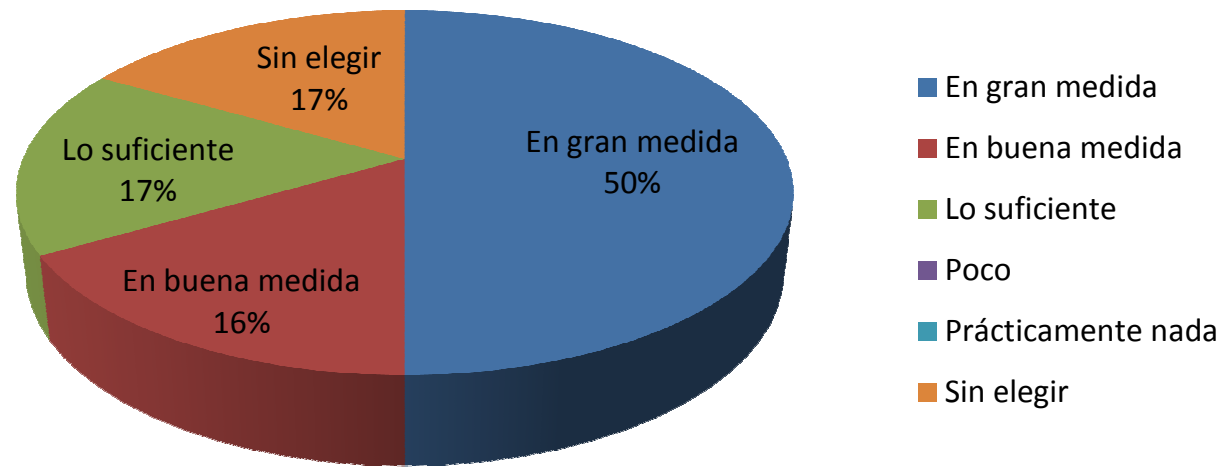

GNS3 como herramienta de software

Figura 5-81 E10: La configuración de dispositivos se independiza del fabricante 


\section{Permite realizar cambios en la topología fácilmente para adecuarla a las necesidades}

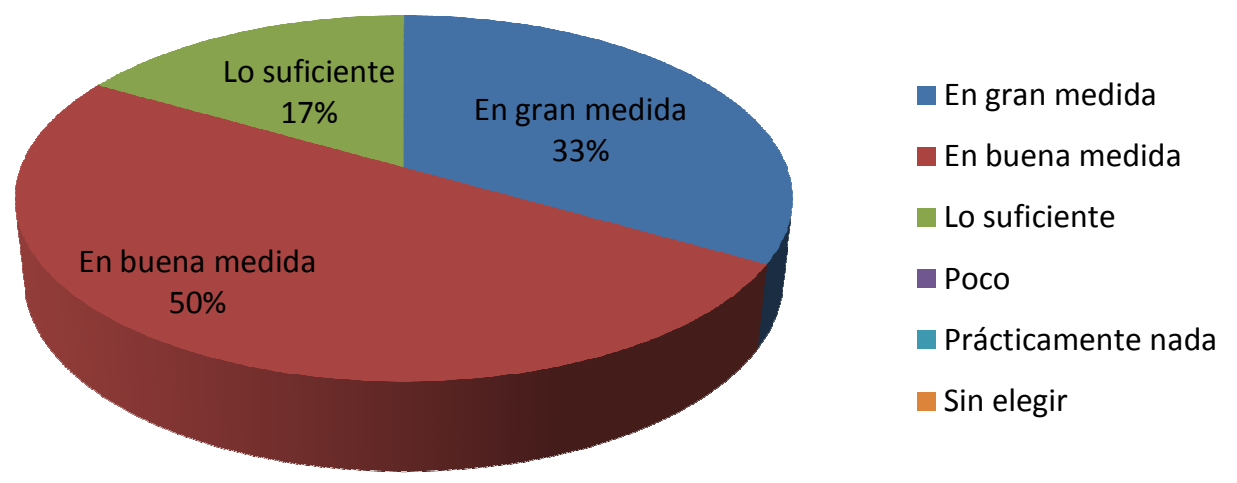

GNS3 como herramienta de software

Figura 5-82 E10: Permite el cambio de la topología fácilmente

\section{Permite simular cambios en dispositivos de manera efectiva en una determinada topología}

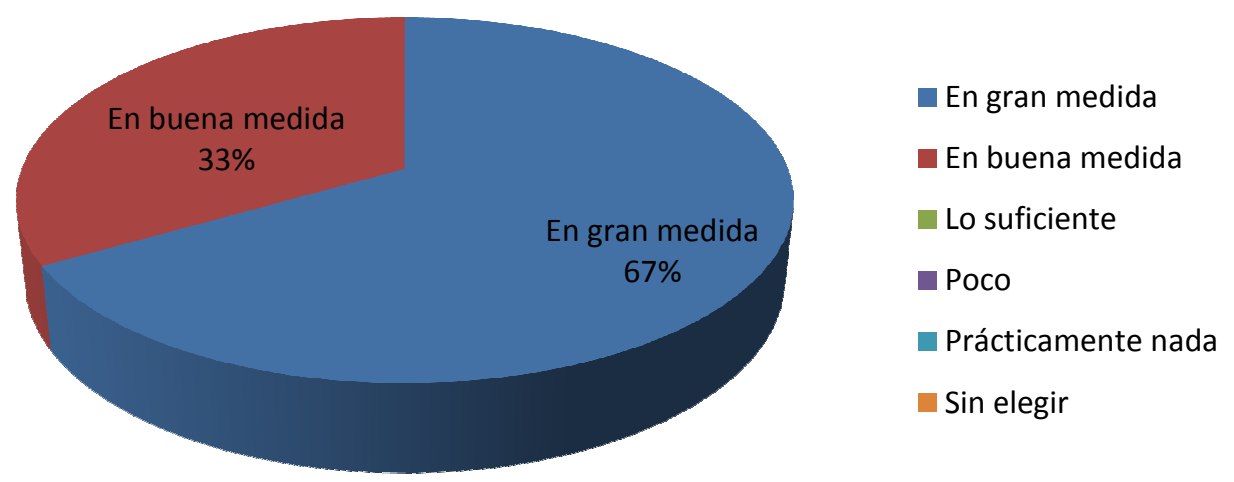

GNS3 como herramienta de software

Figura 5-83 E10: Permite cambios en dispositivos de manera efectiva 


\section{La herramienta facilita el seguimiento de los eventos ocurridos en cada uno de los dispositivos dentro de la red}

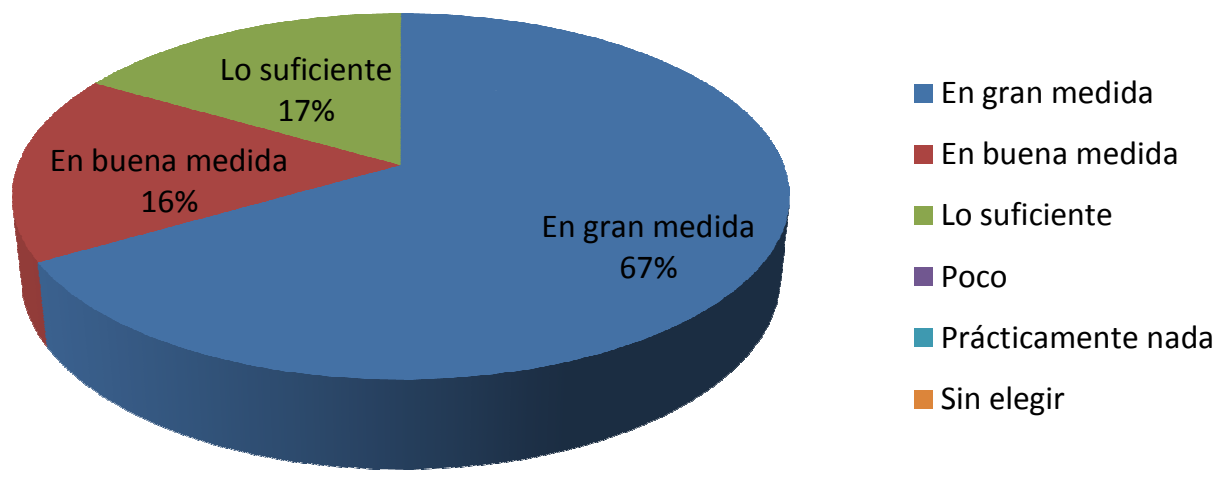

GNS3 como herramienta de software

Figura 5-84 E10: Facilita el seguimiento de eventos

\section{Con GNS3 se potencializa la educación no presencial}

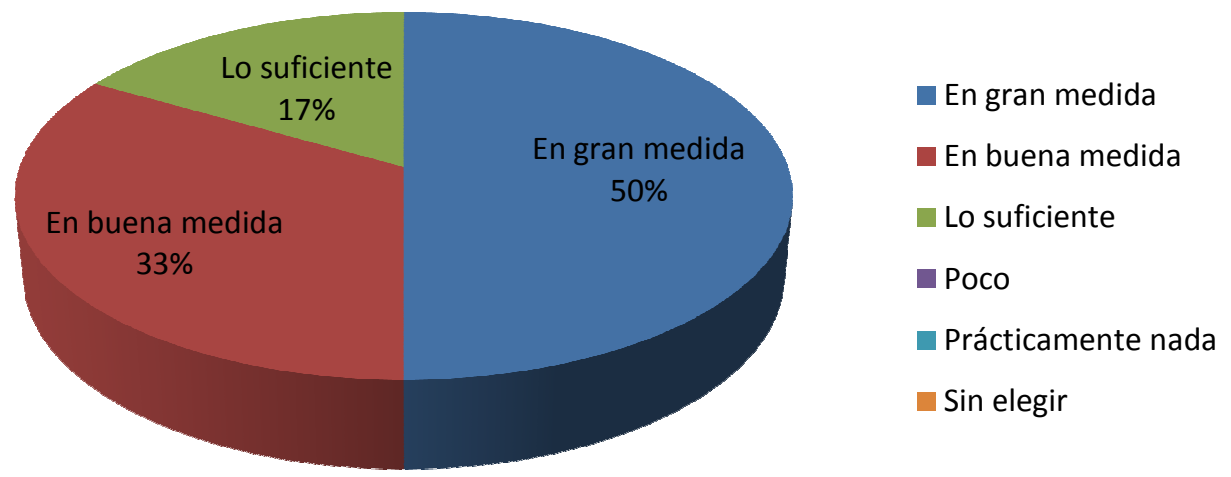

GNS3 como herramienta de software

Figura 5-85 E10: GNS3 potencializa la educación no presencial 


\section{GNS3 es adecuado para el estudio y análisis del ruteo IP}

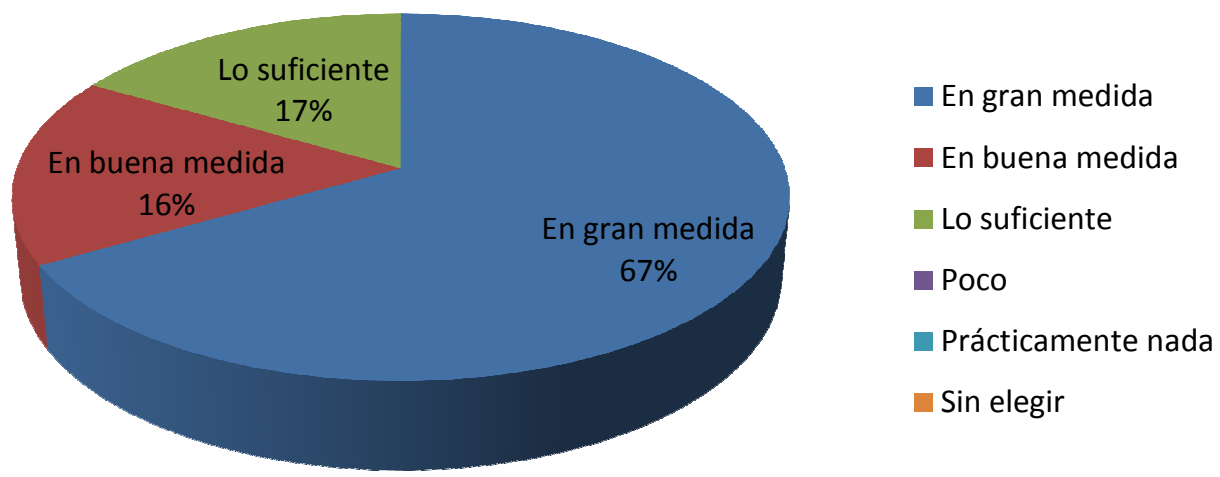

GNS3 como herramienta de software

Figura 5-86 E10: GNS3 es adecuado para el estudio de ruteo IP

\section{Considera adecuado el práctico propuesto}

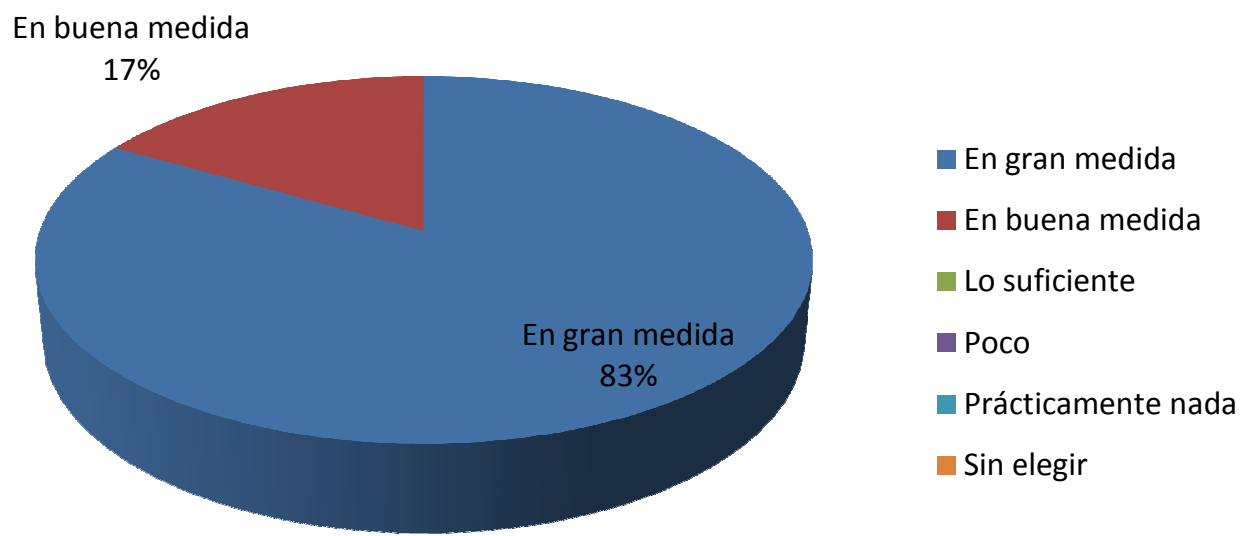

GNS3 como herramienta de software

Figura 5-87 E10: El práctico propuesto es adecuado

A continuación se enumeran textualmente algunas opiniones sobre la experiencia de los estudiantes.

\section{Comentarios adicionales de los estudiantes}

- Muy bueno

- Me gustaría que lo implementen en la enseñanza en Santiago del Estero 


\subsubsection{Conclusiones de la experiencia}

De acuerdo a los resultados de las encuestas realizadas a los estudiantes para determinar el impacto de la utilización de GNS3 en el curso de extensión "Herramientas de simulación y virtualización de dispositivos de red para el diseño de redes multiplataforma simples y complejas", se concluye que en términos generales el acercamiento inicial fue considerado por los estudiantes como positivo.

Ahora bien, mediante la utilización de GNS3 como simulador de topologías de red, se concluyó que esta herramienta fue en gran medida aceptada y apoyó el proceso de enseñanza de redes IP, en particular los conceptos y fundamentos sobre ruteo estático y dinámico con el protocolo RIP (temática del curso).

Acerca de GNS3 como herramienta de software, se evidenció que en gran medida se consideró a la interfaz como intuitiva, la simulación fue clara y real, facilitó el seguimiento de los eventos ocurridos en la simulación, la instalación y puesta en funcionamiento fueron sencillas, contó con ayuda al usuario, la configuración se independizó del fabricante (ya que la misma integra todos los dispositivos, simplemente es necesario disponer de las imágenes de los equipos necesarios), permitió realizar cambios en una topología fácilmente y cambios en dispositivos de manera efectiva.

Además fue posible observar que los prácticos propuestos para el simulador, en general fueron considerados adecuados por los estudiantes. 


\subsection{Experiencia $N^{0}$ 11: Simulador Packet Tracer y el Direccionamiento IP en Redes de Computadoras I}

Esta experiencia se realizó con los estudiantes que se encontraban cursando la asignatura Redes I en la Facultad de Ingeniería e Informática en la Universidad Católica de Salta, durante el primer semestre del año 2015, en el marco de un convenio existente entre las dos universidades UNSa - UCASAL, a través del Proyecto de Investigación CIUNSa ${ }^{\circ}$ 2230/0. El taller se realizó paralelamente al cursado de la asignatura, lo que permitió evaluar el desempeño tanto de los estudiantes que participaron del mismo, como de los que no participaron.

Considerando que el simulador Packet Tracer es intuitivo y estos estudiantes utilizaron el simulador para toda la temática que abarca la asignatura Redes de Computadoras I, el taller se llevó a cabo en tres clases teórico-prácticas de dos horas cada una. El equipo docente se enfocó en la enseñanza del Direccionamiento IP, los conceptos de subredes IP, CIDR y máscara de red. En primer lugar, se realizó una exposición para todos los estudiantes con transparencias ilustrativas de los conceptos teóricos. Posteriormente se realizó la práctica tradicional en papel, también para todos los estudiantes, donde tenían que resolver problemas de direccionamiento IP. Para el taller con el simulador se seleccionaron aleatoriamente la mitad de los estudiantes y se procedió a la resolución de una guía práctica con problemas sobre el simulador.

Finalmente, con una semana de posterioridad y luego de una clase de consulta, se evaluó el concepto de Direccionamiento IP, con un cuestionario de doce preguntas a todos los estudiantes del curso.

\subsubsection{Análisis estadísticos de datos}

\section{Histogramas (Normal)}


Estudio de la influencia de un entorno de simulación en la enseñanza de redes de computadoras en el nivel universitario

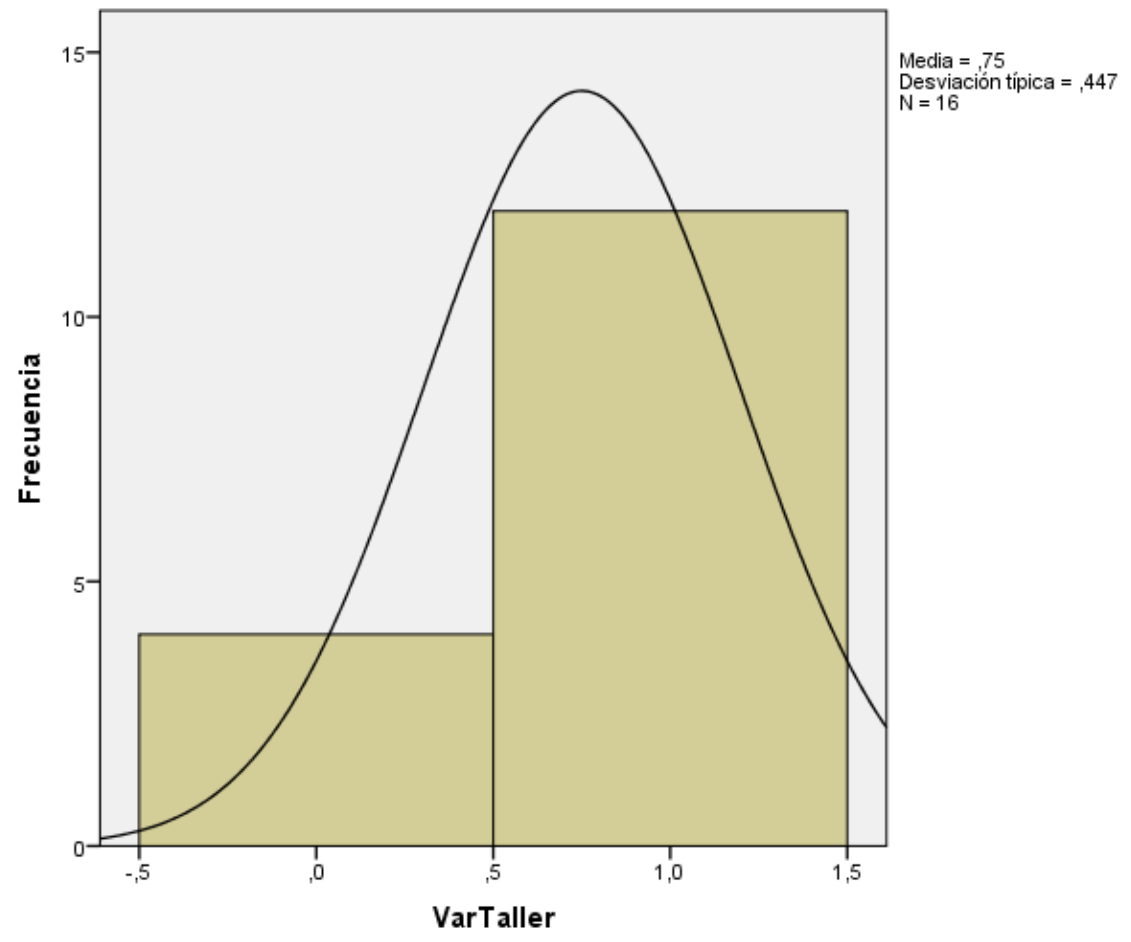

Figura 5-88 E11: Histograma de la variable Taller 


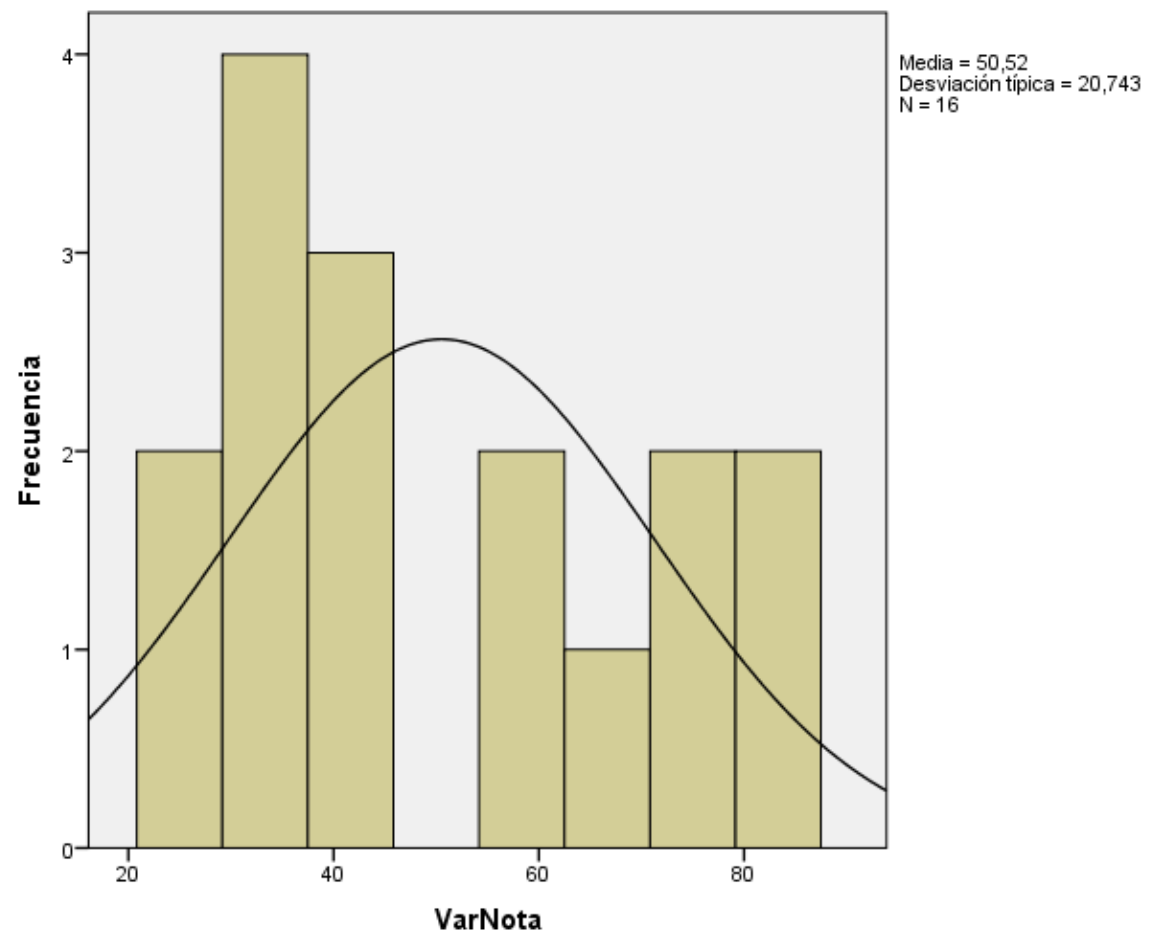

Figura 5-89 E11: Histograma de la variable Nota

\section{Test de Kolmogorov-Smirnov - No paramétrica}

\section{Resumen de prueba de hipótesis}

\begin{tabular}{|c|c|c|c|}
\hline & Hipótesis nula & Sig. & Decisión \\
\hline 1 & $\begin{array}{l}\text { Las categorias definidas por } \\
\text { VarTaller }=\text { Con simulación y Sirfueba binomial } \\
\text { simulación se producen con las de una muestra } \\
\text { probabilidades de } 0,5 \text { y } 0.5 \text {. }\end{array}$ & $.077^{1}$ & $\begin{array}{l}\text { Retener la } \\
\text { hipótesis } \\
\text { nula. }\end{array}$ \\
\hline 2 & 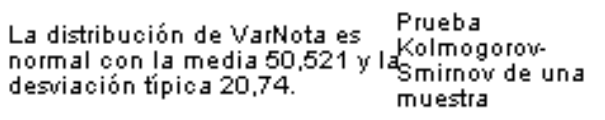 & .378 & $\begin{array}{l}\text { Retenerla } \\
\text { hipótesis } \\
\text { nula. }\end{array}$ \\
\hline
\end{tabular}

Se muestran las significancias asintóticas. El nivel de significancia es , 0 E

1 Se muestra la significancia exacta para esta prueba.

Tabla 5-69 E11: Test de Kolmogorov-Smirnov

Para la variable taller, con un nivel de significancia del 0,77\% se acepta la hipótesis nula. Para la variable nota, con un nivel de significancia del $0,37 \%$, se acepta la hipótesis nula de que los datos provienen de una población con distribución normal. 


\section{Prueba de los rangos con signo de Wilcoxon - Prueba no paramétrica}

\begin{tabular}{|c|c|c|c|c|}
\hline \multicolumn{5}{|c|}{ Rangos } \\
\hline & & $\mathrm{N}$ & $\begin{array}{c}\text { Rango } \\
\text { promedio }\end{array}$ & $\begin{array}{c}\text { Suma de } \\
\text { rangos }\end{array}$ \\
\hline \multirow{4}{*}{$\mathrm{Gc}-\mathrm{Gx}$} & Rangos negativos & $2^{a}$ & 3,50 & 7,00 \\
\hline & Rangos positivos & $2^{b}$ & 1,50 & 3,00 \\
\hline & & $0^{c}$ & & \\
\hline & Total & 4 & & \\
\hline
\end{tabular}
a. $G c<G x$
b. $G c>G x$
c. $G c=G x$

Tabla 5-70 E11: Prueba de los rangos con signo de Wilcoxon

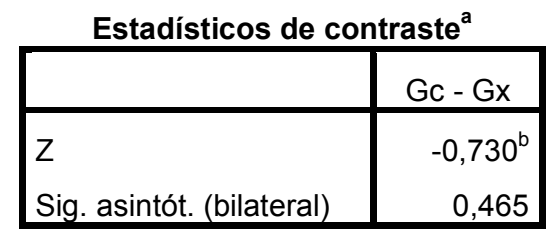
a. Prueba de los rangos con signo
de Wilcoxon
b. Basado en los rangos positivos.

Tabla 5-71 E11: Estadísticos de contraste

En ella se observa que la significancia asintótica bilateral es aproximadamente 0,465 , el cual resulta no ser menor que el nivel de significancia $(0,05)$, sin embargo, el percentil $\mathrm{z}$ asociado $Z=-0,730$ es menor en valor absoluto que el valor crítico de la normal estándar $\mathrm{Zc}=1,96$ con lo cual existen elementos estadísticos que permiten aceptar la hipótesis nula de independencia entre ambos métodos.

\section{Estadísticos descriptivos}

\begin{tabular}{|l|r|r|r|r|r|r|r|}
\hline & \multicolumn{1}{|c|}{$\mathrm{N}$} & \multicolumn{1}{|c|}{ Mínimo } & Máximo & Media & Desv. típ. & \multicolumn{2}{|c|}{ Curtosis } \\
\cline { 2 - 8 } & Estadístico & Estadístico & Estadístico & Estadístico & Estadístico & Estadístico & Error típico \\
\hline Gx & 4 & 33 & 83 & $\mathbf{6 4 , 5 8}$ & $\mathbf{2 1 , 9 1 6}$ & 2,235 & 2,619 \\
Gc & 12 & 25 & 83 & $\mathbf{4 5 , 8 3}$ & $\mathbf{1 8 , 9 7 0}$ & $-0,138$ & 1,232 \\
N válido (según & 4 & & & & & & \\
lista) & & & & & & & \\
\hline
\end{tabular}

Tabla 5-72 E11: Estadísticos descriptivos

El valor de la media para el grupo de estudiantes que realizaron simulación es 64,58, mayor que el correspondiente a los estudiantes que no realizaron simulación 45,83. 
Sin embargo, se observa en este caso que el desvío estándar en el primer grupo, es levemente mayor que el del segundo grupo.

Dado que las medias son distintas, a fin de comparar cual de los métodos es más eficiente relativamente, corresponde calcular el coeficiente de variación relativa (cociente entre el desvío estándar y la media). El método con menor variación relativa es el más eficiente.

El coeficiente para $\mathrm{Gx}=0.339$, coeficiente para $\mathrm{Gc}=0.413$. Coeficiente de $\mathrm{Gx}<$ Coeficiente de Gc.

\section{Gráfico descriptivo del concepto evaluado}

\section{Evaluación de Direccionamiento IP}

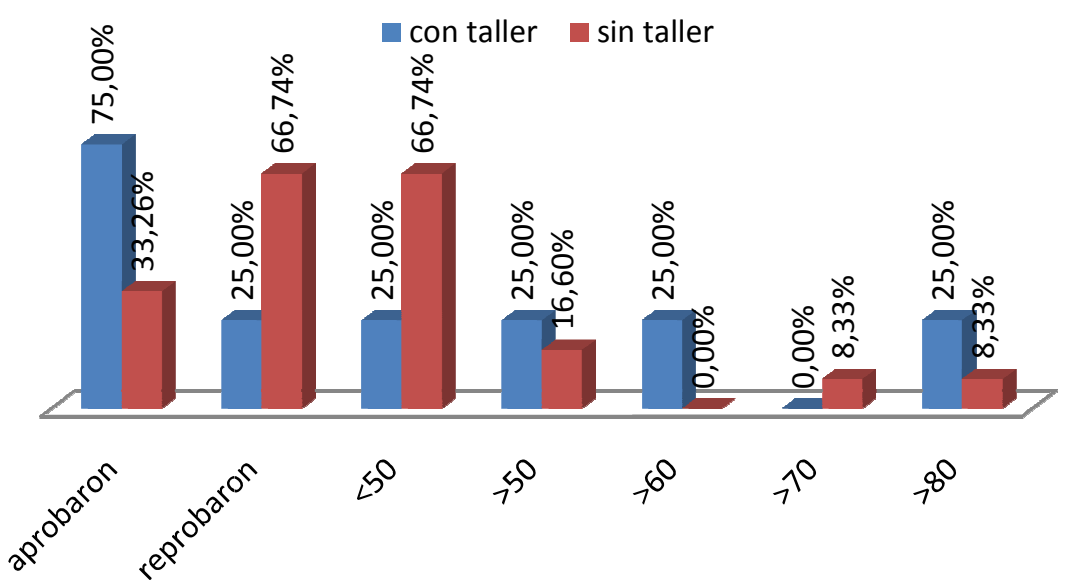

Figura 5-90 E11: Evaluación de Direccionamiento IP

\subsubsection{Conclusiones de la experiencia}

De acuerdo a los resultados obtenidos, se pudo determinar el impacto de la utilización del simulador Packet Tracer en la enseñanza del concepto de Direccionamiento IP en la asignatura Redes de Computadoras I de la carrera Licenciatura en Análisis de Sistemas. Del análisis realizado, se puede observar en la Figura 5-91 E11, que el 66\% de los estudiantes que no realizó el taller obtuvo notas menores a 50 puntos (desaprobaron). Además, se advirtió, que los estudiantes que sí realizaron el taller, aprobaron con mejores notas.

Para esta experiencia realizada, se concluyó que existió diferencia estadísticamente significativa a favor de los estudiantes que emplearon una estrategia basada en simulación para el concepto de Direccionamiento IP evaluado. 


\subsection{Experiencia N$^{0}$ 12: Simulador Packet Tracer y el Ruteo IP en Redes de Computadoras I}

Esta experiencia se realizó con los estudiantes que se encontraban cursando la asignatura Redes de Computadoras I del nuevo Plan de Licenciatura en Análisis de Sistemas - Plan 2010, durante el primer semestre del año 2015. El taller se realizó paralelamente al cursado de la asignatura, lo que permitió evaluar el desempeño tanto de los estudiantes que participaron del mismo, como de los que no participaron.

Considerando que el simulador Packet Tracer es intuitivo y este grupo de estudiantes lo viene utilizando para toda la temática que abarca la asignatura Redes de Computadoras I, el taller se llevó a cabo en cuatro clases teórico-prácticas de dos horas. Nos enfocamos en la enseñanza del Ruteo IP, los conceptos de ruteo estático y ruteo dinámico con el protocolo RIP. En primer lugar, se realizó una exposición para todos los estudiantes con transparencias ilustrativas de los conceptos teóricos. Posteriormente se realizó la práctica tradicional en papel, también para todos los estudiantes, donde tenían que resolver problemas sobre ruteo. Para el taller con el simulador se seleccionaron aleatoriamente 5 estudiantes y se procedió a la resolución de una guía práctica con problemas sobre el simulador.

Cabe aclarar que estas evaluaciones no tuvieron incidencia en las notas para la regularidad de la asignatura. La misma se regularizó con cuatro parciales correspondientes a cada uno de los temas del programa de la asignatura.

\subsubsection{Análisis estadísticos de datos}

\section{Histogramas (Normal)}


Estudio de la influencia de un entorno de simulación en la enseñanza de redes de computadoras en el nivel universitario

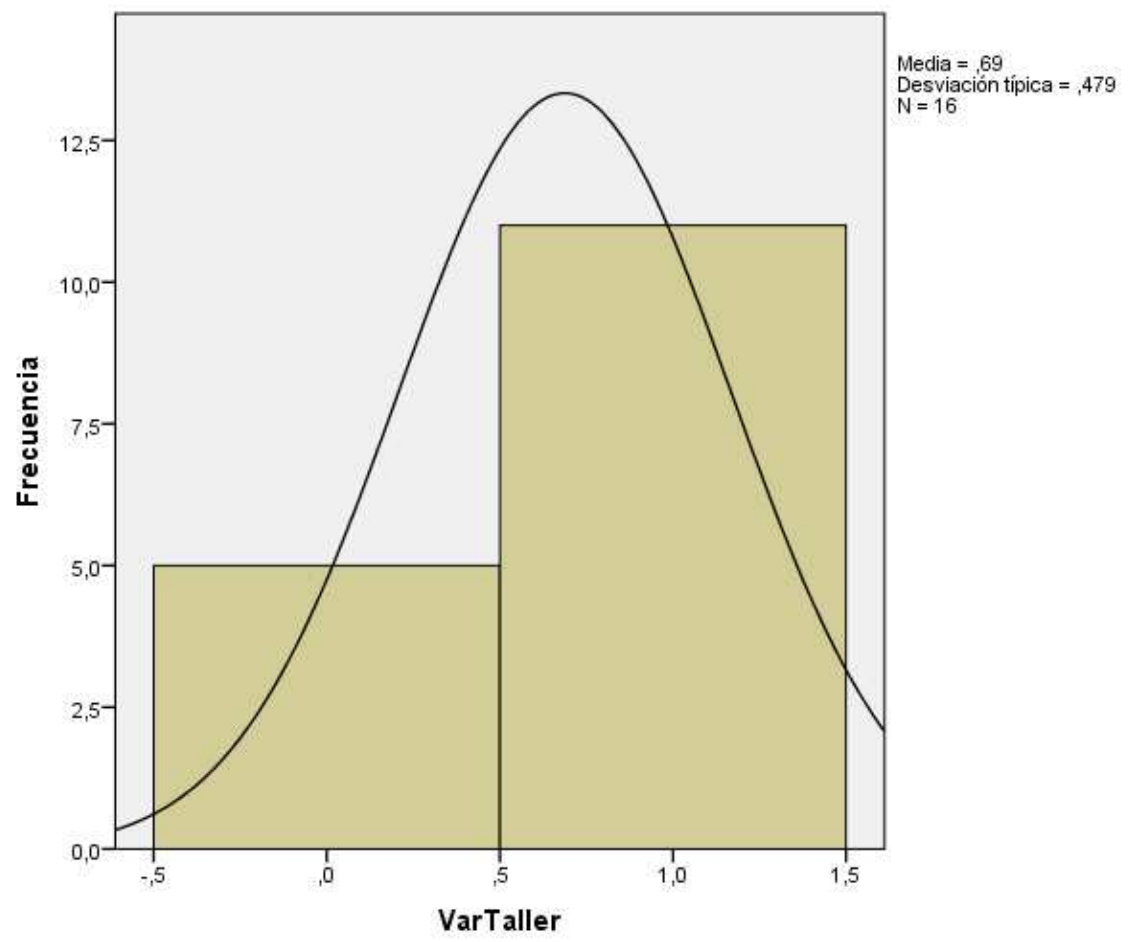

Figura 5-91 E12: Histograma de la variable Taller

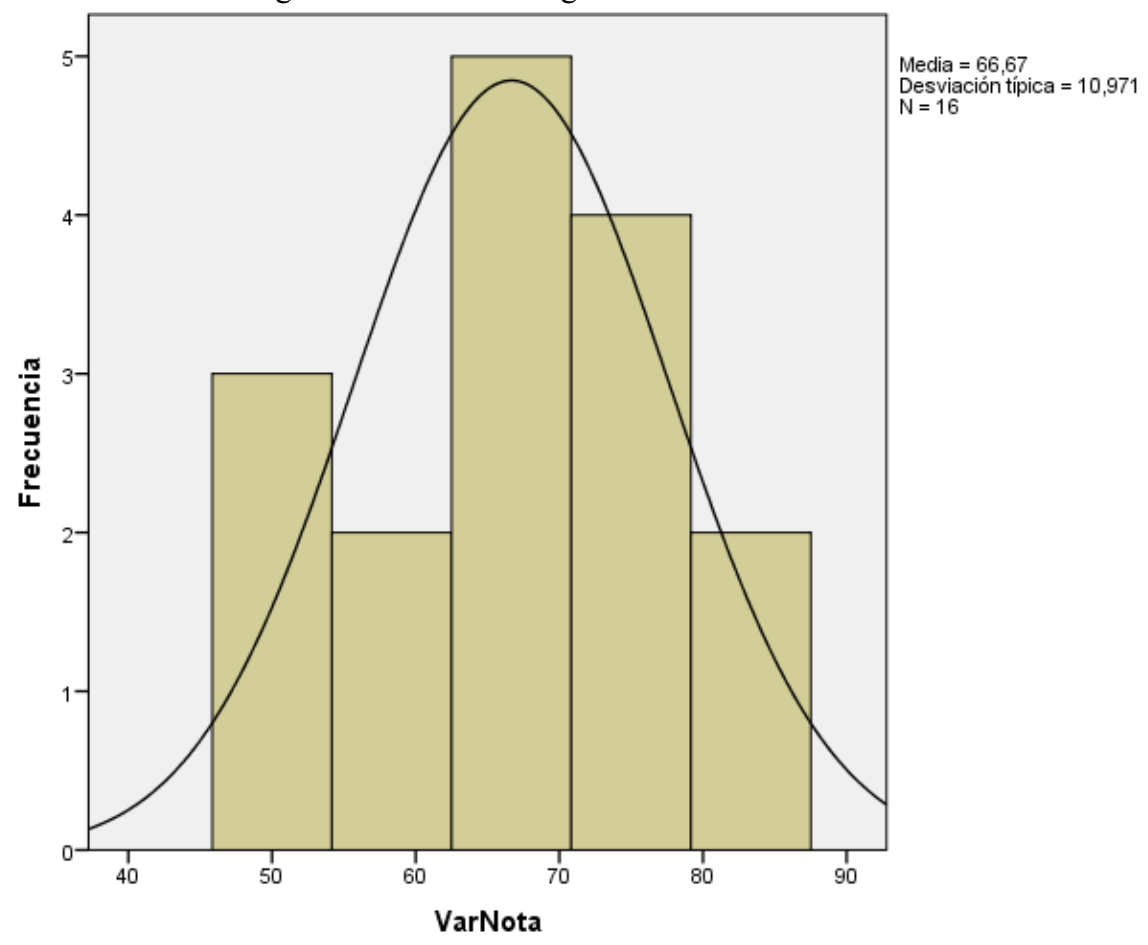

Figura 5-92 E12: Histograma de la variable Nota

Test de Kolmogorov-Smirnov - No paramétrica 
Resumen de prueba de hipótesis

\begin{tabular}{|c|c|c|c|c|}
\hline & Hipótesis nula & Test & Sig. & Decisión \\
\hline 1 & $\begin{array}{l}\text { Las categorías definidas por } \\
\text { VarTaller }=\text { Con simulación y Sir } \\
\text { simulación se producen con las } \\
\text { probabilidades de } 0,5 \text { y } 0,5 \text {. }\end{array}$ & $\begin{array}{l}\text { irfrueba binomial } \\
\text { s de una muestra }\end{array}$ & $.210^{1}$ & $\begin{array}{l}\text { Retenerla } \\
\text { hipótesis } \\
\text { nula. }\end{array}$ \\
\hline 2 & $\begin{array}{l}\text { La distribución de VarNota es } \\
\text { normal cón la media } 66,667 \text { y la } \\
\text { desuiación típica } 10,97 \text {. }\end{array}$ & $\begin{array}{l}\text { Prueba } \\
\text { Kolmogorov- } \\
\text { a Smirnov de una } \\
\text { muestra }\end{array}$ & .627 & $\begin{array}{l}\text { Retenerla } \\
\text { hipótesis } \\
\text { nula. }\end{array}$ \\
\hline
\end{tabular}

Se muestran las significancias asintóticas. El nivel de significancia es , 0 e

${ }^{1}$ Se muestra la significancia exacta para esta prueba.

Tabla 5-73 E12: Test de Kolmogorov-Smirnov

Para la variable taller, con un nivel de significancia del 0,21\% se acepta la hipótesis nula. Para la variable nota, con un nivel de significancia del $0,62 \%$, se acepta la hipótesis nula de que los datos provienen de una población con distribución normal.

\section{Prueba de los rangos con signo de Wilcoxon - Prueba no paramétrica}

\begin{tabular}{|c|c|c|c|c|}
\hline \multicolumn{5}{|c|}{ Rangos } \\
\hline & & $\mathrm{N}$ & $\begin{array}{c}\text { Rango } \\
\text { promedio }\end{array}$ & $\begin{array}{c}\text { Suma de } \\
\text { rangos }\end{array}$ \\
\hline \multirow{4}{*}{$G c-G x$} & Rangos negativos & $4^{a}$ & 3,13 & 12,50 \\
\hline & Rangos positivos & $1^{b}$ & 2,50 & 2,50 \\
\hline & Empates & $0^{c}$ & & \\
\hline & Total & 5 & & \\
\hline
\end{tabular}
a. $\mathrm{Gc}<\mathrm{Gx}$
b. $G c>G x$
c. $\mathrm{Gc}=\mathrm{Gx}$

Tabla 5-74 E12: Prueba de los rangos con signo de Wilcoxon

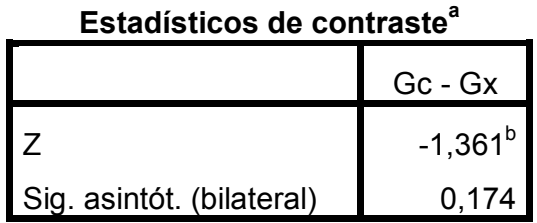

a. Prueba de los rangos con signo

de Wilcoxon

b. Basado en los rangos positivos.

Tabla 5-75 E12: Estadísticos de contraste 
En ella se observa que la significancia asintótica bilateral es aproximadamente 0,17 , el cual resulta no ser menor que el nivel de significancia $(0,05)$, sin embargo, el percentil $\mathrm{z}$ asociado $Z=-1,361$ es menor en valor absoluto que el valor crítico de la normal estándar $\mathrm{Zc}=1,96$ con lo cual existen elementos estadísticos que permiten aceptar la hipótesis nula de independencia entre ambos métodos.

\section{Estadísticos descriptivos}

\begin{tabular}{|l|r|r|r|r|r|r|r|}
\hline & \multicolumn{1}{|c|}{$\mathrm{N}$} & \multicolumn{1}{|c|}{ Mínimo } & Máximo & Media & Desv. típ. & \multicolumn{2}{|c|}{ Curtosis } \\
\cline { 2 - 8 } & Estadístico & Estadístico & Estadístico & Estadístico & Estadistico & Estadístico & Error típico \\
\hline Gx & 5 & 50 & 83 & $\mathbf{7 3 , 3 3}$ & $\mathbf{1 3 , 6 9 3}$ & 3,251 & 2,000 \\
Gc & 11 & 50 & 75 & $\mathbf{6 3 , 6 4}$ & $\mathbf{8 , 5 5 8}$ & $-0,594$ & 1,279 \\
N válido (según & 5 & & & & & & \\
lista) & & & & & & & \\
\hline
\end{tabular}

Tabla 5-76 E12: Estadísticos descriptivos

El valor de la media para el grupo de estudiantes que realizó simulación es 73,33, mayor que el correspondiente a los estudiantes que no realizaron simulación 63,64.

Sin embargo, se observa en este caso que el desvío estándar en el primer grupo, es mayor que el del segundo grupo. Dado que las medias son distintas, a fin de comparar cual de los métodos es más eficiente relativamente, corresponde calcular el coeficiente de variación relativa (cociente entre el desvío estándar y la media). El método con menor variación relativa es el más eficiente. El coeficiente para $\mathrm{Gx}=0.186$, coeficiente para $\mathrm{Gc}=0.13$. En este caso el Coeficiente de Gx > Coeficiente de Gc.

\section{Gráfico descriptivo del concepto evaluado}

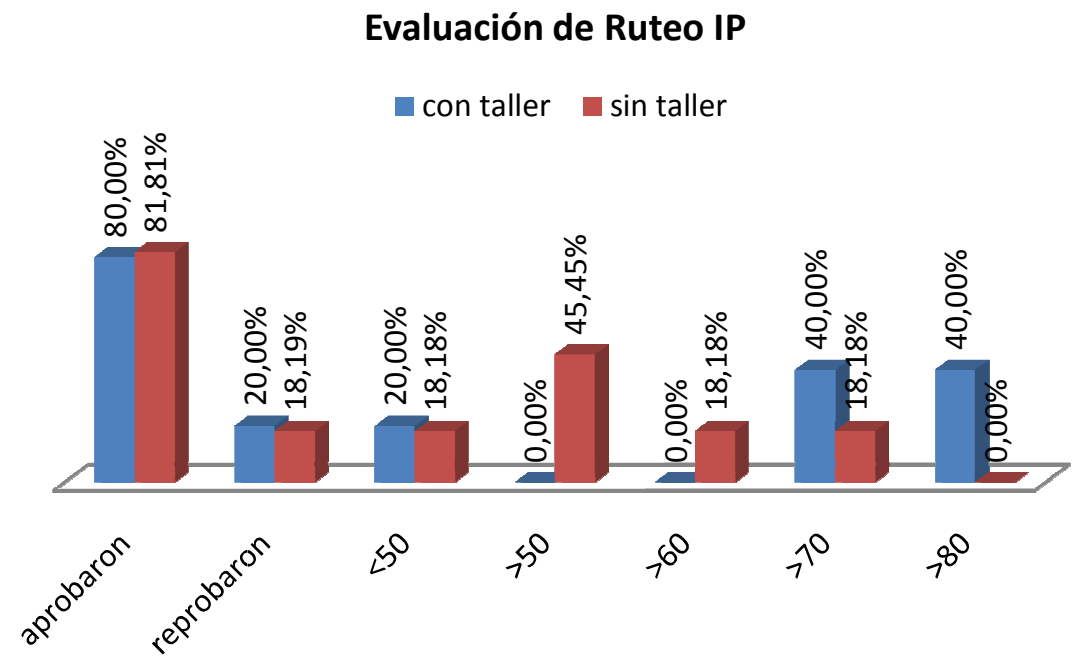

Figura 5-93 E12: Evaluación de ruteo IP 


\subsubsection{Conclusiones de la experiencia}

De acuerdo a los resultados obtenidos, se pudo determinar el impacto de la utilización del simulador Packet Tracer en la enseñanza del concepto de Ruteo IP en la asignatura Redes de Computadoras I de la carrera Licenciatura en Análisis de Sistemas.

Del análisis realizado se puede observar en la Figura 5-94 E12, que el porcentaje de aprobados-reprobados es casi el mismo para ambos grupos. Sin embargo, se puede observar que los estudiantes que realizaron el taller con simulación, obtuvieron mejores notas.

Para esta experiencia realizada, se concluyó que NO existe diferencia estadísticamente significativa a favor de ninguna de las estrategias, para el concepto de Ruteo IP evaluado. 


\subsection{Experiencia $N^{0}$ 13: Simulador MACSim en Redes I en la UCASAL}

Esta experiencia se realizó con un grupo de estudiantes que se encontraba cursando la asignatura Redes I en la Facultad de Ingeniería e Informática en la Universidad Católica de Salta, durante el primer semestre del año 2015, en el marco de un convenio existente entre las dos universidades UNSa - UCASAL, a través del Proyecto de Investigación CIUNSa $\mathrm{N}^{0} 2230 / 0$. El taller se realizó paralelamente al cursado de la asignatura, lo que permitió evaluar el desempeño tanto de los estudiantes que participaron del mismo, como de los que no participaron.

Esta experiencia fue una réplica de lo realizado en la Experiencia $\mathrm{N}^{0} 6$ y en la Experiencia $\mathrm{N}^{\circ}$ 8, utilizando el mismo diseño metodológico.

\subsubsection{Análisis estadísticos de datos}

\section{Histogramas (Normal)}

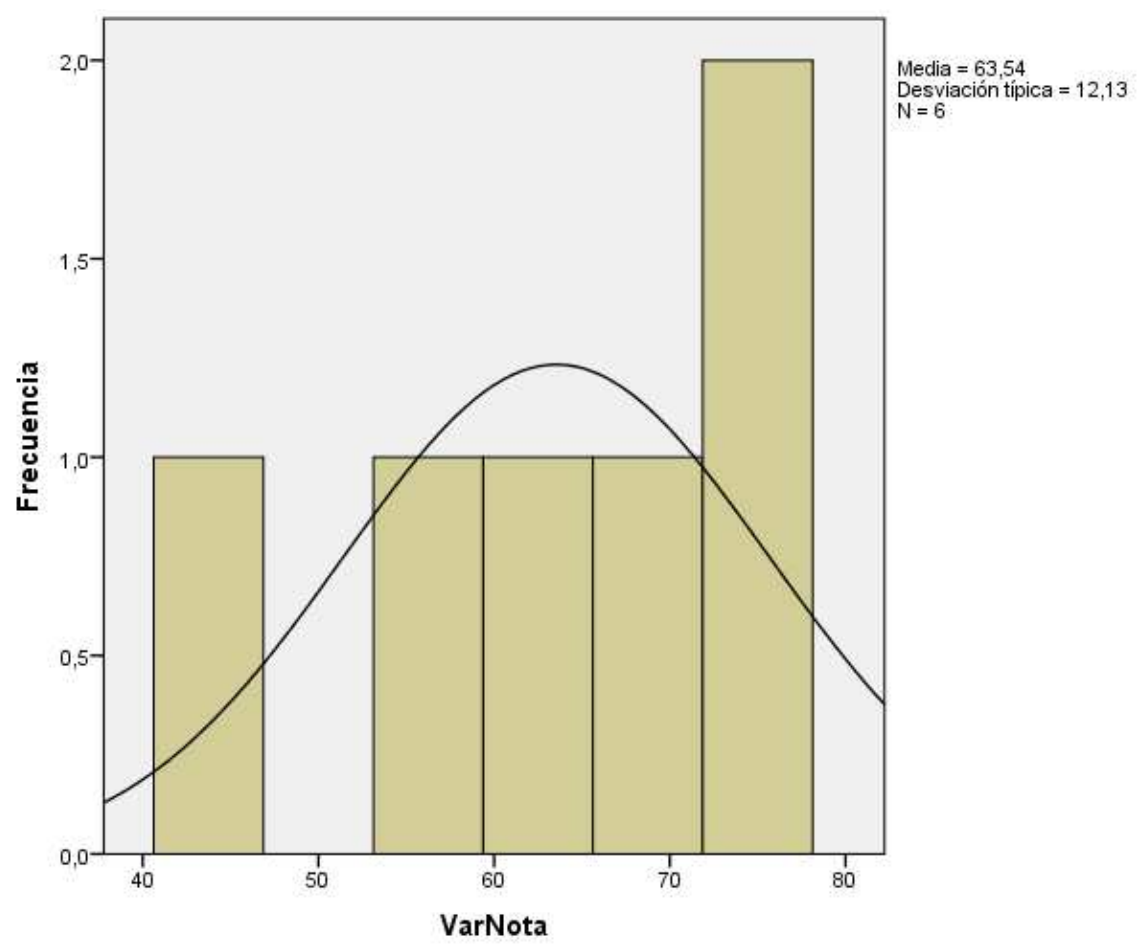

Figura 5-94 E13: Histograma de la variable Nota 


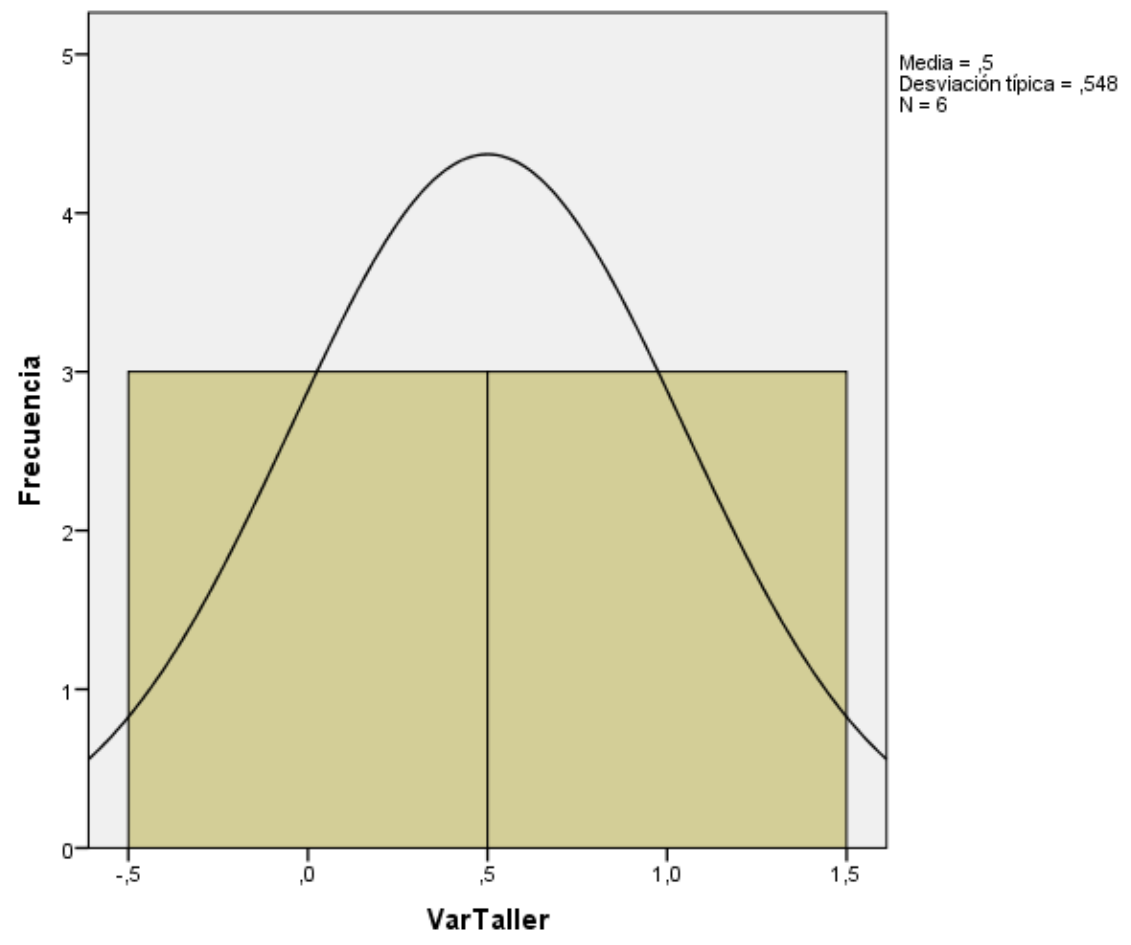

Figura 5-95 E13: Histograma de la variable Taller

\section{Test de Kolmogorov-Smirnov - No paramétrica}

\section{Resumen de prueba de hipótesis}

\begin{tabular}{|c|c|c|c|c|}
\hline & Hipótesis nula & Test & Sig. & Decisión \\
\hline 1 & $\begin{array}{l}\text { Las categorias definidas por } \\
\text { VarTaller = Con simulación y Sirf } \\
\text { simulación se producen con las d } \\
\text { probabilidades de } 0,5 \text { y } 0,5 \text {. }\end{array}$ & $\begin{array}{l}\text { IPrueba binomial } \\
\text { de una muestra }\end{array}$ & $1,000^{-1}$ & $\begin{array}{l}\text { Retener la } \\
\text { hipótesis } \\
\text { nula. }\end{array}$ \\
\hline 2 & $\begin{array}{l}\text { La distribución de VarNota es } \\
\text { normal con la media } 63,542 \text { y I } \\
\text { desuiación típica } 12,13 \text {. }\end{array}$ & $\begin{array}{l}\text { Prueba } \\
\text { Kolmogorov- } \\
\text { Smirnov de una } \\
\text { muestra }\end{array}$ & .994 & $\begin{array}{l}\text { Retener la } \\
\text { hipótesis } \\
\text { nula. }\end{array}$ \\
\hline
\end{tabular}

Se muestran las significancias asintóticas. El nivel de significancia es , 0 e

${ }^{1}$ Se muestra la significancia exacta para esta prueba.

Tabla 5-77 E13: Test de Kolmogorov-Smirnov

Para la variable taller, con un nivel de significancia del 1\% se acepta la hipótesis nula.

Para la variable nota, con un nivel de significancia del 0,99\%, se acepta la hipótesis nula de que los datos provienen de una población con distribución normal. 


\section{Prueba de los rangos con signo de Wilcoxon - Prueba no paramétrica}

\begin{tabular}{|c|c|c|c|c|}
\hline \multicolumn{5}{|c|}{ Rangos } \\
\hline & & $\mathrm{N}$ & $\begin{array}{c}\text { Rango } \\
\text { promedio }\end{array}$ & $\begin{array}{c}\text { Suma de } \\
\text { rangos }\end{array}$ \\
\hline \multirow{4}{*}{$G c-G x$} & Rangos negativos & $3^{a}$ & 2,00 & 6,00 \\
\hline & Rangos positivos & $0^{\mathrm{b}}$ & 0,00 & 0,00 \\
\hline & Empates & $0^{c}$ & & \\
\hline & Total & 3 & & \\
\hline
\end{tabular}
a. $\mathrm{Gc}<\mathrm{Gx}$
b. $G c>G x$
c. $G c=G x$

Tabla 5-78 E13: Prueba de los rangos con signo de Wilcoxon

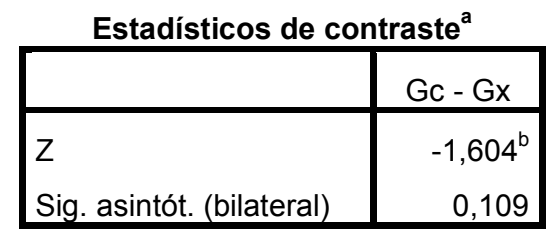
a. Prueba de los rangos con signo
de Wilcoxon
b. Basado en los rangos positivos.

Tabla 5-79 E13: Estadísticos de contraste

En ella se observa que la significancia asintótica bilateral es aproximadamente 0,11 , el cual resulta no ser menor que el nivel de significancia $(0,05)$, sin embargo, el percentil $\mathrm{z}$ asociado $Z=-1,604$ es menor en valor absoluto que el valor crítico de la normal estándar $\mathrm{Zc}=1,96$ con lo cual existen elementos estadísticos que permiten aceptar la hipótesis nula de independencia entre ambos métodos.

\section{Estadísticos descriptivos}

\begin{tabular}{|l|r|r|r|r|r|r|r|}
\hline & \multicolumn{1}{|c|}{$\mathrm{N}$} & \multicolumn{1}{|c|}{ Mínimo } & Máximo & \multicolumn{1}{c|}{ Media } & Desv. típ. & \multicolumn{2}{|c|}{ Curtosis } \\
\cline { 2 - 8 } & Estadístico & Estadístico & Estadístico & Estadístico & Estadístico & Estadístico & Error típico \\
\hline Gx & 3 & 69 & 75 & $\mathbf{7 2 , 9 2}$ & $\mathbf{3 , 6 0 8}$ & & \\
Gc & 3 & 44 & 63 & $\mathbf{5 4 , 1 7}$ & $\mathbf{9 , 5 4 7}$ & & \\
N válido (según & 3 & & & & & & \\
lista) & & & & & & & \\
\hline
\end{tabular}

Tabla 5-80 E13: Estadísticos descriptivos 
El valor de la media para el grupo de estudiantes que realizó simulación es 72,92, mayor que el correspondiente a los estudiantes que no realizaron simulación 54,17.

Se destaca además que el desvío estándar en el primer grupo, es aproximadamente del orden de la tercera parte del segundo grupo, lo cual significa que los estudiantes que realizaron simulación presentan una manifiesta homogeneidad o poca variabilidad. Esto puede considerarse como un indicador que resalta el beneficio de la enseñanza con simulación.

\section{Gráfico descriptivo del concepto evaluado}

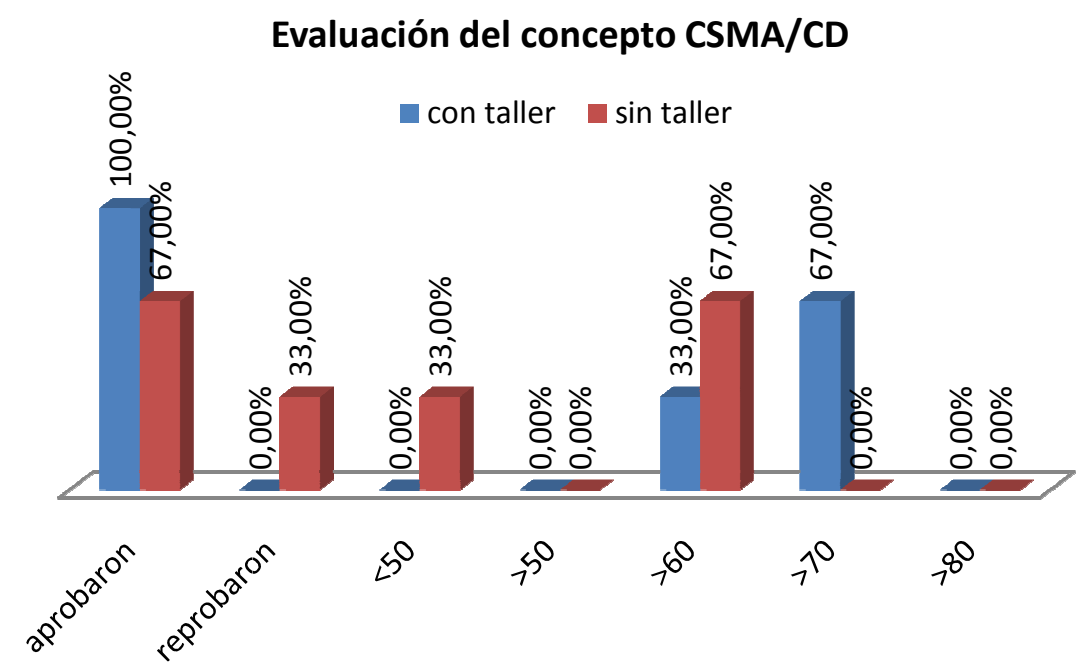

Figura 5-96 E13: Evaluación del concepto CSMA/CD

\subsubsection{Conclusiones de la experiencia}

De acuerdo a los resultados obtenidos, se pudo determinar el impacto de la utilización del simulador MACSim en la enseñanza del algoritmo CSMA/CD en la asignatura Redes I de la carrera Ingeniería en Telecomunicaciones de la Universidad Católica de Salta.

Se puede observar en la Figura 5-97 E13, que el 33\% de los estudiantes que no realizó el taller obtuvo notas menores a 50 puntos (desaprobados). Además, se pudo advertir del análisis realizado, que los estudiantes que sí realizaron el taller, aprobaron con mejores notas, lo que se traduce en respuestas mucho más acabadas y precisas del concepto evaluado.

De manera que, para esta experiencia realizada, se concluyó que existió diferencia estadísticamente significativa a favor de los estudiantes que emplearon una estrategia basada en simulación para el concepto del algoritmo CSMA/CD evaluado. 


\subsection{Experiencia $N^{0}$ 14: Simulador GNS3 en un curso organizado por el CIDIA}

Esta experiencia se realizó con el grupo de estudiantes que se inscribió al curso de extensión "Ruteo IP. De la teoría a la práctica. Simulación de redes IP con ruteo estático y dinámico con RIP y OSPF" organizado por el C.I.D.I.A. y el Proyecto CIUNSa 2230/0, con una duración de 15 horas reloj. El mismo se desarrolló durante los mese de agosto y setiembre de 2015. RESD-EXA: 621/2015. EXP-EXA: 8381/2015.

El objetivo del curso fue presentar el entorno de virtualización GNS3 y su aplicación al ruteo estático y dinámico. Se referenciaron los routers Cisco, Mikrotik y PC-Routers basados en Linux y la incorporación de imágenes IOS a GNS3.

Luego se realizó una práctica de configuración de estas 3 plataformas en el ruteo estático y dinámico con el protocolo RIP.

El taller se llevó a cabo en dos encuentros de 4 horas cada uno. Se presentaron los conceptos teóricos en cada clase y a continuación se realizó la práctica con el simulador. Fue requisito del curso haber cursado alguna asignatura introductoria de redes por lo que permitió al equipo docente concentrarse en la presentación de la herramienta y su utilización. Similar a la Experiencia $\mathrm{N}^{\mathrm{o}} 10$ descripta anteriormente.

Al finalizar el curso, se realizó una encuesta, en la cual se evaluó a GNS3 como herramienta de software

El objetivo de esta encuesta fue analizar el impacto del uso de la herramienta por los estudiantes, asociado a los diferentes temas y protocolos tratados.

\subsubsection{Análisis estadísticos de datos}

Para este análisis la media aritmética supera, en todos los casos, al menos el valor medio de la escala (3.00), lo que confirma la validez del contenido de todos los ítems incluidos.

Como puede observarse en la Tabla 5-81, el coeficiente Alfa de Cronbach calculado es de 0,814 que supera el valor de 0,7 , lo que permite afirmar el grado de fiabilidad del cuestionario. Por lo tanto, se aprecia una alta polarización de respuestas confiables por parte de los estudiantes.

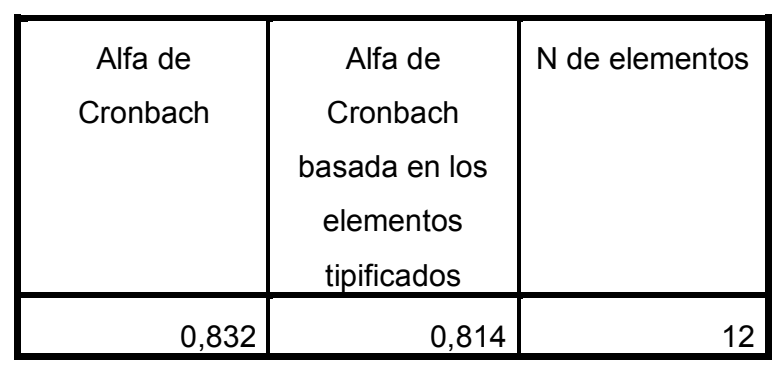

Tabla 5-81 E14: Estadísticos de fiabilidad 
Estudio de la influencia de un entorno de simulación en la enseñanza de redes de computadoras en el nivel universitario

\begin{tabular}{|l|r|r|r|}
\hline & \multicolumn{1}{|c|}{ Media } & \multicolumn{1}{|c|}{$\begin{array}{c}\text { Desviación } \\
\text { típica }\end{array}$} \\
\hline item1 & 3,83 & 1,472 & 6 \\
item2 & 4,17 & 0,753 & 6 \\
item4 & 4,83 & 0,408 & 6 \\
item5 & 3,67 & 0,816 & 6 \\
item6 & 3,17 & 0,753 & 6 \\
item7 & 4,33 & 0,516 & 6 \\
item9 & 3,83 & 0,753 & 6 \\
item10 & 3,50 & 0,548 & 6 \\
item11 & 3,83 & 0,983 & 6 \\
item12 & 3,17 & 0,983 & 6 \\
item13 & 4,33 & 0,816 & 6 \\
item14 & 4,33 & 0,816 & 6 \\
\hline
\end{tabular}

Tabla 5-82 E14: Estadísticos de los elementos

\begin{tabular}{|l|r|r|r|r|r|r|r|}
\hline & Media & Mínimo & Máximo & Rango & $\begin{array}{r}\text { Máximo/ } \\
\text { mínimo }\end{array}$ & Varianza & \multicolumn{1}{c|}{$\begin{array}{c}\mathrm{N} \text { de } \\
\text { elementos }\end{array}$} \\
\hline $\begin{array}{l}\text { Medias de los elementos } \\
\begin{array}{l}\text { Varianzas de los } \\
\text { elementos }\end{array}\end{array}$ & 0,711 & $\begin{array}{r}3,167 \\
0,167\end{array}$ & $\begin{array}{r}4,833 \\
2,167\end{array}$ & $\begin{array}{r}1,667 \\
2,000\end{array}$ & 1,526 & 0,255 & 12 \\
$\begin{array}{l}\text { Covarianzas inter- } \\
\text { elementos }\end{array}$ & 0,208 & $-0,333$ & 0,867 & 1,200 & $-2,600$ & 0,271 & 12 \\
$\begin{array}{l}\text { Correlaciones inter- } \\
\text { elementos }\end{array}$ & 0,268 & $-0,728$ & 0,894 & 1,622 & $-1,229$ & 0,152 & 12 \\
\hline
\end{tabular}

Tabla 5-83 E14: Estadísticos de resumen de los elementos

\begin{tabular}{|r|r|r|r|}
\hline \multicolumn{1}{|c|}{ Media } & Varianza & \multicolumn{1}{|c|}{$\begin{array}{c}\text { Desviación } \\
\text { típica }\end{array}$} & N de elementos \\
\hline 47,00 & 36,000 & 6,000 & 12 \\
\hline
\end{tabular}

Tabla 5-84 E14: Estadísticos de la escala 


\section{Gráficos descriptivos}

A continuación se presentan gráficamente las respuestas de los estudiantes, para cada una de las preguntas del cuestionario realizado

\section{GNS3 como herramienta de software}

1. La instalación y puesta en funcionamiento de la herramienta es sencilla.

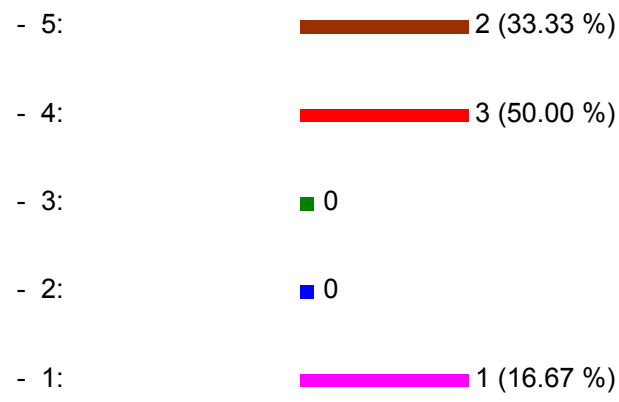

2. La configuración de la interfaz en idioma español es sencilla.

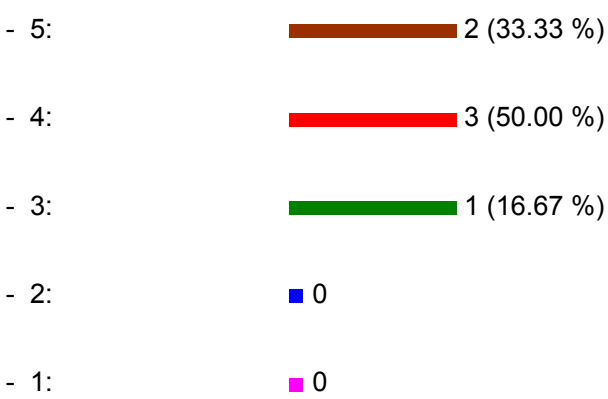

3. La interfaz gráfica que ofrece la aplicación es amigable e intuitiva.

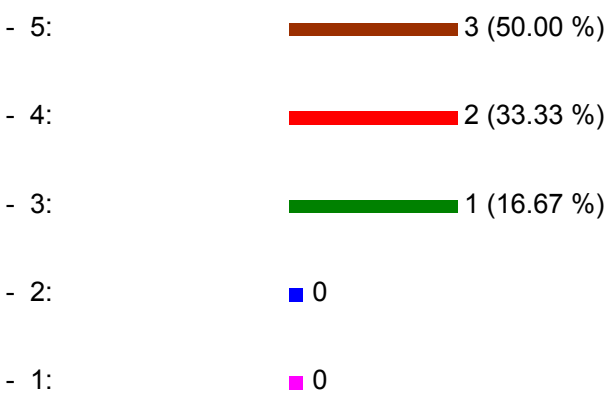

4. La aplicación posee los componentes necesarios para realizar un laboratorio de redes IP.
- 5: $5(83.33 \%)$
- 4: $1(16.67 \%)$ 


$\begin{array}{ll}-3: & =0 \\ -2: & \\ -1: & \\ -0\end{array}$

5. La herramienta ofrece disponibilidad que garantice la realización de los laboratorios sin interrupciones.

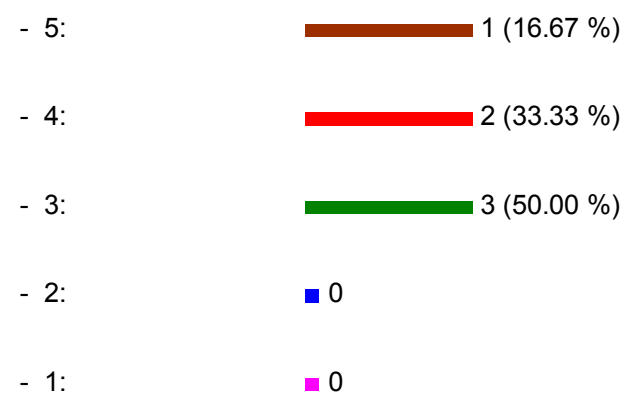

6. Se cuenta con ayuda que permita resolver dudas sobre el uso de la herramienta.

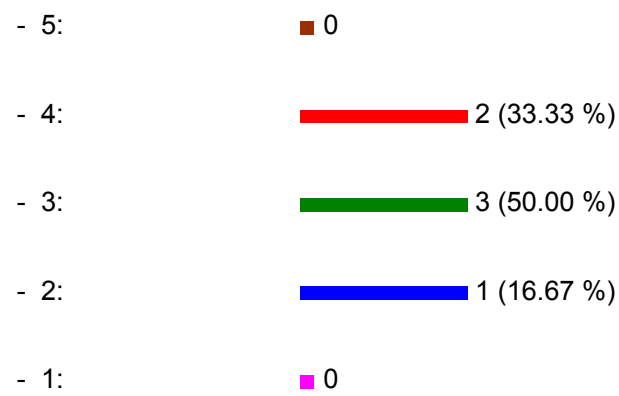

7. La herramienta permite realizar simulaciones claras y reales.

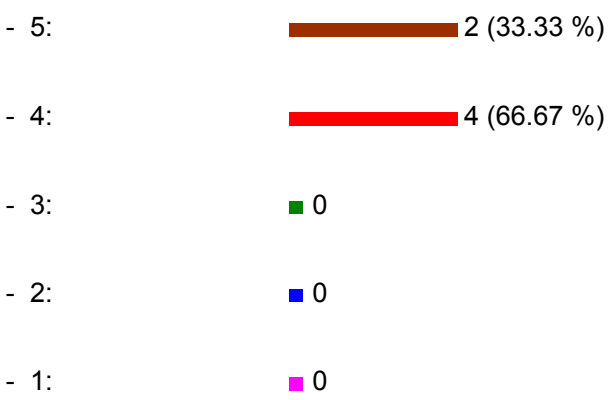

8. Con esta herramienta, la configuración de los dispositivos se desentiende de una marca particular, concentrándose en el concepto teórico.

$-5: \quad-0$ 


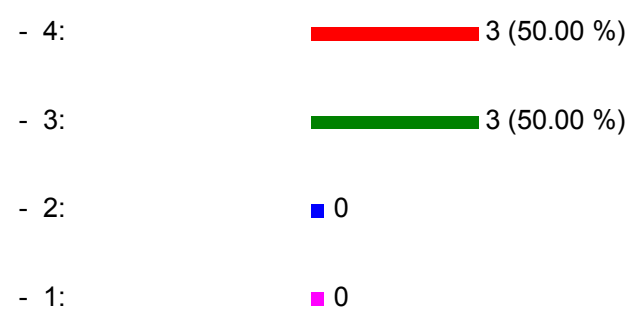

9. Permite realizar cambios en la topología fácilmente para adecuarla a las necesidades.

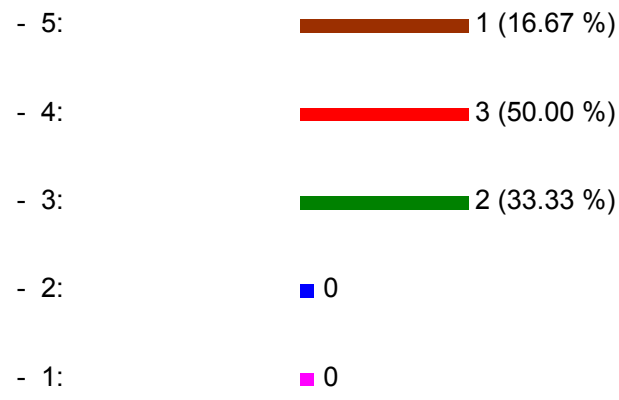

10. Permite simular cambios en dispositivos de manera efectiva en una determinada topología.

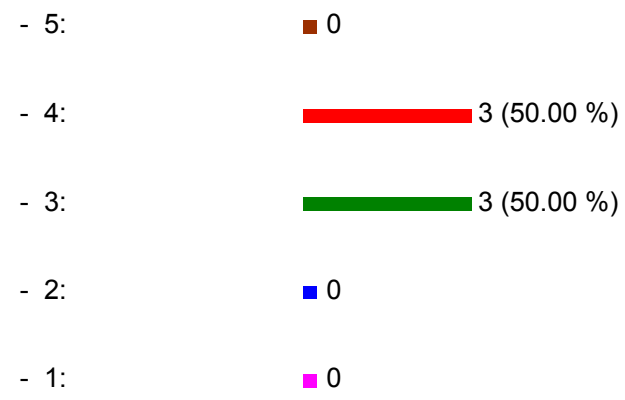

11. La herramienta facilita el seguimiento de los eventos ocurridos en cada uno de los dispositivos dentro de la red.

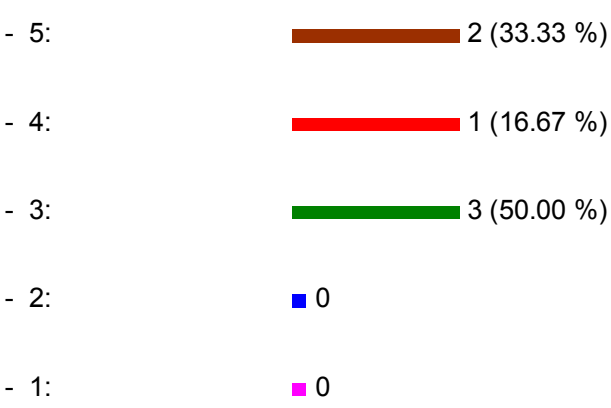

12. Con GNS3 se potencializa la educación no presencial. 
Estudio de la influencia de un entorno de simulación en la enseñanza de redes de computadoras en el nivel universitario

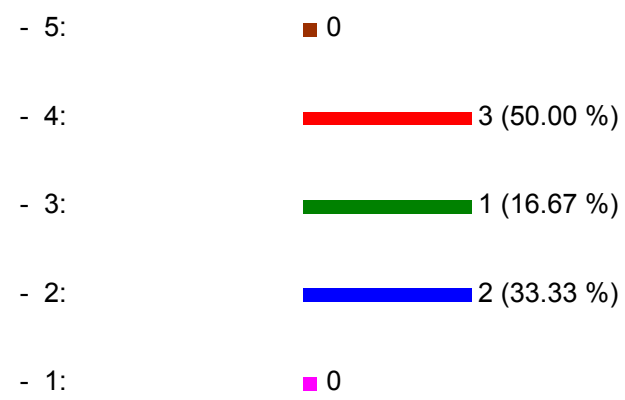

13. GNS3 es adecuado para el estudio y análisis del ruteo IP.

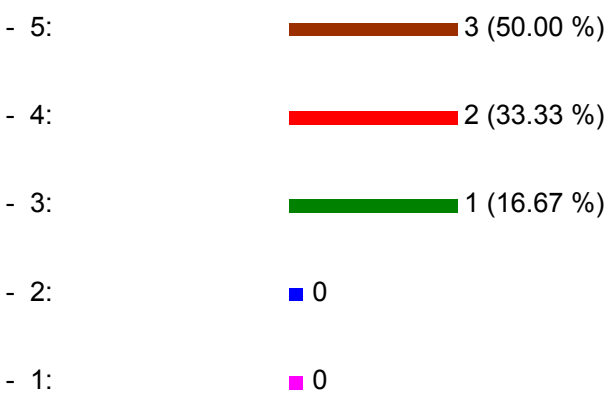

14. Considera adecuado el Práctico propuesto.

\begin{tabular}{|c|c|}
\hline$-5:$ & $3(50.00 \%)$ \\
\hline$-4:$ & $2(33.33 \%)$ \\
\hline - 3: & $1(16.67 \%)$ \\
\hline$-2:$ & - 0 \\
\hline$-1:$ & $\square 0$ \\
\hline
\end{tabular}

15. Podría citar al menos tres características distintivas comparando la simulación que permite realizar Packet Tracer frente a la virtualización en GNS3?

- $\quad$ 1. Creo que lo más importante de la herramienta GNS3, es que esta complementada con Wireshark permitiendo, una mejora notable en el análisis de los protocolos a estudiar.

2. En favor a packet tracer, es una herramienta que no pide demasiados recursos de HW por lo que es prácticamente más accesible, aunque es más sencillo.

3. Creo que GNS3, es más completo y para un ámbito más profesional, dado que se puede realizar simulaciones de peso, y nos sirve como una puerta al mercado laboral, sin duda alguna para un curso más avanzado de redes.

- 1) Según el profesor, el uso de GNS3 se asemeja al $100 \%$ de la vida real

2) Buena interfaz gráfica

3) Es de fácil comprensión y uso.

- $\quad$ 1) GN3 permite el diseño de topologías de red

2) GN3 que permite emular enrutadores

3) GN3 puede trabajar con la IOS de routers reales. 
- $\quad$ - La posibilidad de cargar las imágenes de otros routers en GNS3

- La interfaz de packet Tracer es mas user friendly

- La posibilidad de utilizar wireshark en conjunto con GNS3

- La posibilidad de seguir los "paquetes" en Packet Tracer.

- Packet tracer permite realizar mejores análisis de los paquetes que se envían a través de la red. Además al ser una simulación no posee grandes requerimientos del hardware sobre el que se va a hacer correr el programa. Otra característica distintiva de Packet tracer sobre gns3 es que el entorno gráfico que ofrece permite centrar más la atención en los conceptos teóricos y generales que se pretenden estudiar, en gns3 se deben conocer los comandos para poder configurar adecuadamente los dispositivos.

- $\quad$ Packet Tracer tiene mayores menús gráficos que permiten alejarse de los comandos propios de cada dispositivo.

Packet Tracer está muy destinado a los dispositivos Cisco por lo cual es muy oportuno el cambio a GNS3.

Packet Tracer permite la creación de una topología de red y puesta en marcha más rápido que GNS3.

16. Observaciones y comentarios adicionales de los estudiantes

- Lamentablemente el curso se vio retrasado por el desconocimiento de algunos estudiantes de los requerimientos para virtualizar.

- $\quad$ El dictado del curso fue muy didáctico y se pudo implementar varios conceptos teóricos.

- Considero que gns3 es una buena herramienta, sobre todo para testear con dispositivos físicos compatibles. Sin embargo creo que demanda mucha memoria del hardware sobre el que se está corriendo y eso dificulta en cierto modo el aprendizaje, ya que no todos poseemos computadoras portátiles que cumplan con los requerimientos de memoria.

- La primera pregunta no es posible de contestar del todo. Dado que no instalamos la herramienta por nuestra cuenta, sino que nos la dieron en la Maquina virtual. Si se refiere a eso creo que fue bastante eficiente.

- $\quad$ Para la instalación es conveniente tener recursos con buena memoria RAM.

- $\quad$ Por favor publiquen apuntes con el contenido visto en clase.

Figura 5-97 E14: Análisis del simulador GNS3

\subsubsection{Conclusiones de la experiencia}

De acuerdo a los resultados de las encuestas realizadas a los estudiantes para determinar el impacto de la utilización de GNS3 en el curso de extensión "Ruteo IP. De la teoría a la práctica. Simulación de redes IP con ruteo estático y dinámico con RIP y OSPF", se concluyó que en términos generales el acercamiento inicial fue considerado por los estudiantes como positivo.

Ahora bien, mediante la utilización de GNS3 como simulador de topologías de red, se evidenció que esta herramienta fue en gran medida aceptada y apoyó el proceso de enseñanza de redes IP en general, en particular la enseñanza de conceptos y fundamentos sobre ruteo estático y dinámico con RIP (temática del curso). 
Acerca de GNS3 como herramienta de software, se evidenció que en gran medida se consideró a la interfaz intuitiva, la simulación fue clara y real, facilitó el seguimiento de los eventos ocurridos en la simulación, la instalación y puesta en funcionamiento fueron sencillas, contó con ayuda al usuario, la configuración se independizó del fabricante (ya que integra todos, simplemente fue necesario disponer de las imágenes de los equipos necesarios), permitió realizar cambios en una topología fácilmente y cambios en dispositivos de manera efectiva.

También se pudo observar que los prácticos propuestos para el simulador, en general fueron considerados adecuados por los estudiantes. 


\subsection{Experiencia $\mathbf{N}^{0}$ 15: Simulador MACSim en Redes de Computadoras II}

Esta experiencia se realizó con un grupo de estudiantes que se encontraba cursando la asignatura Redes de Computadoras II del Plan de Licenciatura en Análisis de Sistemas 2010 durante el segundo semestre del año 2015. El taller se realizó paralelamente al cursado de la asignatura, lo que permitió evaluar el desempeño tanto de los estudiantes que participaron del mismo, como de los que no participaron.

Esta experiencia fue una réplica de lo realizado en las Experiencias $\mathrm{N}^{\circ} 6,8$ y 13, utilizando el mismo diseño metodológico.

\subsubsection{Análisis estadísticos de datos}

\section{Histogramas (Normal)}

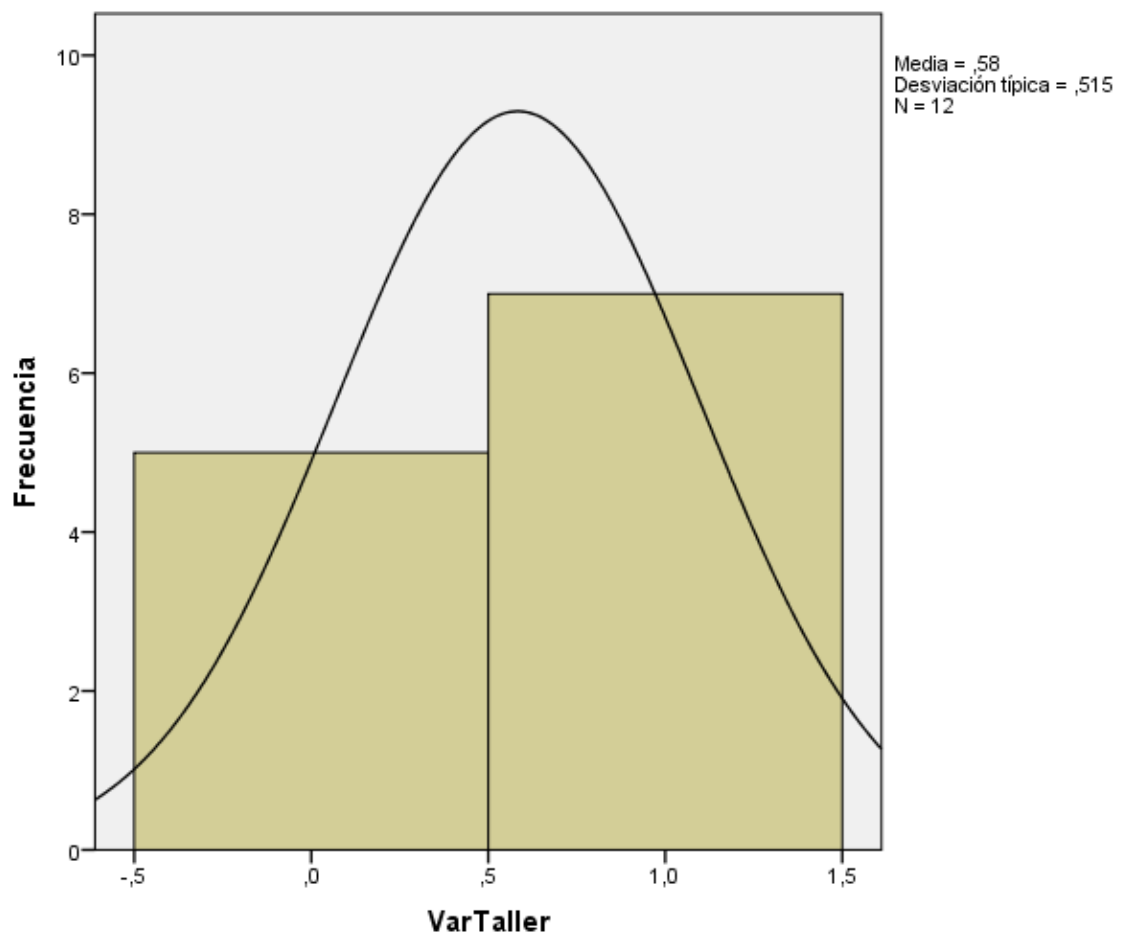

Figura 5-98 E15: Histograma de la variable Taller 


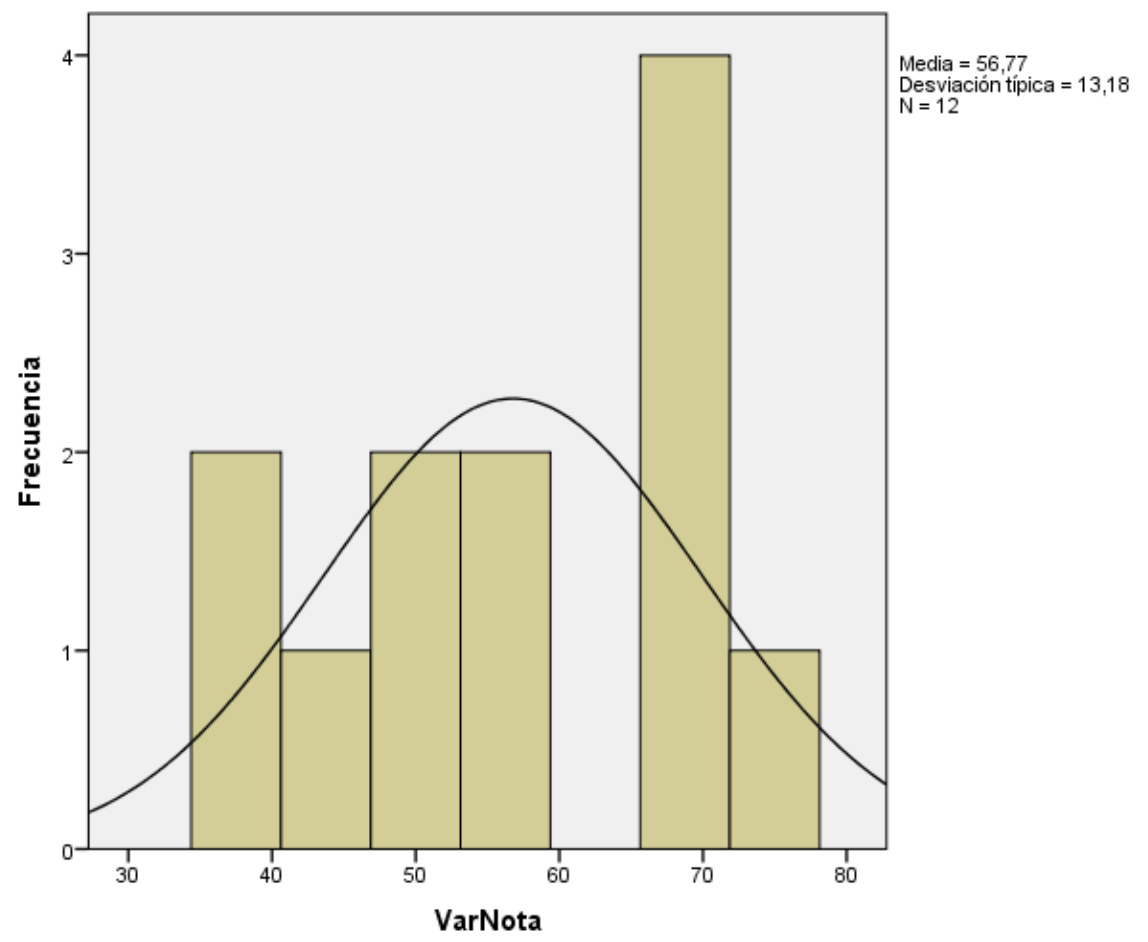

Figura 5-99 E15: Histograma de la variable Nota

\section{Test de Kolmogorov-Smirnov - No paramétrica}

\section{Resumen de prueba de hipótesis}

\begin{tabular}{|c|c|c|c|c|}
\hline & Hipótesis nula & Test & Sig. & Decisión \\
\hline 1 & $\begin{array}{l}\text { Las categorias definidas por } \\
\text { VarTaller = Con simulación y Sin } \\
\text { simulación se producen con las } \\
\text { probabilidades de } 0,5 \text { y } 0,5 \text {. }\end{array}$ & $\begin{array}{l}\text { IPrueba binomial } \\
\text { de una muestra }\end{array}$ & $.774^{1}$ & $\begin{array}{l}\text { Retener la } \\
\text { hipótesis } \\
\text { nula. }\end{array}$ \\
\hline 2 & $\begin{array}{l}\text { La distribución de VarNota es } \\
\text { normal con la media } 56.771 \text { y la } \\
\text { desuiación típica } 13,18 \text {. }\end{array}$ & $\begin{array}{l}\text { Prueba } \\
\text { Kolmogorov- } \\
\text { amirnou de una } \\
\text { muestra }\end{array}$ & .522 & $\begin{array}{l}\text { Retener la } \\
\text { hipótesis } \\
\text { nula. }\end{array}$ \\
\hline
\end{tabular}

Se muestran las significancias asintóticas. El nivel de significancia es , 06

${ }^{1}$ Se muestra la significancia exacta para esta prueba.

\section{Tabla 5-85 E15: Test de Kolmogorov-Smirnov}

Para la variable taller, con un nivel de significancia del $0,77 \%$ se acepta la hipótesis nula. Para la variable nota, con un nivel de significancia del $0,52 \%$, se acepta la hipótesis nula de que los datos provienen de una población con distribución normal. 


\section{Prueba de los rangos con signo de Wilcoxon - Prueba no paramétrica}

\begin{tabular}{|c|c|c|c|c|}
\hline \multicolumn{5}{|c|}{ Rangos } \\
\hline & & $\mathrm{N}$ & $\begin{array}{c}\text { Rango } \\
\text { promedio }\end{array}$ & $\begin{array}{c}\text { Suma de } \\
\text { rangos }\end{array}$ \\
\hline \multirow{4}{*}{$G c-G x$} & Rangos negativos & $4^{a}$ & 2,50 & 10,00 \\
\hline & Rangos positivos & $0^{\mathrm{b}}$ & 0,00 & 0,00 \\
\hline & & $1^{\mathrm{c}}$ & & \\
\hline & Total & 5 & & \\
\hline
\end{tabular}
a. $\mathrm{Gc}<\mathrm{Gx}$
b. $G c>G x$
c. $\mathrm{Gc}=\mathrm{Gx}$

Tabla 5-86 E15: Prueba de los rangos con signo de Wilcoxon

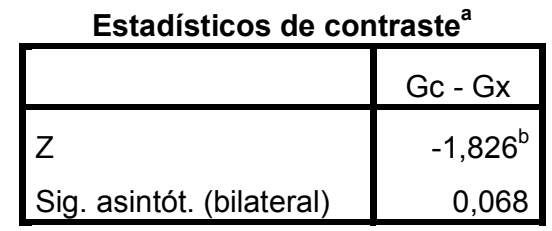
a. Prueba de los rangos con signo
de Wilcoxon
b. Basado en los rangos positivos.

Tabla 5-87 E15: Estadísticos de contraste

En ella se observa que la significancia asintótica bilateral es aproximadamente de 0,07 , la cual resulta ser menor que el nivel de significancia $(0,05)$. Esto habilita a rechazar la hipótesis nula planteada.

\section{Estadísticos descriptivos}

\begin{tabular}{|l|r|r|r|r|r|r|r|}
\hline & \multicolumn{1}{|c|}{$\mathrm{N}$} & \multicolumn{1}{|c|}{ Mínimo } & Máximo & \multicolumn{1}{c|}{ Media } & Desv. típ. & \multicolumn{2}{|c|}{ Curtosis } \\
\cline { 2 - 8 } & Estadístico & Estadístico & Estadístico & Estadístico & Estadístico & Estadístico & Error típico \\
\hline Gx & 5 & 50 & 75 & $\mathbf{6 3 , 7 5}$ & $\mathbf{1 0 , 2 7 0}$ & $-1,687$ & 2,000 \\
Gc & 7 & 38 & 69 & $\mathbf{5 1 , 7 9}$ & $\mathbf{1 3 , 3 6 3}$ & $-1,690$ & 1,587 \\
N válido (según & 5 & & & & & & \\
lista) & & & & & & & \\
\hline
\end{tabular}

Tabla 5-88 E15: Estadísticos descriptivos 
El valor de la media para el grupo de estudiantes que realizaron simulación es 63,75 , mayor que el correspondiente a los estudiantes que no realizaron simulación 51,79.

Se destaca además que el desvío estándar en el primer grupo, es menor que el desvío del segundo grupo, lo cual significa que los estudiantes que realizaron simulación presentan una mayor homogeneidad o poca variabilidad.

Esto puede considerarse como un indicador que resalta la bondad de la enseñanza con simulación.

Además, se destaca que el Estadístico de Curtosis en valor absoluto es menor para el grupo experimental, lo cual ofrece una base estadística robusta desde el punto de vista de la aceptación o validación del método experimental.

\section{Gráfico descriptivo del concepto evaluado}

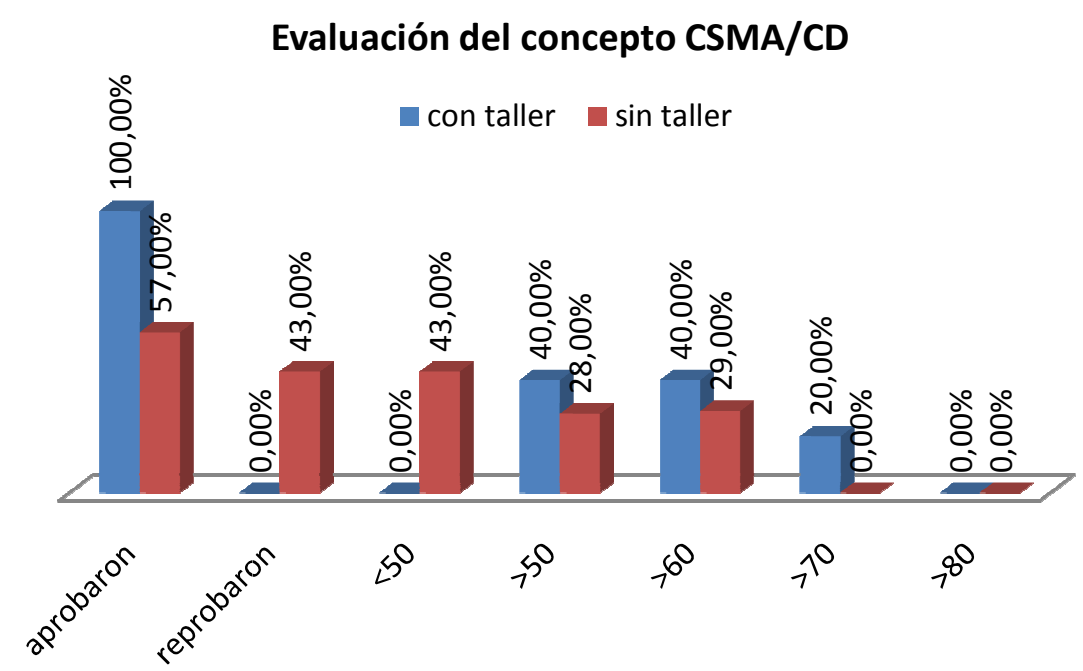

Figura 5-100 E15: Evaluación del concepto CSMA/CD

\subsubsection{Conclusiones de la experiencia}

De acuerdo a los resultados obtenidos, se pudo determinar el impacto de la utilización del simulador MACSim en la enseñanza del algoritmo CSMA/CD en la asignatura Redes de Computadoras II.

Se puede observar en la Figura 5-101 E15, que el 43\% de los estudiantes que no realizó el taller obtuvo notas menores a 50 puntos. Además se pudo advertir del análisis realizado, que los estudiantes que sí realizaron el taller, aprobaron con mejores notas, lo que se traduce en respuestas mucho más acabadas y precisas del concepto evaluado, $20 \%$ con notas mayores a 70 puntos.

De manera que, para esta experiencia realizada, se concluyó que existió diferencia estadísticamente significativa a favor de los estudiantes que emplearon una estrategia basada en simulación para el concepto del algoritmo CSMA/CD evaluado. 


\subsection{Experiencia No 16: Simulador Packet Tracer y el Protocolo ARP en Redes de Computadoras II}

Esta experiencia se realizó con un grupo de estudiantes que se encontraba cursando la asignatura Redes de Computadoras II del nuevo Plan de Licenciatura en Análisis de Sistemas 2010 durante el segundo semestre del año 2015. El taller se realizó paralelamente al cursado de la asignatura, lo que permitió evaluar la utilización del simulador Packet Tracer como herramienta de software, como soporte para el estudio del Protocolo ARP y el tema de redes Ethernet correspondientes a la Capa de Enlace.

El taller se llevó a cabo durante un mes, cada clase teórica fue acompañada con su correspondiente clase práctica sobre papel y además con la clase práctica sobre el simulador. Las clases teóricas y prácticas impartidas facilitaron la realización del taller, permitiendo al equipo docente, concentrarse en la herramienta y su utilización.

Para el Protocolo ARP, el enfoque se centró en la resolución local en la misma LAN y resolución remota cuando el destino está fuera de la LAN y se debe atravesar un router.

Se intentó realizar la evaluación del concepto del Protocolo ARP, pero solo se presentaron tres estudiantes a la instancia de evaluación (dos que realizaron el taller y uno que no lo había realizado) por lo que se decidió no realizar el análisis.

Al finalizar el curso se realizó una encuesta, para evaluar a Packet Tracer como herramienta de software. El objetivo de esta encuesta fue analizar el impacto del uso de la herramienta por los estudiantes.

\subsubsection{Análisis estadísticos de datos}

Para este análisis la media aritmética supera, en todos los casos, al menos el valor medio de la escala (3.00), lo que confirma la validez del contenido de todos los ítems incluidos.

Como puede observarse en la Tabla 5-89, el coeficiente Alfa de Cronbach calculado es de 0,749 que supera el valor de 0,7 , lo que nos permite afirmar que el grado de fiabilidad del cuestionario. Por lo tanto, se aprecia una alta polarización de respuestas confiables por parte de los estudiantes.

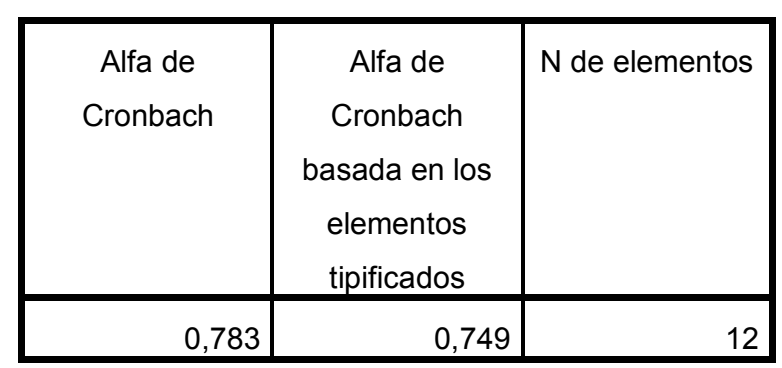

Tabla 5-89 E16: Estadísticos de fiabilidad 
Estudio de la influencia de un entorno de simulación en la enseñanza de redes de computadoras en el nivel universitario

\begin{tabular}{|l|r|r|r|}
\hline & Media & \multicolumn{1}{|c|}{$\begin{array}{c}\text { Desviación } \\
\text { típica }\end{array}$} & $\mathrm{N}$ \\
\hline VAR00001 & 4,88 & 0,354 & 8 \\
VAR00002 & 4,13 & 0,641 & 8 \\
VAR00003 & 4,13 & 0,835 & 8 \\
VAR00004 & 3,63 & 0,744 & 8 \\
VAR00005 & 4,25 & 0,707 & 8 \\
VAR00006 & 3,25 & 0,886 & 8 \\
VAR00007 & 4,13 & 0,641 & 8 \\
VAR00008 & 3,63 & 0,744 & 8 \\
VAR00009 & 4,25 & 0,707 & 8 \\
VAR00010 & 3,88 & 0,835 & 8 \\
VAR00011 & 4,38 & 0,518 & 8 \\
VAR00012 & 3,88 & 0,835 & 8 \\
\hline
\end{tabular}

Tabla 5-90 E16: Estadísticos de los elementos

\begin{tabular}{|c|c|c|c|c|c|c|c|}
\hline & Media & Mínimo & Máximo & Rango & $\begin{array}{l}\text { Máximo/ } \\
\text { mínimo }\end{array}$ & Varianza & $\begin{array}{c}\mathrm{N} \text { de } \\
\text { elementos }\end{array}$ \\
\hline Medias de los elementos & 4,031 & 3,250 & 4,875 & 1,625 & 1,500 & 0,176 & 12 \\
\hline $\begin{array}{l}\text { Varianzas de los } \\
\text { elementos }\end{array}$ & 0,516 & 0,125 & 0,786 & 0,661 & 6,286 & 0,037 & 12 \\
\hline $\begin{array}{l}\text { Covarianzas inter- } \\
\text { elementos }\end{array}$ & 0,120 & $-0,250$ & 0,482 & 0,732 & $-1,929$ & 0,034 & 12 \\
\hline $\begin{array}{l}\text { Correlaciones inter- } \\
\text { elementos }\end{array}$ & 0,199 & $-0,552$ & 0,867 & 1,419 & $-1,571$ & 0,148 & 12 \\
\hline
\end{tabular}

Tabla 5-91 E16: Estadísticos de resumen de los elementos

\begin{tabular}{|r|r|r|r|}
\hline Media & Varianza & $\begin{array}{c}\text { Desviación } \\
\text { típica }\end{array}$ & N de elementos \\
\hline 48,38 & 21,982 & 4,689 & 12 \\
\hline
\end{tabular}

Tabla 5-92 E16: Estadísticos de la escala 


\section{Gráfico descriptivo}

A continuación se presentan gráficamente las respuestas de los estudiantes, para cada una de las preguntas del cuestionario realizado.

Se utilizó la siguiente escala donde 5 es el valor máximo.

5 -> En gran medida, 4 -> En buena medida, $3 \rightarrow$ Lo suficiente, 2-> Poco, 1-> Prácticamente nada

\section{Packet Tracer como herramienta de software}

La instalación y puesta en funcionamiento de la herramienta es sencilla.

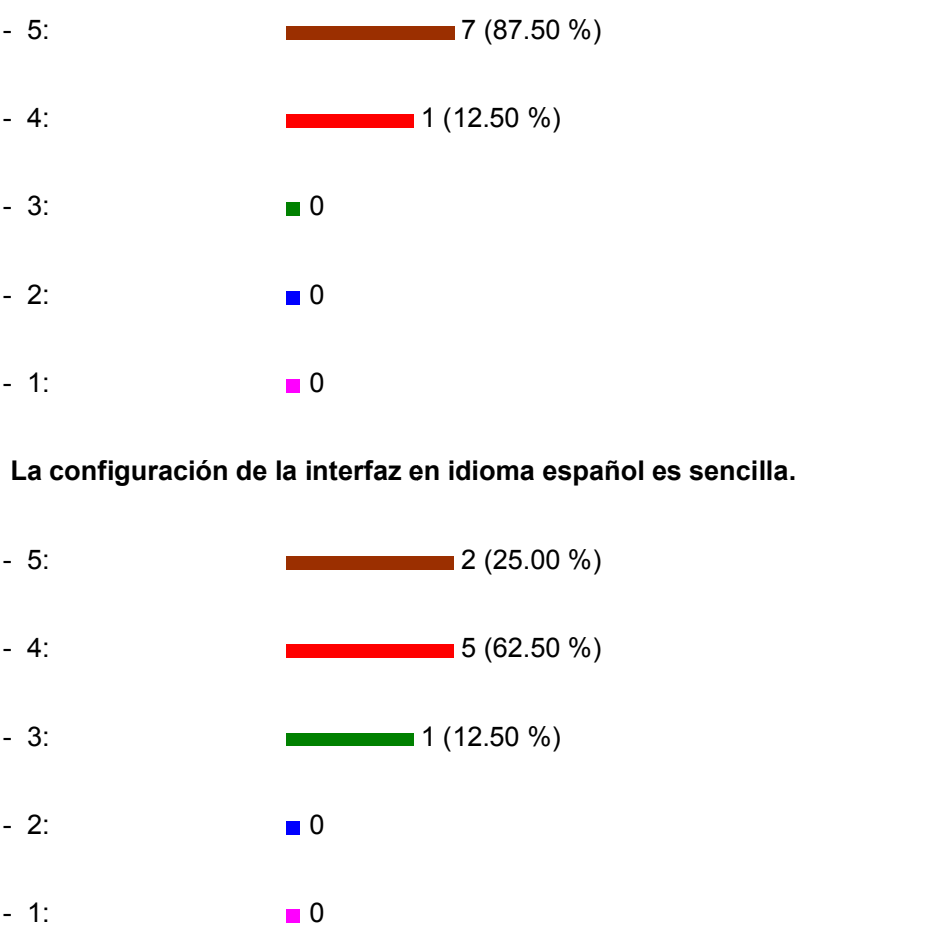

La interfaz gráfica que ofrece la aplicación es amigable e intuitiva.

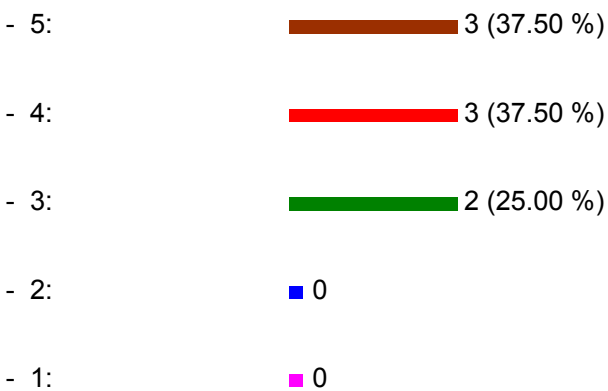

La aplicación posee los componentes necesarios para realizar un laboratorio de redes IP. 


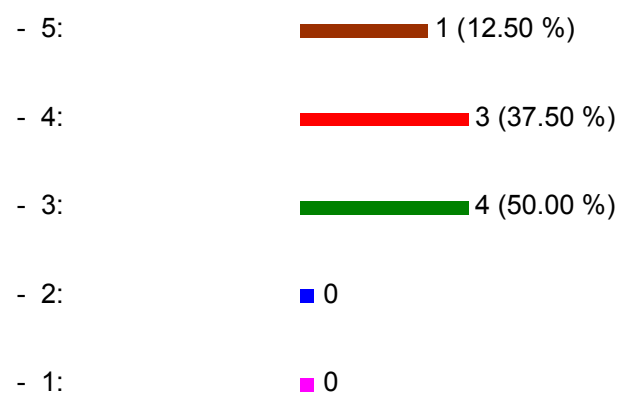

La herramienta ofrece disponibilidad que garantice la realización de los laboratorios sin interrupciones.

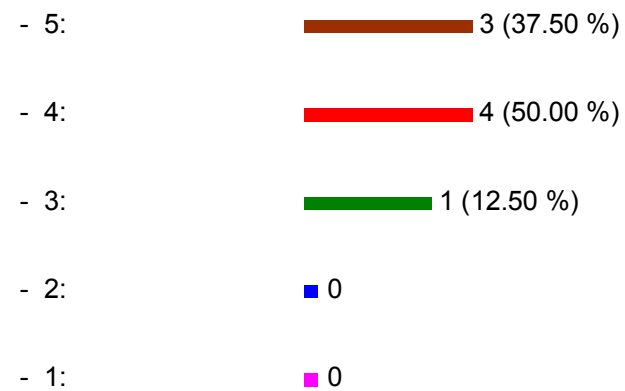

PT cuenta con ayuda que permita resolver dudas sobre el uso de la herramienta.

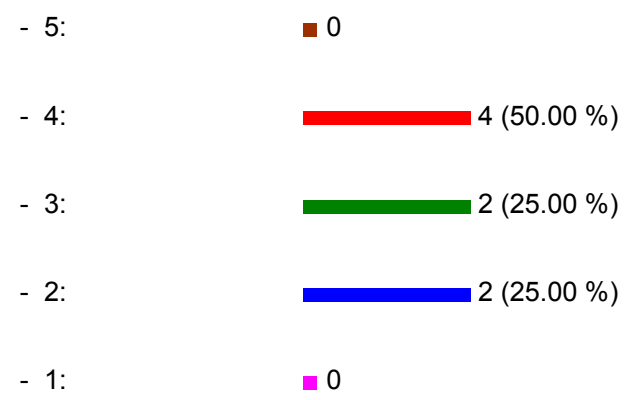

La herramienta permite realizar simulaciones claras y reales.

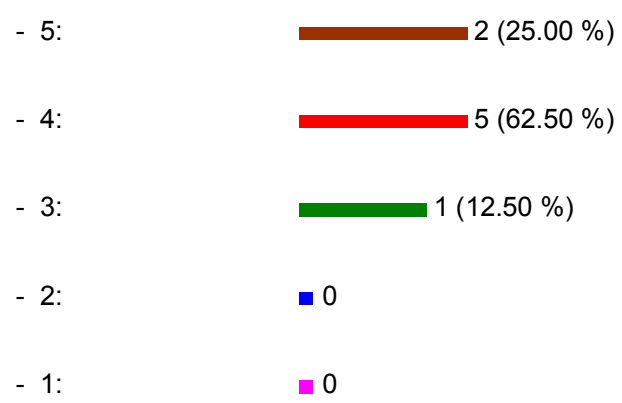

Con esta herramienta, la configuración de los dispositivos se desentiende de una marca particular, 
concentrándose en el concepto teórico.

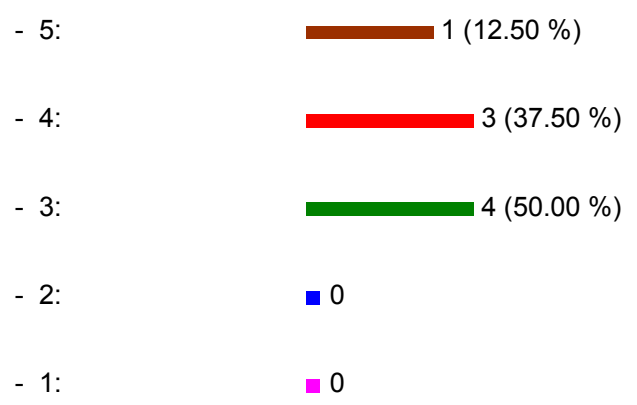

Permite realizar cambios en la topología fácilmente para adecuarla a las necesidades.

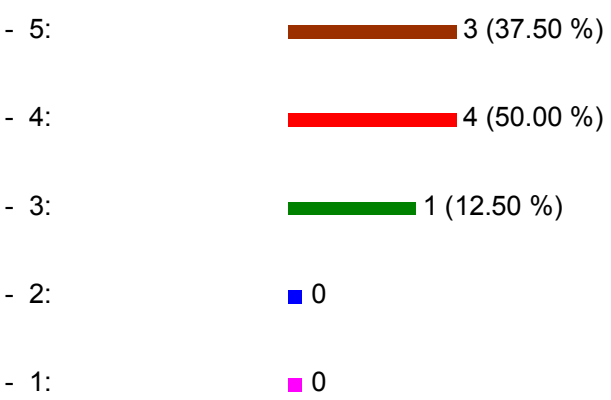

Permite simular cambios en dispositivos de manera efectiva en una determinada topología.

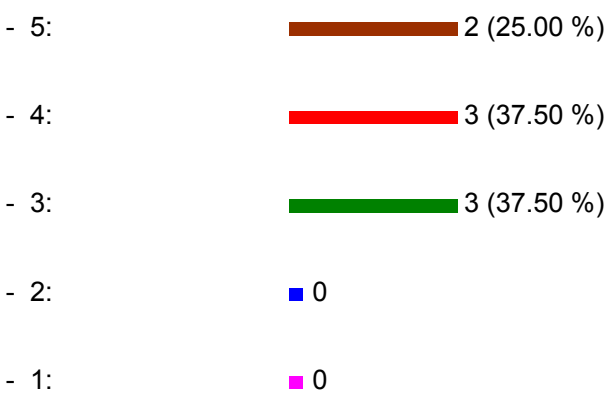

La herramienta facilita el seguimiento de los eventos ocurridos en cada uno de los dispositivos dentro de la red.

\begin{tabular}{|c|c|}
\hline - 5: & $3(37.50 \%)$ \\
\hline$-4:$ & $5(62.50 \%)$ \\
\hline - 3: & - 0 \\
\hline ? & 0 \\
\hline
\end{tabular}




$$
\begin{aligned}
& -1: \quad \square 0 \\
& \text { Con PT se potencializa la educación no presencial. }
\end{aligned}
$$

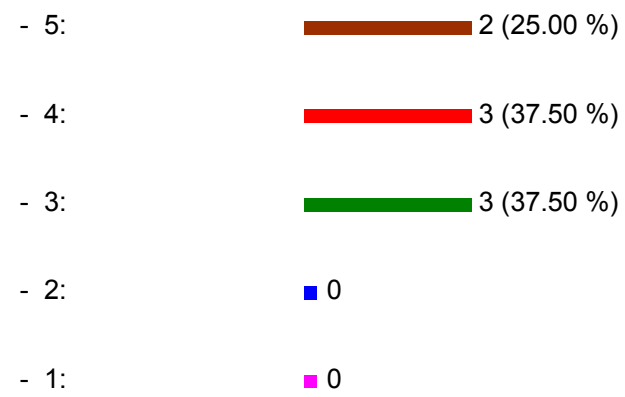

Observaciones y comentarios adicionales de los estudiantes sobre la herramienta PT

- La herramienta, a pesar de ser un poco limitada, ofrece lo suficiente para un curso introductorio en redes.

- $\quad$ Obliga a utilizar el sistema operativo Windows.

- $\quad$ Creo que la herramienta es una parte importante para la práctica de redes, pero creo que se omiten algunos detalles y explicaciones que nos servirían para entender más las cosas, como el contenido de los paquetes que se envían.

- Muy Intuitivo y fácil de aprender

- A mi parecer la herramienta PT brinda muchas facilidades y clarifica muchas aplicaciones teóricas, llevándolas a la práctica.

- $\quad$ muy buena herramienta

- $\quad$ En general una herramienta muy potente para aprender redes aunque algunos conceptos no los abarque como a otros

Figura 5-101 E16: Análisis de Packet Tracer

\subsubsection{Conclusiones de la experiencia}

De acuerdo a los resultados de las encuestas realizadas a los estudiantes para determinar el impacto de la utilización de Packet Tracer en la asignatura Redes de Computadoras I, se concluye que en términos generales el acercamiento inicial es considerado por los estudiantes como positivo.

Acerca de Packet Tracer como herramienta de software se evidenció que en gran medida se consideró que la interfaz fue intuitiva, la simulación fue clara y real, facilitó el seguimiento de los eventos ocurridos en la simulación, la instalación y puesta en funcionamiento fueron sencillas, contó con ayuda al usuario, la configuración se independizó del fabricante, permitió realizar cambios en una topología fácilmente y cambios en dispositivos de manera efectiva. 


\subsection{Experiencia $N^{0}$ 17: Simulador Packet Tracer y el Direccionamiento IP en Redes de Computadoras I}

Esta experiencia se realizó con un grupo de estudiantes que se encontraba cursando la asignatura Redes de Computadoras I del nuevo Plan de Licenciatura en Análisis de Sistemas Año 2010 durante el primer semestre del año 2016. El taller se realizó paralelamente al cursado de la asignatura, lo que permitió evaluar el desempeño tanto de los estudiantes que participaron del mismo, como de los que no participaron.

Se replicó la Experiencia $\mathrm{N}^{\circ} 11$. Siguiendo el mismo esquema metodológico.

\subsubsection{Análisis estadísticos de datos}

\section{Histogramas (Normal)}

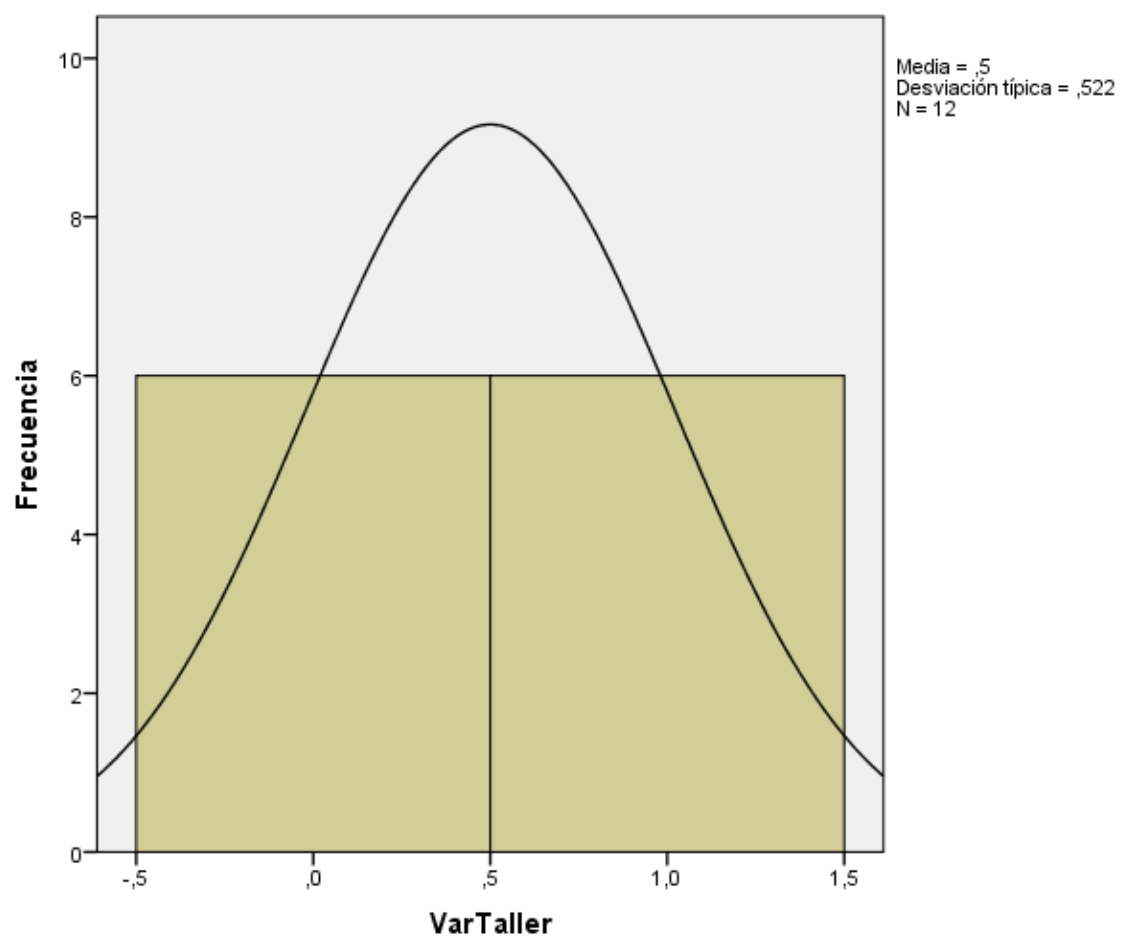

Figura 5-102 E17: Histograma de la variable Taller 


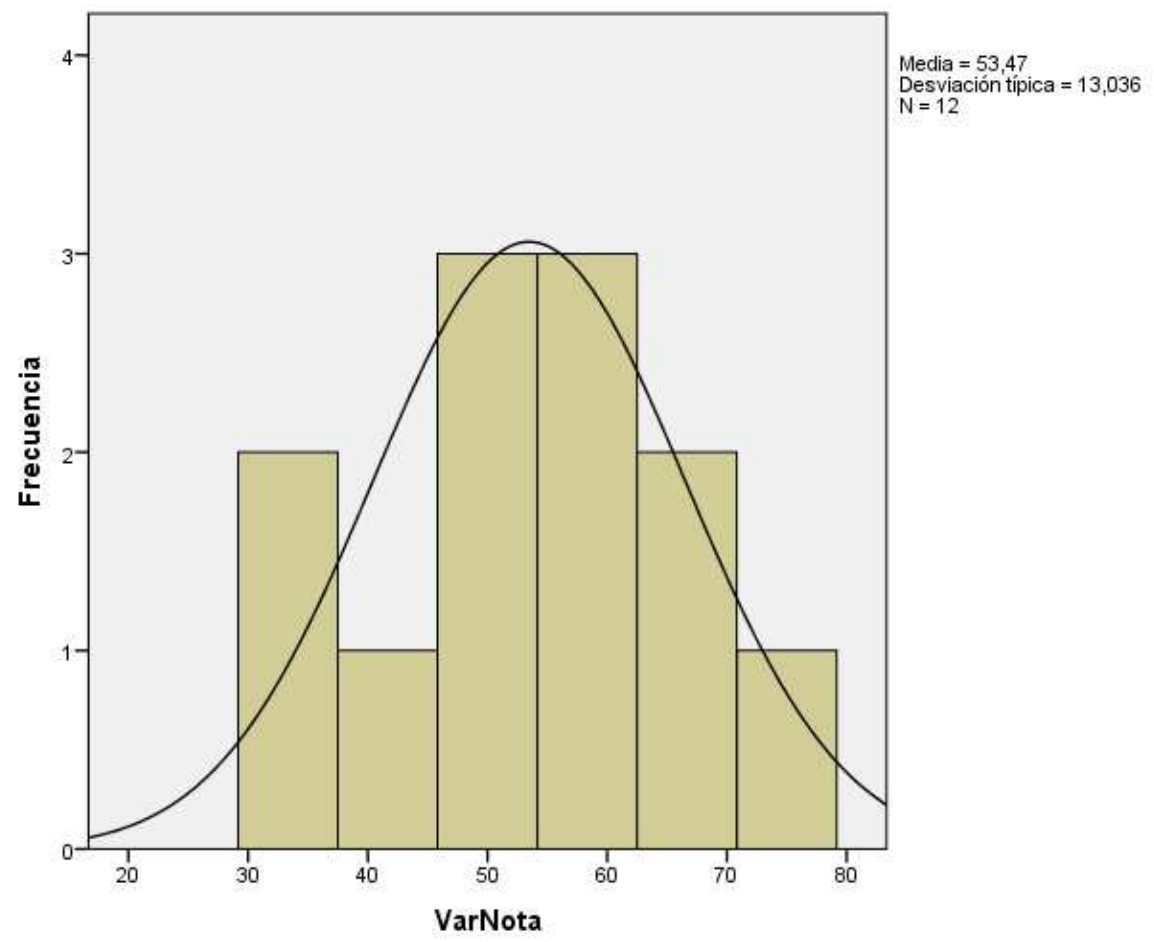

Figura 5-103 E17: Histograma de la variable Nota

\section{Test de Kolmogorov-Smirnov - No paramétrica}

\section{Resumen de prueba de hipótesis}

\begin{tabular}{|c|c|c|c|c|}
\hline & Hipótesis nula & Test & Sig. & Decisión \\
\hline 1 & $\begin{array}{l}\text { Las categorías definidas por } \\
\text { VarTaller }=\text { Con simulación y Sirf } \\
\text { simulación se producen con las } \\
\text { probabilidades de } 0,5 \text { y } 0.5 \text {. }\end{array}$ & $\begin{array}{l}\text { ifrueba binomial } \\
\text { de una muestra }\end{array}$ & $1,000^{-1}$ & $\begin{array}{l}\text { Retener la } \\
\text { hipótesis } \\
\text { nula. }\end{array}$ \\
\hline 2 & $\begin{array}{l}\text { La distribución de VarNota es } \\
\text { normal con la media } 53,472 \text { y la } \\
\text { desuiación típica } 13,04 \text {. }\end{array}$ & $\begin{array}{l}\text { Prueba } \\
\text { Kolmogorov- } \\
\text { amirnou de una } \\
\text { muestra }\end{array}$ & .962 & $\begin{array}{l}\text { Retenerla } \\
\text { hipótesis } \\
\text { nula. }\end{array}$ \\
\hline
\end{tabular}

Se muestran las significancias asintóticas. El nivel de significancia es , 0 e

${ }^{1}$ Se muestra la significancia exacta para esta prueba.

Tabla 5-93 E17: Test de Kolmogorov-Smirnov

Para la variable taller, con un nivel de significancia del 1\% se acepta la hipótesis nula.

Para la variable nota, con un nivel de significancia del $0,96 \%$, se acepta la hipótesis nula de que los datos provienen de una población con distribución normal. 


\section{Prueba de los rangos con signo de Wilcoxon - Prueba no paramétrica}

\begin{tabular}{|c|c|c|c|c|}
\hline \multicolumn{5}{|c|}{ Rangos } \\
\hline & & $\mathrm{N}$ & $\begin{array}{c}\text { Rango } \\
\text { promedio }\end{array}$ & $\begin{array}{c}\text { Suma de } \\
\text { rangos }\end{array}$ \\
\hline \multirow{4}{*}{$G c-G x$} & Rangos negativos & $6^{a}$ & 3,50 & 21,00 \\
\hline & Rangos positivos & $0^{b}$ & 0,00 & 0,00 \\
\hline & & $0^{c}$ & & \\
\hline & Total & 6 & & \\
\hline
\end{tabular}
a. $\mathrm{Gc}<\mathrm{Gx}$
b. $G c>G x$
c. $\mathrm{Gc}=\mathrm{Gx}$

Tabla 5-94 E17: Prueba de los rangos con signo de Wilcoxon

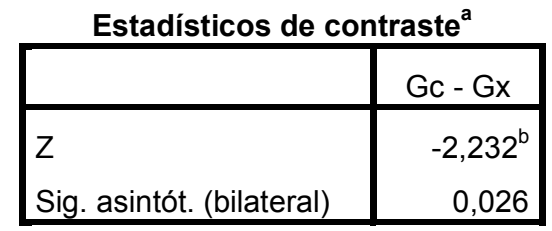
a. Prueba de los rangos con signo
de Wilcoxon
b. Basado en los rangos positivos.

Tabla 5-95 E17: Estadísticos de contraste

En ella se observa que la significancia asintótica bilateral es aproximadamente 0,02 , el cual resulta ser menor que el nivel de significancia $(0,05)$. Esto habilita a rechazar la hipótesis nula planteada.

\begin{tabular}{|l|r|r|r|r|r|r|r|}
\hline & \multicolumn{1}{|c|}{$\mathrm{N}$} & \multicolumn{1}{|c|}{ Mínimo } & Máximo & \multicolumn{1}{c|}{ Media } & Desv. típ. & \multicolumn{2}{|c|}{ Curtosis } \\
\cline { 2 - 8 } & Estadístico & Estadístico & Estadístico & Estadístico & Estadístico & Estadístico & Error típico \\
\hline Gx & 6 & 50 & 75 & $\mathbf{6 2 , 5 0}$ & $\mathbf{8 , 7 4 0}$ & $-0,248$ & 1,741 \\
Gc & 6 & 33 & 58 & $\mathbf{4 4 , 4 4}$ & $\mathbf{1 0 , 0 9 2}$ & $-1,550$ & 1,741 \\
N válido (según & 6 & & & & & & \\
lista) & & & & & & & \\
\hline
\end{tabular}

Tabla 5-96 E17: Estadísticos descriptivos

El valor de la media para el grupo de estudiantes que realizó simulación es de 62,50, mayor que el correspondiente a los estudiantes que no realizaron simulación 44,44. 
Se destaca además que el desvío estándar en el primer grupo, es menor que el del segundo grupo, lo cual significa que los estudiantes que realizaron simulación podrían presentar mayor homogeneidad o poca variabilidad. Esto puede considerarse como un indicador que resalta la bondad de la enseñanza con simulación para esta experiencia.

\section{Gráfico descriptivo del concepto evaluado}

\section{Evaluación de Direccionamiento IP}

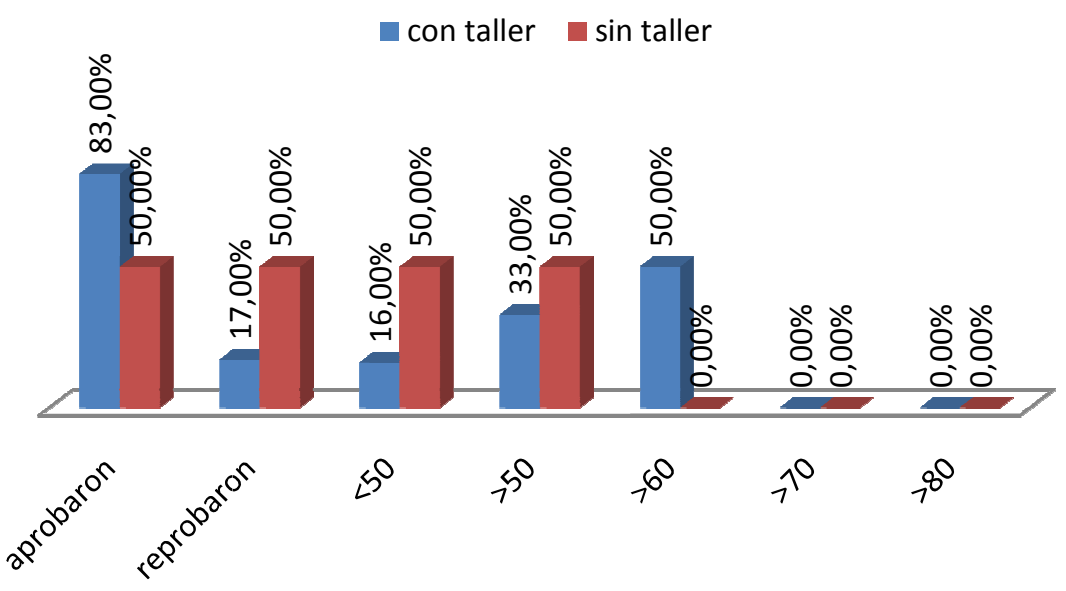

Figura 5-104 E17: Evaluación de Direccionamiento IP

\subsubsection{Conclusiones de la experiencia}

De acuerdo a los resultados obtenidos, se pudo determinar el impacto de la utilización del simulador Packet Tracer en la enseñanza del concepto de Direccionamiento IP en la asignatura Redes de Computadoras I.

Del análisis realizado se puede observar en la Figura 5-105 E17, que el 50\% de los estudiantes que no realizó el taller obtuvo notas menores a 50 puntos. Además se pudo advertir, que los estudiantes que sí realizaron el taller, aprobaron con mejores notas, lo que se traduce en respuestas mucho más acabadas y precisas del concepto evaluado.

De manera que, para esta experiencia realizada, se concluyó que existió diferencia estadísticamente significativa a favor de los estudiantes que emplearon una estrategia basada en simulación para el concepto del Direccionamiento IP evaluado. 


\subsection{Experiencia $N^{0}$ 18: Simulador Packet Tracer y el Ruteo IP en Redes de Computadoras I}

Esta experiencia se realizó con los estudiantes que se encontraban cursando la asignatura Redes de Computadoras I del nuevo Plan de Licenciatura en Análisis de Sistemas - Plan 2010 durante el primer semestre del año 2016. El taller se realizó paralelamente al cursado de la asignatura, lo que permitió evaluar el desempeño tanto de los estudiantes que participaron del mismo, como de los que no participaron.

Esta experiencia fue una réplica de la Experiencia $\mathrm{N}^{\mathrm{o}} 12$ descripta anteriormente, respetando su diseño metodológico.

Cabe aclarar que las evaluaciones de concepto no tuvieron incidencia en las notas para la regularidad de la asignatura. La misma se regularizó con 4 parciales correspondientes a cada uno de los temas del programa.

\subsubsection{Análisis estadísticos de datos}

\section{Histogramas (Normal)}

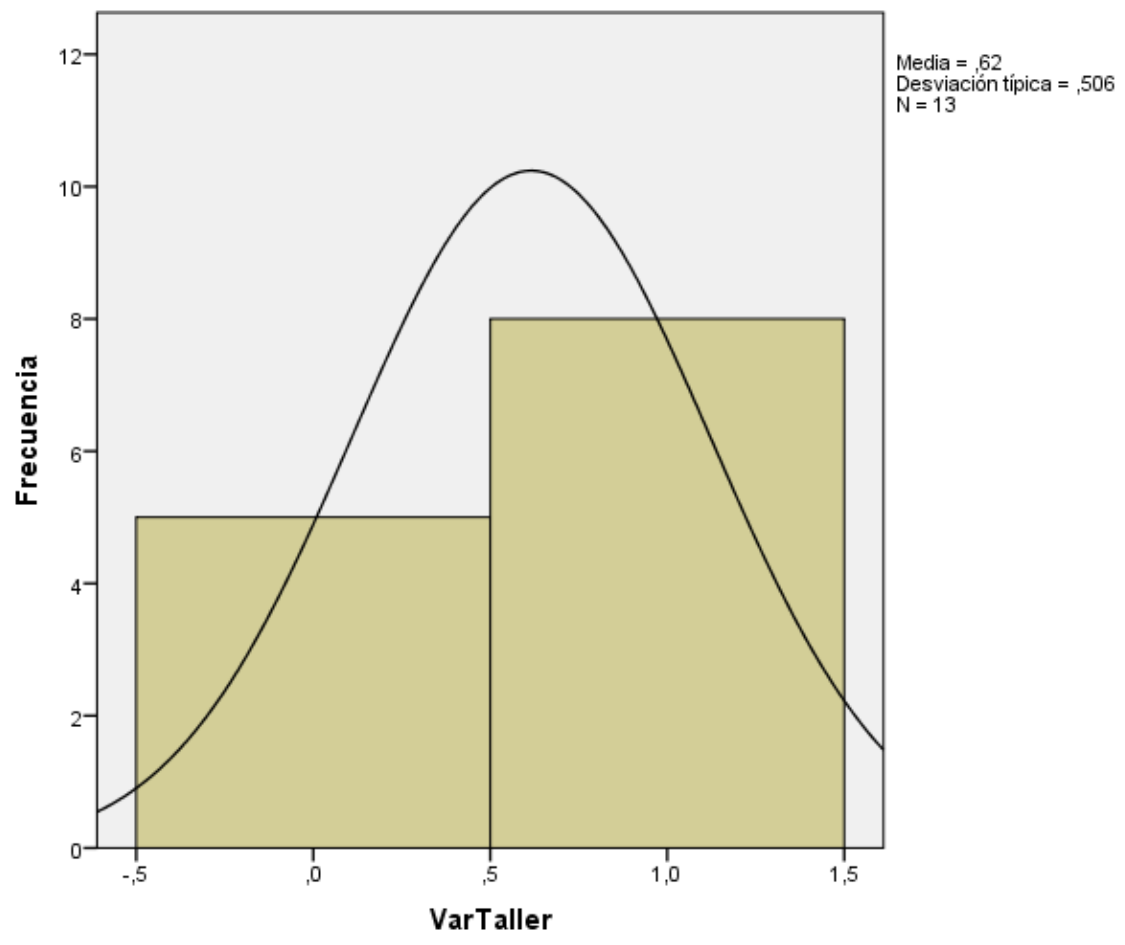

Figura 5-105 E18: Histograma de la variable Taller 


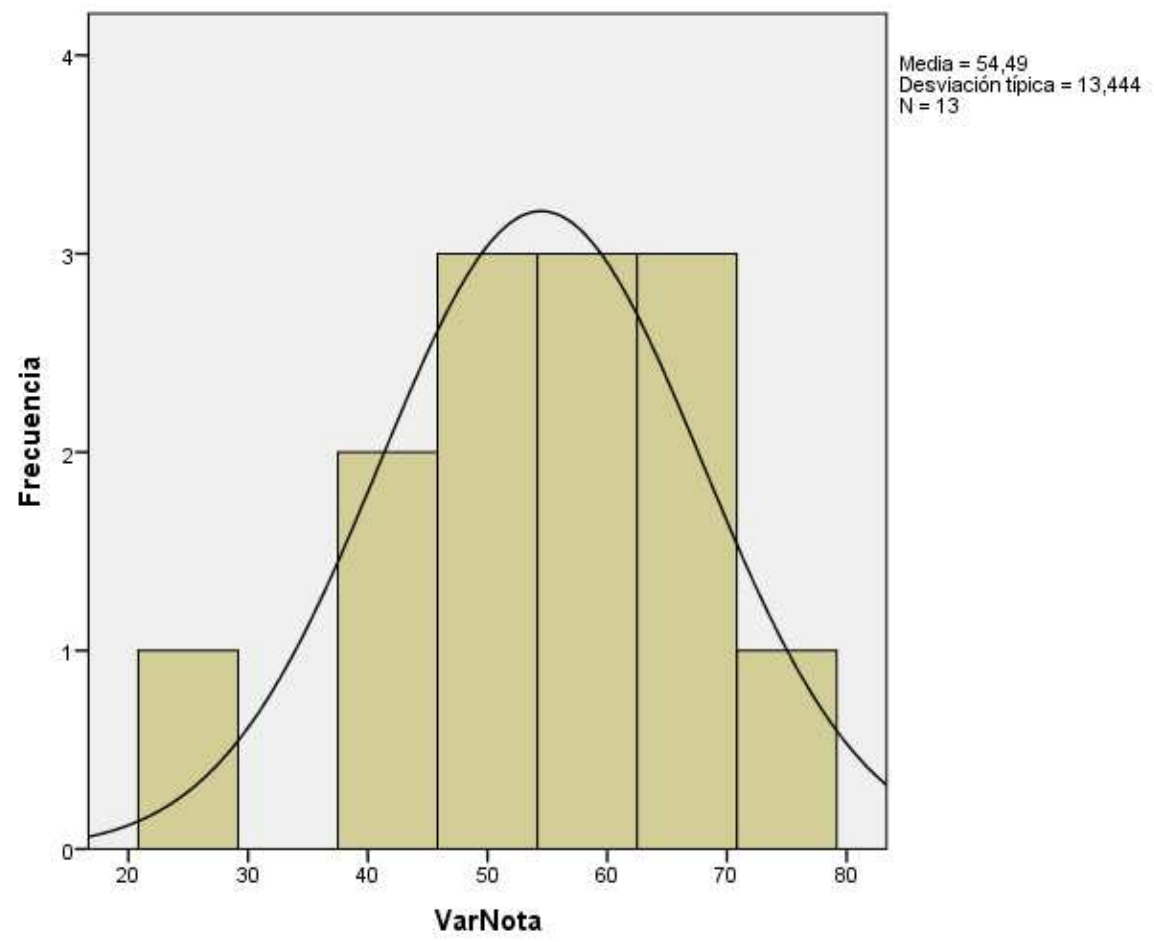

Figura 5-106 E18: Histograma de la variable Nota

\section{Test de Kolmogorov-Smirnov - No paramétrica}

\section{Resumen de prueba de hipótesis}

\begin{tabular}{|c|c|c|c|c|}
\hline & Hipótesis nula & Test & Sig. & Decisión \\
\hline 1 & $\begin{array}{l}\text { Las categorias definidas por } \\
\text { VarT aller = Con simulación y Sinh } \\
\text { simulación se producen con las } \\
\text { probabilidades de } 0,5 \text { y } 0,5 \text {. }\end{array}$ & $\begin{array}{l}\text { iPrueba binomial } \\
\text { de una muestra }\end{array}$ & $.581^{1}$ & $\begin{array}{l}\text { Retener la } \\
\text { hipótesis } \\
\text { nula. }\end{array}$ \\
\hline 2 & $\begin{array}{l}\text { La distribución de VarNota es } \\
\text { normal con la media } 54,487 \text { y la } \\
\text { desuiación típica } 13,44 \text {. }\end{array}$ & $\begin{array}{l}\text { Prueba } \\
\text { Kolmogorov- } \\
\text { amirnou de una } \\
\text { muestra }\end{array}$ & .928 & $\begin{array}{l}\text { Retener la } \\
\text { hipótesis } \\
\text { nula. }\end{array}$ \\
\hline
\end{tabular}

Se muestran las significancias asintóticas. El nivel de significancia es , 0 e

${ }^{1}$ Se muestra la significancia exacta para esta prueba.

\section{Tabla 5-97 E18: Test de Kolmogorov-Smirnov}

Para la variable taller, con un nivel de significancia del $0,58 \%$ se acepta la hipótesis nula. Para la variable nota, con un nivel de significancia del 0,92\%, se acepta la hipótesis nula de que los datos provienen de una población con distribución normal. 


\section{Prueba de los rangos con signo de Wilcoxon - Prueba no paramétrica}

\begin{tabular}{|r|r|r|r|}
\hline & $N$ & \multicolumn{1}{|c|}{ Rangos } \\
& $N$ & \multicolumn{1}{c|}{$\begin{array}{c}\text { Ruma de } \\
\text { promedio }\end{array}$} \\
\hline \multirow{2}{*}{ rangos }
\end{tabular}
a. $\mathrm{Gc}<\mathrm{Gx}$
b. $G c>G x$
c. $\mathrm{Gc}=\mathrm{Gx}$

Tabla 5-98 E18: Prueba de los rangos con signo de Wilcoxon

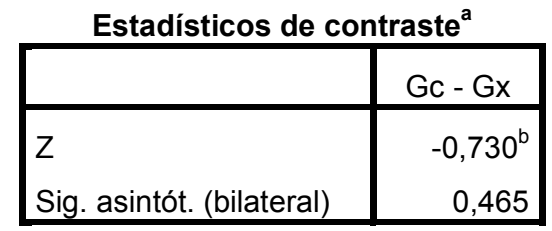
a. Prueba de los rangos con signo
de Wilcoxon
b. Basado en los rangos positivos.

Tabla 5-99 E18: Estadísticos de contraste

En ella se observa que la significancia asintótica bilateral es aproximadamente 0,465 , el cual resulta no ser menor que el nivel de significancia $(0,05)$, sin embargo, el percentil z asociado $Z=-0,730$ es menor en valor absoluto que el valor crítico de la normal estándar $\mathrm{Zc}=1,96$ con lo cual existen elementos estadísticos que permiten aceptar la hipótesis nula de independencia entre ambos métodos.

\section{Estadísticos descriptivos}

\begin{tabular}{|l|r|r|r|r|r|r|r|}
\hline & \multicolumn{1}{|c|}{$\mathrm{N}$} & \multicolumn{1}{|c|}{ Mínimo } & Máximo & \multicolumn{1}{c|}{ Media } & Desv. típ. & \multicolumn{2}{|c|}{ Curtosis } \\
\cline { 2 - 8 } & Estadístico & Estadístico & Estadístico & Estadístico & Estadístico & Estadístico & Error típico \\
\hline Gx & 5 & 42 & 75 & $\mathbf{6 0 , 0 0}$ & $\mathbf{1 3 , 6 9 3}$ & $-1,687$ & 2,000 \\
Gc & 8 & 25 & 67 & $\mathbf{5 1 , 0 4}$ & $\mathbf{1 2 , 9 3 9}$ & 1,654 & 1,481 \\
N válido (según & 5 & & & & & & \\
lista) & & & & & & & \\
\hline
\end{tabular}

Tabla 5-100 E18: Estadísticos descriptivos 
El valor de la media para el grupo de estudiantes que realizó simulación es 60,00, mayor que el correspondiente a los estudiantes que no realizaron simulación 51,04.

Sin embargo, se observa en este caso que el desvío estándar en el primer grupo, es levemente mayor que el del segundo grupo.

Dado que las medias son distintas, a fin de comparar cual de los métodos es más eficiente relativamente, corresponde calcular el coeficiente de variación relativa (cociente entre el desvío estándar y la media). El método con menor variación relativa es el más eficiente.

El coeficiente para $\mathrm{Gx}=0.228$, coeficiente para $\mathrm{Gc}=0.253$. Coeficiente de $\mathrm{Gx}<$ Coeficiente de Gc.

\section{Gráfico descriptivo del concepto evaluado}

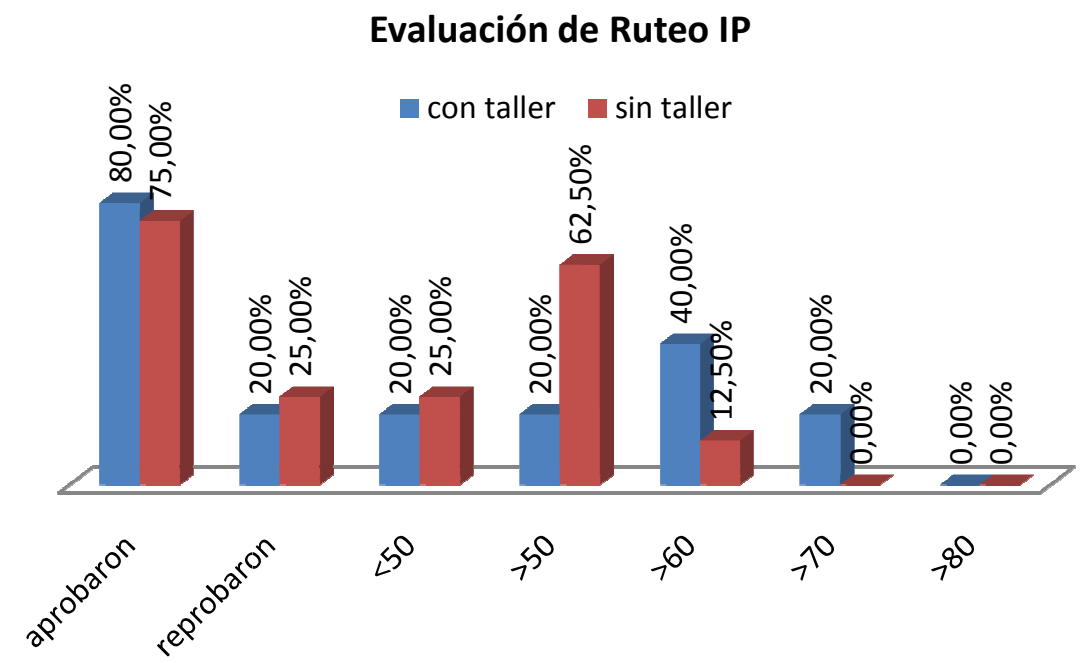

Figura 5-107 E18: Evaluación de Ruteo IP

\subsubsection{Conclusiones de la experiencia}

De acuerdo a los resultados obtenidos, se pudo determinar el impacto de la utilización del simulador Packet Tracer en la enseñanza del concepto de Ruteo IP en la asignatura Redes de Computadoras I.

Del análisis realizado se puede observar en la Figura 5-108 E18, que el 25\% de los estudiantes que no realizó el taller, obtuvo notas menores a 50 puntos (reprobaron), mientras que los que sí realizaron el taller, el $40 \%$ obtuvo notas menores a 60 puntos. Además se pudo advertir, que los estudiantes que sí realizaron el taller, aprobaron con mejores notas, $20 \%$ mayores que 70 puntos.

De manera que, para esta experiencia realizada, se concluyó que existió diferencia estadísticamente significativa a favor de los estudiantes que emplearon una estrategia basada en simulación para el concepto de Ruteo IP evaluado. 


\subsection{Experiencia $N^{0}$ 19: Direccionamiento IP con Router Cisco 3600 en Redes de Computadoras I}

Esta experiencia se realizó con la totalidad de los estudiantes que se encontraban cursando la asignatura Redes de Computadoras I del nuevo Plan de Licenciatura en Análisis de Sistemas 2010, durante el primer semestre del año 2016. El taller se realizó paralelamente al cursado de la asignatura, lo que permitió contrastar la practica con simulación realizada anteriormente para el mismo tema, con este laboratorio con equipo físico Cisco modelo 3600. La temática fue la aplicación del direccionamiento IP correspondiente a la Capa de Red. Como se describió anteriormente, la misma práctica se realizó previamente con el simulador Packet Tracer, sin embargo, fue necesaria la preparación de un práctico con una explicación de los comandos necesarios para llevar adelante la práctica. En el caso del simulador, es posible realizar toda la configuración para direccionamiento IP solicitada, prácticamente desde la solapa de configuración general, independizando al estudiante de la necesidad de conocer la sintaxis de los comandos del IOS.

El taller se llevó a cabo en una sola clase teórica-practica. Los estudiantes formaron grupos y realizaron la configuración solicitada en la hoja del enunciado práctico distribuida.

Al finalizar el taller, se realizó una encuesta, con el objeto de evaluar la actitud de los estudiantes con respecto al simulador Packet Tracer y al laboratorio con equipo real Cisco.

El objetivo de esta encuesta fue contrastar la actitud de los estudiantes frente a cada laboratorio realizado.

La encuesta se realizó con la herramienta módulo de encuesta de Moodle a fin de facilitar su cumplimentación y se publicó en la plataforma que disponen los estudiantes durante el cursado de la asignatura. La encuesta se dividió en 3 partes, en la primera se indagó sobre el laboratorio con simulación, respecto de la dificultad para el armado de la topología, configuración de dispositivos, verificación de la funcionalidad propuesta, seguimiento de los eventos y finalmente si considera adecuada la herramienta para el aprendizaje de fundamentos de redes. En la segunda parte se repitieron las mismas preguntas pero para el laboratorio utilizando equipo físico Cisco 3600. Finalmente se le preguntó al estudiante si considera que la simulación puede reemplazar al laboratorio con equipo real en este contexto.

\subsubsection{Análisis estadísticos de datos}

Para este análisis la media aritmética no supera, en casi todos los casos, el valor medio de la escala (3.00), lo que confirma la validez del contenido de todos los ítems incluidos. Para esta encuesta se deberían haber considerado las preguntas negadas, a fin de evitar los valores de la media por debajo del valor medio de la escala.

Como puede observarse en la Tabla 5-101, el coeficiente Alfa de Cronbach calculado de 0,6 no supera el valor de 0,7 , sin embargo, este valor todavía se puede tomar como aceptable para la fiabilidad del cuestionario.

Se puede concluir que existe menor polarización en las respuestas de los estudiantes. 
Estudio de la influencia de un entorno de simulación en la enseñanza de redes de computadoras en el nivel universitario

\begin{tabular}{|r|r|r|}
\hline \multicolumn{1}{|c|}{$\begin{array}{c}\text { Alfa de } \\
\text { Cronbach }\end{array}$} & $\begin{array}{c}\text { Alfa de } \\
\text { Cronbach } \\
\text { basada en los } \\
\text { elementos } \\
\text { tipificados }\end{array}$ & \\
\hline 0,667 & 0,600 & \\
\hline
\end{tabular}

Tabla 5-101 E19: Estadísticos de fiabilidad

\begin{tabular}{|l|r|r|r|}
\hline & \multicolumn{1}{|c|}{ Media } & \multicolumn{1}{c|}{$\begin{array}{c}\text { Desviación } \\
\text { típica }\end{array}$} \\
\hline VAR00001 & 4,40 & 0,966 & 10 \\
VAR00002 & 4,10 & 0,568 & 10 \\
VAR00003 & 4,00 & 0,667 & 10 \\
VAR00004 & 4,20 & 0,919 & 10 \\
VAR00005 & 4,10 & 0,738 & 10 \\
VAR00006 & 3,30 & 1,160 & 10 \\
VAR00007 & 2,80 & 1,398 & 10 \\
VAR00008 & 3,80 & 1,619 & 10 \\
VAR00009 & 2,80 & 1,619 & 10 \\
VAR00010 & 2,40 & 1,578 & 10 \\
VAR00011 & 3,60 & 1,174 & 10 \\
\hline
\end{tabular}

Tabla 5-102 E19: Estadísticos de los elementos

\begin{tabular}{|c|c|c|c|c|c|c|c|}
\hline & Media & Mínimo & Máximo & Rango & $\begin{array}{c}\text { Máximo/mín } \\
\text { imo }\end{array}$ & $\begin{array}{c}\text { Varianz } \\
\text { a }\end{array}$ & $\begin{array}{c}\mathrm{N} \text { de } \\
\text { elementos }\end{array}$ \\
\hline Medias de los elementos & 3,591 & 2,400 & 4,400 & 2,000 & 1,833 & 0,451 & 11 \\
\hline $\begin{array}{l}\text { Varianzas de los } \\
\text { elementos }\end{array}$ & 1,409 & ,322 & 2,622 & 2,300 & 8,138 & 0,782 & 11 \\
\hline $\begin{array}{l}\text { Covarianzas inter- } \\
\text { elementos }\end{array}$ & 0,217 & $-1,067$ & 2,400 & 3,467 & $-2,250$ & 0,800 & 11 \\
\hline $\begin{array}{l}\text { Correlaciones inter- } \\
\text { elementos }\end{array}$ & 0,120 & $-0,717$ & 0,962 & 1,679 & $-1,342$ & 0,258 & 11 \\
\hline
\end{tabular}

Tabla 5-103 E19: Estadísticos de resumen de los elementos 
Estudio de la influencia de un entorno de simulación en la enseñanza de redes de computadoras en el nivel universitario

\begin{tabular}{|r|r|r|r|}
\hline Media & Varianza & \multicolumn{1}{|c|}{$\begin{array}{c}\text { Desviación } \\
\text { típica }\end{array}$} & N de elementos \\
\hline 39,50 & 39,389 & 6,276 & 11 \\
\hline
\end{tabular}

Tabla 5-104 E19: Estadísticos de la escala

\section{Gráficos descriptivos}

A continuación se presentan gráficamente las respuestas de los estudiantes, para cada una de las preguntas del cuestionario realizado

Se utilizó la siguiente escala donde 5 es el valor máximo.

5 -> En gran medida, 4 -> En buena medida, $3->$ Lo suficiente, 2-> Poco, 1-> Prácticamente nada

\section{Simulación con Packet Tracer - Laboratorio Real con router Cisco 3600}

Con el simulador Packet Tracer. La configuración de la topología (conectorización de dispositivos y cables) es sencilla.

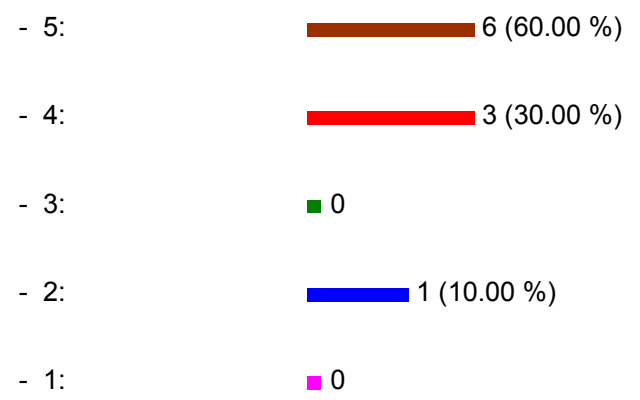

Con el simulador Packet Tracer. La configuración de los dispositivos (routers, hosts, etc.) es sencilla.

\begin{tabular}{|c|c|}
\hline - 5: & $2(20.00 \%)$ \\
\hline - 4: & $7(70.00 \%)$ \\
\hline - 3: & $1(10.00 \%)$ \\
\hline - 2: & $\square$ \\
\hline - 1: & $\square 0$ \\
\hline
\end{tabular}

Con el simulador Packet Tracer. Considera adecuada la herramienta para el aprendizaje de fundamentos de redes.
-5 :
$2(20.00 \%)$
$-4:$
$6(60.00 \%)$ 


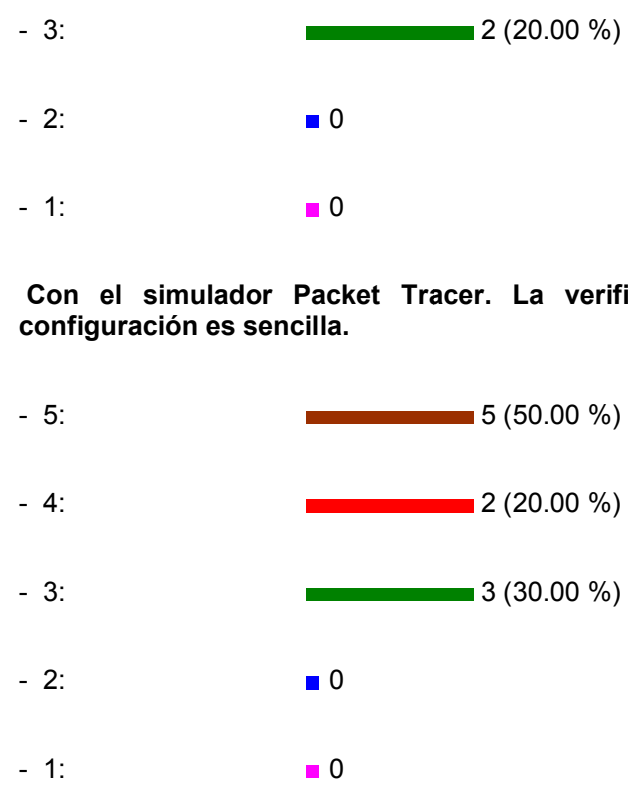

Con el simulador Packet Tracer. Se facilita el seguimiento de los eventos ocurridos en cada uno de los dispositivos dentro de la red.

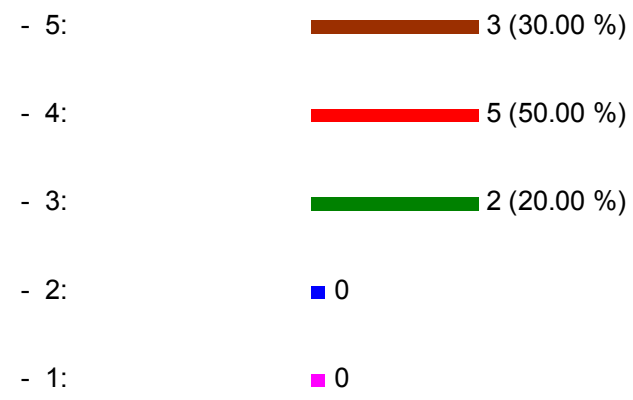

Con router Cisco 3600 . La configuración de la topología (conectorización de dispositivos y cables) es sencilla.

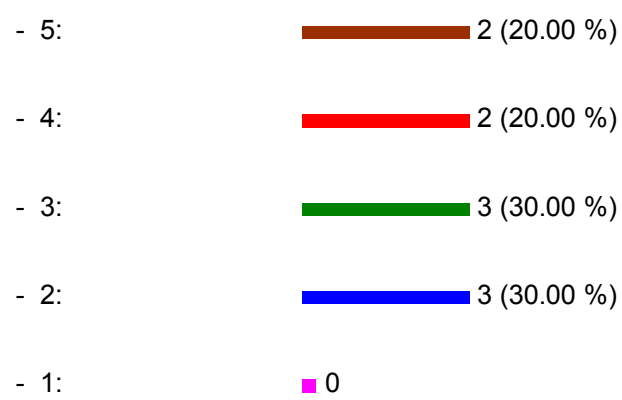

Con router Cisco 3600 . La configuración de los dispositivos (routers, hosts, etc.) es sencilla.

$-5: \quad=0$ 


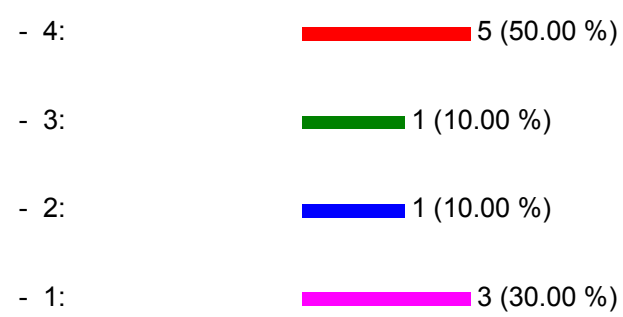

Con router Cisco 3600 . Considera adecuado el laboratorio real para el aprendizaje de fundamentos de redes.

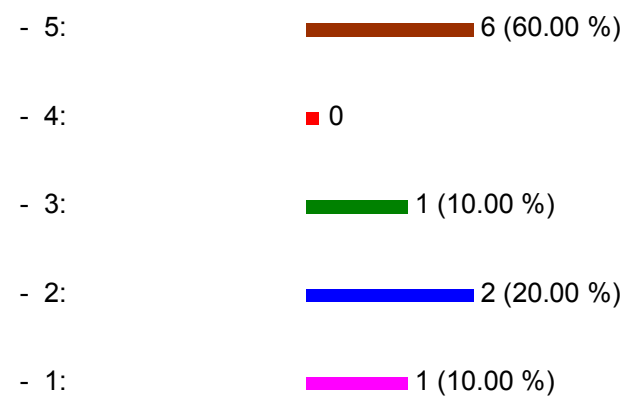

Con router Cisco 3600. La verificación de la funcionalidad de una topología y configuración es sencilla.

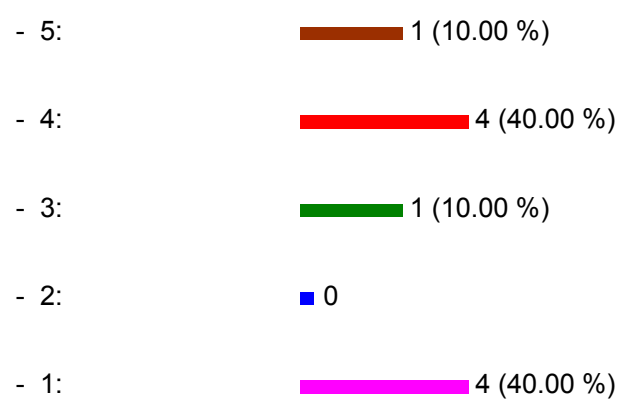

Con router Cisco 3600 . Se facilita el seguimiento de los eventos ocurridos en cada uno de los dispositivos dentro de la red.

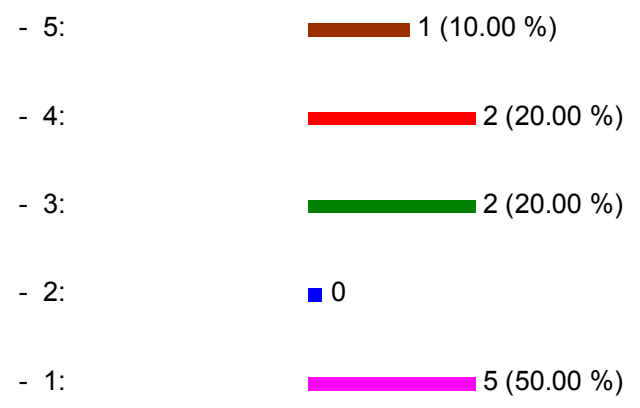

La práctica con simulación puede reemplazar la práctica con equipo real. 


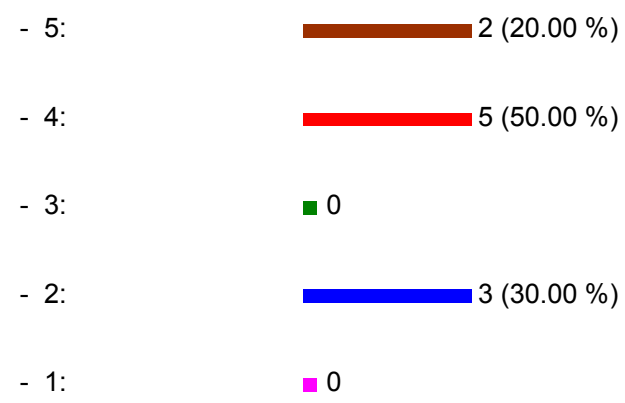

Observaciones y comentarios adicionales de los estudiantes sobre el laboratorio real

- Sería bueno hacer varios laboratorios real, ya que me pareció que ayuda mucho a terminar de entender los conceptos.

- $\quad$ Me parece que realmente seria un aporte rotundamente positivo en la cátedra, desde mi experiencia personal pude visualizar mejor lo practicado con el laboratorio real.

- El laboratorio real brinda una experiencia más cercana a los comandos necesarios para configurar los routers ya que no se dispone de una interfaz para hacerlo como sucede en el simulador. Por otra parte, la determinación de los motivos que causan un error en el laboratorio con equipos reales no resulta tan sencilla como en el simulador.

- $\quad$ El laboratorio real nos permitió ver físicamente a algunos equipos que no había tenido la oportunidad de conocerlo físicamente y sobre todo de hacer algunas configuraciones sobre esos equipos. La cual no me costó mucho hacer algunas configuraciones sobre equipos reales ya que con las practica realizadas en el simulador Packet Trace y que prácticamente eran similares las configuraciones que había que hacer. La cual fue una experiencia muy buena y fructífera para mi.

- $\quad$ En un simulador se pueden observar muchos detalles que en un laboratorio no, pero hasta no tener experiencia real no se pueden fijar los conocimientos exactos, las personas no trabajan con simuladores, el laboratorio real es muy necesario, deja en evidencia dudas que el simulador no y permite resolver problemas que en el simulador no se contemplan, como son incompatibilidades de algún software, accesos y permisos y mas.

- $\quad$ Creo que fue muy productivo el laboratorio real, sobre todo para tener un contacto directo con el equipo y para poder ver los resultados del esfuerzo realizado durante el cuatrimestre. En mi opinión deberían realizarse más laboratorios reales.

Figura 5-108 E19: Análisis de Laboratorio Real con Direccionamiento IP

\subsubsection{Conclusiones de la experiencia}

En base al análisis realizado, se evidenció para la primera parte de la encuesta, que los estudiantes consideraron sencilla la configuración de la topología, la configuración de dispositivos, la verificación de la funcionalidad y el seguimiento de los eventos cuando se trata de simulación.

Para la segunda parte de la encuesta, con equipo real, los resultados no evidenciaron una polarización tan marcada, un $40 \%$ consideró que la configuración de la topología fue sencilla frente a un 30\% que la consideró compleja. El 50\% consideró que la configuración de los dispositivos fue sencilla frente a un $40 \%$ que la consideró compleja. Respecto de la verificación de la funcionalidad 50\% lo consideró sencillo y un $40 \%$ complejo. Sin embargo, respecto del seguimiento de los eventos $30 \%$ consideró sencillo frente a un $50 \%$ que lo consideró complejo. 
Para la pregunta si la simulación puede reemplazar a la práctica con equipo real, el $70 \%$ consideró que sí.

Estas conclusiones se condicen con un valor para el Alfa de Cronbach en el límite para considerar los datos fiables. 


\subsection{Experiencia $\mathbf{N}^{\circ}$ 20: Ruteo IP con Router Cisco 3600 en Redes de Computadoras I}

Esta experiencia se realizó con la totalidad de los estudiantes que se encontraban cursando la asignatura Redes de Computadoras I del nuevo Plan de Licenciatura en Análisis de Sistemas 2010, durante el primer semestre del año 2016. El taller se realizó paralelamente al cursado de la asignatura, lo que permitió contrastar la practica con simulación realizada anteriormente para el mismo tema, con este laboratorio con equipo físico Cisco modelo 3600. La temática fue la configuración del Ruteo IP correspondiente a la Capa de Red. Como se describió anteriormente, la misma práctica se realizó previamente con el simulador Packet Tracer, sin embargo, fue necesaria la preparación de una guía práctica con una explicación de los comandos necesarios para llevar adelante la práctica. En el caso del simulador, es posible realizar buena parte de la configuración para ruteo estático y dinámico con RIP solicitado, prácticamente desde la solapa de configuración general, independizando al estudiante de la necesidad de conocer la sintaxis de los comandos del IOS.

El taller se llevó a cabo en una sola clase teórica-practica. Los estudiantes formaron grupos y realizaron la configuración solicitada en la hoja del enunciado práctico distribuida.

Al finalizar el taller, se realizó una encuesta, con el objeto de evaluar la actitud de los estudiantes con respecto al simulador Packet Tracer y al laboratorio con equipo real Cisco.

El objetivo de esta encuesta fue contrastar la actitud de los estudiantes frente a cada tipo de laboratorio realizado.

\subsubsection{Análisis estadísticos de datos}

Para este análisis la media aritmética supera, en todos los casos, al menos el valor medio de la escala (3.00), lo que confirma la validez del contenido de todos los ítems incluidos.

Como puede observarse en la Tabla 5-105, el coeficiente Alfa de Cronbach calculado es de 0,863 que supera el valor de 0,7 , lo que permite afirmar que el grado de fiabilidad del cuestionario. Por lo tanto, se aprecia una alta polarización de respuestas confiables por parte de los estudiantes.

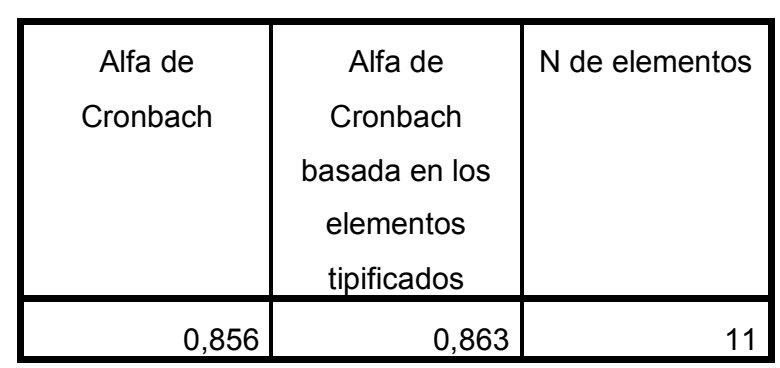

Tabla 5-105 E20: Estadísticos de fiabilidad 
Estudio de la influencia de un entorno de simulación en la enseñanza de redes de computadoras en el nivel universitario

\begin{tabular}{|l|r|r|r|}
\hline & \multicolumn{1}{|c|}{ Media } & \multicolumn{1}{c|}{$\begin{array}{c}\text { Desviación } \\
\text { típica }\end{array}$} \\
\hline VAR00001 & 4,56 & 1,014 & 9 \\
VAR00002 & 4,00 & 1,000 & 9 \\
VAR00003 & 4,11 & 0,928 & 9 \\
VAR00004 & 4,44 & 1,014 & 9 \\
VAR00005 & 4,33 & 1,000 & 9 \\
VAR00006 & 2,56 & 1,236 & 9 \\
VAR00007 & 2,22 & 1,716 & 9 \\
VAR00008 & 3,00 & 1,323 & 9 \\
VAR00009 & 2,56 & 1,667 & 9 \\
VAR00010 & 2,33 & 1,414 & 9 \\
VAR00011 & 4,00 & 0,707 & 9 \\
\hline
\end{tabular}

Tabla 5-106 E20: Estadísticos de los elementos

\begin{tabular}{|l|r|r|r|r|r|r|r|}
\hline & Media & Mínimo & Máximo & Rango & $\begin{array}{c}\text { Máximo/ } \\
\text { mínimo }\end{array}$ & Varianza & \multicolumn{1}{c|}{$\begin{array}{c}\mathrm{N} \text { de } \\
\text { elementos }\end{array}$} \\
\hline Medias de los elementos & $\begin{array}{r}3,465 \\
1,492\end{array}$ & $\begin{array}{r}2,222 \\
0,500\end{array}$ & $\begin{array}{r}4,556 \\
2,944\end{array}$ & $\begin{array}{r}2,333 \\
2,444\end{array}$ & $\begin{array}{r}5,050 \\
5,889\end{array}$ & 0,859 & 11 \\
$\begin{array}{l}\text { Varianzas de los } \\
\text { elementos }\end{array}$ & 0,524 & $-0,625$ & 2,736 & 3,361 & $-4,378$ & 0,551 & 11 \\
$\begin{array}{l}\text { Covarianzas inter- } \\
\text { elementos }\end{array}$ & 0,365 & $-0,466$ & 0,957 & 1,423 & $-2,053$ & 0,198 & 11 \\
$\begin{array}{l}\text { Correlaciones inter- } \\
\text { elementos }\end{array}$ & & & & & & 11 \\
\hline
\end{tabular}

Tabla 5-107 E20: Estadísticos de resumen de los elementos

\begin{tabular}{|r|r|r|r|}
\hline \multicolumn{1}{|c|}{ Media } & Varianza & \multicolumn{1}{c|}{$\begin{array}{c}\text { Desviación } \\
\text { típica }\end{array}$} & N de elementos \\
\hline 38,11 & 74,111 & 8,609 & 11 \\
\hline
\end{tabular}

Tabla 5-108 E20: Estadísticos de la escala 


\section{Gráficos descriptivos}

A continuación se presentan gráficamente las respuestas de los estudiantes, para cada una de las preguntas del cuestionario realizado.

Se utilizó la siguiente escala donde 5 es el valor máximo.

5 -> En gran medida, 4 -> En buena medida, 3 -> Lo suficiente, 2-> Poco, 1-> Prácticamente nada

\section{Simulación con Packet Tracer - Laboratorio Real con router Cisco 3600}

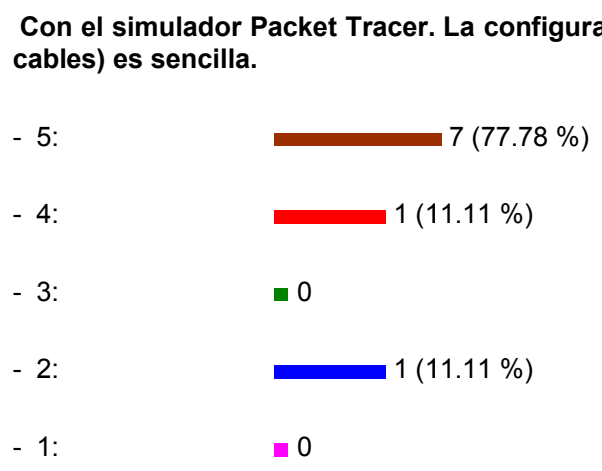

Con el simulador Packet Tracer. La configuración de los dispositivos (routers, hosts, etc.) es sencilla.

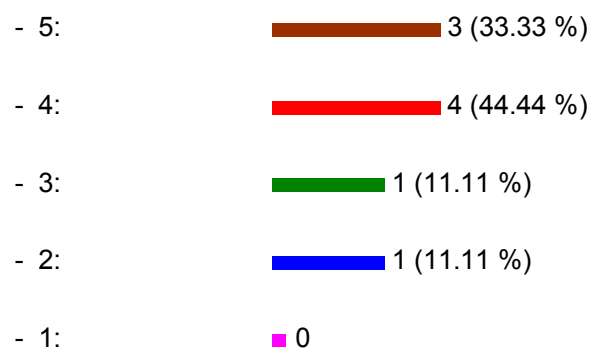

Con el simulador Packet Tracer. Considera adecuada la herramienta para el aprendizaje de fundamentos de redes.

- 5: $\quad 3(33.33 \%)$

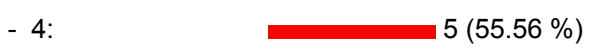

- 3: $\quad \square 0$

- 2: $1(11.11 \%)$

- 1: $\quad$ - 0

Con el simulador Packet Tracer. La verificación de la funcionalidad de una topología y configuración es sencilla.
- 5:
$6(66.67 \%)$
- 4:
$2(22.22 \%)$ 


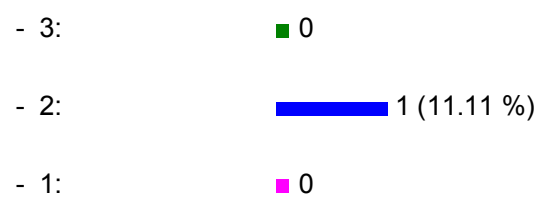

Con el simulador Packet Tracer. Se facilita el seguimiento de los eventos ocurridos en cada uno de los dispositivos dentro de la red.

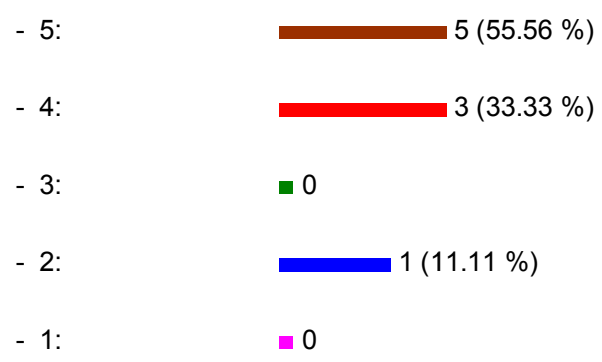

Con router Cisco 3600 . La configuración de la topología (conectorización de dispositivos y cables) es sencilla.

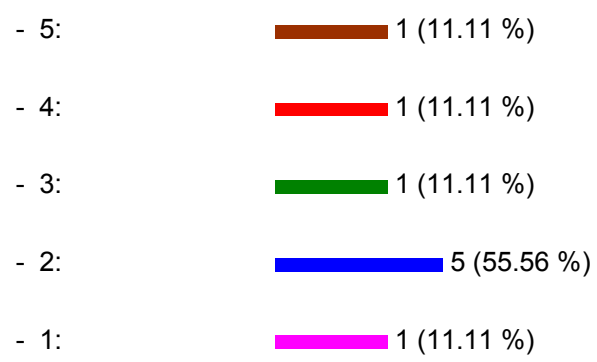

Con router Cisco 3600. La configuración de los dispositivos (routers, hosts, etc.) es sencilla.

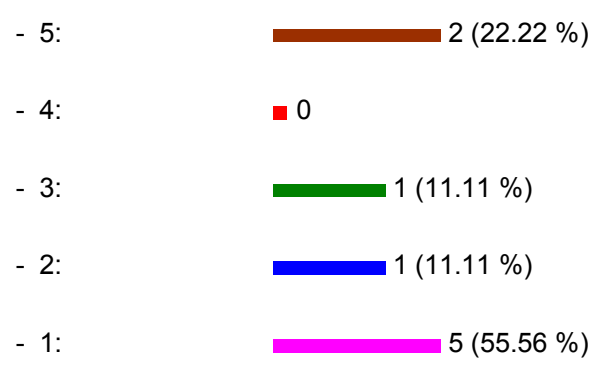

Con router Cisco 3600. Considera adecuado el laboratorio real para el aprendizaje de fundamentos de redes.
-5 :
$2(22.22 \%)$
- 4:
$1(11.11 \%)$
- 3:
$1(11.11 \%)$
- 2:
$5(55.56 \%)$ 


$$
-1:-0
$$

Con router Cisco 3600 . La verificación de la funcionalidad de una topología y configuración es sencilla.

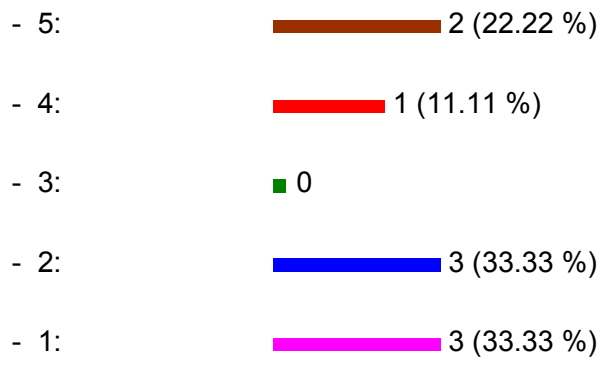

Con router Cisco 3600 . Se facilita el seguimiento de los eventos ocurridos en cada uno de los dispositivos dentro de la red.
$-5: \quad-0$
- 4: $3(33.33 \%)$
- 3: $1(11.11 \%)$
- 2: $1(11.11 \%)$
- $1:-4(44.44 \%)$

Con router Cisco 3600 . La práctica con simulación puede reemplazar la práctica con equipo real.

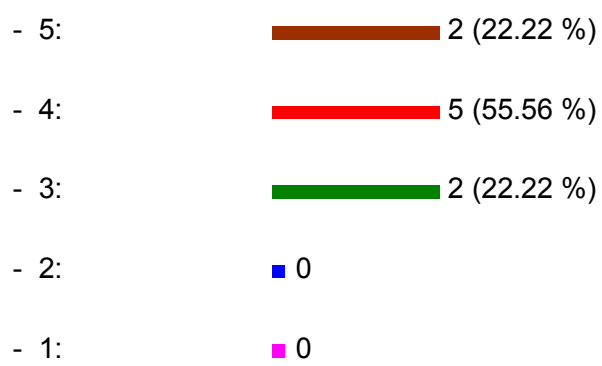

Observaciones y comentarios adicionales de los estudiantes sobre el laboratorio real

- El único inconveniente que le veo al laboratorio real es la falta de equipos y que algunos de ellos no funcionen correctamente, lo cual hace que la conectividad tarde demasiado, fuera de ello es una buena experiencia dado que se asemeja más a la realidad.

- Es una muy buena experiencia. En lo personal la creo necesaria, teniendo en cuenta que tanto redes 1 como redes 2 son las únicas materias de la carrera en las que podemos ver este tipo de equipos, es una buena práctica para poder defendernos si el día de mañana nos toca trabajar con los mismos.

- En el laboratorio real se pudo comprobar que lo que se hizo en el simulador prácticamente era hacer lo mismo solo que con equipos reales y adquirir una mejor experiencia.

Figura 5-109 E20: Análisis de Laboratorio Real con Ruteo IP 


\subsubsection{Conclusiones de la experiencia}

Del análisis realizado para esta experiencia, se evidenció que los estudiantes consideraron más sencillo de realizar la configuración de la topología, la configuración de los dispositivos, la verificación de la funcionalidad y el seguimiento de los eventos en una práctica con simulación que con equipo real.

Cabe aclarar que el grupo de estudiantes que realizó esta experiencia, es el mismo que realizó la experiencia anterior, Experiencia $\mathrm{N}^{0} 19$.

Además, resulta interesante destacar que los estudiantes se sintieron muy motivados en los laboratorios con equipo real, a pesar de todas las limitaciones comentadas respecto de la cantidad de equipos e interfaces de los mismos para la realización de la práctica propuesta. 


\subsection{Experiencia $\mathbf{N}^{0}$ 21: Simulador MACSim en Redes de Computadoras II}

Esta experiencia se realizó con un grupo de estudiantes que se encontraba cursando la asignatura Redes de Computadoras II del Plan de Licenciatura en Análisis de Sistemas 2010 durante el segundo semestre del año 2016. El taller se realizó paralelamente al cursado de la asignatura, lo que permitió evaluar el desempeño tanto de los estudiantes que participaron del mismo, como de los que no participaron.

Esta experiencia fue una réplica de lo realizado en las Experiencias $\mathrm{N}^{\mathrm{o}} 6,8,13$ y 15, utilizando el mismo diseño metodológico.

\subsubsection{Análisis estadísticos de datos}

\section{Histogramas (Normal)}

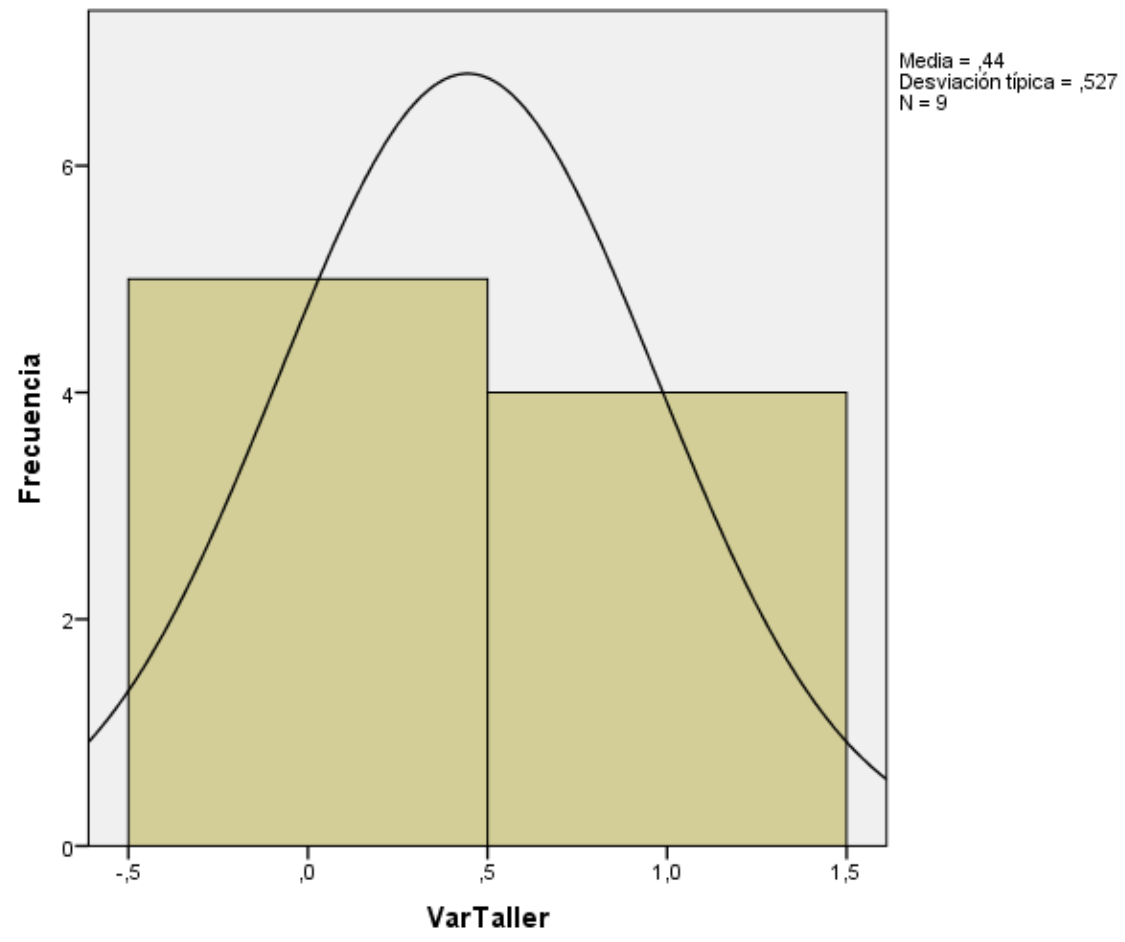

Figura 5-110 E21: Histograma de la variable Taller 


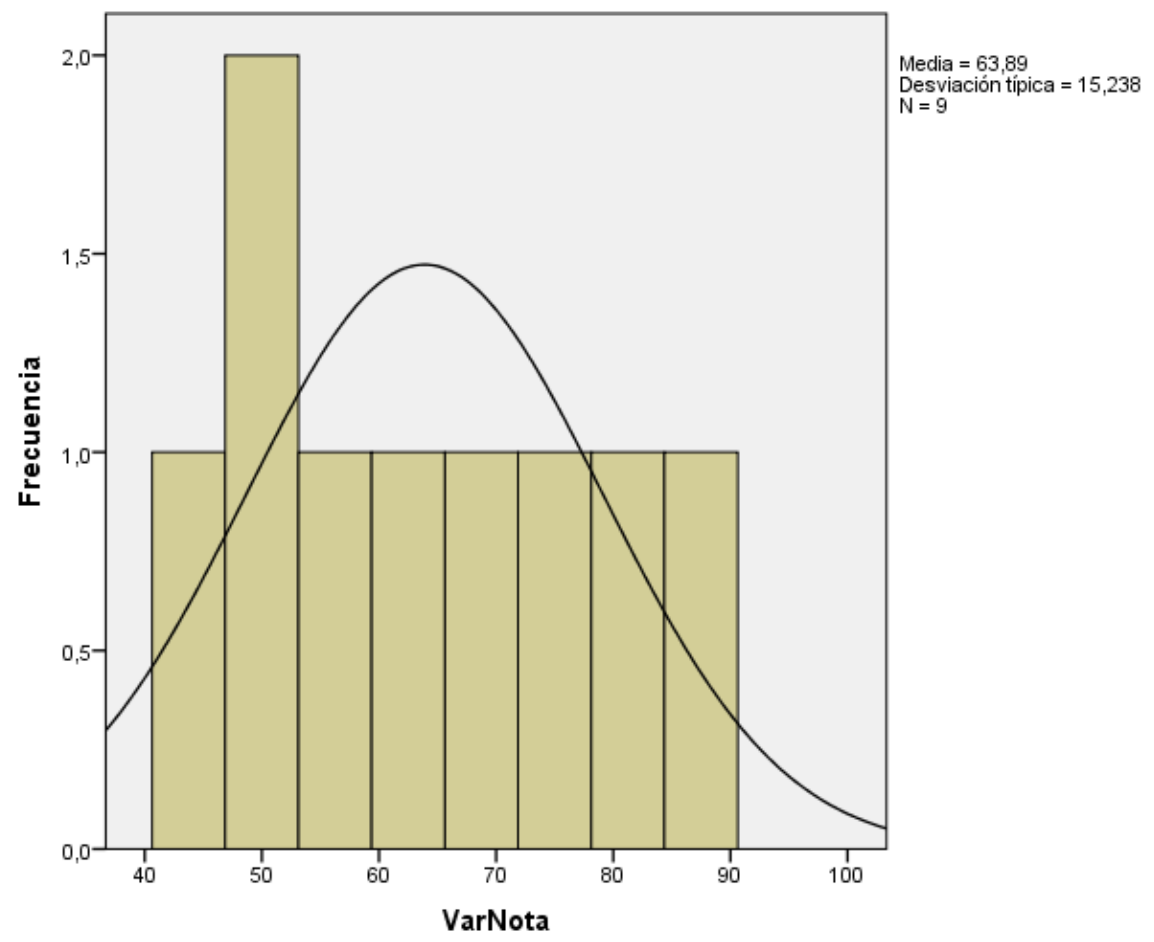

Figura 5-111 E21: Histograma de la variable Nota

\section{Test de Kolmogorov-Smirnov - No paramétrica}

\section{Resumen de prueba de hipótesis}

\begin{tabular}{|c|c|c|c|c|}
\hline & Hipótesis nula & Test & Sig. & Decisión \\
\hline 1 & $\begin{array}{l}\text { Las categorias definidas por } \\
\text { VarTaller = Con simulación y Sinf } \\
\text { simulación se producen con las } \\
\text { probabilidades de } 0,5 \text { y } 0,5 \text {. }\end{array}$ & $\begin{array}{l}\text { iPrueba binomial } \\
\text { de una muestra }\end{array}$ & $1,000^{-1}$ & $\begin{array}{l}\text { Retener la } \\
\text { hipótesis } \\
\text { nula. }\end{array}$ \\
\hline 2 & $\begin{array}{l}\text { La distribución de VarNota es } \\
\text { normal con la media } 63,889 \text { y la } \\
\text { desviación típica } 15,24 \text {. }\end{array}$ & $\begin{array}{l}\text { Prueba } \\
\text { Kolmogorov- } \\
\text { amirnou de una } \\
\text { muestra }\end{array}$ & .985 & $\begin{array}{l}\text { Retener la } \\
\text { hipótesis } \\
\text { nula. }\end{array}$ \\
\hline
\end{tabular}

Se muestran las significancias asintóticas. El nivel de significancia es ,0

${ }^{1}$ Se muestra la significancia exacta para esta prueba.

Tabla 5-109 E21: Test de Kolmogorov-Smirnov

Para la variable taller, con un nivel de significancia del 1\% se acepta la hipótesis nula.

Para la variable nota, con un nivel de significancia del 0,98\%, se acepta la hipótesis nula de que los datos provienen de una población con distribución normal. 


\section{Prueba de los rangos con signo de Wilcoxon - Prueba no paramétrica}

\begin{tabular}{|c|c|c|c|c|}
\hline \multicolumn{5}{|c|}{ Rangos } \\
\hline & & $\mathrm{N}$ & $\begin{array}{c}\text { Rango } \\
\text { promedio }\end{array}$ & $\begin{array}{c}\text { Suma de } \\
\text { rangos }\end{array}$ \\
\hline \multirow{4}{*}{$G c-G x$} & Rangos negativos & $3^{a}$ & 2,33 & 7,00 \\
\hline & Rangos positivos & $1^{\mathrm{b}}$ & 3,00 & 3,00 \\
\hline & & $0^{c}$ & & \\
\hline & Total & 4 & & \\
\hline
\end{tabular}
a. $\mathrm{Gc}<\mathrm{Gx}$
b. $G c>G x$
c. $\mathrm{Gc}=\mathrm{Gx}$

Tabla 5-110 E21: Prueba de los rangos con signo de Wilcoxon

Estadísticos de contraste ${ }^{a}$

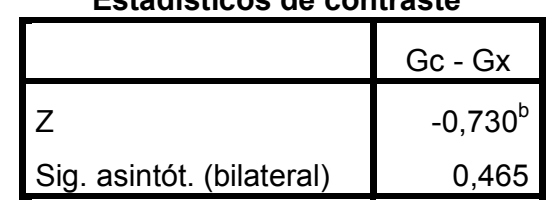
a. Prueba de los rangos con signo
de Wilcoxon
b. Basado en los rangos positivos.

Tabla 5-111 E21: Estadísticos de contraste

En ella se observa que la significancia asintótica bilateral es aproximadamente 0,46 , el cual resulta no ser menor que el nivel de significancia $(0,05)$, sin embargo, el percentil $\mathrm{z}$ asociado $Z=-0,73$ es menor en valor absoluto que el valor crítico de la normal estándar $\mathrm{Zc}=1,96$ con lo cual existen elementos estadísticos que permiten aceptar la hipótesis nula de independencia entre ambos métodos.

\section{Estadísticos descriptivos}

\begin{tabular}{|l|r|r|r|r|r|r|r|}
\hline & \multicolumn{1}{|c|}{$\mathrm{N}$} & \multicolumn{1}{|c|}{ Mínimo } & Máximo & \multicolumn{1}{c|}{ Media } & Desv. típ. & \multicolumn{2}{|c|}{ Curtosis } \\
\cline { 2 - 8 } & Estadístico & Estadístico & Estadístico & Estadístico & Estadístico & Estadístico & Error típico \\
\hline Gx & 5 & 50 & 88 & $\mathbf{6 7 , 6 0}$ & $\mathbf{1 6 , 2 8 8}$ & $-2,318$ & 2,000 \\
Gc & 4 & 44 & 75 & $\mathbf{5 9 , 5 0}$ & $\mathbf{1 4 , 8 4 4}$ & $-4,455$ & 2,619 \\
N válido (según & 4 & & & & & & \\
lista) & & & & & & & \\
\hline
\end{tabular}

Tabla 5-112 E21: Estadísticos descriptivos 
El valor de la media para el grupo de estudiantes que realizaron simulación es 67,60, mayor que el correspondiente a los estudiantes que no realizaron simulación 59,50. Esto puede considerarse como un indicador que resalta la bondad de la enseñanza con simulación.

Sin embargo, se destaca que el desvío estándar en el primer grupo, es mayor que el desvío del segundo grupo.

Considerando el Estadístico de Curtosis en valor absoluto, se puede apreciar que su valor es menor para el grupo experimental, lo cual también significa que los estudiantes que realizaron simulación presentan una mayor homogeneidad o menor variabilidad.

Estas conclusiones pueden reforzarse aún más mediante el uso del coeficiente de variabilidad relativa, que para el grupo experimental da un valor de 0,2409, y para el grupo de control 0,2494. En consecuencia, el grupo experimental posee una menor variabilidad relativa o mayor homogeneidad que el grupo de control.

\section{Gráfico descriptivo del concepto evaluado}

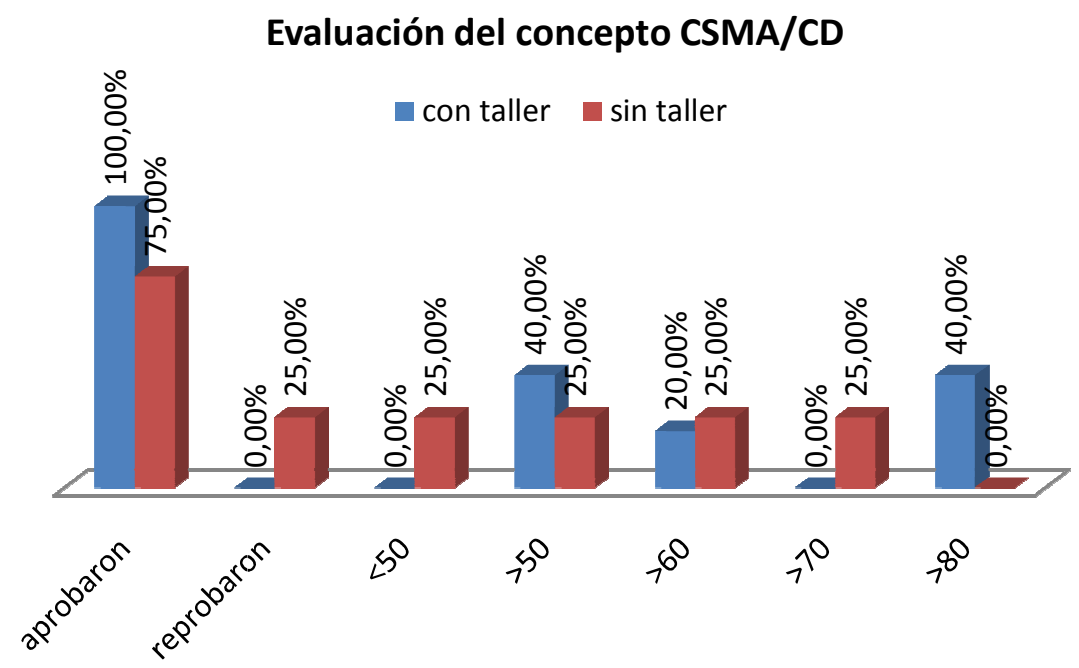

Figura 5-112 E21: Evaluación del concepto CSMA/CD

\subsubsection{Conclusiones de la experiencia}

De acuerdo a los resultados obtenidos, se pudo determinar el impacto de la utilización del simulador MACSim en la enseñanza del algoritmo CSMA/CD en la asignatura Redes de Computadoras II de la carrera Licenciatura en Análisis de Sistemas.

Se puede observar en la Figura 5-112 E21, que el 43\% de los estudiantes que no realizó el taller obtuvo notas menores a 50 puntos. Además se pudo evidenciar del análisis realizado, que los estudiantes que sí realizaron el taller, aprobaron con mejores notas, lo que se traduce en respuestas mucho más acabadas y precisas del concepto evaluado, $20 \%$ con notas mayores a 70 puntos.

De manera que, para esta experiencia realizada, se concluyó que existió diferencia estadísticamente significativa a favor de los estudiantes que emplearon una estrategia basada en simulación para el concepto del algoritmo CSMA/CD evaluado. 


\subsection{Experiencia $\mathrm{N}^{0}$ 22: Curso para certificación Mikrotik organizado por el CIDIA}

Esta experiencia se realizó durante la primera semana del mes agosto del año 2016, con un grupo de estudiantes que se encontraban realizando el curso para certificación de Mikrotik. $\mathrm{Si}$ bien la temática del curso fue amplia, 9 módulos, introducción al RouterOS, RouterBOARD, DHCP, Bridging, Routing, Wireless, Firewall, QoS, Tunnels, Misc, el taller con el simulador GNS3 se realizó al finalizar el mismo solo para el tema de ruteo IP estático y dinámico con RIP y OSPF, al que asistieron 10 estudiantes de un total de 25.

El objetivo fue que los estudiantes contrasten la realización de la misma actividad práctica con equipo real Mikrotik y utilizando el simulador GNS3, para lo cual se realizó una encuesta dividida en tres partes. En la primera parte se indagó respecto del uso del simulador GNS3 y su facilidad para diseñar una topología, configurar dispositivos, verificar la funcionalidad y realizar seguimiento de los eventos. En la segunda parte se realizaron las mismas preguntas pero negadas respecto del laboratorio con equipo real Mikrotik, es decir, si la configuración de la topología y dispositivos es compleja, al igual que la verificación de la funcionalidad y seguimiento de los eventos. Finalmente se indagó sobre la posibilidad que la simulación reemplace al laboratorio con equipo real, cuando el objetivo es la enseñanza de conceptos y fundamentos de redes.

\subsubsection{Análisis estadísticos de datos}

Para este análisis, la media aritmética supera, en todos los casos, al menos el valor medio de la escala (3.00), lo que confirma la validez del contenido de todos los ítems incluidos.

Como puede observarse en la Tabla 5-113, el coeficiente Alfa de Cronbach calculado es de 0,64 , que no supera el valor de 0,7 , pero todavía se puede afirmar cierto grado de fiabilidad del cuestionario. Por lo tanto, se aprecia menor polarización de respuestas confiables por parte de los estudiantes.

\begin{tabular}{|c|c|c|}
\hline $\begin{array}{c}\text { Alfa de } \\
\text { Cronbach }\end{array}$ & $\begin{array}{c}\text { Alfa de } \\
\text { Cronbach } \\
\text { basada en los } \\
\text { elementos } \\
\text { tipificados }\end{array}$ & $\mathrm{N}$ de elementos \\
\hline 0,609 & 0,642 & 11 \\
\hline
\end{tabular}

Tabla 5-113 E22: Estadístico de fiabilidad 
Estudio de la influencia de un entorno de simulación en la enseñanza de redes de computadoras en el nivel universitario

\begin{tabular}{|c|r|r|r|}
\hline & Media & \multicolumn{1}{|c|}{$\begin{array}{c}\text { Desviación } \\
\text { típica }\end{array}$} & $\mathrm{N}$ \\
\hline VAR00001 & 4,4444 & 0,72648 & 9 \\
VAR00002 & 4,2222 & 0,66667 & 9 \\
VAR00003 & 4,4444 & 0,72648 & 9 \\
VAR00004 & 4,4444 & 0,72648 & 9 \\
VAR00005 & 4,3333 & 0,70711 & 9 \\
VAR00006 & 3,1111 & 1,16667 & 9 \\
VAR00007 & 3,7778 & 1,09291 & 9 \\
VAR00008 & 3,2222 & 1,09291 & 9 \\
VAR00009 & 3,6667 & 0,86603 & 9 \\
VAR00010 & 3,4444 & 1,23603 & 9 \\
VAR00011 & 4,4444 & 0,52705 & 9 \\
\hline
\end{tabular}

Tabla 5-114 E22: Estadísticos de los elementos

\begin{tabular}{|l|r|r|r|r|r|r|r|}
\hline & Media & Mínimo & Máximo & Rango & $\begin{array}{c}\text { Máximo/ } \\
\text { mínimo }\end{array}$ & Varianza & $\begin{array}{c}\mathrm{N} \text { de } \\
\text { elementos }\end{array}$ \\
\hline $\begin{array}{l}\text { Medias de los } \\
\text { elementos }\end{array}$ & 3,960 & 3,111 & 4,444 & 1,333 & 1,429 & 0,280 & 11 \\
\hline
\end{tabular}

Tabla 5-115 E22: Estadísticos de resumen de los elementos

\begin{tabular}{|c|r|r|r|}
\hline Media & Varianza & $\begin{array}{c}\text { Desviación } \\
\text { típica }\end{array}$ & N de elementos \\
\hline 43,5556 & 19,778 & 4,44722 & 11 \\
\hline
\end{tabular}

Tabla 5-116 E22: Estadísticos de la escala 
A continuación se presenta gráficamente el análisis estadístico para cada una de las partes de la encuesta realizada.

\section{Con herramientas de simulación, (como GNS3, Packet Tracer, etc.)}

\begin{tabular}{|c|c|c|c|c|c|c|c|c|c|c|c|c|}
\hline & \multicolumn{2}{|c|}{$\begin{array}{l}\text { Prácticamente } \\
\text { Nada } \\
\text { (1) }\end{array}$} & \multicolumn{2}{|c|}{$\begin{array}{c}\text { Poco } \\
\text { (2) }\end{array}$} & \multicolumn{2}{|c|}{$\begin{array}{c}\text { Lo } \\
\text { Suficiente } \\
\text { (3) }\end{array}$} & \multicolumn{2}{|c|}{$\begin{array}{l}\text { En Buen } \\
\text { Medida } \\
\text { (4) }\end{array}$} & \multicolumn{2}{|c|}{$\begin{array}{l}\text { En Gran } \\
\text { Medida } \\
\text { (5) }\end{array}$} & \multirow[b]{2}{*}{$\varnothing$} & \multirow[b]{2}{*}{ \pm} \\
\hline & $\Sigma$ & $\%$ & $\Sigma$ & $\%$ & $\Sigma$ & $\%$ & $\Sigma$ & $\%$ & $\Sigma$ & $\%$ & & \\
\hline Config topología sencilla. & - & - & - & - & $1 \mathrm{x}$ & 10,00 & $4 x$ & 40,00 & $5 x$ & 50,00 & 4,40 & 0,70 \\
\hline Config. dispositivos sencil... & - & - & - & - & $1 x$ & 11,11 & $5 x$ & 55,56 & $3 x$ & 33,33 & 4,22 & 0,67 \\
\hline Adecuada aprendizaje de ... & - & - & - & - & $1 x$ & 10,00 & $4 x$ & 40,00 & $5 x$ & 50,00 & 4,40 & 0,70 \\
\hline Verif. funcionalidad sencilla. & - & - & - & - & $1 x$ & 10,00 & $3 x$ & 30,00 & $6 x$ & 60,00 & 4,50 & 0,71 \\
\hline Sencillo seguimiento even... & - & - & - & - & $1 \mathrm{x}$ & 10,00 & $4 x$ & 40,00 & $5 x$ & 50,00 & 4,40 & 0,70 \\
\hline
\end{tabular}

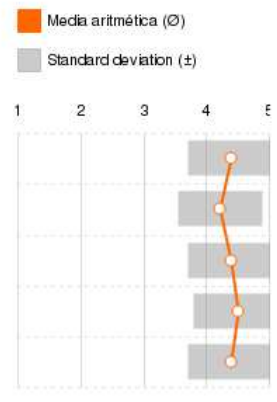

Tabla 5-117 E22: Análisis con simulación

Para la configuración de la topología el $90 \%$ consideró que es sencillo con el simulador, para la configuración de los dispositivos el $88 \%$ consideró sencillo, el $90 \%$ consideró que la verificación de la funcionalidad y el seguimiento de los eventos se realizaron de manera sencilla con simulación.

En laboratorio con equipo real, (como Mikrotik, Ubiquiti, Cisco, etc.)

\begin{tabular}{|c|c|c|c|c|c|c|c|c|c|c|c|c|}
\hline & Práct & ente & & $\begin{array}{l}\text { oco } \\
\text { (2) }\end{array}$ & Sufi & $\begin{array}{l}\text { Lo } \\
\text { ciente } \\
\text { (3) }\end{array}$ & & $\begin{array}{l}\text { Buen } \\
\text { dida } \\
\text { (4) }\end{array}$ & & $\begin{array}{l}\text { Gran } \\
\text { dida } \\
\text { (5) }\end{array}$ & & \\
\hline & $\Sigma$ & $\%$ & $\Sigma$ & $\%$ & $\Sigma$ & $\%$ & $\Sigma$ & $\%$ & $\Sigma$ & $\%$ & $\varnothing$ & \pm \\
\hline Config. topología compleja & - & - & $4 x$ & 40,00 & $1 x$ & 10,00 & $4 x$ & 40,00 & $1 \mathrm{x}$ & 10,00 & 3,20 & 1,14 \\
\hline Config. dispositivos compl... & - & - & $1 \mathrm{x}$ & 10,00 & $3 x$ & 30,00 & $2 x$ & 20,00 & $4 x$ & 40,00 & 3.90 & 1,10 \\
\hline Considera adecuado el lab.. & - & - & $4 \mathrm{x}$ & 40,00 & $2 x$ & 20,00 & $3 x$ & 30,00 & $1 x$ & 10,00 & 3,10 & 1,10 \\
\hline Verif. funcionalidad compl... & - & - & $1 \mathrm{x}$ & 10,00 & $2 x$ & 20,00 & $6 x$ & 60,00 & $1 \mathrm{x}$ & 10,00 & 3,70 & 0,82 \\
\hline Se complica el seguimient... & - & - & $3 x$ & 30,00 & $1 x$ & 10,00 & $3 x$ & 30,00 & $3 x$ & 30,00 & 3,60 & 1.26 \\
\hline
\end{tabular}

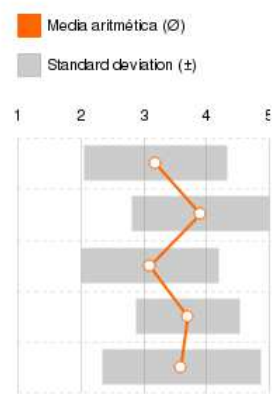

Tabla 5-118 E22: Análisis con equipo real

El 40\% de los estudiantes consideró que la configuración de la topología fue sencilla con equipo real, solo el $10 \%$ consideró que la configuración de dispositivos fue sencilla. Para la verificación de la funcionalidad, solo el $10 \%$ consideró que fue sencillo y el $30 \%$ para el seguimiento de los eventos.

Cuando el objetivo es la enseñanza de fundamentos y no la de formar técnicos en redes, ¿considera que la simulación puede reemplazar a la práctica con equipo real? 

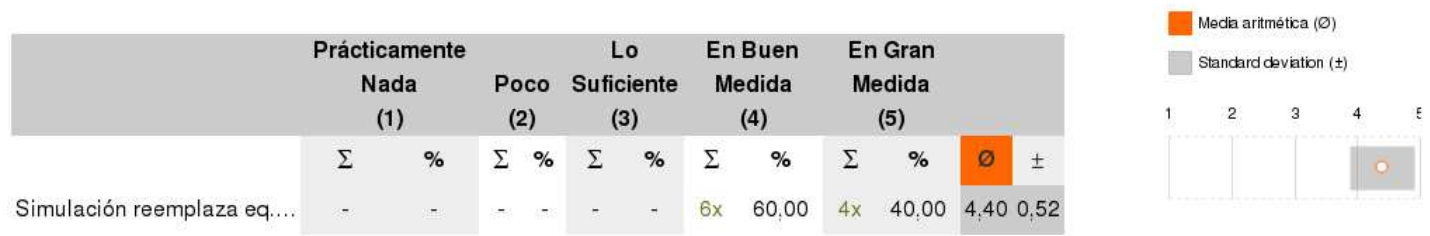

Tabla 5-119 E22: Simulación vs Equipo real

El $100 \%$ de los estudiantes consideró que la simulación puede reemplazar al laboratorio con equipo real cuando el objetivo es la enseñanza de fundamentos.

A continuación se enumeran textualmente algunas opiniones sobre la experiencia de los estudiantes con las herramientas de simulación:

\section{Comentarios y sugerencias de los estudiantes}

- En general muy bueno todo. Con la simulación se puede lograr rápidamente configuraciones como si lo hiciéramos con equipos reales. Como sugerencia, sería bueno no dejar de incluir algunos equipos reales para así combinar las prácticas con equipos simulados.

\subsubsection{Conclusiones de la experiencia}

Considerando que los destinatarios de este curso fueron ingenieros de redes y técnicos que se desempeñan en la configuración de redes, se pudo evidenciar en el análisis realizado, que los estudiantes entendieron que la simulación simplificó el proceso de configuración de la topología y dispositivos, como así también la verificación de la funcionalidad y seguimiento de los eventos. Asimismo, consideraron que la práctica con simulación puede reemplazar a la práctica con equipo real cuando el objetivo es aprender conceptos y fundamentos sobre redes. 


\subsection{Experiencia No 23: GNS3 y Laboratorio real en Redes I - UCASAL}

Esta experiencia se realizó con un grupo de estudiantes, al finalizar el cursado de la asignatura Redes I de la carrera Ingeniería en Telecomunicaciones en la Universidad Católica de Salta.

Durante el cursado de la misma, los estudiantes realizaron para cada tema del programa analítico, una actividad práctica con simulación y con equipo real.

El objetivo fue que los estudiantes contrasten la realización de la misma práctica con equipo real y utilizando los simuladores Packet Tracer y GNS3, para lo cual se realizó una encuesta dividida en tres partes. En la primera parte se indagó respecto del uso de los simuladores y su facilidad para configurar una topología y dispositivos, verificar la funcionalidad y realizar seguimiento de los eventos. En la segunda parte se realizaron las mismas preguntas pero respecto del laboratorio con equipo real. Finalmente se indagó sobre la posibilidad que la simulación reemplace al laboratorio con equipo real, cuando el objetivo es la enseñanza de conceptos y fundamentos de redes.

\subsubsection{Análisis estadísticos de datos}

A continuación se presenta gráficamente el análisis estadístico para cada una de las partes de la encuesta realizada.

Con herramientas de simulación, (como GNS3, Packet Tracer, etc.)

\begin{tabular}{|c|c|c|c|c|c|c|c|c|c|c|c|c|}
\hline & \multicolumn{2}{|c|}{$\begin{array}{l}\text { Prácticamente } \\
\text { Nada } \\
\text { (1) }\end{array}$} & \multicolumn{2}{|c|}{$\begin{array}{c}\text { Poco } \\
\text { (2) }\end{array}$} & \multicolumn{2}{|c|}{$\begin{array}{c}\text { Lo } \\
\text { Suficiente } \\
\text { (3) }\end{array}$} & \multicolumn{2}{|c|}{$\begin{array}{c}\text { En Buen } \\
\text { Medida } \\
\text { (4) }\end{array}$} & \multicolumn{2}{|c|}{$\begin{array}{l}\text { En Gran } \\
\text { Medida } \\
\text { (5) }\end{array}$} & \multirow[b]{2}{*}{$\emptyset$} & \multirow[b]{2}{*}{ \pm} \\
\hline & $\Sigma$ & $\%$ & $\Sigma$ & $\%$ & $\Sigma$ & $\%$ & $\Sigma$ & $\%$ & $\Sigma$ & $\%$ & & \\
\hline Config topología sencilla & - & - & - & - & $1 \mathrm{x}$ & 10,00 & $1 \mathrm{x}$ & 10,00 & $8 x$ & 80,00 & 4,70 & 0,67 \\
\hline Config. dispositivos sencilla & - & - & $1 \mathrm{x}$ & 10,00 & $2 x$ & 20,00 & $4 x$ & 40,00 & $3 x$ & 30,00 & 3,90 & 0,99 \\
\hline Herramienta adecuada pa... & - & - & - & - & $3 x$ & 30,00 & $3 x$ & 30,00 & $4 x$ & 40,00 & 4,10 & 0,88 \\
\hline Verif. funcionalidad sencilla & - & - & - & - & $4 x$ & 40,00 & $2 x$ & 20,00 & $4 x$ & 40,00 & 4,00 & 0,94 \\
\hline Seguimiento de eventos s... & - & - & $2 x$ & 20,00 & $1 \mathrm{x}$ & 10,00 & $6 x$ & 60,00 & $1 \mathrm{x}$ & 10,00 & 3,60 & 0.97 \\
\hline
\end{tabular}

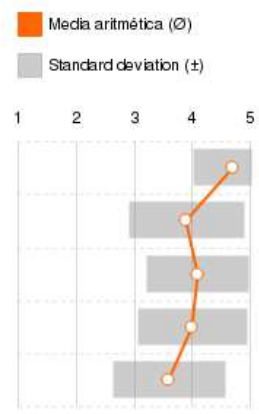

5-120 E23: Análisis con simulación

Para la configuración de la topología el $90 \%$ consideró que es sencillo con el simulador, para la configuración de los dispositivos el 70\% consideró sencillo, el 60\% consideró que la verificación de la funcionalidad y $70 \%$ el seguimiento de los eventos se realizó de manera sencilla con simulación. 


\section{En laboratorio con equipo real, (como Mikrotik, Ubiquiti, Cisco, etc.)}

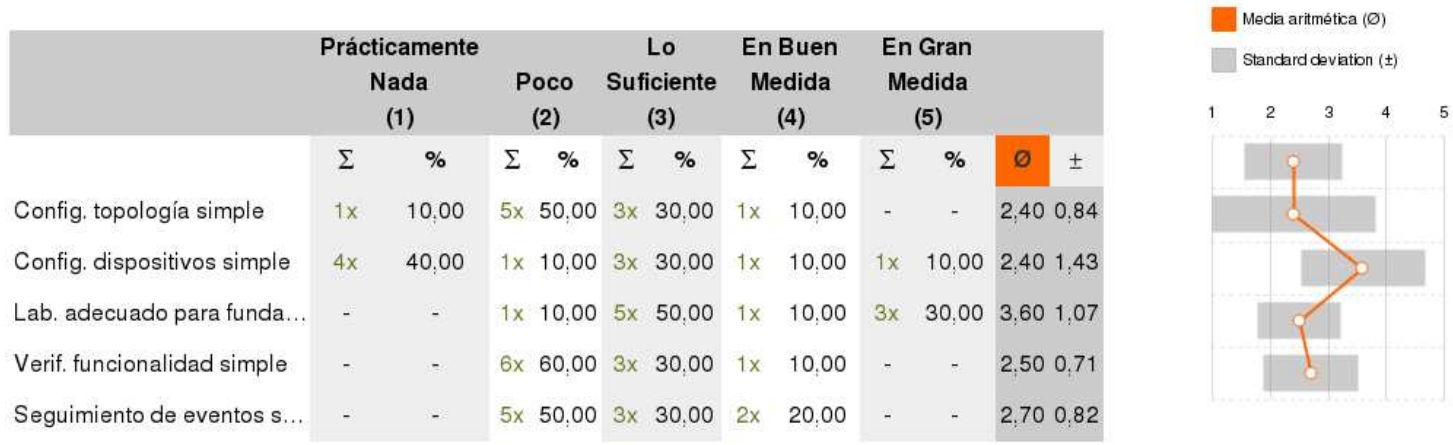

Tabla 5-121 E23: Análisis con equipo real

El $60 \%$ de los estudiantes consideró que la configuración de la topología no fue sencilla con equipo real, el 50\% consideró que la configuración de dispositivos no fue sencilla. Para la verificación de la funcionalidad, el $60 \%$ consideró que no fue sencillo y el $50 \%$ para el seguimiento de los eventos.

Cuando el objetivo es la enseñanza de fundamentos y no la de formar técnicos en redes, ¿considera que la simulación puede reemplazar a la práctica con equipo real?

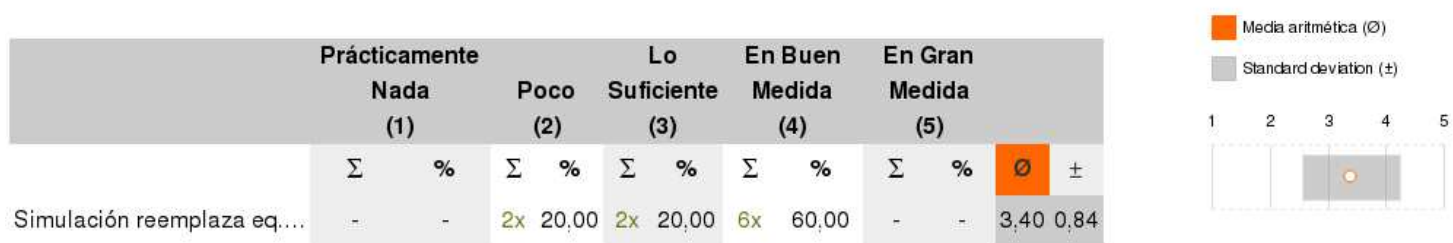

Tabla 5-122 E23: Simulación vs Equipo real

El 60\% de los estudiantes consideró que la simulación puede reemplazar al laboratorio con equipo real cuando el objetivo es la enseñanza de fundamentos.

A continuación se enumeran textualmente algunas opiniones sobre la experiencia de los estudiantes con las herramientas de simulación:

\section{Comentarios y sugerencias de los estudiantes}

- Hace falta más tiempo y práctica para entender al $100 \%$ los programas de simulación de redes. Es didáctico pero falta desarrollarlo más.

- El uso de simuladores es muy conveniente debido a la imposibilidad de obtener los equipos físicos, pero cuando sea posible es conveniente realizar la práctica en equipos reales y con simulador para poder observar que es prácticamente lo mismo.

- Cuando no contamos con los equipos a la hora de realizar prácticas y demás, es muy interesante trabajar con los simuladores, para poder visualizar como va a ser nuestra topología y funcionalidad de la misma 


\subsubsection{Conclusiones de la experiencia}

Se puede evidenciar del análisis realizado, que los estudiantes entendieron que la simulación simplificó el proceso de configuración de la topología y dispositivos, como así también la verificación de la funcionalidad y seguimiento de los eventos. Asimismo, consideraron que la simulación puede reemplazar a la práctica con equipo real, cuando se trata de aprender fundamentos. 


\subsection{Encuesta a docentes de asignaturas de redes de computadoras}

A fin de conocer la opinión de los docentes de asignaturas de redes se realizó una encuesta con la finalidad de tener una idea de la visión respecto del uso de simulación en la enseñanza de redes en sus diferentes contextos.

Para facilitar su cumplimentación, los cuestionarios fueron implementados directamente en la web, mediante la herramienta gratuita Online Encuesta (Sitio https://www.onlineencuesta.com/), distribuyéndose la URL de acceso, mediante correo electrónico, a los docentes de las distintas universidades.

La encuesta se dividió en tres partes. En la primera, el docente debía responder sobre sus datos filiatorios, carrera y asignatura en la que enseñaba, si utilizaba la simulación en la enseñanza y si la formación era de técnicos o profesionales en sistemas. La segunda parte se indagó sobre laboratorios con simulación, cómo consideraba la curva de aprendizaje del estudiante para el armado de la topología y también para la configuración de los dispositivos de networking. En la tercera parte se realizaron las mismas preguntas pero para laboratorios con equipo real, es decir, cómo consideraba la curva de aprendizaje del estudiante para el armado de la topología y configuración de dispositivos en un ambiente con equipo real.

En la primera parte de la encuesta se combinaron preguntas abiertas y dicotómicas. En la segunda y tercera parte de la encuesta se optó por una escala de valoración de Likert de 5 puntos para cada una de las preguntas. Este último tipo de preguntas, resulta especialmente útil emplearla en situaciones en las que se quiere que la persona matice su opinión. En este sentido, las categorías de respuesta sirven para capturar la intensidad de los sentimientos del encuestado hacia dicha afirmación.

\section{La muestra}

La muestra se compuso de 13 docentes entre profesores y auxiliares de docencia, pertenecientes a las siguientes universidades, carreras y asignaturas:

- Universidad Nacional de Salta - Licenciatura en Análisis de Sistemas - Redes de Computadoras I, Redes de Computadoras II y Conectividad y Teleinformática (Plan viejo).

Tecnicatura Universitaria en Programación - Optativa I; Introducción a las Redes.

- Universidad Católica de Salta - Ingeniería en Telecomunicaciones - Redes I y Redes II.

- Universidad Nacional de Santiago del Estero - Licenciatura en Sistemas de Información - Redes I y Redes II.

- Universidad Nacional de Río Cuarto - Ingeniería en Telecomunicaciones - Arquitectura de Redes.

- Universidad Nacional de San Juan - Licenciatura en Ciencias de la Computación y Licenciatura en Sistemas de Información - Redes (Plan 2011) y Redes y Sistemas Distribuidos (Plan 2006). Tecnicatura en Programación Web (Sede Jachal) - Sistemas Operativos y Redes. 


\subsubsection{Análisis estadísticos de los datos}

En el análisis estadístico de los datos se destaca que el $61.54 \%$ de los encuestados, tiene cargo de profesor, mientras que el $39.46 \%$ restante tiene cargo de auxiliar de docencia. Esto puede apreciarse en la figura 4.

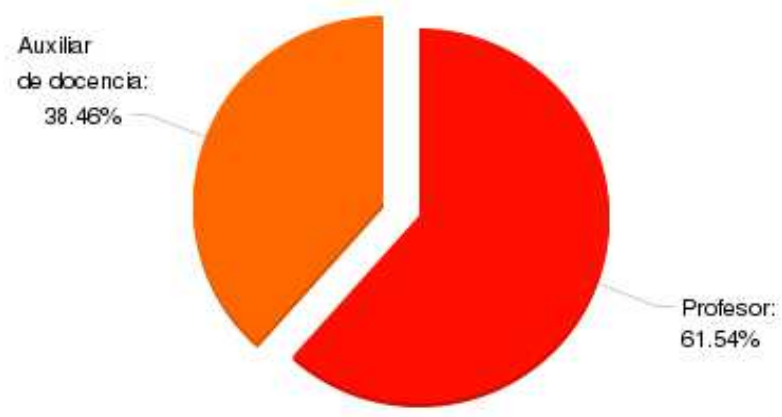

Figura 5-113: Cargo docente de los encuestados

El $84.62 \%$ de los docentes enseña fundamentos de redes en carreras de sistemas y el $15.38 \%$ restante, forma profesionales específicos en redes (figura 5). A su vez, el 100\% de los docentes enseña utilizando herramientas de simulación en las prácticas (figura 6).

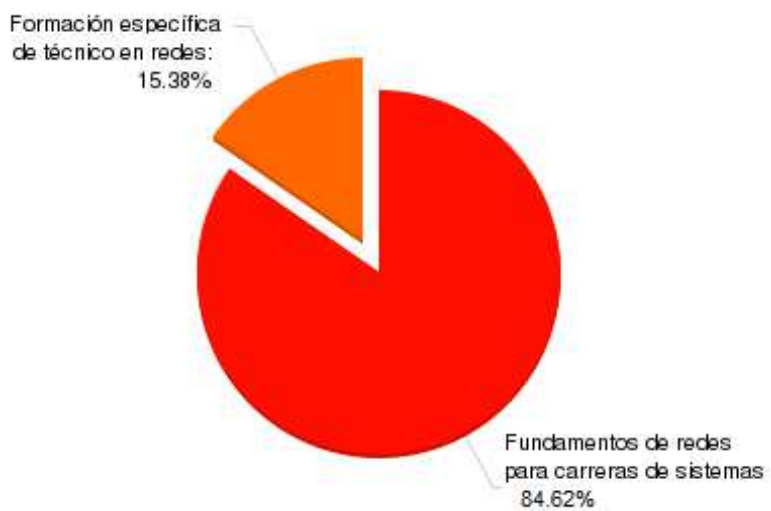

Figura 5-114: Objetivo de la enseñanza de redes

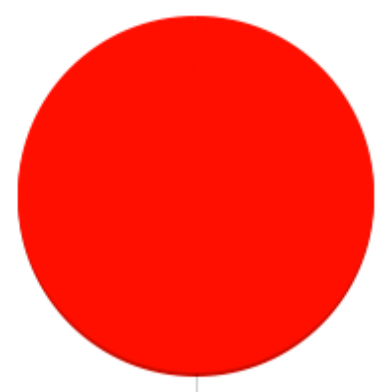

SI: $100.00 \%$ 
Figura 5-115: Enseñanza con simulación

Las preguntas sobre la enseñanza con herramientas de simulación se pueden resumir en el siguiente cuadro.

\begin{tabular}{|c|c|c|c|c|c|c|c|c|c|c|c|c|}
\hline & \multicolumn{2}{|c|}{$\begin{array}{c}\text { Muy Larga } \\
\text { (1) }\end{array}$} & \multicolumn{2}{|c|}{$\begin{array}{l}\text { Larga } \\
\text { (2) }\end{array}$} & \multicolumn{2}{|c|}{$\begin{array}{c}\text { Mediana } \\
\text { (3) }\end{array}$} & \multicolumn{2}{|c|}{$\begin{array}{l}\text { Corta } \\
\text { (4) }\end{array}$} & \multicolumn{2}{|c|}{$\begin{array}{l}\text { Muy corta } \\
\text { (5) }\end{array}$} & \multirow[b]{2}{*}{$\varnothing$} & \multirow[b]{2}{*}{ \pm} \\
\hline & $\Sigma$ & $\%$ & $\Sigma$ & $\%$ & $\Sigma$ & $\%$ & $\Sigma$ & $\%$ & $\Sigma$ & $\%$ & & \\
\hline El armado de la topología & - & - & - & - & $4 x$ & 30,77 & $6 x$ & 46,15 & $3 x$ & 23,08 & 3,92 & 0,76 \\
\hline La configuración de los dispo... & - & - & $1 \mathrm{x}$ & 7,69 & $6 x$ & 46,15 & $6 x$ & 46,15 & - & - & 3,38 & 0.65 \\
\hline
\end{tabular}

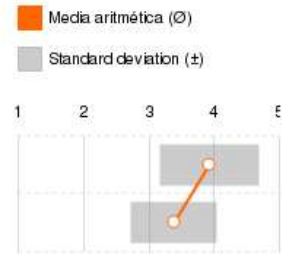

Tabla 5-123: Enseñanza con simulación, resultados para armado de topología y configuración de dispositivos

Analizando la pregunta del armado de la topología, se puede apreciar que para casi el $70 \%$ de los docentes, consideró que la curva de aprendizaje es corta. Para la configuración de dispositivos, el 46\% de los encuestados consideró que la curva de aprendizaje es corta.

Las preguntas sobre la enseñanza con equipo real se pueden resumir en el siguiente cuadro.
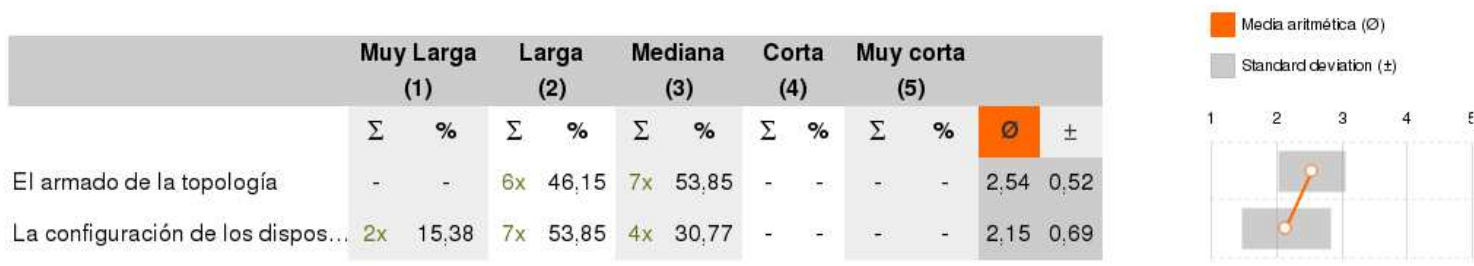

Tabla 5-124: Enseñanza con equipo real, resultados para armado de topología y configuración de dispositivos

En la pregunta sobre el armado de la topología, el 46,15\% consideró larga la curva de aprendizaje. Mientras que para la configuración de dispositivos, casi el 70\% consideró entre larga y muy larga la curva de aprendizaje.

En la pregunta sobre si la simulación puede reemplazar a la práctica con equipo real, cuando el objetivo es la enseñanza de fundamentos y no formar técnicos, se resume en este cuadro:

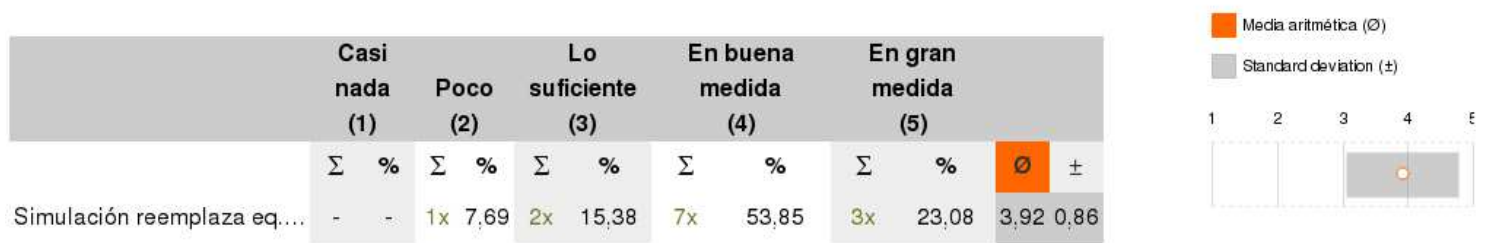

Tabla 5-125: Enseñanza con simulación reemplaza práctica con equipo real

Se puede observar en la tabla que el $76.93 \%$ consideró que la simulación puede sustituir a la práctica con equipo real en este contexto. 
También se pueden destacar algunos comentarios y sugerencias textuales de los docentes, que surgen de una pregunta abierta:

- Es importante la utilización de Simuladores en la enseñanza de Redes, permite que el estudiante comprenda rápidamente los conceptos y el funcionamiento de los protocolos.

- Considero que el uso de herramientas de simulación realizan un gran aporte a la enseñanza de los fundamentos de redes de computadoras, ya que permiten focalizar en los aspectos fundamentales sobre el modelo de capas, funcionalidad de protocolos, entre otros, minimizando los tiempos de armardo y configuración de equipos y topologías necesarias para poder "visualizar" los aspectos antes mencionados

- Considero que en carreras específicas que comprenden la enseñanza de redes de computadoras, el uso de herramientas de simulación permiten cubrir en buena parte los aspectos sobre fundamentos, funcionalidad de protocolos, entre otros. Sin embargo, es necesario su uso en combinación con la interacción con equipos reales, ya que las primeras, no alcanzan a cubrir tecnologías de redes de área extensa, redes móviles y redes inalámbricas

- La simulación se utilizó mucho en los primeros tiempos, cuando la necesidad obligaba a tomar decisiones que permitieran un aprendizaje más profundo acerca de las redes. Se disminuyó su uso en los casos en que el equipo físico era factible de configurar. Se sigue utilizando en los casos de redes de gran envergadura o cuando se desean estudiar algunos protocolos.

- Las herramientas de software de simulación para redes de comunicaciones intentan imitar el comportamiento real de equipos físicos interconectados. Si bien un simulador no puede sustituir el trabajo directo con equipos, puede proveer en cambio facilidad de acceso, manejo de diversas topologías, equipos y protocolos, rapidez en el armado, trabajar con diferentes tipos de escenarios, algunos de estos escenarios pueden ser configurados erróneamente o incompletos para corregirlos y un punto clave es la visualización gráfica. Aunque no son reales, imitan de cerca la realidad

- Mientras más complejos sean los dispositivos, y por lo tanto más costosos, se nota más la ayuda de los simuladores

- En nuestro caso usar simuladores es la única forma de trabajar con cierto tipo de equipamiento que no se cuenta. Por ejemplo routers o switchs administrables

\subsubsection{Conclusiones de la experiencia}

Si bien la muestra fue pequeña y no permitió una generalización de los resultados, sí posibilitó tener una visión de los datos indagados para las carreras encuestadas.

Para esta muestra, se pudo concluir que los docentes en su mayoría consideraron que utilizando simulación el armado de la topología por parte del estudiante, tiene una curva de aprendizaje corta, mientras que la configuración de dispositivos presenta una curva de aprendizaje entre mediana y corta.

Cuando se trata de enseñanza empleando laboratorio con equipo real, los docentes consideraron en su mayoría que la curva de aprendizaje del estudiante es larga a mediana en el armado de la topología y una curva de aprendizaje larga, para la configuración de los dispositivos.

En la pregunta "Cuando el objetivo es enseñar fundamentos de redes y no formar técnicos en redes, considera que la práctica con simulación puede reemplazar la práctica con equipo real", en su mayoría (casi el 80\%) los docentes respondieron que sí.

Es necesario resaltar que los hallazgos de este estudio no pueden ser extrapolados a otros contextos educativos, tanto por el tipo de muestra elegida como por el propio diseño de investigación realizado.

Como futuro trabajo se propone agrandar la muestra con el objeto de mejorar la representatividad de los resultados. 


\section{RESULTADOS Y CONCLUSIONES}

Los resultados alcanzados en esta investigación pretenden ser un aporte en la toma de decisiones de futuras propuestas curriculares y didácticas que tengan en cuenta los métodos de simulación, aplicados a contenidos concretos en el área de las redes de computadoras.

En relación a las preguntas de investigación que se plantearon, se llegó a las siguientes conclusiones:

¿Cómo influyen en la enseñanza y el aprendizaje, los TP realizados con un software de simulación?

Contribuyen poderosamente a afianzar los conocimientos que se imparten. El estudiante puede verificar en topologías virtuales, como responde una variable dependiente a las variaciones de otra, u otras.

De las encuestas, se observa que despierta en los estudiantes la sensación de tener a su disposición un "laboratorio". Los métodos de simulación son una herramienta que permite expandir la imaginación y las posibilidades de la realidad física, ampliando las posibilidades de aprender.

¿Qué efectos causan los programas de simulación, en lo que hace a motivar al estudiante a aprender a resolver los problemas analizados en las clases teóricas?

Los estudiantes se mostraron muy receptivos e interesados en las diferentes herramientas de software utilizadas, manifestando decididamente en las encuestas realizadas, que el uso de las mismas los ha motivado al aprendizaje.

¿Cuánto pueden contribuir los trabajos sobre el simulador a que se reafirmen los conceptos teóricos y la comprensión de los fundamentos y funcionamiento en general de las redes?

La posibilidad de variar la configuración de los componentes y visualizar el cambio de comportamiento potencia el aprendizaje. También en las encuestas, los estudiantes manifestaron su satisfacción.

¿Cuánto le hace sentir la seguridad de quien ha explorado un tema acabadamente, al tener la posibilidad de variar arbitrariamente los valores de los componentes?

Según las evaluaciones, las experiencias realizadas contribuyeron a brindarles una comprensión acabada de los conceptos teóricos, en mayor medida que los trabajos prácticos tradicionales.

Dado que el estudiante puede diseñar e inventar topologías y experimentar con ellas ¿hasta qué punto favorece la creatividad?

En la medida que el estudiante se sienta motivado a utilizar las herramientas de simulación, tendrá flexibilidad y oportunidades, que no es posible en la práctica tradicional. No tiene prácticamente limitaciones para crear y probar diferentes topologías, dando "rienda suelta" a su imaginación. Los estudiantes manifestaron su actitud favorable hacia esta posibilidad de diseñar e inventar, sin costo ni peligros. 
¿Hasta qué punto contribuyen a reemplazar un aprendizaje memorístico por aprendizaje significativo?

En general puede decirse que el uso de métodos de simulación potencia el aprendizaje significativo de los conceptos que se aprenden en las clases, donde se enseñan los conceptos teóricos y se realizan ejemplos de aplicación. Las evaluaciones de conceptos realizadas lo evidencian.

¿En qué momento conviene aplicar estos métodos, antes y/o después de los trabajos prácticos tradicionales? ¿Qué condiciones deben darse para la aplicación de estos métodos?

Por el nivel alcanzado por los estudiantes en las evaluaciones realizadas de las actividades prácticas, se considera que es conveniente su utilización después de la presentación teórica y la práctica tradicional en aula, para permitir que el estudiante llegue al mismo con los conceptos más asimilados y más motivado. Los beneficios que se obtienen de las experiencias con programas de simulación dependen siempre de la habilidad y conocimientos con que el docente prepare las mismas. También en ellas, el docente juega un rol fundamental.

\section{¿Cómo estructurar una actividad práctica utilizando métodos de simulación?}

Por lo expuesto, se considera que las mismas deben realizarse en forma muy coordinada con las clases en las que se explica la teoría y la práctica tradicional. Debe buscarse la forma de que el estudiante se confronte con los conceptos aprendidos. Se considera que las experiencias realizadas avalan la postura inicial en el sentido que estas experiencias con simulación complementan las prácticas tradicionales, y ponen de manifiesto que son un recurso excelente para complementar la enseñanza, haciendo de "puente" entre clases en el aula y clases en el laboratorio con equipo real.

\subsubsection{Hallazgos}

Los resultados obtenidos en las Experiencias $\mathrm{N}^{0} 1,2,3,4,5,6,10,14,16,19$ у 20 descriptas previamente, donde se trataron temas correspondientes a las Capa de Aplicación, Capa de Transporte y Capa de Red del Modelo TCP/IP, evidencian que los estudiantes consideran por una parte que las herramientas utilizadas (Kiva-NS, Packet Tracer y GNS3) cuentan con toda la potencialidad para realizar simulaciones claras de los protocolos estudiados y por otro lado consideran apropiados los laboratorios propuestos. De manera que, en relación con el primer objetivo del estudio, se establece que, para el nivel universitario, la utilización del software de simulación tiene una incidencia significativamente alta en el desarrollo de una buena actitud hacia el estudio de las asignaturas Redes de Computadoras I y Redes de Computadoras II del plan de estudios de la Licenciatura en Análisis de Sistemas.

En relación al segundo objetivo del estudio, y en función de los resultados obtenidos en las Experiencias $\mathrm{N}^{\mathrm{o}} 2,6,7,8,9,11,12,13,15,17,18$ y 21 descriptas anteriormente, donde se realizaron evaluaciones de los conceptos Algoritmo CSMA/CD, Protocolo ARP, Protocolo DNS, Direccionamiento IP y Ruteo IP, se evidencia que el uso de software de simulación influye positivamente en el mejoramiento del nivel de comprensión de los conceptos. Se 
concluye en este aspecto que existe diferencia estadísticamente significativa a favor de los estudiantes que emplearon una estrategia basada en simulación.

Las Experiencias $\mathrm{N}^{\circ} 22$ y 23 permitieron contrastar la práctica con simulación y la práctica con equipo real, donde se evidencia que los estudiantes consideran que la simulación simplifica el proceso de configuración de topologías y dispositivos y el seguimiento de los eventos. Asimismo, consideran que la práctica con simulación puede reemplazar a la práctica con equipo real, cuando se trata de aprender fundamentos y conceptos sobre redes de computadoras.

Finalmente, la encuesta a docentes de asignaturas de redes de distintas universidades, evidencia que los docentes consideran que la curva de aprendizaje es menor cuando se realiza práctica con simulación frente a la práctica con equipo real, considerando también que la simulación podría reemplazar a los laboratorios con equipo real cuando el objetivo es la enseñanza de conceptos y fundamentos de redes.

Se considera que:

- las experiencias realizadas tienen "validez externa", en cuanto a que pueden extrapolarse los resultados a otras asignaturas, de la misma carrera, que compartan contenidos y metodologías,

- los métodos de simulación tienen una influencia muy poderosa sobre la enseñanza, $\mathrm{y}$ un gran potencial a futuro.

\subsubsection{Recomendaciones}

Sería importante complementar el estudio con un avance acerca de los modos de organizar el contenido de los trabajos con simulación como expresión de criterios amplios donde la mirada docente se posicione no sólo en el contenido conceptual a enseñar sino en el contexto en que ese contenido será requerido en el ejercicio profesional en el ámbito laboral. El tema merece seguir siendo investigado, por la importancia detectada en cuanto a su influencia en el aprendizaje.

Se recomiendan estudios cualitativos que permitan conocer con mayor profundidad el nivel de conceptualización alcanzado por los estudiantes con el uso del software de simulación y ampliar la visión sobre el tema. También se sugiere la realización de otros experimentos que permitan contrastar el aprendizaje con simulación y el aprendizaje con equipo real considerando la enseñanza de conceptos y la formación de técnicos.

Como futuras investigaciones se sugieren estudios sobre el impacto de software de simulación en otros ámbitos de las redes, así como en otras asignaturas del plan de estudios de la carrera.

Otro factor que influye en el estudio es la homogeneidad en el nivel de habilidad para utilizar este tipo de herramientas, la formación en informática de los estudiantes, facilitó la realización de las experiencias.

Por otro lado, la rigidez del enfoque cuantitativo limita la comprensión del fenómeno.

Finalmente, otro punto a considerar es la influencia de diversos factores en la eficacia del software. 


\section{BIBLIOGRAFIA}

SAKAR, N. I. (2006) Teaching TCP/IP Networking Using Practical Laboratory Exercises, International Journal of Information and Communication Technology Education, Vol. 2, No. 4, pp. 39-50.

GOLDSTEIN, G., M LEISTEN, S, STARK, K.,\& TICKLE, A. (2005) Using a Network Simulation Tool to Engage Students in Active Learning Enhances Their Understanding of Complex Data Communications Concepts, Proceedings of the 7th Australasian conference on Computing Education, pp. 223-228.

JAVIDI, G. \& SHEYBANI, E. (2008) Content-Based Computer Simulation of a Networking Course: An Assessment, Journal of Computers, Vol. 3, No. 3, pp. 64-72.

DIXON, M. W., MCGILL, T. J. \& KARISOON, J. M (1997) Using a Network Simulation Package to Teach the Client-server Model. Proceedings of the 2nd Conference on Integrating Technology into Computer Science Education, pp. 71-73.

CAMERON, B. (2003): Effectiveness of simulation in a hybrid online networking course. Quarterly Review of Distance Education, 4(1), 51.

GATTO, D. (1993): The use of interactive computer simulations in training. Australian Journal of Educational Technology, 9(2), 144-156.

YAVERBAUM, G., \& NADARAJAN, U. (1996): Learning basic concepts of telecommunications: an experiment in multimedia and learning. Computers \& Education, 26( 4), 215-224.

ZHU, S. Y. (2011).Teaching Computer Networks through Network Simulation Programs. Faculty of Business, Computing and Law - School of Computing. University of Derby. Learning Teaching \& Assessment Conference.

KUROSE, J.F. \& ROSS, K.W. (2015). Computer Networking: A Top-Down Approach. 6th Edition. Pearson Education. ISBN: 9780132856201.

AVILA BLAS, Orlando José (2003). Probabilidad y estadística inferencial: teoría y aplicaciones. ISBN: 978-987-9381-23-6.Editorial: Universidad Nacional de Salta.

GEORGE, D., \& MALLERY, P. (2003). SPSS for Windows step by step: A simple guide and reference. 11.0 update (4th ed.). Boston: Allyn \& Bacon.

GLIEM, J \& GLIEM, R. (2003). Calculating, Interpreting, and Reporting Cronbach's Alpha Reliability Coefficient for Likert-Type Scales. Conference in Adult, Continuing, and Community Education. Midwest Research to Practice. 
SIJTSMA, K. (2009). On the use, the misuse and the very limited of the Cronbach's Alpha. Psychometrika, 74(1) 107-120. DOI: 10.1007/S11336-008-9101-0

CÁMARA, ALZUGARAY (2011). Trabajos Prácticos, Métodos de Simulación y aprendizaje significativo. La Tecnología Educativa al servicio de la Educación Tecnológica.

SPAGNI, BEATRIZ (2007). Técnicas estadísticas aplicadas en la investigación con empleo del software específico S.P.S.S.”. Material del curso dictado en UTN, Regional Santa Fe.

GAMO, J. et al. (2015). Validación de requisitos funcionales de un Laboratorio Virtual Remoto como apoyo al blended learning. Revista de Educación a Distancia. 45(1).

\section{Referencias bibliográficas}

AUSUBEL, DAVID (1997). "Psicología educativa: un punto de vista cognoscitivo". Seg. Edición. México: Ed. Trillas.

PERKINS, DAVID (1997). “La escuela inteligente”. Barcelona: Ed. Gedisa.

POZO, JUAN (1994). "La solución de problemas”. Madrid: Ed. Santi llana S.A.

POZO, JUAN (1994). "Aprendizaje de la ciencia y pensamiento causal". Visor, Madrid: Aprendizaje.

POZO, JUAN (1997). “Teorías cognitivas del aprendizaje”. Madrid: Morata.

RIVIERE, ANGEL (1998). “La psicología de Vygotski”. Visor, Madrid: Ed. Aprendizaje.

ANDREW TANENBAUM, DAVID WETHERALL (2013). Computer Networks 5th Edition. Pearson New International Edition.

WILLIAM STALLINGS (2014). Data and Computer Communications, Tenth Edition. Pearson Prentice Hall..

LARRY L. PETERSON, BRUCE S. DAVIE (2012). Computer Networks a systems approach. Fifth Edition. Morgan Kaufmann Publishers - Elsevier.

RICHARD STEVENS (2012). TCP/IP Illustrated, Vol. 1: The Protocols 2da Edition. (Addison-Wesley Professional Computing Series).

DOUGLAS COMER (2014). Computer Networks and Internets (6th Edition). Pearson Prentice Hall. 
J.F. KUROSE, K.W. ROSS (2015). Computer Networking: A Top-Down Approach (6th Edition). Pearson Education.

SAMPIERI, ROBERTO (1998) et. al.: "Metodología de la investigación". Segunda edición. Méjico: Ed. McGraw-Hill.

DANKHE, G. (1989). “Investigación y comunicación”. México: Ed. Mc Graw Hill.

BABBIE, E. (1979). “The practice of social research”. 2da. Belmont: Ed. Wadsworth.

EDMONDSON, D. R. (2005). Likert scales: a history. En L. C. Neilson (Ed.), The Future of Marketing's Past. Proceedings of the 12th Conference on Historical Analysis and Research in Marketing (CHARM) (págs. 127-133). Long Beach, CA, USA: Association for Historical Research in Marketing.

CROMBACH, L. (1951). Coefficient alpha and the internal structure of tests. Psychometrika, 16, 297 - 334.

LIKERT, R. (1932). A technique for the measurement of attitudes. Archives of Pyschology, 140,5 - 55.

GEORGE, D., \& MALLERY, P. (1994). SPPS/PC + Step by Step: A Simple Guide and Reference. Belmont, CA,: Wadsworth.

GIL PEREZ (1998). "El fracaso en la resolución de problemas: una investigación orientada por nuevos supuestos". Enseñanza de las Ciencias, 6(2), pp. 131-146.

GIL PÉREZ, D. (1993). "Contribución de la historia y filosofía de la ciencia al desarrollo de un modelo de enseñanza-aprendizaje como investigación". Enseñanza de las Ciencias, $11(2)$.

LAZAROWITZ R. y TAMIR P (1994). "Research on using laboratory instruction in science", in D. L. Gabel. (Ed.) Handbook of research on science teaching and learning (pp. 94-130). New- York: Macmillan.

LUNETTA, V.N. (1998). "The school science laboratory: historical perspectives and centers for contemporary teaching", In P. Fensham (Ed.). Developments and dilemmas in science education (pp 169-188). London: Falmer Press.

BUNGE, M. (1976). "La investigación científica”. Barcelona: Ariel.

HACKING, I. (1982). “Experimentation and Scientific Realism”, Philosophical Topics, 13, pp. 154-172.

HANSON, N. (1958). "Patterns of discovery". Cambridge: University Press.

MAIZTEGUI, A. (2002). "Papel de la tecnología en la educación científica: una dimensión 
olvidada”. La Habana: Academia.

SALINAS, J. (1998). "Tópicos de electrostática a nivel universitario básico: factores subyacentes a las incomprensiones de los estudiantes". Enseñanza de las ciencias número extra V congreso 215-216.

SAMPIERI, ROBERTO (1998). "Metodología de la investigación". Segunda edición. Méjico: Ed. McGraw-Hill, 1998.

BABBIE, E. (1979). “The practice of social research”. 2da. Belmont: Ed. Wadsworth.

DANKHE, G. (1989). “Investigación y comunicación”. México: Ed. Mc Graw Hill.

GARCÍA, A. Y GIL, M. (2006). Entornos constructivistas de aprendizaje basados en simulaciones interactivas. Revista Electrónica de Enseñanza de las Ciencias, 5 (2).

KOFMAN, H. A., CATALÁN, L. C. Y CONCARI, S. B. (2004). A training distance course on the use of simulations for physics teaching. Presentado en el World Congress on Engineering and Technology Education. Guarujá, São Paulo, Brasil.

ESQUEMBRE, F. (2005). Creaciones de simulaciones interactivas en Java. Madrid, España: Pearson Educación.

DEBEL, E., CUICAS, M., CASADEI, L., Y ÁLVAREZ, Z. (2009). Experimento real y simulación como herramientas de apoyo para lograr aprendizajes significativos en la asignatura Laboratorio de Física II. Multiciencias, 9, (1), 80-88. 


\section{APENDICE I: CONTRIBUCIONES}

\section{Libros publicados con referato}

- "NORMA TÉCNICA PARA EL CABLEADO ESTRUCTURADO DE LA UNSa" Editorial de la Universidad Nacional de Salta - EUNSa - Año 2013

Autores: Daniel Arias Figueroa y Gustavo D. Gil.

ISBN 978-987-633-079-4; con colaboración de Jorge Alberto Silvera - 1a ed. - Salta E-Book - CDD 005.3.

- "REDES DE COMPUTADORAS I CON PACKET TRACER"

Editorial de la Universidad Nacional de Salta - EUNSa - Año 2015

Autor: Daniel Arias Figueroa.

ISBN 978-987-633-132-6-1; 1a ed. - Salta - E-Book - CDD 004.68.

\section{Publicaciones con referato}

Los resultados obtenidos durante el desarrollo del trabajo de investigación asociado a esta tesis, fueron presentados en las siguientes publicaciones con referato:

- "KIVA: Un simulador para la enseñanza de Redes IP". VII Congreso Tecnología en Educación y Educación en Tecnología (TE\&ET 2012). Ciudad de Pergamino, Provincia de Buenos Aires - Junio de 2012. Daniel Arias Figueroa, Gustavo D. Gil, Ernesto Sánchez (C.I.D.I.A)

- $\quad$ Un caso de estudio en Extensiones de Seguridad para el Sistema de Nombres de Dominio (DNSSEC). Resultados parciales". XVIII Congreso Argentino de Ciencia de la Computación (CACIC 2012) - Octubre de 2012 - Universidad Nacional Del Sur - Bahía Blanca. Ernesto Sánchez, Javier Díaz, Daniel Arias Figueroa, Sergio H. Rocabado.

- "Caso de estudio de comunicaciones seguras sobre redes móviles ad hoc" XIX Congreso Argentino de Ciencia de la Computación (CACIC 2013) - Octubre de 2013 - CAECE Mar del Plata. Sergio H. Rocabado Moreno, Daniel Arias Figueroa, Javier Díaz. C.I.D.I.A. - Centro de Investigación y Desarrollo en Informática Aplicada (UNSa). L.IN.T.I. - Laboratorio de Investigación en Nuevas Tecnologías Informáticas (UNLP)

- "DNSCurve, una alternativa para la seguridad en el Sistema de Nombres de Dominio". 2do Congreso Nacional de Ingeniería Informática / Sistemas de Información - CoNaIISi. San Luis 13 y 14 de Noviembre de 2014. Ernesto Sánchez, Daniel Arias Figueroa, Sergio Rocabado.

- "Enseñanza del Protocolo DNS basada en simulación". Daniel Arias Figueroa, Gustavo D. Gil, Ernesto Sánchez. Demo Educativa presentada en el IX Congreso de Tecnología en Educación y Educación en Tecnología (TE\&ET 2014). Ciudad de Chilecito - La Rioja, 12 y 13 de Junio de 2014. 
- "Protocolo DNS jerárquico multinivel con Packet Tracer". Daniel Arias Figueroa, Gustavo D. Gil, Ernesto Sánchez, Jorge Silvera. Demo Educativa presentada en el X Congreso de Tecnología en Educación y Educación en Tecnología (TE\&ET 2015). Ciudad de Corrientes, 11 y 12 de Junio de 2015.

- "Enseñanza de Direccionamiento IP con el simulador GNS3". Álvaro Gamarra, Daniel Arias Figueroa, Gustavo D. Gil. Demo Educativa aceptada para el XI Congreso de Tecnología en Educación y Educación en Tecnología (TE\&ET 2016). Universidad de Morón - Buenos Aires, 9 y 10 de Junio de 2016.

- "Limitaciones del Simulador Packet Tracer en la enseñanza de redes TCP/IP". XI Congreso de Tecnología en Educación y Educación en Tecnología (TE\&ET 2016). Universidad de Morón - Buenos Aires, 9 y 10 de Junio de 2016. Daniel Arias Figueroa, Ernesto Sánchez, Gustavo D. Gil, Loraine Gimson.

- "Simulación en la enseñanza de redes de computadoras: visión de docentes". 4to Congreso Nacional de Ingeniería Informática / Sistemas de Información - CoNaIISi. Salta - UCASAL 17 y 18 de Noviembre de 2016. Daniel Arias Figueroa, Ernesto Sánchez, Loraine Gimson, Gustavo Gil, Álvaro Gamarra, Nelson Rodríguez, María Murazzo, Jorge Mercado, Marcelo Moreno.

- "Análisis de impacto en la implementación de DNSSEC en un servidor DNS Recursivo". XXII Congreso Argentino de Ciencia de la Computación (CACIC 2016). Octubre de 2016 - Universidad Nacional de San Luis. Ernesto Sánchez, Daniel Arias Figueroa, Sergio Rocabado.

- "Aplicación del enfoque descendente para la enseñanza de Redes de Computadoras, un estudio comparativo". XXII Congreso Argentino de Ciencia de la Computación (CACIC 2016) - Octubre de 2016 - Universidad Nacional de San Luis. Nelson Rodríguez, Daniel Arias Figueroa, María Murazzo, Jorge Mercado, Marcelo Moreno, Ernesto Sánchez, Álvaro Gamarra, Gustavo Gil. Universidad Nacional de San Juan - Universidad Nacional de Salta.

- "Una experiencia en la implementación de Extensiones de Seguridad para el Sistema de Nombre de Dominio" CoNaIISi 2016 - 4to Congreso Nacional de Ingeniería en Informática / Sistemas de Información 17 y 18 de Noviembre - Salta Argentina. Ernesto Sánchez, Daniel Arias Figueroa, Sergio Rocabado, Álvaro Gamarra, Javier Díaz.

- "Estudio de la influencia del uso del simulador KIVA-NS en la enseñanza de redes IP". Décima Quinta Conferencia Iberoamericana en Sistemas, Cibernética e Informática (CISCI 2016), del 5 al 8 de julio de 2016, en Orlando, Florida, EE.UU. Daniel Arias Figueroa, Gustavo Gil, Loraine Gimson (CIDIA). ISBN-13: 978-1941763-45-2

- "Experiencia en la asignatura Redes I con herramientas de simulación y prácticas con equipo real". XII Congreso de Tecnología en Educación y Educación en Tecnología (TE\&ET 2017). Universidad Nacional de La Matanza - Buenos Aires, 22 y 23 de Junio de 2017. Daniel Arias Figueroa, Loraine Gimson, Álvaro Gamarra, Ernesto Sánchez, Gustavo Gil 


\section{Revistas internacionales}

Los resultados obtenidos durante el desarrollo del trabajo de investigación asociado a esta tesis, fueron presentados en las siguientes revistas:

- "Estudio de la influencia de la enseñanza de redes LAN con simulación en el nivel universitario". REABTIC Vol 1, No 6 (2017). ISSN: 2446-7634 - Revista Eletrônica Argentina-Brasil de Tecnologias da Informação e da Comunicação. Enero de 2017. Daniel Arias Figueroa, Javier F. Díaz, María Cecilia Gramajo (UNSa-UNLP).

- "Enseñanza de redes IP con simulación en el nivel universitario: un estudio de la influencia". Informática na educação: teoria \& prática. e-ISSN: 1982-1654. Daniel Arias Figueroa, Javier F. Díaz, María Cecilia Gramajo (UNSa-UNLP). Aceptada para publicación en la Segunda Edición de 2017.

- "Estudio de la influencia de métodos de simulación en la enseñanza del tema Direccionamiento IP". TE\&ET - Revista Iberoamericana de Tecnología en Educación y Educación en Tecnología. ISSN: 1850-9959. Daniel Arias Figueroa, Javier F. Díaz, Loraine Gimson (UNSa-UNLP). En evaluación.

\section{Exposiciones en congresos y jornadas}

Los resultados obtenidos durante el desarrollo del trabajo de investigación asociado a esta tesis, fueron presentados en los siguientes congresos y jornadas con referato:

- $\quad$ Líneas de investigación en Redes de Computadoras en el Centro de Investigación y Desarrollo en Informática Aplicada". XIV Workshop de Investigadores en Ciencias de la Computación (WICC 2012). Ciudad de Posadas, Misiones - Abril de 2012. Daniel Arias Figueroa, Ernesto Sánchez, Sergio Rocabado Moreno, Alejandro Barrena, Miguel Ángel Aguirre (C.I.D.I.A).

- "Investigación en Tecnología Informática aplicada en Educación en el Centro de Investigación y Desarrollo en Informática Aplicada". XIV Workshop de Investigadores en Ciencias de la Computación (WICC 2012). Ciudad de Posadas, Misiones - Abril de 2012. Gustavo D. Gil, Daniel Arias Figueroa, Loraine Gimson, Ernesto Sánchez, Jorge Ramírez, Jorge Silvera, Sergio Rocabado (C.I.D.I.A).

- $\quad$ Transaction Signature (TSIG) Una alternativa de seguridad para transferencias de zonas DNS". XV Workshop de Investigadores en Ciencias de la Computación (WICC 2013). Paraná, Entre Ríos - Abril de 2013. Ernesto Sánchez, Daniel Arias Figueroa, Jorge A.Silvera (C.I.D.I.A).

- $\quad$ "La ingeniería de software y los objetos de aprendizaje como herramientas para las TICs aplicadas a la educación". XV Workshop de Investigadores en Ciencias de la Computación (WICC 2013). Paraná, Entre Ríos - Abril de 2013. Gustavo Gil, Daniel Arias Figueroa, Loraine Gimson Saravia, Ernesto Sánchez, Jorge A. Silvera, Sergio Rocabado (C.I.D.I.A). 
- "Implementación de Objetos de Aprendizaje con Realidad Aumentada en la Educación" XVI Workshop de Investigadores en Ciencias de la Computación (WICC 2014). 7 y 8 de mayo de 2014, Ushuaia, Tierra del Fuego. Gustavo Gil, Daniel Arias Figueroa, Loraine Gimson, Ernesto Sánchez, Jorge Silvera, Sergio Rocabado (C.I.D.I.A).

- "Estudio de la influencia del uso de simulación en la enseñanza de redes de computadoras" XVI Workshop de Investigadores en Ciencias de la Computación (WICC 2014). 7 y 8 de mayo de 2014, Ushuaia, Tierra del Fuego. Daniel Arias Figueroa, Javier Díaz, Cecilia Gramajo, Gustavo Gil, Ernesto Sánchez, Jorge Silvera, Miguel Aguirre, Juan Antonio Torres (C.I.D.I.A).

- "Experiencia en la formación de docentes para el dictado de cursos on-line". X Jornadas de Ciencia y Tecnología de Facultades de Ingeniería del NOA - Salta, 21 y 22 de mayo de 2015. Gustavo Gil, Daniel Arias Figueroa, Loraine Gimson (C.I.D.I.A)

- "Estudio de la influencia del uso de simulación en la enseñanza de redes de computadoras (resultados parciales)". XVII Workshop de Investigadores en Ciencias de la Computación (WICC 2015) 16 y 17 de abril de 2015, Corrientes. Daniel Arias Figueroa, Javier Díaz, Cecilia Gramajo, Gustavo Gil, Ernesto Sánchez, Álvaro Gamarra, Mariana Cabral, Jorge Silvera, Miguel Aguirre, Juan Antonio Torres, Diego Gil (C.I.D.I.A).

- "Uso de realidad aumentada como complemento a los prácticos tradicionales de enseñanza-aprendizaje". XVII Workshop de Investigadores en Ciencias de la Computación (WICC 2015) 16 y 17 de abril de 2015, Salta. Gustavo Gil, Daniel Arias Figueroa, Loraine Gimson, Ernesto Sánchez, Jorge Silvera (C.I.D.I.A).

- $\quad$ "Un estudio comparativo en extensiones de seguridad para el sistema de nombres de dominio. Resultados finales". XVII Workshop de Investigadores en Ciencias de la Computación (WICC 2015) 16 y 17 de abril de 2015, Salta. Ernesto Sánchez, Daniel Arias Figueroa, Sergio Rocabado, Verónica Aguero, Gustavo Molina (C.I.D.I.A).

- "Ruteo IP. De la teoría a la práctica. Simulación de redes IP con ruteo estático y dinámico con OSPF". X Jornadas de Ciencia y Tecnología de Facultades de Ingeniería del NOA. 21 y 22 de mayo de 2015. Salta. Álvaro Ignacio Gamarra - Daniel Arias Figueroa.

- "Simulación de Redes con Toggit". V Jornadas Estudiantiles de Divulgación de Actividades de Investigación de la Facultad de Ciencias Exactas. 27 y 28 de Agosto de 2015. Salta. Diego Gil, Daniel Arias Figueroa.

- "Simulación de ruteo IP con GNS3". V Jornadas Estudiantiles de Divulgación de Actividades de Investigación de la Facultad de Ciencias Exactas. 27 y 28 de Agosto de 2015. Salta. Álvaro Ignacio Gamarra - Daniel Arias Figueroa.

- "Estudio de la influencia del uso de simulación en la enseñanza de redes de computadoras (resultados parciales)". XVIII Workshop de Investigadores en Ciencias de la Computación (WICC 2016). 13 y 14 de abril de 2016, Concordia - Entre Ríos. Daniel Arias Figueroa, Javier Díaz, Cecilia Gramajo, Gustavo Gil, Ernesto Sánchez, 
Álvaro Gamarra, Loraine Gimson, Jorge Silvera, Diego Gil (C.I.D.I.A) Nelson Rodríguez, María Murazzo, Marcelo Moreno, Miguel Guevara (UNSJ).

- "Estudio de la influencia del uso de simulación en la enseñanza de redes de computadoras (resultados finales)". XIX Workshop de Investigadores en Ciencias de la Computación (WICC 2017). 27 y 28 de abril de 2017, Instituto Tecnológico de Buenos Aires. Daniel Arias Figueroa, Javier Díaz, Cecilia Gramajo, Gustavo Gil, Ernesto Sánchez, Álvaro Gamarra, Loraine Gimson, Jorge Silvera, Diego Gil (C.I.D.I.A) Nelson Rodríguez, María Murazzo, Marcelo Moreno, Miguel Guevara (UNSJ).

\section{Actividades de transferencia}

- CURSO "Simulador KivaNS en la enseñanza de redes IP" Organizado por el C.I.D.I.A. en el marco de la tesis doctoral UNLP

Daniel Arias Figueroa. Con una duración de 15 horas reloj. Diciembre de 2012. RESD-EXA: 801/2012. EXP-EXA: 8676/2012.

- CURSO DE POSTGRADO "TICs: Herramientas Libres para el Desarrollo de Actividades Didácticas"

C.I.D.I.A - Universidad Nacional de la Patagonia "San Juan Bosco".

MSc. Daniel Arias Figueroa - Esp. Jorge Ramírez Morales. Sede Comodoro Rivadavia - Resolución R/7 No 267-2012. Junio de 2012

- CURSO "Taller de Redes con Packet Tracer"

Organizado por el C.I.D.I.A. y la Cátedra Conectividad y Teleinformática

Con una duración de 12 horas reloj. Mayo de 2012. - RESD-EXA: 233/2012. EXPEXA: 8121/2012.

- CURSO "Taller de Redes con el Simulador Packet Tracer 5.3.3"

Organizado por el C.I.D.I.A. y la Cátedra Redes de Computadoras I

Con una duración de 20 horas reloj. Setiembre de 2013. - RESD-EXA: 458/2013. EXP-EXA: 8243/2013.

- $\quad$ CURSO "Taller de telefonía IP"

Organizado por el Proyecto de Investigación CIUNSa No 2123/0 "Extensiones de Seguridad para DNS" en conjunto con el CIDIA y la Cátedra de Ofimática IV de la Carrera Tecnicatura en Informática de Gestión de la Sede Orán de la UNSa

Con una duración de 40 horas reloj. Setiembre de 2013 - Res. $\mathrm{N}^{\circ} 454 / 13$. Expte $\mathrm{N}^{\circ}$ SO-19.404/13

- $\quad$ CURSO DE POSTGRADO "Extensiones de Seguridad para el Sistema de Nombres de Dominio"

Organizado por el Proyecto de Investigación CIUNSa No 2123/0 "Extensiones de Seguridad para DNS" en conjunto con el CIDIA. Facultad de Ciencias Exactas - UNSa Con una duración de 60 horas reloj. Noviembre de 2013 - Res. CD-EXA: 460/13. EXP-EXA: 8092/13. 
- CURSO TALLER: "NUEVAS TECNOLOGÍAS Y NUEVOS ENTORNOS DIDÁCTICOS: EXE-LEARNING UNA HERRAMIENTA SCORM"

Organizado por el I.I.E.Di. y la Dirección de Orientación y Desarrollo Universitario dependiente de Secretaría Académica. Con una duración de 24 horas reloj.

Directores: MSc. Daniel Arias Figueroa - Mgr. Gustavo Daniel Gil. Tutores: Esp. Ernesto Sánchez - Prof. Andrea Sayago. Septiembre de 2014. - RES.R-N: 1257-14. Expte. $\mathrm{N}^{\mathrm{o}} 24.726 / 14$.

- CURSO: "Ruteo IP. De la teoría a la práctica. Simulación de redes IP con ruteo estático y dinámico con RIP y OSPF"

Organizado por el C.I.D.I.A. y la Cátedra Redes de Computadoras I. Proyecto $\mathrm{N}^{\mathrm{o}}$ 2230/0 CIUNSa. Con una duración de 15 horas reloj.

Director: MSc. Daniel Arias Figueroa

\section{Tesis de postgrado dirigidas, relacionadas a esta investigación}

- Tema: Extensiones de seguridad para el Sistema de Nombre de Dominio (DNSSEC).

Especialidad en Redes y Seguridad - Universidad Nacional de La Plata

Ernesto Sánchez - Expte. 3300-5001/12-000. Aprobada en el año 2013.

- Tema: Caso de estudio de comunicaciones seguras sobre redes móviles ad-hoc Magister en Redes de Datos - Uiversidad Nacional de La Plata

Sergio H. Rocabado Moreno - Expte. 3300-001937/10-000. Aprobada en el año 2014.

- Tema: Herramientas de Software de Simulación para Redes de Comunicaciones. Especialidad en Redes y Seguridad - Universidad Nacional de La Plata Juan Antonio Torres - Expte. 3300-5305/12-000. Aprobada en el año 2015.

- Tema: Un estudio comparativo en extensiones de seguridad para el sistema de nombre de dominio (DNS).

Magister en Redes de Datos - Universidad Nacional de La Plata

Ernesto Sánchez - Expte. 3300-002113/10-000. Aprobada para defensa.

- Tema: Virtualización para la enseñanza de redes IP.

Especialidad en Redes y Seguridad - Universidad Nacional de La Plata

Miguel Ángel Aguirre - Expte. 3300-3489/11-000. En etapa de escritura del informe final.

- Tema: Cableado Estructurado, estándares y nuevos componentes.

Especialidad en Redes y Seguridad - Universidad Nacional de La Plata

Alejandro Ignacio Barrena - Expte. 3300-3768/11-000. En etapa de elaboración. 


\section{APENDICE II: ESTADÍSTICA DESCRIPTIVA}

\section{Exploración de datos}

La estadística descriptiva incluye las medidas de la posición o tendencia central de la distribución de frecuencias de los datos a estudiar, y las medidas de dispersión o variabilidad de la población o muestra, dos parámetros que permiten formar una idea somera del tipo de la distribución. El cálculo es necesario, por lo general, para poder pasar a realizar un tratamiento más complejo de los mismos.

El tipo de distribución que posean los datos definirá la clase de análisis estadístico que se pueden utilizar a posteriori. Algunos tratamientos estadísticos que se utilizan mucho, como por ejemplo el análisis de la varianza, se basan en la comparación de la media y dispersión de los datos, ambos incluidos dentro de la estadística descriptiva. Por lo tanto, antes de aplicar los métodos avanzados de análisis como, por ejemplo, el análisis discriminante y de componentes principales, se debe observar qué revelan los datos, con el fin de identificar las tendencias, localizar una anomalía o simplemente tener la información esencial disponible, como mínimo, máximo o promedio de una muestra de datos.

El "software" usado en este trabajo, el XLSTAT, ofrece un gran número de estadísticos descriptivos y gráficos que permiten tener una vista previa útil de los datos, detallados a continuación.

\section{Medidas de tendencia central}

\section{Media aritmética}

La media aritmética, que también se conoce como media o promedio, se calcula como:

$$
\begin{aligned}
& \bar{x}=\frac{\sum_{i=1}^{n} x_{i}}{n} \text { (para muestras) } y \\
& \mu=\frac{\sum_{i=1}^{N} x_{i}}{N} \text { (para poblaciones) }
\end{aligned}
$$

Ésta es la medida de uso más frecuente de la tendencia central de los datos, porque es la que tiene un error estándar más pequeño, es la más fácil de estimar, tiende hacia una Distribución Normal incluso si los datos originales no tienen esta distribución y, por último, es más sensible a cambios en la distribución de los datos, lo cual es muy importante en estadística para establecer diferencias entre series de datos. El problema que plantea la media aritmética deriva de su sensibilidad, ya que está más afectada por los datos fuera de rango o anómalos que otras medidas de la tendencia central.

\section{Mediana}

Es el valor que se encuentra en el medio de los datos cuando éstos se ordenan de acuerdo a su magnitud. Si el número de datos es par, se la calcula como la media aritmética de los dos datos del centro. Se la interpreta como un verdadero valor central y su característica más 
importante es su insensibilidad a los valores extremos de la muestra de datos, que a veces son atípicos o incluso erróneos. Su símbolo es $\mathrm{M}_{\mathrm{e}}$.

\section{Modo o moda}

Es el valor de variable que tiene la mayor frecuencia y se lo simboliza con $\mathrm{M}_{\mathrm{o}}$. Si todos los datos se presentan una sola vez, se dice que no existe el modo.

En el caso detener una distribución de frecuencias moderadamente asimétrica es útil disponer de una relación entre las distancias que presentan dos de las medidas de tendencia central definidas anteriormente. El científico británico Karl Pearson en el siglo XIX, a partir de observaciones de datos experimentales, logró formular una relación empírica que se considera muy útil para medir el grado de asimetría de una distribución. Esta relación establece que la distancia entre la media y la mediana es aproximadamente la tercera parte de la distancia entre la media y el modo. Esta relación puede verse gráficamente en la Figura A1-1.

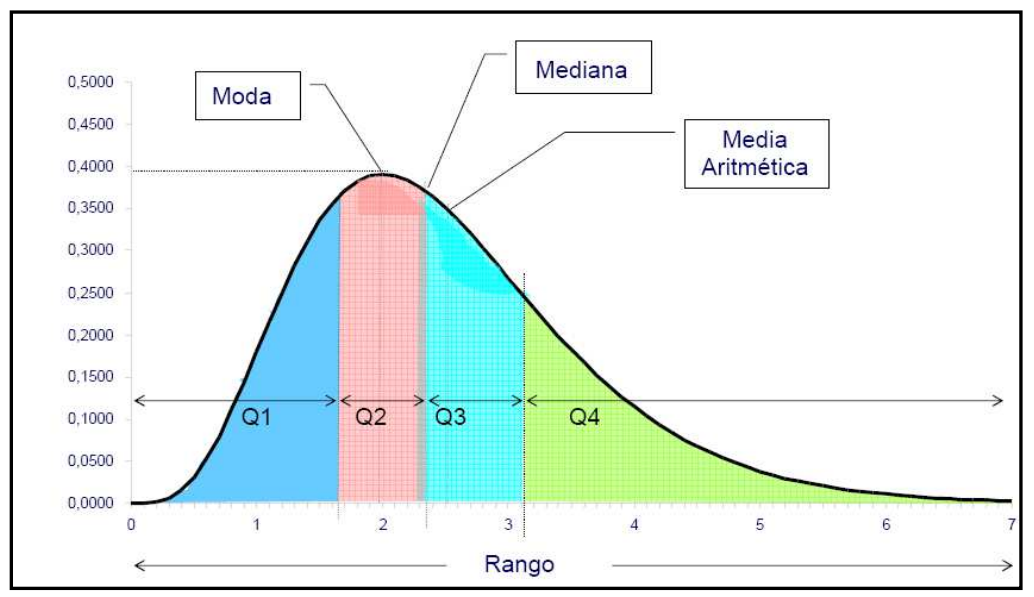

FiguraA1-1: Relación de Pearson entre medidas de tendencia central

\section{Otras medidas de posición}

Se definen los cuantiles de orden $\boldsymbol{k}$ como los valores de la variable, una vez ordenados de menor a mayor, que la dividen en $\boldsymbol{k}$ partes con la misma frecuencia de observaciones. Por lo tanto existirán $\boldsymbol{k}-\boldsymbol{1}$ cuantiles de orden $\boldsymbol{k}$.

El primer cuantil de orden $\boldsymbol{k}$ deja a su izquierda la fracción $1 / \boldsymbol{k}$ de frecuencia de observaciones. El segundo cuantil de orden $\boldsymbol{k}$ deja a su izquierda la fracción $2 / \boldsymbol{k}$ de frecuencia de observaciones. El $\boldsymbol{r}$-ésimo cuantil de orden $\boldsymbol{k}$ de a su izquierda la fracción $\boldsymbol{r} / \boldsymbol{k}$ de frecuencia de observaciones. Por ejemplo el cuantil 15 de orden 100 deja por debajo el $15 \%$ de los valores del total de la serie completa de valores.

Los cuantiles más utilizados son los percentiles, cuartiles y deciles. Los percentiles son los 99 puntos que dividen la distribución en 100 partes, tales que en cada una esté incluido el $1 \%$ de los valores de la distribución. Los cuartiles son los tres valores de la variable que dividen a la distribución en cuatro partes iguales, es decir, en 4 intervalos, de modo que dentro de cada uno está incluido el $25 \%$ de los valores de la distribución. El percentil 25 $\left(\boldsymbol{P}_{25}\right)$ es igual al cuartil $1\left(\boldsymbol{Q}_{1}\right)$ y el percentil $50\left(\boldsymbol{P}_{50}\right)$ es igual al cuartil $2\left(\boldsymbol{Q}_{2}\right.$ es igual a la mediana), etc. 


\section{Medidas de dispersión}

Además de la posición, es importante la dispersión o variabilidad de los datos. Las medidas de dispersión tienen como finalidad estudiar hasta qué punto, para una determinada distribución de datos, las medidas de posición representan bien el conjunto de datos de la distribución. Por ejemplo la media aritmética serátanto más representativa de los datos cuanto más agrupados estén éstos en torno a ella. Por lo tanto, para completar la información que se obtiene a partir de la media es necesario un tipo de parámetro que mida la dispersión o variabilidad de los datos.

\section{Rango}

También conocido como amplitud, es la diferencia entre el valor máximo y el mínimo de las serie de datos.

\section{Varianza}

La mejor forma de medir la dispersión de una población de $\mathrm{N}$ datos es comparar cada uno de ellos con la media poblacional $\mu$, cuando ésta es representativa. Esto se ve en el cálculo de la varianza:

$$
\sigma^{2}=\frac{\sum_{1}^{\mathrm{N}}\left(\mathrm{x}_{\mathrm{i}}-\mu\right)^{2}}{\mathrm{~N}}
$$

A menudo no se dispone de la totalidad de los datos de la población, sino solamente de una parte de tamaño n, llamada muestra. En estos casos se usa como estimador de la varianza de la población lo que se denomina varianza de la muestra $\left(s^{2}\right)$, que se calcula como la anterior, pero cambiando el denominador por $\boldsymbol{n}$. Para garantizar que en promedio los valores que tome en diferentes muestras de la misma población, sea un estimador confiable de $\boldsymbol{\sigma}^{2}$, el denominador se reemplaza por $\boldsymbol{n}-\boldsymbol{1}$ y el nombre se cambia a cuasivarianza, siendo éste un estimador insesgado:

$$
\mathrm{s}^{2}=\frac{\sum_{\mathrm{i}=1}^{\mathrm{n}}\left(\mathrm{x}_{\mathrm{i}}-\overline{\mathrm{x}}\right)^{2}}{\mathrm{n}-1} 6.3
$$

La mayoría de los programas de estadística utilizan solo la cuasivarianza y no la varianza. Hasta es frecuente que $\sigma^{2}$ (varianza de la población) y $\boldsymbol{s}^{2}$ (varianza de una muestra) se usen indistintamente para indicar varianza o cuasivarianza, sin un criterio definido.

\section{Desviación Típica y Cuasidesviación Típica}

Para tener la medida de dispersión en las mismas unidades que la media, se usan la desviación típica y la cuasidesviación típica $(\sigma$ y $s)$ que se calculan simplemente como la raíz cuadrada de la varianza y de la cuasivarianza, respectivamente:

$$
\sigma=\sqrt{\frac{\sum_{1}^{N}\left(x_{i}-\mu\right)^{2}}{N}}
$$




$$
s=\sqrt{\frac{\sum_{i=1}^{n}\left(x_{i}-\bar{x}\right)^{2}}{n-1}}
$$

Otro nombre que se usa frecuentemente para estos estimadores es desviación estándar. Es necesario mencionar que la mayoría de los programas estadísticos sólo utilizan la cuasidesviación típica y, al igual que ocurre con la varianza, es frecuente observar que se hace mención a la desviación típica cuando en realidad se ha calculado la cuasidesviación típica. También es frecuente el uso indistinto de $\sigma$ y $s$ para desviación o cuasidesviación típica, sin especificar un criterio.

\section{Coeficiente de variación}

Cuando se comparan series de datos que tienen medias muy diferentes, o cuando las series fueron medidas en distintas escalas, la desviación típica no permite comparar en forma correcta cuál de las dos series de datos presenta una mayor variación, ya que normalmente la serie de datos con una mayor media también suele tener una mayor variabilidad. En este caso se usa el coeficiente de variación $(\boldsymbol{C V})$, que se calcula como el porcentaje que representa la desviación típica o cuasidesviación típica con respecto a la media:

$$
C V=\frac{s * 100}{\bar{x}}
$$

\section{Error estándar}

Proporciona una medida de la precisión de la estimación de la media poblacional a partir de la media de una muestra. El error estándar se calcula a partir de la desviación típica (o cuasidesviación típica) teniendo en cuenta el tamaño de la muestra tomada:

$$
E S=\frac{S}{\sqrt{n}}
$$

\section{Recorrido intercuartílico}

El recorrido intercuartílico $(\boldsymbol{D} \boldsymbol{Q})$ se calcula a partir de los percentiles $75\left(\boldsymbol{P}_{75}\right)$ y $25\left(\boldsymbol{P}_{25}\right)$ de la siguiente forma:

$$
D Q=P_{75}-P_{25}
$$

Esta medida de dispersión se utiliza cuando la medida de posición central es la mediana.

\section{Distribución de frecuencias de datos}

Otra información importante es la relacionada con el tipo de distribución de frecuencias que tiene una variable. Se puede dar el caso de que dos variables tengan exactamente la misma media y la misma dispersión, pero que presenten tipos de distribución completamente 
diferentes. Por lo tanto, además de la información sobre las medidas de posición y dispersión, es necesario también conocer el tipo de la distribución de frecuencias de los valores de la variable.

Para estudiar la distribución de frecuencias de una variable, e incluso para la comparación de medias y varianzas, se deben comparar las frecuencias de los valores de la variable con las probabilidades resultantes de modelos teóricos de distribuciones. El modelo teórico de distribución a utilizar varía en función del tipo de variable con la que se trabaja.

Las variables cualitativas pueden ser de dos tipos: nominales, si sus valores no están ordenados de modo natural, y ordinales, si sus valores tienen un orden.

Las variables cuantitativas también pueden ser de dos tipos: discretas y continuas. Una variable es discreta cuando está asociada a un proceso de conteo, es decir, cuando toma valores que pueden ponerse en correspondencia biyectiva con los números naturales, y no es posible ningún valor entre dos consecutivos. Para este tipo de variables, a cada valor de ellas le corresponde una probabilidad dada por el cociente entre el número de veces que se repite ese valor y el número total de valores, siempre y cuando haya uniformidad en los mismos.

Las variables cuantitativas continuas son aquellas que pueden tomar cualquier valor a lo largo de un continuo, de modo que no hay dos valores consecutivos aislados, ya que entre dos valores dados siempre existen infinitos valores posibles. Las variables continuas se pueden agrupar en categorías, pero de una forma arbitraria. A diferencia de lo que ocurre con las variables discretas, para las variables continuas no es útil establecer la correspondencia entre valores y probabilidades. Lo que se hace es calcular la probabilidad contenida en un determinado segmento o rango de valores, que, dividida por la amplitud del segmento da la densidad media de probabilidad del segmento, a partir de la cual se determina la densidad de probabilidad para cada valor. La correspondencia entre los valores y su respectiva densidad de probabilidad se llama función de densidad.

\section{Distribuciones de frecuencia de datos para variables continuas}

\section{La distribución de frecuencias Normal(o de Gauss)}

La distribución de frecuencias Normal o Gaussiana es una de las distribuciones más importantes. Por un lado la mayoría de las series de datos se ajustan a este tipo de distribución, y por otro la legitimidad de la aplicación de numerosos tipos de análisis estadísticos está sujeta a la condición de la normalidad de la distribución de frecuencias de los datos. La función de densidad de la Distribución Normal se describe por medio de la siguiente ecuación:

$$
f(x, \mu, \sigma)=\frac{1}{\sqrt{2 \pi \sigma^{2}}} e^{-\frac{(x-\mu)^{2}}{2 \sigma^{2}}}
$$

donde $\boldsymbol{f}(\boldsymbol{x}, \boldsymbol{\mu}, \boldsymbol{\sigma})$ es la densidad de probabilidad del valor $\boldsymbol{x}$, siendo $\boldsymbol{\mu}$ la media y $\boldsymbol{\sigma}$ la desviación típica de la serie de datos. La forma general de la Distribución Normal es la de una campana (campana de Gauss), pero varía en función de la media $(\boldsymbol{\mu})$ y la desviación típica $(\sigma)$, de modo que un cambio en la media, dejando fija la desviación típica, implica una traslación a derecha o izquierda de la distribución sobre el eje de valores de la variable 
estudiada; y cuando se modifica la desviación típica, dejando la media fija, se produce un cambio en el máximo de la distribución sobre el eje de frecuencias.

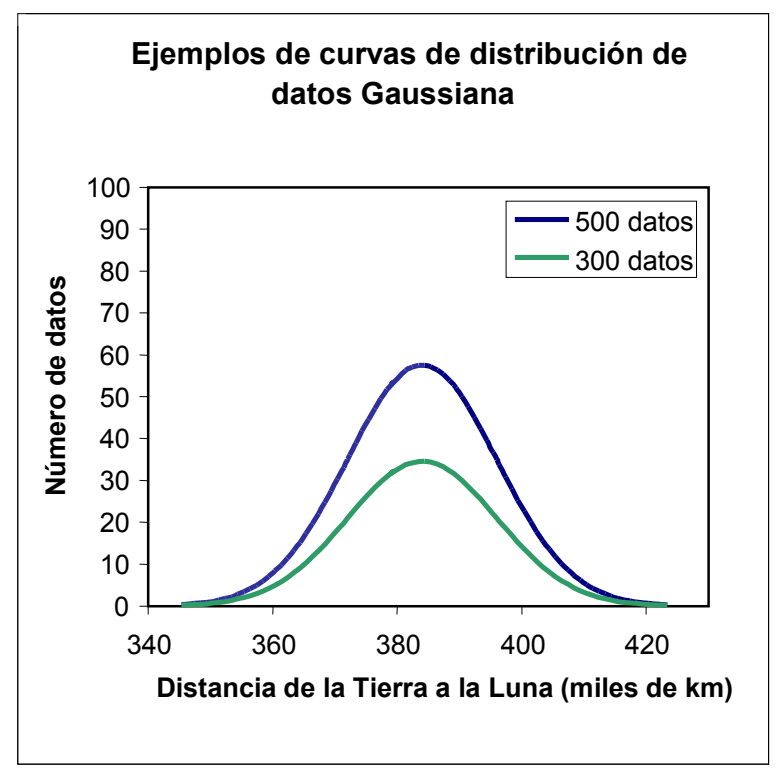

Figura A1-2: Campana de Gauss

La distribución de densidad de probabilidad Normal

Una de las propiedades más importantes de la Distribución Normal es que, si se extraen aleatoriamente muestras de $\boldsymbol{n}$ datos de una población que sigue este tipo de distribución, las medias de estas muestras también seguirán una distribución normal, cuya media es igual a la de la población, $\boldsymbol{\mu}$, con desviación típica $\sigma_{\bar{x}}$, menor que la de la población, $\sigma$, dada por:

$$
\sigma_{\bar{x}}=\frac{\sigma}{\sqrt{n}}
$$

Pero aun cuando la población no tenga distribución normal, la distribución de las medias de las muestras extraídas al azar de ella tenderá a la normalidad al aumentar el tamaño de las muestras (en general se acepta que deben ser de más de 30 datos).

Éste es el resultado del Teorema de Límite Central, una herramienta fundamental que sostiene, de manera confiable, muchos de los procedimientos estadísticos que se aplican en la Teoría de Estadística Inferencial, algunos de ellos usados a lo largo del desarrollo de esta Tesis.

Para efectuar cálculos de probabilidades usando la distribución de frecuencias de Gauss es conveniente obtener una curva general, que no dependa del número total de datos, ni de la magnitud de los mismos, ni de su dispersión: la curva de Gauss normalizada. Para ello el número de datos se transforma en frecuencia, dividiendo el número de datos de igual valor por el número total de éstos, con lo cual el área total de la curva, que representa la totalidad de los datos, se reduce a 1. En el eje de abscisas, para independizarse de la magnitud de los datos y de sus unidades ( $\mathrm{km}, \mathrm{g}$, etc.), así como de la media aritmética y de la dispersión particulares de un conjunto de datos, se representa la diferencia entre el valor de los datos y 
la media aritmética de los mismos, dividido por la desviación estándar, obteniéndose de esta manera la variable estandarizada adimensional llamada $\mathbf{z}$ :

$$
z_{i}=\frac{x_{i}-\mu}{\sigma}
$$

La variable $\boldsymbol{z}$ tiene distribución normal con media $\boldsymbol{0}$ y desviación estándar 1 .

\section{Aplicaciones de la Distribución Normal}

Mediante la expresión de la densidad de la distribución de Gauss se puede calcular la probabilidad correspondiente a cualquier valor de $\boldsymbol{x}$ de una población normal de datos conociendo su media y su desviación típica. Los valores de $\boldsymbol{x}$ se transforman en unidades de variable estandarizada mediante el cálculo definido anteriormente y luego se consulta la tabla de densidades de probabilidad universal (la tabla de $\boldsymbol{z}$ ) en función de la variable $\boldsymbol{z}$.

\section{Simetría de la Distribución Normal}

La distribución de frecuencias normal es simétrica, de modo que uno de los aspectos importantes del estudio de la normalidad de una distribución de frecuencias es su grado de asimetría. Las medidas de asimetría tienen como finalidad determinar si una variable se distribuye de la misma manera a ambos lados del valor central, o bien la distribución de los datos tiene una forma diferente del lado derecho que del lado izquierdo. La distribución tiene asimetría positiva si las frecuencias más altas se encuentran en el lado izquierdo de la media (gran número de datos menores a la media) y es negativa cuando las frecuencias más pequeñas están del lado izquierdo (muchos datos mayores a la media).

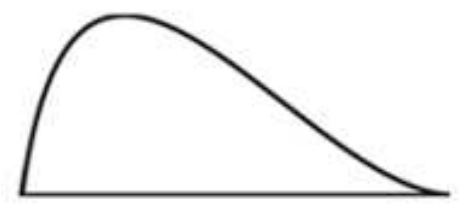

Asimetría Positiva

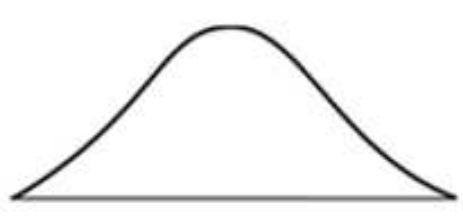

Distribución Simétrica

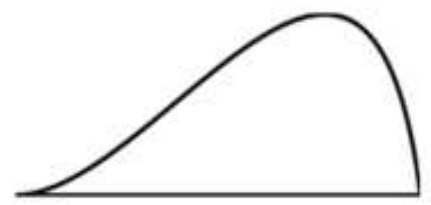

Asimetría Negativa

Figura A1-3: Diferentes tipos de asimetría

Frecuencia en función de la magnitud de la variable observada

Existen diversas formas de medir la asimetría, como por ejemplo mediante el coeficiente de asimetría de Pearson, el de Fishery el de Bowley; este último se describe a continuación.

\section{Coeficiente de asimetría de Bowley}

En una distribución de asimetría positiva el valor de la mediana es menor que el de la media, y en una de asimetría negativa la media tiene menor valor que la mediana. Sólo en una distribución simétrica coinciden las dos medidas de tendencia central. Por ello un coeficiente recomendado cuando en el lote de datos existen valores extremos, es el de Bowley definido por:

$$
A_{\beta}=\frac{\left(Q_{3}-M e\right)-\left(M e-Q_{1}\right)}{Q_{3}-Q_{1}}
$$


Este coeficiente no tiene en cuenta todos los datos, sino sólo el $50 \%$ central, por lo que resulta especialmente adecuado para el estudio de los datos de contaminación del aire, como se verá en su descripción estadística. Tiene la ventaja que es un valor acotado entre -1 y 1. El denominador es el desvío intercuartil definido antes como DQ. En una distribución simétrica el tercer cuartil estará a la misma distancia de la mediana que el primer cuartil por lo que $A_{\beta}=0$. Si la distribución es de asimetría positiva o con cola por derecha $A_{\beta}>0$, y si la distribución es negativa o de cola por izquierda $A_{\beta}<0$. Los tipos de asimetría que se presentan más frecuentemente se muestran en la Figura 6.3.

\section{Curtosis o apuntamiento}

La medida de curtosis (o de apuntamiento) estudia la distribución de los datos en la zona central de la serie. La mayor o menor concentración de frecuencias en la zona central de la distribución da lugar a una distribución más o menos apuntada. Las medidas de curtosis se aplican a distribuciones cercanas a la normalidad, es decir, unimodales, simétricas o con ligera asimetría. En general cuando el valor del coeficiente de curtosis es positivo se dice que la distribución está más apuntada que la Normal y se la denomina leptocúrtica. Cuando el valor es cero o cercano a cero la distribución tiene el mismo apuntamiento que la Distribución Normal y se la denomina mesocúrtica. Por último, cuando el valor es negativo, el apuntamiento es menor que el de la Distribución Normaly se la denomina platicúrtica.

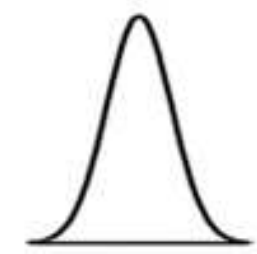

Leptocúrtica

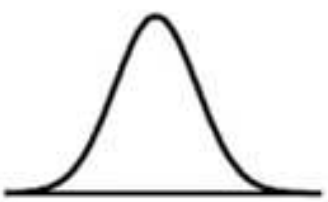

Mesocúrtica

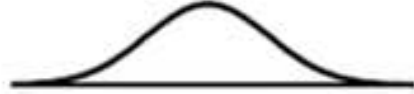

Platicúrtica

Figura A1-4: Tipos de curtosis de la distribución normal Frecuencia en función de la magnitud de la variable observada

Al igual que lo que ocurría con la asimetría existen diversas formas de estimar la curtosis de una distribución de datos, como la Curtosis de Pearson, de Fosher y el coeficiente $\boldsymbol{k}$. Este último se define empleando los percentiles 10, 25, 75 y 90:

$$
\kappa=\frac{1}{2} \frac{Q_{3}-Q_{1}}{\left(P_{90}-P_{10}\right)} \rightarrow\left\{\begin{array}{c}
\approx 0,5 \text { distribucuón leptocúrtica } \\
\approx 0,25 \text { distribución mesocúrtica } \\
\rightarrow \infty \text { distribución platicúrtica }
\end{array}\right.
$$

Esta medida es muy usada en casos en que las pruebas usuales de normalidad, como las que se usan en la estadística descriptiva de los contaminantes del aire, arrojan una probabilidad muy alta de cometer un error de tipo I (rechazar la hipótesis nula que plantea distribución normal, cuando ésta es realmente verdadera). En esos casos conviene complementar el estudio mediante la observación, por ejemplo, del Box Plot, el que debe ser simétrico, con colas casi del mismo largo y mediana casi igual a la media, sin datos extremos. 


\section{Cálculo de intervalos de confianza de la media}

El estadístico calculado a partir de una muestra es una estimación del parámetro de la población correspondiente, con un cierto margen de error:

$$
\text { Parámetro }=\text { Estadístico } \pm \text { error }
$$

Para el caso de la media aritmética:

$$
\mu=\bar{x} \mp \text { error }=\bar{x} \mp z \sigma_{\bar{x}}=\bar{x} \mp z \frac{\sigma}{\sqrt{n}}
$$

De aquí se puede expresar un intervalo de confianza para el valor de la media de la población usando la desviación típica muestral de las medias y el valor de la tabla de densidad de probabilidades de $\boldsymbol{z}$ al nivel de significación deseado.

\section{La distribución de frecuencias de Student}

Cuando el número de datos de las muestras es menor de 30, la estimación de la desviación típica poblacional a través de la desviación típica muestral es poco precisa. En estos casos el intervalo de confianza exacto para poblaciones normales con desviación típica desconocida se puede calcular usando la Distribución t de Student, elaborado por William Gosset, una distribución de probabilidad similar a la normal, que usa la variable $\boldsymbol{t}$ definida como:

$$
t=\frac{\mu-\bar{x}}{\frac{s}{\sqrt{n}}}
$$

Como en este caso el denominador no es un parámetro, sino un estadístico, la distribución de probabilidades de $\boldsymbol{t}$ depende del número de datos de la muestra, o más correctamente, del número de grados de libertad $\boldsymbol{v}$ definido como el número de datos de la muestra menos uno (debido a que se perdió un grado de libertad al calcular la media aritmética). La Distribución de $\boldsymbol{t}$ se aproxima a la Distribución Normal a medida que el número de datos tiende a infinito, como se ve en la Figura A1-5. 


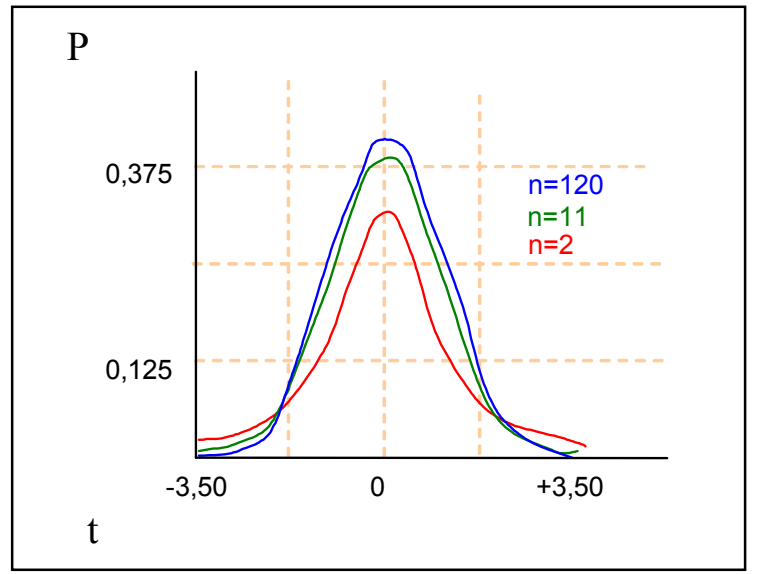

Figura A1-5: Curvas de distribución de densidad de probabilidades de $t$

La distribución de $\boldsymbol{t}$ de Student sirve para estadísticos de distribución aproximadamente normal, o sea cuando se cumple alguna de las siguientes condiciones:

- La población es de distribución normal

- La distribución muestral es simétrica, unimodal, sin datos aberrantes, con muestras de $n \leq 15$

- La distribución muestral es moderadamente asimétrica, unimodal, sin aberrantes y el tamaño de la muestra es tal que $16<\mathrm{n}<40$

- La distribución muestral no tiene datos aberrantes y $n>40$

No se debe usar la distribución de $\boldsymbol{t}$ de Student para muestras pequeñas que no pueden considerarse aproximadamente normales. A pesar de que la hipótesis para el uso de la distribución de $\boldsymbol{t}$ de Student es que la población de la cual proviene la muestra tiene Distribución Normal, simulaciones con computadora demostraron que si las desviaciones de la normalidad de la población no son grandes, los cálculos en base a valores de $\boldsymbol{t}$ resultan confiables.

Estimación de intervalos de confianza para la media poblacional.

Se usa la ecuación:

$$
\mu=\bar{x} \mp t_{c} s_{\bar{x}}=\bar{x} \mp t_{c} \frac{s}{\sqrt{n}}
$$

Donde $\boldsymbol{t}_{\boldsymbol{c}}$ es el valor crítico de $\boldsymbol{t}$ que figura en tablas, seleccionado para abarcar la probabilidad deseada, dado el número de grados de libertad de la muestra.

\section{Prueba de hipótesis sobre una diferencia de medias}

Cuando se desea decidir, con un cierto nivel de confiabilidad, si las medias de dos o más poblaciones son significativamente iguales o no, a partir de la información proporcionada por las muestras respectivas, se calculan los límites de confianza de ambas medias y se estudia el grado de solapamiento. 
La hipótesis o asunción para poder aplicar la distribución de $\boldsymbol{t}$ de Student es que en cada grupo la variable estudiada siga una distribución Normal, pudiendo haber o no, homogeneidad de las varianzas. En caso de ausencia de homogeneidad, se suele emplear la solución de Welch.

\section{La distribución de frecuencias de Chi cuadrado $\left(\chi^{2}\right)$ con $v$ grados de libertad}

La distribución de frecuencias (o densidad de probabilidad) de los valores de la desviación típica de muestras pertenecientes a un misma población sigue la distribución de frecuencias de $\chi^{2}$. Esta función de densidad cumple con la propiedad estadística de aproximarse a la distribución normal cuando los grados de libertad son suficientemente grandes. Tal como ocurre con la Distribución de $\boldsymbol{t}$ de Student, la forma de la distribución de $\chi^{2}$ depende de los grados de libertad.

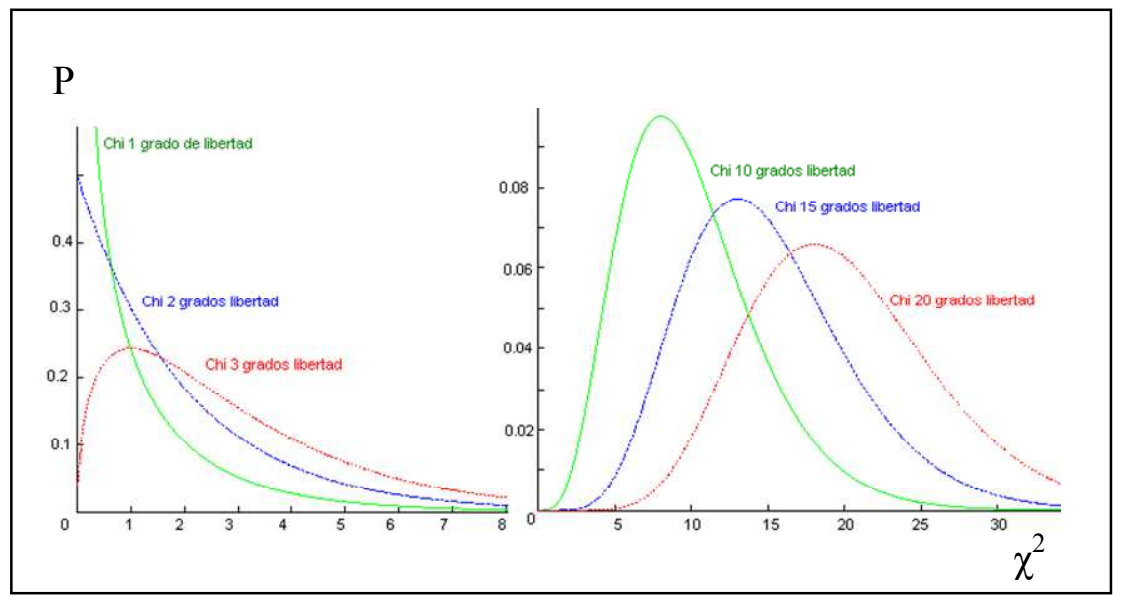

Figura A1-6: Curvas de densidad de probabilidad de $\chi^{2}$

El valor de la variable que deja a su derecha un área $\alpha$ bajo la curva de densidad se llama el punto crítico correspondiente al nivel de significación $\alpha$ y se representa por $\chi^{2}$. Están tabulados los puntos críticos de distintos niveles de significación y distintos grados de libertad.

\section{Aplicaciones principales de la distribución de $\chi^{2}$}

\section{Prueba de bondad de ajuste}

La prueba de la bondad de ajuste consiste en el planteamiento de hasta qué punto una muestra se puede considerar como perteneciente a una población con una distribución teórica ya conocida. Se utiliza frecuentemente para determinar si una serie de datos presenta una distribución Normal, de Poisson, etc.

\section{Prueba de independencia}

La prueba de independencia determina si dos características $\boldsymbol{X}$ e $\boldsymbol{Y}$ de una población son dependientes o independientes. 


\section{Prueba de homogeneidad}

La prueba de homogeneidad permite determinar si varias muestras que estudian el mismo carácter $\boldsymbol{A}$ han sido tomadas de la misma población o no, respecto de la característica $\boldsymbol{A}$.

Los contrastes no paramétricos son análogos al contraste paramétrico de $\boldsymbol{t}$ de Student y tratan de determinar si las diferencias observadas entre dos muestras se deben al azar o si en realidad éstas pertenecen a dos poblaciones distintas. En todas estas pruebas los datos pertenecientes a los sitios de monitoreo se ordenan de forma ascendente sin tener que recurrir a consideraciones previas y se observa si existen datos que se solapan, para elegir luego el método a aplicar.

\section{La distribución de frecuencias de $\boldsymbol{F}$ (de Fisher-Snedecor)}

Dadas dos muestras de desviación típica $\boldsymbol{s}_{1}$ y $\boldsymbol{s}_{2}$, extraídas de dos poblaciones de desviaciones típicas $\sigma_{1}$ y $\sigma_{2}$,el estadístico $\boldsymbol{f}$ se define con el cociente:

$$
f=\frac{s_{1} / \sigma_{1}}{s_{2} / \sigma_{2}}
$$

Al depender de dos tipos de grados de libertad, la función de densidad puede tener muy diversas formas, como se puede observar en la Figura A1-7.

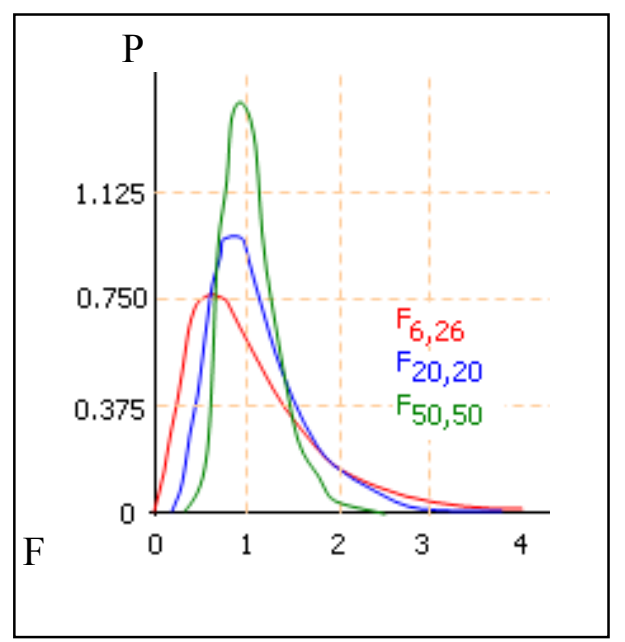

Figura A1-7: Distribución de densidad de probabilidad de $F$

\section{Prueba de Kruskall-Wallis}

Cuando entre los datos no hay solapamiento, se puede usar el método de contraste para $\mathbf{k}$ muestras independientes de Kruskal - Wallis. Este contraste no paramétrico es análogo al análisis de varianza, por lo que se denomina ANOVA, pero el estadístico de contraste calculado tiene una distribución similar a $\chi^{2}$. Es la prueba más utilizada para la comparación de más de dos muestras independientes.

Si $\mathbf{M}_{\mathbf{i}}$ es el parámetro de posición para la muestra i, la hipótesis nula $\mathbf{H}_{\mathbf{0}}$ y alternativa $\mathbf{H}_{\mathbf{a}}$ para la prueba de Kruskal-Wallis son los siguientes: 
$\mathrm{H}_{0}: \mathrm{M}_{1}=\mathrm{M}_{2}=\ldots=\mathrm{M}_{\mathrm{k}}$

$H_{a}$ : Hay por lo menos un par $(i, j)$ de manera que $M_{i} \neq M_{j}$

El estadístico $\mathbf{k}$ de la prueba de Kruskal-Wallis se define como:

$$
k=\frac{12}{N(N+1)} \sum_{i=1}^{k} R_{i}^{2} / n_{i}-3(N+1)
$$

donde $\mathbf{n}_{\mathbf{i}}$ es el tamaño de la muestra $\mathbf{i}, \mathbf{N}$ es el número total de datos, o sea la suma de los $\mathbf{n}_{\mathbf{i}}$, y $\mathbf{R}_{\mathbf{i}}$ es la suma de todos los $\boldsymbol{k}$ rangos correspondientes a cada uno de los datos de la muestra i. Para obtener el valor de $\mathrm{R}$ para cada una de las muestras la totalidad de los $\mathrm{N}$ datos se ordenan de menor a mayor, manteniendo para cada dato su procedencia, con lo cual se le asigna un número de orden a cada dato. Estos números de orden se suman para cada una de las muestras. Una vez reemplazados $\operatorname{los} \mathrm{R}_{\mathrm{i} 2}$ en la ecuación de $\mathrm{K}$, con el valor de éste se obtiene el valor de $\mathrm{p}$ asociado mediante la tabla de Kruskall-Wallis de acuerdo con el tamaño de las k muestras, o bien se usa la tabla de Chi-cuadrado con $\boldsymbol{k}$ - $\boldsymbol{1}$ grados de libertad para obtener el valor de $\boldsymbol{p}$ asociado.

Para identificar las muestras que son responsables del rechazo de la $\boldsymbol{H}_{\boldsymbol{0}}$ se puede utilizar un procedimiento de comparación múltiple (Dunn, 1963), que se basa sobre la distribución de $z$ definida de la siguiente manera:

$$
\left|\bar{R}_{l}\right|-\bar{R}_{\jmath} \geq Z \alpha / k(k-1) \sqrt{\left(\frac{1}{r_{i}}+\frac{1}{r_{j}}\right)} \frac{n(n+1)}{12}
$$

Para tener en cuenta el hecho de que hay $\boldsymbol{k}(\boldsymbol{k}-\mathbf{1}) / \mathbf{2}$ comparaciones posibles, se aplica la corrección del nivel de significación propuesto por Bonferroni, que se explica a continuación.

Cuando se efectúa más de un contraste estadístico en el análisis de los datos, el criterio aplicado por la mayoría de los investigadores es el de "ajustar" o "corregir" el nivel de corte (inicialmente $\boldsymbol{p}<\mathbf{0 , 0 5}$ ) dependiendo del número de contrastes efectuado. El razonamiento es el siguiente: si la hipótesis nula (igualdad de las muestras) es en realidad correcta y para rechazarla se usa un nivel de significación $\boldsymbol{\alpha}=\mathbf{0 , 0 5}$ se está declarando que existe una probabilidad de $\mathbf{0 , 9 5}$ de aceptarla siendo cierta. Si se efectúan dos pruebas diferentes e independientes para contrastar la hipótesis nula, hay cuatro posibles resultados: ninguna de las dos es estadísticamente significativa (en ambas se obtiene $\boldsymbol{p}>\mathbf{0 , 0 5}$ ), las dos son significativas (ambas con $\boldsymbol{p}<\mathbf{0 , 0 5}$ ) y una de ellas es significativa y la otra no. La probabilidad de que ninguna de las dos sea significativa, al considerar sucesos independientes, es $0,95 \times 0,95 \approx 0,90$. Luego la probabilidad de que al menos una de ellas sea significativa (suceso complementario) es $1-0,9=0,1$. Por lo tanto la probabilidad global de que se rechace una hipótesis nula, siendo ésta verdadera, es 0,1 y no 0,05 como se deseaba. Por lo tanto se debe usar: 


$$
\alpha^{\prime}=\frac{2 \alpha}{k(k+1)}
$$

\section{Prueba de Mann-Whitney}

Cuando entre los datos se encuentran valores repetidos, la prueba de Kruskal-Wallis se reemplaza por la prueba de Mann-Whitney, que contrasta las muestras de a pares. Ésta es una prueba que compara la tendencia central de dos muestras (que no necesariamente tienen el mismo tamaño) partiendo de la hipótesis nula de que en ambas muestras la medida central es la misma. Es un contraste muy utilizado, aunque no es muy satisfactorio para la evaluación de otras características como, por ejemplo, asimetría o dispersión de los datos.

La prueba de $\boldsymbol{U}$ de Mann-Whitney postula como hipótesis nula de contraste que las dos muestras, de tamaño $\boldsymbol{n} \mathbf{1}$ y $\boldsymbol{n} \mathbf{2}$, respectivamente, proceden de poblaciones continuas idénticas:

$$
H_{0}: f_{1}(x)=f_{2}(x)
$$

La hipótesis alternativa propuesta es bilateral y únicamente supone que la tendencia central de una población difiere de la otra, pero no si en cuanto a diferencias de forma o de dispersión. Por esta razón esta prueba es el equivalente no paramétrico de la prueba de $t$ para la diferencia de dos medias cuando las muestras son independientes, solo que en este caso no es necesario suponer la normalidad de las poblaciones de origen.

Para realizar el contraste se ordenan conjuntamente las observaciones de las dos muestras, de menor a mayor, y se les asignan números de orden (rangos) de 1 a $\boldsymbol{n}_{1}+\boldsymbol{n}_{2}$, de la misma manera que para la prueba de Kruskall-Wallis. Para aquellos datos que tienen números de orden repetidos, se les asigna el mismo rango, calculado como el promedio de los rangos que les corresponderían. El estadístico de prueba $\boldsymbol{U}$ de Mann-Whitney se construye a partir de la suma de rangos para cada una de las muestras, $\boldsymbol{R}_{\boldsymbol{i}}$, definida de la misma manera que en la prueba de Kruskall-Wallis.

El estadístico de prueba para el contraste es el valor:

$$
\begin{gathered}
U_{1}=n_{1} n_{2}+\frac{n_{1}\left(n_{1}+1\right)}{2}-\sum R_{1} \\
U_{2}=n_{1} n_{2}+\frac{n_{2}\left(n_{2}+1\right)}{2}-\sum R_{2}
\end{gathered}
$$

Para muestras que tienen más de 20 datos la distribución de $U$ se aproxima a la del estadístico $z$, y con su valor se determina la probabilidad ( $p$-valor) que se compara con el nivel de significación elegido. Si el $p$-valor es menor que la $\alpha$ elegida, se rechaza la $H_{0}$, que postula la equivalencia de las dos muestras. 


\section{Métodos para determinar el tipo de distribución}

Es común en los estudios estadísticos suponer que los datos de una muestra se distribuyen normalmente. Sin embargo, a menudo se descuida la comprobación de que esto es realmente cierto. Por ejemplo, rara vez se comprueba la normalidad de los residuos obtenidos en una regresión lineal, a pesar de que regula la calidad de los intervalos de confianza alrededor de los parámetros y de las predicciones.

Para seleccionar las herramientas estadísticas correctas a utilizar fue necesario el estudio previo de la normalidad de la distribución de todos los datos bajo estudio en esta Tesis. También la normalidad de los residuos de los modelos matemáticos hallados se tuvo en cuenta para evaluar su validez.

Para determinar si las variables se ajustan a alguna de las distribuciones que se describieron anteriormente es necesario determinar si las diferencias entre la función de densidad y la distribución de frecuencias experimental se deben al azar. Los contrastes estadísticos utilizados con este fin se denominan pruebas de bondad de ajuste. Existen varias de éstas, utilizadas de acuerdo al tipo de datos y la distribución teórica esperada. A continuación se consideran los ajustes más empleados.

\section{Muestras categorizadas (Distribuciones para variables continuas o discretas)}

\section{La prueba de Chi cuadrado $\left(\chi^{2}\right)$}

Se la puede aplicar tanto a distribuciones continuas (con los datos previamente agrupados en clases) como a distribuciones discretas. Se basa en cuantificar la diferencia entre las frecuencias observadas en cada clase y las esperadas, partiendo de la hipótesis nula de que los datos se ajustan a una cierta distribución $\boldsymbol{f}(\boldsymbol{x})$ (que puede ser Normal, Poisson, etc.). Para la estimación se contabiliza el número de casos observados $\left(\boldsymbol{O}_{\boldsymbol{i}}\right)$ en cada una de las $\boldsymbol{n}$ clases existentes y, a través de la función teórica que se desea probar, se calcula el número de casos esperados $\left(\boldsymbol{E}_{\boldsymbol{i})}\right.$. Luego se calcula el valor del estadístico $\chi^{2}$, con la siguiente ecuación:

$$
\chi^{2}=\sum_{i=1}^{n} \frac{\left(O_{i}-E_{i}\right)^{2}}{E_{i}}
$$

Si el número de casos esperados dentro de una clase es menor que 5 se aconseja combinar varias clases en una, hasta conseguir que todas tengan una frecuencia esperada mayor o igual a 5. A continuación se calculan los grados de libertad (v) de la muestra. Si los valores esperados se pueden calcular independientemente de la muestra, el número de $\boldsymbol{v}$ es $\boldsymbol{n}$-1. En cambio sí para calcular los valores esperados es necesario estimar algunos parámetros mediante estadísticos obtenidos de la muestra (como, por ejemplo, $\boldsymbol{\mu}$ o $\boldsymbol{\sigma}$ para una Distribución Normal) el número de $\boldsymbol{v}$ es $\boldsymbol{n}-\boldsymbol{r}-\boldsymbol{1}$ donde $\boldsymbol{r}$ es el número de estadísticos necesarios para calcular el valor esperado. Una vez determinados $\chi^{2}$ y $v$, se busca en la tabla $\chi^{2}$ el valor crítico correspondiente a $v$ y para el nivel de significación elegido (generalmente para $\alpha=0,05$ ). Si el $\chi^{2}$ crítico es mayor que el $\chi^{2}$ calculado se acepta la hipótesis nula de que los datos observados se ajustan a la distribución esperada, mientras que si el $\chi^{2}$ crítico es menor que el $\chi^{2}$ calculado la hipótesis nula se rechaza. 


\section{Independencia de variables categóricas}

Las tablas de contingencia se utilizan para examinar la relación entre dos variables categóricas, o bien para explorar la distribución que posee una variable categórica en diferentes muestras. La independencia de dos variables consiste en que la distribución de una de las variables no cambia sea cual sea el nivel de la otra. Esto se puede visualizar en una tabla de contingencia en que las frecuencias de las filas (y de las columnas) son aproximadamente proporcionales. La prueba de independencia chi cuadrado contrasta la hipótesis de que las variables son independientes, frente a la hipótesis alternativa de que una variable se distribuye de modo diferente para diversos niveles de la otra.

\section{Muestras no categorizadas (Distribuciones continuas)}

\section{Prueba de Kolmogorov-Smirnov (prueba $K-S$ )}

Esta prueba tiene la ventaja de que se la puede aplicar a todo tipo de distribuciones de frecuencias de datos, y se la puede usar tanto para muestras grandes como para pequeñas. Es un test muy conservador, que se aplica a variables continuas. Se basa en la determinación de la máxima diferencia (D) entre las frecuencias acumuladas observadas (AO) y las frecuencias acumuladas esperadas (AE), partiendo de la hipótesis nula de que los datos se ajustan a una distribución determinada. La fórmula de la prueba es:

$$
D=\max \left|A O_{i}-A E_{i}\right|
$$

Si este valor es menor que el de tablas al nivel de significación elegido se acepta la hipótesis nula de que los datos de la muestra siguen la ley de distribución que se usó para el cálculo de los valores esperados.

\section{Prueba de Lilliefors (prueba $K-S-L$ )}

Los valores de la tabla de la prueba $K-S$ fueron recalculados por Lilliefors (prueba K-S-L) para una Distribución Normal, estudiando las frecuencias esperadas a partir de la media y la varianza de la muestra, pero su aplicación no se aconseja cuando existen pocos datos.

Una vez calculado el estadístico $D$ se lo contrasta con el valor de $D$ crítico para el nivel de significación elegido, que aparece en la tabla para el test K-S-L. La hipótesis nula se acepta cuando $D$ observado es menor al $D$ tabulado $(\mathrm{D}=0,886 / \sqrt{ } \mathrm{n}$ para $\alpha=0,05$ y $\mathrm{n} \geq 30)$.

\section{Prueba de contraste de normalidad de Shapiro-Wilk}

La aplicación de esta prueba se restringe a las distribuciones de frecuencia normales. Es la prueba más recomendada para comprobar la normalidad de una muestra con un número pequeño de datos $(n<30)$. Se basa en medir el ajuste de los datos a una recta probabilística normal. Si el ajuste fuera perfecto los puntos formarían una recta de $45^{\circ}$ (frecuencia esperada igual a frecuencia observada). El estadístico de contraste se expresa por medio de la siguiente ecuación:

$$
W=\frac{1}{\sum_{j=1}^{n}\left(x_{j}-\mu\right)^{2}}\left[\sum_{j=1}^{h} a_{j, n}\left(x_{(n-j+1)}-x_{j}\right)\right]^{2}
$$


donde $\boldsymbol{n}$ es el número de datos, $\boldsymbol{x}_{j}$ es el dato de orden ascendente de la muestra que ocupa el lugar $\boldsymbol{j}, \boldsymbol{\mu}$ es la media, $\boldsymbol{h}$ es $\boldsymbol{n} / \mathbf{2}$ si n es par, o (n-1)/2 si $\boldsymbol{n}$ es impar y $\boldsymbol{a}_{\boldsymbol{j}, \boldsymbol{n}}$ es un valor tabulado.

Una vez calculado el valor del estadístico $\boldsymbol{W}$, se lo contrasta con el valor $\boldsymbol{W}$ crítico para el nivel de significación elegido. Como este estadístico mide el ajuste a una recta y no la distancia a la distribución Normal (como en los casos anteriores) la hipótesis nula se acepta cuando el valor de $\boldsymbol{W}$ es superior al valor de contraste tabulado (valor de ajuste muy alto).

\section{Prueba de contraste de normalidad de Anderson-Darling}

Esta prueba, no paramétrica, propuesta por Stephens (1974), es una modificación de la prueba de Kolmogorov-Smirnov y se adapta a varias distribuciones, incluida la distribución normal para aquellos casos en que los parámetros de la distribución poblacional no se conocen y tienen que ser estimados en base a los datos de la muestra. Esta prueba pone más énfasis en las colas de la distribución que la prueba de Kolmogorov-Smirnov, en el sentido de que puede ocurrir que una distribución tenga colas pesadas sin estar muy alejada de un comportamiento cuasi-normal. La prueba tiene en cuenta todas las diferencias entre las frecuencias acumuladas experimentales y calculadas mediante una función, no solamente la diferencia máxima encontrada ${ }^{(6.5)}$.

El estadístico, calculado mediante la siguiente ecuación, determina si los datos, previamente ordenados, pertenecen a una distribución con función acumulativa teórica $\boldsymbol{F}$.

$$
A_{n}^{2}=n \int_{-\infty}^{+\infty} \frac{\left[F_{n}(x)-F(x)\right]^{2}}{F(x)[1-F(x)]} f(x) d(x)
$$

Para definir la regla de rechazo para esta prueba el estadístico calculado se compara con los valores críticos de la tabla de Anderson-Darling. La regla de decisión es análoga a la utilizada en la Prueba K-S. 


\section{INDICE DE FIGURAS}

Figura 2-1: Tipos de aprendizaje en relación a la enseñanza (Pozo, J. 1997: 211) .............. 14

Figura 2-2: Clase en un aula, sin experiencias (Cámara, Alzugaray, 2011)....................... 15

Figura 2-3: Experiencias sin participación de un docente (Cámara, Alzugaray, 2011) ....... 15

Figura 2-4: Experiencias con participación de un docente (Cámara, Alzugaray, 2011)..... 15

Figura 4-1: Distribución de las actividades, prácticas tradicionales y prácticas con

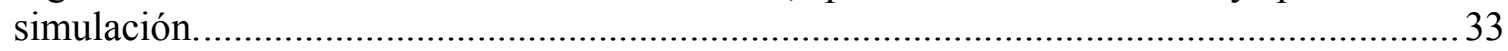

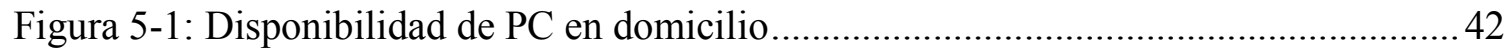

Figura 5-2: Disponibilidad de conexión a Internet en domicilio ....................................... 42

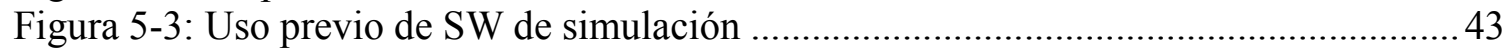

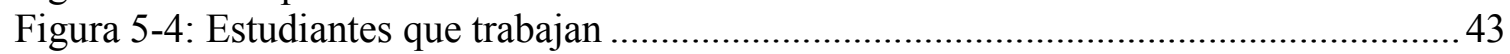

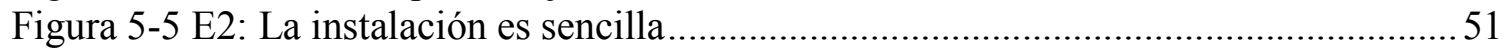

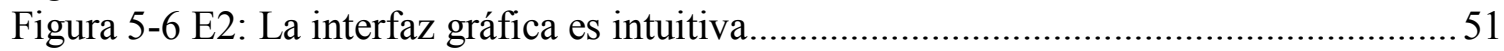

Figura 5-7 E2: Posee los componentes necesarios para un laboratorio IP .........................52

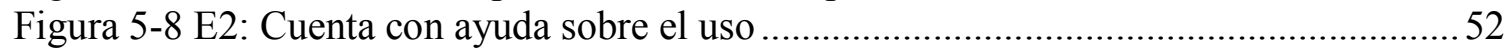

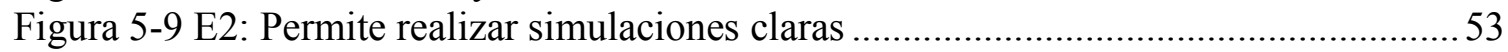

Figura 5-10 E2: La portabilidad de la herramienta independiza .........................................53

Figura 5-11 E2: La configuración de los dispositivos se desentiende del fabricante............54

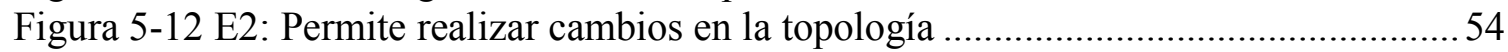

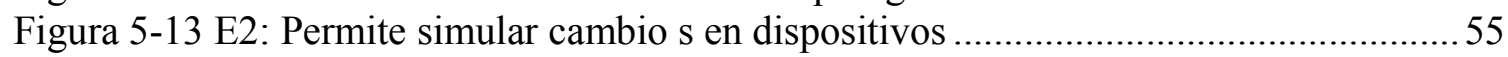

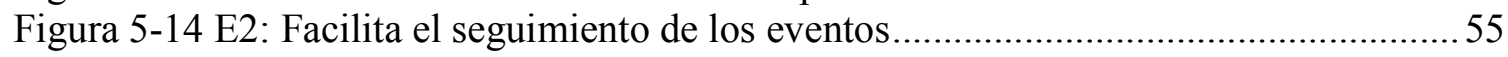

Figura 5-15 E2: KivaNS optimiza el tiempo para laboratorios .................................... 56

Figura 5-16 E2: KivaNS minimiza el riesgo de daños en dispositivos ................................56

Figura 5-17 E2: Facilita el entendimiento de topologías de red......................................57

Figura 5-18 E2: KivaNS potencializa la educación no presencial ...................................57

Figura 5-19 E2: Herramienta adecuada para el aprendizaje del protocolo IP ......................58

Figura 5-20 E2: Herramienta adecuada para el aprendizaje del protocolo ARP..................58

Figura 5-21 E2: Herramienta adecuada para el aprendizaje del protocolo ICMP................59

Figura 5-22 E2: Herramienta adecuada para el aprendizaje de fragmentación IP ...............59

Figura 5-23 E2: Herramienta adecuada para el aprendizaje de ruteo estático IP .................60

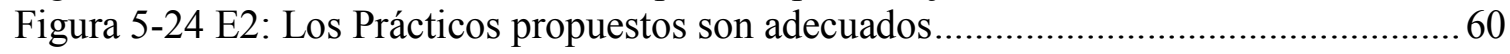

Figura 5-25 E2: Tiempo asignado a la resolución del práctico adecuado .............................61

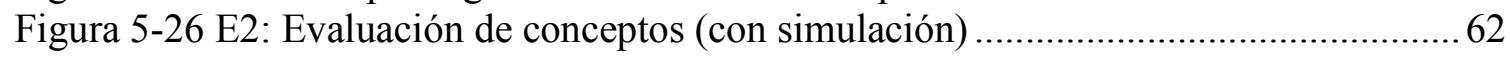

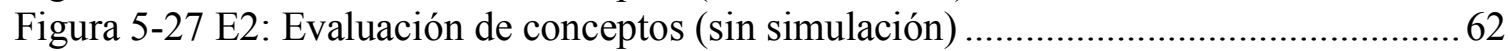

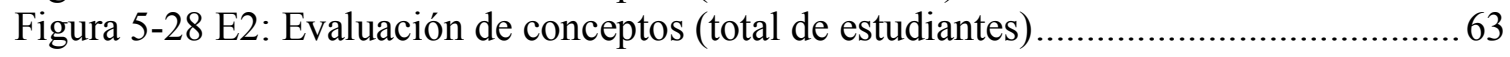

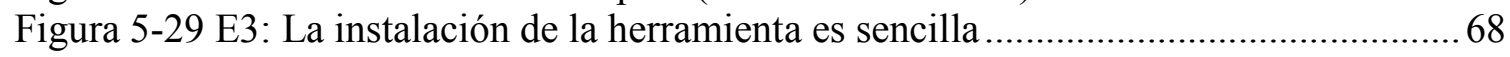

Figura 5-30 E3: La configuración de la interfaz en español es sencilla .............................69

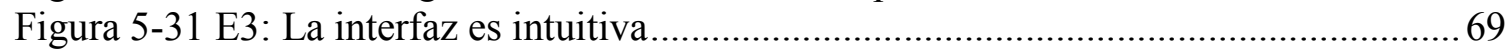

Figura 5-32 E3: Posee componentes necesarios para un laboratorio IP ............................ 70

Figura 5-33 E3: Disponibilidad para la realización de laboratorios .................................. 70

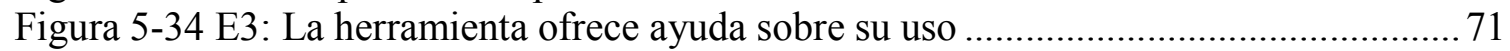

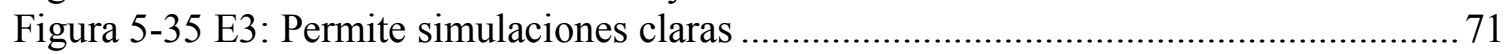

Figura 5-36 E3: La configuración de dispositivos es independiente del fabricante..............72

Figura 5-37 E3: Permite realizar cambios en la topología .............................................. 72

Figura 5-38 E3: Permite simular cambios en dispositivos .............................................. 73 
Figura 5-39 E3: Facilita el seguimiento de los eventos..................................................... 73

Figura 5-40 E3: Con Packet Tracer se potencializa la educación no presencial .................. 74

Figura 5-41 E3: PT es adecuado para el estudio de fundamentos de redes........................ 75

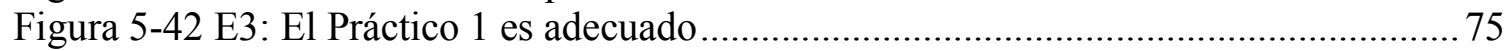

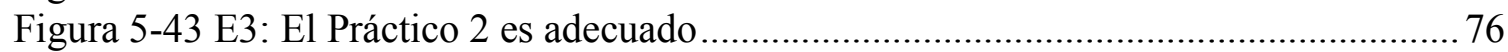

Figura 5-44 E3: El Práctico 3 es adecuado........................................................................... 76

Figura 5-45 E3: PT es adecuado para el estudio de protocolos de aplicación ......................77

Figura 5-46 E3: PT es adecuado para el estudio del protocolo HTTP ................................. 78

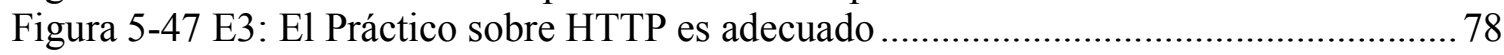

Figura 5-48 E3: PT es adecuado para el estudio del protocolo FTP ................................ 79

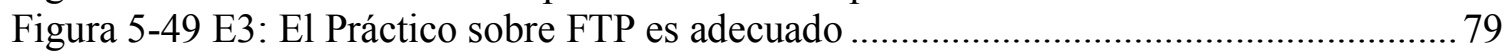

Figura 5-50 E3: PT es adecuado para el estudio del protocolo SMTP y POP3 ................... 80

Figura 5-51 E3: Considera adecuado el Práctico sobre SMTP y POP3 ……........................ 80

Figura 5-52 E3: PT es adecuado para el estudio del protocolo DNS .............................. 81

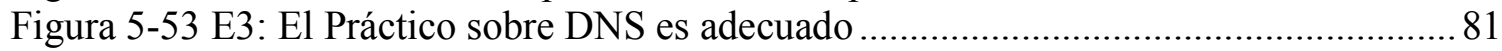

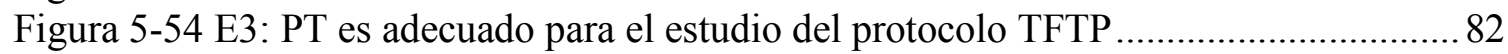

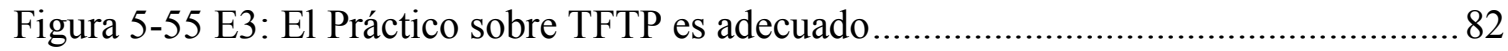

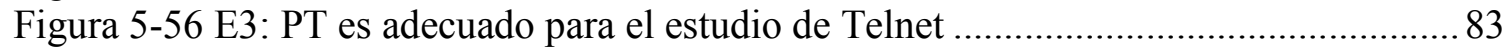

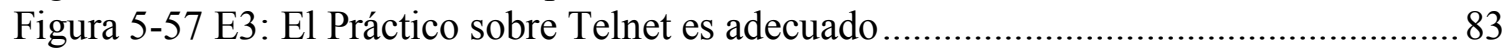

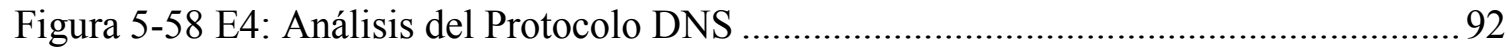

Figura 5-59 E5: Análisis de Packet Tracer y los Fundamentos de Redes .......................... 106

Figura 5-60 E5: Análisis de Packet Tracer y las Capas de Aplicación, Transporte y Red. 118

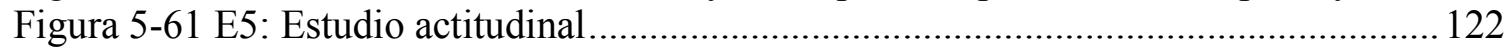

Figura 5-62 E6: Histograma para la variable Taller ................................................. 125

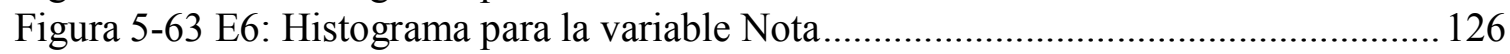

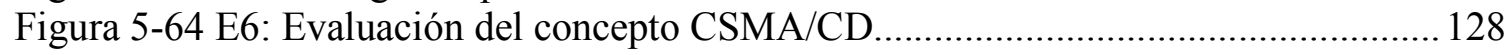

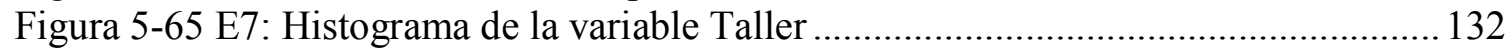

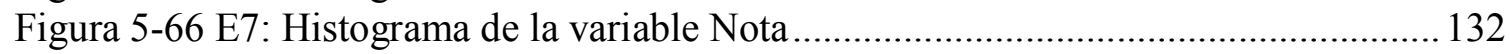

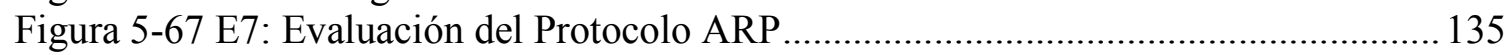

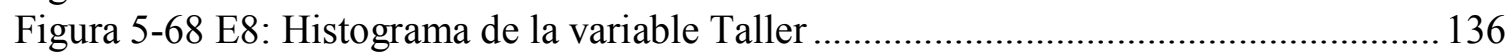

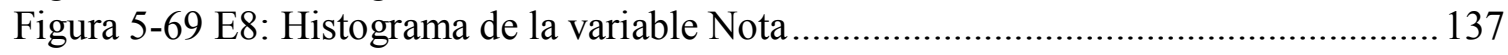

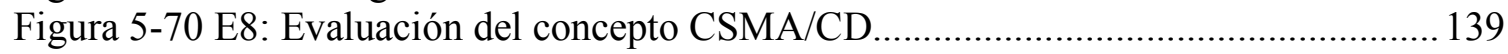

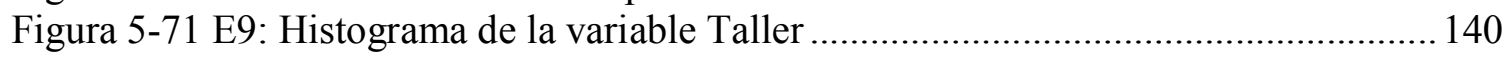

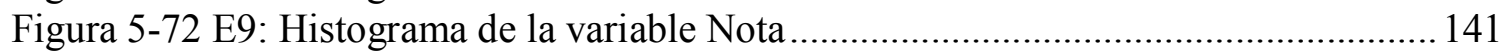

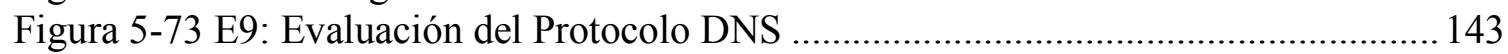

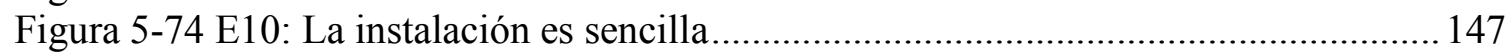

Figura 5-75 E10: La configuración de la interfaz es sencilla ...................................... 147

Figura 5-76 E10: La interfaz gráfica es amigable .................................................... 148

Figura 5-77 E10: Posee los componentes necesarios para un laboratorio IP ..................... 148

Figura 5-78 E10: Ofrece disponibilidad que garantice la realización del laboratorio......... 149

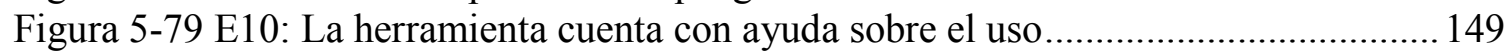

Figura 5-80 E10: La herramienta permite simulaciones claras ..................................... 150

Figura 5-81 E10: La configuración de dispositivos se independiza del fabricante............. 150

Figura 5-82 E10: Permite el cambio de la topología fácilmente ...................................... 151

Figura 5-83 E10: Permite cambios en dispositivos de manera efectiva ............................ 151

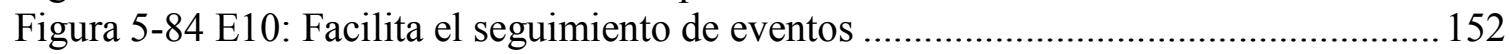

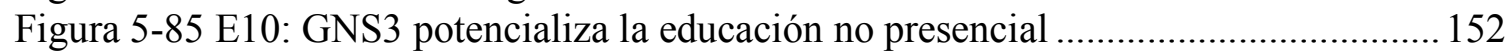


Figura 5-86 E10: GNS3 es adecuado para el estudio de ruteo IP.................................... 153

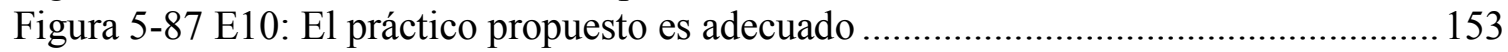

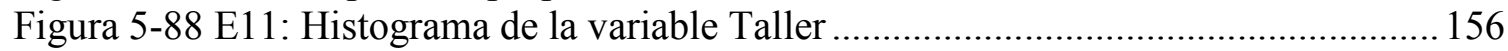

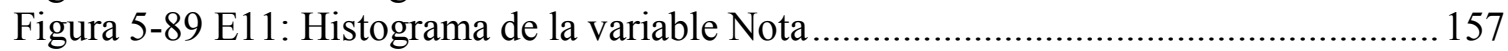

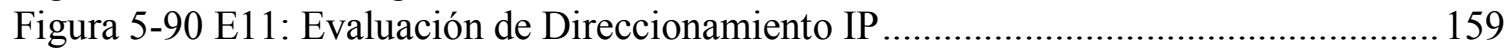

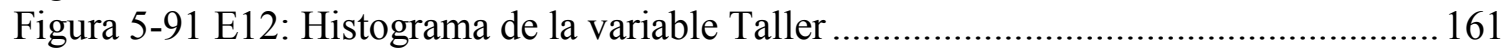

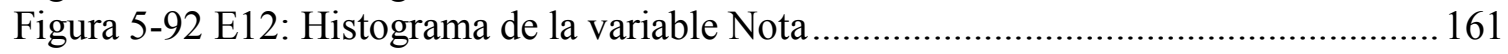

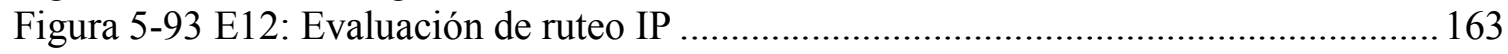

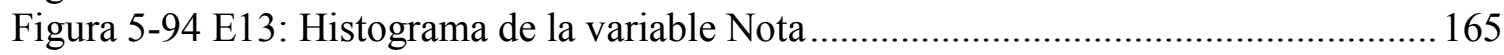

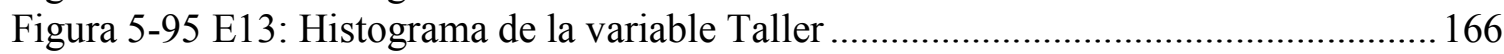

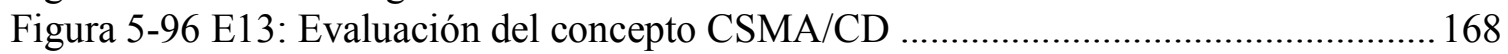

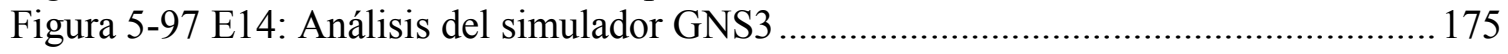

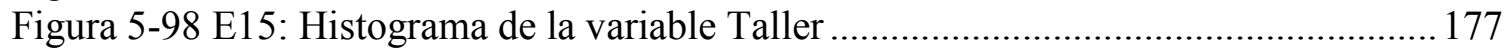

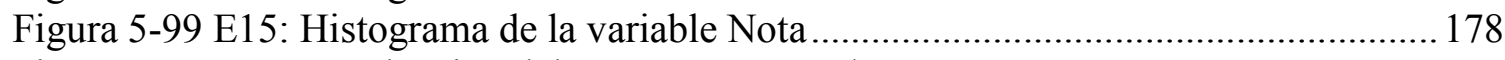

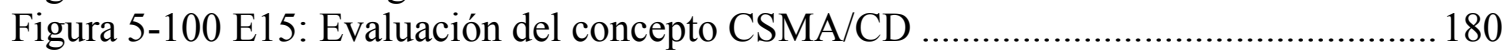

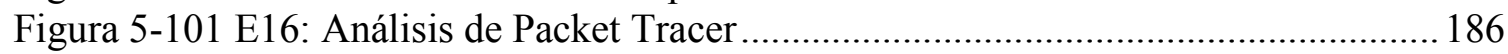

Figura 5-102 E17: Histograma de la variable Taller ..................................................... 187

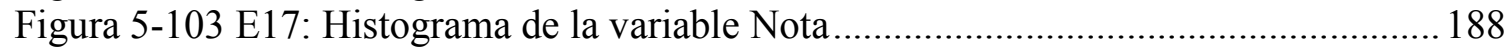

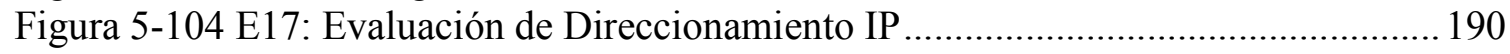

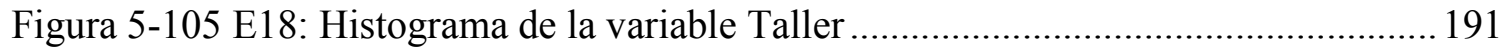

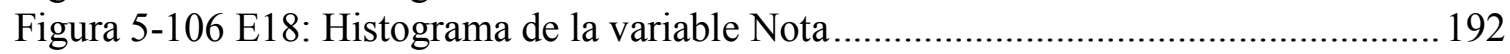

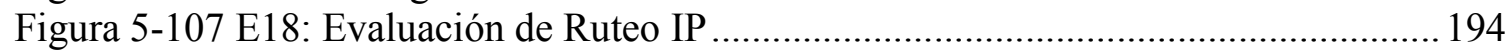

Figura 5-108 E19: Análisis de Laboratorio Real con Direccionamiento IP........................200

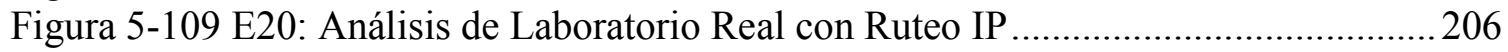

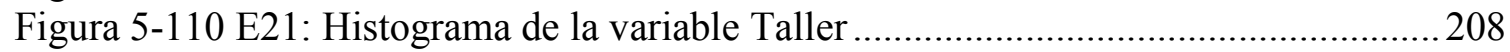

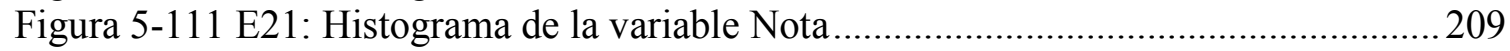

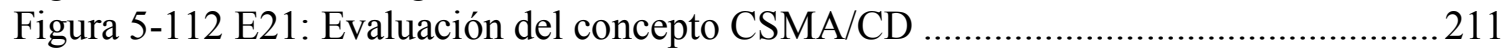

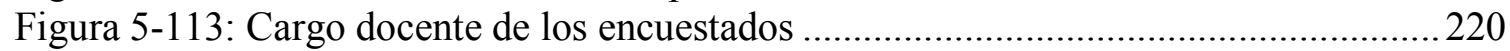

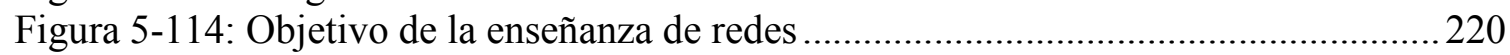

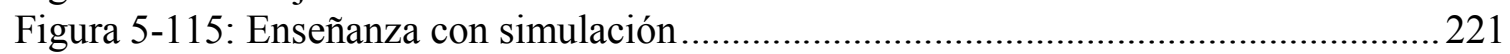




\section{INDICE DE TABLAS}

Tabla 3-1: Comparación entre trabajos prácticos con equipo real y .................................22

Tabla 4-1: Actividades en las distintas etapas de investigación........................................ 32

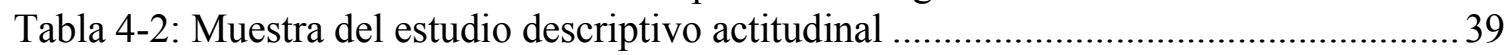

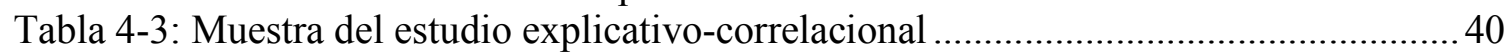

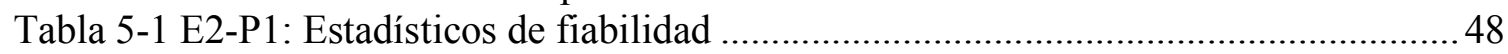

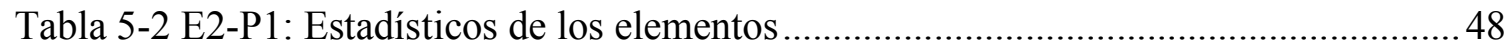

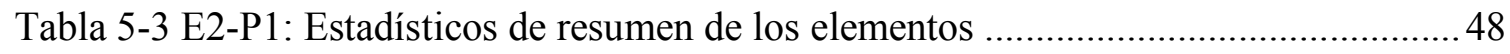

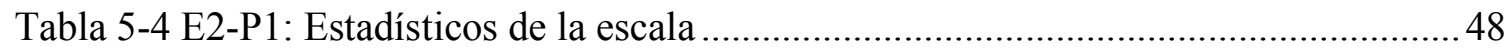

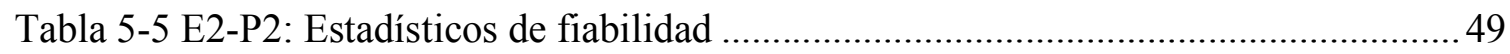

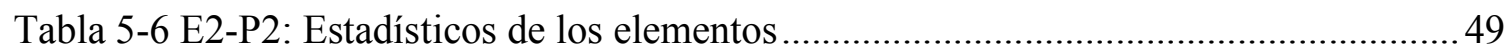

Tabla 5-7 E2-P2: Estadísticos de resumen de los elementos ................................................4 49

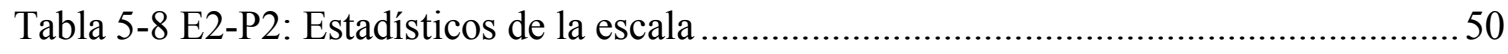

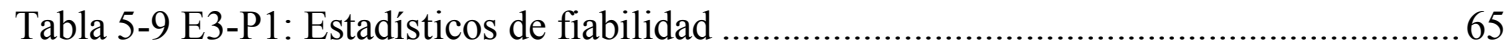

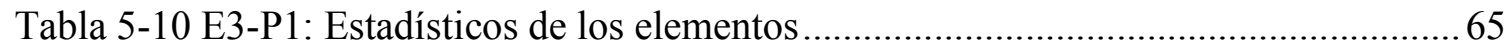

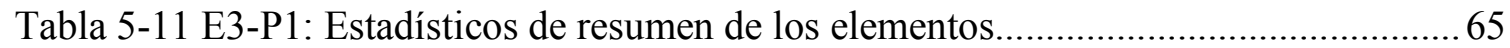

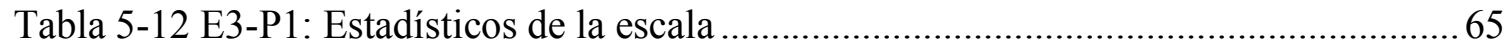

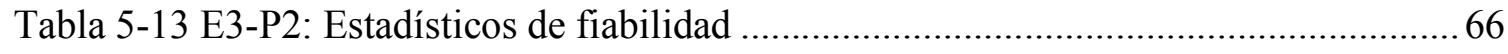

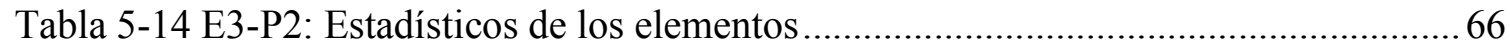

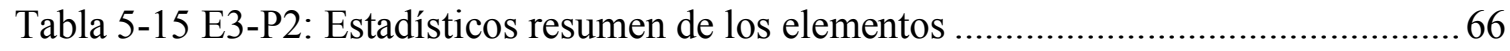

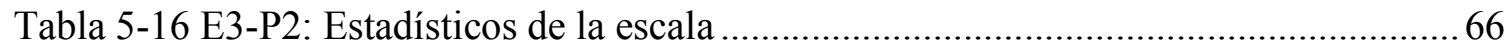

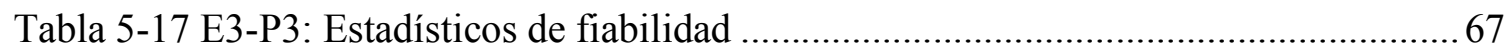

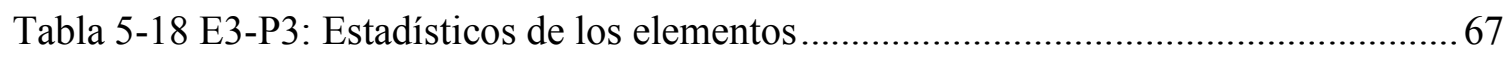

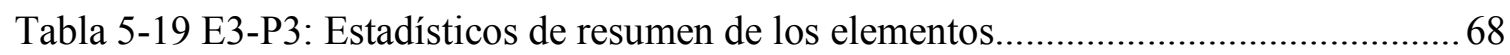

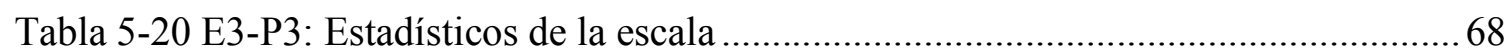

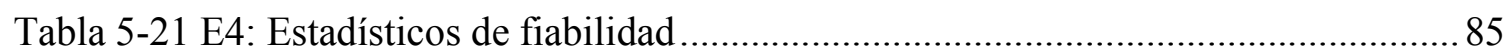

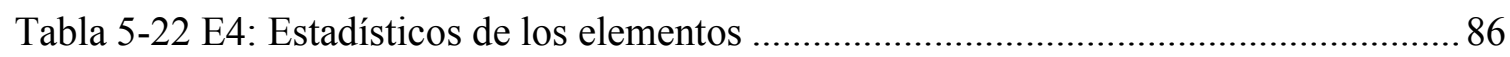

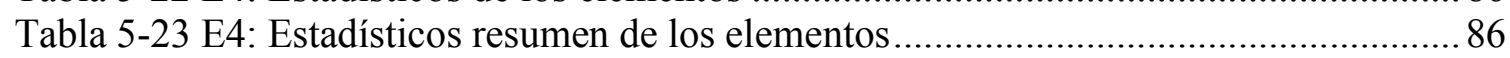

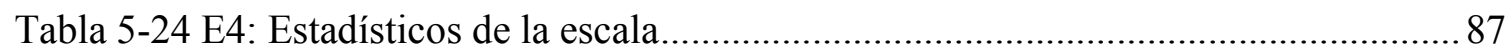

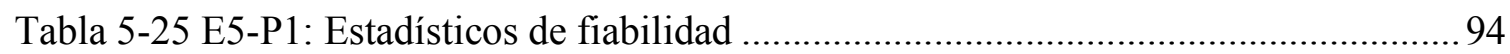

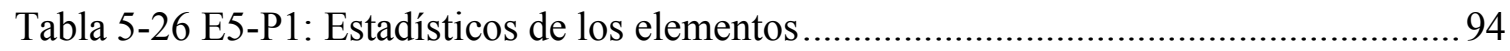

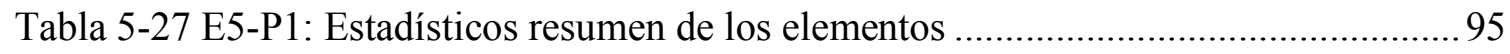

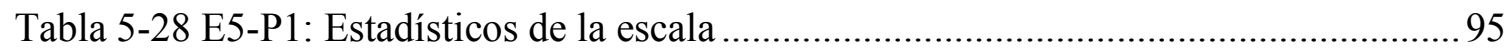

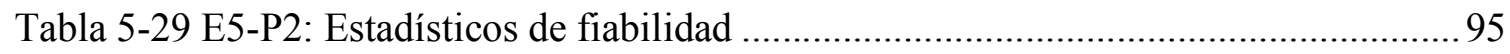

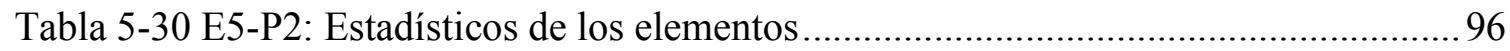

Tabla 5-31 E5-P2: Estadísticos de resumen de los elementos..............................................96

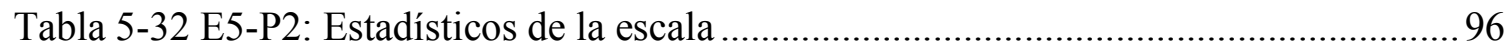

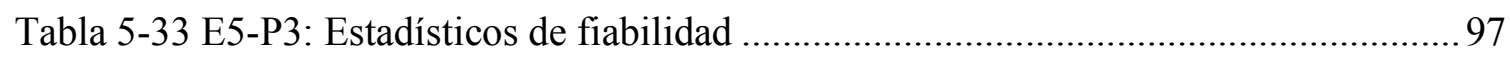

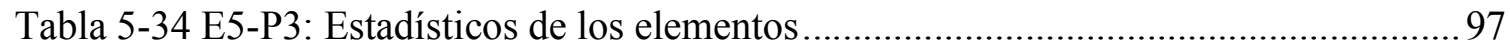

Tabla 5-35 E5-P3: Estadísticos de resumen de los elementos............................................ 98

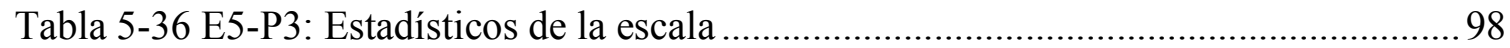

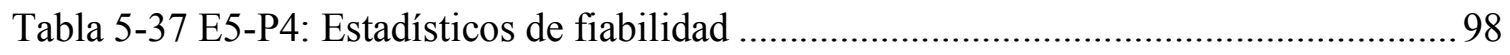

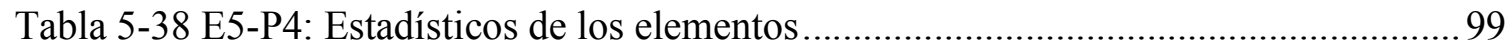

Tabla 5-39 E5-P4: Estadísticos de resumen de los elementos.............................................99

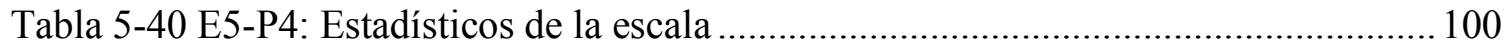




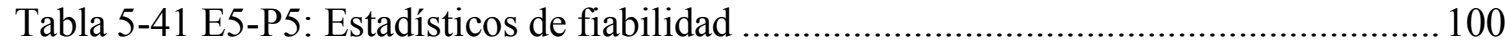

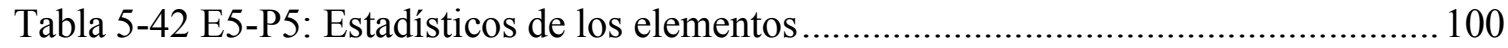

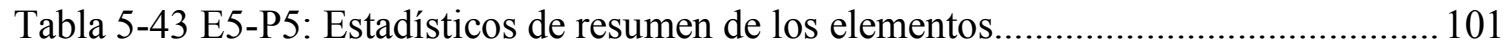

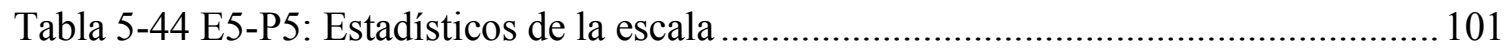

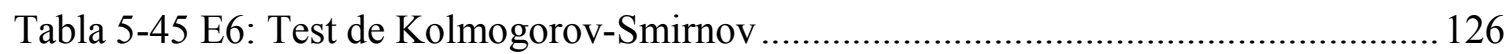

Tabla 5-46 E6: Prueba de los rangos con signo de Wilcoxon ....................................... 127

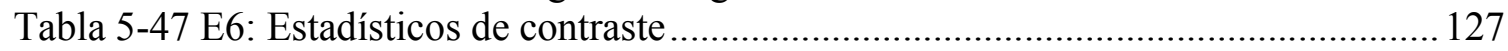

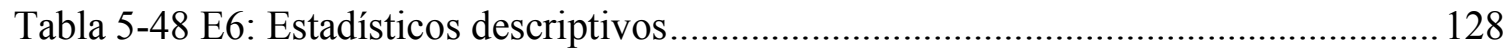

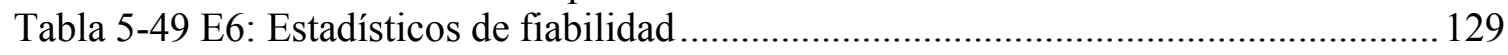

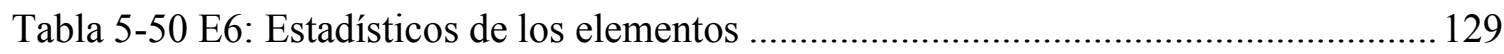

Tabla 5-51 E6: Estadísticos de resumen de los elementos ............................................... 130

Tabla 5-52 E6: Estadísticos de la escala..................................................................... 130

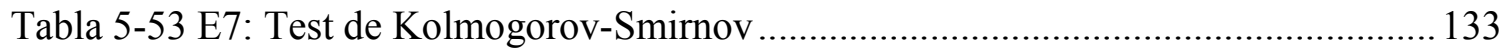

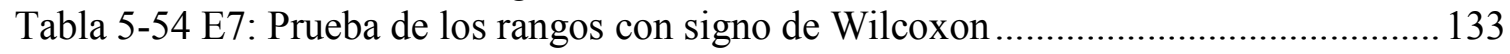

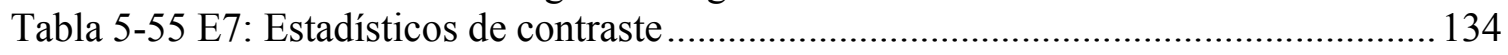

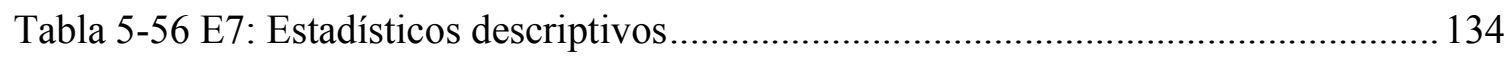

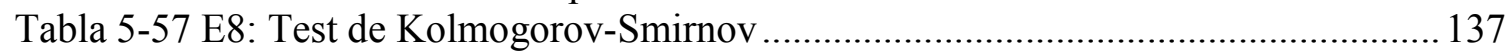

Tabla 5-58 E8: Prueba de los rangos con signo de Wilcoxon ........................................ 138

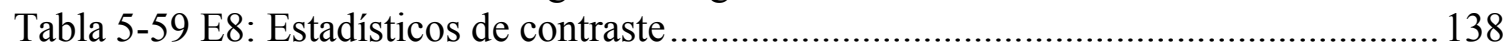

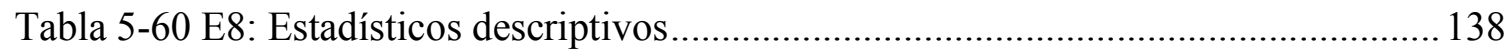

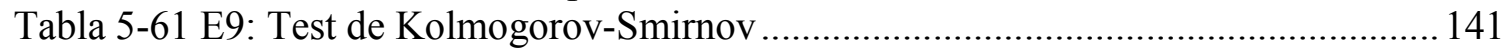

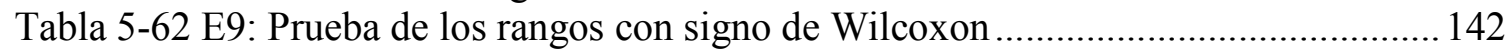

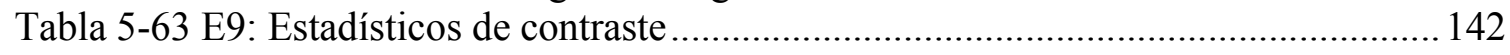

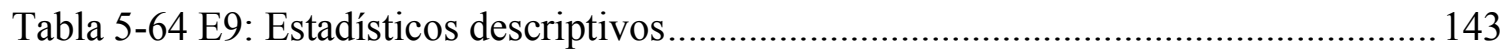

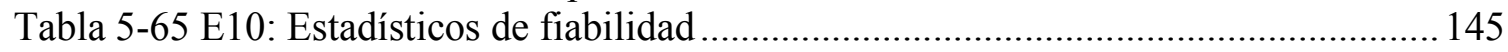

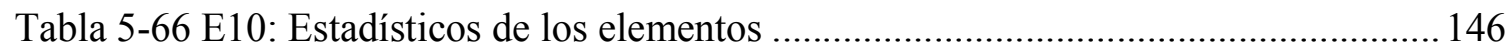

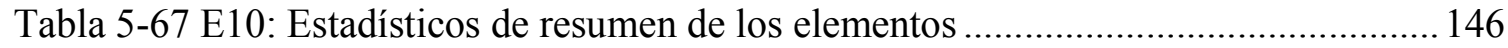

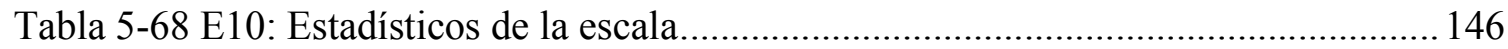

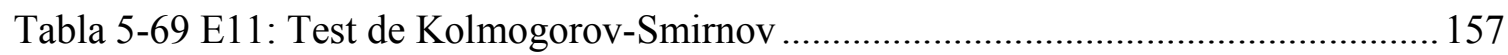

Tabla 5-70 E11: Prueba de los rangos con signo de Wilcoxon ............................................. 158

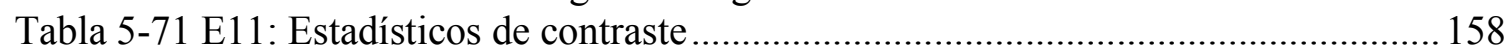

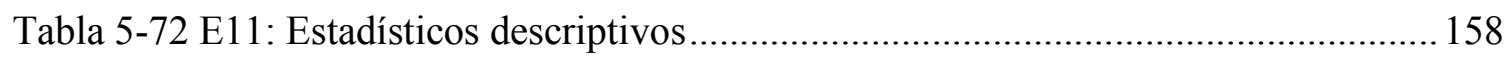

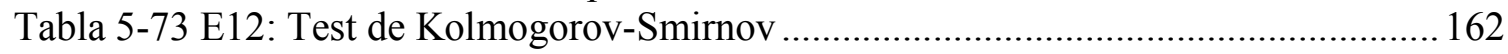

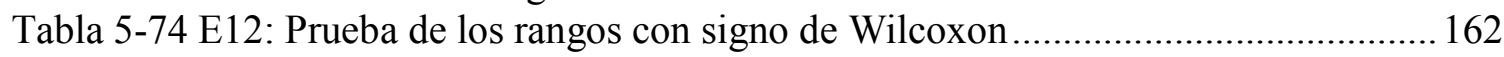

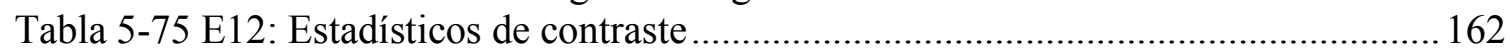

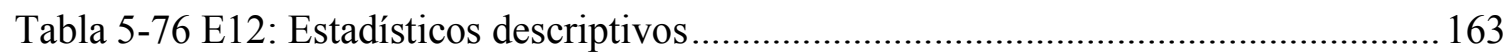

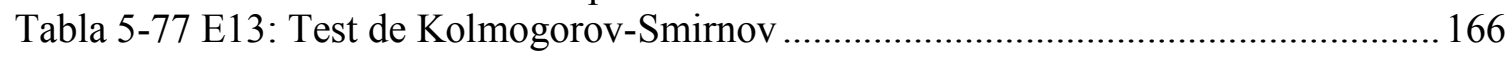

Tabla 5-78 E13: Prueba de los rangos con signo de Wilcoxon ........................................ 167

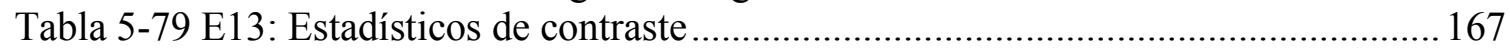

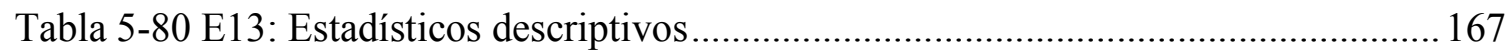

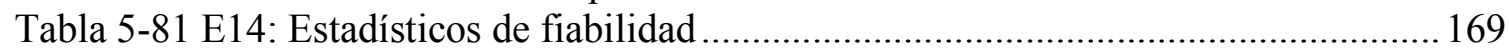

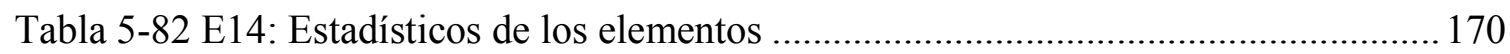

Tabla 5-83 E14: Estadísticos de resumen de los elementos ............................................. 170

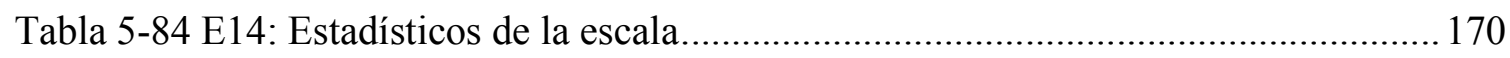

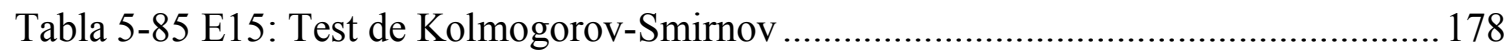

Tabla 5-86 E15: Prueba de los rangos con signo de Wilcoxon ......................................... 179

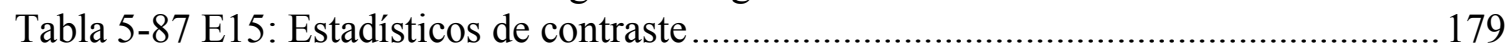




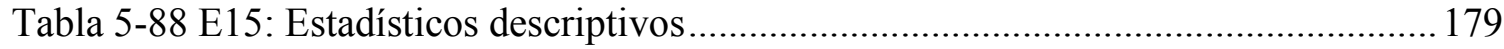

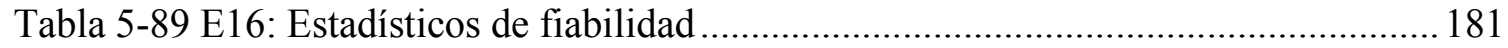

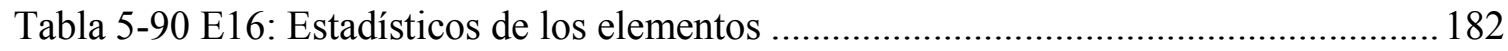

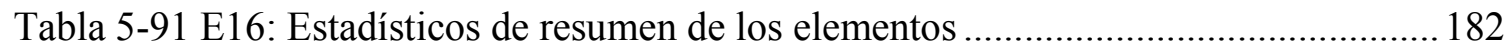

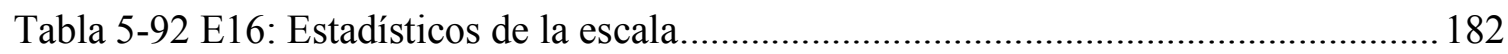

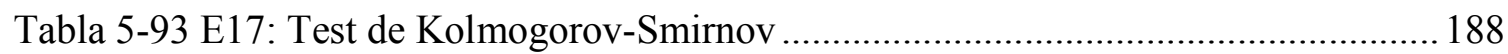

Tabla 5-94 E17: Prueba de los rangos con signo de Wilcoxon ...................................... 189

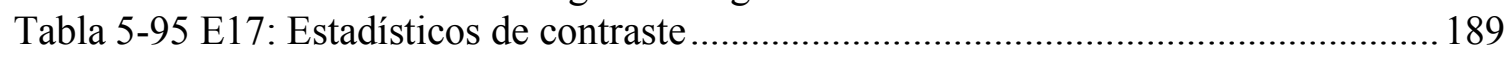

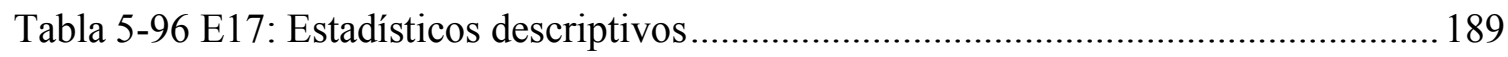

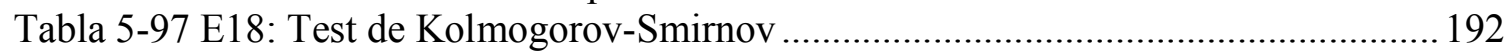

Tabla 5-98 E18: Prueba de los rangos con signo de Wilcoxon ........................................ 193

Tabla 5-99 E18: Estadísticos de contraste ........................................................................ 193

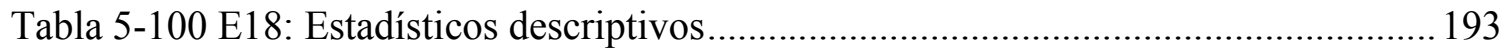

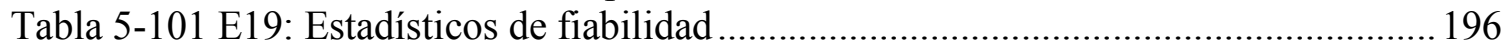

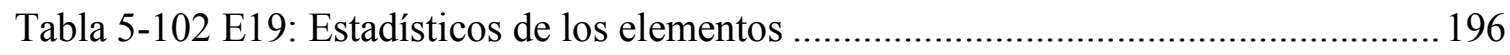

Tabla 5-103 E19: Estadísticos de resumen de los elementos ........................................... 196

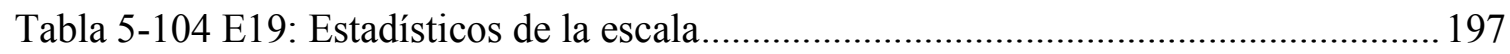

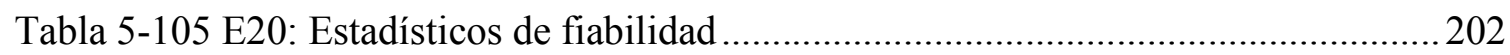

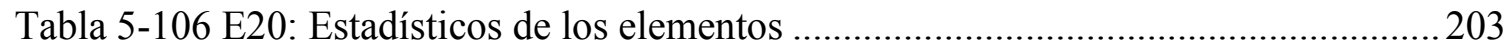

Tabla 5-107 E20: Estadísticos de resumen de los elementos ...........................................203

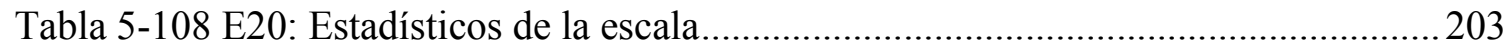

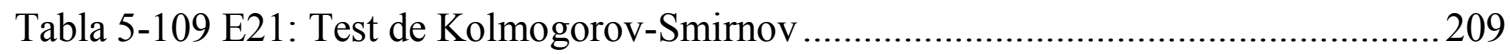

Tabla 5-110 E21: Prueba de los rangos con signo de Wilcoxon .........................................210

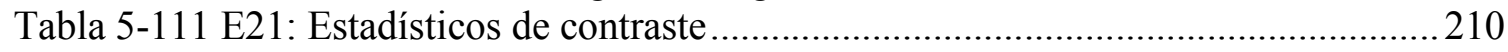

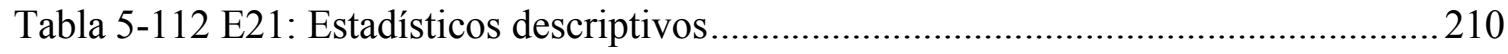

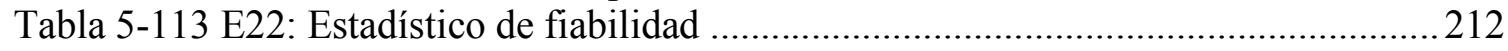

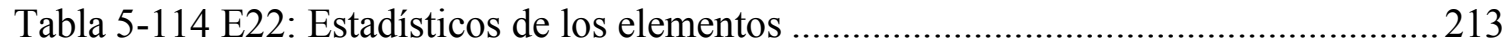

Tabla 5-115 E22: Estadísticos de resumen de los elementos ...........................................213

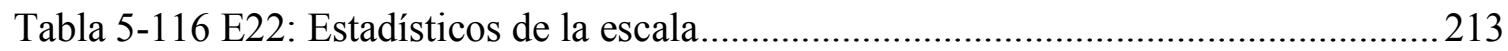

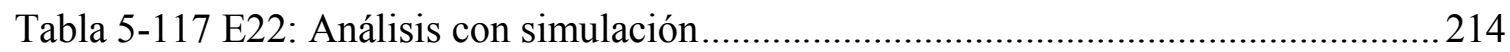

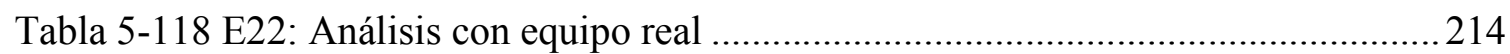

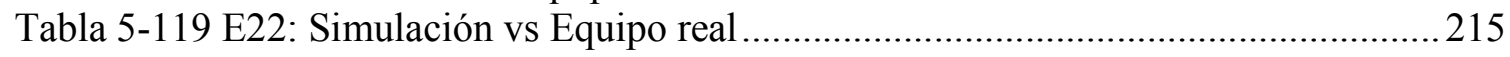

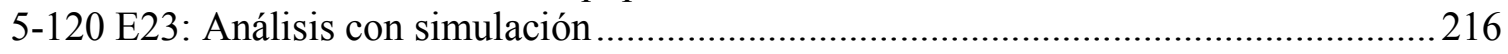

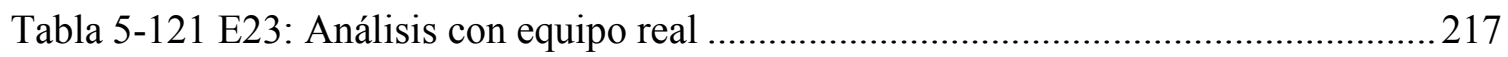

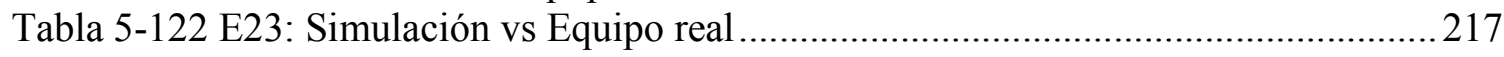

Tabla 5-123: Enseñanza con simulación, resultados para armado de topología y

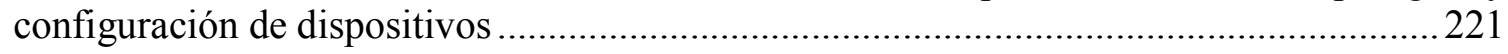

Tabla 5-124: Enseñanza con equipo real, resultados para armado de topología y

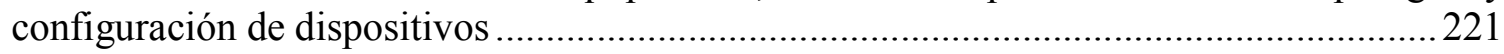

Tabla 5-125: Enseñanza con simulación reemplaza práctica con equipo real ....................221 